Au. Cat, Ti. Cat

401

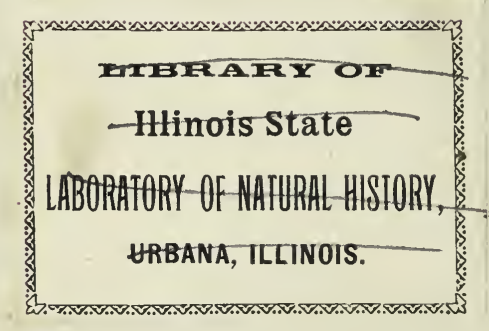





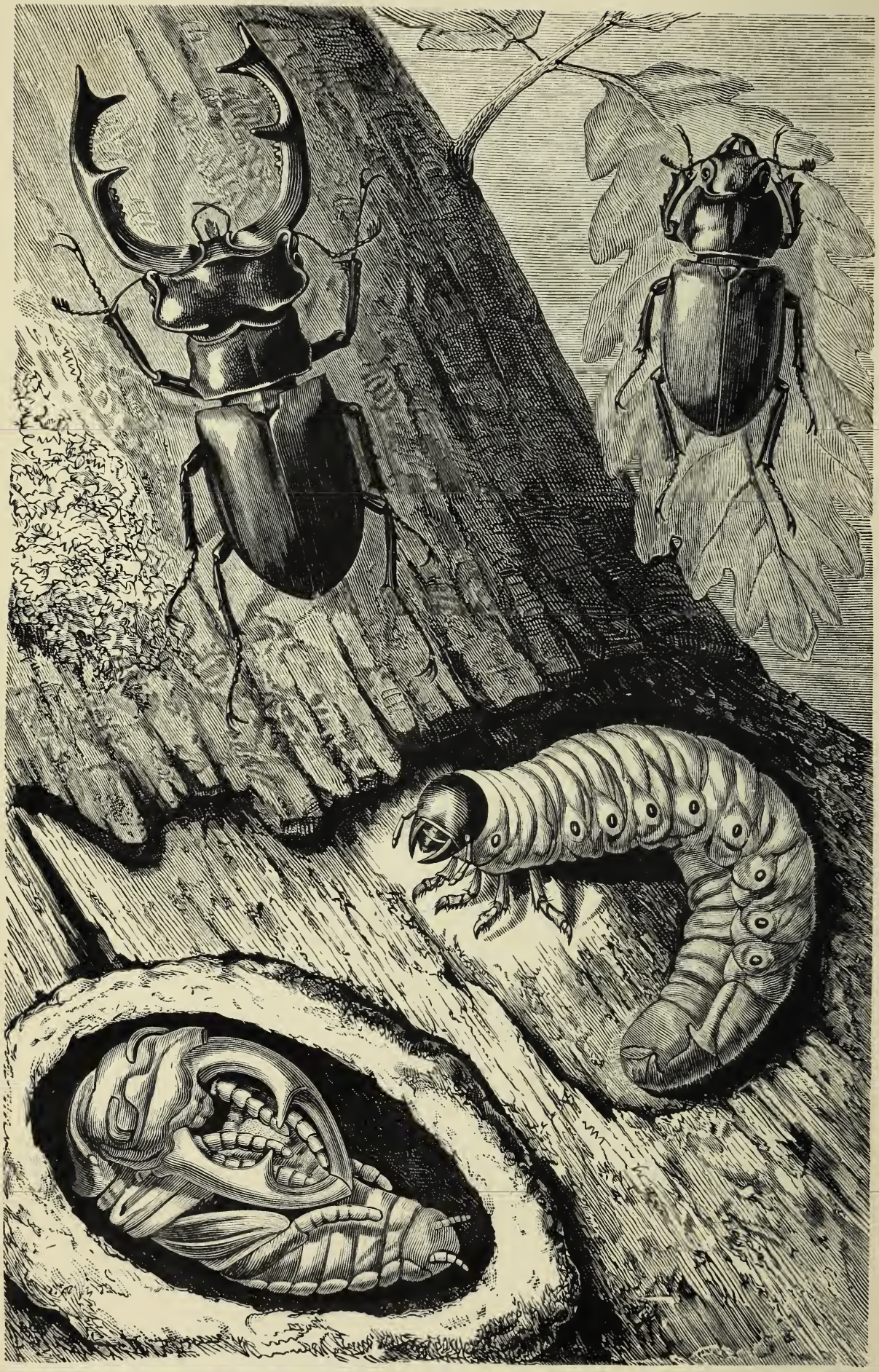




\section{THE}

\section{TRANSFORMATIONS}

(OR METAMORPHOSES)

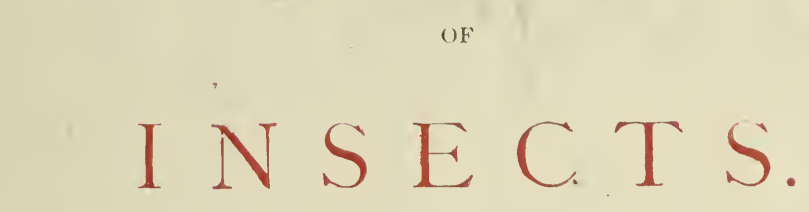

(Insecta, Myriapoda, Arachnida, and Crustacea.)

BEING AN ADAPTATION, FOR ENGLISH READERS, OF M. ÉMILE BLANCHARD'S “METAMORPHOSES, MEURS ET INSTINCTS DES INSECTS;" AND A COMPILATION FROM THE WORKS OF NEWPORT, CHARLES DARWIN, SPENCE BATE, FRITZ MÜLLER, PACKARD, LUBBOCK, STAINTON, AND OTHERS.

BY

\section{P. MARTIN DUNCAN, F.R.S.,}

Professor of Geology in Kingr's College, London.

Ist. Ed. 1870

$2 d$. "187-

3 it. . $1882(?)$

CASSELL, PETTER, AN J) GALPIN LONDON AND NEW YORK. 



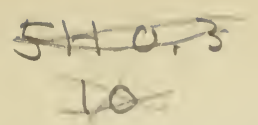

\title{
TABLE OF CONTENTS.
}

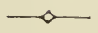 \\ CHAPTER I.
}

THE Insect WORld

PAGE

CHAPTER II.

Structures Implicated in Metamorphosis

CHAPTER III.

Metamorphoses of the Nervous, Digestive, and Respiratory Systems, and the Nature of Metanorphosis . . . . . . . . 3 I

CHAPTER IV.

The Metamorphoses of the Lepidoptera.

CHAPTER V.

The Metamorphoses of the Lepidop'era-Continued

CHAPTER VI.

The Metamorphoses of the Hymexoptera 162

CHAPTER VII.

The Metamorphoses of the Coleoptera. 264

CHAPTER VIII.

The Metamorphoses of the Orthoptera . $33^{6}$

CHAPTER IX.

The Metalorphoses of the Thysanoptera 35 I

CHAPTER X.

Tine Metanorphoses of the Neuroptera .

\section{CHAPTER XI.}

The Metamorphoses of the Hemiptera . 
CHAPTER XII.

The Metamorphoses of the Aphaniptera and Strepsiptera.

CHAPTER XIII.

The Metamorphoses of the Diptera .

CHAPTER XIV.

The Anoplura and Thyshura . . . . . . . . 408

CHAPTER XV.

THE MYriapola

CHAPTER XVI.

The Metamorphoses of the Arachnida

CHAPTER XVII.

The metamorphoses of the Crustacea . . . . . . . . 448 


\section{TABLE OF ILLUSTRATIONS.}

\section{FULL-PAGE PLATES.}

The Metamorphoses of the Stag Beetle

The Metamorphoses of Papilio machaon

The Metamorphoses of Vanessa Io

The Metamorphoses of the Marbled White (Arge galathea)

The Metamorphoses of Sesia apiformis -

The Metamorphoses of Zygana filipendula, the "Six Spot Burnet"

The Metamorphoses of the Sphinx euphorbice

The Metamorphoses of Attacus luna

The Metamorphoses of the Bombyx processionea and of Calosoma sycophanta

The Metamorphoses of Psyche graminella

The Metamorphoses of the Goat Moth (Cossus ligniperda)

The Moths and Caterpillars of Cucullia verbasci

Galls of Cynips terminalis

Chrysidide

The Nest of Formica rufa

The Metamorphoses of Scolia Alavifrons

Vespa sylvestris and Nest

Polistes gallica and Nests

Polybia palmarum and Nests

Tatua morio and Nest

Leaf-cutting Bees and Nests

Anthocopa papaveris and Nests

The Metamorphoses of Anthophora personata

Bombus muscorum

The Nest of Melipona scutellaris

The Metamorphoses of the Cockchafer (Melolontha vulgaris)

The Metamorphoses of Dytiscus marginalis

The Metamorphosis of Acanthophorus serraticornis - -

The Metamorphoses of the Great Green Grasshopper

The Metamorphoses of the Mole Cricket (Gryllotalpa vullaris)

The Metamorphoses of Locusts (Acridium peregrinum) .

The Metamorphoses of the May Flies .

The Metamorphoses of the Dragon Fly (Asshna maculatissima) -

The Metamorphoses of Cicada fraxini .

The Garden Spider (Epeira diadema) -

Mygale fodiens and its Nest -

Carcinus manas .

The Spiny Lobster (Palinumus vulgaris)

Lobster Fishery on the Coast of Normandy -

Frontispiece.

To face Page 78

,, , 82

$,, \quad, \quad 84$

, $\quad,, 96$

,, , , 98

$,, \quad, \quad 100$

, , I I 2

, , , II4

, , , I20

, $\quad$, 122

, , , I30

,, , , 180

, , , 194

,, , , 200

,, , 218

,, , 234

,, , 236

,, , , 238

,, $\quad, \quad 240$

, , , 248

, , , 250

, , , 252

,, , , 254

,, , , 260

, , , 274

,, , , 298

,, , , 324

$, \quad, \quad 338$

$, \quad, \quad 340$

, , 342

,, , , 344

$, \quad, \quad 354$

, $\quad, \quad 356$

,, , , 366

, , , 427

,, , , 428

, , , 456

,, , , 462

,, , 464 


\section{ILLUSTRATIONS IN THE TEXT.}

CHAPTER II.

Caterpillar of Sphinx ligustri

Moth of Sphinx ligustri

Larvæ of a Dipterous Insect

Chrysalis of Sphinx ligustri .

Larva and Moth of Attacus pavonia major - _ _ _ _ _ _ _ _ $\quad$ - 13

Membranous Legs of Silkworm Caterpillar - _ _ _ _ _ _ _ $\quad$ - 14

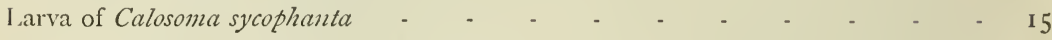

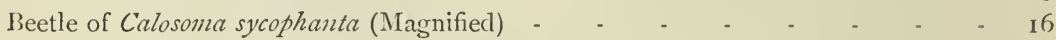

Larva of Silkworm with True and Membranous Legs - _ _ _ _ _ $\quad$ I8

Legless Larvæ of the Bee; Nymphs of Bee - _ _ _ _ _ _ _ $~ 19$

Caterpillar of a "Looper" - _ _ _ _ _ _ _ _ _ _ _ _ - $\quad$ - 19

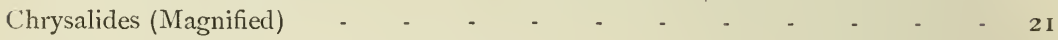

Anatomy of the Mouth of Locusta viridissima - - _ - - _ - - $\quad 22$

Mouth of Larva of Sphinx ligustri; Head of Moth (Magnified) - _ _ $\quad 23$

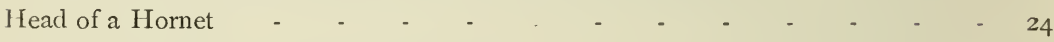

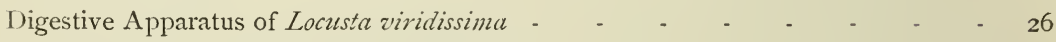

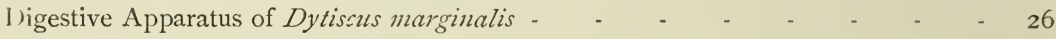

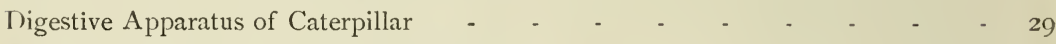

Digestive Apparatus of the Moth (Silkworm) - _ _ _ _ _ $\quad$ - 29

CHAPTER III.

Nervous System of the Larva of the Bee (Magnified) - _ _ _ _ _ 32

Nervous System of the Full-grown Bee (Magnified) - _ _ - _ - 34

Brain and Optic Nerves, \&c., of Larva of Water Beetle - _ - - - $\quad 36$

Brain and Optic Nerves, \&c., of Adult Water Beetle - _ _ _ _ - $\quad 36$

Nervous System of Larva of Silkworm - - - - - - - - - $\quad 38$

Nervous System of Moth of Silkworm - - - - - - - - - - $\quad 3^{8}$

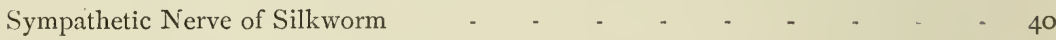

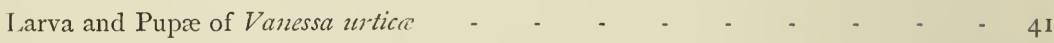

Metamorphoses of the Nervous System of Vanessa urtica - - - - $\quad 42,43,44$

A Trachea Magnified - $\quad$ - $\quad$ - $\quad$ - $\quad$ - $\quad$ - $\quad$ - $\quad$ - 46

Respiratory Organs of Larvæ of Cloe bivculata and Ephemera vulgata - _ - 47

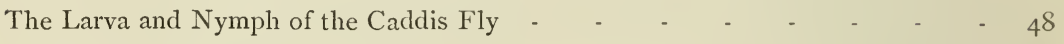

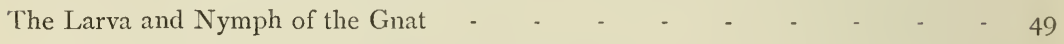

The Respiratory Apparatus of the Bee (Magnified) - - _ - - $\quad 52$

Sections of the Larva, Pupa, and Moth of Sphinx ligustri - _ _ _ - $6 \mathbf{I}$

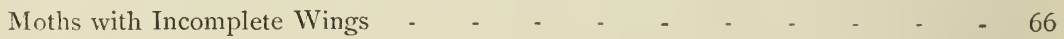

CHA P TER I V.

A Portion of the Wing of Attacus paronia major $\quad$ - $\quad$ - $\quad$ - $\quad$ - $\quad$ - 69

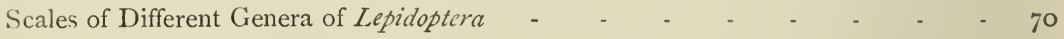

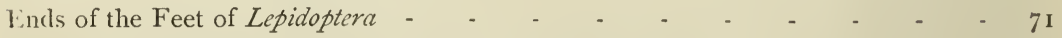

Moth of Sthinx ligustri, and the Wings, Hook, and Catch - - _ - $\quad 75$ 
Terminal Parts of Antennæ

Membranous Feet of Caterpillars _ _ _ _ _ _ _ _ _ $\quad$ - 78

Caterpillar and Chrysalis of Papilio machaon - _ _ _ - _ - $\quad$ - 78

Caterpillars and Butterflies of Thecla W. album - _ _ _ _ $\quad$ - $\quad$ - 86

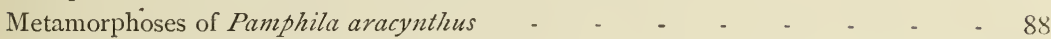

Caterpillars suspending themselves _ _ _ _ _ _ _ _ _ $\quad$ - 90, 9I

CHA PTER V.

Antennæ of Moths

Larva of the Death's Head Moth

Chrysalis of the Death's Head Moth

Caterpillar of Charocampa nerii -

Chrysalis of Charocampa nerii

Moth of Charocampa nerii -

Death's Head Moth

Moth and Larva of Attacus pavonia major

Feet of Caterpillars and Moths

The Lackey Moth

Metamorphoses of Orgyia antiqua

Female and Chrysalis of Psyche graminulla

The Puss Caterpillar and Male Moth

The Lobster Moth

Erebus strix

Caterpillars of Ennomos illustraria

Caterpillars and Moths of Aoraxas grossulariata -

The Male and Female Moths of the Mottled Umber

The Metamorphoses of Halias quercana

The Metamorphoses of the Vine Pyralis

The Metamorphoses of Tinea tapetzella

Larva Cases of Tineina

The Larva and Moths of Lithocolletis emberizcpennella - 
Larvæ, Nymph, and Cocoon of Red Ant - _ - _ - _ - - 202

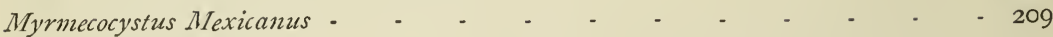

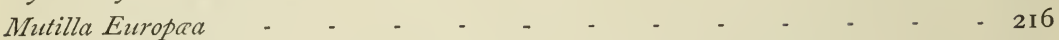

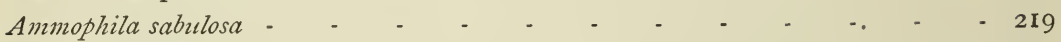

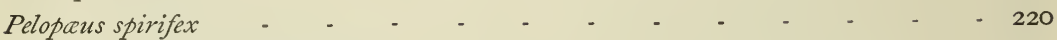

Pelopaus spirifex, Nest detached - - _ _ _ - - _ - _ - - 222

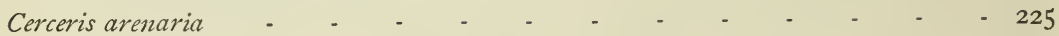

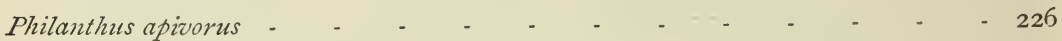

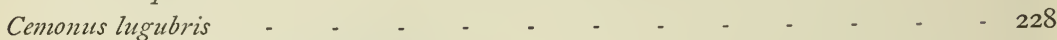

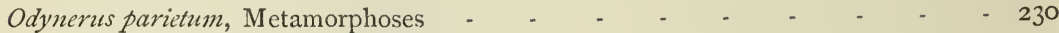

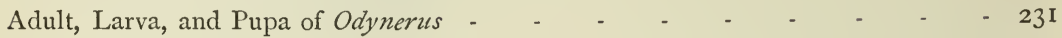

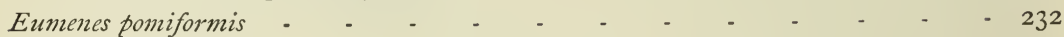

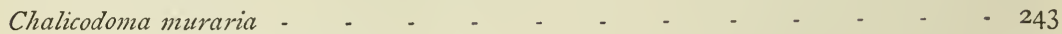

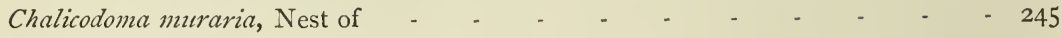

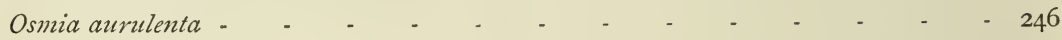

Xylocopa violacea

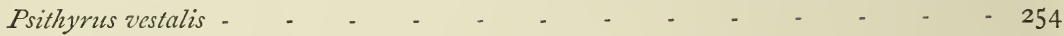

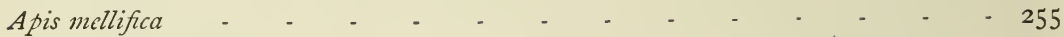

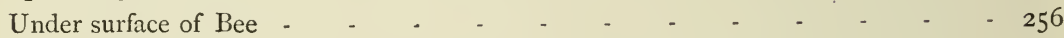

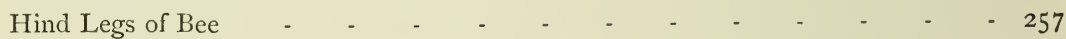

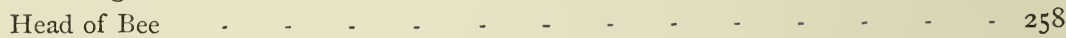

Sting and Venom Glands of Bee - _ _ _ _ _ _ _ _ _ _ $\quad$ - $_{2} 258$

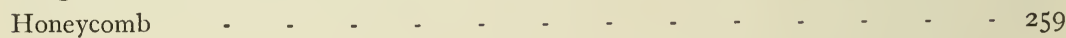

CHAPTER VII.

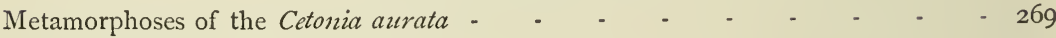

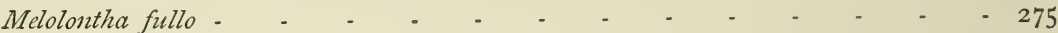

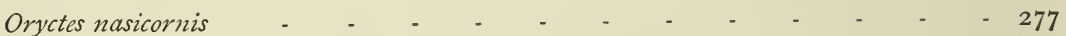

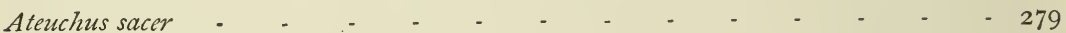

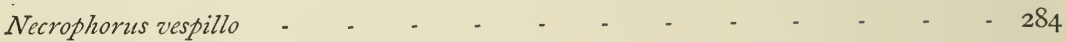

Silpha quadripunctata

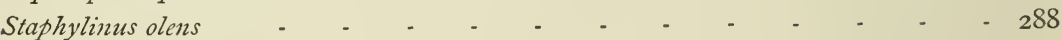

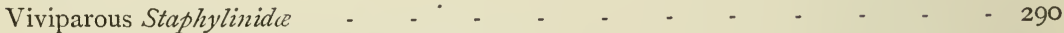

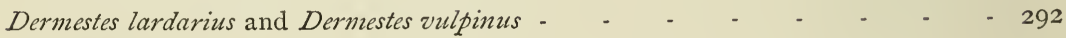

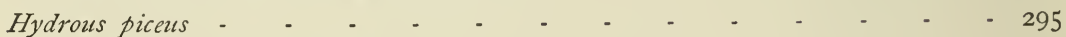

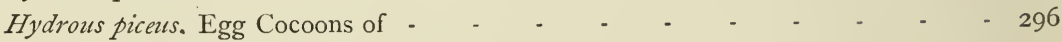

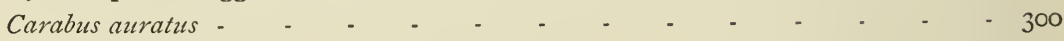

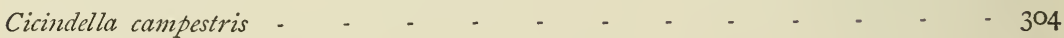

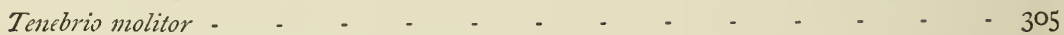

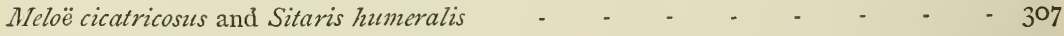

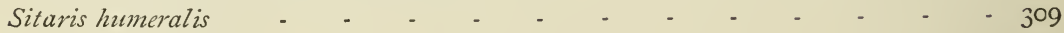

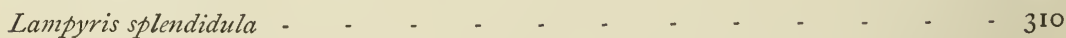

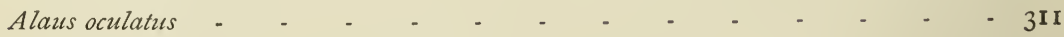

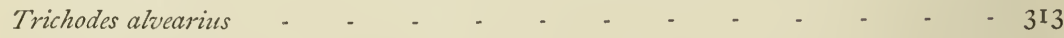

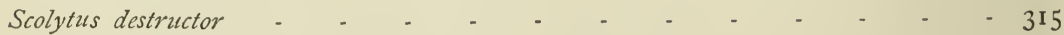

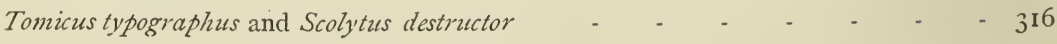


Rynchites Bacchus and Apoderus coryli

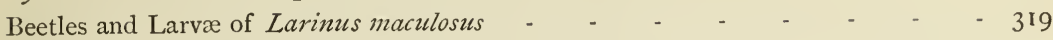

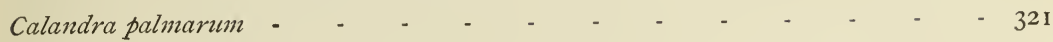

Calandra oryza, and Calandra granaria

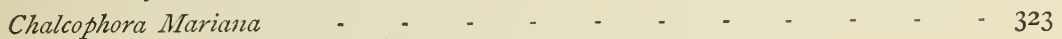

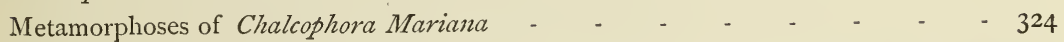

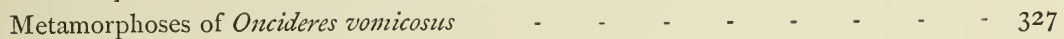

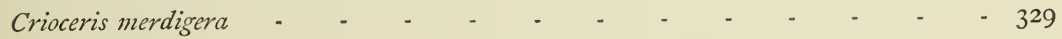

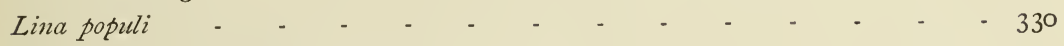

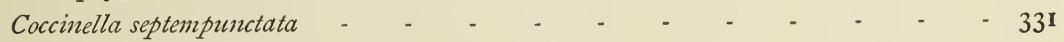

CHAPTER VIII.

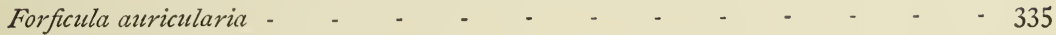

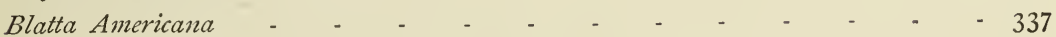

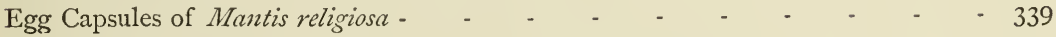

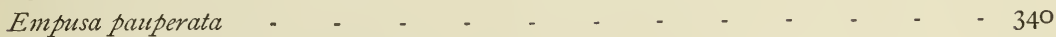

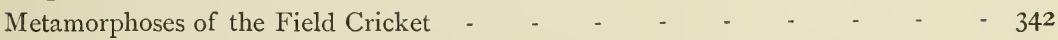

CHAPTER IX.

The Incomplete Metamorphosis of Thrips cerealium

CHA P TER X.

Termes lucifugum

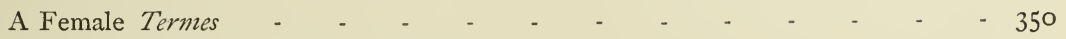

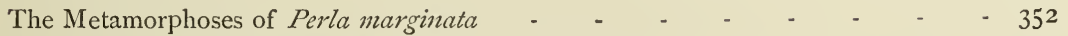

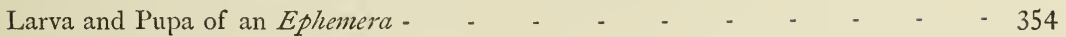

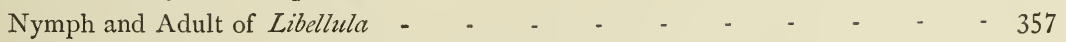

The Metamorphnses of Myrmeleon formicarium - _ - _ _ - - $\quad$ - 358

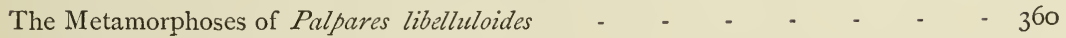

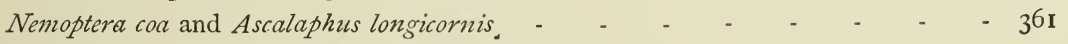

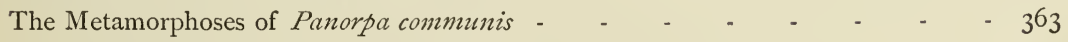

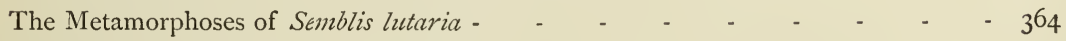

The Metamorphoses of the Caddis Flies - $\quad$ - $\quad$ - $\quad$ - $\quad$ - $\quad$ - 366

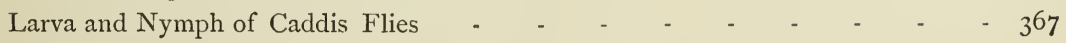

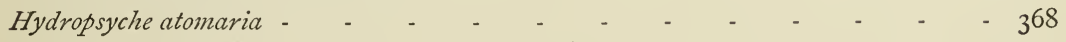

CHAPTER XI.

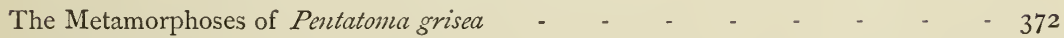

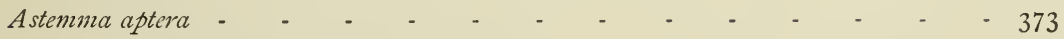

The Metamorphoses of Reduvius personatus _ $\quad$ - $\quad$ - $\quad$ - $\quad$ - $\quad$ - $\quad$ - 375

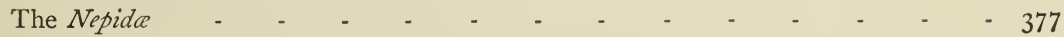

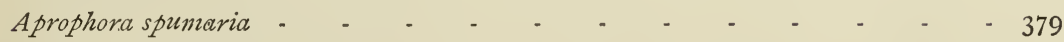

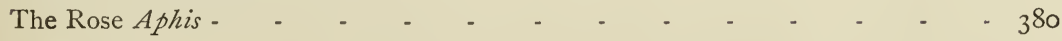

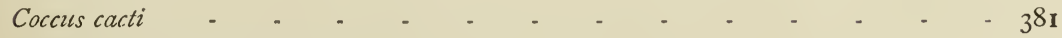

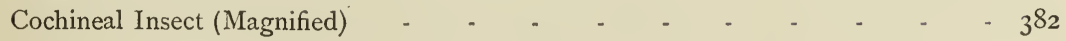


CHAPTER XII.

The Metamorphoses of the Flea -

Stylops aterrimus

Female and Larva of Stylops aterimus .

CHAPTER XIII.

Metamorphoses of the Gnat

Cecidomyia and Viviparous Larvæ

Tabanus bovinus

Strationys chamcleo

Volucella zonaria

Eristalis tenax

Gymnosona rotundata

Meat Flies

Ticks

CHAPTER XIV.

Philopterus selcifrons and Pediculus capitis.

Lepisma and Podura .

CHAPTER XV.

Fulus terrestris

Scolopendra morsitans -

Development of Fulus

CHAPTER XVI.

The Scorpion

Hydrachna geographica

Hydrachna globula

Itch Insect

Argyroneta aquatica

CHAPTER XVII.

Carcinus manas-Zö̈a

Young Lobsters -

Nauplius of Prawn

Zoëa of Prawn .

Older Zoëa

Mysis Form of Prawn

Palinumus-Zoёa

Species of Praniza and Anceus 


\section{P R E F A C E.}

THIS volume consists mainly of an adaptation of M. Émile Blanchard's popular work on the metamorphoses of insects for English readers. In order to complete the history of the evolution of some of the articulate animals which M. Emile Blanchard has not fully described I have selected much matter from the wellknown writings of George Newport, Dugès, Charles Darwin, Heroldt, Schiödte, Fritz Müller, Packard, Sir John Lubbock, Stainton, and Spence Bate; but at the same time I have eliminated large portions of M. Émile Blanchard's work, which, although very interesting, do not refer directly to the phenomena of metamorphosis. I have endeavoured to suppress all doubtful facts; and I have introduced here and there some opinions upon the nature of metamorphosis and its relation to the evolution of the creatures subjected or not to it. It is only just that $M$. Emile Blanchard should be relieved from the authorship of such opinions.

Students of the Articulata will, perhaps, be astonished at the amount of work there still remains to be done in the examination of the transformations of many important families of the Insecta, and I venture to express a hope that carcinologists will give me their kind consideration-owing to the great difficulty of the subject-when they read the chapter on the metamorphoses of the Crustacea, and especially that part which is an analysis of Charles Darwin's wonderful monograph. 



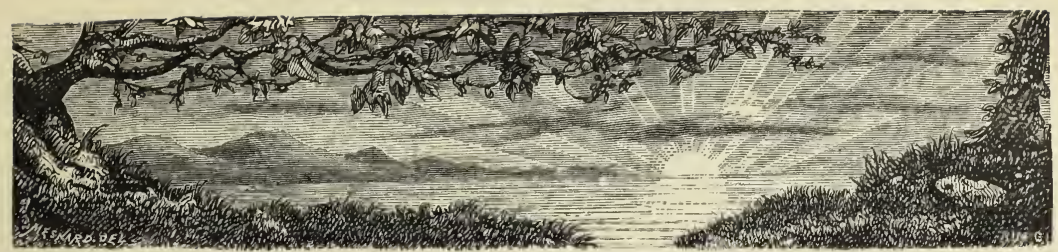

\title{
TRANSFORMATIONS OF INSECTS.
}

\author{
CHAPTER I. \\ THE INSECT WORLD.
}

THE beings which belong to the great zoological group of the Articulatic are found in enormous numbers in nearly every part of the world.

The articulate animals comprise those which the great Linnæus called "insects"- that is to say, the true insects, the hundred-legs, the spiders, and the crabs.

Insects existed in very remote geological ages, and their wings have been found beautifully preserved in the remains of those old forests and swamps which have been formed into coal.

Thus early in the world's history the beetle droned at eventide, and the merry chirp of the grasshopper was added to the song of Nature. Moreover, the hundred-legs of the period enjoyed the quietude of the great tree stems, and many a spider spread its web on the ferns and the close underwood. Coal is dug up from depths of hundreds of fathoms, and is covered by sediments which are the remains of old continents, and sea bottoms, the thickness of which is a measure of the time they took to form; yet so far back in the annals of Nature the tiny insects came from the egg, lived as gormandising grubs, changed into sleepy pupæ, and burst forth into lively winged creatures. Ever since, and during all the successive changes of the world's surface, insect life has manifested itself, and now articulate animals are found everywhere. 
Insects fly, crawl, and hum in the forest, along the fields, and about the marsh; and they swim, fight, and devour in the tranquil glassy pools hour after hour and without ceasing. They embody the very principles of vitality, activity, and destruction.

Myriads dance in airy flight over the frozen sea, and alight on the ice-bound coasts, where life appears to be impossible, and where a few Esquimaux lead a desolate and adventurous existence. They tease the reindeer, and drive them to the region of bitter frost; and they live upon the offal left by the hunters, or cast up by the tide.

Many a wandering butterfly has been welcomed by the Alpine climber in his solitude, and vast columns of them have clothed the rigging and sails of ships far out at sea with their painted wings. In the tropics, where Nature revels in an excess of gorgeous splendour, the beetles and the flies compete with the floral world in numbers and in magnificence of colouring. The fire-flies illuminate the shades in the short twilight, and move in graceful curves through the dense woods; and until night sets in the insect war continues.

In our temperate climates, where the sun is not so fierce and so constantly shining, the decorations of insects are not so intensely beautiful, but they are immensely appreciated; and the study of the anatomical details of all the kinds, and the examination of their habits and peculiarities, afford endless delight.

During one part of the year the activity displayed by the little world of insects is unequalled. The caterpillars, grubs, and larvæ eat with an incomparable appetite; they nibble and devour their food incessantly, and make haste to grow as fast as possible. They change their skins over and over again, and sleep for a while as nymphs, pupæ, or chrysalides, and awake to a new life, which has but a slight resemblance to the old. The winged insects pursue each other, and dance in great companies, urging their short love chase amidst the pendant boughs and the gayest flowers, and then seek restlessly and skilfully the proper places for their eggs.

Such industrious flies as the bees appear to live in order to work, and are so preoccupied with their undertakings that they seem never to have a moment to lose. There they are, making 
holes in the soil or in old walls, and building cells, or rushing from flower to flower gathering honey, collecting pollen, and not in a temper to be disturbed at their business, for they are putting by for the rainy day, and thinking of the store they must lay up with their eggs. A caterpillar is in great distress, and is traversing the sunshine in the strons grip of a gaily-coloured Sphex, which is about to place it in the nest, where its young will make a meal of it some day or other; and an Ichneumon fly, with its slim waist and long, slender body, armed with a sharp ovipositor, is just about to attack another heavy feeder, and to lay an egg beneath its skin. Well armed and cuirassed carnivorous beetles and dragon-flies are busy slaying and eating the quiet munchers of leaves and the suckers of flowers; and the delicate water insects are revelling in a constant fight, or are gormandising on their weaker prey.

Elsewhere there is a different scene of intense vitality. The blow-flies are hovering around, and are placing their eggs in the putrid dead body of a small animal, some beetles are burying portions of it, and soon a mass of maggots will revel in the rest.

Most wonderful are the uses of insects. They fertilise the soil by scattering decomposing matters, and prevent them from vitiating the atmosphere. A plant grows luxuriantly and increases too rapidly; the caterpillars arrest its growth and propagation; the caterpillars after a while become too destructive, and the Ichneumons kill them by myriads. The vegetarian insects which lead a luxurious and quiet life tend to increase greatly in number, and yet the carnivorous kinds are ever at hand to keep this prolific race within bounds. Century after century this curious equilibrium is maintained in Nature, and although occasionally locusts increase to such an extent as to ruin great districts, still, as a rule, the interference of man produces the ravages of the flies that injure his crops, for he constantly disarranges the balance of insect power.

The crab tribe represents the insects in the seas, along the coasts, and in the rivers, and its members lead all sorts of lives under very diverse circumstances.

It would appear that Nature requires the multiplication of the Articulata to be carried to the greatest excess, and that they 
should often lead different lives during the successive stages of their growth and development; that they should be able to live under most opposite conditions of existence, being clothed in most varied garb; that they should undergo metamorphoses.

Every civilised nation, during its early days, produced students of Nature who wondered at the metamorphoses of insects. They considered that there was a complete transformation of one being into another, and that the metamorphosis of the fable was repeated as a common condition in these lowly winged tribes. Scientific research and the results of the microscope proved, many years since, that this opinion was incorrect, and that the transformations were phases in the development or evolution of the animal.

The butterfly-the metamorphoses of which are most striking to the young observer-could never have existed unless it had completed its regular course of development, separated by distinct stages. The insect is born in an embryonic condition, that is, immature and imperfectly developed-born, as it were, too soon. The imperfectly developed insect is the caterpillar. The caterpillar receives in the egg the gift of the principal vital organs which are to be traced in the chrysalis and butterfly, but they have to be modified and perfected, and others have to appear at a more advanced stage of the development of the insect. During the early part of its existence the insect only requires an abundant supply of food, and grows daily in bulk, without there being any changes in its outlines and shape. Then, with increasing dimensions, come repeated skin sheddings and many internal alterations. It attains its greatest size, and then traces of new organs are to be discovered by the anatomist. Oftentimes old structures disappear.

The caterpillar then ceases to eat, and appears to shorten and to contract; the skin splits and falls off, and there remains an almost quiescent mass, the vitality of which is often doubtful in the eyes of the curious. It is an armoured being, some of whose outlines foreshadow a future condition; it is a mould wherein the changes of the animal alchemy are proceeding slowly and surely; it is the dross before the gold; it is the chrysalis, out of which, in due time, flies the butterfly. 
The beetles are born in a comparatively imperfect state, and no one could guess from their immature forms that they would eventually become what they do. In the first stage of their existence, after having escaped from the egg, they are grubs or larvæ, and they generally remain in this condition for a considerable time before changing into the quiet and motionless nymph, pupa, or beetle chrysalis. But the life of the mature insect, which escapes fully and elaborately formed and decorated from the shroud of the nymph, is usually limited to a few days.

The bees, wasps, and flies commence their existence as maggots or grubs, and have to submit to metamorphoses like those of the other insects.

But the grasshoppers resemble their fully-developed parents from the first. They are only deficient in the wings, which of all organs are those the most indicative of perfection. The young grasshoppers have very much the shape of the old ones, and their habits and dispositions also. Old and young grasshoppers, the first with and the others without wings, the adults and the larvæ, live very much the same sort of life, but the young ones change their skins several times during their growth. After the last moulting but one there are traces of wings which swathe the body, and the insect is then said to be a nymph; but it is not like the quiet chrysalis of the butterfly or the pupa of the beetle, for it is as active as the perfect adult into which it speedily grows.

Some insects do not undergo any metamorphosis, and in this they are imitated by the hundred-legs, and the greater part, but not all, of the spiders.

In the sea many of the Crustacea present transformations during their growth and adolescence quite as wonderful and interesting as those just noticed amongst the terrestrial insects. In most of the species of Crustacea successive changes of shape and of habits precede the perfection of the adult form. The heavy, slow-moving crab that crawls sideways over the rocks was once a sprightly, free-swimming larva, and so were all the shrimps; moreover, there are long-legged, active things, swimming in every sea, which are larvæ that have a most extraordinary fate. They are destined to be fixed by their heads to rocks, ships, and even 
to sharks and whales, and to turn into something much more dissimilar than butterflies are to caterpillars - into barnacles. Instead of their development progressing during the metamorphosis it retrogrades, and the adult creature is less perfect than the young.

Swammerdam, the great Dutch naturalist of the 17 th century, laboured to prove that the structural elements of the perfect insect were already within the caterpillar or larva, and he impressed upon his contemporaries and upon many of his successors that all the parts of the adult were in the creature as it escaped from the egg, but on a small scale. He considered that the glories of the fullydeveloped insect were masked in the tiny grub, and hence the name of larva. But careful anatomical researches and dissections, with the aid of the microscope, gradually disproved this idea of Swammerdam's, and by the beginning of this century the opinions of naturalists concerning the nature of the metamorphoses of the Articulata were much nearer the truth.

It had become known that some important organs which existed at one period of insect life were not to be found at others, and that new combinations of structures having peculiar functions and uses appeared during.growth.

Every one knows that a young chicken differs in shape from one just hatched. Now, the anatomists of the early part of this century laboured at the investigation of the alterations in the arrangement of the internal parts and organs which took place during the egg life of the bird, and they proved that the development within the egg was akin to that which entomologists were obtaining dim notions about with respect to the metamorphoses of insects. Later still, Von Baer and Rathke asserted that the early condition within the egg-the embryo-of all animals, had one aspect, but that soon essential differences in structure commenced, and determined the future shape and peculiarities of the adults. This is not consistent with modern research, nor is it true that the most important organs appear first of all in the earliest stages of life; but these theories had excellent effects upon the progress of science. And Milne-Edwards proved that the embryos of the kinds of Crustacea, which, when fully grown, are of the same genera or groups of species, resembled each 
other, and he demonstrated that in the case of kinds whose adults were very unlike in shape, the resemblance of the young existed for a certain period, and then anatomical distinctions began and progressed until perfection was arrived at. There are, therefore, changes inside the egg, and moultings and metamorphoses outside, during the life history of most of the Articulata.

Perhaps, when the matter has been more studied, the animal kingdom will be classified by observing the nature of the changes from the embryo to the adult form, and during the embryonic condition, but at present there are some difficulties to be overcome, for very similar creatures have different metamorphoses and grades of changes of shape.

That is to say, there are animals which resemble each other so far as their structures and habits are concerned, and which go through complete metamorphoses, and others that only have to submit to slight changes of shape and structure. The difference is most striking, but, nevertheless, when the immature forms, and even the adults, are anatomised, the greatest resemblances are detected between them. The beetles-for instance, the cockchafer and the stag beetle-are born in a very incomplete or embryonic condition. Insects of the order of the Orthoptera - the grasshoppers or the earwigs-on the contrary, when they come out of their eggs nearly resemble their parents, and they do not undergo true metamorphoses. But the beetles and the grasshoppers, so far as the details of their construction are concerned, do not show any but secondary differences. The beetles have greater structural resemblances to the grasshoppers than they have to the butterflies, yet they resemble these last in their method of development and evolution. Similar peculiarities may be detected amongst the Crustacea. The lobster and the prawn are closely allied by their similarity of construction; but the first hardly undergo a change, whilst the last present three forms before reaching the mature beauties of prawn life.

It would appear-after studying the metamorphoses of the Articulata and their skin sheddings, which are really the external evidences of an inward transformation, which is not marked by a great break or phase in the insect economy-that these inte- 
resting phenomena have been added to insect life since the beginning of it.

How clearly it is the truth that the metamorphosis of insects is but a progressive development of the immature into the mature being, can best be seen by a slight examination of some of those structures which are altered during growth, and of those which appear during the consecutive stages of life.

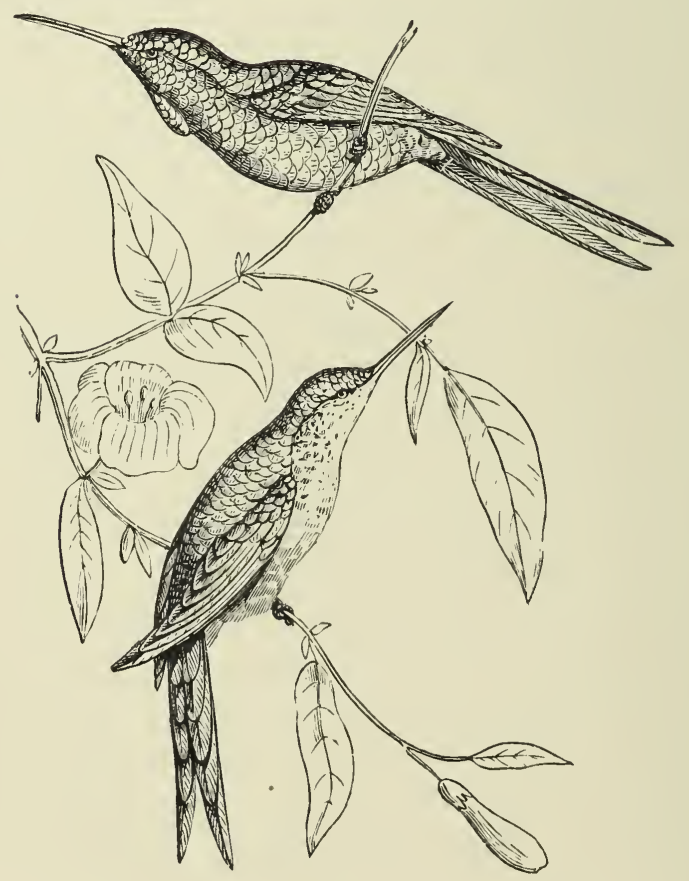




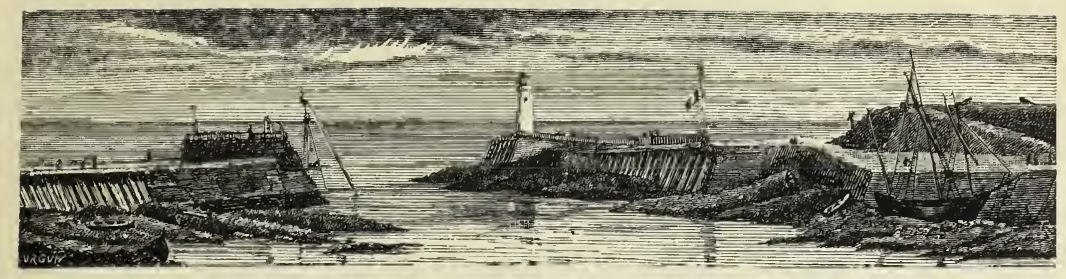

CHAPTER II.

STRUCTURES IMPLICATED IN METAMORPHOSIS.

THE external covering of insects varies greatly in its consistence. It is generally a tough and flexible skin. The integument of some full-grown insects is almost leathery, but in the majority all the outside tissues are very thick, solid, and hard. They look like horn, but their intimate composition is very different. Horn dissolves away, but the integument of insects carbonises and retains its form when exposed to great heat, and their chemical composition is different. This integument, whether it is as thin and flexible as the skin of a silkworm, or as hard and dense as the envelope of a beetle, is always composed of a particular substance, called chitine.

The skin is formed of two layers, one deep, soft, and not made up of chitine, and the other external and constituted mainly of this substance, to which are added, according to the advanced or retarded condition of the development of the insect, more or less colouring matter, fat, and calcareous salts. The deep layer is the true skin, and the superficial is the epidermis or scarf skin. It is the epidermis which is detached and moulted off during the progress of growth and development, for instance, when silkworms change their skins, during their caterpillar state. Both layers are intimately connected, and the true skin has small glands in it whose tiny ducts traverse the epidermis, and even enter the hairs. The epidermis is composed of an assemblage of very regularly-shaped cells containing colouring matter. If the skin of a caterpillar, a chrysalis, and a butterfly is examined, the marvellously beautiful cells and hairs of the perfect insect can be seen to be modified 
epidermal cells, whose predecessors were infinitely more simple and less elegant in the immature insect.

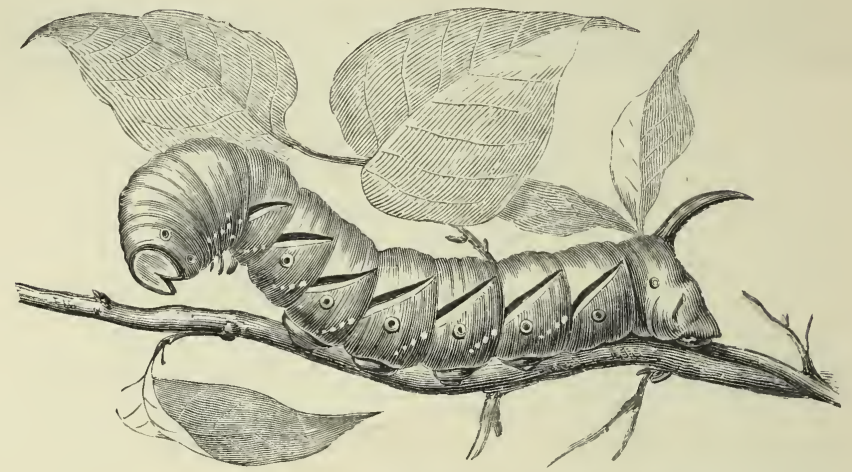

THE CATERPILLAR OF Sphinx ligustri (THE PRIVET IIAWK MOTH).

It is the essential peculiarity of articulate animals to be divided into segments or rings, and these somites, as they are sometimes

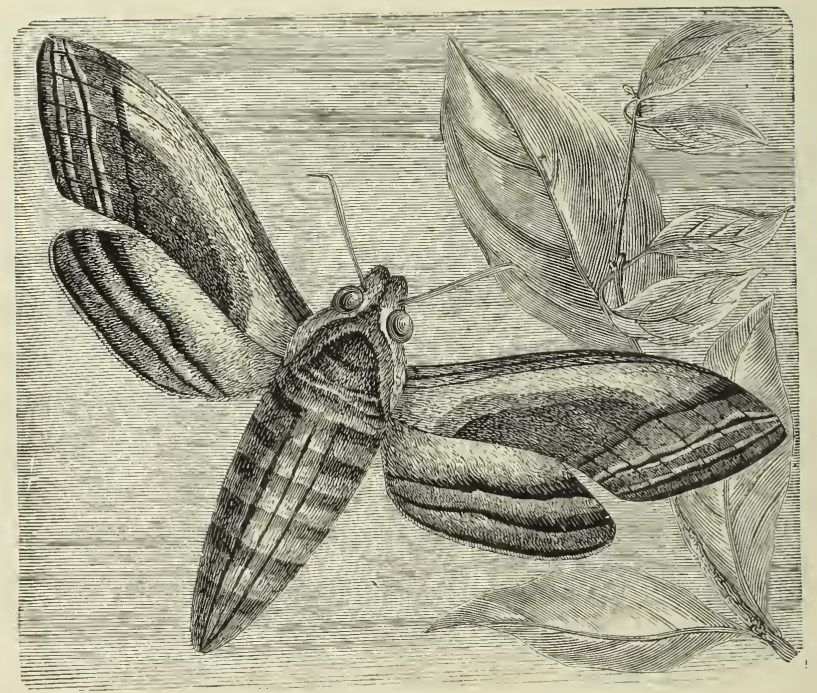

TIE MOTH OF Sphinx ligustri.

called, can be traced in the embryo within the egg, in the larva, nymph, or chrysalis, and in the perfect insect. Huxley distinguished six segments in the head of the young insect, and he 
has expressed the opinion that less than four are never found in that part. But after growth has proceeded even for a short time the segments of the head become fused, as it were, in one mass, and are no longer distinguishable. The body segments of many larvæ present very slight differences, and have, therefore, a general likeness to each other; but the perfect insect is evidently furnished with three sets of segments, those of the head, body, or thorax, and abdomen. The segments of the head of the larva are fused together, but those of the thorax, or chest, and of the abdomen, remain distinct. The head of the larva is readily distinguishable

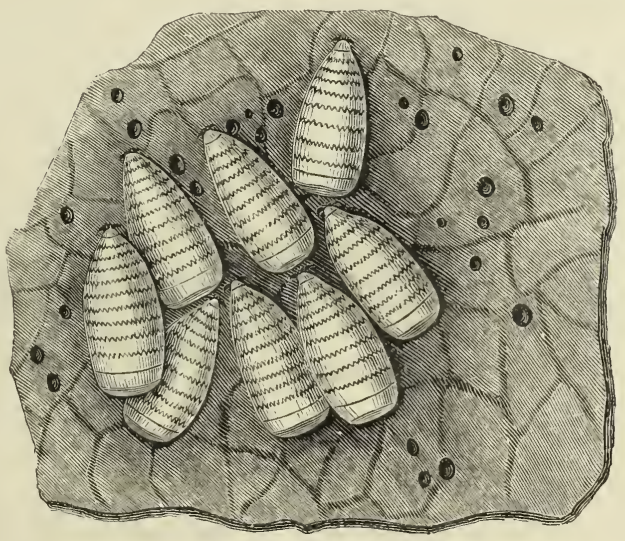

LARTE OF A DIPTEROUS INSECT.

from the rest of the body, but as there are no feet attached to the segments of the thorax and abdomen in hymenopterous and dipterous larvæ (bees and flies), no satisfactory distinction can be made between the parts of those insects. However, in most caterpillars and beetle grubs the presence of two classes of legs enables the rings of the chest and abdomen to be numbered and recognised. In its most simple condition, as seen in a great many larvæ, a segment is homogeneous throughout, and a transverse depression along a line where the tissues are thin separates it from the others. These separations of the segments are shown in the representation of the legless larva of the dipterous insect. In other instances there are two arches in each of the growing segments, one above and the other below, and a mem- 
branous space is to be observed on either side of the body between them. Moreover, each arch is formed of two side halves, and there is often a very distinct line of separation to be noticed between the portions of the arches, and also a mark which occupies this position on the head and along every segment of the body of the grub or caterpillar. This middle or median line is well seen in the immature Calosoma sycophanta. (See page I 5.)

The segments of the abdomen, which are not provided with true legs, appear to be at first nine in number, and there are some larvæ which have twelve or more of them. Now, on comparing the segments of the larva, chrysalis, and perfect insect of the same species, it is noticed that the changes in the form of the

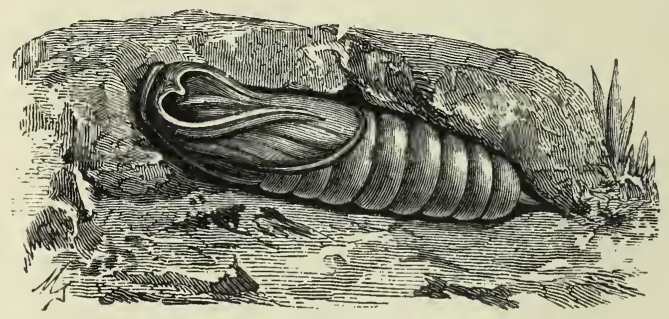

CHRYSAI.IS OF Sphınx ligustri.

insect are not brought about by an alteration in the consistence of the integuments only, but by a diminution in the number of the rings or segments. It is true that this diminution is rather deceptive in its appearance, for there has not been any fading away of the segments, but really a union and a consolidation of several in one or more single and separate pieces. Thus it is not uncommon for the first rings of the abdomen to become united to the last segment of the thorax or body, or for several of them to conjoin and leave very faint traces of their former distinctness.

Take as an example a kind of lepidopterous insect-a mothwhose metamorphosis, so far as regards the shape of the caterpillar and perfect insect is less than is usual. The large Attacus pavonia maior is admirably adapted for our purpose.

The abdomen of the caterpillar commences at the fourth segment of the body, as in all other insects, and is formed of nine nearly equal rings; the last but one is, however, shorter than the others, 
and the body ends in a tubercle. Their consistence is the same throughout, and the constituent membrane is almost homogeneous. The third, fourth, fifth, sixth, and the ninth segments of the abdomen have a pair of tubercles furnished with spines on their underneath or ventral surface. These tubercles, which are destined to disappear when the insect passes into the chrysalis

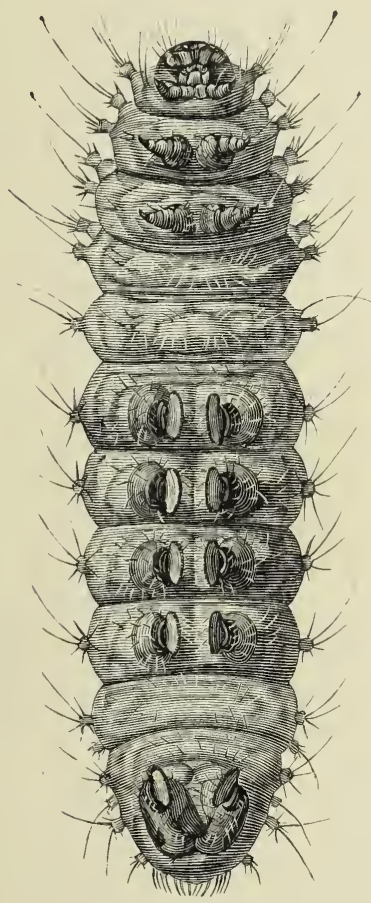

LARVA, OR CATERPILLAR.

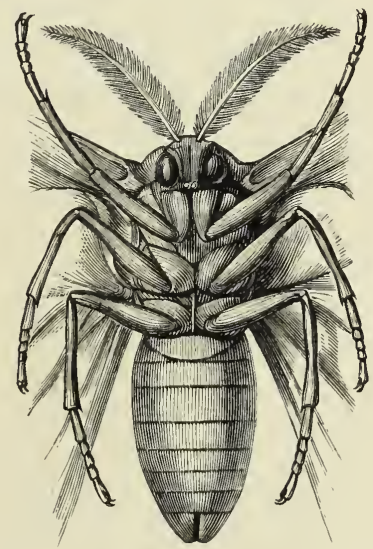

ADULT FORM, OR MOTH.

The same insect, Attacus pavonia major, in the larval and adult stage, seen from underneath.

condition, act as legs. They are not true legs, but only prolongations of the skin; but they are used as holders and locomotive organs, and under the term of membranous feet or legs are invariably present in caterpillars.

Now compare the abdomen of the moth with that of the caterpillar.

The number of the segments is no longer the same, and only seven can be counted. The first has joined itself to the chest-piece 
or thorax; the last two are rudimentary, and have become closed in at the end of the abdomen, like the slides of a telescope. A closer examination of the inside of the moth proves that certain changes in the length and grouping of the important nervous organs have accompanied this shortening and coalescence of the abdominal segments.

The change in the consistence of the integuments is very decided in the chrysalis. It is not at first very evident in the moth, but if the body of one is cleared from the hairs which clothe it, the dorsal (back) and ventral (underneath) portions will be noticed to have become coriaceous, whilst the lateral parts or the sides have retained their former softness. The vestiges of the two arches of the original segments are thus preserved.

Many insects, instead of having soft skins like the moths and
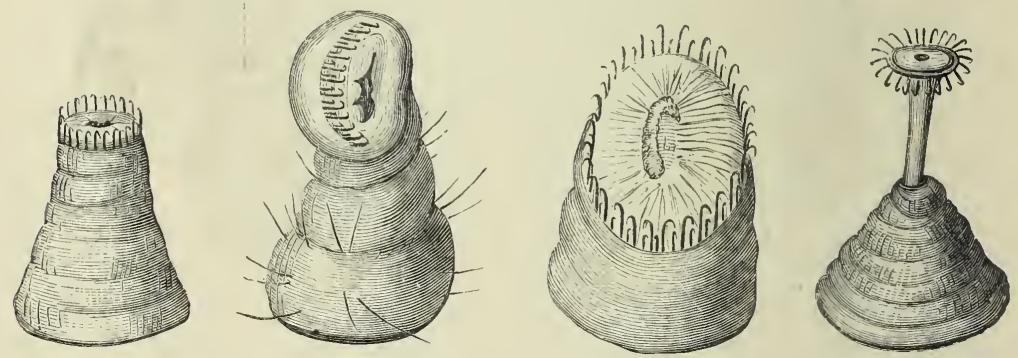

MEMBRANOUS LEGS OF THE SILKWORM CATERPILLAR NOT FOUND ON THE MOTH.

caterpillars, have the integument of the abdomen very hard and strong. Such is the case with most of the larvæ of flesh-eating beetles, which come out of the egg much more mature than many others, and whose abdominal segments are nearly covered with solid plates.

Let us examine the larva of a large carnivorous beetle, the Calosoma sycophanta. The abdomen consists, as in the caterpillars, of nine distinct segments; ten might be counted if the terminal tubercle were considered to be a ring. Examined from above (dorsal), the rings show a large back piece, divided by a groove in the middle, and on either side a small plate answering to those which are to be seen just above the junction of the legs to the thorax. It may be noticed as a faint line between the 
large back plate and the margin of the body, in the engraving. The large cross piece and the smaller side plates form the dorsal arch. In the centre of the lower side of the segment two
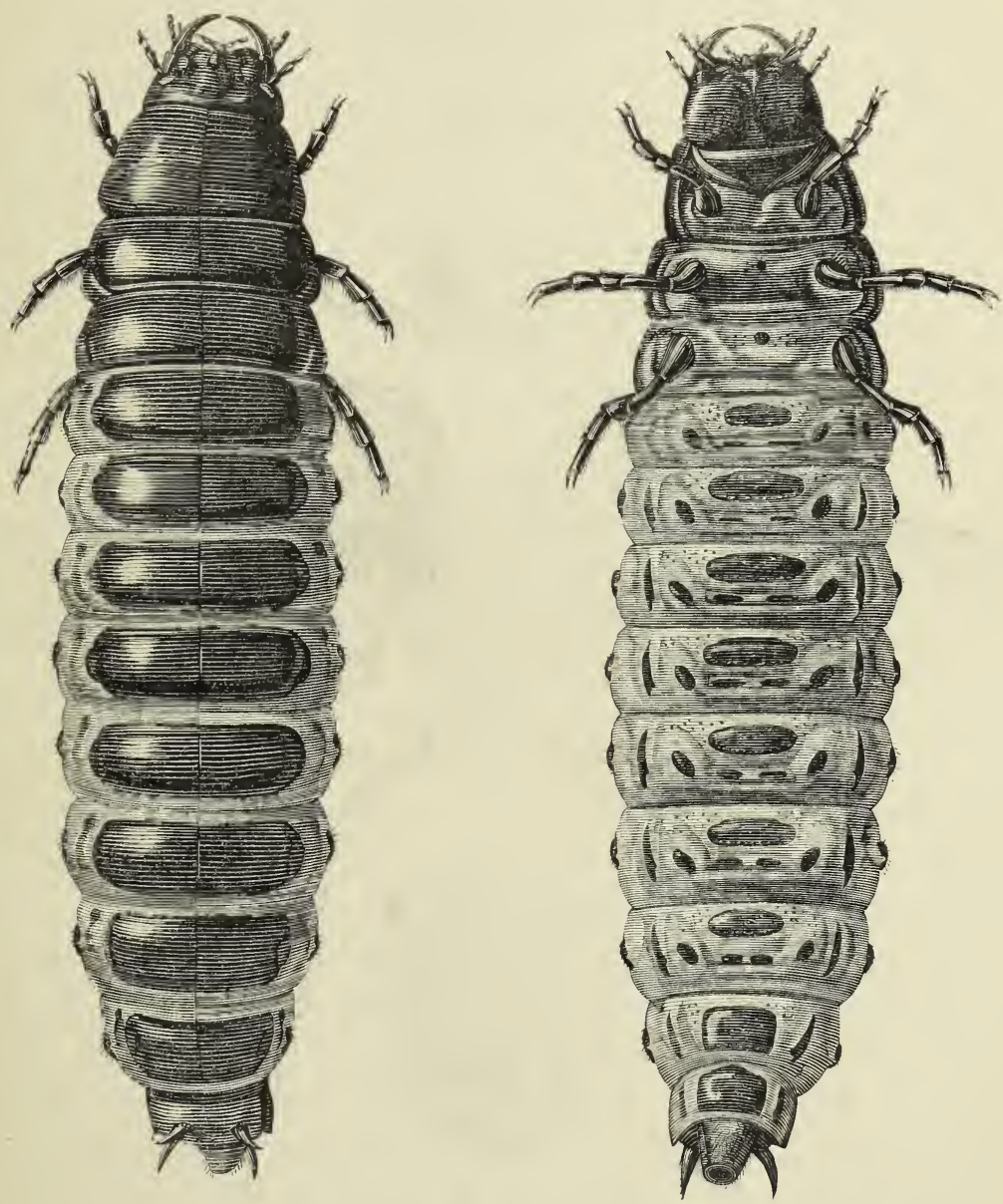

LARVA OF Calosoma sycophantu.

Magnified upper and under sides (dorsal and ventral).

transverse series of solid plates may be noticed, the first formed of a single large piece, the second of a range of four very small ones. By their coalescence these separate portions will eventually form the ventral or sternal lamina or plate. The simple arch of the segments of the abdomen of lepidopterous 
insects or butterflies is formed by a single lamina or plate, commencing from two points of induration; but the more complicated

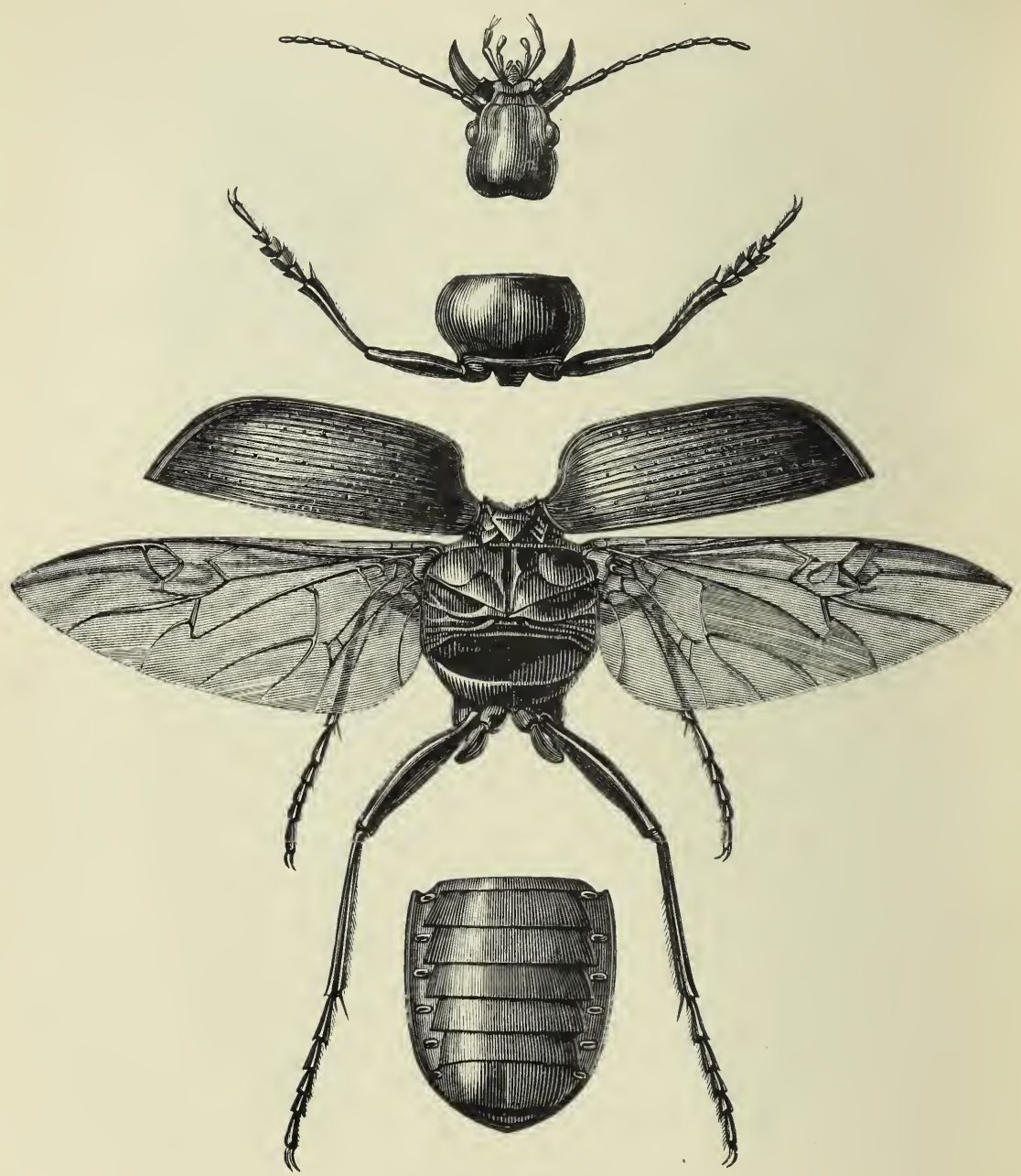

Calosoma sycophanta.

The beetle with the head, the portions of the thorax, and the aldomen separated and magnified.

arch of the larva of the beetle results from the union of two series of pieces.

The thorax is that part of the body which gives origin to the legs and wings. In this class of insects the thorax is invariably formed by the three segments which follow the head, and the 
second and third rings support the wings. The presence of legs and wings involves a considerable development of the segments of the thorax, and particularly of the second and third, for there must be abundance of space within for the passage and attachment of the muscles, which, influenced by the will of the insect, move the legs and the organs of flight.

The description of the parts of the thorax is not difficult to understand.

The first segment of the thorax which articulates with the back of the head is called the prothorax; the second, to which the first pair of wings is attached, is the mesothorax; and the third, bearing the second pair of wings, is the metathorax. The method of the formation of the abdominal segments is the key to that of those of the thorax. The great development of the mesothorax and metathorax does not usually take place until chrysalis life has progressed.

The larva of the Calosoma has its thorax well armoured. Above, the three segments are clothed-as is the case with the abdominal rings - with a double dorsal plate with the small lateral piece on either side. This is the upper arch. The dorsal plate is very large, but it does not exhibit any cross markings or any transverse division, but in the adult beetle four distinct parts are added to the two segments that support the wings. The rings of the under part of the thorax of the same larva are principally membranous. A small plate which is to be observed in the centre of each is the sternal piece. It is very small and rudimentary, but it becomes very large and fully developed in the beetle.

The mesothorax and metathorax become very large in proportion to the rest of the body in the insects which have wings, and are often so united by growth that they cannot be separated. The mesothorax, which supports the first pair of wings, is almost always better developed than the metathorax, and the constituent parts of the first ring are generally more distinguishable than in the last.

The dorsal piece, so simple in the larva, has four transverse divisions in the beetle, marked out either by ridges or grooves. They can be readily distinguished in the Calosoma sycophanta 
These pieces are intimately united, and have been called prescutum, scutum, scutellum, and postscutellum. The first is always very rudimentary, and is a little lamina placed vertically to the edge of the segment, and remains in a membranous condition in a great number of insects. The second, which supports the wings, is larger. The third, often very small, is placed between the wing cases of most beetles. The last piece, often reduced to a mere ridge behind the third piece, assists in the formation of the joints of the wings.

The thorax sustains the locomotive organs. These are the true legs which belong to the lower arches of the segments, and the wings which are connected to the upper arches.

The true legs often exist in the young insect, but are then very small and scale-like, and they do not attain a considerable size until adult age is reached. They are from the first in three

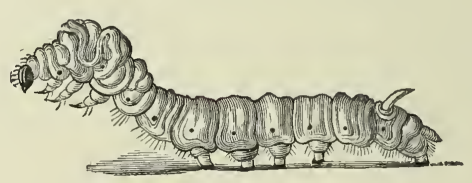

L.ARVA OF THE SILKWORM.

TRUE AND MEMBRANOUS LEGS.

pairs. Those attached to the prothorax are the anterior legs; those of the mesothorax are the intermediate; and the posterior are in relation with the metathorax.

The legs upon the segments of the abdomen are, as has already been noticed, not persistent; they exist in caterpillars especially, and are really membranous feet, being provided with hairs, spines, and hooks to hold on with, but they are lost during the metamorphosis into the chrysalis condition. The front or true legs are the curious jointed structures so finely hairy and so well provided with suckers, claws, and brushes of hair, and are mainly developed during the period of rest which characterises the chrysalis state.

The distinction between the true legs and the sucker-like feet of the caterpillar is very observable in the engraving of the silkworm larva; the true or scale-like legs are in front, and are not adhering to anything, but the membranous legs support the insect. 
The joint in the legs of the perfect insect nearest the body is called the hip or coxa, the next the thigh or femur; then the leg or tibia succeeds, and finally the many jointed tarsus with its hooks.

It has already been noticed that the larvæ of many kinds of insects are entirely destitute of legs and feet. Thus the grubs of the hornet, Vespa crabro, are legless; and yet the remarkably

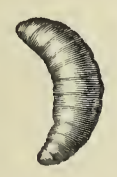

THE LEGLESS LARVA OF THE BEE.

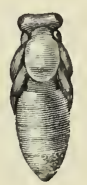

NYMPHS OR PLPA OF THE BEE.

active limbs of the perfect insect have to be developed with all their muscles and nerves during metamorphosis; and the apodal or legless condition of the larvæ and pupæ of the worker bees may be understood by examining the engraving of them.

The legs of insects, although true locomotive organs, are often adapted to an infinitude of uses, and they are formed in numerous shapes, and present innumerable special structural adaptations, so

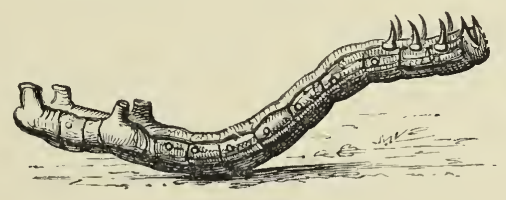

CATERPILLAR OF A "LOOPER."

that their study is really most interesting. Nevertheless, whatever may be the shape of the legs, their uses and functions, or their condition of development, they are always formed upon a definite plan, and have certain anatomical peculiarities. No better idea of the extraordinary development of these locomotive organs in the perfect insect, and of their rudimentary condition in the larva and before metamorphosis has taken place, can be obtained than by comparing the figures of the larva and adult Calosoma.

The membranous feet are not fully developed in some caterpillars, and the "loopers" in particular have rarely more than two instead 
of five pairs of them. The absence of the central legs produces the curious appearance of these well-known insects. In the engraving the fore-legs are also shown, but they are very small and pointed, whilst the two pairs of membranous legs are short and distinct.

The wings exist in the great majority of perfect insects. They are four in number, and are in two pairs: one is attached to the mesothorax and the other to the metathorax. One of the largest divisions of the class of insects (the Diptera) is supposed to contain species that only have two wings; but the wings of the second pair do exist, although they are in a very rudimentary condition.

In most insects the wings are either like a transparent membrane, or are covered with dusty scales of microscopic size, the whole being stretched upon hard radiating nervures; but in one entire order the anterior wings have the consistence of the skin of the body, and form a sort of case to the upper parts of the insect. The membrane of the wings is to all appearance simple, but it is really double. There is no trace of a wing, or anything approaching to it, in the caterpillar, but the shape of the thorax of the chrysalis indicates that these wonderful organs are in course of formation whilst it is motionless and inactive. Immediately after the chrysalis is formed, and just before the caterpillar's skin which covers it for a while is burst and detached, the wings and some other organs may be traced in a very rudimentary condition. Réaumur has given the two accompanying views of chrysalides, to show the wing cases in their natural position, and when removed by a little management with the antennæ from the lately-formed pupa. When the butterfly bursts forth from the skin of the chrysalis, its wings are often so moist and so unfinished that it is easy to see they are formed of two membranes, between which run the nervures which enable the insect to move them in its flight.

The heads of insects are composed, like the other portions of the body, of several segments; but, although this is a fact, its demonstration has not been satisfactorily completed. At the birth of the larva no satisfactory division of the head into segments can be detected; but knowing, as we do, that each pair of appendages-legs and wings-is attached to a particular seg- 
ment, and observing that the lower part of the head has four pairs of attached organs - the upper lip, the mandibles, the jaws, and the lower lip-the early separation of the head into four segments is fairly inferred. Probably there were six.

There is an evident design in the manifold differences of the jaws and eating apparatus of insects, and the long tubular sucker of the butterfly refers to it quite as much as the horny crushing
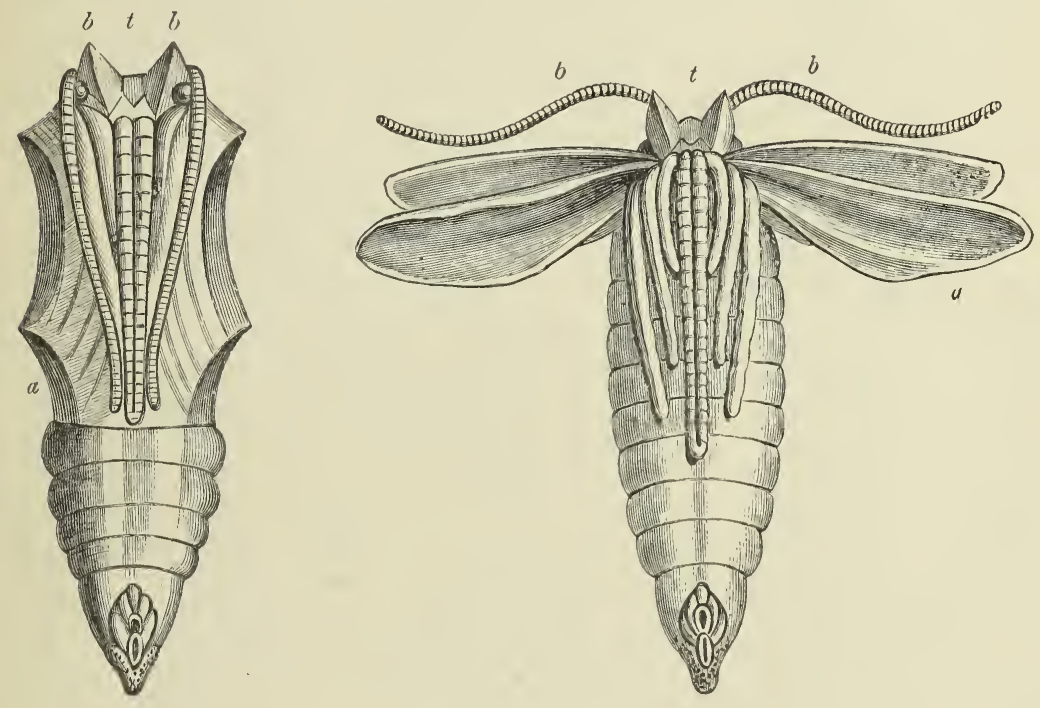

CHRYSALIDES.

Magnified to show the wing-cases and the rudimentary antennæ and other organs.

(After Réaumur.)

a. Wings. b. Antennx. t. Proboscis.

jaws of many hard-skinned beetles. The change from the leafcutting jaws of the caterpillar to the suction tube of the butterfly is a proof of this unity of plan, and that with different instincts, habits, and methods of life there arise different modifications of structures. The examination of the mouth of an eating or mandibulate insect is very instructive. Take, for instance, one of the grasshopper tribe, and examine the different pieces attached around the opening down which the food passes into the stomach.

The mouth is provided with six articulated pieces:-a labrum, or the upper lip, two mandibles, two jaws, or maxillæ, and an 
inferior labrum. The curved appendages to the maxillæ and the lower labrum are palpi. Now in caterpillars the upper lip is well grown, and there are two strong mandibles working from without inwards, two jaws, and a lower lip. There is thus the clearest resemblance between the mouth of the grasshopper, when it is a
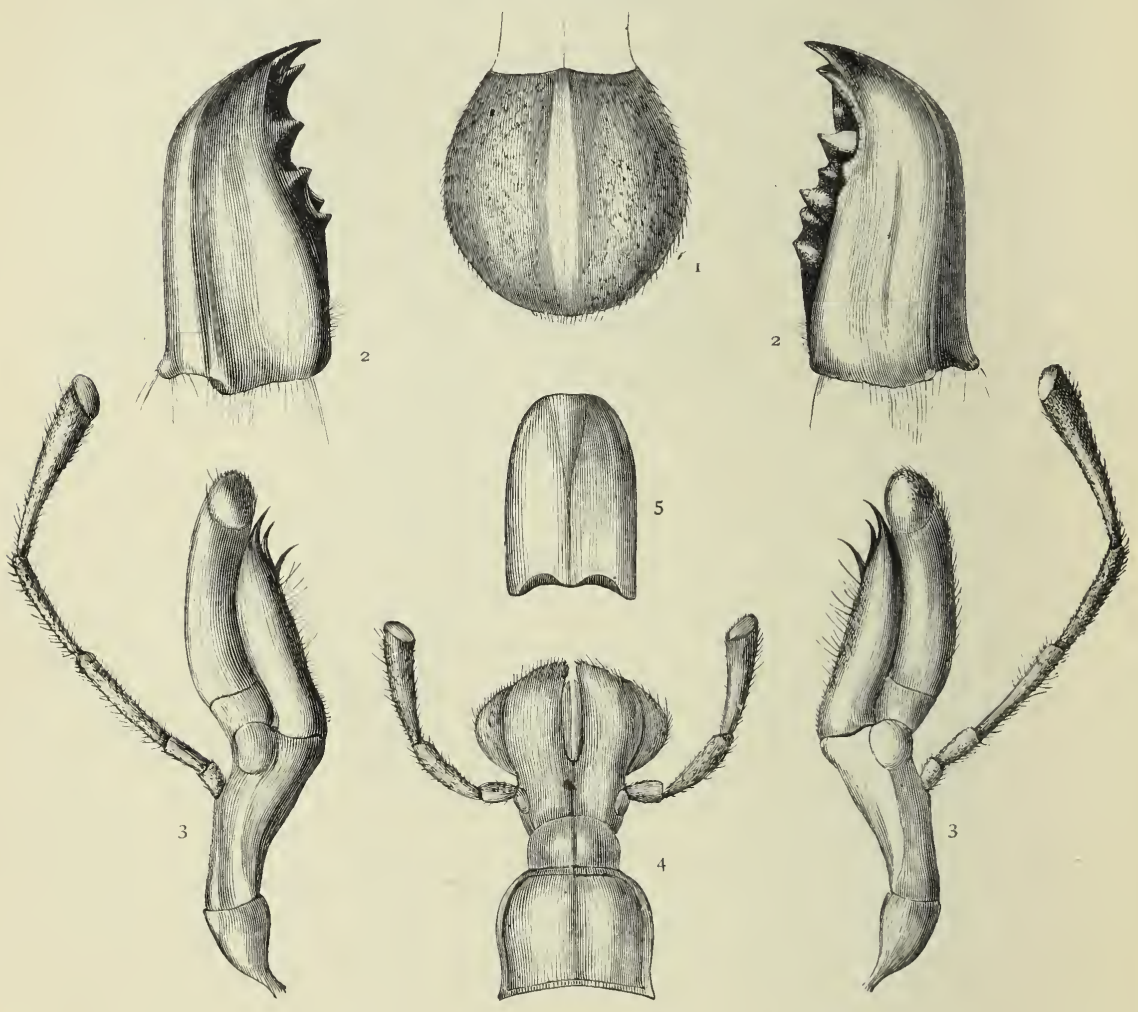

ANATOMY OF THF, MOUTH OF Locusta viridissima.

I. The labrum or upper lip. 2. Mandibles. 3. Jaws. 4. The lower labrum. 5. Tongue.

perfect insect, and that of the immature caterpillar. Let metamorphosis go on, and the browsing caterpillar becomes a sucking butterfly; though at first, no one would think there was the slightest connection between the early and the late condition of the mouth. A slender trunk and two scale-like feelers, or palpi, below it are the only apparent structures of the butterfly's mouth. But a careful examination reveals the fact that the three pairs of mouth 
pieces are all present, although in a very different condition of form. By removing the fine hairs and scales from the front of the butterfly's head, a small transverse lamina is observable, and its relative position determines it to be the small upper lip, once so large in the caterpillar. On either side and beneath the labrum is a very small piece of skin-the remnant of the once formidable and trenchant mandible. Beneath these is the long trunk, formed by two long and flexible structures, hollow and tubular, and at their base is a pair of small palpi. The flexible tubes are altered inflexible jaws, and the palpi are accessory organs. Below all
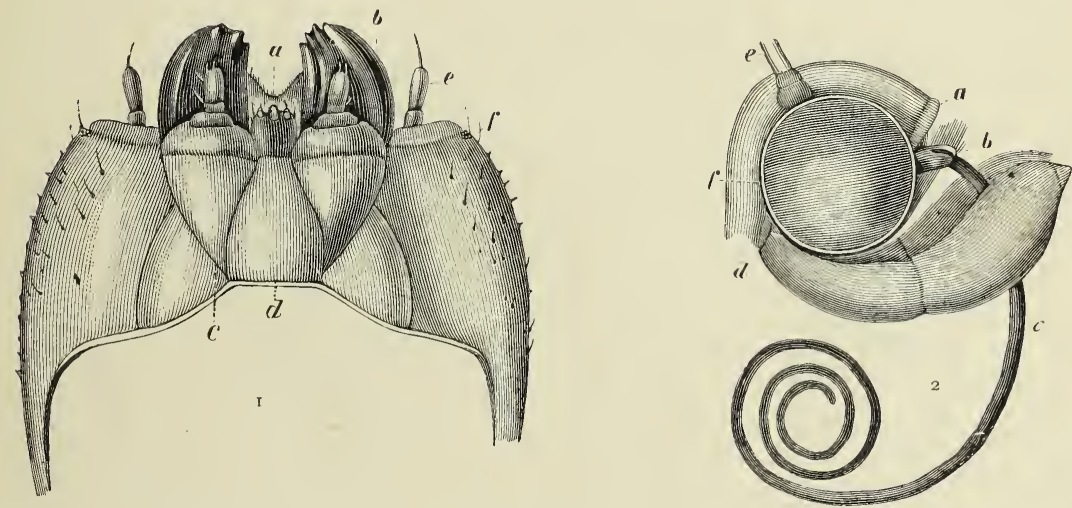

MOUTH OF THE PRIVET HAWK MUTh (Sphinx lygustri) Magnified.

I. The Larva. 2. The Perfect Insect.

a. Upper lip. b. Mandibles. c. Jaws. d. Lower lip. e. Antennæ. f. Eyes.

is the inferior labrum, with large palpi attached to it instead of small ones. The suctorial insects, such as the bees and flies, have transformations of the structures of the mouth quite as wonderful as those just mentioned, and they will be noticed further on ; but enough has been said to show what is the nature of the metamorphosis in these organs.

The other appendages to the heads of insects are the antennæ, commonly called feelers, and the eyes. The eyes are generally developed rather late. Many larvæ are blind, and others have immature organs of vision. But in the perfect and adult insects, the eyes are often enormous in size, and most recondite in structure. There are often two kinds of them. Some are very large, and 
are situated on either side of the head; these are the compound or facetted eyes. The others are found upon the head, above the upper lip, and they are simple eyes or ocelli. The compound eyes are never found in the larva, and yet it is evident that the simple organ of the caterpillar is developed into the wonderful eye of the butterfly, with its ten or fifteen thousand hexagonal lenses. The compound eyes are generally largest in the male insects, and they are frequently magnificently decorated with hairs and with metallic colours. The ocelli are often placed between the compound, and glance like diamonds.
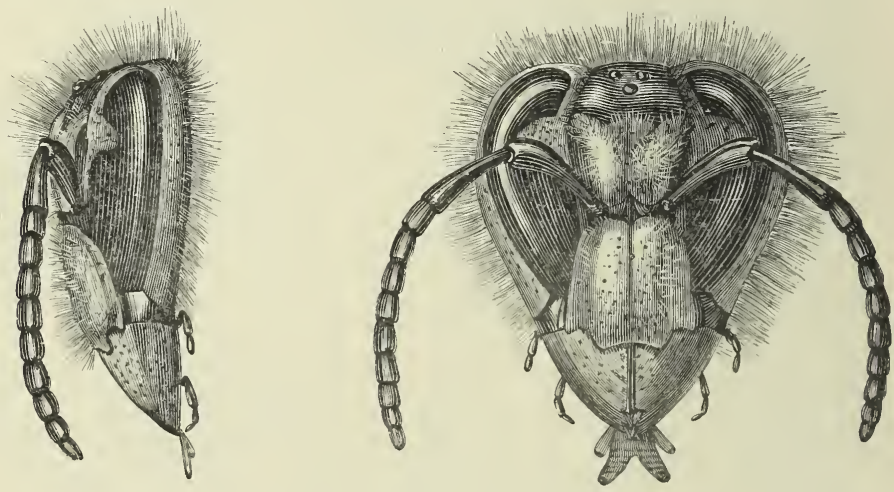

HEAD OF A HORNET (Vespa cralro).

Enlarged view, showing the lateral compound eyes, the ocelli in front on the forehead, and the antennæ.

The antennæ present every imaginable shape and length, and are situated on different parts of the head in different insects. They are always very small in the larva; they have, however, important functions in the perfect insect, and in which they attain their greatest development.

One of the results of the progressive development of the insect is the addition of the organ of hearing to that of touch, which last probably exists in the small antennæ of the larvæ. Erichson, a German entomologist, and Dr. Braxton Hicks, F.R.S., discovered numerous depressions in the antennæ of fully developed insects, which are lined with a delicate membrane; and the last-named naturalist found that a small cell, made up of several others, and 
situated beneath the membrane, was continuous with a nerve which is supplied to the antennæ. This may be the organ of hearing or that of smelling; and to whichever sense it may truly belong, it is clearly a new structure, developed after caterpillar life came to a close.

Having thus briefly noticed some of the modifications of the outsides of insects during the metamorphosis, let us consider how the digestive, nervous, and respiratory organs are altered during the progressive evolution of the perfect insect from the caterpillar condition.

The digestive organs in insects are more or less tubular, and are continuous with the structures of the mouth. They extend from one end of the body to the other, and are either short and straight or long and convoluted. Certain swellings and contractions of the digestive tube mark the principal divisions of it, and enable us to distinguish an œesophagus, a stomach, a small and a large intestine. Some glandular appendages, tubular in shape, complete the digestive apparatus; they are the salivary glands, the liver, and urinary tubes. The alimentary canal is formed of several layers : first there is on the outside a delicate, structureless mem.brane; then beneath it a muscular coating, consisting of fibres arranged across and lengthwise, and which become very dense at both ends of the canal; a mucous membrane is situated beneath this muscular coat, and its inside is covered with multitudes of epithelium cells, which have to do with the production of the fluids of the digestive function and to come in contact with the food.

After the food has been masticated or sucked in, as the case may be, it passes into the mouth, and then into the gullet or œsophagus, being, first of all, mingled with saliva from the glands.

The œsophagus is a passage possessing very dilatable walls, and passes through the thorax in a straight line. In the insects which live on fluid aliments it is usually narrow, but in those which devour more or less solid morsels it is large and has a considerable calibre. There is, in many perfect insects, a considerable enlargement at the back part of the gullet, called the crop. It permits the insect to accumulate and keep a store of nourishing things, without digesting them all at once. This crop is very generally to 


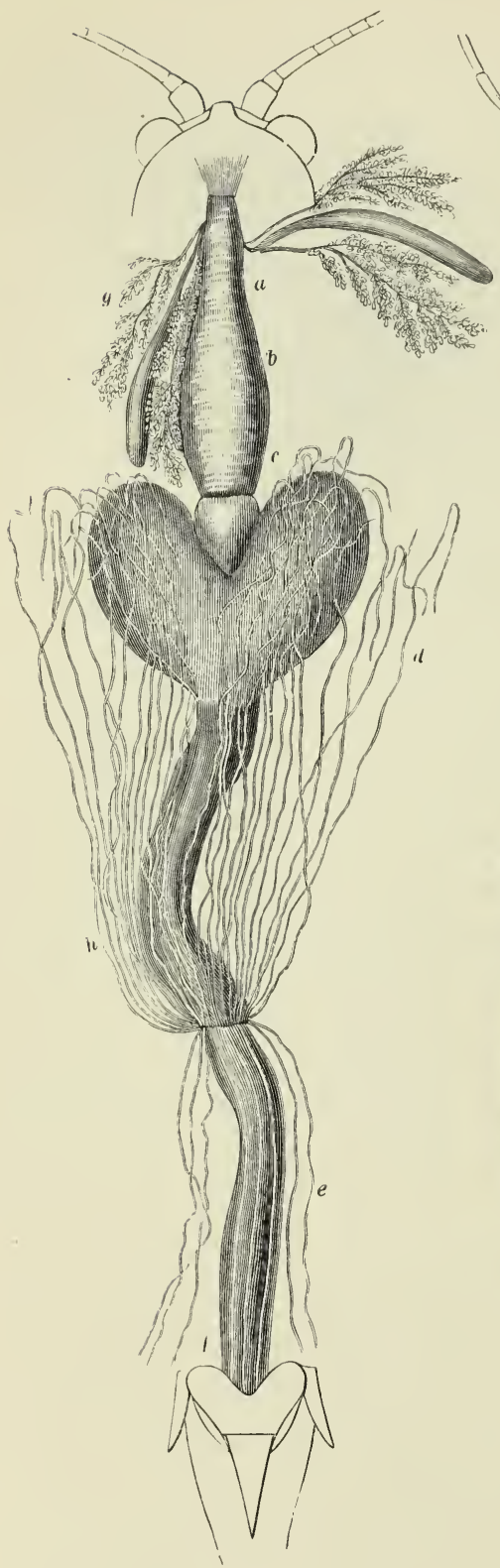

DIGESTIVE APPARATUS OF AN HERIIVOROUS INSECT,

THE GREEN GRASSHOPPER

(Locusta viridissima).

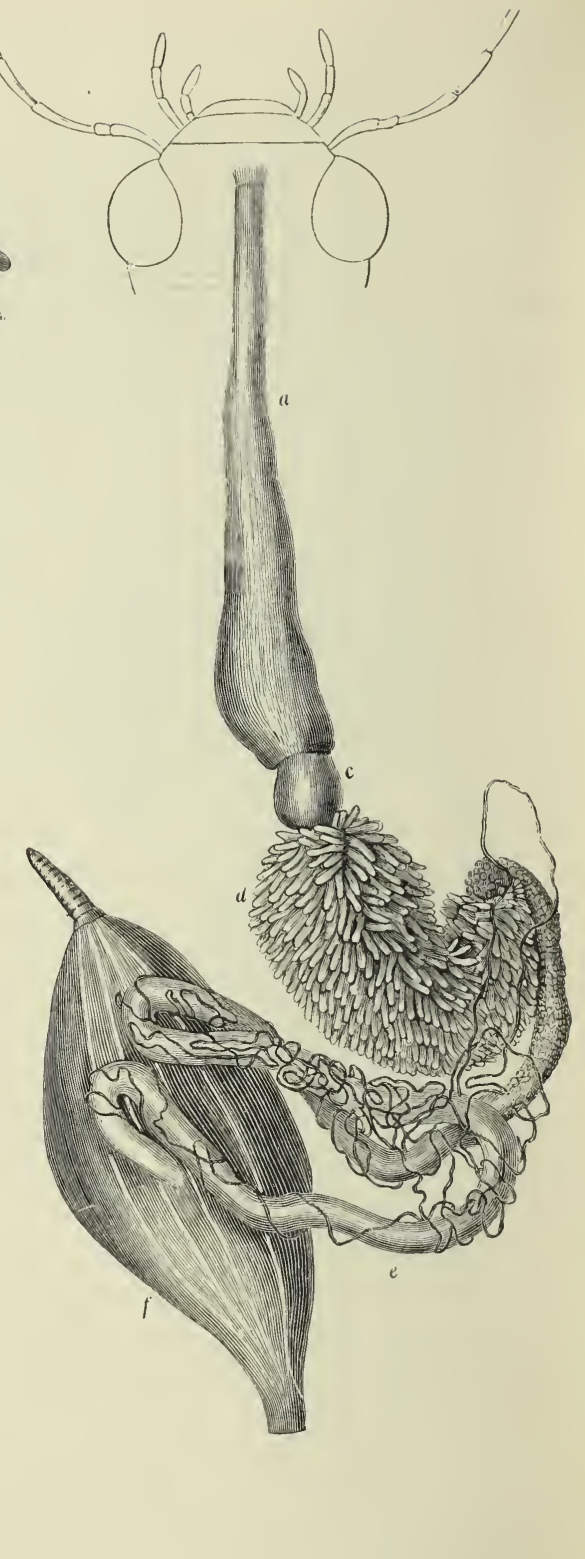

DIGESTIVE APPARATUS OF $\Lambda$ CARNIVOROUS INSECT. THE WATER BEETLE (Djtiscus marginalis).

a (Esophagus. b Crop. c Gizzard. $d$ stomach. e Small intestine. $f$ Large intestine. $g$ Salivary glands. $h$ Biliary and urinary canals. 
be distinguished in insects which are great eaters, such as the crickets, grasshoppers, and locusts, as well as in those which make some provision for the larvæ which are to come after them.

Many have the power of disgorging their food from the crop ; and the bee empties the honey which it has collected from its favourite flowers out of this receptacle into the cells of the hive. Sometimes the crop forms a side pocket to the gullet, and becomes almost an appendix. This is the case in the Lepidoptera (the butterflies and moths). Occasionally in the Diptera (the fly tribe) the sac or crop, when thus more or less separated, is provided with a long neck which opens into the gullet close to the mouth. When thus formed it has something to do with the suction of food, but the mechanism by which it acts as a sucking-pump is not exactly understood.

Usually the stomach follows upon the osophagus, but a constriction is noticed in most insects at the end of the gullet, which is made up of hard muscular tissue; it is the gizzard, and its inside is thrown into long folds more or less dense, and is often covered with hard growths which triturate the semi-masticated food before it passes into the stomach.

A gizzard only being necessary to herbivorous and carnivorous insects is not found in those which live by suction or whose food does not require unusual breaking up.

The stomach varies greatly in its length and general dimensions; sometimes, as in the grasshopper, it is a large and somewhat heart-shaped sac terminating in the form of a tubular canal, and its walls are thick. More frequently it is elongated, and is either smooth or covered with a multitude of such glands, as in the water beetles and other carnivorous kinds. It is the principal organ of digestion, and the food is mixed there with the gastric juice. This liquid, always acid when digestion is going on, possesses the same qualities as that of the higher animals, and reduces the aliments into a pulp, and finally into chyme. The gastric juice is more freely secreted in some insects than in others, and is most abundant in those which live upon animal food. The glands which produce the juice in these carnivorous insects are very well developed and may be recognised as tiny blunt projections upon the outside of the stomach; they are hollow, 
and evolve the fluid from their cellular structures. But the glands of the herbivorous insects are not visible on the outside of the stomach, and are contained in its walls instead. The secretion of the gastric juice is determined by the stomach being more or less filled, just as in man, and when this is the case the little glands give forth their cellular and fluid contents in great abundance. When the stomach is empty, the digestive fluid is very scanty, loses its acidity, and is even occasionally alkaline. Now this repeated secretion of a special acid fluid which continues during the life of the caterpillar-for it is constantly eating, except when moulting, or perhaps when in the dark-is discontinued during the chrysalis state, and the glandular structures become atrophied and often lost altogether, especially in those perfect insects which do not take food.

The intestine follows the stomach, and its commencement is indicated by a constriction and by the attachment of the liver canals; the constriction has a fold internally which prevents the too rapid passage of the food out of the stomach into the intestine. It is very remarkable that the variation in the length and shape of the intestine should not depend upon the food or upon the habits of the insect, and that it should not differ much in these respects in the larva, the chrysalis, and the perfect insect. The intestinal canal ends in pocket-shaped enlargements or in simple odd-shaped swellings, one of which is shown in the case of Dytiscus.

The salivary glands are situated on each side of the osophagus, and look like twisted tubes, or sacs with cellular walls. Usually there are two or three pairs of glands, and they are of two kinds. For instance, in the grasshopper, whose salivary glands are large, they consist of one pair of bunches of bay-like swellings, and of another pair of elongated tubes. Both kinds secrete special fluids, and their admixture is effected in the canal which is common to the two sorts of glands, and the saliva flows straight into the mouth. The saliva is slightly alkaline, and not only lubricates the morsel during deglutition, but assists in the digestion of it also. In the Lepidoptera, or butterfly tribe, the salivary glands are simple elongated tubes, which are largely developed in the caterpillar, and more or less atrophied in the chrysalis and 


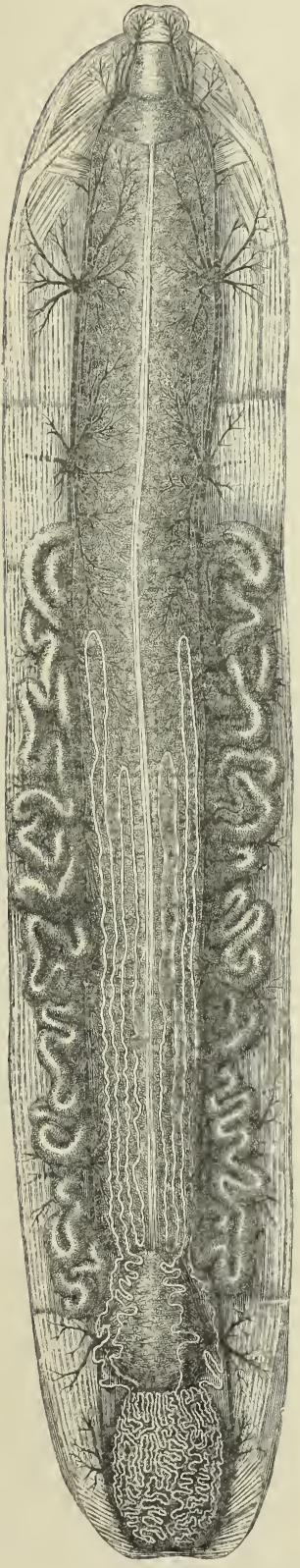

Caterpillar.

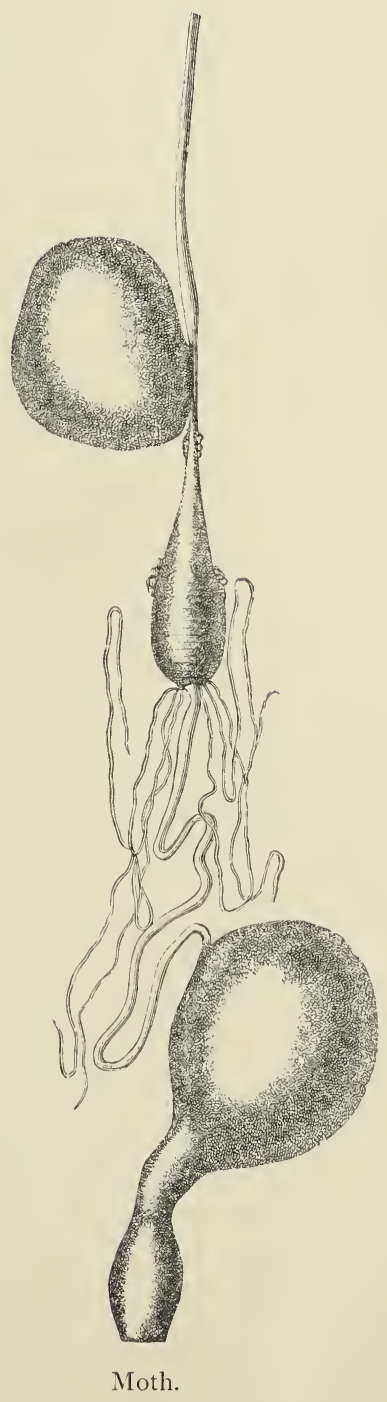

THE DIGESTIVE ORGANS OF THE SILKWORM AND SILKWORM MOTH. 
perfect insect. These long tubes form the web-spinning apparatus in the larva; but after the cocoon is finished, and the first transformation takes place, not only do they become small, but their function alters. The small glands of the perfect insect secrete saliva instead of web, and assist in digestion.

In the silkworm the œesophagus is short; the stomach, a kind of long cylinder, composes the bulk of the digestive apparatus, and the intestine is remarkably limited in its length. But in the moth the œsophagus is long and has a crop; moreover, the stomach is shorter, whilst the intestine has greatly increased in length, its end being very large and globular.

If the chrysalis be examined, the gradual passage of the large stomach of the caterpillar into the small organ of the moth can be traced, and also the formation of the crop and the changes in the glands.

Many larvæ get very fat before the chrysalis or pupa condition sets in, and the oily matter collects in the tissue around the digestive organs, and even pushes itself amongst the internal structures of the insect. During the mysterious pupa state this fat disappears, and doubtless it goes to make the beautiful tissues which do not exist in the caterpillar, but which characterise the full grown creature.

The differences in the blood and its circulation in the larvæ and the perfect insects are not satisfactorily determined, but the quantity of the first and the force of the latter evidently diminish in the chrysalis.

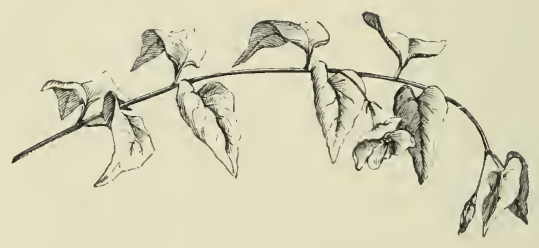




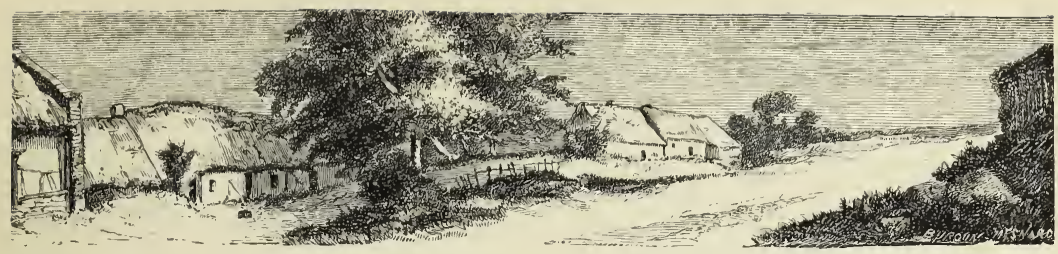

CHAPTER III.

THE METAMORPHOSES OF THE NERVOUS SYSTEM.

Nothing can be more striking at first sight than the difference between the nervous apparatus of the larva, of the bee, for instance, and that of the perfect insect; or between that of the larva of the water-beetle and the mature Dytiscus. But a careful examination of the anatomy of the nervous masses, and of the conducting cord between them, will tend to show that there is not a perfect alteration in their arrangement before and after metamorphosis. There is great modification, but the original design never loses its impression, through all the eccentricities of growth, upon the structures of the nervous system of the most elaborately-formed perfect insect. We have seen that the segments of the-larva become apparently less numerous in the imago or perfect insect, and it has been stated that the diminution of the number of these important body-rings is brought about by their coalescence. Now, there is a remarkable relation between the segments of the body of the articulate animal and the disposition of its nervous structures, and it will be noticed that as the segments coalesce, so do also portions of those wonderful parts which enable the will to be exercised, instinct to be made manifest, and the senses to be enjoyed.

The nervous masses coalesce in order to become more perfect in their functions; they concentrate their influence and make the insect less vegetative and more intelligent. The feeble nerves of many larvæ are remarkable when the activity and importance of those of the perfectly developed insect are considered; there is an evident relation between the wants of the animal and its gifts, and these are showered down according to that wonderful 
but incomprehensible law that directs the growth, the development, and the variations of shape of all living things in definite directions according to special requirements. It happens, then, that a great enlargement of the nerves supplying the feeble

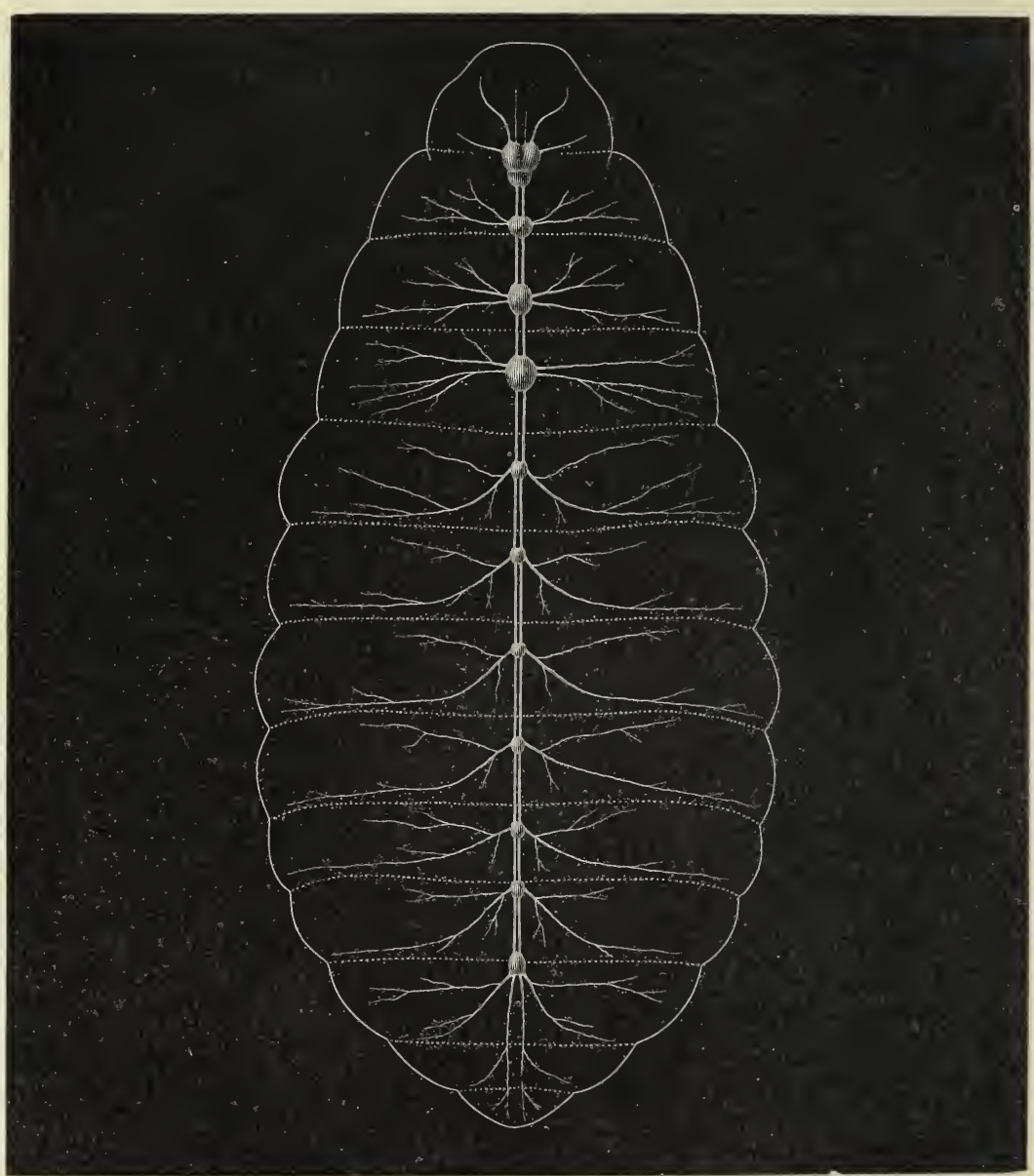

THE NERVOUS SYSTEM OF THE LARVA OF THE BEE. (Magnified.)

sensitive organs of the larva takes place as they become more elaborate and requisite. Moreover, certain nerves which supply many structures with vital force in the larva, become atrophied and withered, as it were, in the imago (or perfect insect) when those particular structures are no longer required, or when they 
do not form important parts of the insect's economy. Concentration, growth, further development, absorption, and atrophy take place in the nervous system, then, as the insect progresses from the embryonic condition within the egg to the perfect state; and these phenomena are most gradual when there is no metamorphosis; less so when it is incomplete; and most marked when it is very decided.

When the apparatus which vivifies the muscles and all the organs of insects is considered, its bulk and elaborate mechanism impress us with the importance of these active and energetic beings in the economy of nature.

The nervous structures of insects constitute a series of enlargements united by intervening cords, and they correspond to the brain and spinal cord of the higher animals. The cords are double, and extend from the tail end of the body, beneath the stomach, up the middle line to the gullet; they encircle this, and re-unite above it in the head. The enlargements are placed in definite order, one in front of the other, and are really double, although apparently single to the superficial observer; the largest is in the head and over the gullet, and is called the brain; whilst the others are termed ganglions, or medullary centres. The cords are made up of the nerve-fibres which conduct the nervous force from the ganglions, where it originates, and the impressions derived from without through the medium of the senses to these medullary centres. The ganglions are formed principally of cells intimately connected with the fibres, and they originate the nerves of sensation and motion, and regulate the animal life of the insect. The vegetative life-that which is beyond the will, and relates to the digestive functions, for instance-is maintained through the agency of an offshoot from the main nervous structures. The heads of insects being formed of several segments, there is little doubt that in the earliest stage of life the ganglionic cords were continued forwards, but the fusion of the rings occurs so soon, and the coalescence of the separate ganglions is so rapid, that only one pair of medullary enlargements is ever distinguishable. The ganglions which form the brain are small in the larva in relation to the size of the inside of the head. During the condition of nymph, pupa, or chrysalis, they increase in bulk; and in the 


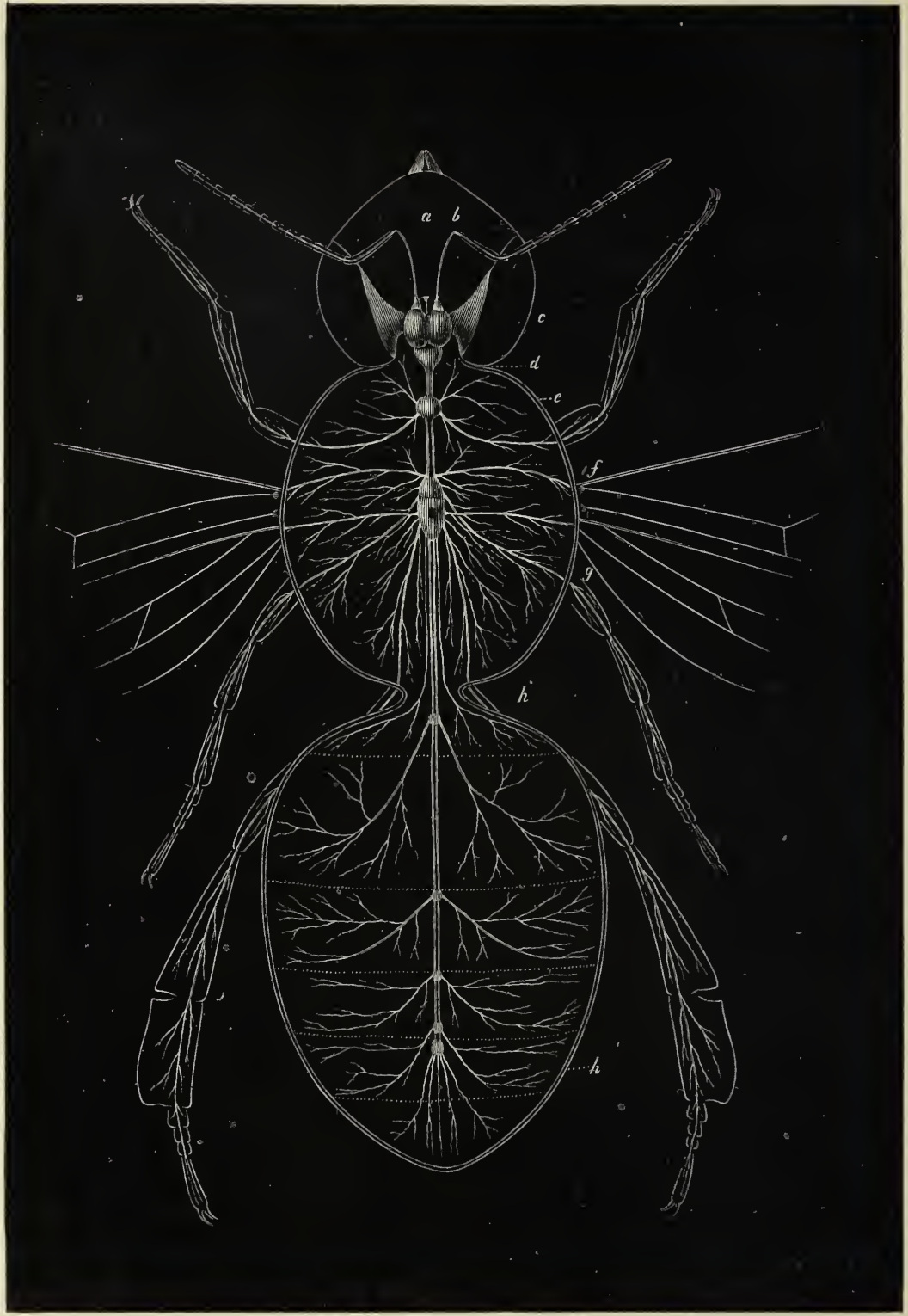

THE NERVOUS SYSTEM OF A FULL-GROWN BEE-A DRONE. (Magnitied.)

$a$ The brain and nerves passing to the ocelli or small single eyes. $b$ The nerves of the antennæ. $c$ The optic nerves, reaching from the side of the brain to the back of the great side eyes. $d$ The ganglion beneath the gullet - the sub-œsophageal; it is immediately behind the brain. $e$ The first ganglion of the thorax, or the prothoracic. $f$ Mesothoracic ganglion. $g$ Metathoracic ganglion. $h h$ Abdominal ganglions. (Compare this with the representation of the nervous structures of the larva.) 
imago, or perfect insect, they fill up the greater part of the cavity which encloses them. In every case these cerebral ganglions are more or less united centrally, so as to form a bilobed mass.

The nerves of the eyes (optic nerves), of the antennæ, of the upper lip, and of the cords which encircle the gullet and unite with those of the series of enlargements already noticed, spring from the bilobed mass or brain, and also a series of nervous fibres, which supply the digestive organs.

In some insects which have two kinds of eyes, the simple ocelli are situated in the middle of the head, immediately above the brain-in the bee, for instance. These eyes are furnished with a nerve from each side portion of the brain-a pair of nerves. They are very short twigs, and are called the first pair. The antennæ are supplied by the second pair, which originate from the under side of the brain, and pass forwards, having oftentimes a considerable swelling upon them, into the so-called "feelers." The size of these nerves depends upon the development of the antennæ, and therefore they are much larger in the adult than in the early condition of insect life.

The nerves which supply the side eyes are usually so large that they seem to form a part of the brain from which they spring; but there are many insects which, possessing small optical organs, have correspondingly puny optic nerves. These nerves form the third pair, and like those already mentioned, have their size in direct relation with that of the organ they supply; consequently, they only begin to attain a considerable growth in the middle life of the insect-in its pupa or nymph condition.

Some larvæ which are blind have very delicate optic nerves. In others which have several ocelli grouped together on either side of the head, and which will become altered into a pair of compound eyes when adult age commences, the nervous fibrils are numerous. These unite near the brain in early life, and form large and closely-connected masses as the development of the eyes progresses. The larva of Dytiscus affords a good example of the separate condition of the nervous fibres supplying the mass of simple eyes; and the examination of the 


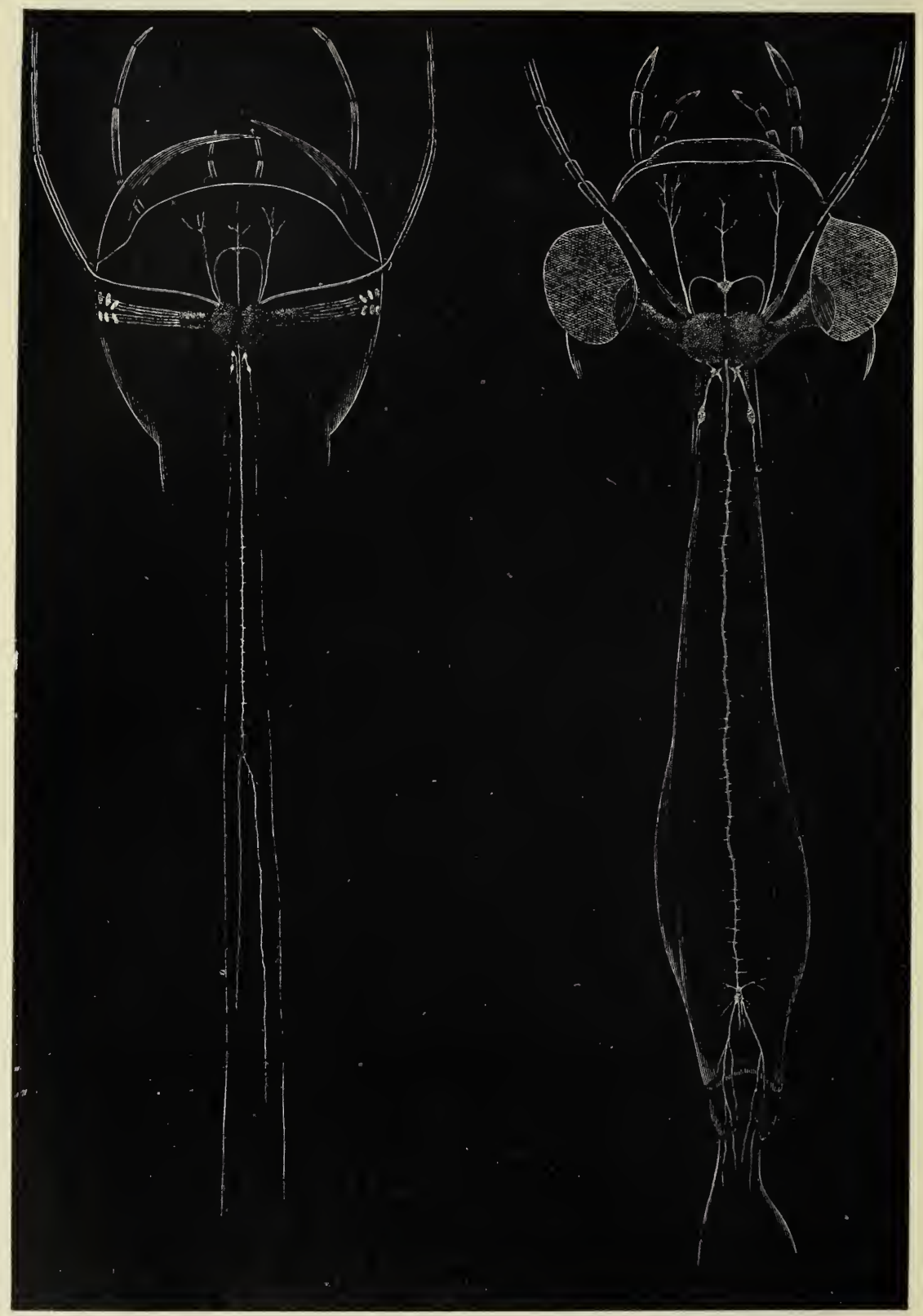

THE GRAIN AND SEPARATE OPTIC NERVES, AND OTHER NERVOUS STRUCTURES OF THE LARVA OF THF WATER BEETIF.
THE BRAIN AND THE UNITED OPTIC NERVES, AND OTHER NERVOUS STRUCTURES OF THE PERFECT WATER BEETLE. 
adult beetle shows how the nerves unite laterally to supply the one large compound eye on each side of the head.

The nerves just noticed are given off from the brain, above the gullet.

The lower ganglion of the head, or the sub-œsophageal, is a mass of nerve tissue, whose arms, as it were, enclose the gullet, and unite above with the brain proper. Its prolongation in the opposite direction is continuous with the double cord, and the ganglions which run down the inside of the insect, below and beneath the digestive organs. In some larvæ the subœsophageal ganglion is double, but it soon becomes single as their growth proceeds. The nerves which supply the masticatory organs are derived from this ganglion, and there is a twig sent off on each side to the jaws, mandibles, and to the lower lip. The size of the twigs depends upon that of the parts of the mouth, and it diminishes during any metamorphosis which is accompanied by a diminution of the masticatory apparatus.

There are three sets or pairs of ganglions, united into three enlargements in the thorax in perfect insects. One is in the segment called the prothorax, another in the mesothorax, and the third in the metathorax. These three nervous centres remain perfectly distinct and separate in all larvæ; but as the metamorphosis proceeds, the cords which connect them are absorbed, and usually the second and third ganglions unite and fuse together. Very frequently this takes place with regard to the first also, and one thoracic medullary centre is produced.

By comparing the number and the position of the thoracic ganglions of the silkworm when in the caterpillar state with those of the moth, a very good idea can be formed of the important modifications in the nervous system which occur in consequence of the alterations in the general development of the insect.

The first or prothoracic ganglion is invariably united by longer or shorter nervous links to the sub-œsophageal mass, and all the medullary centres or ganglions are united to those in front and behind in the same manner. In the silkworm caterpillar the three thoracic nervous centres are small and wide apart, and each one is in a segment of the body; but in the moth condition 
these formerly separate ganglions are united, and form a bulky mass in the middle of the thorax. Nevertheless, the points of

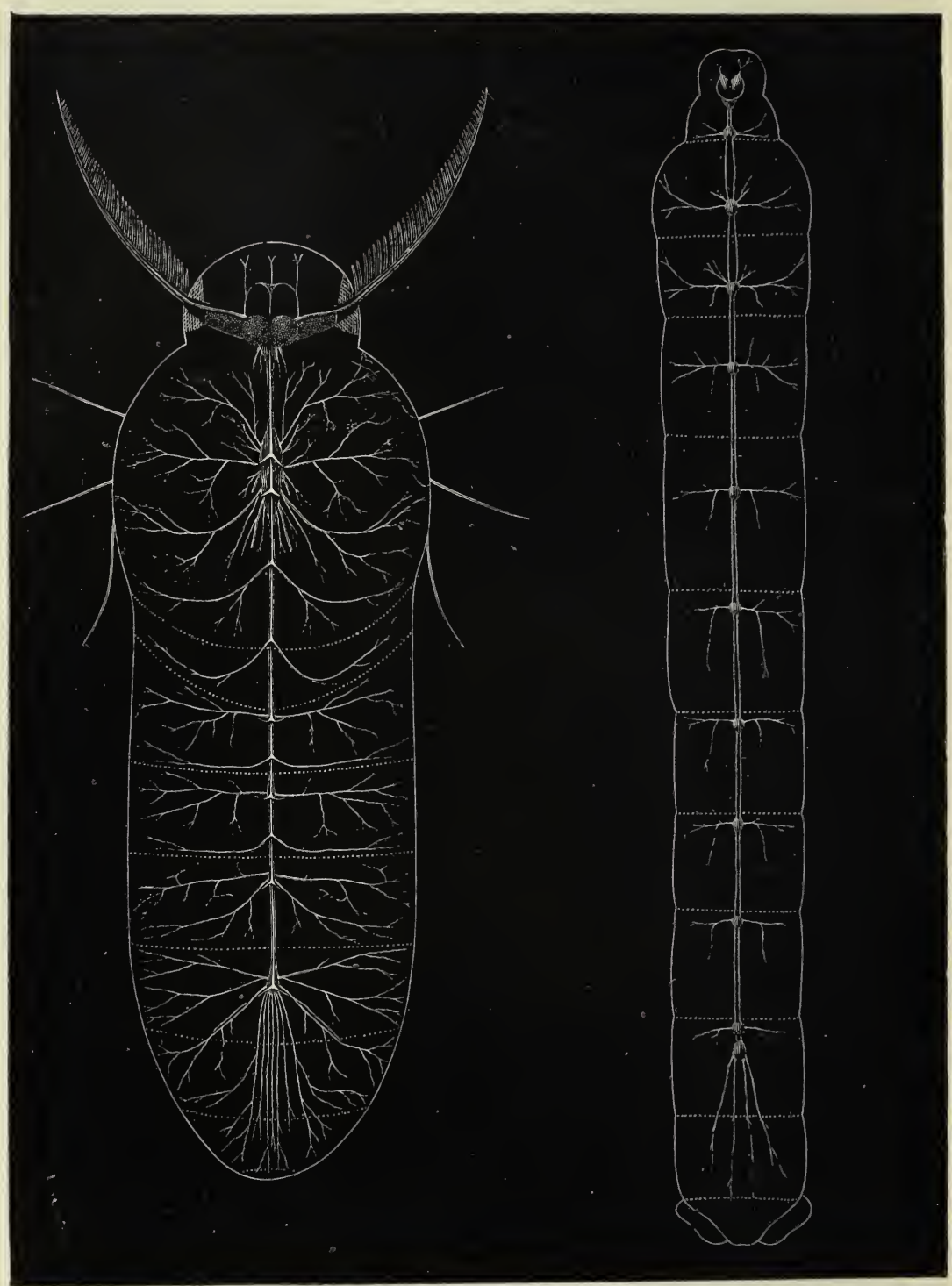

THE NERYOUS SYSTEM OF THE SILKWORM MOTH (Magnified).
THE NERVOUS SYSTEM OF THE SILKWORM CATERPILLAR (Magnified).

union may be detected by unusual care. The connecting cords are, however, lost. 
The beetles (Coleoptera), the locusts (Orthoptera), and the bees (Hymenoptera), do not have their thoracic ganglions all fused into one mass when they attain adult age, and the nervous centre, which is known as the first of the thoracic segmentsthe prothorax-never unites with the others. But the next two ganglions do become fused together in those species which attain great perfection of organisation. In the larva of the bee the three thoracic nervous centres are like those of the silkworm caterpillar, but in the perfect insect these ganglions enlarge, and the hindermost are confounded together. This concentration does not exist in all adult insects, and the ganglions remain separate in most of them.

The nerves which supply the muscles of the first pair of legs in the perfect insect arise from the first ganglion of the thorax or the prothoracic. Those destined for the innervation of the first pair of wings and the second pair of legs come from the mesothoracic nervous centre, and the metathoracic enlargement originates the nerves of the third pair of legs and of the second pair of wings. Nothing appears to interfere with this relation between the ganglions and the legs and wings.

A great number of larvæ have nine pairs of ganglions in the abdomen, and this arrangement often persists during adult age; as a rule these nervous centres are small, and they even remain detached in pairs in some imperfect insects. In the caterpillar of the silkworm there are eight ganglions in the abdomen. Seven of them are located in the anterior seven segments, and the eighth is situated near the front part of its body ring. It is very large, and evidently is composed of two nervous centres united. But in any other insects whose development is less advanced, the eighth and ninth abdominal ganglions are found to occupy their corresponding segments. The size of the nerves which pass off on either side from the ganglions in the abdomen of the larva, is usually much less than that of the twigs which arise from corresponding situations in the perfect insects. The lateral nerves have much to do with the respiratory efforts, which are feeble in most larvæ, but very vigorous in the perfect adult insects. There is no comparison to be entertained between the amount of the breathing energy of a sluggish maggot, grub, and caterpillar, and that of a lively 
fly, beetle, or moth. Consequently, the most active condition obtains the greatest development of the lateral nerves.

The sympathetic nerves, as they are called, are independent of the chain of nervous cords and ganglions, and their twigs supply the muscles of respiration to a certain extent, and those of the stomach.

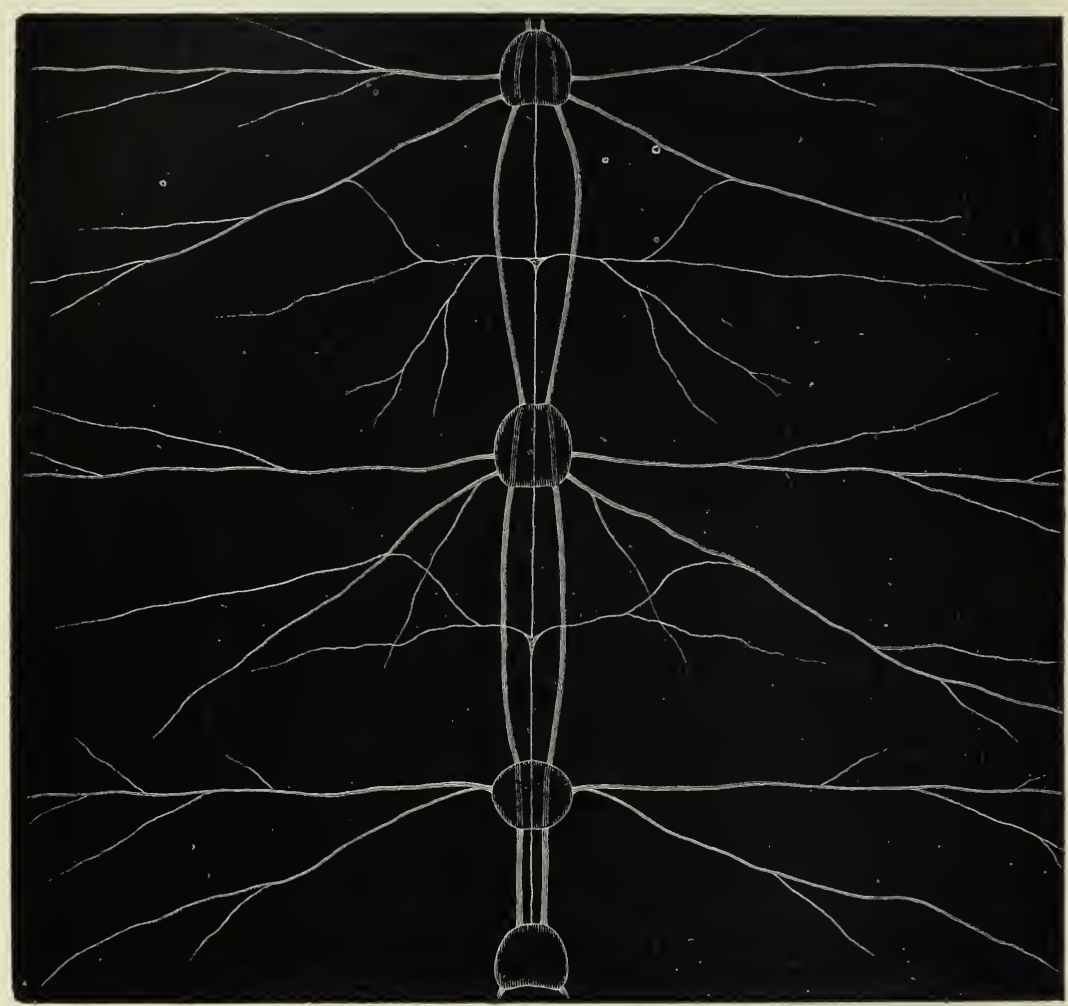

THE SYMPATHETIC NERVE OF THE SILKWORM MOTH. (Magnified.)

It passes down and above the ganglionic chain.

No sooner has the caterpillar become transformed into the chrysalis, than the ganglionic chain suffers considerable changes; the cords which united the nervous centres have become wavy in their course; then they shorten; and thus the ganglions are drawn together. Day by day the first ganglia of the abdomen are gathered towards the thoracic centres, which have become closer together. The middle part of the chain is altered the 
least and the most tardily. The butterfly, once escaped from its chrysalis case, is found to have undergone extraordinary alterations in the nervous system. The abdominal chain of ganglions appears to be formed of four masses only; the nervous centres of the first two segments of the abdomen of the caterpillar state have disappeared by uniting with the enlargement in the metathorax; and those of the last four rings have become concentrated into one mass.

Newport has given us the results of his study of the progressive
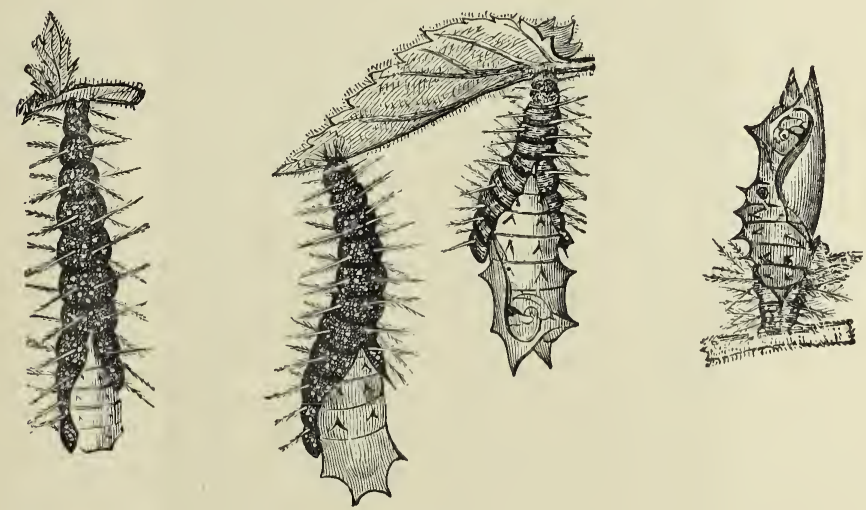

LARVA AND PUPA OF Vanessa urtica.

The larva just suspended; three stages of chrysalis development ; the larva-skin gradually separating.

changes in the nervous system of the small tortoiseshell butterfly (Vanessa urtica), and his history of the structural alterations that take place hour after hour is certainly most remarkable. This butterfly undergoes its changes in fourteen days, and the caterpillar suspends itself to undergo its transformation into the pupa or chrysalis. "Two hours," writes this excellent observer, " after the larva of Vanessa urtica has suspended itself to undergo its transformation, and in which state it remains from six, eight, ten, or even twenty-four hours-according to the strength of the individual and other circumstances-before it throws off its last larva skin, a considerable alteration has already taken place in the body of the larva. The ganglions in the head are still 
distinct from each other, but are a little altered in form, although not yet enlarged. The sub-œsophageal ganglion is enlarged to nearly twice its original size, and the cords which join it to the brain are shortened, and so are those that connect the second,

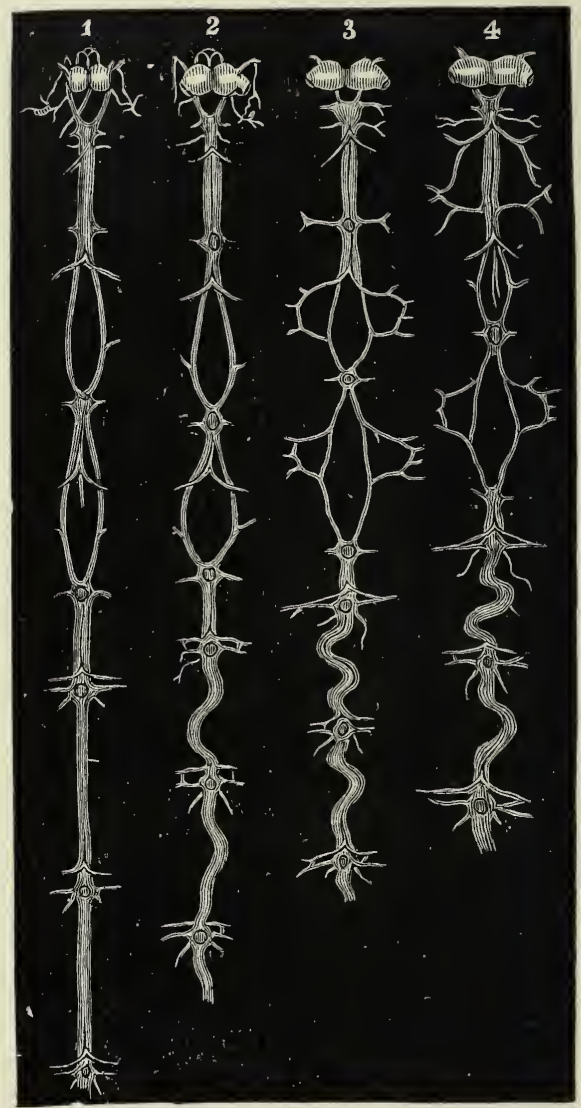

METAMORPHOSIS OF THE NERVOUS SYSTEM OF Vanessa urtica.

I. Nervous system of full-grown larva. 2. Half an hour before changing. 3. Immediately after change into a pupa or chrysalis. 4. One hour after changing. (After Newport.)

third, fourth, and fifth ganglions. The last two are separated only by a short interval. The fifth, sixth, and seventh are drawn closer together, the ends between them are disposed in a zig-zag manner, and the longitudinal direction of the nervous chain is in consequence altered.

"The ganglions, from the seventh to the terminal one, remain as 
in the active larva. A little while before the old skin is thrown off there is great excitement throughout the body of the insect. About half an hour before this occurs there is a considerable enlargement of the brain, the sub-œsophageal, and the second, third, fourth, and fifth ganglions. The cords that extend between

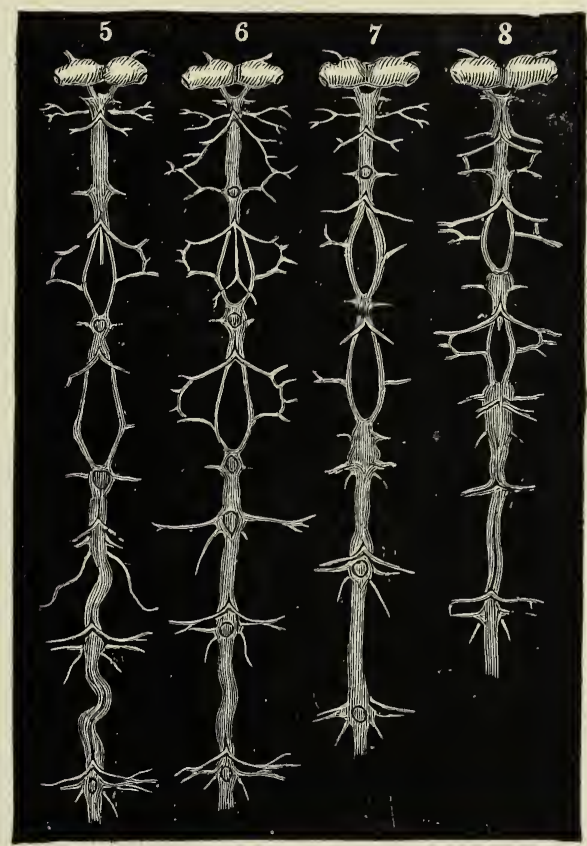

METAMORPHOSIS OF THE NERVOUS SYSTEM OF Vanessa urtica.

5. Twelve hours after changing. 6. Eighteen hours after changing. 7. Twenty-four hours after changing. 8. Thirty-six hours after changing. (After Newport.)

them diverge very much, and those between the fifth, sixth, and seventh ganglions are disposed in a zig-zag direction.

"Immediately after the insect has entered the pupa state all the ganglions are brought closer together, in consequence of the cords being disposed more irregularly than at any other period, which has been occasioned by the shortening that has taken place in every segment, by which the cords are rendered too long to lie in a direct line. Seven hours afterwards there is a greater enlargement of the brain, optic nerves, and ganglions of the thoracic segments, which begin to approach each other, 
At twelve hours the last thoracic ganglions have united, and at eighteen the nerves of the wings have increased in size, and the nervous chain in the abdomen has become straight again. At

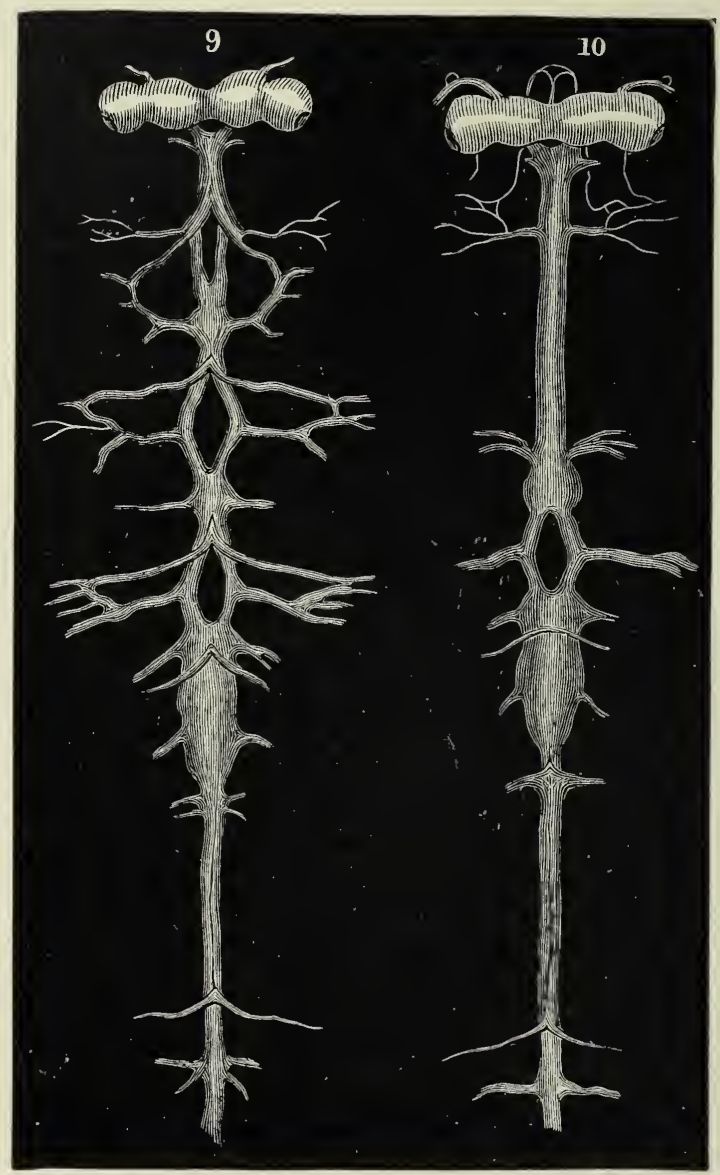

METAMORPHOSIS OF THE NERVOUS SYSTEM OF Vanessa urtica.

9. Forty-eight hours after changing. Io. Fifty-eight hours after changing (more highly magnified than the previous illustrations). (After Newport.)

thirty-six hours the optic nerves have grown nearly as large as the brain, and the gullet is completely surrounded by an extension of the ganglion under it and the brain above. The sixth ganglion has disappeared; and at the end of forty-eight hours the seventh is no longer seen, but the thoracic centres increase in size gradually. 
"At fifty-eight hours the middle part of the chest has greatly increased in size, and the great nervous centres and nerve twigs which will supply the wings eventually with energy occupy it. The optic and antennal nerves have nearly attained their full development, and the arrangement of the whole nervous system is now nearly as it exists in the perfect insect. The whole of these important changes are thus seen to take place within the first three days after the insect has undergone its metamorphosis, and they precede those of the digestive system." The nervous system is matured first of all. Newport considers that the contraction of the muscles which draw up the segments of the body as metamorphosis proceeds, initiates and influences these wonderful ch anges in the nervous structures.

If the alterations in the nervous structures are wonderful, what must be said of the changes in the activity, in the instincts, in the amount of energy and will, and in the whole of the habits that spring into existence when the perfect insect emerges into its peculiar life?

The study of the metamorphosis of the structures which enable insects to breathe and thus keep up their heat and the purity of their blood, and to become more or less filled with air during their flight is almost as interesting as that of the nervous system. When an insect is placed in water and opened carefully, beautiful tiny tree-like branches of silvery-looking threads are noticed covering the digestive organs, entering amongst the tissues and on the inside of the skin. If the microscope be used these threads can be seen to divide, subdivide, and unite, and their minuteness is wonderful. They are called trachea. A trachea is a tube formed by two layers of membrane, between which is a spiral thread. It is kept open by the spiral, which is capable of much compression, so that the quantity of air any trachea may contain varies according to circumstances. They are the very perfection of delicacy of structure combined with elasticity. The centre of each trachea is occupied by air, and the layer of membrane in contact with it is continuous with the outside skin of the body. The spiral tissue is produced during the growth of the insect, and the fine membrane which covers it acts like a loose investment. The outside air enters the tracheæ through several openings like 
button-holes, which are usually situated upon the sides of the body. When a smooth-skinned, light-coloured caterpillar is examined, these orifices or spiracles can be seen ornamenting its sides. Their

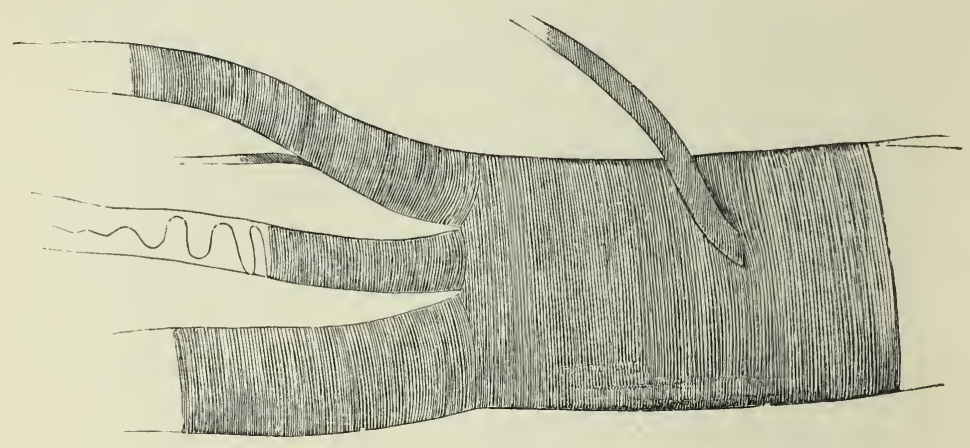

A TRACHEA MAGNIFIED.

margins are rather hard, and are tinted black, red, orange, or brown. Most frequently the spiracles are placed exactly on the sides of the body, and there is a pair for the prothorax and a pair for each of the first eight segments of the abdomen. The spiracles are not found on the mesothorax and metathorax, which sustain the wings, but these organs are full of

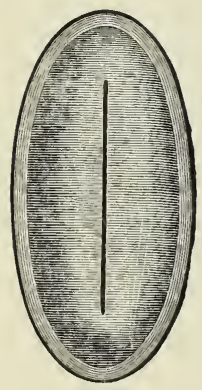

A SPIRACLE (Magnified). tracheæ. Nature has arranged the position of the spiracles in some insects with an evident design; thus in the larvæ of many flies there is only one pair of spiracles, and these external organs of respiration-mouths, as it were-are situated quite at the end of the body. Were it not so the larvæ would soon be stifled, for they dig deep into the bodies of the unfortunate creatures they infest, and feed luxuriantly, being embedded in their nourishment. When a man eats voraciously he often has to stop to take breath, and no one can drink for any length of time without doing the same; but these parasitic larvæ gormandise fearlessly. They breathe through the spiracles in the end of their bodies which are left sticking out in the open air. Many of the larvæ that bury themselves in decomposing animal and vegetable matters breathe safely in this manner. 
Dust is kept out of the spiracles by some fine hairs which are attached to them, and noxious gases and impure air can be shut
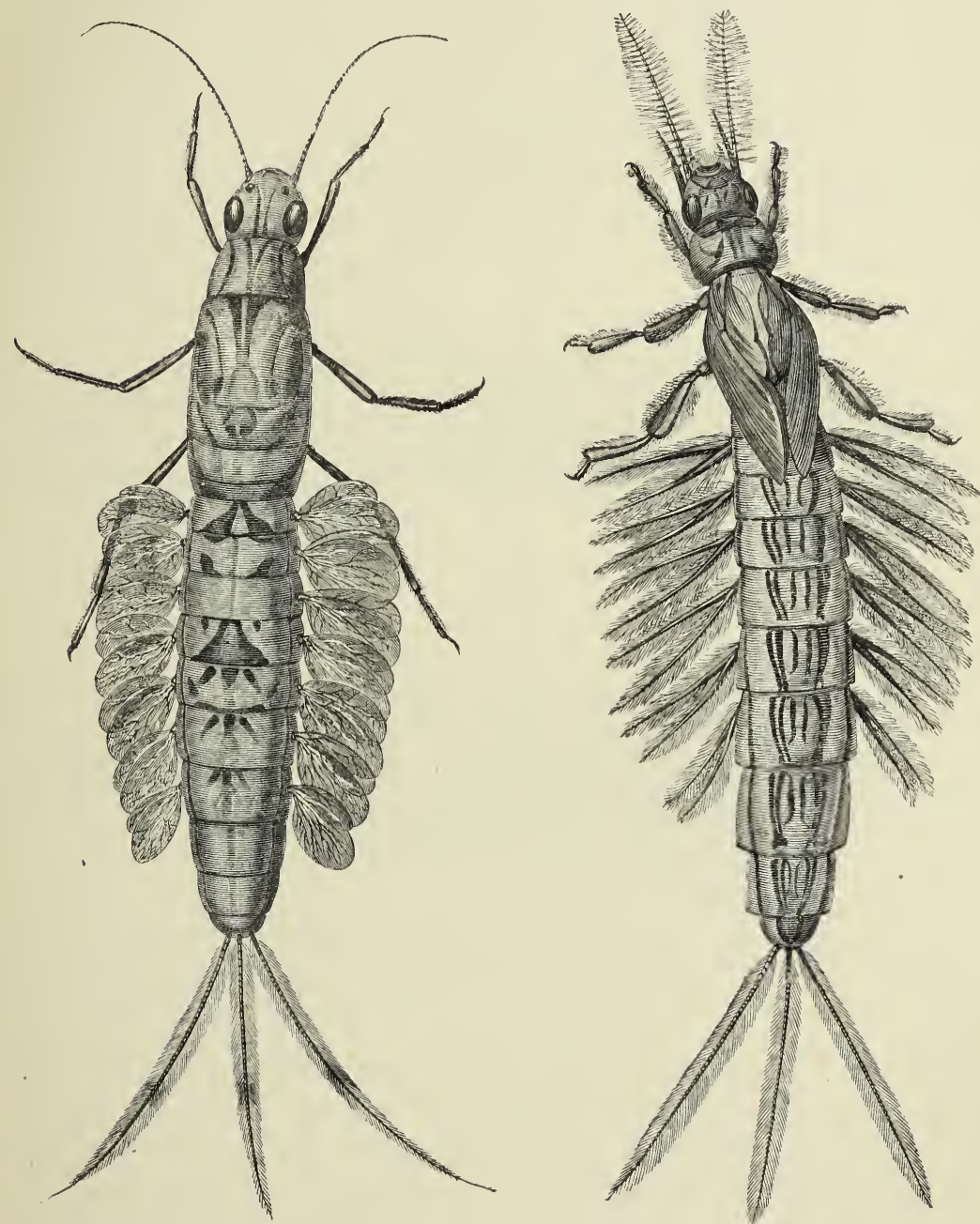

THE RESPIRATORY ORGANS (BRANCHIE) OF THE AQUATIC LARVE OF Cloe bioculata AND Ephemera vulgata.

out by the action of certain muscles that close the tracheæ more or less hermetically. The same apparatus enables the insect to retain a large quantity of air in its respiratory tubes.

When the larvæ and nymphs of insects live in water they 
do not always have spiracles, but they often breathe like fishes, by branchiæ or gills.

The imago or adult insect, which is produced by metamorphosis from the water larva and nymph, becomes an air breather -and spiracles are developed in its sides exactly in the places where the gills were attached during its fish-like life. In the larvæ of the May flies the branchiæ are formed of expansions of the skin, which are very delicate, thin, and variously folded and fringed, and they are attached in pairs to the first seven seg-
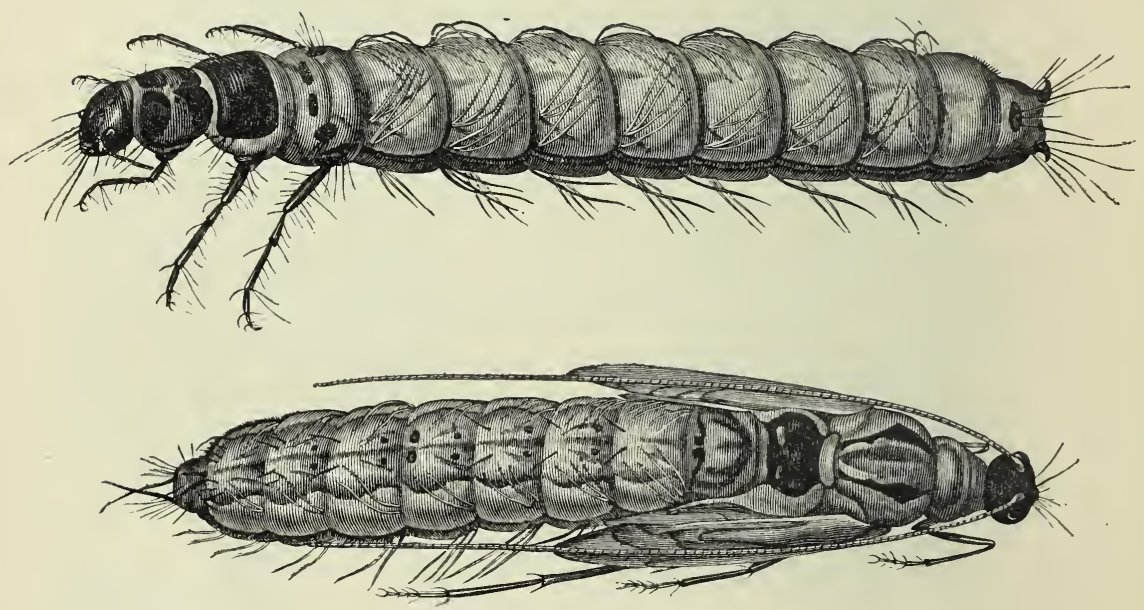

THE AQUATIC LARVA AND NYMPH OF THE CADDIS FLy (Phryganea flavicornis).

ments of the abdomen. The tracheæ are included in the folds and are continued into the body of the larva, and they transmit the purified air to it; but the gills disappear during metamorphosis.

Some packets of filaments of thin tissue derived from the skin occupy the same position in the larvæ and nymphs of caddis flies, and have the same function and fate as the branchiæ of the May fly larvæ. These branchiæ are not found in all aquatic larvæ, for many which do not become metamorphosed eventually into winged insects still continue to breathe air, although they live in the water. Such larvæ come to the surface to breathe every now and then, and they do so by the means of their swimming 
apparatus and some short horny tubes, which are often surrounded by strong hairs. The tubes are always open at their free ends, and generally project beyond the body of the insect. The common water scorpions are furnished with these structures, and they inspire as well as expire air by means of this curious

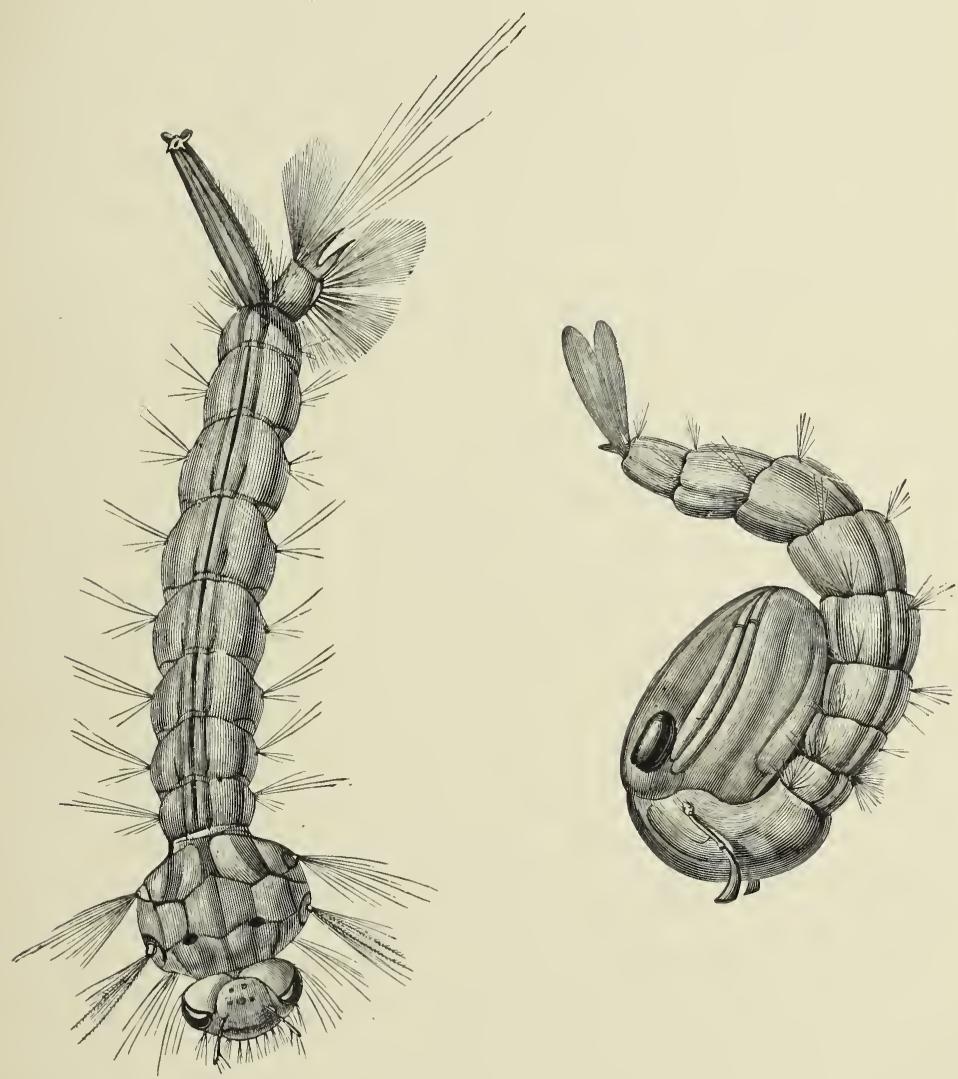

THE LARVA AND NYMPH OF THE GNAT.

(The breathing-tube of the larva points upwards, and those of the nymph downwards.)

respiratory apparatus, without being drowned in their swimming to and fro. The larvæ of the Dytiscus, the water beetle, possess these elongated air-breathing tubes, and after metamorphosis the perfect insect, which leads an amphibious sort of life, has the ordinary spiracles for its respiratory purposes, but they are situated on the 
back, so that it can breathe by coming up to the surface, and allowing the wing-cases to appear above water. Other insects in the larva state support themselves at the surface of the water by a coronet of hairs, arranged in a star-shaped manner, which includes a bubble of air ; they descend with it for the purposes of respiration, and return for a fresh supply. During their metamorphosis, the ordinary spiracles of flying insects are added to their organisation, and that which was so well adapted for the larval condition can no longer be distinguished. The larva of the gnat breathes through a tube in its tail, and the nymph by means of two tubes on its back, but the perfect insect has the usual spiracles.

A most interesting alteration takes place in the tracheæ of those insects which fly, or are great jumpers in the adult state. The tubular nature of the respiratory apparatus in the caterpillar has already been noticed, and it is evident from what has been stated that there is a definite relation between the habits of the larvæ, generally speaking, and the form and arrangement of the tracheæ, within and without the body. It might be anticipated that the arrangement of the tracheæ of the slow-moving caterpillar, or of the sluggish grub, would hardly suit the purpose of the restless moth or the vigorous beetle; and that Nature, which has specially adapted the varieties of the respiratory structures in the larvæ of the aquatic insects to meet the exigencies of their position, would do as much for the flying kinds. During the metamorphosis of the larva into the chrysalis, and just previously, the future requirements of the adult insect are recognised, for the tracheæ begin to suffer some curious modifications before the pupa state commences.

When the metamorphosis of the pupa or chrysalis into the beetle or butterfly, as the case may be, is complete, the tracheæ are no longer perfectly tubular structures, for many of them are enlarged and dilated into sacs or vesicles, which can be filled with air at the will of the insect. Their use is to enable the insect to alter its specific gravity by enlarging its bulk, the weight remaining the same, and thus rendering it better able to support itself on the wing with as little muscular effort as is possible. The development of the vesicles begins to take place at about the 
period when the larva ceases to feed, preparatory to changing into the pupa state. Newport examined their growth in the same chrysalis which yielded such interesting details concerning the alterations in the nervous system during metamorphosis. The dilatation of the tracheæ of the larva of the Small Tortoise-shell butterfly begins as soon as it suspends itself in its silken hangings. During its suspension it makes several powerful respiratory efforts, accompanied by much muscular exertion, and these efforts are continued at intervals, until the old skin is fissured and thrown off. It is at this period that the tracheæ become much enlarged, and Newport found them so about two hours after the insect had suspended itself. At about half an hour before the insect becomes a pupa, the whole of the tracheæ become more distended, particularly those on the under surface of the thorax, from which branches are given to the legs, so that the enlargement of these tracheæ is probably connected with the subsequent rapid development and extension of those locomotive organs. It is at the actual period of transformation that the changes take place most rapidly. At that time the laborious respiratory efforts made by the insect appear to affect the condition of all the organs greatly. When the skin is thrown off these efforts cease for a few minutes; after which the abdominal segments become shortened, and the wings, then scarcely as large as hemp-seeds, are gradually distended at their base, and are perceptibly enlarged at each respiration. It seems probable that the dilatation of the tracheæ is partly occasioned by the closing of the spiracles and the expansion of the air within the tubes, due to muscular efforts and the alteration in the bulk of the insect. Half an hour after the transformation the tracheæ which ramified over the gullet are enlarged to double their former size, and in forty-eight hours the vesicular structures are all complete and ready for use.

The side vesicles of the abdomen of the bee may be noticed in the engraving on the next page, and the tracheæ issuing from them.

The respiration of the bee can be observed when it has ceased flying, and is at rest; then the muscles of the abdomen shorten the segments, and by relaxing allow them to lengthen again. Air is thus pumped into the tracheæ through the spiracles. When quiet, and especially if the temperature is low, insects 
breathe very slowly. The energy and the rapidity of the respiratory efforts increase during any agitation. An insect may be crawling over the leaves, or upon the ground, with very little air

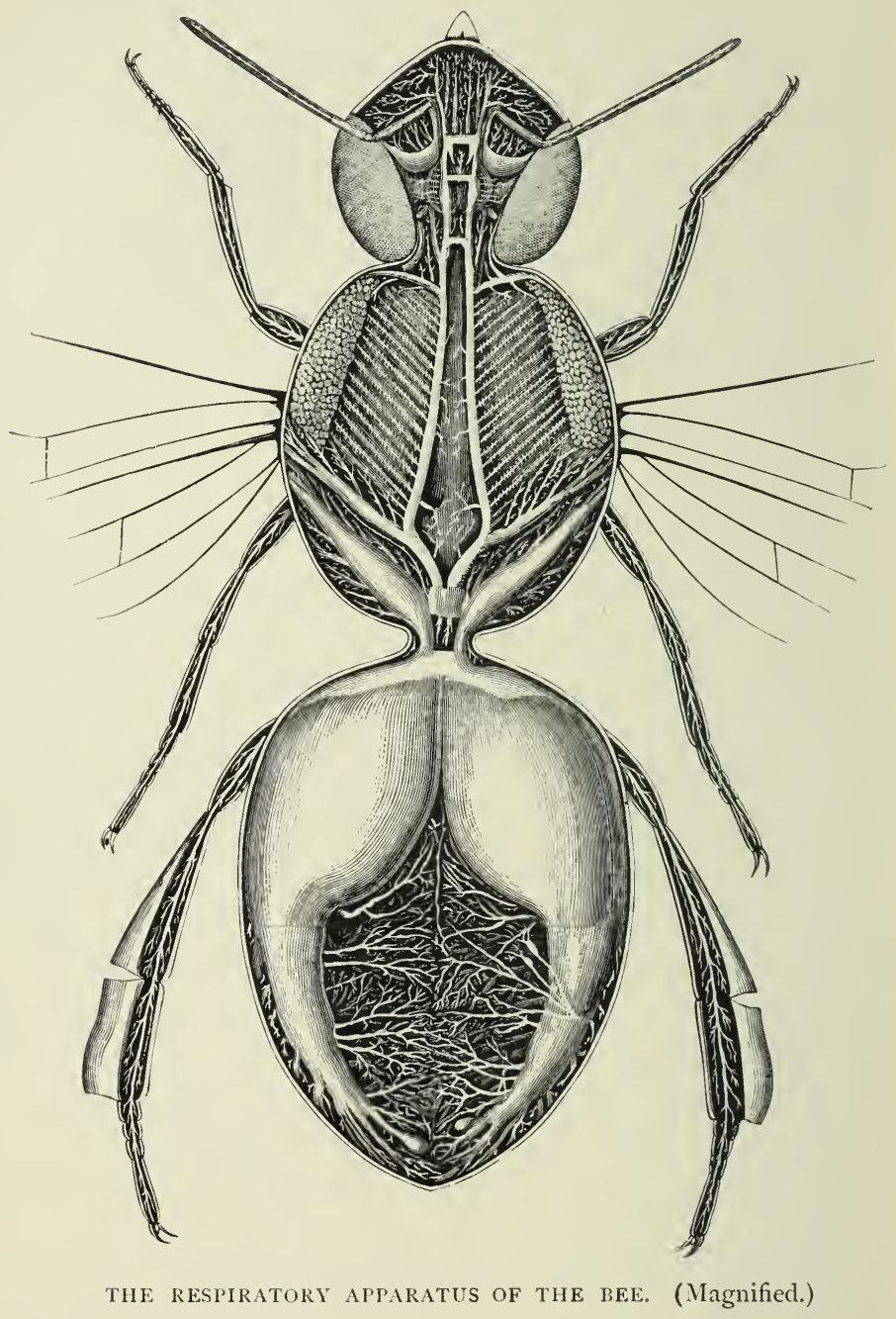

in its trachere. Its body is heavy, and it could not fly unless it contained more air; so the insect lifts up its wings, and makes a few energetic movements of its abdomen, in order to fill the vesicles and trachere to the utmost, and sails away.

The long voyages of immense columns of locusts are well 
known; but the indisposition of their allies, the grasshoppers, to fly for any distance, is readily to be noticed by any one walking in the fields. They will jump and fly for a few yards, but it is very unusual to see them doing anything more. How, then, is it that these heavy and not over-active insects can occasionally maintain a prolonged and elevated flight? Their respiratory system explains the apparent anomaly. When they are quiet their trachex are as flat as ribbons, and contain but little air. On departing for their long voyage, however, the locusts, like the cockchafers, blow themselves full of air, and their bodies become very light in relation to the bulk of air they replace. Moreover, the muscular efforts of prolonged flight produce a certain amount of animal heat, and this rarefies the air contained in the vesicles and trachex; so that the principles of Montgolfier's balloon were foreshadowed in the insect long before they were elaborated by man.

The vesicles are evidently superadded to the tracheæ of the larva and caterpillar, and their growth during metamorphosis is accompanied by a prolongation of the sympathetic nerve over them.

There are two kinds of transformations noticed in the insects or the Articulata, the complete and the incomplete, and, besides, there are hyper and retrograde metamorphoses. The stages or phases of development are usually three in number, but there are four in some instances, and a great many more when skin-shedding is accompanied by contemporaneous internal structural changes. Some Articulata do not undergo any metamorphosis.

The vast majority of the articulate animals bring forth eggs which contain the embryo; this becomes, after hatching, the larva, caterpillar, grub, or maggot; and either the larva differs considerably from the embryo, or it is so much like it as to merit the term of hatched embryo. But a few of the Articulata produce living larvæ, the process of hatching going on within the body of the mother, which is then said to be ovoviparous; or the young are developed within the parent more as offshoots of parts of her tissues than as the contents of eggs. The union of the males and females before every production of eggs is found to occur in the great majority of instances, but there are some insects which 
produce fertile eggs without fecundation having occurred just previously, and indeed this operation need not take place for several generations. The egg-bearing by virgin females is termed parthenogenesis, and will be noticed further on.

In complete metamorphosis the larva is transformed into an immobile chrysalis, pupa, or nymph, from which results a winged imago, butterfly, moth, beetle, fly, or perfect insect. In the Crustacea, the nauplius, zoëa, and the perfect forms differ so much, that although the quiet stage is not witnessed, the metamorphosis almost deserves to be called something more than incomplete. When the larva differs but slightly from the nymph (an active chrysalis), which lives the same kind of life as and differs comparatively speaking little from the imago or perfect insect, the metamorphosis is said to be incomplete.

Hyper-metamorphosis will be noticed in considering the Sitaris beetle, and it is only necessary to state here that a second larval form springs from the pupa in that instance.

A kind of hyper-metamorphosis occurs also in the creatures which come from the nymphs of those spiders which respire by means of tracheæ- the mites and the water-mites-for these are not perfect, and have to undergo an important skin-shedding, with many internal alterations, before they are sufficiently organised to reproduce their kind.

Retrograde metamorphosis occurs in the true insects and in the Crustacea. For instance, the female moths which come from the chrysalides of the Vapourers and of some Psyches are less structurally elaborate than their caterpillars; and the barnacles, which are immobile Crustacea, were once more highly organised, free, swimming, and active creatures.

The majority of the spiders, and, indeed, all those which do not respire solely with the aid of trachex, do not undergo metamorphosis, and the phehomenon is neither observed in the scorpions, nor in the Myriapoda, or hundred-legs tribe, the Thysamura, or skip-tails, or in the Anoplura, or lice. But the evolution of these exceptional insects is accompanied by repeated sheddings of the skin and mucous membranes; and the moults often assume so much importance as to approach metamorphoses.

Some insects belonging to the same family, and even to the 
same genus, may present different grades of metamorphosis; some are more fully developed when they leave the egg than others; and nearly all those which are destined to lead a parasitic life suffer more decided changes of form at the different stages of their existence than the tribes which do not live upon unwilling hosts.

The following description of the different conditions of the insect is taken from Newport's essay, already quoted :-

"The life of an insect that undergoes a true metamorphosis is one continued series of changes from the period of its leaving the egg to that of its assuming the perfect state. These are not merely from the larva to the pupa, and from that to the perfect animal, during which the insect gradually acquires new organs, but consist also of repeated sheddings of its skin, which occur at certain intervals, before the larva has attained its full size. These changes, and the circumstances connected with them, have been more particularly watched in lepidopterous insects, and have been carefully noted by many naturalists, especially by those of the last century, Redi, Malpighi, Gœdart, Merian, Ray, Swammerdam, Réaumur, Lyonet, Bonnet, De Geer, and others, who concur in their statements respecting the manner in which these changes are effected. Almost immediately after the insect is liberated from the egg it begins to feed with avidity, and increases much in size. The larva of the Splinx ligustri, at the moment of leaving the egg, weighs about one-eightieth of a grain ; at about the ninth day it casts its second skin, and then weighs about one-eighth of a grain ; on the twelfth day it changes its skin again, and then weighs rather more than nine-tenths of a grain; on the sixteenth day it casts its fourth skin, and weighs three grains and a half; and on the twenty-second day enters its sixth and last skin, and weighs very nearly twenty grains; but on the thirty-second day, when it has acquired its greatest size, it weighs nearly 125 grains; so that in the course of thirty-two days this larva increases about 9,976 times its original weight. At this period it is sometimes more than four inches in length. But this is not the greatest weight that the larva attains. One specimen, which was bred in its natural haunts, weighed I4 $\frac{7}{10}$ grains; so that in this instance the insect had increased at the rate of I I,3 I 2 times its original weight. But great as is this proportion of increase, it is exceeded by 
some other larvæ. Lyonet found that the larva of Cossus ligniperda, which remains about three years in that state, increased to the amount of 72,000 times its first weight. This amazing increase is occasioned chiefly by a prodigious accumulation of fat, which exists in a greater quantity in this than in most other larvæ. We have ourselves removed forty-two grains of fat from one specimen, which was more than one-fourth of the whole weight of the insect. The occasion for this prodigious accumulation is chiefly to supply the insect during its continuance in the pupa state, while the muscular structure of the limbs and other parts of the body are in the course of development, and also to serve, perhaps, as an immediate source of nutriment to the insect at the period of its assuming the perfect state, and more particularly during the rapid development of its generative functions; since, when these have become perfected, the quantity that remains is very inconsiderable. But all larvæ do not increase in these amazing proportions, although their actual increase may be more rapid. Those in which the proportion of increase is the greatest are usually those which remain longest in the pupa state, as in the species first noticed. Thus Redi observed in the maggots of the common flesh flies a rate of increase amounting to about 200 times the original weight in twenty-four hours; but the proportion of increase in these larvæ does not at all approach that of the Sphinx and Cossus. From observations made on the larva of one of the wild bees, Anthophora retusa, we believe that this is also the case with the Hymenoptera. The weight of the egg of this insect is about the I50th part of a grain, and the average weight of a full-grown larva is six and eight-tenths grains, so that its increase is about $\mathrm{I}, \mathrm{O} 2 \mathrm{O}$ times its original weight, which, compared with that of the Sphinx of medium size, is but as one to nine and three quarters, and to a Sphinx of maximum size, only as one to a little more than eleven.

"The changes of skin which a larva undergoes before it enters the pupa state are more or less frequent in different species. In the generality of lepidopterous insects it occurs about five times, but in one of the Tiger-moths, Arctia caja, according to Messrs. Kirby and Spence, ten times. A few hours before the change is to take place the larva ccases to eat, and remains motionless, 
attached by its abdominal legs to the under surface of the twig or leaf upon which it has been feeding. Many species spin a slight web, or carpet of silk, in which they attach their posterior legs, as observed by Pallas in Apatura iris (Purple Emperor), and in this manner await their change, which appears to be attended with much uneasiness to the insect. The whole body is wrinkled and contracted in length. In the Sphinx this contraction occurs to so great an extent in some of the longitudinal muscles of the anterior and middle part of the body, that the larva assumes that peculiar attitude from whence the genus derives its name. In this attitude the larva remains for several hours, during which there are occasionally some powerful contractions and twitchings of its whole body; the skin becomes dry and shrivelled, and is gradually separated from a new but as yet very delicate one which has been formed beneath it, and the three or four anterior segments are greatly enlarged on their dorsal but contracted on their under surface. After several powerful efforts of the larva, the old skin cracks along the middle of the dorsal surface of the second segment, and by repeated efforts the fissure is extended into the first and third segments, and the covering of the head divides along the top. The larva then gradually presses itself through the opening, withdrawing first its head and thoracic or fore legs, and subsequently the remainder of its body, slipping off the skin from behind, like the finger of a glove. This process, after the skin has once been ruptured, seldom lasts more than a few minutes. When first changed, the larva is exceedingly delicate, and its head, which does not increase in size until the skin is again changed, is very large in proportion to the rest of its body. In a few hours the insect begins to feed again most voraciously, particularly after it has entered its last skin, when its growth is most rapid. Thus, a larva of Sphinx ligustri, which at its last change weighed only about nineteen or twenty grains, at the expiration of eight days, when it was full grown, weighed nearly $\mathrm{I} 20$ grains.

"Most larvæ remove to fresh plants immediately after changing their skins, but some, as the larvæ of a beautiful moth, Episema coruleocephala, devour their old skins almost immediately they are cast, and sometimes one another, when deprived of food. But it is not merely the external covering which is thrown off 
during these changes, the whole internal lining of the alimentary canal also comes away with the skin, as was formerly noticed by Swammerdam, and repeatedly observed by ourselves and others. The lining of the mouth and gullet, and that of the mandibles, is detached with the covering of the head, and that of the large intestines with the skin of the posterior part of the body; and besides these the lining of the tracheal tubes comes away. The lining of the stomach itself, or that portion of the alimentary canal which extends from the termination of the œesophagus to the insertion of the so-called biliary vessels, is also detached, and becomes completely disintegrated, and appears to constitute part of the mass voided by the insect on assuming its imago state. Herold, however, has denied that this change ever occurs in the alimentary canal, and says that in the tracheæ it takes place only in the larger stems. But Swammerdam states that he saw it in the larva of the rhinoceros beetle, Oryctes nasicomis, which sheds both the lining of the colon and of the delicate as well as larger branches of the tracheæ; and Bonnet had witnessed a similar occurrence. Burmeister has also seen it, both with respect to the intestine and tracheæ, in some of the Libellula; and we now add our own testimony to the fact of its occurring, not simply at the extremities of the canal, but throughout its whole extent, as we have distinctly seen during the changes of the nettle butterfly, Vanessa urtica. It is more distinctly observed when the larva is changing into the pupa state than at any other period, although we believe that it really does take place at every change of skin. Hence these changes are of the greatest importance to the larvæ, which often perish during their occurrence. They are undergone by all larvæ which possess the true organs of locomotion, but it has been questioned whether they are common also to the apodal or footless kinds, more particularly to those which constantly remain in the same locality until they have changed into pupæ, or nymphs.

"Réaumur and Huber state that the larva of the common hivebee does not change its skin, but only grows larger. Swammerdam, on the contrary, asserts that it does, and also that he has observed the same thing in the alimentary canal of the hornet. Burmeister believes that it does not take place, and states positively that the larva of Diptcra do not moult. We have watched for these 
changes in the larvæ of the wild bee, Anthophora retusa, but have been unable to observe them, although we believe they do really occur. But the universally acknowledged accuracy of most of Swammerdam's observations, supported as they are in this instance by analogy, fully warrants us in considering this subject as still open for inquiry.

"When a full-grown larva is preparing to change into the pupa state, it becomes exceedingly restless, ceases to eat, and diminishes much in weight. Many species spin for themselves a covering of silk termed a cocoon, or case, in which they await their transformation. Others prepare little cavities in the earth, and line them with silk for the same purpose; and some suspend themselves by their hindermost legs to the under surface of a leaf. In each of these instances this important change takes place in the same manner. Before the larva thus prepares itself for metamorphosis, its alimentary canal is completely evacuated of its contents ; its body, as at the previous changes of skin, becomes dry and shrivelled, and much contracted in length; and certain enlargements at the sides of the anterior segments indicate the now rapidly developing parts of the future pupa. These changes take place in all insects in a similar manner, but have been most frequently watched in the Lepidopterc, upon which also our own observations have been made. We have also observed the same changes in the Hymenoptera.

"The larva of the Sphinx, when it is ready to undergo its changes, penetrates the earth to the depth of a few inches, and there forms for itself a little chamber, in which it awaits its transformation. But the larva of the butterfly either fastens itself by a little rope of silk carried across its thorax to the under-surface of some object, as a ceiling, \&c., or suspends itself vertically by its hind legs, with its head directed downwards, as is the case with the common nettle butterfly, Vanessa urtica. We have watched the changes with much care in this insect, which frequently remains thus suspended for more than ten or twenty hours before the transformation takes place. During this time the four anterior segments of the larva become greatly enlarged. Then the segments assume a curved direction, occasioned by the contraction or shortening of those muscles of their under-surface which are repeatedly slowly 
extended and shortened, as if the insect were in the act of laborious respiration. This generally takes place at short intervals during the two hours immediately preceding the change, and increases in frequency as that period approaches. When that period has arrived, the skin bursts along the back part of the third segment, or mesothorax, and is extended along the second and fourth, while the coverings of the head separate into three pieces. The insect then exerts itself to the utmost to extend the fissure along the segments of the abdomen, and in the meantime, pressing its body through the opening, gradually withdraws its antennæ and legs, while the skin, by successive contortions of the abdomen, is slipped backwards, and forced towards the extremity of the body, just as a person would slip off his glove or his stocking. The efforts of the insect to get entirely rid of it are then very great; it twists itself in every direction, in order to burst the skin, and when it has exerted itself in this manner for some time, twirls itself swiftly, first in one direction and then in the opposite, until at last the skin is broken through and falls to the ground, or is forced to some distance. The new pupa then hangs for a few seconds at rest, but its change is not yet completed. The legs and antennæ, which when withdrawn from the old skin were disposed along the under-surface of the body, are as yet separate, and do not adhere together as they do a short time afterwards. The wings are also separate, and very small. In a few seconds the pupa makes several slow but powerful respiratory efforts, during which the abdominal segments become more contracted along their under-surface. The wings are then much enlarged and are extended along the lower surface and sides of the body ; moreover, a very transparent fluid, which facilitated the slipping off of the skin, is now diffused among the limbs, and when the pupa becomes quiet, dries and unites the whole into one compact covering. Exactly the same thing occurs in the changes of the Sphinx. The limbs at first are all separate, each one being enclosed in its distinct sheath, but within a very short period after the change they become agglutinated together by the fluid diffused between them, and form the solid exterior of the pupa case.

"The three thoracic legs can be distinguished from the membranous legs of the hinder segments. Within the body, and 
crossing the œsophagus, $c$, is the nervous cord, and it passes down between the stomach and the skin. The shape of the digestive apparatus is noticed to be very different in the three conditions, and the shortening of the body is very distinctly shown: $a$ is the dorsal vessel, or the heart, and $i$ part of the reproductive apparatus

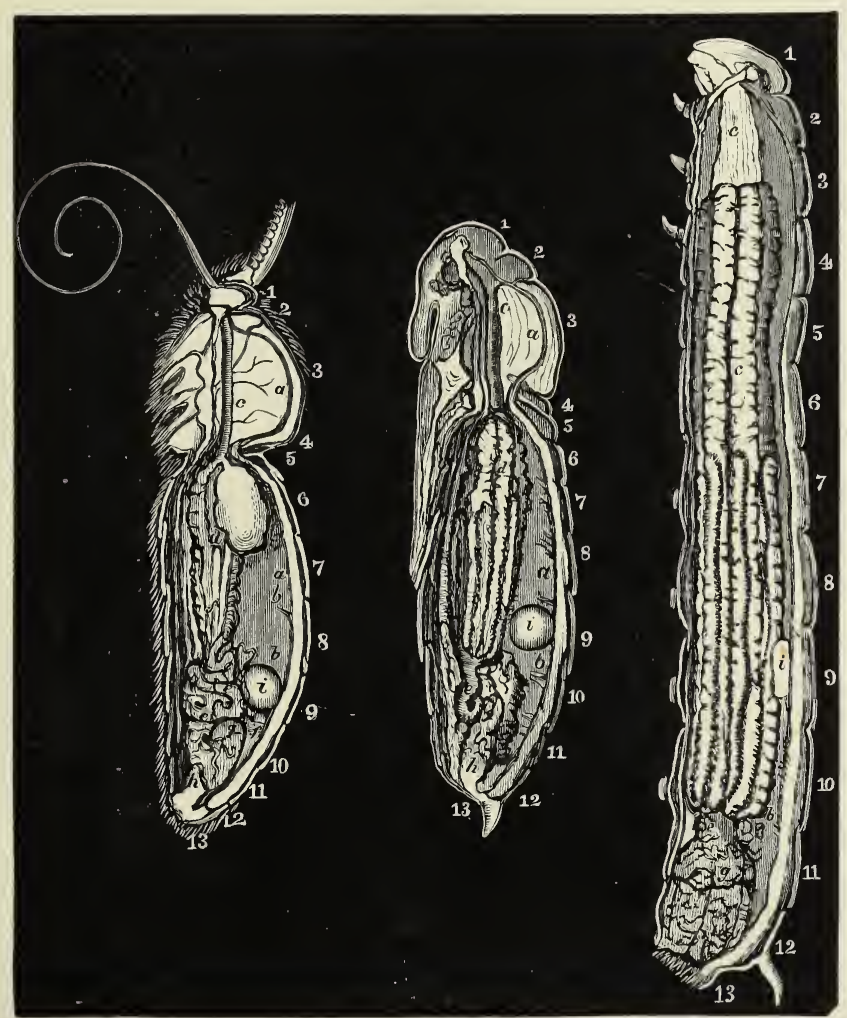

SECTIONS OF THE LARVA, PUPA, AND MOTH OF Shhinx ligustri. (After Newport.)

(In all the figures the numbers from I to I3, upon the dorsal or upper surfaces, note the segments.)

"The body of the insect is now divided into three distinct regions-head, thorax, and abdomen. The first step towards this division is the contraction which takes place in all the longitudinal and diagonal muscles of the body soon after the larva has acquired its full size, by means of which each segment of the insect forms a slight intussusception, the anterior margin of one segment being 
drawn under the posterior margin of the one which immediately precedes it. This occurs in all the segments which form the abdominal region of the future moth, the nine posterior ones of the larva. When the period of changing into the pupa state has arrived, a much greater shortening takes place in the muscles of the fifth and sixth segments, and in some insects this is carried to so great an extent, that the whole body becomes constricted in the fifth segment like an hour-glass, and is thus divided into two distinct regions-the thorax and abdomen. The same change takes place also in the muscles of the first and second segments, by means of which the region of the head is divided from that of the thorax. The fifth segment becomes almost entirely atrophied, and the sixth very much shortened. A part of the fifth segment forms a portion of the posterior surface of the thorax of the perfect insect, while the remainder constitutes the petiole or neck which connects the abdomen with the thorax, the sixth being the first true segment of the abdominal region."

The engravings of Vanessa urtice (page 4I) will assist in the comprehension of these changes, as will also the drawing of the larva, pupa, and moth of Splinxx ligustri. In this last engraving the segments are marked so that the alterations in the three phases may be recognised.

"Exactly the same changes take place in hymenopterous insects, and in every other species in which we have had opportunities of watching them. It is the opinion of Dr. Ratzeburgh, that the head in hymenopterous insects is composed of two segments of the larva, because just before the change into the nymph or pupa state, a portion of the head is found beneath the integuments of the second segment. The fact is indisputable, but the explanation of it appears to be this:- The true head of the hymenopterous larva consists of but one segment, which is provided with the organs of manducation and sensation, the same as in the lepidoptera; but the head in this larva ceases to become larger after a certain period, while the other segments of the body continue to grow, and ultimately acquire a diameter more than double that of the head. Now the parts which are to form the head of the future nymph continue also to grow beneath the unyielding cranium, from which, as the change approaches, they 
become detached, and are gradually developed backwards, and encroach upon the anterior portion of the second segment. This, in accordance with the laws of development as established by Geoffroy St. Hilaire, that in proportion as one part of an organised body is increased beyond its ordinary size, the part or parts in its immediate vicinity are in a corresponding degree arrested in their development, becomes so much reduced, that in the nymph the second segment, which in the larva is of the same size as the third and succeeding ones, has not half its original extent, and being still further reduced in that state, constitutes at length the atrophied and almost obliterated prothorax of the perfect insect. But while the second segment is thus encroached upon by the first, it is in like manner encroached upon from behind by the third-the immense mesothorax, which supports the chief organs of flight in the perfect insect. The fourth segment, from the same cause, is developed backwards; and the fifth, diminished to a very small size, exists only, as in the Sphinx, as the petiole which connects the thorax with the abdomen, thus leaving the nine posterior segments of the larva to the latter region, as stated when alluding more particularly to the number of segments in hymenopterous larvæ. The necessity for this additional segment in the abdomen of these larvæ is a matter of much interest, and appears to be connected with the development of an apparently additional organ in the females of this class.

"We have seen that after leaving the larva, or feeding condition, the insect assumes one of a very different form, which is called the pupa, nymph, aurelia, or chrysalis state. The two latter terms were applied by the older entomologists to this stage of transformation in butterflies and moths. The term 'aurelia' was used as expressive of the beautiful golden colours or spots with which many species are adorned, as Vanessa urtica, Vanessa Atalanta, and others. The term 'chrysalis' had a similar signification. Linnæus, desirous of employing a term that would be applicable to this stage of transformation in all insects, adopted that of 'pupa,' because in a large majority of the class the insect is as it were swathed or bound up, just as children were formerly swathed. The kind of pupa, in which the future limbs are seen on the outside of the case, is called 'obtected.' Such chrysalides are represented in 
page 2I. The term 'nymph,' which is sometimes employed, is applicable only to those species in which the limbs remain free, but are folded up, as in the pupæ of the butterfly and moth, and are not covered with a hard uniform case, as in many Coleopterous and most Hymenopterous insects." At present the term nymph is usually restricted to active pupæ. "When the pupa is cnclosed in a smooth uniform case, but no signs of the limbs and other parts of the body are visible, as in the Diptcra, it is called 'coarctate.' (Sce page I I.) In these insects the skin of the larva is not cast off at the period of changing, but becomes the covering or cocoon of the included pupa, which is also enclosed in its own proper skin within it.

"In all insects which undergo a complete metamorphosis this is the period of quiescence and entire abstinence. Many species remain in this state during the greatest part of their existence, particularly the true pupæ of moths and sphinxes, which often continue in it for nearly nine months of the whole year. But in most of those insects which assume the particular condition in which the body remains soft and delicate-as the hornets, ants, and bees-this pupa state is the shortest period of their existence, being often scarcely more than a week or ten days. In every species the length of this period is much affected by the influence of external circumstances. Thus if the larva of the common nettle butterfly, Vanessa urtica, changes to a chrysalis in the hottest part of the summer, it will often, as we have found, be developed into the perfect insect in eight or nine days; whilst if its change into the chrysalis takes place at the beginning of summer, it is fourteen days before the perfect insect appears; and if it enters the chrysalis state at the end of summer, it remains in that condition through the winter, until the following spring. On the other hand, it was proved by Réaumur, if the chrysalis be placed in an ice-house, its development into the perfect insect may be retarded for two or three years. Again, if the chrysalis be taken in the midst of winter into a hothouse, it is developed into the perfect insect in from ten to fourteen days. This period of quiescence is absolutely necessary in all those species which undergo an entire change of form and habits for the completion of those structural metamorphoses by which the creature is not only 
adapted to the performance of new functions, but is equally incapacitated for the continuance of some of those which it has previously enjoyed. It is during this period that new parts are developed, and the insect's mode of life is in consequence entirely changed. Whilst these alterations are taking place in the organic structures, the functions of the organs themselves are in a great measure suspended, and the condition of the insect becomes that of the hybernating animal. Respiration and circulation are reduced to their minimum, and the cutaneous expenditure of the body is then almost inappreciable, even by the most delicate tests. Thus a pupa of Sphinx ligustri which in the month of August, immediately after its transformation, weighed $7 \mathrm{I}^{\circ} \mathrm{I}$ grains, in the month of April following weighed 67.4 grains, having thus lost only 3.7 grains in the long period of nearly eight months of entire abstinence. The whole of this expenditure, therefore, had passed off by the cutaneous and respiratory surfaces. But when the changes in the internal structures are nearly completed, and the perfect insect is soon to be developed, the respiration of the pupa is greatly increased, and the gaseous expenditure of its body is augmented in the ratio of the volume of its respiration, which is greatest the nearer the period of perfect development. Thus, in the same insect in which the diminution of weight was so trifling during eight months' quiescence and abstinence, it amounted in the succeeding fifty-one days to nearly half the original weight of the pupa, since the perfect insect, immediately after its appearance on the 24th of May, weighed only thirty-six grains. This increased activity of function is attended with a correspondent alteration in the general appearance of the pupa.

"In the Sphinx all the parts of the future imago become more and more apparent on the exterior of the pupa case, the divisions into head, thorax, and abdomen are more distinctly marked; the eyes, antennæ, and the limbs appear as if swollen, and ready to burst their envelope, and the pupa gives signs of increasing activity by frequent and vigorous contortions of its abdominal segments. The naked pupa, or nymph, in which, as we have seen, all the parts of the body are free, and encased only in a very delicate membrane, acquires a darker colouring and a firmer texture; while the species which undergo their metamorphosis 
into nymphs in the water-the caddis-flies, for instance-acquire a power of locomotion as the period of their full development approaches, to enable them to creep up the stems of plants, and leave that medium in which it is impossible for them to exist as perfect insects. In every instance the assumption of the perfect state is accompanied by a slipping off of the external covering. Before this can be effected many Lepidoptera have first to remove themselves from the locality in which they have undergone their previous metamorphosis. When this happens to be in the interior of trunks of trees, or in other situations from which it is difficult to escape, the abdominal segments of the pupa are often beset
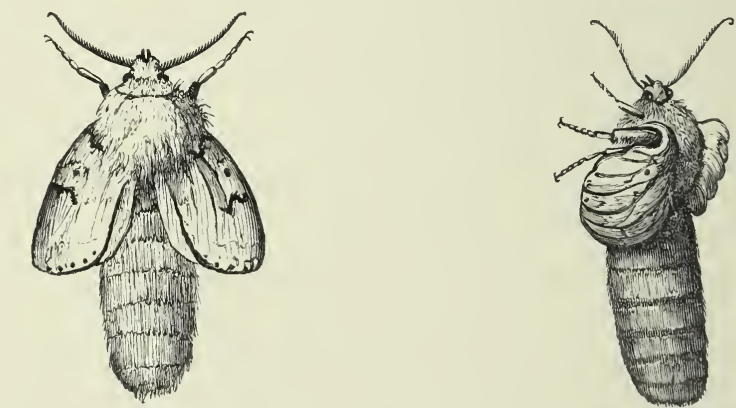

MOTHS WITH WINGS INCOMPLETE, JUST AFTER EMERGENCE.

with minute hooks, similar to those on the feet of the larva. By means of these, by alternately contracting and extending its abdominal segments, the pupa is enabled to force an opening through its silken cocoon, or to move itself along until it has overcome the obstacles which might oppose its escape as a perfect insect.

"Immediately after the insect has burst from the pupa case it suspends itself in a vertical position, with its new organs, the wings, somewhat depending, and makes several powerful respiratory efforts. At each respiration the wings become more and more enlarged by the expansion and extension of the tracheal vessels within them, accompanied by the circulatory fluids. When these organs have acquired their full development, the insect remains at rest for a few hours, and gains strength, and the exterior of the body becomes hardened and consolidated, and forms the dermo- 
skeleton. This is what takes place in lepidopterous insects. Some of the Colcoptera, as in the instance of Mclolontha iulgaris, the common Chaffer Beetle, remain for a greater length of time in their nests before they come abroad, after entering the imago state. This is also the case with the humble-bees. When these insects first come from their cells they are exceedingly feeble, their bodies are soft, and covered with moisture, their thick coating of hairs has not acquired its proper colour, but is of a greyish white, and they are exceedingly susceptible of diminished warmth. They crowd everywhere among the cells and near other bees, where there is most warmth. In a few hours this great susceptibility is diminished, and their bodies acquire their proper colours, but they do not become sufficiently strong to be capable of great muscular exertion, and undertake the labours of the nest, until the following day. When an insect has once entered its perfect state, it is believed to undergo no further metamorphosis or change of covering. But there exists an apparent exception to this general law in the Ephcmeride, which are noted for the shortness of their existence in the imago state. When these insects have crept out of the water and rid themselves of the pupa covering, and their wings become expanded, they soon take flight, but their first movements in the air are performed with some difficulty, and they shortly alight again and throw off a very delicate membrane with which every part of the body has been covered, and then resume their flight with increased activity. The condition of the insect previous to this final change has been called the pseud-imago state."

The structural changes which occur during metamorphosis are certainly equalled, in the interest they must excite, by the psychical; and the habits, instincts, and passions witnessed during the different phases of existence are indeed most diverse. 


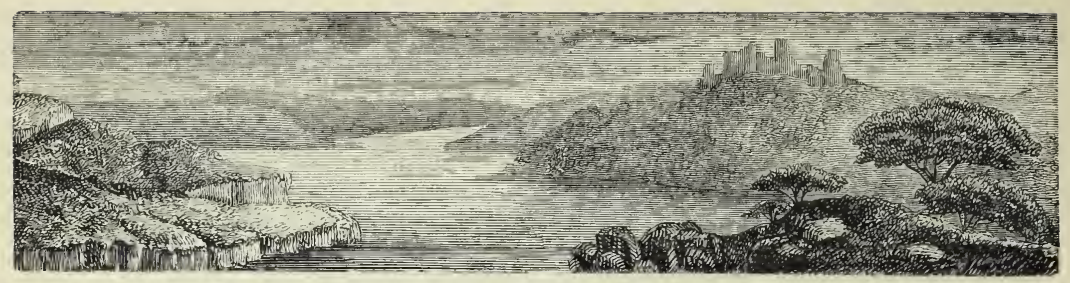

CHAPTER IV.

TH E LEPIDOPTERA.

THERE is some advantage in commencing the description of the metamorphoses of insects with the Lepidoptcra, for nearly everybody knows something about their transformations.

No one has any hesitation in distinguishing an insect of this order, for its shape proclaims it to be a butterfly or a moth at once.

The very name, scale-wing (Lcpidoptera), calls up delicate and airy forms with elegant proportions and beautiful colouring.

The wings, usually very large in proportion to the body, give that peculiar jerking flight to most of the Lepidoptera which attracts the attention. There are four wings, each formed by a double layer of colourless membrane, traversed by nervures which are differently arranged according to the species of the insect; and these delicate expansions are covered with microscopic scales fixed on like the tiles of a roof.

The beautiful colouring of the butterfly's wing depends upon the scales. This nature painting, which seems to deal with glaring and strongly contrasted colours, is so perfect that it never offends the eye. Yet, if we place certain tints in direct opposition, an unpleasing effect is invariably produced. Thus, there are many Lepidoptcra with a red, yellow, or bright blue band crossing a black ground; but there is a beautiful softening off of the intermediate tints produced by rows of diverselycoloured scales, which, although it escapes us in a general view, does away with all harshness, and conveys an excellent lesson to the painter. 
At first sight the scales look like dust, and they come off on to the finger and thumb when the wings are touched; but under the microscope they present most elegant shapes and singularly elaborate details of structure. Variable according to the genera and species of the Lepidoptera, and equally so in different parts of the same wing; the scales may be more or less elongated or even fan-tailed in shape, and rounded at the free edge, or incised, so as to resemble dentations or pointed festoons. There is a short stalk at the base of each scale, which resembles a handle under the magnifying power of the microscope, and it is the portion

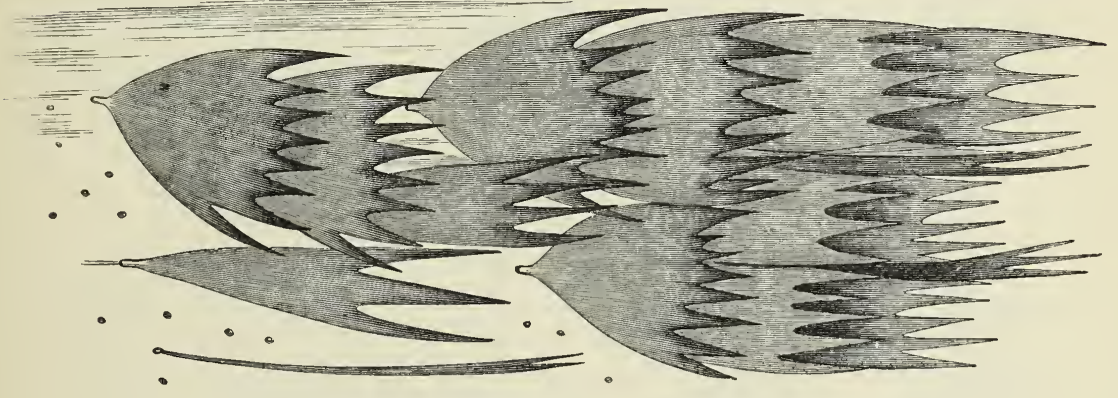

A PORTION OF THE WING OF Attacus patonia major.

Showing the method of implantation of the wing scales. (Magnified.)

which is implanted into the alar membrane. The surface of the scales ordinarily presents several longitudinal keel-like prominences, which are parallel and equidistant. Some cross markings, which are very close together, form a very delicate network between the keel-shaped lines, and they appear to have something to do with the connection between the neighbouring scales. The scales are formed by two layers of excessively delicate tissue, and the colours are produced by extremely small dots, beads, or corrugations, which act upon the rays of light, and produce the phenomena of "interference." There is no special colouring matter in the scales, and all the effect is brought about by the "interference" and decomposition of light. Dr. Pigott and others have lately shown that the so-called ribs of the scales are corrugations of one or both of the layers of tissue, and that the beads-which 
are so difficult to resolve into such shapes, except with very good microscopes, handled by first-rate histologists-are dried drops of some secretion which is upon the scale when the whole wing is moist, immediately after metamorphosis.

All the Lepidoptera, although the name implies to the contrary, have not their wings perfectly covered with scales. The wings of
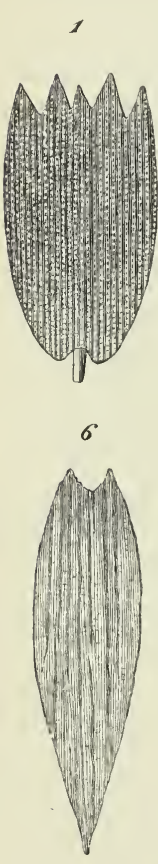

2
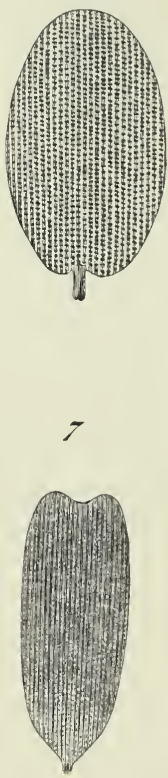

3

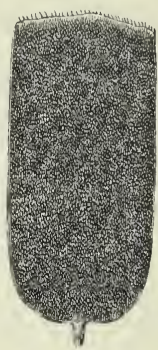

8

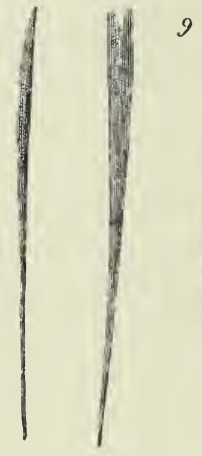

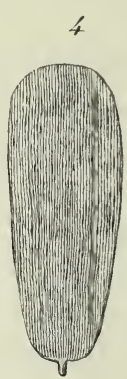
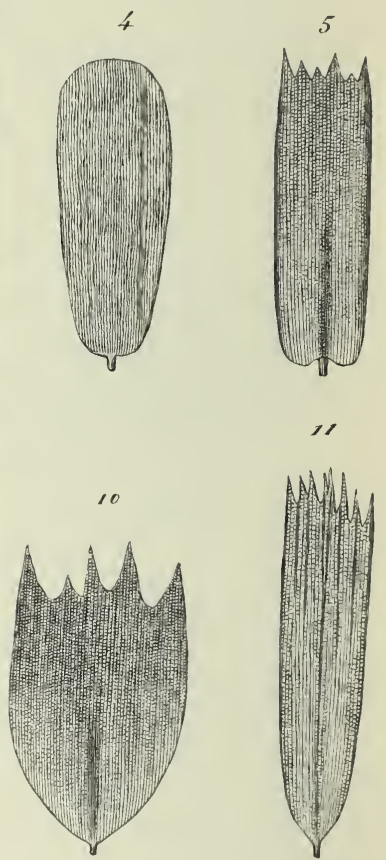
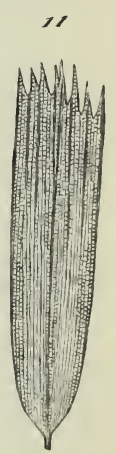

SCALES OF DHFERENT GENERA OF LEPIDUPTERA.

I, 2. Papilio machaon. 3, 4. Morpho menelas. 5. Pamphila aracanthus. 6. Sesia apiformis. 7. Zygæna filipendulæ. 8, 9, Io. Sphinx ligustri. II. Pterophorus pentadactylus.

some are more or less transparent, and this is because they are not covered with scales; nevertheless these elegant structures are to be found on the margins, upon the nervures, and on some parts of the wings. They are never entirely deficient, and must be looked upon in all the Lepidoptcra as structures superadded during the second metamorphosis.

The legs of the Lepidoptera are almost always very slender in proportion to the size and weight of the body. The adult insects, 
of whose legs we are now treating, do not walk much, and this is particularly the case with regard to those that fly by day-the diurnal or butterfly Lepidopterc - which only use their extremities as supports to rest upon. Generally the three pairs of legs are equally developed, but the first are often atrophied in some kinds of butterflies. These ill-developed legs are smaller than the others,
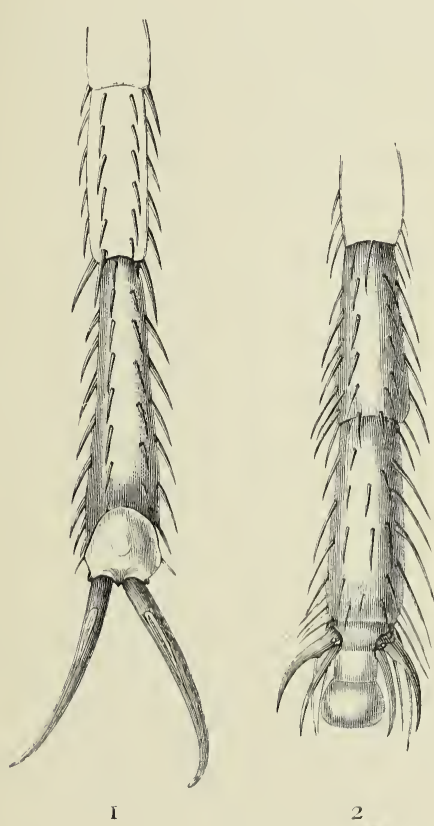

2

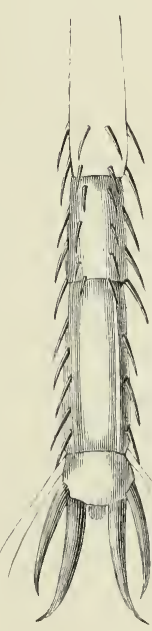

j

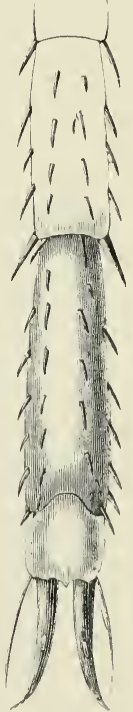

4

ENUS OF THE FEET OF I.EPIDOPTERA.

I. Papilio machaon. 2. Heliconia. 3. Vanessa Io. 4. Sphinx ligustri.

and do not have hooks or claws on their extremities; they are very hairy, and are usually kept close against the chest or thorax.

The legs of the Lepidoptera are covered with hairs and scales, and the feet terminate in hooks, which are always of one shape in the moths or nocturnal kinds, and which are greatly modified in the butterflies or diurnal flyers.

Nearly every kind of butterfly has the endings of its feet modified to meet its peculiar habits and the nature of the foliage it crawls over.

We have noticed the wonderful transformation which occurs 
of the mouth of the caterpillar into the long trunk-like suction tube of the perfect insect, and it is therefore only necessary to state that the lower palpi, which are attached to the lower lip or labrum, are large, and that they probably act as organs of touch.

The antennæ are formed by a long row of joints, and are of different shapes in a great number of the Lepidoptera. They form, with the eyes, very beautiful objects for low magnifying powers, and the globular shape of these compound organs of vision is well shown with the binocular microscope, which exhibits the extraordinary long hairs between the hexagonal facettes of the cornea to perfection.

All these structural details refer to the perfect insect, and they have been superadded to those characteristic of the larva or caterpillar condition during metamorphosis; they are the product of a definite growth and development, and which is more or less invariable, according to the species, but they are often modified and varied in order to meet the exigencies of altered external circumstances.

The most beautiful insects in the world belong to the Lepidoptera, but it is remarkable that they' should not be very interesting in their habits and peculiar instincts. The gift of superior beauty, like as in the highest of all animals, is not frequently accompanied by remarkable intelligence and superior sense; and the most gaudy butterfly is a fool in comparison to a dingy-coloured bee. The butterflies have some curious instincts when in the caterpillar state, but they only live to increase and multiply their race, and to embellish Nature. Their existence is usually very brief; it is one of the prettiest of honeymoons, and often love subdues and destroys every other passion. The gormandising caterpillar is never troubled by the ardent flame which consumes even the thought of sipping the nectar of the flowers that rival in beauty the wings of the perfect representation of elegance and love. The early insect lives and eats, and the perfect form loves and dies.

The female butterfly's instincts are principally restricted to selecting proper positions for her eggs. She never sees her hatched progeny, and can have no ideas about the respective 
merits of cabbages, carrots, or oak leaves as their future nourishment, for, at the most, she dips her long sucker into a few flowers to enjoy their sweetness. Nevertheless she deposits her eggs in a safe place, and as near as possible to the ordinary nourishment of the future caterpillar.

It is impossible to explain the varieties of the colouring of some groups of the Lepidoptera, or the remarkable resemblances which exist between the tints of others. Sometimes all the species of a genus have the same shades of colour and markings. The most brilliantly tinted kinds belong to the hottest and moistest climates; for instance, South America, the Moluccas, and certain parts of India.

Several groups of species belonging to the great genus Papilio have a very uniform system of decoration. Species of this genus, which are found in the Moluccas, in the neighbourhood of the Straits of Sunda, in India, and in Southern China, have black velvety wings, dusted with a metallic blue or green tint, and ornamented with spots or bands of the same shade. Other species of the genus belonging to South America, to the Antilles, and to Mexico, are distinguished on account of a flaring red spot, or a band with opalescent tints, which ornament the black hinder wings. Multitudes of others have their wings variegated with yellow and black colours.

The Picridi, whose type is the great Cabbage Butterfly, have usually white wings, and the species of the genus Colias have them tinted yellow; moreover, most of those of the genus Morphos, of South America, have their wings brilliantly coloured with a metallic blue.

Thus there is a sort of uniformity in the ornamentation and colouring of more or less widely spread natural groups of the Lepidoptera. But if we seek the reason why, and endeavour to discover the end that Nature had in view in giving certain shades of colour to certain species, we shall not obtain very satisfactory answers. It is known that the brilliant colouring depends upon the presence of the scales, so far as the Lepidoptera are concerned, and the microscope has proved that no inherent and tangible colouring matters exist in those tiny dust-like particles. The delicate ridges and net-work of the scales act 
upon the colourless rays of light that fall upon them, and decompose them into a variety of tints that emulate the rainbow.

Many animals, such as birds and insects, live beneath the branches and amongst the sombre foliage of trees, and their colours are correspondingly quiet in tone; they take on a livery which enables them to escape observation, and they thus owe their safety to their mistress Nature. Hundreds of caterpillars escape destruction and extirpation in this manner; but the butterflies of the Lepidoptera do not hide, and they rather glory in the brightness of the full light of day.

The inquiry is rather complicated by the fact, elaborated by Wallace, that Lcpidoptcra which belong to different genera have often a similarity of colouring; but a hint from Mr. Bates, that admirable naturalist, who has given us such vivid descriptions of tropical nature in the district watered by the Amazons, throws no little light upon this difficult subject. He noticed immense flocks of Lcpidopter, belonging to the genus Heliconia, and that there were several other kinds mingling with them which belonged to different genera. Now these strangers in the crowd borrowed the Heliconian decorations, and would have passed muster to superficial observers as having a legitimate right to them. But the eye of the entomologist discovered that some belonged to the Picridi, which we have already noticed as usually having white wings. The insect was clearly one of the Picridi, but its clothing was that of Heliconia. It was a dove in peacock's attire, all glowing with red, yellow, and dark colours. Some of the other butterflies of the crowd had the same habits and peculiarities of flight of the Lcpidoptcra, whose garments they imitated. These were not accidental mimicries, for the descendants of these masqueraders do the same thing year after year. Why does Nature then mimic the decorations and colours? Mr. Bates suggests that in clothing a Picris with the garb of a Heliconia, Nature has provided it with a means of escape from insectivorous creatures, that do not care for Hcliconic-natural selection being at the bottom of the matter.

The colours of both sexes are often the same in the Lcpidoptera, but in some instances the ornamentation and tinting of the males and females differ, as also do their growth and development. 
Many females have no wings, and others are so imperfectly developed that they can hardly be distinguished from larvæ.

It is evident, then, that there is design in the decorations of the Lepidoptera; that they are for the good of the insect; that they vary under certain conditions of life, the other structures remaining the same; that they have some reference to sex; that they are inherited, variations and all; and that, besides all this, they are proofs of the high art in Nature, and the beauty of God's thoughts.

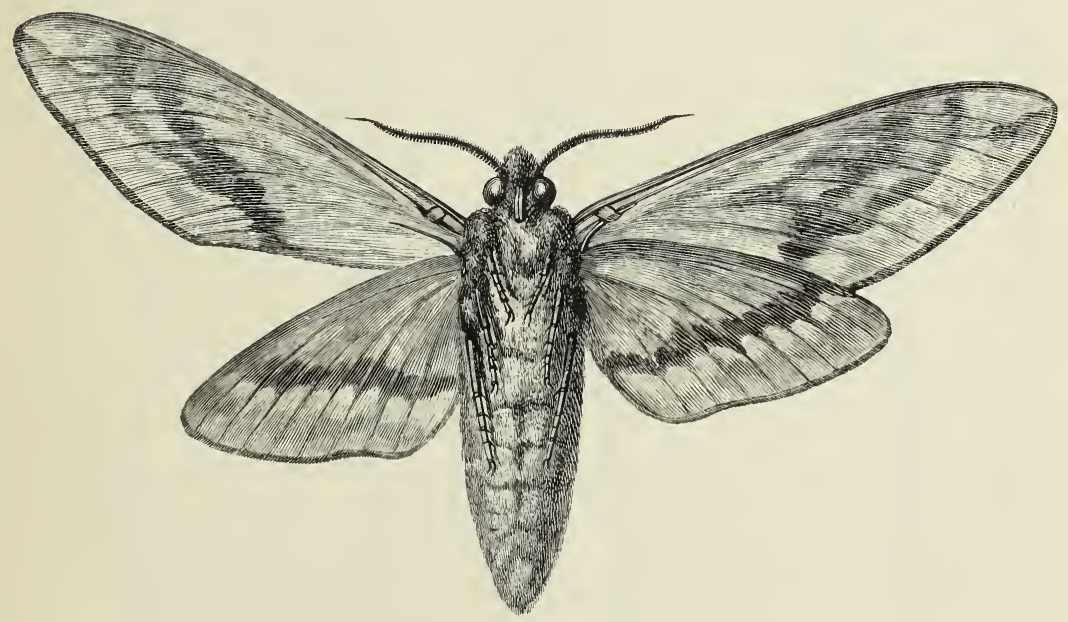

MOTH OF Sphinx ligustr ('RIVET MOTH),

Showing on one side the "catch" of the lower wing filled into a flat ring in the upper one; and on the other side, the catch out of the ring, and the wings separated.

There is a curious structure which is found on the wings of those Lepideptera that fly very strongly and rapidly, and not in the jerking, irregular manner of butterflies. A sort of hook arises from one of the nervures of the hind wing, and fits into a ring on the large nervure of the front one. Both wings act then very strongly together.

As a general rule, which is subject to a few exceptions, the diurnal Lepidoptera - the butterflies-do not have this structure, and they are therefore classified as Achalinoptera-wings without hooks. The rest of the Lepidoptera are Chalinopterous, and have the strengthening structures. 
THE LEPIDOPTERA WITHOUT HOOKS TO THEIR WINGS. (Achalinoptera.)

These Lepidoptera are celebrated for the elegance of their shape and brilliant colour. The wings of the butterflies, or diurnal flyers, are usually very large, and very varied in their

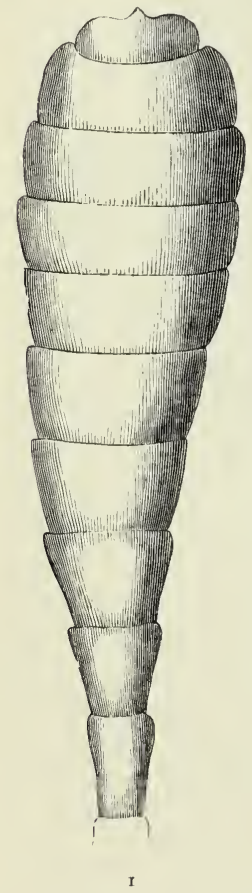

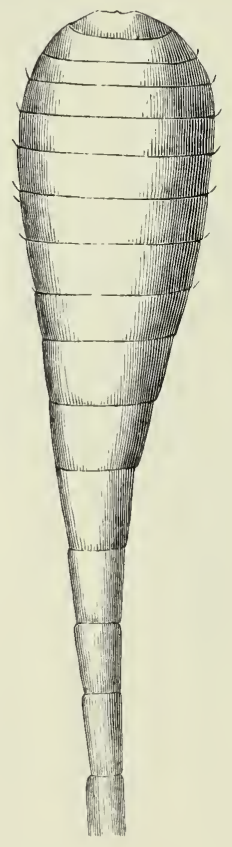

2

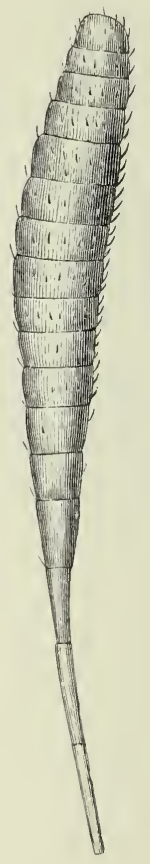

3

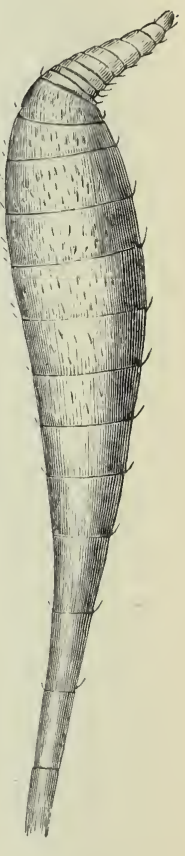

TERMINAL PARTS OF THE ATTENN $Æ$ IN DIFFERENT GENERA. (Magnified.)

I. Papilio machaon. 2. Argynnis paphia. 3. Thecla IV. album. 4. Hesperia sylvanus.

outlines. Some have them gracefully rounded off, and others have them prolonged backwards symmetrically. When these insects are at rest, their wings are set up, so that only their lower surfaces can be seen; they can hardly walk, and their legs are principally employed to keep the body steady, and to support it. The antennæ of all the species are clubbed, and are useful to distinguish the different kinds. 
The swallow tail Papilio machaon is a well known butterfly in England, France, and the rest of Europe; it is also found in Asia as far as the Himalayas, and even in South Africa. Every one has seen it flying in the fields and resting on the milk parsley and other umbelliferous plants, and has admired its great size, its yellow wings, marked and splashed with black, and its hinder ones so beautifully ornamented with a row of eye-shaped spots of light blue. The butterfly appears for the first time every year in the month of May and a second time in the month of July.

A very pretty caterpillar, about an inch and a half in length, may be found on the wild fennel and carrot plants during June and September. It is of a very vivid green colour, and is ornamented with black velvety rings and large dabs of a reddish fawn colour.

When this caterpillar-which is that of Papilio machaon-is quietly browsing upon its favourite plant, it resembles many others, and there is nothing very remarkable about the insect; but if it be touched it suddenly pokes out a spotted tentacule from between the head and the first segment of the body, and there being one on each side, they look like horns. Doubtless the insect believes that its enemies are alarmed by this proceeding, and a faint smell is certainly produced at the same time. These horns are common in the caterpillars of the genus Papilio. The caterpillar of Papilio machaon has rather a small head, the skin of which is not much harder than that of the rest of the body. It feeds upon soft leaves, and the mandibles are weak and their cutting edge is not toothed. The upper lip or labrum is not split, but simply notched, and this indicates that the insect browses upon small leaves or upon those which are very "compound," as the botanists have it, and which do not require to be held steadily whilst the masticating is going on. The membranous legs of this caterpillar are evidently admirably adapted for a larva that crawls upon easily grasped stems and twigs. They end in an inner margin, which is covered with spines, and in an outer, which is furnished with little hairs that materially assist the sense of touch.

There are two caterpillars of Papilio machaon represented 
in the engraving, and their peculiar horn-shaped prominences may be noticed behind their heads. An angular chrysalis is represented hung by its tail end and slung also by a girdle of silk to

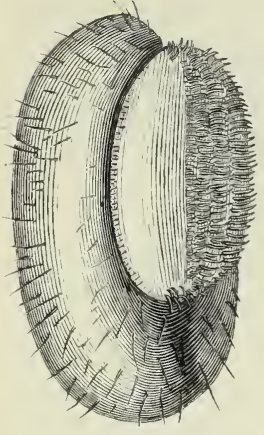

I

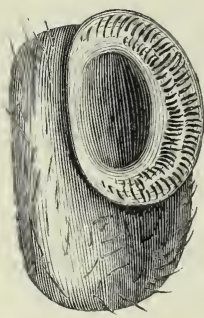

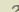

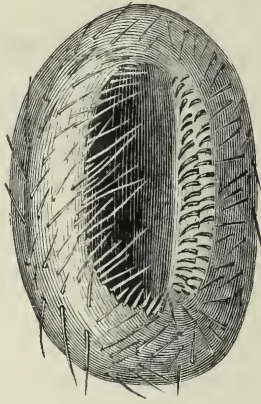

3

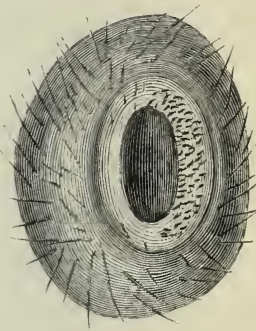

4

MEMBRANOUS FEET OF CATERPILLARS.

I. Papilio machaon. 2. Vanessa urticæ. 3. Charaxes jasius. 4. Thecla W. album.

a stem. The caterpillar does not spin a cocoon, but slings itself, and the chrysalis stage is completed in May.

The special adaptation of the external organs of the caterpillar to definite methods of existence is very noticeable. Thus, in Carolina, Virginia, and Louisiana, there are swallow-tails

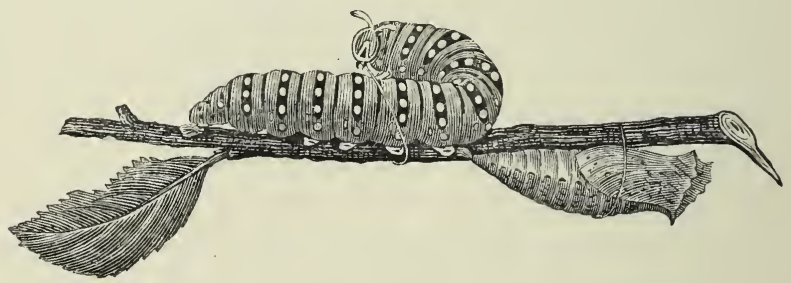

CATerpillar and chrysalis of Papilio machaom.

(Papilio astcrias) whose caterpillars live on umbelliferous plants, like those of Papilio machaon, and their oral (mouth) structures, and their feet, are like those of the common European insect. In the same districts a Papilio troilus lives on laurels in its caterpillar state, and the larva has its labrum or upper lip more split than the others, so as to hold the leaf it gnaws -moreover, the spines of the feet are stronger, so as to enable 


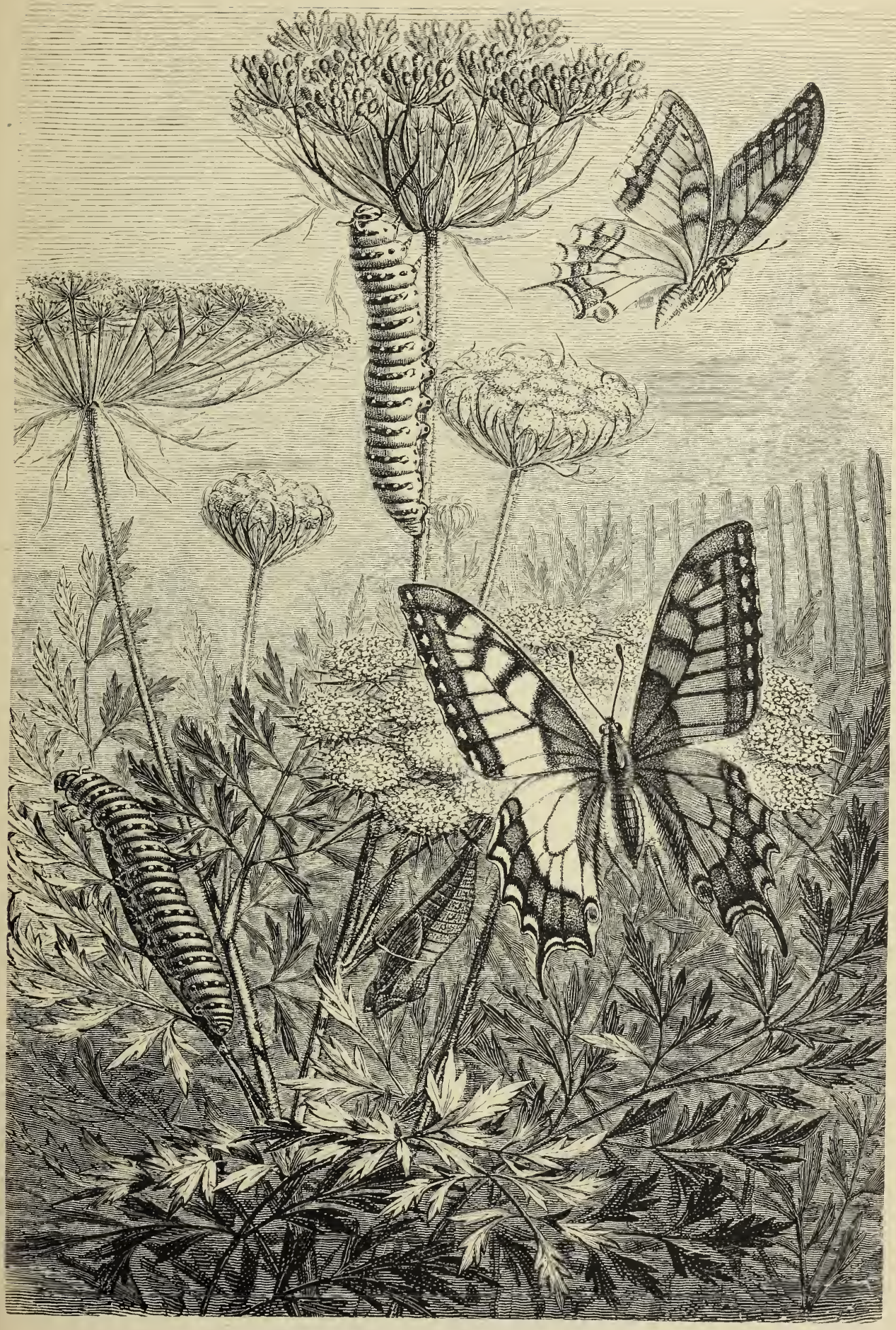

THE METAMORPHOSFS OF Patilio machaom. 

the creature to walk over the stems and leaves of the plants, which are more difficult to grasp than those of the Umbellifere. These species may be compared with a swallow-tail from Bengal (Papilio Hector), which has its black wings spotted with white and red. Its caterpillar has a very hard head, and its labrum is deeply notched; the mandibles are powerful, and are armed with saw-like edges, and the legs are much more spined than those of the other kinds. The Bengalese caterpillar evidently crawls over vegetable tissues which are not easily climbed, and lives upon large and hard leaves, and it is said that herbaceous Aristolochiacea are its favourite food. This caterpillar's peculiar structures relate distinctly to its habits. It has, however, two rows of tubercles on the back, whilst the body of our species is smooth.

Several very closely-allied genera, which belong to the same little group of Lepidoptera as the genus Papilio, are very remarkable, for more reasons than one. The Ornithoptera are readily distinguished by their great size, their strongly-formed head, their long anterior wings, and their toothed hind ones which have not a vestige of a swallow-tail; they are magnificent butterflies, which inhabit the Moluccas, the Philippines, and the islands of Sumatra, Java, and Borneo. Travellers in Amboina are always struck with the beauty of the great Ornithoptera Priamus, whose wings have a diameter of from six to eight inches. The black velvety colour and the brilliant and silky green tints of the wings of the male are most harmoniously contrasted, and he is a glorious fellow; but the female, although larger than its beautiful companion, is very quietly clothed in deep brown with white spots.

In most mountainous countries there are species of the genus Pamassius, which have a short body, short antennæ, and wings as crisp as parchment, and almost without any scales on their surfaces. The Pamassius Apollo is common during the summer on the Alps, the Jura mountains, the Puy-de-Dôme, the Pyrenees, the Caucasus, and the Sierra Nevada; and it has rather a striking appearance, on account of its great white wings being semi-transparent, spotted and dotted with black, and ornamented with splashes of vermilion, surrounded by black tints, 
and marked with white eye-shaped circles. Its caterpillar is velvety black, and has tubercles which are more or less blue, with orange-coloured points. It lives upon the Saxifrages and the Crassulaceous plants of the hills. When it undergoes the transformation into the chrysalis state, it forms a silken net around the body, and attaches the end of the abdomen to its resting-place, and forms the usual girdle by which it is safely anchored.

Most of the pupæ or chrysalides of the Lepidoptera are naked, but from the above example it is evident that the protecting nature of a silken coverlet bears some reference to the exposure of the quiet insect to cold and rain, which are common enough in Alpine districts, and which would tend to destroy were there no natural clothing. Nevertheless, the protection it gives must be slight, for the insect has to sling itself, after being invested by it.

The Pieridi, which are vulgarly termed Cabbage Butterflies, on account of the favourite food of the caterpillars of one genus, are found in Europe, Asia, Africa, and Australia. The larvæ are remarkable on account of the small size of the head and the end of the body, and their hairy skin. The pupæ are very angular, and have a pointed projection in front. The butterflies always have wings, without tails, and the legs are long and hairy.

The type of the genus is the Pieris brassica, the great Cabbage Butterfly, which is to be seen in every garden and field in Europe. The butterfly is, moreover, well known in Asia Minor, in Egypt, in Northern Africa, in Siberia, in Nepaul, and even in Japan. The caterpillar makes sad havoc amongst the cabbages, and it is not a pleasant-looking nor a nice-smelling vegetarian. Its greenish body, marked with three long yellow lines broken into here and there, by little black hairy tubercles, excites indignation in the breast of every gardener. Unfortunately, they are not solitary in their habits, for they generally abound in swarms, and destroy the tenderest leaves of the hardest-hearted cabbages with infinite relish, and with an utter disregard of consequences. Everybody has met with some of these caterpillars wandering about the roads and paths, and crawling up walls and palings, in order to find a 
cornice, or a safe projection under which they may turn into chrysalides, and rest in safety until the spring-time of the next year. Myriads of them are killed by remorseless market gardeners, and devoured by birds; but were it not for a little ichneumon fly (Microgaster glomerator) the existence of cabbages would indeed be imperilled.

The caterpillars change their skin several times during their growth, and finally hang themselves up by the tail, and sling a silken girdle round their body before undergoing the metamorphosis into the chrysalis.

Some small Pieridi, whose delicate wings are ordinarily variegated with green colours, form the genus Anthocharis. This name indicates the grace and exquisite beauty of the little butterflies that rival the flowers they roam over in symmetry. The orangetip Anthocharis cardamines, so common in the spring of the year in wood-side lanes, quite deserves its title, and it is the male whose fore wings are marked with an orange spot. In the centre of France, and in Southern Europe, there is another Anthocharis, whose males have perfectly yellow wings. But so far as colouring is concerned, there are some remarkable facts in reference to some species of the genus which have white tints on the upper surface of the wings in both sexes. The Anthocharis belia of the centre of France sometimes wanders close to Paris, and is found in Southern Europe and in North Africa. There are two generations of it every year. The first butterflies escape from the chrysalis state in the months of March and April, having been in that condition all the winter. Their hinder wings are of a delicate yellow green below or on their under surfaces, and are ornamented with spots of the purest nacreous white. These butterflies produce a new generation, whose adults appear at the end of June or to the beginning of August. These are larger than the first, and their wings are marked with a dull white.

This interesting variation in the colouring of the same species at different times of the year is seen also in one of the Vanessa (Vanessa prorsa), whose successive generations are so different that separate names have been given them. The butterflies of this species, which are common in France, are 
very small; some of them may be seen towards the end of April or the beginning of May, when Nature has awakened from her long sleep, and the leaves are beautiful from their freshness. They play around the nettles under the shade of the damp underwood. Their wings look new and unworn, for their texture resembles velvet, and they are of a bright fawn colour, being also ornamented with wandering black lines, which give the common name to the insect of the "carte geographique." If the same spots are revisited during the month of June, none of the pretty little butterflies can be seen, but the nettle leaves are covered here and there with little black caterpillars, which have white dots, and fine branching spines. These are the offspring of the pretty April butterflies. When the caterpillars have attained their full growth they separate, and each, after fastening itself, becomes a grey chrysalis, having the angular form, like those of all Vancsse. It is now the month of June, and the temperature of the air is high, so that the development and the metamorphoses are rapid. A fortnight passes, and the little "cartes geographiques" burst from the chrysalis state. Now this second generation differs materially, so far as colouring is concerned, from the first which produced it. The wings of the July butterflies are black, and are scratched with whitish lines.

But this is not all. The Vanesse with the black wings lay their eggs, and little caterpillars are hatched, in August and September. These devour the favourite nettles, and resemble those which did the same thing in June. Like the others, these autumnal caterpillars hang themselves up, and are metamorphosed into pupæ. If the autumn is fortunately a prolonged summer, some butterflies will escape from the chrysalis condition in October. Strange to say, their wings have neither the black colours of the July butterflies, nor the fawn tint of the April brood, but an intermediate ornamentation. This late metamorphosis is rare, but it can be produced artificially by keeping the chrysalides in a warm place. Most of the chrysalides, and sometimes all of them, live in this state through the winter, and are metamorphosed into the true "cartes geographiques" during the spring, and the butterflies are then tinted with fawn colour. 


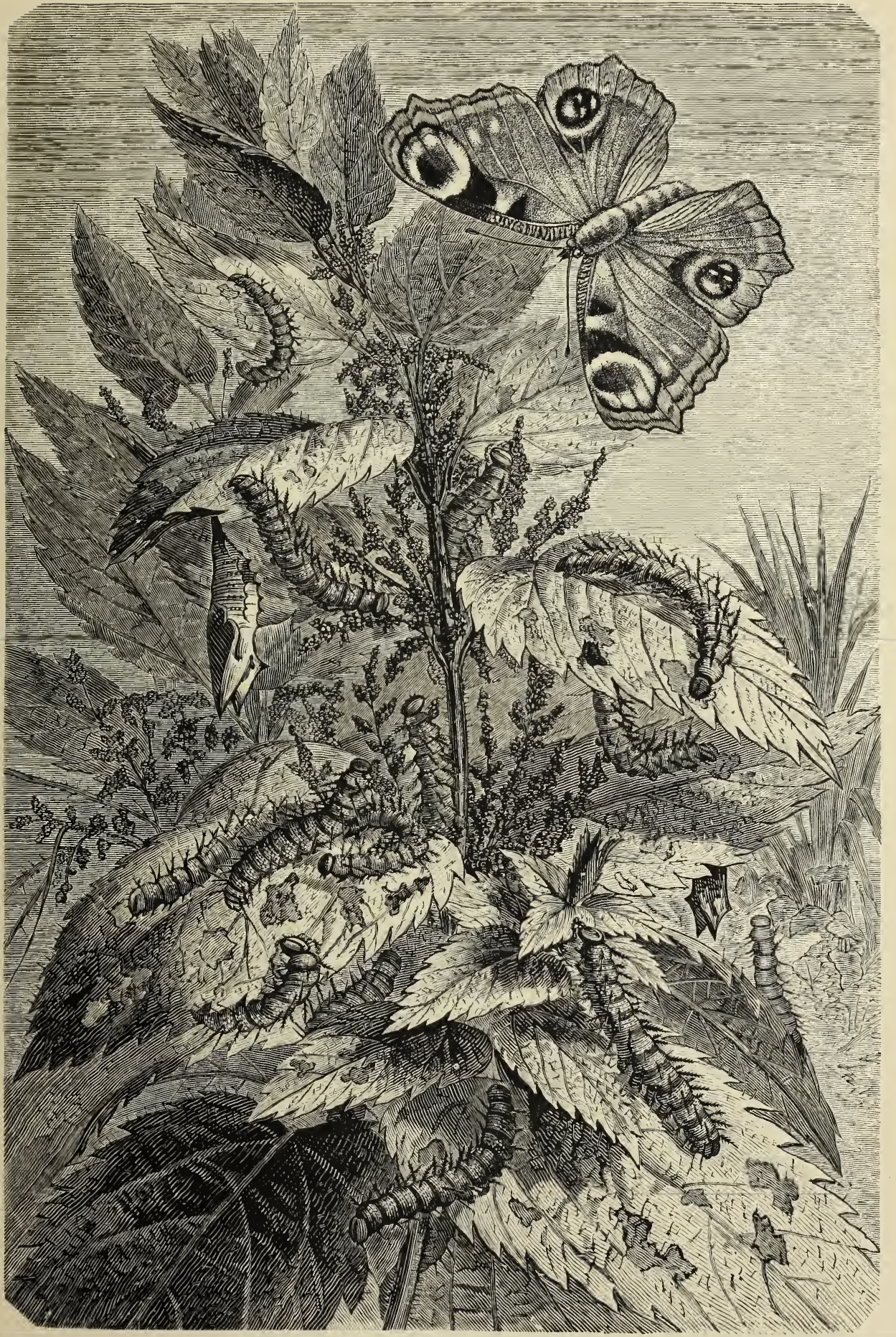

THE METAMORPHOSES OF Vanessa 10. 

An Anthocharis with a larger body than those just mentioned has been noticed in Orenburg, and is not very remarkable in the adult state, but Dr. Rambur having met with it in Andalusia, in the environs of Malaga and Granada, studied its metamorphosis. The caterpillar lives in the fields on coniferous plants. It makes a sort of delicate shroud of silk for itself before becoming a pupa, the shape of which is not at all angular, like those of the other Papilionidi.

The most favourite, perhaps, of all the butterflies is the Peacock-Vanessa Io. If it came from the tropics alone its value would be incalculable, but although it is so common its beautiful ornamentation and splendid colouring always make it prized. This Vanessa appears in the spring-time and also in the summer, and a third generation may ornament the autumn. Nettles are the food of the caterpillar, as they were with the small Vanessa just described. In their early days the caterpillars hatched from one set of eggs keep together and do not separate until the time for metamorphosis is at hand. They crowd upon the same leaf or Łwig, and when this is eaten they move en masse to others. Their colour is velvety black, pointed with white, and each segment of their bodies, except the first, carries six branching spines or stiff hairs. The membranous feet have a circle of very fine spines upon them, and they are constructed so as to climb the rather tender twigs and leaves of the nettle. Before turning into the chrysalis the caterpillars fix themselves usually to the leaves of their favourite plant or to some other in its immediate neighbourhood. Fifteen days after this the butterflies escape. The different generations do not exhibit any alterations in their colouring, so that those noticed in the case of the other Vanesse must have some other cause than the influence of heat and light. Some of the latest metamorphosed peacocks hybernate and fly early in the spring. The pendant chrysalis and the butterfly of Vanessa Io are shown in the plate with several caterpillars. The angular shape of the chrysalis is very evident.

The favourite White Admiral butterfly frequents woods and forest glades in preference to the open fields and gardens, and flies in June, and sometimes as late as September. Its spiny 
caterpillar is well known as a honeysuckle eater, and its green colour blends with that of the plant. The caterpillar of the Papilionidi already mentioned have their feet especially suited for climbing their favourite plants, but the white admiral's larva is badly off in this respect. Its feet are not sufficiently furnished with spines and hairs to enable it to climb with perfect safety, for the twigs of the honeysuckle are smooth, hard, and often long; the spinning glands are, therefore, brought into requisition, and a fine silken thread placed here and there on the plant, and collected more decidedly on the leaves, protects the caterpillar from falling violently to the ground. The chrysalis is very angular in its aspect, and is of a dark greenish brown, but it is ornamented on the upper part of the abdomen with brilliant silvery spots and a large one of pale green.

The great Limenitis populi is rather common in the large forests in France, and its caterpillar choses very inaccessible places, such as the very top of poplar trees, so as to feed safely and well. Many a tired butterfly hunter has given up the chase after this splendid insect, whose flight is very strong and high, and were it not for a peculiar habit of this exquisite and delicate-looking creature specimens of it would be very rare in collections. Many are the evils of dirty habits and common tastes, and curious are the longings of the beautiful for the vulgar. The great Poplar Butterfly loves the moisture of horse dung, and leaves the tree tops to dip its trunk in the nauseous mess: then is the time for the butterfly net.

A large greenish caterpillar which moves very slowly, and looks remarkably stupid and dull, lives during the month of May upon the tops of aspen, willow, and poplar trees, whose constant motion must be very dangerous to it. The feet of the larva are not well furnished with the means of clinging on, but the creature makes use of its spinners and completely covers the leaves upon which it feeds, so that the wind may blow as much as it likes, providing the leaves do not come off. This Nymplialis ilia is a large butterfly with dark wings and yellowish white spots upon them, the whole having beautiful violet tints in certain lights. It flies near long rows of poplars, especially if there is any water near, and loves the shade of the meadows close to great woods. 


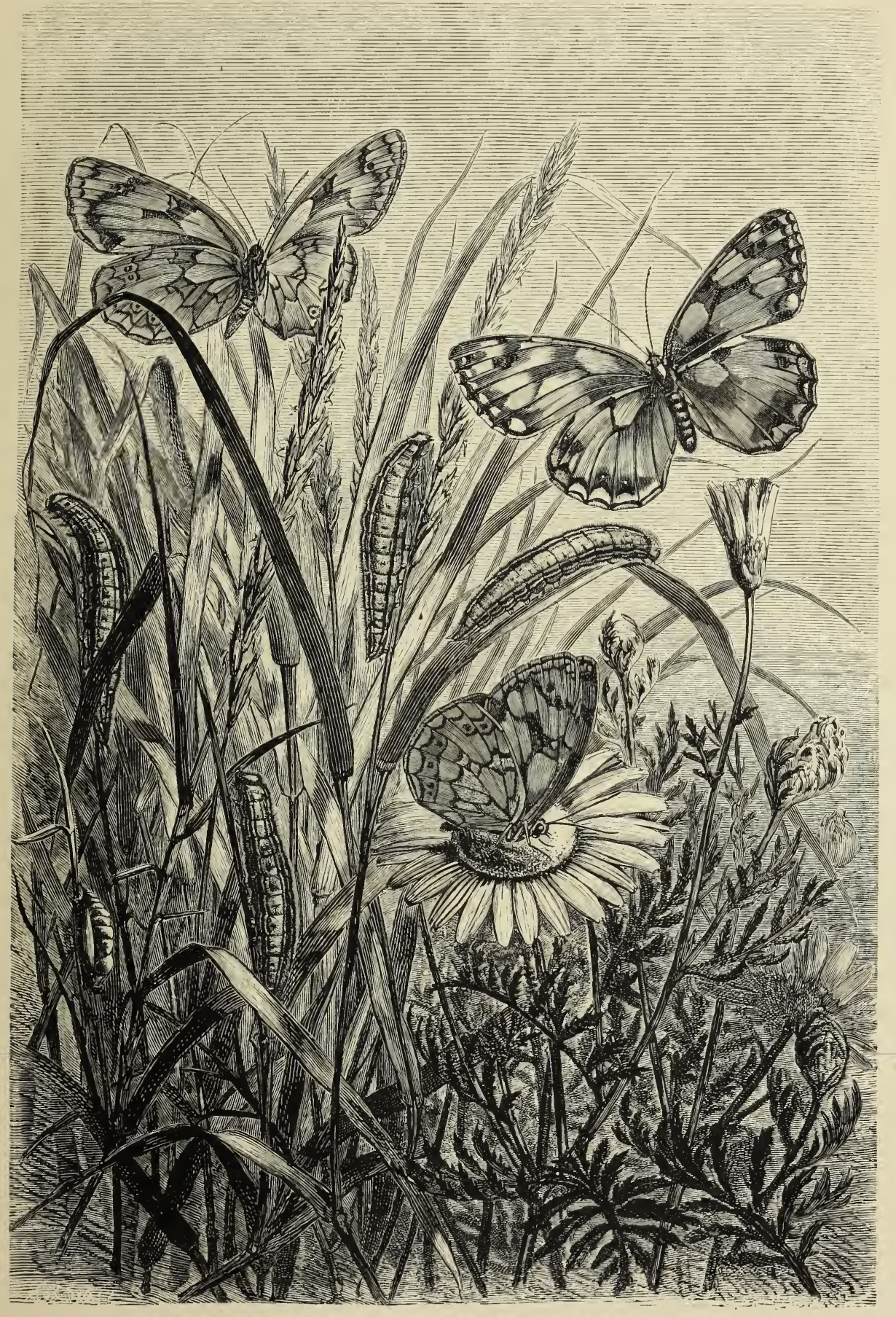

THE METAMORPHOSES OF the marblfd white (Arge galathea). 

The fine Purple Emperor, Apatura iris, whose caterpillars live on the oak trees, is one of the gems of all collections. Its magnificence is greater than its gentility, for Mr. Stainton accuses this monarch of the Lepidoptera of having a penchant for homemade gooseberry wine, and for leaving his realms in the air in order to seek the "shades" of a gooseberry bush. M. Pierret says it condescends to still lower tastes, and the only satisfaction is that they lead it to destruction. All these species of the old genus Nymphalis prefer sucking very nasty things or the sweeter sap and gum of plants and trees to enjoying the nectar of flowers.

The Satyridi are world-wide butterflies. In Europe they are to be found on open plains, arid downs, the road side, forests, and even on the mountains amidst the everlasting snow. From spring to autumn the tawny, grey, and brown butterflies are constantly flying here and there, but for short distainces, wherever there is the rankest and commonest vegetation. Their caterpillars live on the different kinds of grasses, and although they must be very common they are very rarely seen except by those who can look for them scientifically. They do not feed upon the slender grass leaves at all during the day, but hide themselves up at the bottom of the plant, with whose colours their tints harmonise. At night-time, however, they move for short distances and eat. This is an interesting habit, and contrasts with that of the majority of their fellow caterpillars. The larvæ of the Satyridi are all shaped alike. The body is rather hairy, narrowed at each end, and the last segment is furnished with two hooks. The pupæ are short and well set, and do not exhibit any of the strange-shaped projections which are common in the chrysalides of the Nymphalidi.

A pretty butterfly (Arge galathea), the Marbled White, is rather common in the middle of summer in the whole of central and northern Europe, and it is our commonest representative of the Satyridi. The caterpillar lives upon some of the simplest grasses, and frequents the Timothy grass in England. The butterfly has the very delicate antennæ hardly swollen at their ends. The black and white ornamentation of the perfect insect is very distinctive, and the accompanying plate shows the fusiform cater- 
pillars and a chrysalis, attended by a marbled white, upon one of the Compositæ and by two others in different positions.

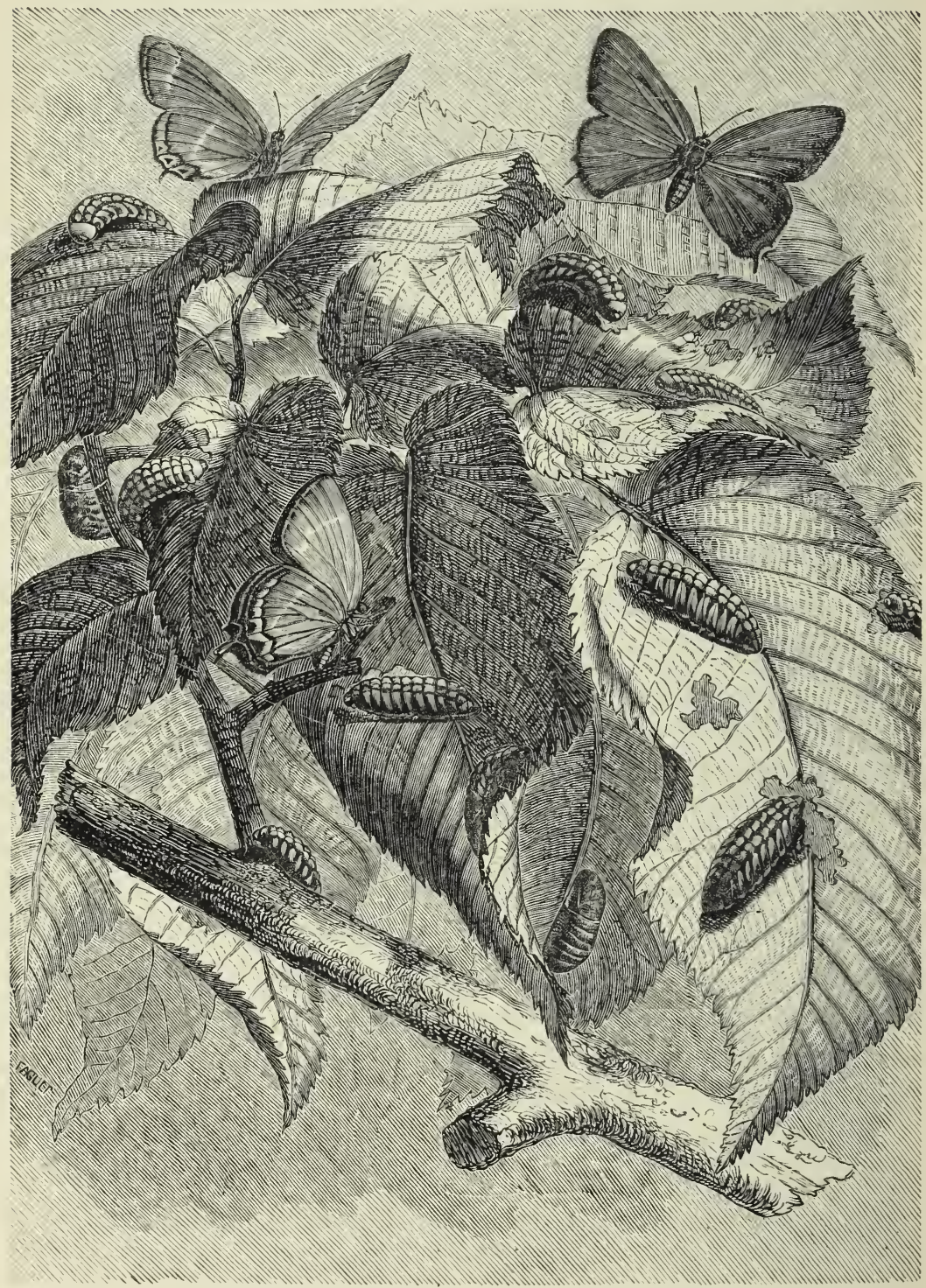

CATERPILLARS AND BUTTERFLIES OF Theda Walbum.

The genus Erebia has its species in abundance in mountainous districts. They are small butterflies, whose black wings are 
ornamented with eye-shaped spots of fawn or red colour; and these negroes, as they are termed, are found upon the Alps, the Pyrenees, the Caucasus, the Himalayas, and even upon the Rocky Mountains. Some closely allied forms, belonging to the genus Clionobas, are of a tawny or pale greyish yellow colour, and are found in the remotest north of Europe, America, Iceland, Siberia, and Kamschatka, and one kind lives in the Alps.

There are some Satyridi in South America, the forms and colour of wings of which are very different to those of the European kinds. Thus, the Hotere of Brazil and Guiana have festoonshaped wings, which are partly transparent. The scales on the wings, scantily sown, as it were, are almost wanting in many spots, where they are often replaced by pretty little hairs. The membrane of the wing is, however, very iridescent, and produces very pretty effects of light and shade.

The caterpillars of the Thecla Walbum, one of the Lyccenida, and so called on account of a curious white mark near the end of the hinder wings like the letter $W$, feeds on the elm and hawthorn, and owes its safety to its colour being so very exactly like that of the foliage upon which it lives. The general shape of the larva and the short legs impede its movements, and the insect is rarely found off a leaf.

After having devoured one leaf the caterpillar crawls on to the next, and this is about the extent of its travels. The caterpillar usually lies very closely upon the under surface of leaves, and its tints so resemble those of the elm that it is not readily perceived. The chrysalis is found attached to the leaves, which have partly contributed to the maintenance of the larva, and the butterfly escapes about a fortnight after the first transformation. One of the species of Thecla-the Green Hair-streak, or Thccla mub-has an ornamentation, so far as colour is concerned, which is, perhaps, exceptional in the Lepidoptera. Its wings are brown above, but of a uniform light blue beneath. A Californian species has its wings of the same colour, and affords an example of the close relationship between the butterflies of North America and the temperate tracts of Europe.

The Hesperida are butterflies that have many points of resemblance with moths, and therefore are unlike those we have 
noticed hitherto. They have a thick body, a large and strong head, and the antennæ swollen and spindle-shaped at their ends, or hooked. Their legs are well developed; the hind ones are particularly strong, and the others are spined. The wings are small in proportion to the size of the bodies, in these Lepidoptera,

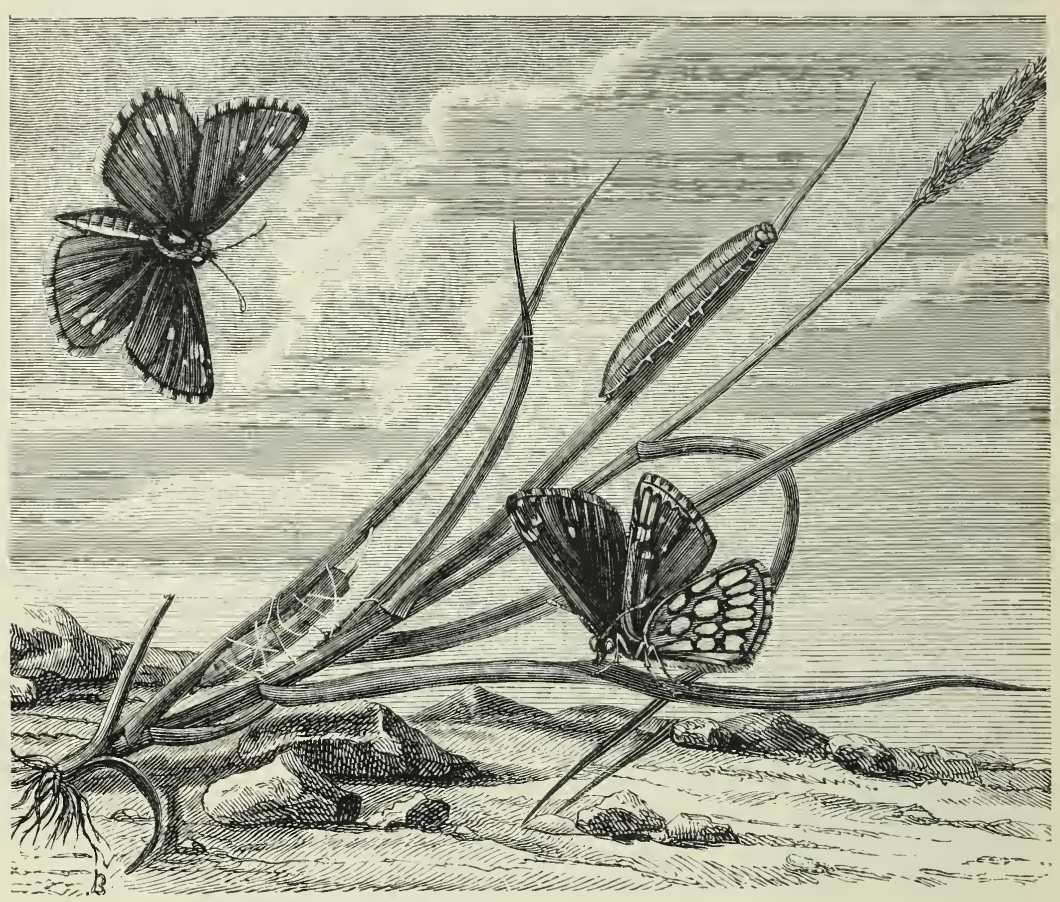

TIIF, mitamorimoses of Pamphila aracynthus.

and they are generally grey, brownish, or fawn in colour. The butterflies have a curious and hesitating flight, and are very properly called Skippers. The caterpillars differ from those of the other Lepidoptera already noticed as much as the butterflies do; they have a long and thin shape, with a large rounded head, and they are remarkable for their brisk movements.

In order to hide safely, the caterpillars roll up the side of a leaf, and fasten it with some of their silk. Before the first metamorphosis they choose a safe hiding-place; then they attach themselves by their extremity like the other diurnal forms. 
Before transformation proceeds, however, they swathe themselves with a set of silken lines, which cross and re-cross the body, and finally the thin, long, and angular chrysalis rests in a slight cocoon. The European species are all small, and the name of Pamphila is given to those of a genus which delight in underwood and thick forests. Their bodies are thinner than those of the other Hesperide, and the ends of their antennæ are egg-shaped.

The engraving represents the long and slender caterpillar and the elongate chrysalis, this being swathed with crossing fibres of silk. The butterfly is brownish black above, and the male is almost without spots, but the female is slightly marked with yellow. The posterior wings are ornamented beneath in both sexes with white spots, encircled with brown, and which resemble so many mirrors. This insect inhabits large woody tracts during June and July. The caterpillar, as shown in the engraving, is found on grasses in the spring; it is of a green colour, like the plant it feeds upon, and as it generally keeps near the stalk, is not readily discovered. The transformation into the pupa form is preceded by the formation of the silken swathing already noticed.

The leaf-rolling propensity is especially noticed in a species of Syrichtus, one of the Hesperida, which curls up the mallow leaves upon which it feeds.

The caterpillars of most of the Papilionida do not swathe their bodies, but place a silken girdle over themselves very cleverly, just before the first metamorphosis. The cabbage butterfly caterpillar, when it has shed its skin several times, and has attained its full growth, retires to a quiet place-on palings, or under the eaves, and fixes its tail-end to the surface upon which it is to hang for many months. It applies its mouth to the wood-work, for instance, and draws out some silk. After doing this several times, and thus producing a small silken tangle, the insect attaches the end of its body to the silk, and hangs head downwards. The caterpillar has thus fixed itself, and the end of the body grasps the silk so perfectly, that the whole hangs safely. But to prevent the wind moving the future chrysalis, and rubbing it against the wood, another operation is commenced. As it hangs head downwards, the caterpillar 
throws back its head, and twists it sideways, so as to touch the wood on one side of the body. The touch pulls out a silken thread, and then the insect carries the head to the other side, and fixes the silk. This is repeated several times, until a sort of sling is placed over the body. Then the first metamorphosis takes place, and the chrysalis finds itself slung by the tail, and girded to the wood-work by a silken sling.

The first step to cocoon making, which is so usual in the next division of the Lepidoptera, is shown in the habit that
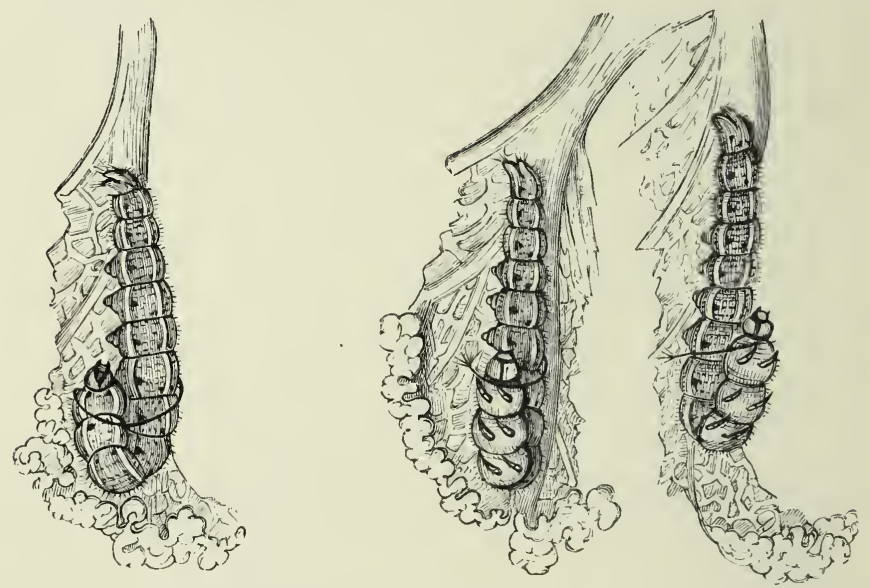

CATERPILlars OF THE CABbAgE BUtTERfly SLINGING THEMSElves BEFORE THE FIRST METAMORPHOSIS.

Pamphila aracynthus has of swathing itself with a network of silk before undergoing the first metamorphosis, and the leafrolling propensities of many caterpillars and moths are foreshadowed by a species of Syrichtus.

The angular shape of the butterfly chrysalides may have something to do with their comparatively unprotected and uncovered state, for this sharpness of outline which causes them to differ in appearance from most living things is not so perfectly seen in the case of the Anthocharis, from Spain, which spins a slight cocoon.

It has already been stated that the repeated sheddings of the skin and mucous (epithelial) tissues of the caterpillars during 
their growth really form a most important part of the phenomena of evolution, for some very necessary alterations in the internal structures progress especially during the last stage of quiet retirement which accompanies the final change of skin before the commencement of the chrysalis state.

Although several broods of caterpillars are born in a year in such species as Anthocharis belia and Vanessa prorsa, yet

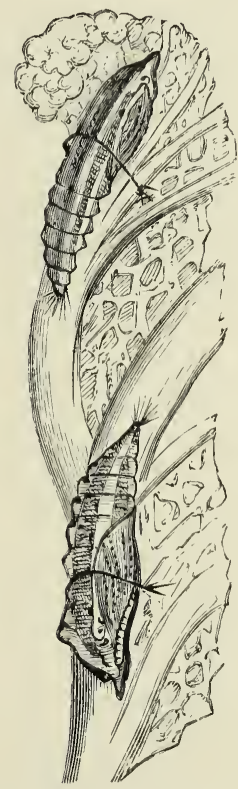

CIIRYSALIDES SLUNG AND SUSPENDED.

the successive larvæ present no distinctions in their external ornamentation, but the perfect insects which are metamorphosed from these similar larvæ do differ very materially. Yet the butterflies of Vanessa Io, a species closely allied to Vanessa prorsa, are always the same, notwithstanding there are successive broods of them in the year.

This variation in the colouring and ornamentation of the butterflies of successive broods is most interesting, especially when it is considered in relation to the opposite state of things so common in some species of moths, whose generations of caterpillars differ, the perfect insects remaining unaltered. The 
change in the butterfly must be determined in the chrysalis state, and during the progress of the second metamorphosis. It has been proved that the duration of the chrysalis condition can be lengthened by placing the pupa in cold and dark places, or in ice, and shortened by increasing the usual amount of warmth. But no variation in the ornamentation of the perfect insect has been produced by this artificial lengthening or shortening of chrysalis life. So that most probably the disposition of these butterflies to vary has some deep significance, which refers to the duration of the species in time-moribund genera and species varying much, and new forms striving to adapt themselves to peculiar conditions.

The hybernation of some of the large butterflies through the winter in temperate climates is very interesting.

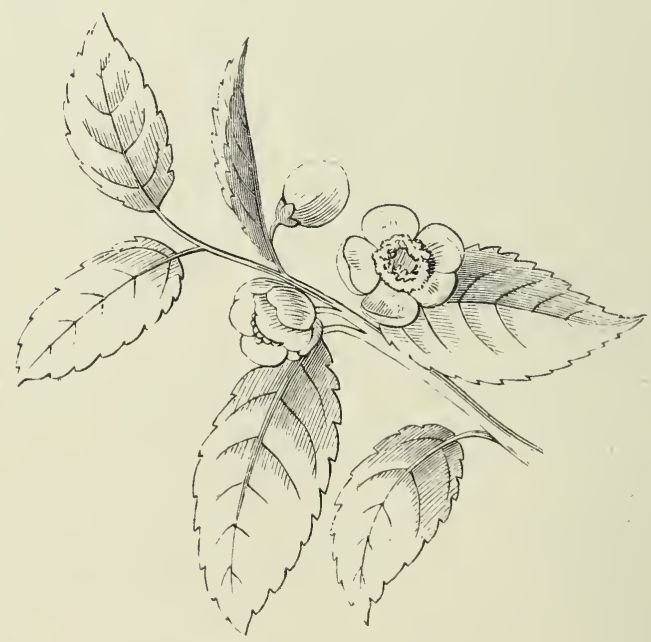




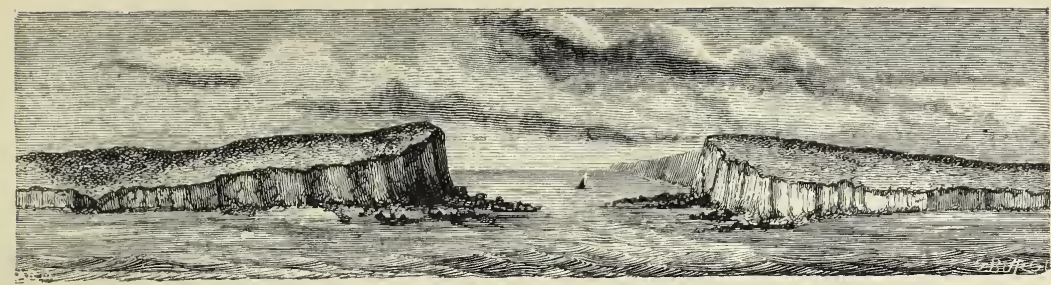

CHAPTER V.

THE LEPHDOPTERA WITH WINGS UNITED BY A HOOK.

(Chalinoptera.)

ALL these Lepidoptera were formerly called moths or crepuscular and nocturnal flyers, but as some of the night-loving tribes were equally active during sunshine, and as none of them really wandered in the depths of the darkness, when everything sleeps, there was no wisdom in keeping up these popular distinctions. The structure which retains the hind and fore wings on each side together is a very good distinction, especially as it is common to most twilight and nocturnal Lepidoptera, it being deficient in the butterflies; nevertheless, it is wanting in some kinds of moths.

The tints of the wings of moths (under this term we include the nocturnal and crepuscular Chalinoptera) are principally shades of grey and brown, and resemble the colours of the trees and walls, when the light is dim, and night is advancing. But the wings of some, although not so brilliant and coruscating as those of the butterflies, are exquisitely delicate and soft in their tone. Some of the moths that fly by day, and thus lead the life of butterflies, often have colours as glowing as these have, but the tints are never brilliant and sparkling. The educated eye can distinguish at once between the scales of a butterfly and those of the brightest of moths.

The wings of moths rest upon the body of the insect when in repose, and are not stuck upright like those of the butterflies.

The antennæ of the moths are very different in shape to those of the butterflies, as can readily be seen by comparing 
the representation of the structures in the accompanying engraving with that of those of the butterflies on page 76 .
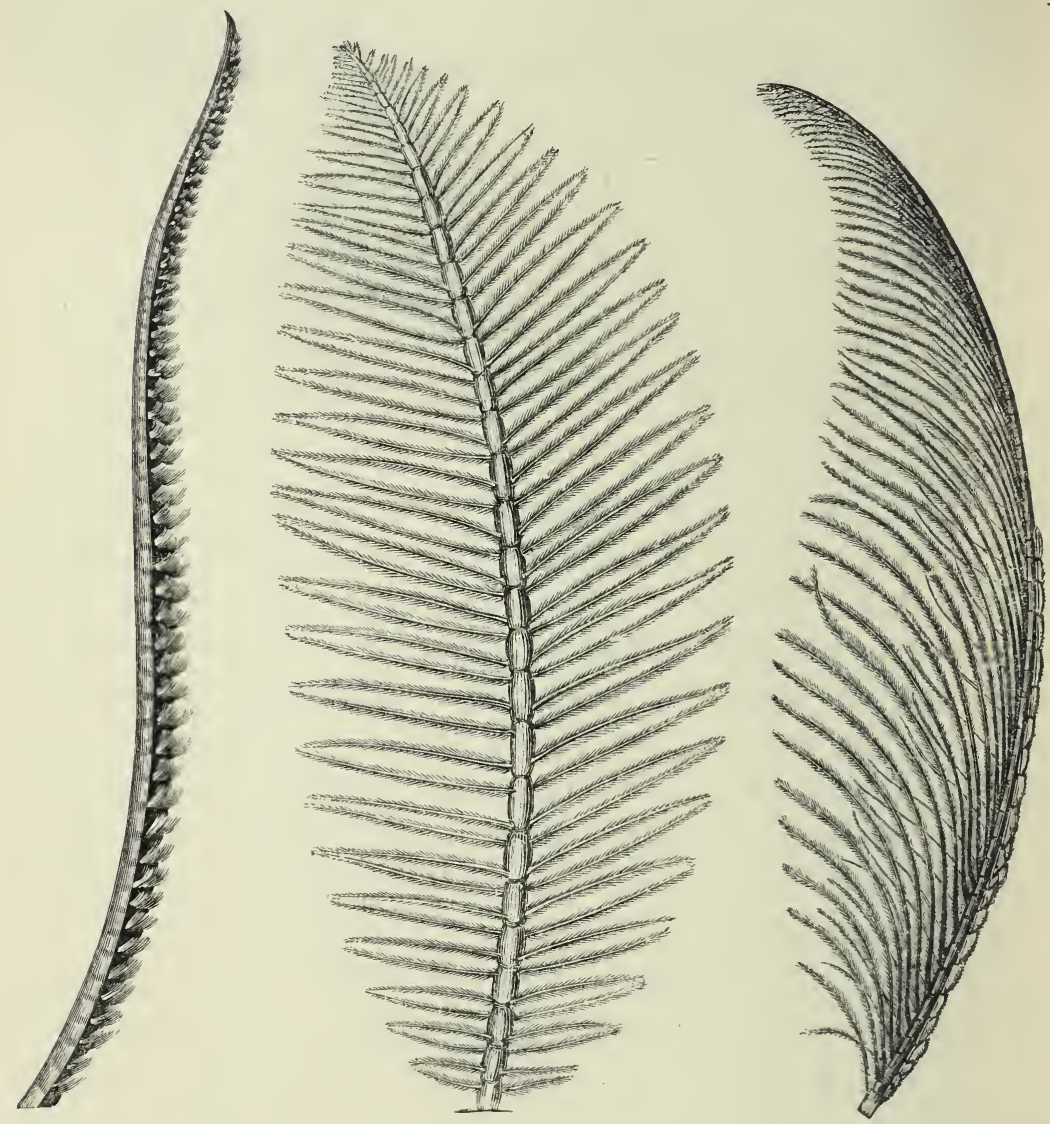

ANTENNÆ OF MOTHS.

Sphinx ligustri. Bombyx cecropia. Fidonia plumaria.

There are some Lepidoptera which come under the division we are now considering, but which may readily be taken for hornet-like flies. Their projecting bodies, and particularly their colouring, which is black with yellow bands, give the individuals of the genus Sesia a very waspish look. They are really moths, the appearance of which in the perfect state is as odd as is that of their caterpillars. Their wings do not look like those of butterflies; narrow, and nearly entirely transparent and naked, they 
are bereft of scales, except upon the nervures, upon the margin, and in some scattered spots. With the essential character of the Lepidoptera, they have almost the physiognomy of the Hymenoptera, or bee tribe.

It is rather curious to notice how the insects of one order mimic those of another with which they have no family connection. The strangest part of the matter is, that the habits of the Sesiide are not in the least like those of the very violenttempered insects whose uniform they wear.

The Sesiida, although moths, fly in the hottest sunshine, and often rest on trees and shrubs, in order to lay their small round eggs. The caterpillars have an elongate, and almost cylindrical body, and they live in the interior of the trunks of trees, of branches, roots, and even in some fruits. Pale, and almost without the least colour, like beings which never see the light, there is no difficulty in determining that they are wood-eating larvæ.

One of these wasp-like moths is called the bee-shaped Sesia (Sesia apiformis), and it may be seen flying to and fro amongst the poplars by the river side, or running with much agility upon their trunks. This moth, which is classified by Mr. Stainton under the genus Sphecia, lays its eggs on the bark of poplar trees, low down and near the ground. When the caterpillars are hatched they gnaw the bark, and each endeavours to penetrate the tree by excavating a tiny gallery. The larvæ live a long time, and drill holes of a considerable size, doing much harm to the trees. They are enabled to do this quietly and effectually, for instead of only living for a few weeks before their metamorphosis into the chrysalis, and having jaws fitted for browsing the tender shoots and leaves, their caterpillar life lasts two years, and their masticating apparatus is strong, and admirably fitted for its purpose. It is very remarkable that they should only flourish upon those trees which have been injured; and it would appear that the abundance of the sap of perfect and healthy poplars is too much for the excavators. An examination of the caterpillar proves how admirably it is adapted for its peculiar method of life, and how perfectly helpless it would be upon a tender succulent plant. The legs are 
smaller than those of most other larvæ, for had they been larger, they would have been in the way in the narrow excavated gallery; the membranous feet also are short, and are not calculated to grasp, but they can adhere strongly to a large surface, and their spines form a complete crown. The head of the larva is covered with a reddish and hard integument, so as to allow a solid foundation for the action of the jaws in grinding the dense tissue of the tree. Curiously enough the labrum, or lip, is not notched as it is in the leaf-eaters, and this fact proves the design that has influenced the development of all the other structures. The body has a soft skin, and is covered with tubercles and a few hairs, which render the larva very sensitive to the touch. The caterpillar produces a small quantity of silk, but not enough to make a comfortable restingplace for the chrysalis, so it utilises the saw-dust which has accumulated during the process of tunnelling and drilling, and forms a comfortable and silken cocoon within, and covers it with the dust outside. The chrysalis resembles those of the other moths in certain respects, but it has an armature which is not merely an ornament, but a most useful mechanism, for it helps the pupa to crawl. Immediately after the transformation into the moth state, the life of the perfect insect is more or less endangered, for in traversing the gallery made when it was a caterpillar, it might be severely scratched, and its wings spoiled. But the enveloping skin of the chrysalis, with its spines and sharp points, acts like a suit of armour to the Sesia, which has just got its legs into the world. The insect drags its body slowly along, and finally reaches the open air, and extricates itself and flies away, leaving the skin behind stuck in the hole. In the engraving of the metamorphoses of Sesia apiformis, the moth on the tree has just escaped from the chrysalis case in the hole below. A larva is shown in its gallery, and two cocoons also.

The Zyganide have some likeness to the Sesizde, and are very common in southern Europe, some being found, however, in France and Great Britain. The moths fly by day, and like the sun and the bright flowers; they are a sluggish set, however, and this peculiarity is found in the larva as well. Some of them have 


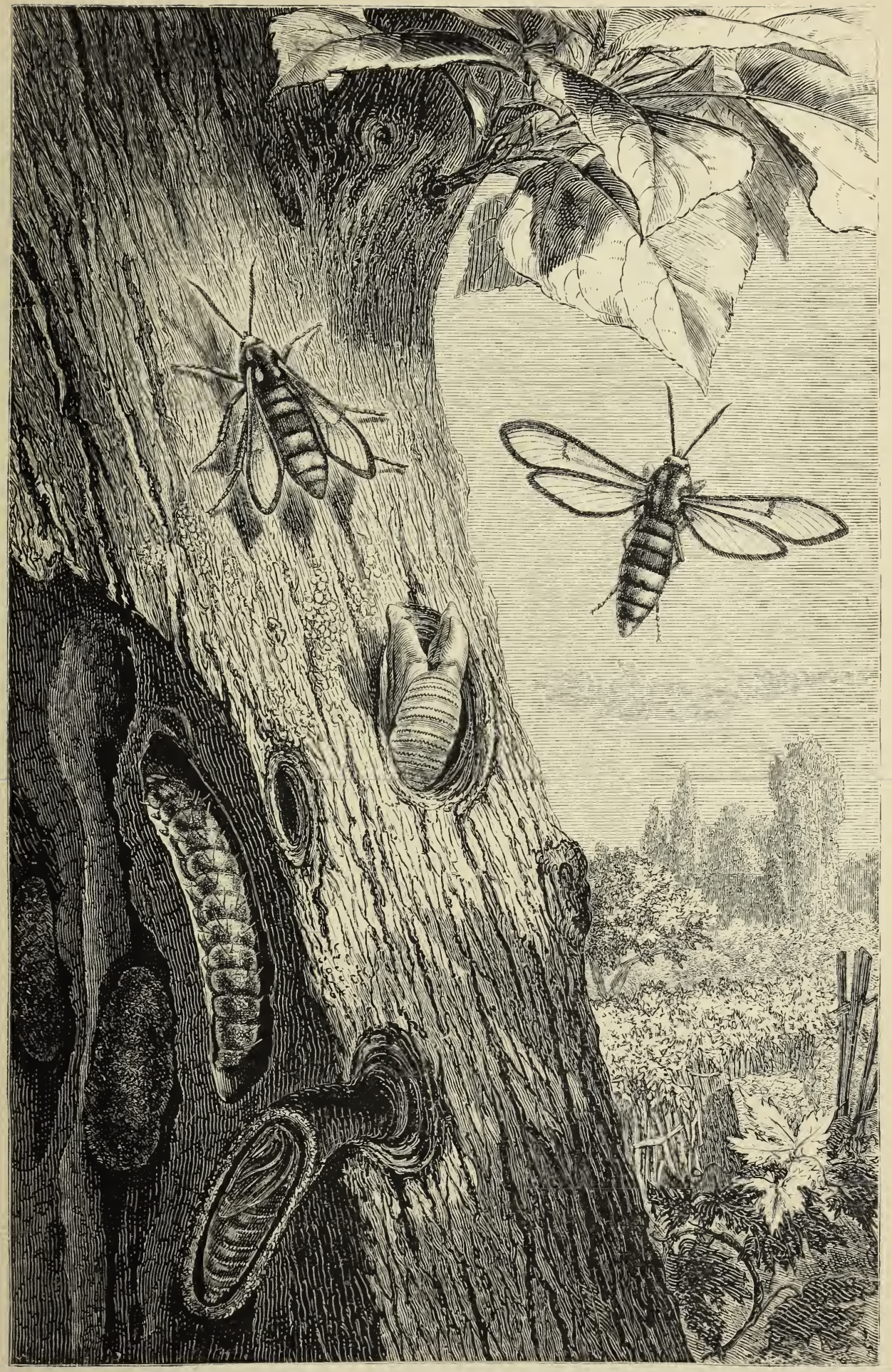



immense antenna upon their very small heads; and the narrow wings, which are green or a very deep blue, with spots or bands of rich carmine, make them to be very much sought after.

One species, Zygena filipendula, is very well known over large districts, and it is amusing to see these "six spot burnets" buzzing about in considerable numbers around the dandelions, thistles, and other common plants, or flying heavily and slowly over the hills. The moth is of a steel-blue colour, and has patches of carmine on its front wings; the hinder wings are red, with a black border. The caterpillar is rather bloated-looking, and is ornamented with small bundles of delicate hairs; it is of a pale yellow colour, and has rows of black spots upon it. Its head is very small, and the jaws are made after the model of those of the tender leaf eaters. It lives upon many kinds of leguminous plants.

When about to undergo the first metamorphosis the caterpillar constructs a long cocoon, of a pale yellow colour, and fixes it on twigs; it is thin, but as strong as parchment, the silk which forms it being mixed with much secretion like varnish. The young larva escape from the egg at the end of summer, and remain dull and stupid during autumn and winter. After this hybernation they wake up in the spring, and seek the plants upon which they can subsist. The engraving of the metamorphosis of the "sixspot burnet," the Anthrocera filipcndule, of Stainton, or the Zygana of the same name, shows the chrysalis in its cocoon, fixed on to a stem, and the moth with the large antennæ.

No family of the Lcpidoptera is better known or more readily distinguished than that of the Sphingide, Sphinges or Sphinxes, as they are commonly called.

The large body, the thick antenna, terminating in a hooked bristle, and the long, narrow, and strong wings, give the sphinges a very marked appearance. These moths are usually large, and their active flight soon makes them noticed. They glide along during the hot summer evenings with immense rapidity, and poise themselves in the air by a peculiar vibration of their wings. The sphinges, which have long trunks, can thus sip up the honey from the nectaries of flowers without touching them, and this peculiarity recalls that of the humming birds of the New World.

The Sphinges are very remarkable, even as caterpillars. They 
are large creatures, which, when quiet, often put on a very curious attitude. Being well and safely fixed on a twig or leaf by their membranous or hind feet, they lift up the front of their bodies, and bend the head, which is buried in the first segment; they then remain perfectly motionless for hours. This attitude-which is represented in the engraving of the Euphorbia sphinx - has excited much attention, and entomologists, whose imaginations are always vivid, and sometimes classical, have had no difficulty in investing

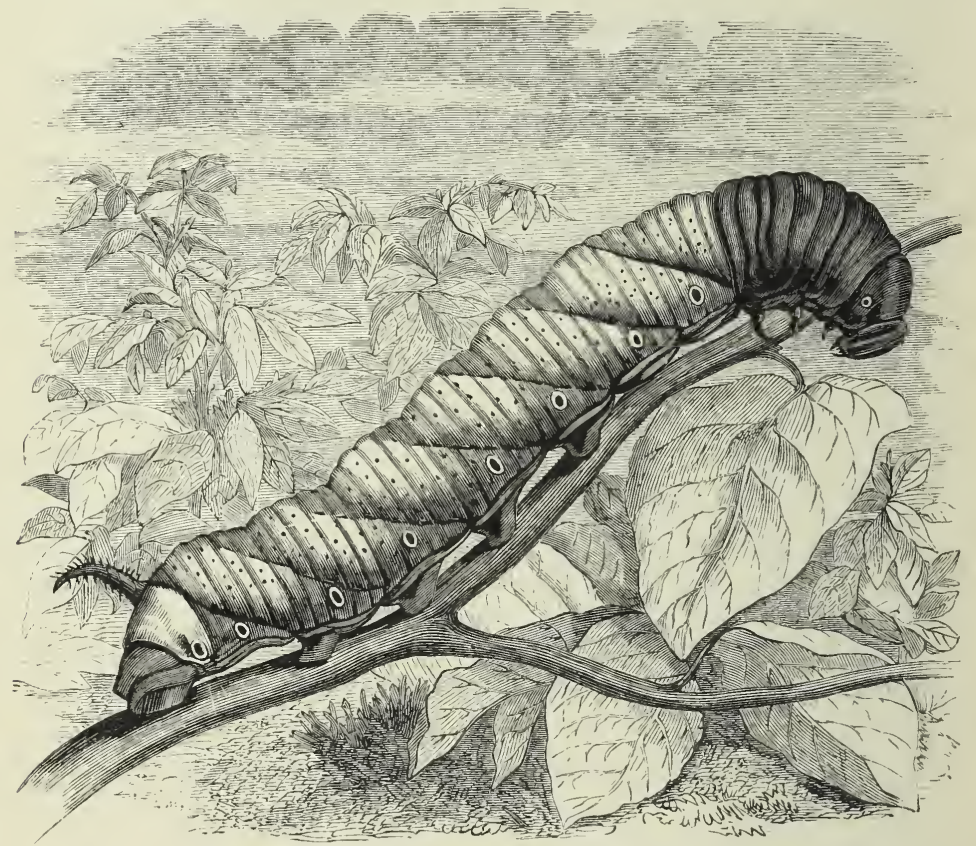

I.ARTA OF THE DEATH'S HEAD SPHINX MOTH.

this larva with the majesty of the Egyptian sphinx. Indeed, one of these stolid larvæ has sufficed to bring up the memories of Thebes and of the great enigma before the enthusiastic naturalist.

The name has become popular, and there is really something enigmatical in the queer posture. Why should the larva imitate the sphinx, which it never saw? The answer may be commonplace, but nevertheless true; it remains thus motionless to prevent itself being gobbled up by birds or attacked by ichneumon flies, which are on the look-out for everything that moves. 


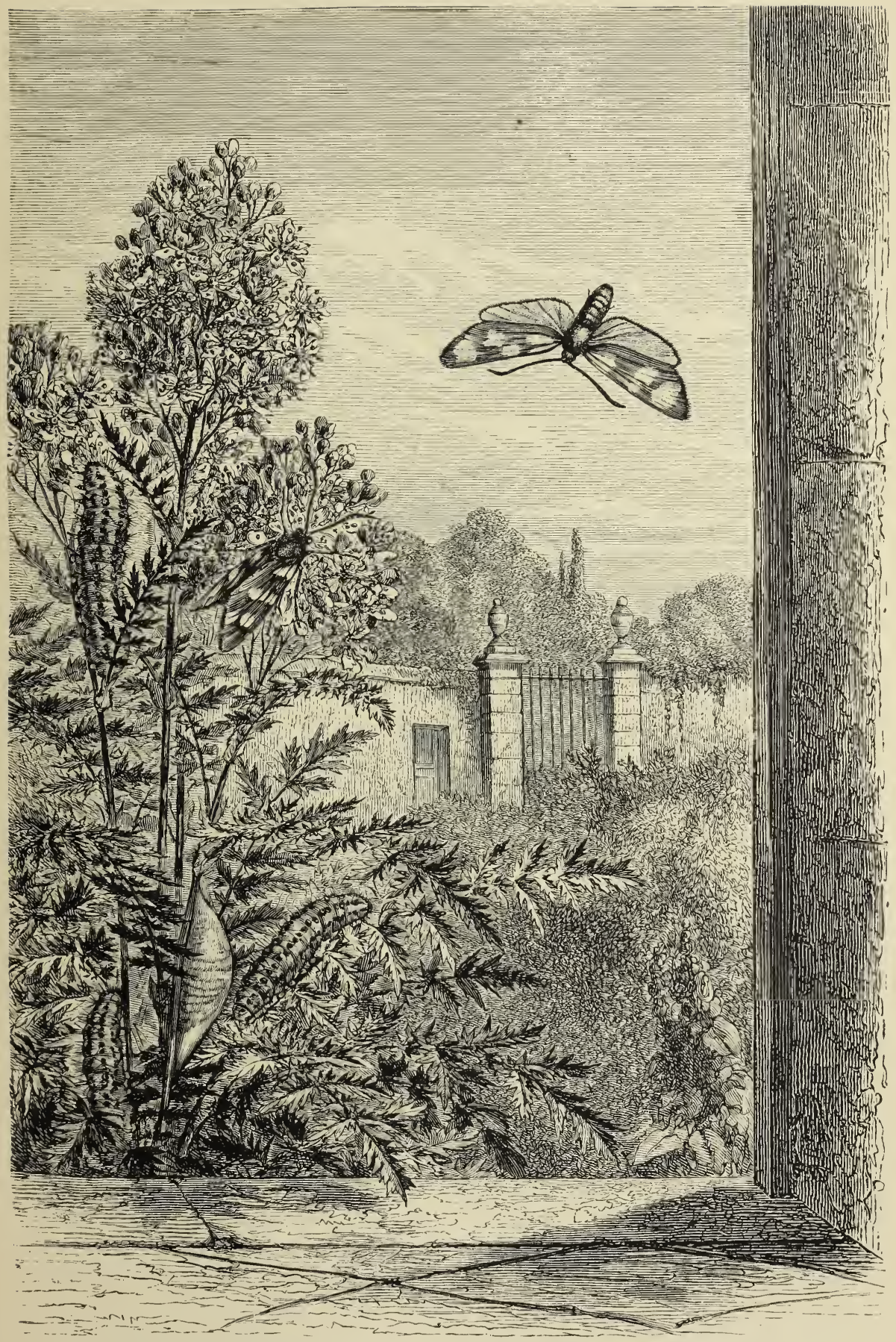

1 HE METAMORPHOSES OF Zygana filipendula, "THE SIX SPOT BURNET." 

These fine caterpillars have a smooth and glossy skin, with bright colours, and pretty ornamentation. Generally speaking, they are rather narrowed in front, and have a curved appendix on the top of the last segment of the body like a horn or tail. When about to become transformed into the pupa condition, the caterpillars hide themselves in the ground, forming a comfortable hole, which they line with all the silk they can muster. It is very wonderful, in this instance, as in all others, how the insects that live in the earth through very inclement seasons manage to make a safe retreat with so very little silk as a covering. The chrysalis has to live in the hole in the ground throughout the winter, and any water draining in would assuredly kill it.

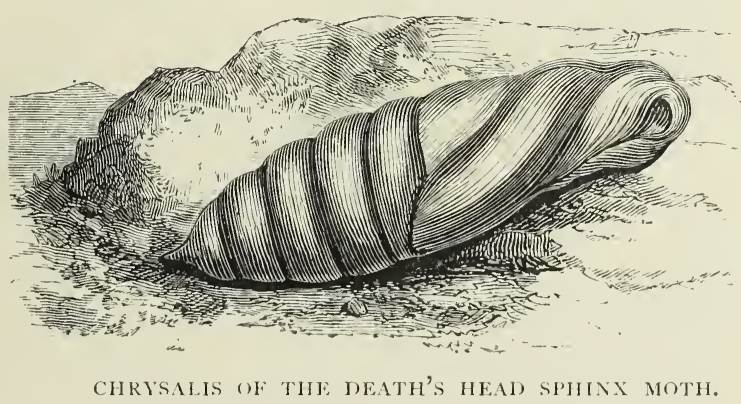

The silk is all expended in lining the cavity, and fortunately, although it is scanty, it is so varnished that it is water-tight; hence the safety of the pupa is hardly a matter of doubt. Some species of Sphingide undergo their metamorphoses on top of the soil, and agglutinate little stones, leaves, and rubbish into a cocoon. The pupæ of these great caterpillars are not very remarkable; they are dark brown or reddish, and have a small point at their end.

The most common sphinges are the Privet Moth, or Sphinx ligustri, and the Convolvulus Hawk, or Sphinx convolvuli. The caterpillars of the first are well known to and prized by young collectors, and are now and then seen upon the privet hedges, or upon the lilac bushes. They are very fine insects, and their size renders their beautiful light green colour and oblique bands of violet very visible. This pretty larva feeds vigorously during 
the summer, and when full grown begins to descend to the ground at the base of the tree, whose leaves it has partly consumed. Towards the end of July, or the commencement of August, it hides up in the earth, where it forms a comfortable cocoon, and becomes metamorphosed into a chrysalis, living, moreover, in that condition all through the winter, and until the month of June in the next year. It then bursts forth as a moth. The anatomy of this sphinx, and the details of its metamorphoses have already been described. The other sphinx has a green or brown larva, marked with seven oblique side streaks, and the spiracles or air openings are black in white rings. It lives on the small bindweed, and on the wild balsam. The moth is rather larger than that of the privet sphinx, and has a very long trunk.

Perhaps the Deilephilce are the prettiest sphinges. Their trunk is only half as long as their body, which has a long and conical abdomen. These insects are rather common, and their caterpillars are really very pretty, on account of the variety of their colours, and the freshness of their tints. The Euphorbia sphinx is one of them, and is interesting, because there are two broods of it every year; one appearing in June and the other in September. Its caterpillars live upon the pretty green leaves of the Euphorbia, whose stems, when broken, exude a milky sap.

Before these larvæ attain their full growth they may be seen in abundance on the same plant, but as they are gross feeders, they soon have to separate, in order to exist. Their bodies are curiously ornamented, being black in colour, and they have three long lines of a carmine tint upon them, one on the back, and the others above the line of the legs; besides these there are some very close points and dots of yellow arranged on each segment, like coronets of pearls, and finally there are two rows on each flank of rounded spots, which are sometimes yellow, or even red or white and red in colour. Sometimes, with all this elaborate colouring, the foundation is a lively green instead of black. They become full grown towards the end of July, and they then hide themselves in the ground, after having formed a hole, and are transformed; but they do 


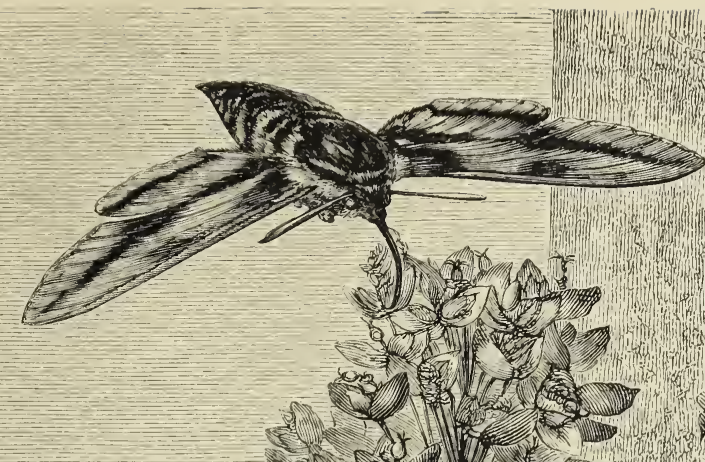

H.

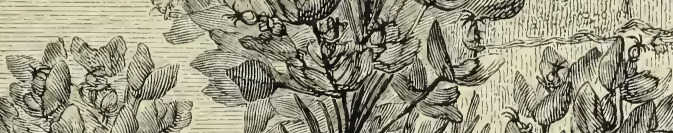
L

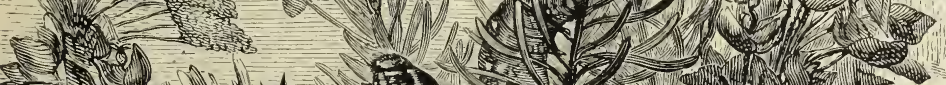

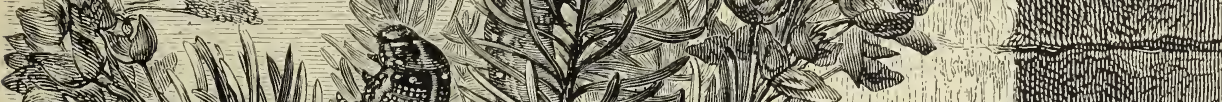

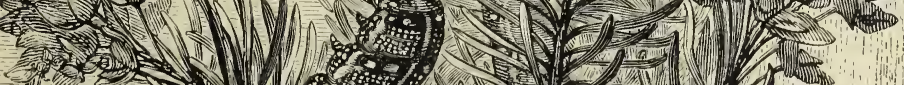
$\sqrt{1}-1 / 10 \%$ 1. 1.5.

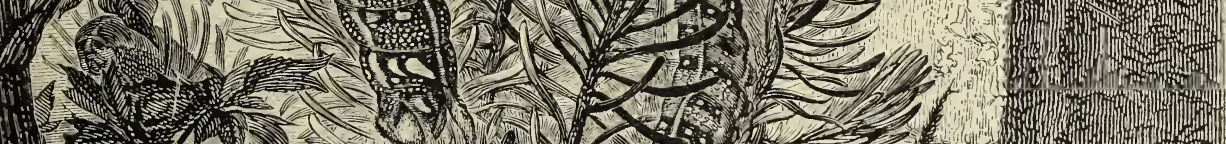
1. 140 -

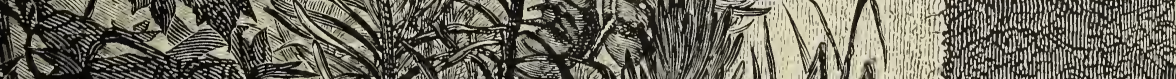

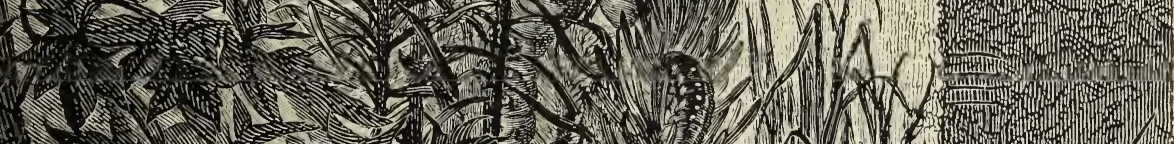
W.

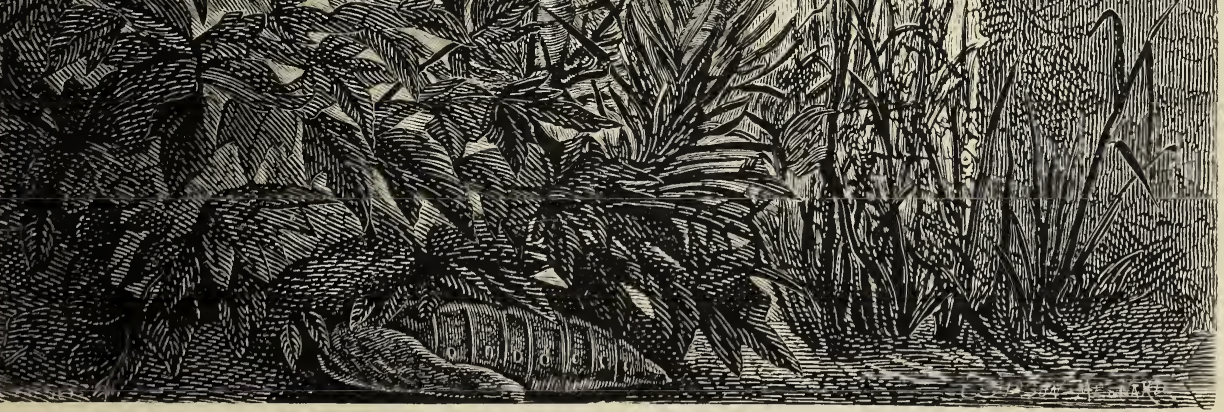



not stop $\mathrm{n}$ it very long, for the chrysalis becomes metamorphosed in a few weeks, and then the Splinx enplorbice may be seen buzzing about the flowers in the early morning and during the evening twilight. It is a very pretty insect, the front wings of which are of a subdued rose colour, with three spots of deep green, and an undulating band of the same shade, and the hind wings are of a rose tint, with black bands.

The caterpillars of this sphinx appear a second time on the Euphorbias in the same year. Towards the end of September they hide themselves in the earth, and become chrysalides, and remain in that state until the next year.

The engraving represents the sphinx hovering over the Euphorbia, and the caterpillars upon the leaves, one being in the quiet, sphinx-like attitude. The chrysalis is on the ground.

This interesting Deileplizla is stated by Mr. Stainton to be found in England at Scarborough and Bideford. This author gives some interesting descriptions of the habits of the larvæ, which were observed by Mr. Melhuish on the coast of Brittany, near St. Pol de Léon. This naturalist collected 400 of these beautiful insects in three days in the first week of September. He says, "All the larvæ that I saw at liberty were seen by me between the hours of three and six P.M. They were invariably actively engaged, either in feeding or in running over the sand, which they did with great ease, from one plant which they had stripped to another with leaves. The eggs must be always laid at the top of the plant, among the soft budding leaves, for this is without exception the position of the youngest larvæ. They then gradually work their way downwards, till, having eaten all the leaves, they reach the ground, and march off in search of more, leaving a broad trail on the sand. They are fond of the milk, and will eat everything except the stringy roots of the plant. The seed vessels they take between their front legs, and raising themselves into the sphinx posture, gnaw away at one till it is demolished, just like a monkey with an apple, their feet being placed close before their mouths.

If interrupted at any time while feeding, they turn round with the greatest fury, and spit out a quantity of green liquid 
of an acid and disagreeable smell, similar to that of the milk of the plant, only worse. When a larva, after rambling about, finds a fresh plant to his taste, he sets to at once upon the bottom leaves, merely raising his head from the ground, and devours all within his reach, before proceeding to climb the stem. These bottom leaves are, of course, very inferior, but were the large larvæ, who are old enough to travel, to mount up to the top of the plant at once, and eat all the tender shoots, of course all the tiny individuals just out of their eggs would be starved."

Some very beautiful sphinges which belong to the genus

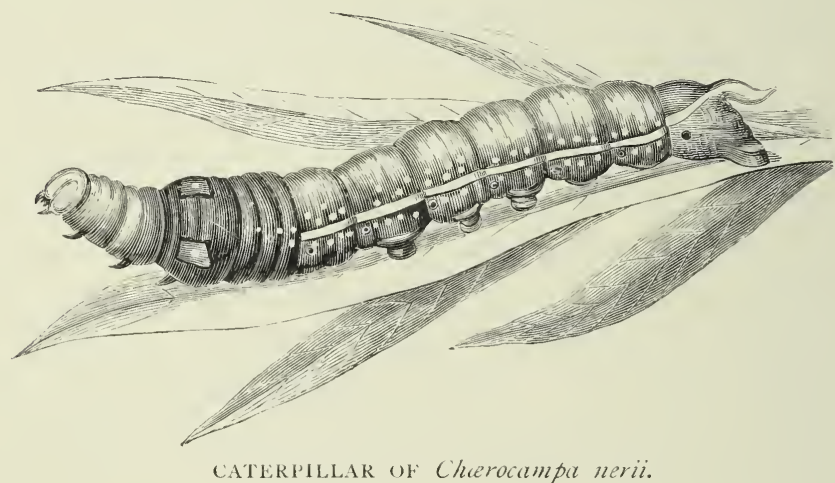

Chcerocampa are occasionally found in England, but their home is on the shores of the Mediterranean sea, where their gigantic caterpillars revel upon the leaves of the delicate oleanders.

In this country they have been found upon those plants and upon fuchsias and the epilobium, and they have their mouths especially adapted for biting the rather dense and thick leaves. The upper lip is very hard and is deeply notched, so that it can hold the leaf tightly, whilst the pair of strong denticulate jaws can cut pieces out of it without any difficulty. Sometimes the Oleander Sphinx wanders to the north, out of the region of the wild oleanders, and it has been taken in Paris, and even on the south coast of England. The caterpillar is green and sometimes yellow, and has two large eye-shaped spots on the fourth segment, a longitudinal white streak on each side, and numerous 
small white dots on the sixth and twelfth segments. The horn is orange-coloured, short, blunt, and curved downwards. Before undergoing the first metamorphosis the caterpillar loses its brilliant appearance, and becomes brown and dirty yellow in colour. The chrysalis is of a hazel brown, streaked with a darker tint, and a black spot marks the position of the spiracles. The insect attains its full growth in the middle of the summer, and then makes a cocoon in the earth with a small quantity of silk and vegetable refuse, and protects the whole with dead leaves. The sphinx bursts from the chrysalis either in September or October, and is one of the handsomest of the Lepidoptera. The wings are rather more than four inches across; the front pair are pale rosy

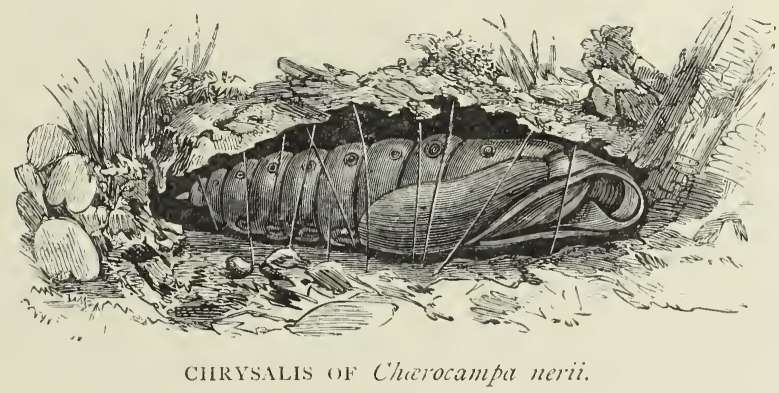

grey in colour; they are marked with large irregular blotches of dull green, more or less intersected with wavy whitish streaks; the hind wings are purplish brown or black at the base, and shade into a green tint towards the margin.

The Elephant Hawk, or, as it is called in France, the Vine Sphinx, has two broods in the year; and the caterpillar, which cannot secrete much silk, does not dig into the ground to undergo its metamorphosis, but makes a small cocoon on the surface by binding together mosses and dry leaves.

The perfect insect has its body tinted with rose red and worked out with a light green. The light green wings have bands of a most delicate and velvety rose colour upon them, and the hinder pair are of the same general tint, but have a black base and a white fringe.

Some sphinges are placed, on account of their very long trunks, 
in the genus Macroglossa, and one of them is well known during hot summers, as the Humming Bird Moth or sphinx. They are to be seen in the bright sunshine flying from plant to plant with great velocity, and sucking nectar from the flowers without resting upon the petals. Like the humming birds, they make a buzzing noise, and hover over their favourite flowers, and feed without crumpling a leaf. They suck up the honey through their

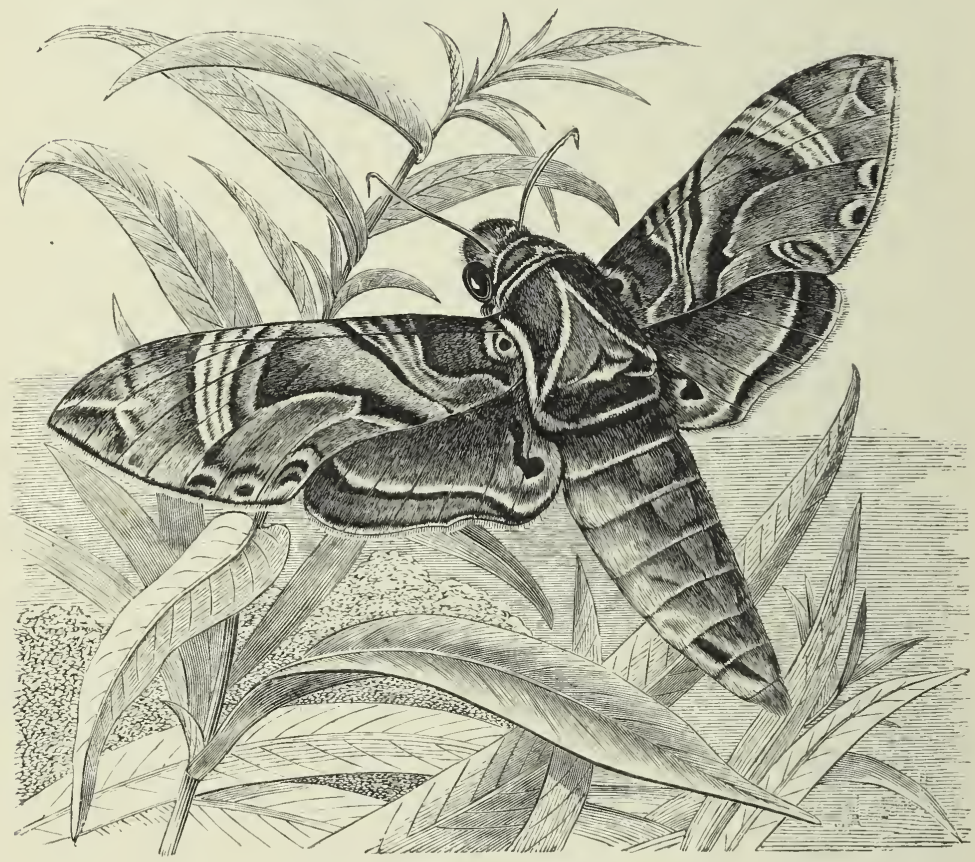

мотн оF Charocampa nerii.

very long trunks with great rapidity. The moth is of a brown colour, and there are black rays on the front wings, and the hinder pair are of a yellow fawn tint. The caterpillar lives upon the bedstraw, Galium molugo.

The Death's Head Moth is a well-known sphinx, on account of its fine size, as well as from there being some markings on the thorax, which, with the aid of a little imagination, can be believed to represent a human skull. Unlike the humming-bird sphinx, the Acherontia atropos has a short and thick trunk; its antennæ, 
moreover, are short, thick, and terminated in a hooked bristle. The head is large, and the abdomen very thick. The front wings are blackish brown, with indistinct tawny markings and a conspicuous yellowish dot near their centres; the hind wings are yellow and have a narrow black central and a broad black marginal band.

The moth possesses the power of squeaking, and this propensity

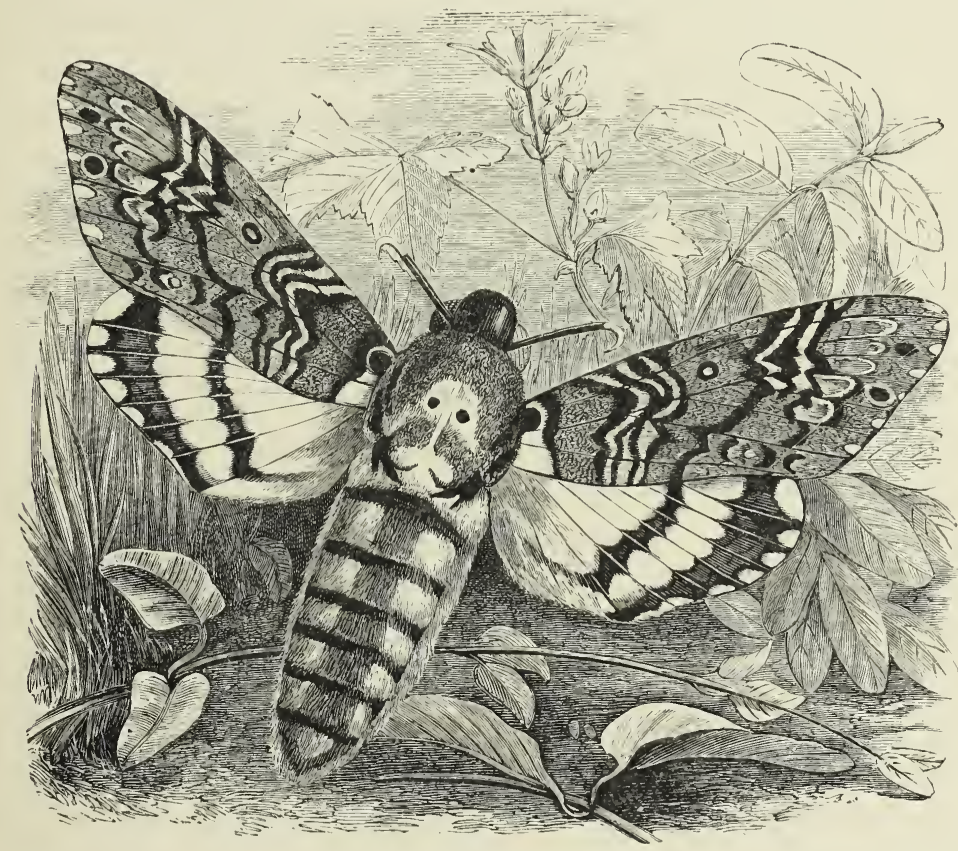

THE DEATH'S HEAD MOTH.

has given an infinitude of trouble to philosophers, who have formed many theories concerning the manner in which the sound can be produced. This gift, combined with the sombre hues of the sphinx, and the presence of the death's head upon its back, have surrounded the moths with much mysterious dread, and there are many people in the most civilised and learned countries in the world that are heartily afraid of them. They are said to be a sign of bad luck, and are supposed to precede a death in the house; and they once produced a downright panic in Brittany. The squeaking appears to be connected in some way or other with a small 
membranous capsule, which is situated on either side of the body at the base of the abdomen, and which is covered with some hairs that can be made to vibrate. The fondness of the moth for honey leads it into bee-hives, and it is most remarkable that the insect should know that honey is to be got there. The bees, moreover, do not rush upon the robber, but employ every artifice to shut it out or wall it up.

The caterpillar is perhaps the largest among the European kinds. It is usually lemon yellow in colour, and a fresh green tint may be noticed towards the head and the lower part of the sides; there are seven oblique violet stripes on the sides, and the spiracles are black, edged with white. The horn is yellowish, rough, and inclined backwards. Sometimes the colour is by no means like this, for some caterpillars have been found whose prevailing colour is brownish olive, and whose lateral stripes are darker. A fresh green tint is accompanied by dark blue stripes in others. This great caterpillar lives on the potato leaf, the jasmine, and the common tea tree (Lycium barbarum); and when full grown it hides in the earth, and undergoes its metamorphosis into the chrysalis.

The death's head moth is more common in Asia and in Africa than in Europe, and there is no doubt that many of the pupx are destroyed in this country and in France during severe winters.

Perhaps the largest sphinges in the world live in Australia, and their caterpillars feed upon the Banksia trees and bushes, which form most important parts of the foliage of the landscape of that country.

The sphinges gradually become more and more like that great tribe of moths which may be considered to be represented by the silkworm moth. Thus there are some sphinges which have slender, flexible, or more or less pectinated antennæ, and rudimentary trunks instead of the long and flexible organs of some of the hawks. Such species of the genus Smerinthus as the eyed hawks, poplar hawks, and lime hawks, live upon willow, poplar, birch, and apple trees, and connect by their structures the death's head moths, the privet, and humming-bird moths with the Bombycina or the spinners.

The insects of this group are very numerous, and often attain 
a great size; they are celebrated for their beauty and strangeness of form, as well as for the simplicity of the decorations of the species which are the most valuable to man. As moths the Bombycina are usually stout and solid about the body without being as robust as the sphinges. Their wings are usually large, and the antennæ, which are formed like the teeth and stem of a comb (pectinated), are sometimes feathery in the males. The trunk is rudimentary and useless, and the legs are short. The majority of the moths live for love, and the lady bombycides are so attractive that their pursuit and courtship are the sole pleasures and delights of the males, which seek them out at great distances and in a most remarkable manner. If a female moth be carried into a house in a town far away from the fields and hedges and be placed upon the window-panes, she will surely attract followers and lovers in abundance. Towards the evening the gentlemen begin to arrive; they are in a great hurry, and usually are very short sighted: so that they can see their cherished object, what else is worthy of consideration? Love laughs at locks, bolts, and bars, but a pane is no joke, and many an ardent bombyx bangs against this deceptive prison wall, maddened by the sight of bombycina and hopelessly in love. An Australian traveller once caught a pretty little moth and placed it in his pocket inside a box. All the evening he was pestered with moths that flew about him and settled upon him in every direction. They followed him into his house, and would not be satisfied without a sight of bombycina.

The males which are thus able to find out the hidden females, have feathery antennæ, and perhaps there is some excessively delicate organisation in them that gives the insect the peculiar power of discovering the distant and desired object. Sight is of no importance, neither is hearing, in this peculiar inquiry; and, although it is difficult to understand, probably the odour of the female insect attaches itself to anything it may touch, and thus attracts the males.

There are many tribes in this great group.

The Bombycide contain the most remarkable species, and they all have almost invisible trunks and small palpi. A section of them, with large wings marked with a spot upon their disc, 
is celebrated for containing the Bombyx mori-the mulberry caterpillar or silkworm. This genus Bombyx has been sub-divided, so that now this well-known pet amongst children, and great care amongst silk growers, is called Sericaria.

This insect is so well known that no description of its rapidlygrowing caterpillar, the lazy chrysalis, and the quiet moth that never eats or sucks, is necessary. What a plain, ugly moth it is, and what a common looking grub comes from the egg. There is nothing charming, no bright tints, and no delicate ornamentation; moreover, it is rather clumsy looking. None of the graces of form or the magnificence of the colouring of the Lepidoptera that enliven the shades of the grandest flowers are here. The caterpillars of some species of the genus are even handsome, and have pretty green globular ornaments on their segments, and others like coral and pearl; but the humble silkworm has none of these. Its beauties are intrinsic, and it yields the most beautiful web that Nature can produce, to render, if possible, the loveliest of all created things more attractive than ever. The comparison of the silkworm caterpillar with those of other moths soon enables us to distinguish between the Sphingide and the Bombycide, and to notice how much they are alike in structure generally speaking. The silkworm caterpillar resembles those of some sphinges in its shape, and in its having the tubercle on the last segment but one of the body, but it differs from all by having its silkbearing glands enormously developed. When a full-grown silkworm caterpillar is opened, the intestinal canal will be seen to fill the greater part of the body, and on either side of the stomach and gullet there will be observed a large twisted tubular gland. This is the silk gland, or rather, of that viscous matter, which as it is drawn out, hardens into silk. These glands pass underneath the gullet, and each is continued in the form of a narrow tube to the mouth; they unite before reaching the head, and form one canal, into which open the ducts of two little glands, whose function is to unite the silken threads of the silk tubes, to varnish and brighten them, and to give them that perfection of texture we all admire and value. The canal opens in the lower lip or labrum, and passes through a small opening in a 
pimple-like projection. The silkworm caterpillar moves its head about in the same manner as other larvæ with spinners, and draws out the silk in regular lengths. It changes its skin in the manner already described in a former chapter, and makes the wonderful cocoon before undergoing its first metamorphosis.

The moths escape from the chrysalis state, which lasts about three weeks, and the eggs which are laid in the autumn are

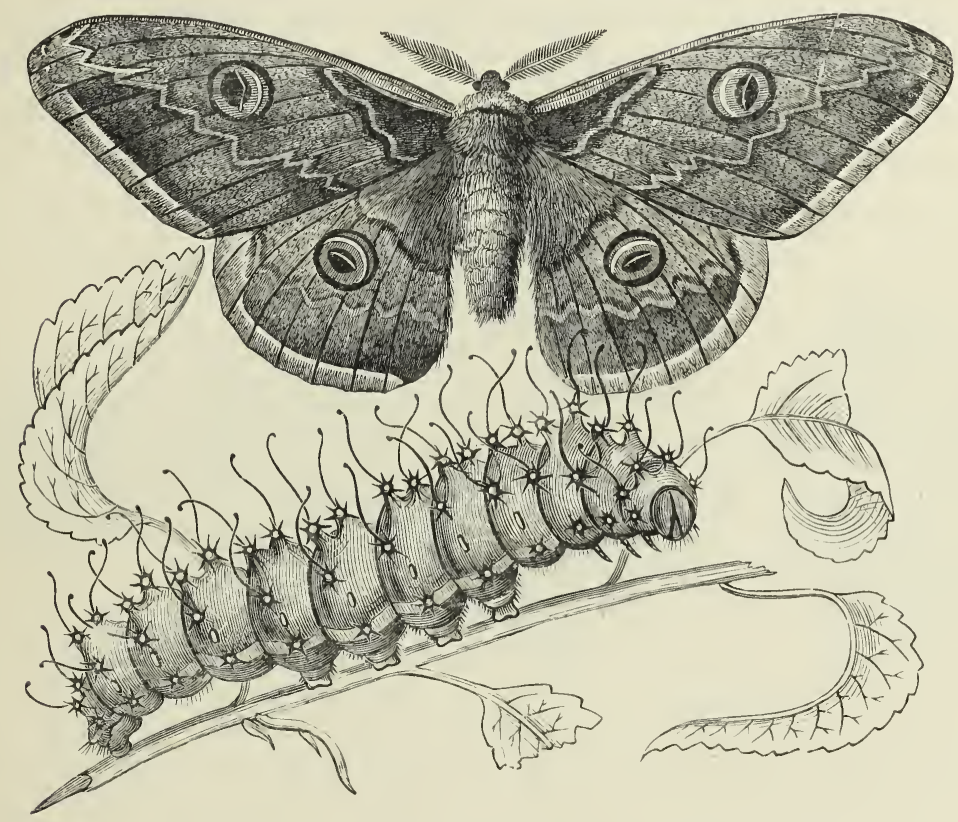

THE MOTH AND LARVA of Attacus pavonia major.

hatched during the next spring. Some species, however, have two and even three broods in the year.

There are some splendid moths belonging to the genus Attacus, which are closely related to the silkworms. They are usually large insects, and with very fine wings. Their antennx are beautifully feathery, and decorate the heads of the moths very prettily. Some have wings with tailed prolongations, like the butterflies of the swallow-tail group, and, indeed, they exceed those of any other Lepidoptera in length. Their caterpillars are large and heavy, but are very beautiful. Some have 
hairy tubercles upon them which are illuminated with vivid colours, and others carry spines which are very elegantly branched and twisted. They produce plenty of silk, and make large cocoons of it between the leaves of the trees they live upon before their metamorphosis.

There is one of them which is rather common in Europe, the Attacus pavonia major, and another, which is found in England, Attacus pavonia minor (or Saturnia) the Emperor Moth. The first-mentioned Attacus, which the French call the Night Peacock, lives, when in the caterpillar state, on fruit trees and elms. The caterpillar prepares for transformation towards August, and leaves the trees, and wanders over the roads, and crawls up walls in

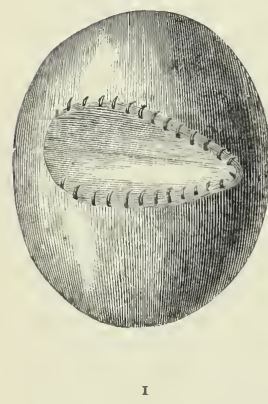

I. Sesia apiformis.

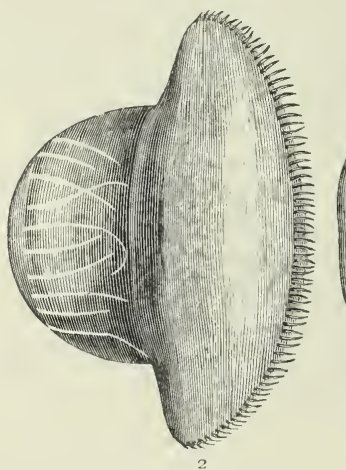

FEET OF THE CATERPIHIARS OF MOTIHS.

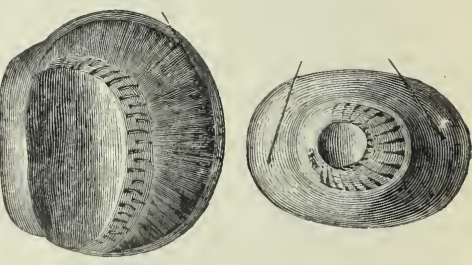

4

. Attacus pavonia major. 3. Cucullia verbasci. 4. Noctua segetum.

order to seek a safe shelter for its cocoon, and it is then often discovered and made captive. But should a comfortable place be obtained, a large, pear-shaped cocoon is spun, which is hard, and contains much gummy matter. It is open at the smaller end, and the fibres of it are so arranged that nothing can come in, whilst the moth, when it is ready, can go out with ease. All insects are thus kept carefully and effectually out of the snug silken house, and the mechanism of this interesting and very safe place depends upon the manner in which the caterpillar weaves the cocoon over itself before passing the silk from one side of it to the other. The feet of some of these caterpillars are very interesting, and those of the Attacus pavonia major are 
especially strong and membranous, in order that it can grasp the twigs safely.

The emperor moth has a very pretty larva, which is often found upon heather in the summer. It is green, and each segment has seven pink tubercles on black rings, and each tubercle has a tuft of short black hair. The spiracles are orange in colour.

The caterpillars of Attacus cecropia, from Louisiana, are remarkable for the changes they undergo in moulting, before transforming themselves into pupæ.

At their birth they are almost black, and are decorated with verticillate hairs, which make them look like little hedgehogs. After a few days their general colour becomes clearer and lighter, and the tubercles which support the hairs become more prominent. The skin is then moulted, and the new one succeeds, and is of a grey green or russet colour, and all the tubercles and spines are brilliantly black. Moulting again occurs, and, behold, a light green creature appears, with five rows of black spots; two magnificent tubercles of a carmine colour are to be observed on the second and third segments, and two of a light yellow are situated upon the dorsal part of every other segment. Each tubercle carries several verticillate hairs, which are black. A third moult finds the body becoming an azure blue on the back, with black spots on the sides and head; the tubercles form two rows on the back, and are much enlarged; they are red in colour, and the other tubercles have a single spine upon them. Finally the last moult takes place, and the caterpillar turns out to be of a pale green colour, with all the lateral tubercles of a light green, and the red tubercles have taken on an orange tint, and have only one spine. These changes of colour and of the development of tubercles and hairs during the skin-shedding are indeed most remarkable.

The cocoons of these caterpillars are double. There is an envelope, hard, and like parchment in its texture, which can readily be separated from the inner and silky one.

An Attacus, whose moth, larvæ, and cocoon are represented in the engraving, is called Attacus luna, and is celebrated for the fine silk of its caterpillar, which feeds especially upon the Liquidambar trees of Carolina and Florida. 
Several of the Bombycida, which are common in England and France, are very interesting to the naturalist, but are very troublesome to the farmer and gardener.

The Eggars, so called from the firm, egg-shaped cocoons spun by the caterpillar, are very numerous, and the Oak Eggar, which is so common, is named Lasiocampa querciis. Although so constantly seen, this species requires much more study than has hitherto been given to it, and one or two points especially deserve attention - namely, the duration of the caterpillar life, and the hybernation which takes place before the transformation into the chrysalis condition. The male moths are of a rich chocolate brown colour; beyond the centre of the wings is a deep yellow band, which shades into chocolate at the hind margin, and there is a white central spot in the fore wings, and a yellowish patch towards their base. The female has pale yellow wings, with the white spot and a very light band. Mr. Stainton says that the colour of the female is tawny. There is thus a great distinction between the colours of the sexes, and, moreover, the females are much larger insects than the males.

These moths appear in the month of July, and the females lay their eggs in August upon leaves. The eggs are hatched in a few days, and the caterpillars do not begin to eat like most others, but to all intents and purposes hybernate, if they can be said to do such a thing, in the month of August. As soon as they are out of the egg, the caterpillars begin to look out for a shelter, and seek cracks in the bark of trees and such places. Having discovered a fit place, the insect hides itself up, does not come forth to feed, and does not become metamorphosed into a chrysalis, but stops there through the auutmn, winter, and far into the spring. The caterpillar does not take any nourishment for nine months, but remains in a stupid and lethargic state until the warmth of the spring drives a little vitality into it. Then it feeds, and soon becomes transformed into a chrysalis. These fasting caterpillars are of a blackish hue, with rusty greyish hairs, which wave gracefully when the insects walk; they feed upon the oak, the briar, and the broom, in woods, and upon gooseberry bushes, plum trees, lilacs, and privet, in gardens and orchards. They fasten their egg-shaped and dense cocoons either 


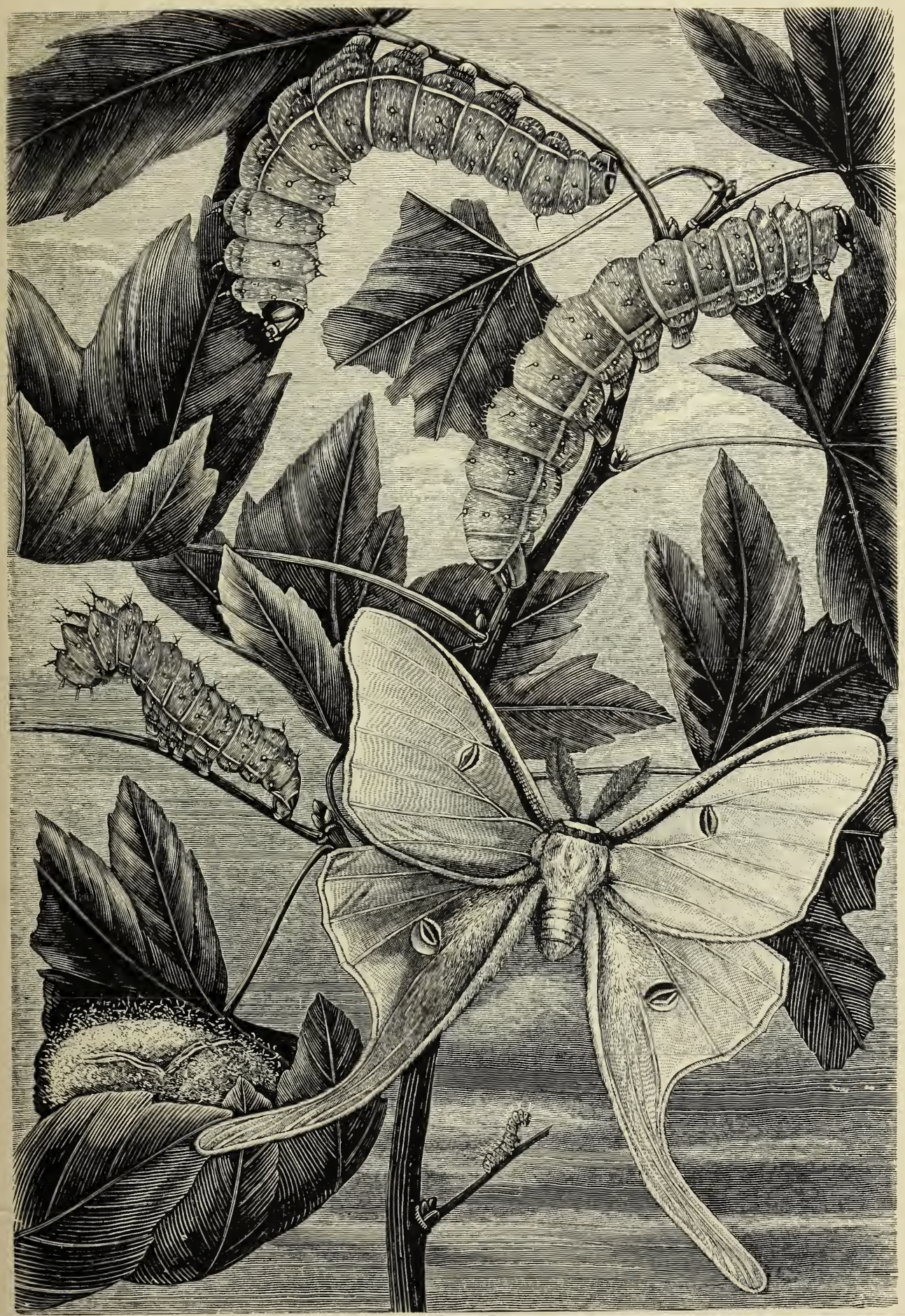



to the branches of trees and shrubs, or in holes in or under the corners of walls.

Another Lasiocampa has a very fine hairy caterpillar; it is golden brown on the back, and is otherwise of a velvety black; it is frequently met with in the autumn, crawling over paths and roads in order to seek its hiding-place. In this it hybernates

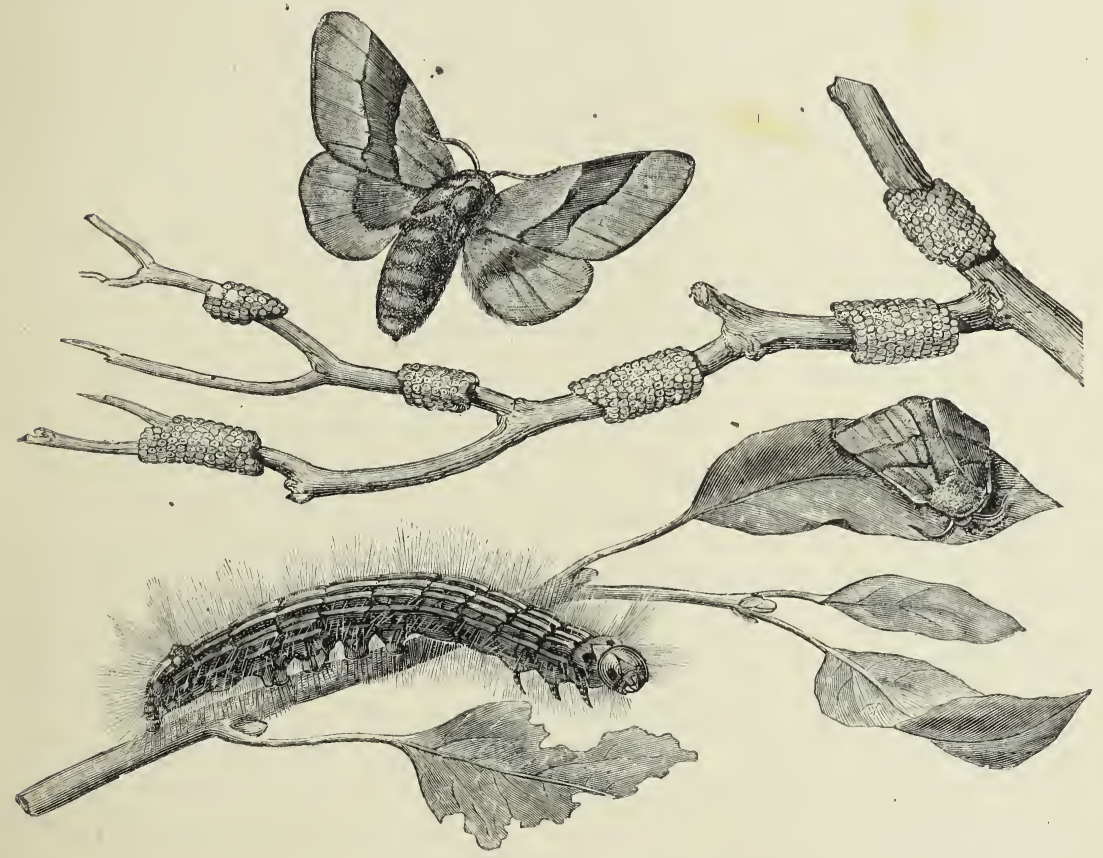

THE LACKEY MOTH (Clisiocampa neustria).

A twig with many collections of eggs upon it. A niale moth on a leaf.

A female flying. The caterpillar.

during the winter, and does not spin its cocoon until the next year, when it becomes transformed. This moth is called by a variety of names; it lives on heath, according to Mr. Stainton, and is termed the Fox by him, but the French say it lives upon everything eatable, and call it "Polyphage." It is usually known as Lasiocampa rubi.

The Lackey Moth (Clisiocampa ncustria) is very common all over Europe, and does a vast deal of mischief in the caterpillar state. The moth has wings coloured a yellow fawn or russet red, 
and the front pair have two transverse brown streaks upon them. It appears in July, and is very fond of orchards. The female lays her eggs in a very regular manner; the eggs are very sticky, and are deposited around small branches and twigs in little rings or a series of bracelets one behind the other, so that when the leaves have fallen, these symmetrical rows of egg-rings become very visible, and then is the time to destroy them. As soon as they escape from the eggs the little caterpillars unite in numerous sets and envelope themselves in a silken web, which covers the leaves and the small branches in their neighbourhood; they remain together until they have attained a considerable amount of growth, and then they separate. They do a great deal of damage to apple-trees. When fully grown the lackeys spin a nearly transparent cocoon, and powder it well with a yellow sulphury looking powder.

It is evident, after reading the history of these species, which are allied to each other, and which are all in the family of the Bombycida, that there is something more than is usually admitted in the philosophy of the first metamorphosis. Why should the first kind have caterpillars which, on escaping from the egg, go into a state of lethargy during nine months, and then transform themselves into a lethargic chrysalis? Why should the larvæ of the next kind eat and grow big, and then hide up all the winter long, before becoming chrysalides? and why should those of the last mentioned species pass in one season from the gormandising caterpillar to the chrysalis state?

The ordinary idea is that the chrysalis condition is a safe refuge during the winter, when food cannot be obtained; but why should not the first two kinds undergo this metamorphosis at once, and without running all sorts of risks? The history of the development of the insects which undergo these perfect metamorphoses certainly receives a light from these considerations, and it is evident that the popular idea is by no means the correct one.

A bombyx, which collects in great assemblages and has peculiar habits, and often a miserable fate, is called the Processional caterpillar. The moth is rather small, and its grey wings, which are very pale coloured in the female and crossed with 


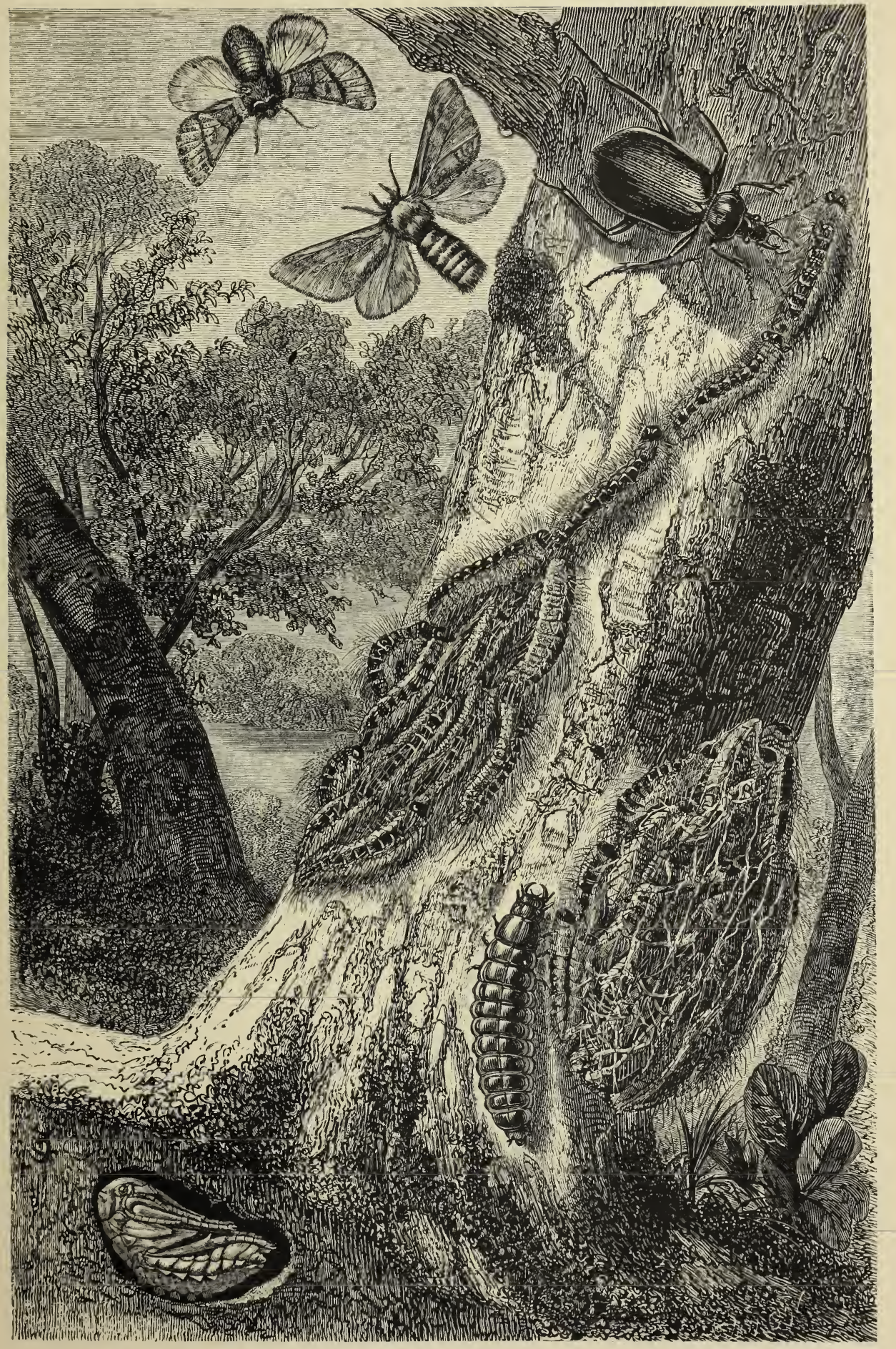

THE METAMORPHOSES OF THE Bombyx processionea AND OF Calosoma sycophanta. 

three darkish bands, give it a very quiet appearance. It appears in the woods about the months of August and September. The females lay their eggs in masses upon the trunks or larger branches of oak trees, and cover them with the hairs from the body. The caterpillars are hatched in the month of May, and are collected in families which contain hundreds of members. They form an irregular web, in which they remain very quietly during the daytime, but in the evening they crawl upon the foliage and eat voraciously. When they have finished their meal they either return to their old home or make another. One of these nests may cover a considerable part of the trunk of a tree, and it consists of several layers of web, one over the other, but very intimately woven together. Every observer must be struck with the manifest order and routine observed by these caterpillars in their peregrinations. If the nests are examined during the daytime all is quiet within, and the caterpillars are crowded one upon the other, and are almost motionless. As soon, however, as the sun has gone down there is a slight movement, and then a general waking up. A caterpillar leaves the nest, and commences climbing the trunk. It is followed by another, and this one by a third, and then comes a rank of three or four individuals, which is followed by one of many more, and so on.

The ranks go on increasing in their numbers in a very regular manner, but the column at last becomes confused. There may be two or three caterpillars instead of one in the second and third ranks, but one larva invariably leads the array in its curious procession. After feasting, the same order is taken up, and the host of caterpillars returns to camp in the same formation. Even if they move from one branch to another this procession is witnessed, and yet nothing distinguishes the leader from the others, so that the instinct which admits of these manœuvres is very remarkable. When the larvæ have attained their full growth they gradually increase the strength of the walls of their nest with their moulted skins, and then each one makes its cocoon inside and becomes transformed. In the engraving, which represents a scene in the Bois de Boulogne, near Paris, the processional caterpillars are on the march and are being attacked by a large beetle and its 
larva-Calosoma sycophanta. The caterpillars are great pests to the oak trees; and it would appear that their hairs perforate the

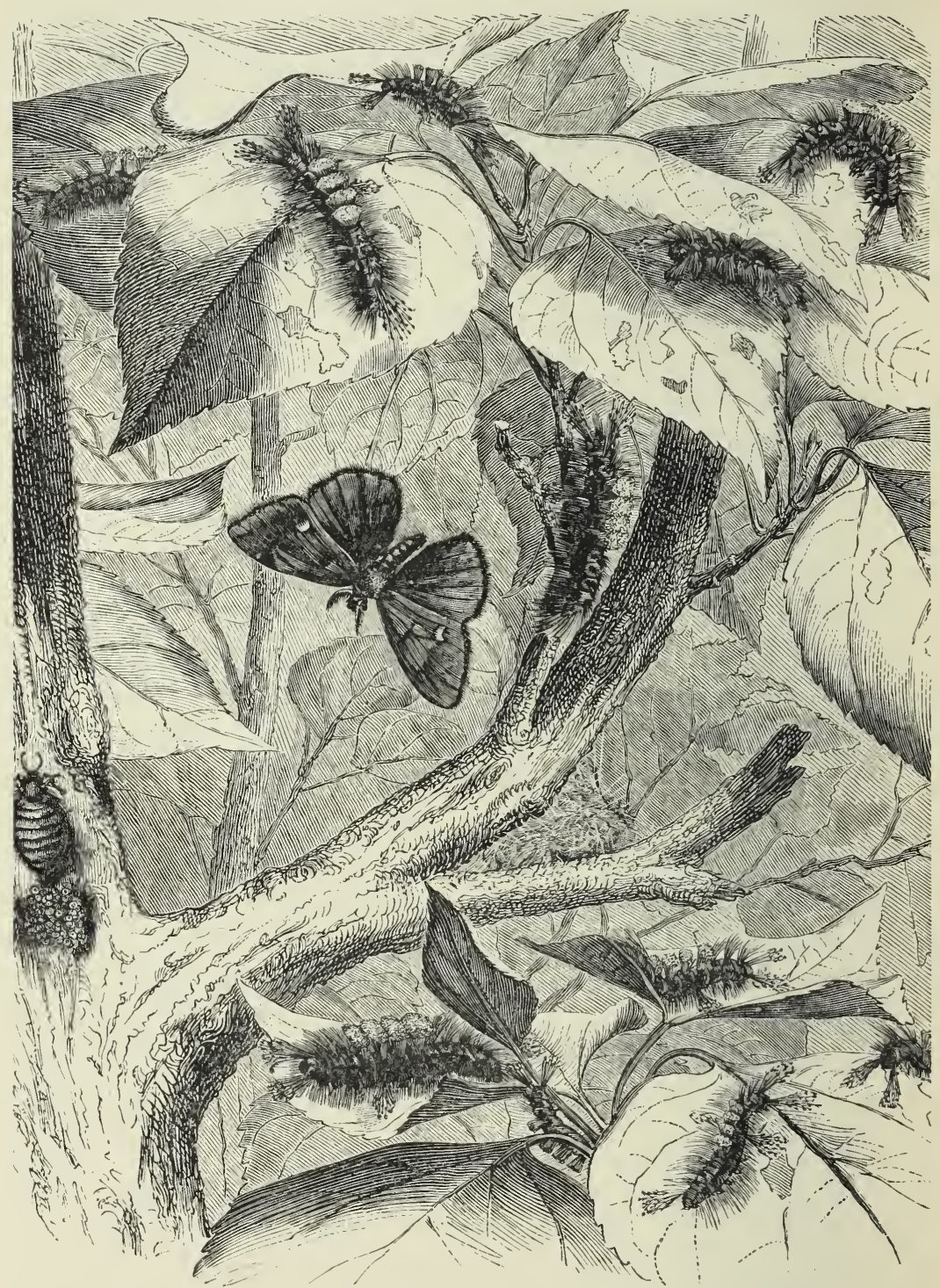

TIE METAMORPHOSES OF THE VAPOURER MOTH (Orgyia antiqua).

human skin, and give much pain and produce inflammation of the face if they are blown against it. Even horses and other 
animals suffer from the irritation of the hairs if they get into the eyes or up the nostrils.

The pretty caterpillars of the Vapourer moths-Orgyig antiqua -with their tufts of variously-coloured hairs and harlequin look, are very common in the summer time on all sorts of trees and shrubs, for there are many broods of them during the year. The larvæ make a cocoon, but as they only have a very small quantity of silk, they mix their long and pretty hairs with it and sometimes unite some leaves together to cover all.

The moth flies two or three weeks after the metamorphosis of the caterpillar into the chrysalis. The male has a thin body, and pectinated antenna, and its wings are of a brown fawn colour, with some darkish rays, and a small white spot; but the female is a brown insect, having very rudimentary and stumpy wings. She moves but with difficulty, for her legs are hardly strong enough for the distended body. Certainly, she is no beauty, yet she has abundance of admirers, and is always at home. In the engraving one of these wingless creatures is to be seen on the tree laying its eggs, and many of the well-known hairy caterpillars are on the leaves.

The pupa of the female is black, and has many tufts of hair upon it, and the perfect insect escapes through the imperfect cocoon very easily. She then commences to lay the eggs upon the silky outside, and she never leaves them. The eggs are greenish at first, and soon become white, with a faint green spot on the top. They are tub-shaped, and may number 200 or more.

There is another moth belonging to this group of Bombycina, whose metamorphoses are as curious as those of the kind just mentioned; indeed, there are two genera of a family called the Psychide, the females of which are not only without wings, but have neither legs nor antennæ. In fact, the female moth is a helpless egg bag, which never quits the case or covering in which it was bred. It is a curious notion to call these moths by the name of Psyche, but really the males are very pretty. They are small; their bodies are thin, and covered with long silken hairs; their wings are almost transparent, for they only have a few grey, brown, and black scales upon them; and they 
have pretty feathery antennæ. Considering what clumsy looking things some of the moths of the Bombycina group are, and how delicate are the little Psyches, which may be blown almost to pieces by a puff of wind, there may be some excuse for the name, especially as they have a very tiny mouth, and as they live for love, having no other passion or appetite. The larvæ live in cases, which they make up of a certain quantity of silk and of pieces of vegetable tissue arranged with great tact and care. Some kinds use pieces of leaves; others straws cut to a proper shape, or morsels of stick; others build up their curious house, which always travels with them, with sprigs of moss; and one in particular constructs some very odd-looking tubes, which, although very rough and funny looking outside, are lined with the softest and finest silk. The Psychide carry their cases just as snails do their shells; and one species, which will be alluded to, especially with reference to its maiden offspring, actually mimics shells in the construction of its case. When they wish to move they put out their head and the thoracic segments, so that their scaly legs can hook on to the leaves or twigs. When they want to be quiet they anchor their house by means of a silken thread, and re-enter it completely. It is really very curious to see these little tubes crawling about, and going here and there over the leaves, without being able to distinguish the insect. The species are all in the larva state in the early spring or middle of summer. One of them, which is the commonest of all, may be found on the sloe, elm, and sallow trees, and its case is composed of pieces of stems of grass placed side by side. The scaly legs (the fore legs) of the larvæ are well developed, and the membranous legs, which are very small, and furnished with a complete ring of hooks, enable the insect to hold on to its snug little house. When the larvæ have attained their full growth, and their time of metamorphosis is at hand, they do not require either to seek a safe spot or to manufacture a cocoon, for their tube is the best shelter they can possibly have.

The insect attaches its tube either to the trunk or branch of a tree, or to a wall, and closes one end very carefully. This operation having been satisfactorily completed, it turns round in the tube so as to allow its head to rest near that end of the 
tube which is still open. It then becomes transformed into the chrysalis. In a few weeks' time the moth escapes from its prison if it is a male, but if it is a female she still stops at home, being none the less attractive, however, to her admirers. She lays her eggs inside the old house and dies. No young caterpillars should have a greater respect for their mother than those which are born after a time in the old house where she died, for she built the house, carried it about with her exposed to numberless dangers, repaired it, and was married in it. But these little thoughtless things not only are ungrateful, but unfeeling, for the first thing they do is to set to work to eat up their mother's body, which they perform very completely, for they only leave the hard parts behind. After having done this they quit the old home and wander about the world. This cannibalism is almost
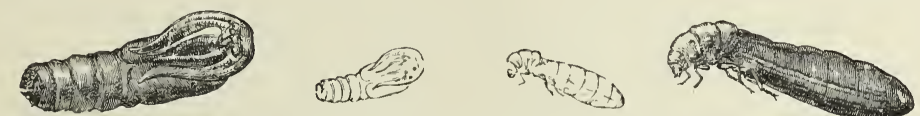

THE CHRYSALIS AND THE FEMALE PERFECT INSECT OF Psyche graminella

but not quite an exceptional proceeding in the Lepicloptera. In the spring-time and in early summer the caterpillar of Psyche graminella may be seen wandering about over the grasses, brooms, heaths, and sometimes upon walls, and it is very visible, for its tube is often nearly an inch long. It is made up of little pieces of leaves all cut to about the same size and placed one within the other like flounces, and its front part has one or two rows of pieces of wood or of sprigs of plants placed longways upon it. These pieces come from the caterpillar's favourite plants. The caterpillar never has but one tube, which it enlarges from time to time by making a slit in it with its jaws. The margins of the slit open, and a piece made up of silk and vegetable matter is stuffed into it. Every time that the larva enlarges its house it repeats this mancuvre. The caterpillar is of a pale grey colour, and its head and its three thoracic segments are of a reddish-brown and are marked with black lines and dots. It is no beauty; but what is the use of being dressed up when one lives in the dark? 
The engraving shows the tubes of the Psyche with the heads and fore parts of the bodies of the larvæ projecting and the male moths flying about. Psyche fusca, which is common in England, covers its case with pieces of leaf and grass, which are put crossways.

A closely allied kind, which belongs to the genus Fumea, has females which have legs and antennæ, and it would appear that they emerge from the case after having escaped from the chrysalis condition, and sit on the outside.

Very large Lepidoptera of the family of the Psychide are found in America and in Australia, and one kind has a tube four or five inches in length, which it hangs on to trees with stout silken threads, so that very strong gales of wind produce little effect upon it.

The remarkably defective development of the females of these families of the Bombycina is almost equalled by that of the larvæ of the Cochliopodida. These singular insects, of which Mr. Stainton says only two species occur in Europe, are unlike any others in the caterpillar state. In one the larvæ are greenish with raised dots and a broad yellow stripe on the back inclining to reddish on the side, and they live on the oak, beech, and poplar trees, and are smooth: they have no legs. In the other, the legs are equally deficient, and the pupæ of both kinds are found in a firm cocoon amongst leaves. The perfect insect flies entirely by day, and soon tatters itself.

There are some interesting moths which, although they have very short antennæ and a long abdomen, with some evidences of the presence of a short oviduct, are still classified among the Bombycina. They constitute the family Hcpialida, and are found in considerable numbers in America, Africa, and Australia, but only rarely in Europe. The caterpillars feed on the roots of many plants, and never come into the light, and they are slim, elongated, and colourless. The largest of the European species is Hepialus mumuli, commonly called the Ghost, and the wings of the males are snowy white in colour with brownish costæ and fringes, whilst the females are decorated with wings of a dull yellow tint, and with brick-red bands. The larva is pale in colour, and has a reddish-brown plate in front on the second segment, and lives 


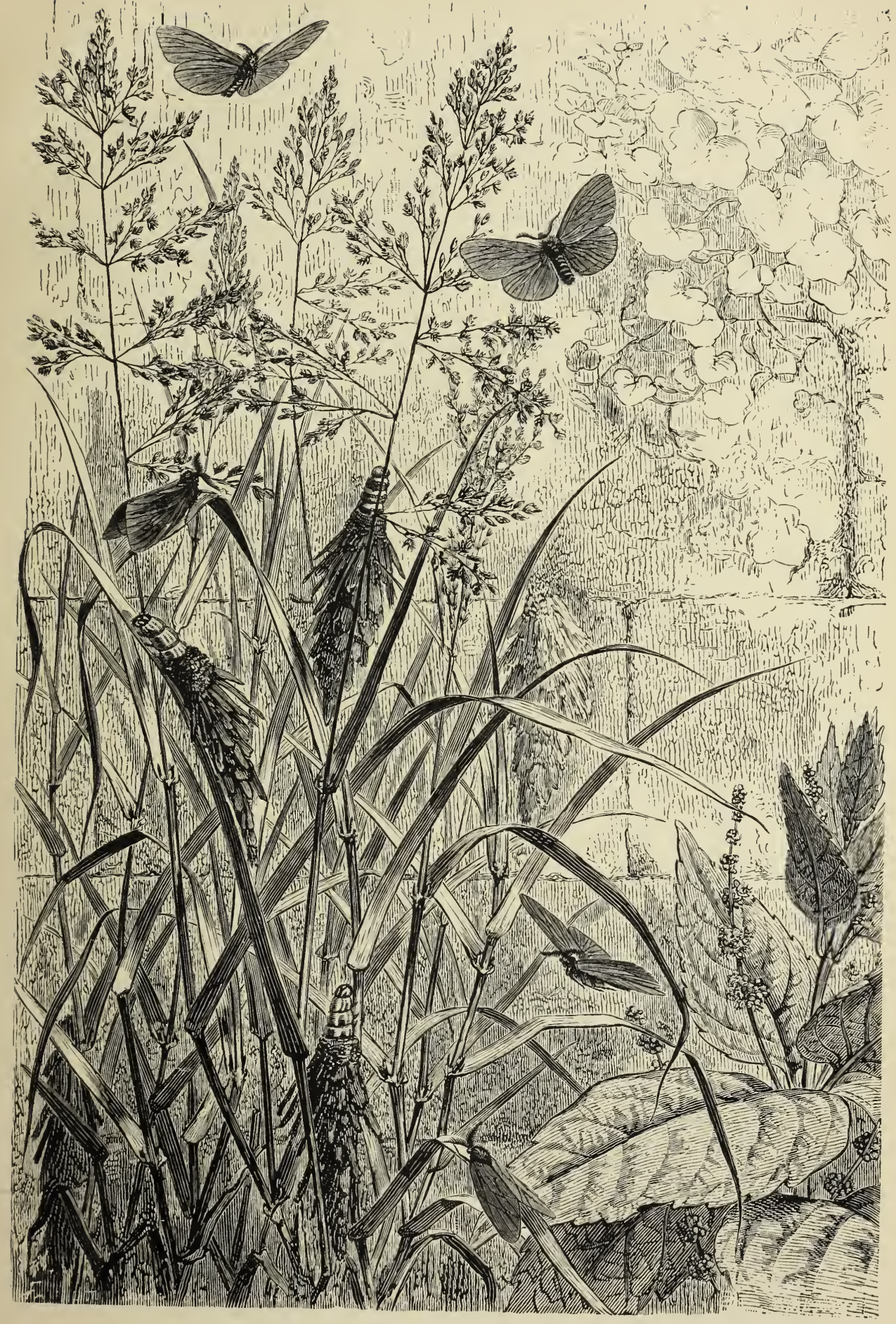

THE METAMORPHOSES OF Psyche graminella. 

upon the roots of hops, nettles, and burdocks, being common all over Europe, and even among the hilly districts.

Australia, however, is the land where the Hepialide flourish. One of them has a caterpillar which may really be called enormous in size; it lives within the trunks of the beef-wood trees, and although it is a flabby, flat, and white-looking grub, it is by no means despised as a luxury by the natives. The Australians eat the caterpillars uncooked, and peel and squeeze them first of all, just as we do a fig or a peach.

The Goat Moth (Cossus ligniperda) is a well-known insect, with a short body and large and broad wings of a pale brownish-white colöur, marked with short wavy lines. The caterpillar of this insect is flesh or wine coloured, and has a few hairs upon it; and a faint and disagreable smell is evolved from it, which is left behind upon the wood over which it has recently crawled. This larva gnaws the old trunks of willows and elms, and by excavating large galleries in the trees, it often destroys some of the largest and finest. It is admirably adapted for this sort of life, and the upper lip is not notched; moreover, the jaws are strongly toothed. The simple lip and the dentated jaws enable the larva to gnaw away at the wood, which it does not want to hold like a leaf. The membranous legs of the larva are short, and are furnished with a ring of hooks, so as to allow it to move readily in the long galleries.

When fully grown the caterpillar is nearly three inches in length, and is as thick as a man's finger ; this size is only attained after at least three years' gnawing and tunneling under the bark of the trees it injures. It makes a cocoon of the gnawings of wood, which it fastens together with a viscous secretion, and then all is lined with soft silk. This case is so placed that the end corresponding to the head of the chrysalis (so writes Dr. Baird) is turned towards a hole which the caterpillar has had the precaution to form beforehand in the bark of the tree on that side from which it is about to escape. This hole remains closed outside, but the partition is so thin that the slightest effort can break it and let the prisoner free. The chrysalis itself bursts this slight partition and escapes about half way through before breaking its own bonds and assuming the perfect form. Some of the moths measure at least three inches across the wings. 
There are some moths belonging to the Bombycina group which have great resemblance to the group Noctuina (or those which are usually night-fliers), on account of the size of their bodies and the proportions of their wings. They have the antennæ longer than the thorax, and they are pectinated in the males. The trunk is rudimentary, but perfectly distinct, and the fore-wings are frequently marked with a projecting tuft of scales on the inner margin. This, when the wings are in repose and in their usual roof shape, forms a little prominence on the outline of the wing, whence the term "prominent," which is applied to several of the species (Stainton). There is nothing very striking about the perfect insects, but the larvæ present many singular structural peculiarities. They are as a whole very variable in form. At one extreme of the series the Cerura larvæ have only fourteen legs, but they have two long projecting tails upon the last segment of the body; at the other extreme the larvæ have sixteen legs and no peculiarity of form-those of the Buff Tip Moth for instance. Most have, however, the gift of holding the hind segments of the body erect when in repose. Many of the larvæ are hairless, but they are downy in the Buff Tip, and usually there are projections on the twelfth segment. The pupæ are smooth, and rarely make a cocoon.

What our country people call the Puss Moth the French term the Fork Tail; it is one of those Notodontida of which we are now taking notice, and English entomologists call it Conura vinula, whilst on the other side of the channel Dicramura is its generic name. This moth is very common in the last week of April, and during the whole of May, and it flies in damp places, near willows, sallows, and poplar trees during the evening. All day it hides under the leaves or in the hollow trees. It has whitish wings with numerous $\mathrm{V}$-shaped markings upon them. The female lays its eggs, which are hatched early in the same month of June, and the caterpillars may be seen here and there, but not in companies, upon the poplar leaves. Their colour is almost black when they are small, but a few weeks elapse, and the caterpillars having moulted several times and grown large, very differentlooking insects result. These smooth caterpillars, with their great heads drawn back as it were into the first segment of the body, 


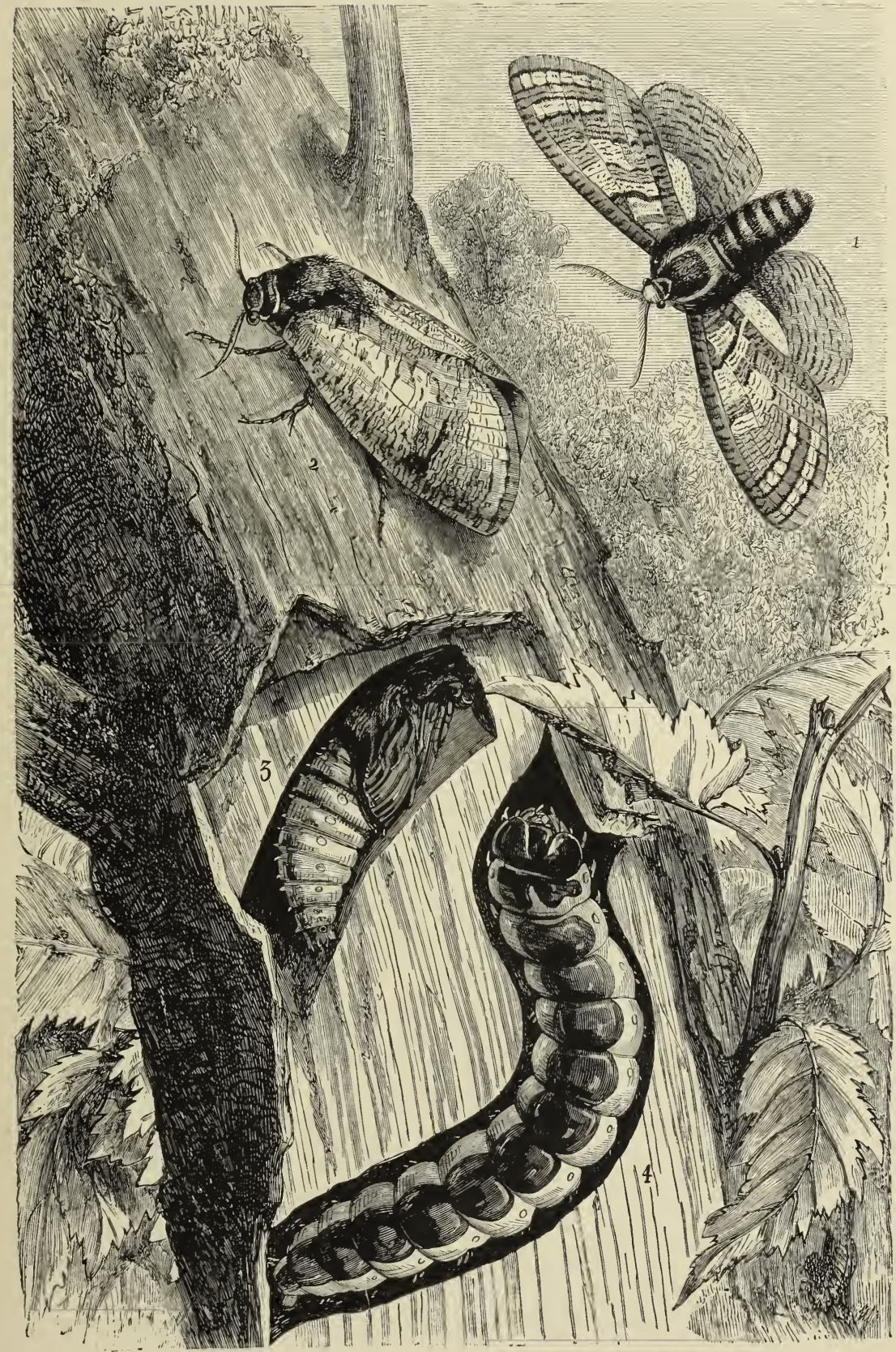

TIE METAMORPHOSES OF THE GOAT MOTH (Cossus ligniperda).
I, 2. Perfect Insect.
3. Pupa.
4. Larva. 

with a hump upon the third or fourth segment, and with their tail ends furnished with two prolongations, have become of a delicate green colour, and they are marked with a lozenge of a brownish tint, and a white border on the back.

The larva has strong membranous legs to carry its heavy body, and they are furnished with long spines. The tails are nearly

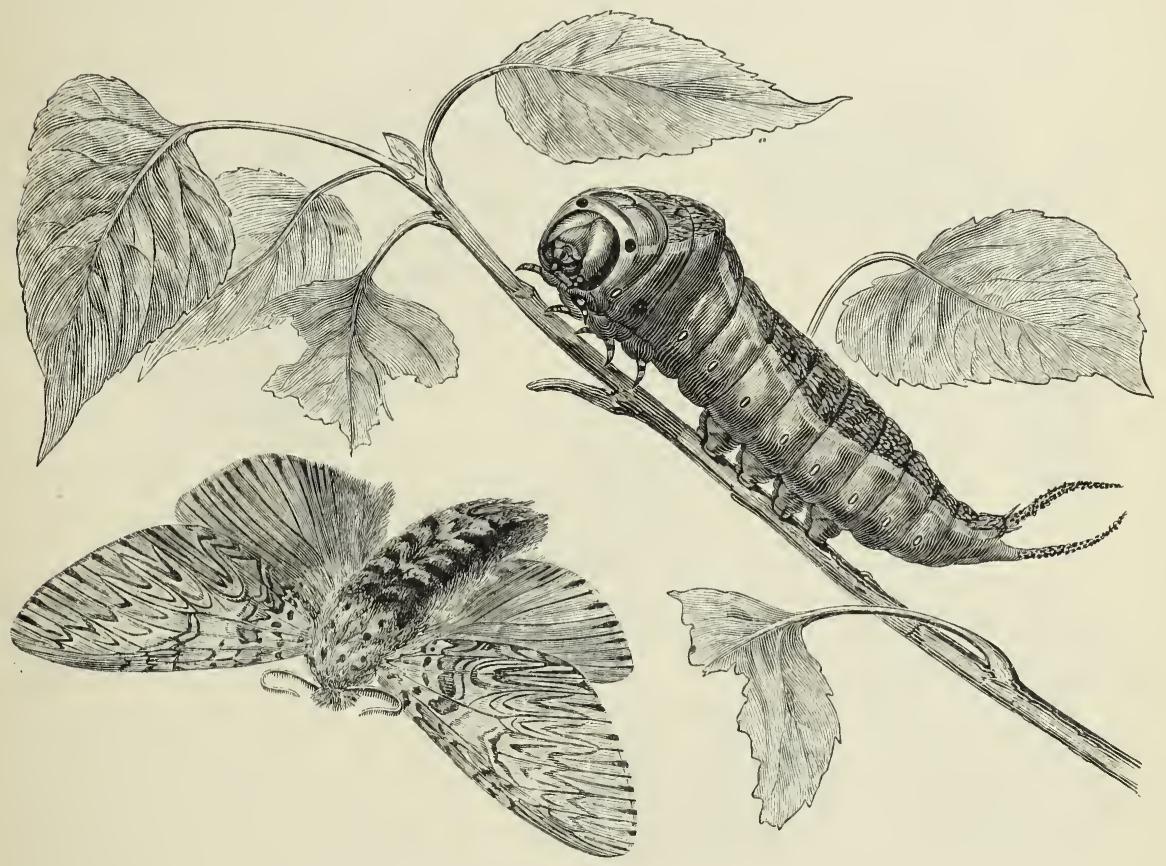

THE PUSS CATERPILLAR AND THE MALE MOTH.

white, and are ornamented with black tubercles. The greatest peculiarity of the insect is this development of the last two legs into two appendages, which are, in fact, tails pierced for the projection of tentacules which are doubtless of use to it. Perhaps the caterpillar may use them to scare the ichneumons away when they are about to lay their eggs in its tempting looking body. When fully grown the larva descends to the foot of the tree upon which it has been feeding, and makes a very thick and tough cocoon, by sticking together vegetable tissues with a great deal of viscous secretion. It is then metamorphosed, and passes the autumn and winter in the chrysalis state. 
The caterpillars of the genus Stauropus, or the Lobster Moths, are more extraordinary looking than those of the puss moth. They are found during August and September in large forests and woods, and usually upon beech, oak, and birch trees, and are very curious objects. They are of a pale or reddish-brown colour, or resemble leather in their tints, so that

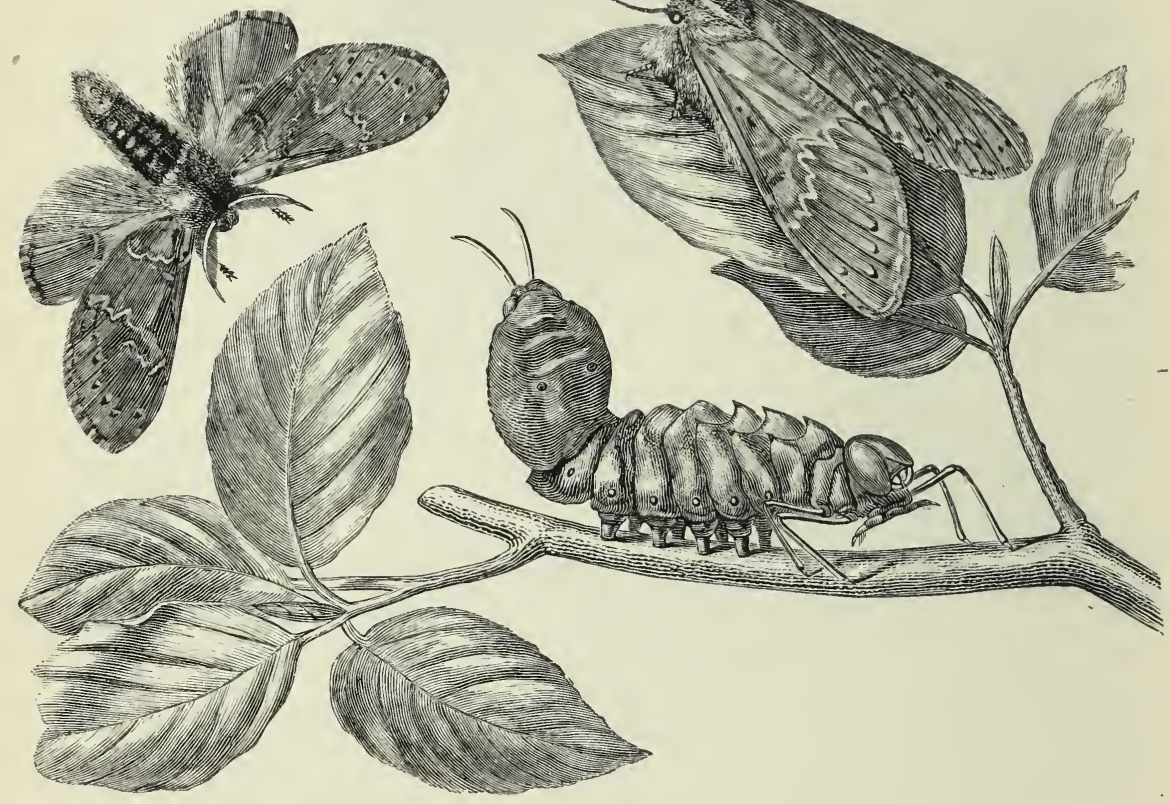

THE LOBSTER MOTH (Stauropus fagi).

The male moth. The female upon the leaf. The caterpillar with its tail end in the air, and the long legs close to the head.

they are not remarkable for beauty; but the second and third pairs of front legs are extremely long, the first pair being absent. There are two sharpish projections on every segment, from the fourth to the seventh, and there is a considerable enlargement of the sides of the ninth and the last segments. There are two little tails.

When quiet the caterpillar usually erects its tail end, as well as the head, and the attitude renders the peculiar shape of the body more striking than ever. The long fore legs are 
not noticed in any other of the Lepidoptera, and their use is by no means evident. When ready to assume the chrysalis state the lobster caterpillar spins a slight cocoon, and protects it with leaves.

The largest group of the order of the Lepidoptera is called Noctuina. The majority of night-flying moths belong to it, and they are very properly named after their nocturnal habits. As there is no rule, even in Nature, without an exception, so we find that several kinds of the Noctuina fly by day, and enjoy the sunlight as much as any butterfly. The number of species in this group is immense, and about 800 are pretty well known in Europe, and there are about 300 British species. Naturalists meet with great difficulties in classifying them into genera, and even their specific differences are either very hard or impossible to make out. There are no satisfactory distinctions between some of the moths which enable any one to say that they are of such and such species, and very frequently they are separated into different kinds, because they happen to feed upon various plants, and because the moths are not all coloured in the same manner. Of course the entomologists that believe in the real nature of species have taken a vast deal of trouble with the Noctuina, but those who do not think a species to be anything more than an abstract idea, and that it really consists of the sum of the variations of a closely allied series of forms, do not see the use of this natural history hair-splitting. The comparative study of a sub-group of the Noctuina is certainly very instructive. There are ten, twenty, thirty, and more kinds of moths whose structures are in the main alike, there being only the appreciable differences produced by the details of their ornamentation. Their distinctive characters are so feeble that no philosophical naturalist would care to call any of the species other than varieties of some common type. In fact, in studying these Noctuina in the adult form, every one must admit that they oppose the notion of species in its ordinary acceptation. The most interesting part of the examination refers to the caterpillars, for those belonging to moths, which are almost exactly alike, present very marked distinctions. The moths resemble each 
other, and the caterpillars are dissimilar. The caterpillars live under very opposite circumstances, they like different plants, and they have their feet specially constructed to enable them to crawl over particular leaves, and one kind would find itself very much out of its place should it attempt to lead the life of others. No group, so far as the caterpillars are concerned, shows greater evidences of design, and offers proofs of the special adaptation of structures to particular ends. In considering how all this bears upon the Darwinian theory, it must be remembered that the moth is the perfect animal, and that the caterpillars and chrysalides are being developed into the perfect form, and that they are undergoing evolution. It is not logical to argue upon the data afforded by the structures of the immature insect, because, during the early conditions of all animals, there are developments going on which cannot be divided naturally into steps or stages for the sake of argument. The details of the organisation of the adult and perfect forms afford the only satisfactory data for comparison, and it is evident that in the instances before us the variability is cut short at the end of caterpillar life, and that Nature asserts her love of persistence of form in reproducing identical moths from different larvæ.

The Noctuina have a stout body, and generally speaking narrow fore wings, under which the hind wings are folded in repose; the insect thus looks much smaller than it does when the wings are all expanded. Mr. Stainton mentions that when he first saw the common "yellow under wing" he thought it a dull, reddish-brown inconspicuous thing; he was surprised to see it grow to three times its previous size, as it displayed its yellow under wings. The Noctuina are generally small; they have a moderately long trunk, and projecting palps, and the antennæ which are thread-shaped, are either simple or finely denticulated. The moths, unlike those we have just noticed amongst the Bombycina, take nourishment, and are very fond of sugar, and they have, therefore, a moderately long sucker. The caterpillars are usually without any hair.

Naturalists have divided the Noctnina into two main groups, the Trifide and the Quadrifide. In the Trifide the moth is 
generally of moderate size; the hind wings are usually much folded under the fore wings, and the inner margins of the latter in repose frequently overlap. The caterpillar generally has sixteen legs, and, consequently, few loop when walking. Their chrysalis is usually found underground. The moths of the Quadrifide have generally broad wings, which sometimes are of very large size; the hind wings are but little folded, and the inner margins of the fore wings rarely overlap in repose. The caterpillars rarely have sixteen legs, and more frequently are noticed with fourteen or twelve, and many of them loop more or less when they walk. The chrysalis is rarely found underground.

There are some Noctuina which particularly put one in mind of the Bombycina, and they are the Acronycta and the allied genera (forming the Bombycoide). A greyish-black caterpillar, with a broad yellow line down the back, having a large black hump on the fifth segment of its body, and a short black one on the twelfth, is very common during the autumn upon the elms, limes, and upon most fruit trees. When it has reached its full growth the insect descends from the branches and hides itself, either in the cracks in the bark of the trunk or in holes at the foot of the tree, where there is safe shelter, and then spins a light cocoon, and undergoes its metamorphosis. The chrysalis remains in its quiet condition until the month of June in the next year, when the metamorphosis into the moth takes place. The moth may be seen during the day-time upon trunks of trees, or upon walls, and may be recognised by a curious mark on the wing, which resembles a Greek letter. Hence the moth is called Acronycta psi. In England it is called the Common Dagger. Now, Acronycta tridens has a caterpillar which is orange red in colour, and which has a small black hump on the fifth, and a whitish black-crowned hump on the twelfth segment. This caterpillar differs, therefore, in its colour and humps from the common dagger caterpillar. But the moths of the two species resemble each other perfectly. The question arises at once in the mind, is this diversity of colouring and humping of very great importance, and of any specific value? It has been noticed in former pages that the caterpillars of succeeding broods of the 
same species differ very much in their ornamentation and tinting. The propriety, then, of separating these kinds of Noctuina is very doubtful.

The little dark caterpillars of the A.cronycta are very fond of the mosses and lichens which grow upon trees, and upon the walls of our towns, and which are often found on the quays and parapets by the water-side. They usually hide themselves in the day-time in holes and corners, and they finally shut themselves up there, and form their cocoons with silk, moss, and pieces of lichen. One of the commonest of the Noctuina does a great deal of mischief. It belongs to the family of the Noctuida, and is usually seen about the flower beds at dusk on a summer's evening. This little moth, Agrotis segetum, is called the Reaper by the French. The fore wings are of a greyish brown or fawn colour, and are marked at the base with two undulating lines, and the hind wings are whitish. The males have lighter tints than the females. The moths fly at the end of May, or the beginning of June, their appearance depending upon the warmth of the season. The females generally lay their eggs in little patches on the lower surfaces of such plants as the chicory and beetroot. The caterpillars do not stop upon these leaves, but descend and hide themselves in the ground during the day. They only move during the nighttime, and then never trouble the leaves, but enjoy the succulent roots, which they gnaw and perforate just where the stem is united to them. By about the middle of July, the caterpillars have attained their full size, and they then measure an inch to an inch and half in length. Their bodies are smooth and shining, and are sombre coloured. They are ornamented with two rows of black wart-like points surmounted with hair, and there is a general greenish hue over all. Their mandibles are strong and trenchant, and the upper lip has no notch, the mouth being admirably adapted. for munching roots. Their hinder or membranous feet are very short, and have a very small hollow in them, surrounded by a hard border, and covered with short hooks. The larva, which gardeners call the grey worm, can crawl over the ground, but its feet are not suited for climbing stems and leaves, or for clasping them. 
When the caterpillars have attained their full size they make a shallow hole in the earth. This they line with a small quantity of silk, so as to keep the water out, and then they undergo the first metamorphosis. The second is completed in August, and the moth escapes from the cocoon in the earth, semi-clad with the chrysalis skin, which prevents the delicate integuments from being torn or rubbed as the perfect insect crawls into the air. The moth does not get rid of this useful armour until it is well out of danger.

When these reapers fly in the middle of summer, their caterpillars may be seen feeding in the autumn, and they transform themselves into pupæ on the approach of winter; but if they are not ready for the change by the advent of cold weather, they hybernate and undergo the metamorphosis in the early spring.

The common Yellow Under-Wing is frequently seen in gardens and houses. The front wings of this moth are excessively variable in colour and marking; some specimens have reddish-yellow tints, others dark brown, variegated with grey, and some reddishbrown. The hind wings are yellow, with a narrow black band. The caterpillar is grey or greenish, and has some yellow lines and black patches placed upon it with tolerable regularity. It feeds on almost all low plants, and is very fond of the best parts of cabbages and lettuces. Before undergoing the first metamorphosis, the full-grown caterpillar hides itself in a hole in the ground late in the autumn, and hybernates through the winter. Its transformation occurs in the spring.

Many Noctuina with simple antennæ have the thorax and abdomen crested, the crests being produced by masses of hairs and scales. Their caterpillars are smooth, long, and are rather brightly coloured; moreover, they like the light, and thus differ from those of many other kinds. The common Hadena oleracca, which is so great a pest in cottage gardens, has a caterpillar whose ornamentation differs with its age. It is green, and has white and yellow lines upon it when it is young; and is usually brown, with a bright yellow side line, when it is old. It constructs a cocoon in the earth, which is made up of pieces of mould, dust, and small stones bound together with silk. A 
closely-allied moth, belonging to the genus Dianthacia, is remarkable both on account of the beautiful colours, vivid tints, and the elaborate ornamentation of the wings of the moth, as well as from the habits of the caterpillars. They choose the buds and the flowers of the pink tribe for their food; they eat the seeds, and before they are much grown they roll themselves up in the buds. The chrysalis terminates in a sharp point, and those parts of it which cover the wings of the future moth protrude considerably.

The family of the Leucanide, belonging to the group Noctnina, has many genera. The moths are small; their bodies are smooth; their wings are of pale colours without ornamentation; their palpi are projecting, and their antennæ are usually pubescent. The caterpillars are almost white in colour, or sometimes are rather rose or yellowish; they live on grasses, and always hide themselves. The colourless decorations of the moths and caterpillars of some of these kinds are very remarkable. The common Wainscot Moth is one of them. The larvæ of the allied genus Vonagria are also uncoloured, for they feed in the dark, inside the stems of reeds and grasses; they are long creatures, and have very distinct horny plates, and shining spots upon them. The pupæ are found enclosed in the stems in which the larvæ have lived.

Another family, that of the Xylinida, has some very beautiful caterpillars; indeed, Mr. Stainton says that no figure can give any idea of the beauty of the living caterpillar of Catocala exolita, and that when he saw it he nearly screamed with delight. They are very long, cylindrical, and attenuated at each end; their colour is a bright green, and the spiracles are connected with pale yellow lines, intersected by a slender scarlet streak. There are also white spots upon them, edged with black, and those of the back are joined together by black patches. The pupx bury themselves at a considerable depth in the ground. One kind has its chrysalis enclosed in a cocoon, which is very papery, and placed on the surface of the ground.

The genus Cucullic has some very pretty moths and caterpillars. The moths have long pointed wings, long bodies, and a sort of hood to their thorax, and are called Sharks. The 


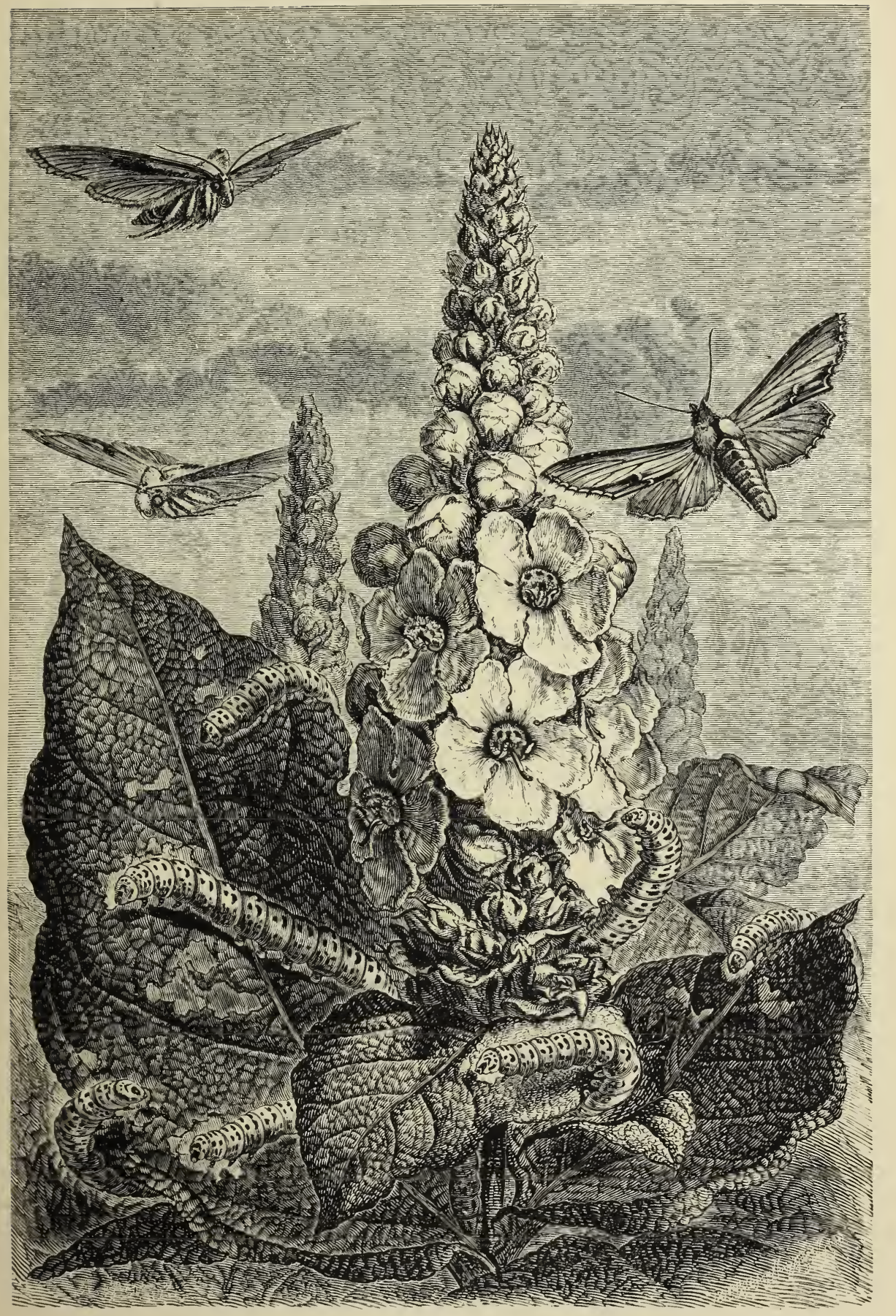

THE MOTHS AND CATERPII.LARS OF Cucullia verbasci. 

caterpillars are remarkable for the ease with which they may be picked off the flowers and leaves on which they feed. The French call them Capuchins, on account of the peculiar hoodshaped projection. The caterpillars come out during the evening from amongst the leaves and flowers of the mullein and other scrophularious plants, where they have been hidden during the day. They are easily known, for they are of a greenish white colour, with a rather broad bright yellow transverse band on each segment, reaching from spiracle to spiracle; the ordinary spots, which are black and very large, are in this band, and a black spot follows each spiracle, two others being below it. The face of the larva is yellowish and spotted with blue. They are of all sizes; and as they grow large they seek the foot of the plant, and make a cocoon underground with some grains of sand and pieces of earth and silk. The moths often fly around the plants which nourish them in the caterpillar state, and are remarkable for their wood-like tints and russet brown colour, the tints passing insensibly into a more or less bright red.

In the engraving the caterpillars are to be noticed upon the leaves of the mullein, and one of the moths, above the flower, shows its Capuchin hood very distinctly.

A few of the Noctuina have metallic markings upon their wings, and one of them is called the Silver $\mathrm{Y}$, or Plusia gamma; it has a silvery mark on its fore wings like the Greek $\gamma$. The caterpillar, which is covered with but few hairs, is green, and has six white lines and two yellow ones upon it. When it is full grown it makes a small cocoon of pure silk, and then turns up a leaf and hides it. This plan of above ground hiding, so different to that usually employed by the Noctuina, also takes place in the genus Catocala. These moths are, as their name implies, "beautiful beneath ;" when they are at rest they form a not particularly handsome flat grey triangle; but when the hind wings, which are either red or greyish-blue, are exposed to view, the elegance of the insect is at once apparent. The larvæ, which have already been noticed, are long, and they have their heads flattened and rather forked at the top, and the face is placed obliquely; they often have small humps, and they feed on trees, and rest attached to the trunks. The moths are of large size, and their thorax 
is slightly crested. When the caterpillars are full grown they spin a slight cocoon of silk amongst the leaves or in the bark, and the chrysalis becomes covered with a curious purple or blue efflorescence, which makes it look like the skin of ripe plums or grapes. Some of the American species are very large, and although very little is known about their metamorphosis, they are worth mentioning on account of the sombre colours of such species as Erebus strix, which is common in the Brazils; its wings, which

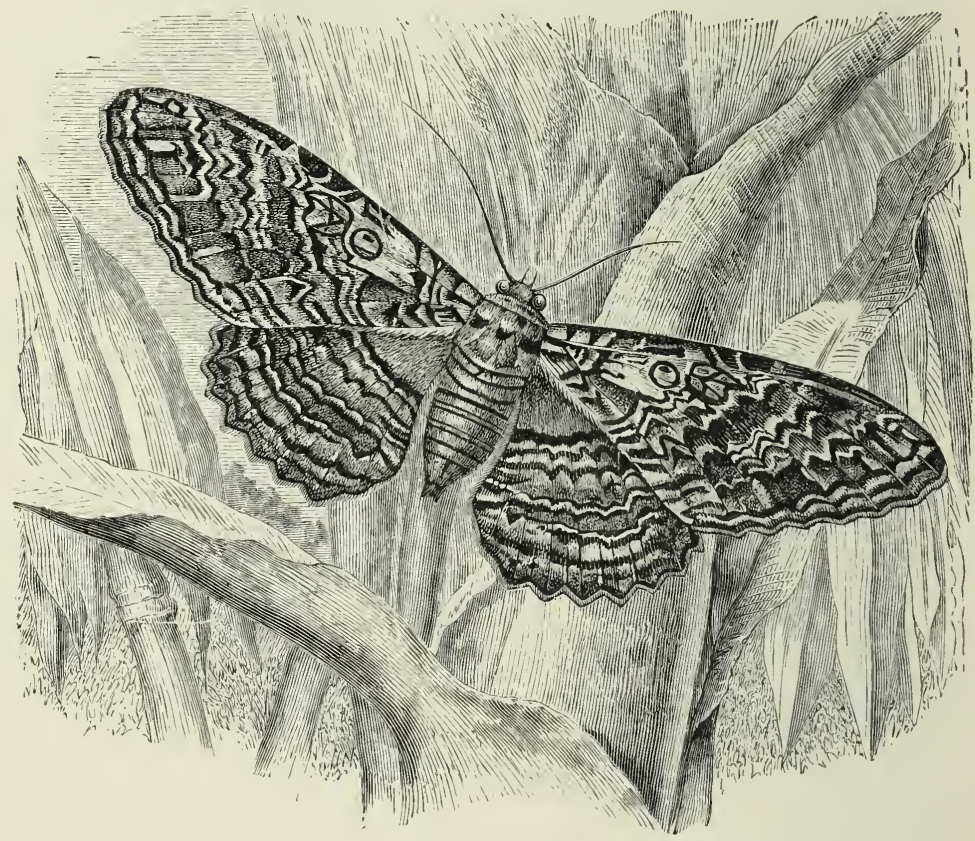

EREBLS STRIX.

are of a pale grey colour with black or grey ornamentations, are nearly seven inches across.

Before concluding this notice of the first great division of the Noctuina, we ought not to pass on without considering the curious habits of the caterpillar of one of the species of the genus Scopelosoma. The larva lives upon the oak, beech, and elm trees, and is a dark black-brown insect, with three white lines on the back of the second segment, and a white spot on most of the others below the spiracles. It is very common, and, according 
to Mr. Stainton, has very depraved tastes. It appears to be omnivorous, and if it is kept with its own brothers, or with the larvæ of other moths, it will not confine itself to the plentiful supply of leaves, but will bite and finally eat, like a cannibal, all that comes in its way. The moth has a curious half-moon shaped pattern at the ends of its fore wings, and is therefore called the Satellite.

The Phalenoide are a very remarkable family. The moths usually have delicate bodies, much more slender than those of the kinds already noticed; they have large wings, thread-shaped antennæ, which are often pectinated and even fan-shaped; they have a rudimentary trunk, which, however, is a useless organ; and very small palpi. The caterpillars are more remarkable than the moths; they are long and cylindrical, like the twigs of a plant, and they have usually only two pairs of membranous legs ; there are three pairs in a few species, but all the segments in the middle of the body, which in other caterpillars maintain two or three sets of legs, as the case may be, do not have these locomotive organs; consequently, the method of walking in these caterpillars is very different to that which is noticed in other larvæ. The group of the Geometrina exhibit this peculiarity in perfection.

In describing the peculiarities of the groups of the Noctuina, it was noticed that one of them had caterpillars which almost always loop when they walk, that is to say, that the back part of the body is brought up against the last of the fore legs-the body thus forming an arch or a loop. When the caterpillar wishes to move forwards it lets go its front legs, holds on with the hinder ones, and straightens itself, and does away with its looped shape; as soon as it is stretched out, the front legs catch hold of the leaf or twig upon which the insect may be moving, and the hind legs are let go, and brought forward. Moreover, from its ability to hold on perfectly by means of its hind legs, the caterpillar is very fond of raising its head and body in the air, and of remaining quite stationary in that attitude even for hours. Their colouring so often resembles that of the plants upon which they feed that, when they are quietly stiffened out, they cannot be distinguished from them; should they be disturbed they fix a 
thread to the twig or leaf, and let themselves drop rapidly by their silken cable. They are called geometric caterpillars, and those of Ennomos illustraria are very good examples of the group; they may be noticed in different positions in the accompanying engraving, which also represents the moth.

The caterpillars of the Zerenidae attack the buds of peaches and apricots early in June, or during the last weeks of May, and are especially fond of the leaves of the red and dark gooseberry

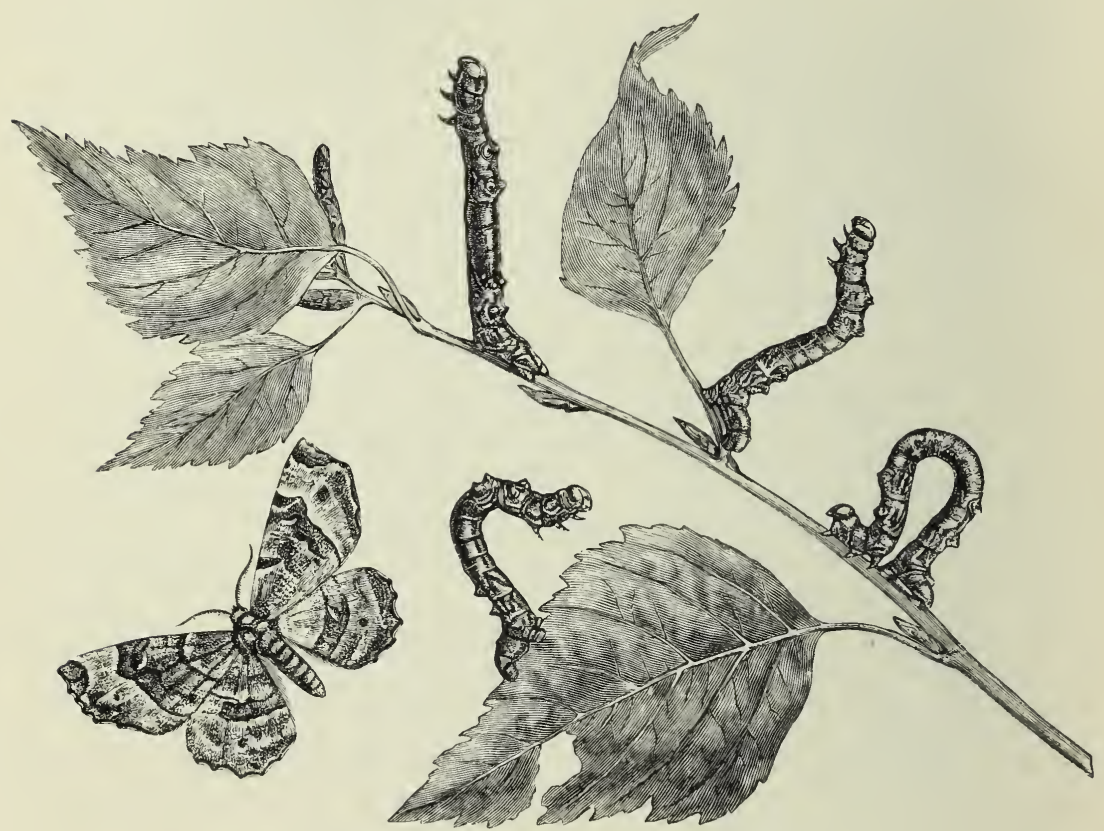

THE CATERPILLARS OF Ennomos illustraria.

bushes; they are geometrical larvæ, and are very distinctly and readily seen, for, singularly to say, their colours do not resemble those of the plants, but have some sort of analogy with those of their moths. They have a dull white or greenish colour, with orange and black patches; they have also black hairs, which are rather prominent and abundant, so that the insects show very distinctly in contrast with the tender green of the leaves and buds they destroy so readily. When in danger they drop down, holding on by a silken thread, and they make 
their cocoon when they have attained their full growth with a little silk, and place it under the leaves. The moths fly in the

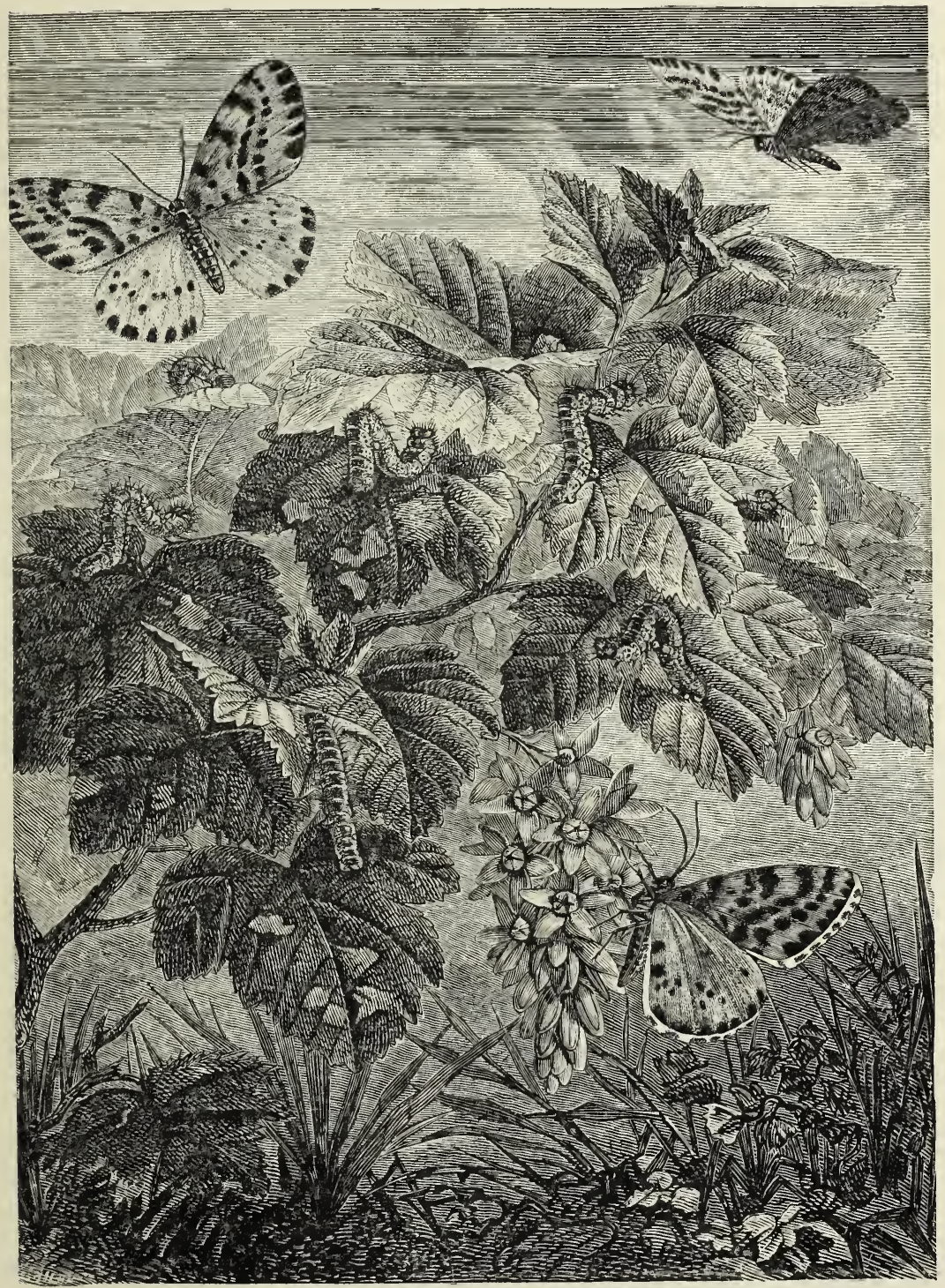

THE CATERPILlaRS AND MOTHS OF Abraxas grossulariata.

month of July, and frequent hedges, gooseberry bushes, and gardens, where they delight, like butterflies, in the open sun- 
shine; in fact, they resemble them very much, and their tints are very vivid and pretty. The engraving shows one of the species of the Zerenide (the Large Magpie) in the moth state and as a caterpillar. There are some moths closely allied to them-but which have stouter bodies and a great dislike of sunshine-whose caterpillars grow to a great size, and are very geometric in their method of walking. Phalana betularia has a caterpillar which is of a green or brown colour, and is covered with little wart-like growths. It goes into the earth, makes an oval-shaped resting place, and is transformed into a chrysalis during the month of September. The moth flies in the month of May, or early in June in the following year, and some specimens measure nearly two inches across the wings. It is very remarkable that some of the female moths of this genus should, like some of the Bombycina, have only rudimentary wings, or organs of flight, that are not sufficiently strong to raise the body in the air. Some of these geometric moths fly in the winter time; and Hybernic mpicapraria, or the Early Moth, may be caught on the Ist of January, and the Dotted Border may be seen on the hedges in February. The females of these have pigmy wings, and so have those of the Spring Usher, another of the same family. After March is passed no more of these moths are seen until the end of autumn, but when the leaves are falling fast, one of them, which is called the Mottled Umber, may be seen on the trunks of trees; they have been found even as late as Christmas. The female of this moth is a long-legged, spider-like insect, without any wings at all. These are most interesting examples of retrograde metamorphosis, so far as the females are concerned.

Another division of the Lepidoptera, which contains a great number of species with very small individuals, is that of the Pyralidina. These insects are as remarkable for the peculiarities of their habits as for the diversity of their shapes. Although usually very small, they are quite as well ornamented as the larger moths, and certainly their instincts, habits, and metamorphoses are quite as interesting as those of the other Lepidopterc. It is rather difficult to separate this division from the Lcpidoptere which have still to be noticed, and this part 
of our subject, as it does not bear very much upon the question of metamorphosis, can just as well, and more appropriately, be studied in classificatory works. The Pyralidina are very numerous, and are generally gregarious. Most of them are readily disturbed by day, are generally active on the wing before dusk, and a few fly late in the night, and others, like butterflies, enjoy the sunshine. The moths may generally be recognised at a glance; the body is slender, the wings are large, the front pair being much longer than the hind ones. Their trunk is usually well developed, and the palpi are always long and often very large. The abdomen and the legs are long. The caterpillars have a remarkably glassy appearance, and their few hairs have an unusually bristly look. They have five pairs of

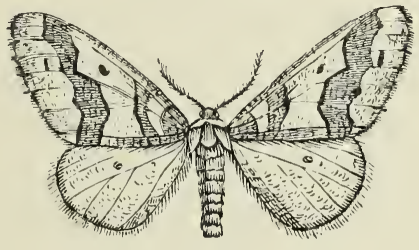

Male.

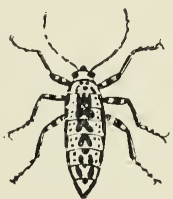

Female.

WINTER MOTH-THE MOTTLED UMBER.

membranous legs, and they are generally very agile, being able to advance and retreat with ease. Disliking the light, they remain hidden up, but they are always ready for any emergency which is likely to produce a fall. Their silk glands are well developed, and the caterpillars, like many others, use this secretion in order to prevent themselves from falling. The moths are very readily attracted by candles and lamps, and this peculiarity has caused them to be brought into association with the Greek word for fire. In England the peculiar lustre of the wings of some has caused them to be called "Pearls." Some of these Lepidoptera form cocoons before metamorphosis, and others, like some of the butterflies, hang themselves up by the tail, and place a silk band round the body before becoming pupæ. The group of the Pyralites contains a singular medley. One species of it was formerly considered to belong to another order of insects altogether, namely, the Neuroptera, or the Dragon Fly tribe. Others 
are classified by some naturalists amongst the Bombycina, which we have already noticed, and in one small family, the Hydrocampida, the caterpillars live in the water, and undergo their metamorphosis there, one species of it being furnished with branchiæ ("fins"). The Meal Moth, Asopia farinalis, which is very common in houses, is a small moth with reddish-brown wings, with their centres patched with fawn or grey colours. Its caterpillar looks as if it were varnished, and has its membranous legs very slightly developed. It has the curious taste of disregarding the crisp leaves of the garden, and of liking pieces of straw or corn, or even animal matter. These insects undergo a regular metamorphosis inside little silken cocoons, and the moths have a rudimentary trunk, and do not take any nourishment. Another moth, the Tabby, Aglossa pinguinalis, is also found in houses and stables. The caterpillar is of a uniform dark brown, with its head and front legs of a darker tint, and it will have nothing whatever to do with the usual food of Lepidopterous larvæ. It has a fancy for greasy horse-cloths, and grease in any form; moreover, its structures are evidently suited for its love of fatty matters. The caterpillar sticks itself into the grease bodily, and without danger of being suffocated, for its spiracles are covered by folds of the outside skin, which prevent the grease and fat from blocking them up. It is always interesting and instructive to notice how Nature provides for the well-being and safety of living things existing under extraordinary circumstances, and it is important to remember that horse-cloths, grease, and kitchen fat are productions of a more or less recent civilisation, and that these moths obtained their peculiarities, which always descend generation after generation, after the invention of this greasy nastiness. They are either new species which have become evolved from others, which led different lives before horse-cloths were invented, or else they were specially created to relieve the world of much fat, and things we don't care about. Which of the two origins is the correct one must be left to the intelligence of all the good people who, if they are not very well qualified to give an opinion upon the origin of species, never hesitate to do it. 
The Bordered Pearls, the Mother of Pearls, the long-winged Pearls, and the small Magpie are well-known moths which belong to the genus Botys. They have long trunks and very pretty wings. The caterpillars are rather long and are extremely rapid in their movements. They twist up the leaves with a few silken threads and make safe hiding places, the small Magpie choosing the stinging nettle for its particular habitation. Its membranous legs are particularly adapted for walking on plain surfaces, but not for climbing. Everybody may recognise them, because when they are disturbed they wriggle about in the most extraordinary manner.

Of all the Lepidoptera the Hydrocampidce are perhaps the most extraordinary so far as their methods of life are concerned. The moths fly and enjoy the air as much as any others, and cannot be distinguished from those whose caterpillars live on dry land. Their breathing apparatus is like that of other moths, and they have the habits of the other night-flyers. But the caterpillars live in the water and respire in two manners. In some kinds of the Hydrocampida the caterpillars live in the water, surrounded by a great bubble of air, and others positively have gills or branchix, and are surrounded and bathed by water. This is a most extraordinary fact, for the moths which are produced by metamorphosis from these caterpillars, resemble each other to a great extent, and it shows how slight the distinction may be between aquatic and air-breathing animals, and how nearly the origin of the separate conditions may be allied. The gills are in the shape of filaments, like those of the larvæ of the caddis flies, but there is one kind (Paraponyx) whose larvæ have large branchiæ and also spiracles. Its pupa is found in a cocoon amongst leaves under water, but it does not appear at present certain how the moth gets out of the chrysalis case without drowning itself.

There is a common species in France which lives upon the pond weed. Whilst in the caterpillar state it cuts two pieces of leaf and fashions them so that they become oval in shape and nearly equal in size. It unites them by their margins, sewing them as it were with a little silk, and leaving an opening for its head and the first segments of the body. It drags this house about under water, but sometimes leaves it for a 
more lasting donicile. It then fixes a portion of a leaf in contact with the lower surface of some floating leaf, and remains inside this retreat for several days at a time. The larva often walks over the surface of the water weeds, and manages to supply its leafy house with fresh air. When the larva has attained its full growth, and is about to undergo the metamorphosis into the chrysalis, it closes its leafy retreat perfectly, having attached it first of all either to plants or stones close by its ordinary dwellingplace.

The small China Mark's caterpillar is long and has a very pale-coloured head. It lives underneath the leaves of duck weed, in the water, and protects itself in a cylindrical silk case covered with leaves. The chrysalis is found in this case, so that metamorphosis takes place in it. The moths differ very much, the male having its fore wings white, with a blackish central spot, and the hind wings white, with some irregular markings, and the female has pale brownish fore wings and clouded grey hind wings.

The caterpillars of some Galleride lead a very singular life. They are dull, whitish looking things, with dark spots and bristles. They make their way into bee hives and the nests of wild bees, but instead of eating the honey they devour the wax. They move through the honeycomb in galleries, which they line with silk, destroy many young bees by pressure, and undergo their metamorphosis in a white cocoon. The perfect insects appear in the summer months, hide by day, and endeavour to enter the hives by night, and finally lay eggs in the honeycomb. We have already noticed that the death's head moth enters hives and makes free with the honey, so that this caterpillar has Lcpidoptcrous companions and fellow thieves.

Curtis states that Ilythic colonella inhabits the nests of Humble Bees, the caterpillars living directly upon the young bees.

The Tortricina, as their name implies, are those moths whose caterpillars twist and fold up the margins of leaves so as to form shelters. Several species, however, do not fold up the leaves, but unite many of them together in bunches by means of silken threads; and there are some kinds that live inside seeds and buds, or in the roots and stems of plants. Ail these caterpillars have very much the same general appearance, although 
they lead very different lives. Their skin is shiny, soft, and frequently covered here and there with hairs which are exquisitely sensitive. They are of different colours; the green tints,

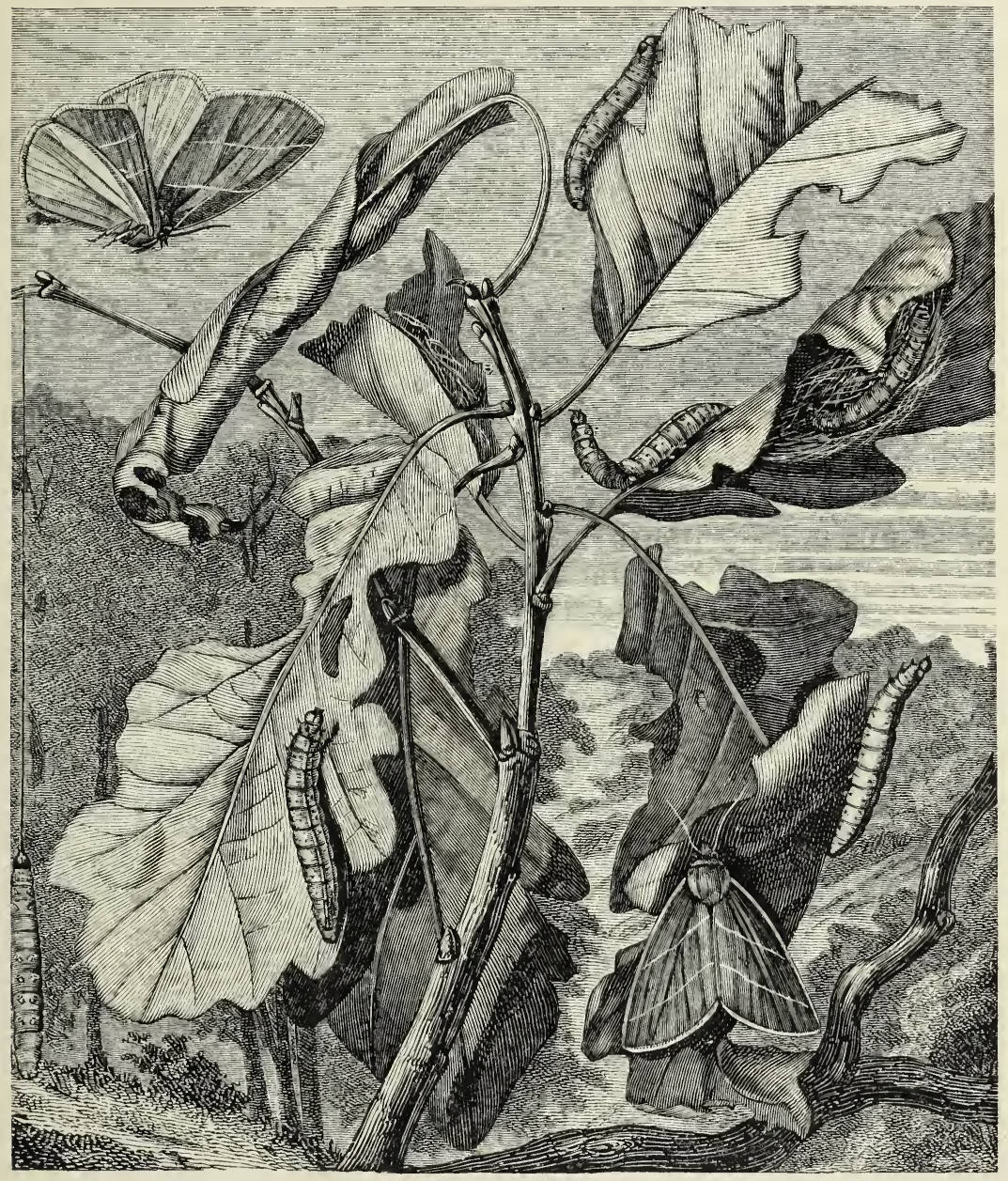

THE METAMORPIIOSIS OF Malias quercana.

however, predominate, and they are not perfectly white like those caterpillars that never see daylight. These Leaf Rollers usually undergo their metamorphoses in the tubes, folds, and packets of leaves which were formed by the caterpillars which shut up all the orifices with silken threads when they have attained their full 
growth; but some, especially those which live on fir trees, spin a cocoon. The moths have simple antennæ, a rudimentary trunk, obtuse palpi, and tolerably large wings. The largest moths of this group belong to the genus Halias, and their trunks are not so rudimentary as is usual; moreover, they may be distinguished by the bright green colour of their wings.

The Halias of the oak, Halias quercana, is the largest of the genus. The caterpillar is of a grey-green colour, and rolls up the leaves of the oak, and undergoes its metamorphosis in a cocoon, which it spins in the shape of a little boat turned upside down. The moth has two white bands upon its pretty bright green wings. Another kind, which is much smaller, is called the Green Tortrix. It does frightful mischief to oak trees, stripping them almost entirely of their leaves during the month of June. It rolls up the leaves in the shape of regular tubes, and undergoes its metamorphosis inside.

The moths are drawn in the engraving one flying and the other at rest. The caterpillars are shown in different conditions, and the rolled-up leaf contains the pupa.

Most of our vegetables are attacked by some caterpillars of this group, and the rose trees often suffer very much from them. One kind is very rare in England, but, unfortunately, is often so common in France that it produces great distress amongst those people that depend upon the cultivation of vineyards for their incomes. It is called Enectra pilleriana. In England Mr. Stainton finds the larva in the seeds of the stinking iris, near Ventnor, but it is rare; in France, however, it attacks vine leaves, and does infinite mischief. The moth, which is not very large, has yellowish wings, which are darker behind. Its palpi are three times as long as the head, and this is a remarkable peculiarity. The moths fly in the month of July, and soon lay their eggs on the top of the vine leaves, in little flat packets, which are very readily seen. During the month of August the little caterpillars are hatched, but they do not begin to eat, although the temperature is high, and there is abundance of food; on the contrary, each one hangs itself by a silken thread, waiting to be moved to and fro by the brecze, until it touches the wooden prop of the vine, or the 
stem of the plant itself. They then get rid of their silk, and enter the cracks of the wood, or beneath the bark, and hybernate until late in the spring; that is to say, they do not

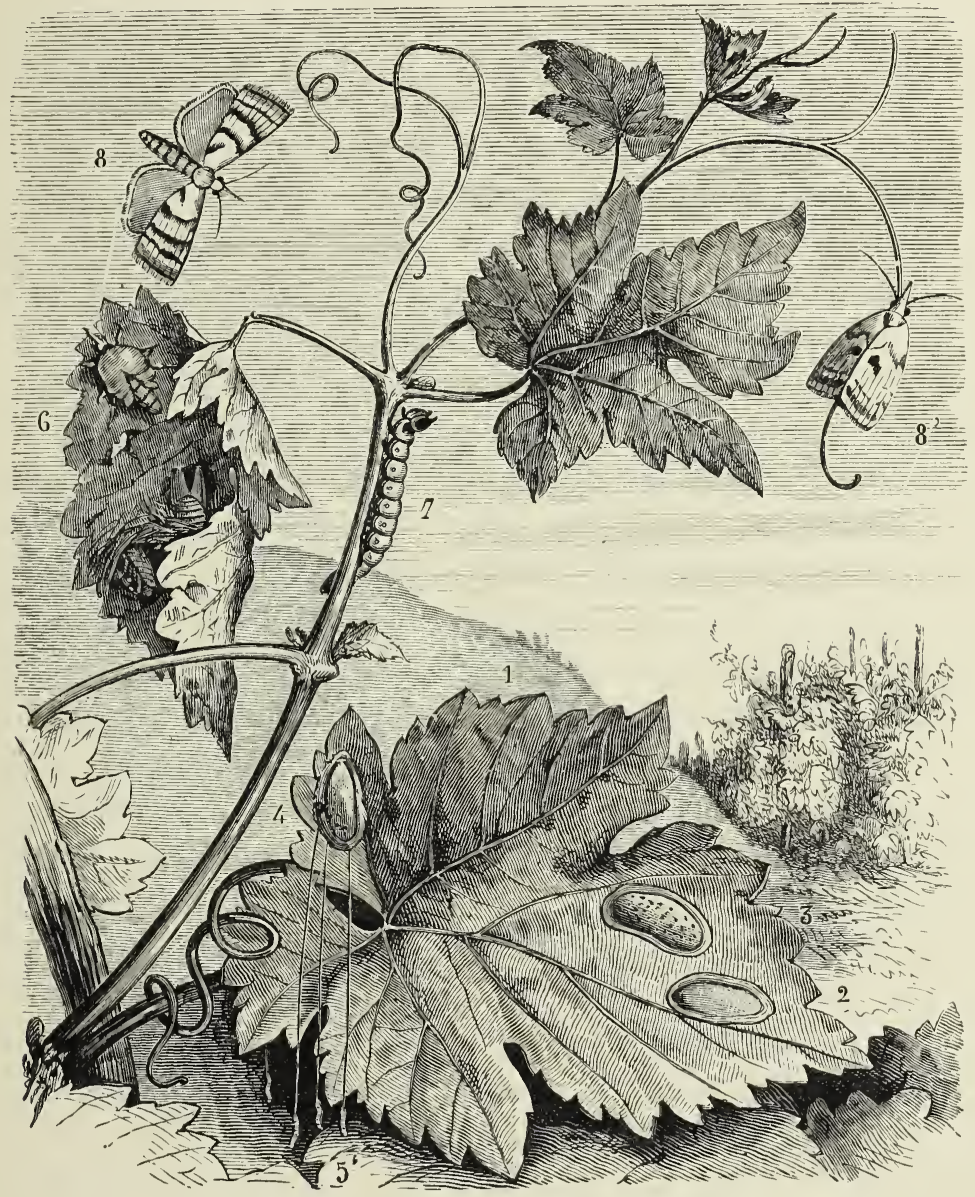

THE METAMORPHOSES OF THE VINE MOTH.

1, 2, 3, 4. Eggs on the leaf. 5. Young caterpillars hanging by their web. 6. Leaf with chrysalis. 7. Caterpillar. 8. Moths.

take any food, and remain in a sleepy and perfectly quiet state, without any metamorphosis; in fact, growth does not go on. When the hot weather commences, they climb up the tender shoots of the vine, and bind up the tiny leaves and 
minute bunches of grapes with their silken threads, uniting them in packets. The caterpillars having thus made a safe home, eat away in the inside, and they do so much harm in this manner that sometimes a whole vineyard is ruined in a few weeks. Towards the end of the last century much attention was paid by naturalists, in order to find a remedy, and to discover how these insects could be destroyed, but they came to no satisfactory conclusion. In I835 and I840 these caterpillars did so much harm in several departments that the French Government ordered Victor Audouin to examine into the question, and he wrote a very fine work upon the insects which are injurious to the vine. He showed that it was easy to destroy the eggs by removing the leaves, but he suggested that inasmuch as the young caterpillars always took refuge in the props and the upright shoots of the vine before they did any mischief, that these should all be burnt, or so heated that the caterpillars would be destroyed. The vines shot up in the next year, and the props contained no caterpillars, and from that time the great pest has hardly ever appeared.

Many years ago one of the moths which are so injurious to the vine became common in Savoy, and after a year or two the caterpillars began to do great mischief. The unfortunate farmers applied to the Archbishop, and requested him to curse the caterpillars, as they were doing a great deal of injury. The Archbishop, being a merciful man, did not think the insects were to blame, because they were only indulging in those habits which were necessary for their existence, and he also considered that they were sent as a punishment to the vineyard men, who had not paid up all their tithes. Consequently, he ordered the Bishop to open a court, where the farmers and the insects were to appear by counsel. A long trial took place, and a commission was ordered to inquire into the truth of the allegations of the farmers, but of course, whilst this was being done the caterpillars had metamorphosed, and the mischief was completed. Many years afterwards the moths and caterpillars re-appeared, and then the farmers proposed to set apart a particular plot of ground for the insects, which were to be under the charge of the Church, and petitioned that if they 
did this the Archbishop should curse the rest, and allow all those out of bounds to be destroyed. The Archbishop, considering that the Church gained a nice piece of ground by this transaction, willingly agreed to form a procession round the country, and to do the required cursing, after which, however the farmers were to do penance, and to pay up all their tithes.

The Tortricina which eat fruits principally belong to the Carpocapsida; one kind, Endopisa proximana, has a yellowish white caterpillar, which feeds upon the peas inside pea-pods; and the Carpocapsa pomonella loves the insides of apples and pears. When this caterpillar is full grown, it eats its way out of the fruit, and then spins a cocoon on some twig or other. The moth is very pretty, and its iron-grey wings are ornamented with brilliant copper-coloured streaks. The caterpillar is of a pinkish colour, and the second segment is pale yellowish brown. Many a plum pie contains the pale red larva of a closely allied kind, and others may be found even in acorns and beech-nuts. One species, Carpocapsa splendana, lives in the edible chesnut. Some of the caterpillars of these fruiteaters move very actively in the insides of the seeds or fruits they are devouring. M. Lucas had some large Euphorbia seeds, which came from Mexico, and which, when exposed to gentle heat, jumped up a few lines into the air. It was difficult to account for this, but it was found that the movements were produced by the caterpillar inside jumping about. Some of the same group choose very different food, and one caterpillar feeds within a hollow resinous exudation from the branches of firtrees; another, which is very common everywhere, feeds on almost any plant. This caterpillar is of a dull olive green colour, with a pale brown head, and is very sluggish. When it is disturbed it does not attempt to run away, or to fall down, hanging on with its silken thread, but curls itself up like a ball, and shams being dead, and trusts to circumstances.

The Tineina are the smallest of the small amongst the Lepidopterc, and they are, perhaps, the most eccentric in their habits of life and peculiarities. The perfect insects have narrow wings, bordered with a long silken fringe, and long palpi. The 
larvæ, according to Mr. Stainton, who has made this group his especial study, vary excessively in the number of legs; sixteen is the usual number, but in several genera fourteen only are found; in the genus Hepticula they number eighteen, and on the other hand, some other larvæ are legless or apodal. The habits of the larvæ vary also; some feed in the open air, others in rolled up leaves, others are miners, some case bearers, and some feed upon clothes, or on the lining of sofas. (Stainton.)

Many naturalists have observed that the species of Solenobia, one of the Tincida, have a most exceptional power of reproduction. The maiden females of the genus lay eggs which can be hatched so as to produce larvæ, and a naturalist may breed a species for years without seeing a male Solenobia. This extraordinary fact is not without parallel amongst the Lepidoptera, as will be noticed at the end of this chapter, and it is common amongst the bees and Aphides, or plant-lice.

Many of the Tineide do a great deal of mischief in houses, to clothes, carpets, household stuffs, and feathers ; for the larvæ, which have soft integuments, have the instinct to clothe themselves artistically, but at our expense. Tinea tapetzella is one of the most destructive species, for the little caterpillar constructs a protecting tube, which is almost cylindrical in shape, out of the fibres and small pieces of the stuff it delights to gnaw. As the caterpillar grows the case becomes too small, so the insect enlarges its home by adding some threads to both of the ends, and a very harlequin appearance may be given to the tube if differently coloured stuffs are placed in the way of the little tube-maker from time to time. The caterpillar closes one end of the case, and hangs it up before becoming metamorphosed into a chrysalis; but the insect turns in the tube before the transformation, and keeps its head turned towards the open and unattached termination. The moth comes out, therefore, easily enough.

Tinea pellionella makes a case with silk and small pieces of hair or fur all cut to the same size, and does a great deal of mischief to furriers' stores; and Tinca crinclla attacks skins, feathers, and horse-hair, doing an infinitude of harm to furniture.

There is a Tinea that lives in cereals when the grain is stored 
in granaries, and it unites several seeds together with a pure white silk, and lives in the midst as in a case. Its house, however, it devours.

Alucita porectella is found in gardens, and its beautiful networked cocoon is hidden within curled-up leaves or underneath

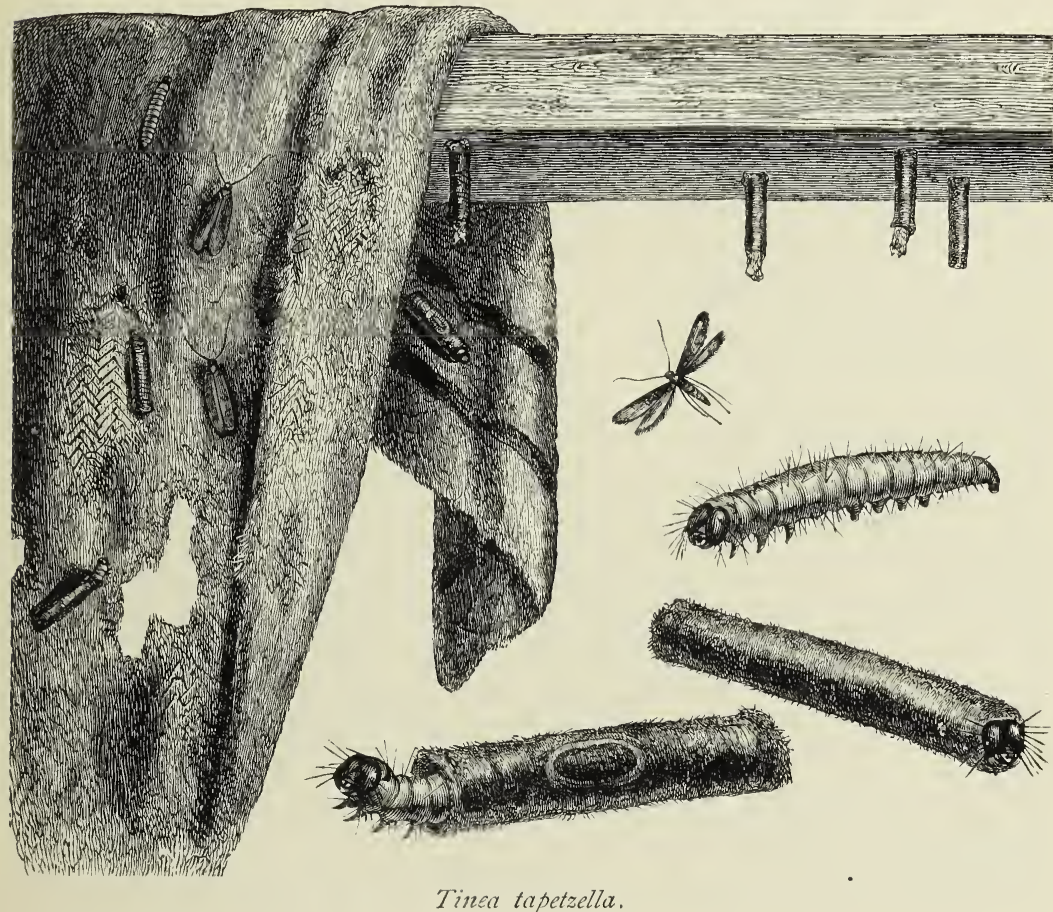

A rug attacked by the caterpillars. Cases suspended on the beam before the metamorphosis into the chrysalis state. The moth, the size of life. A caterpillar out of its case and magnified. Caterpillars and their cases magnified.

them, but the Brazilian species spin most elaborate, perfect, and regular network cocoons, of violet or red-coloured silk, which makes them very distinct and visible.

There are some species of Tineida which represent the habits of the larvæ of the Psyches amongst the Bombycida, and they are called the Coleophora. The moths hide themselves in trees during the day-time, and are nocturnal in their habits. They appear in July, and the eggs being laid and the caterpillars hatched, these last 
pierce into a leaf or a seed, and begin to mine. After a while, and when the caterpillars have grown to a certain size, they leave their solitary mine, eat through the skin of the leaf, and appear on the surface. They divide the leaf, and sew one part on to another, and make themselves a comfortable tube. So readily do these caterpillars make a protecting case, that they do not care

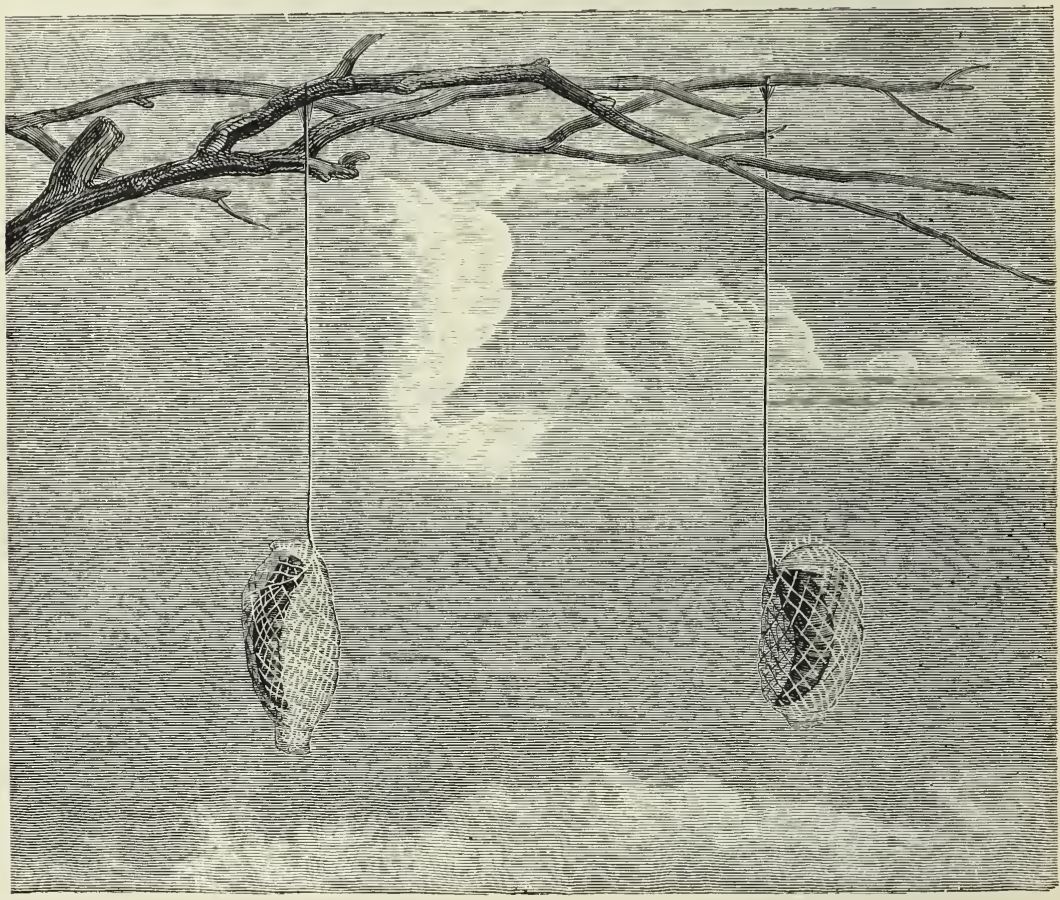

COCOONS OF BRAZILIAN TZ̈nema.

much about repairing old ones, or enlarging their small homes; on the contrary, they leave the old and take refuge in new leafy houses very constantly, after having eaten the best part of the former. Some eat grain, and, after having cleared out the interior of one, find in the skin a most convenient case.

The last segment of the abdomen of the caterpillars of the Colcophore is horny, and so is the second of the body, for this hardness of structure is much required by case-bearing insects, on account of the friction and pressure of the two ends of the tube. The pupre 
being enclosed in the larva case are not ordinarily seen; but, when they are examined, it is observed that the sheaths of the antennæ are rather prominent, and that sometimes the ends of the wing cases are detached from the body. The case of the larva

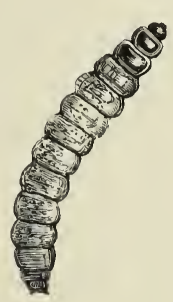

LARVA OF Coleophora juncicolilla.

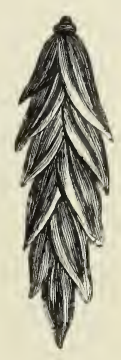

LARVA CASE. (After Stainton.)

of Colcophora juncicolella puts one in mind of that of Gelechia and Psyche, for it is formed of several heath leaves, which are attached on alternate sides to the number of seven or nine. This case, which is firmly spun together with silk, is then attached to the

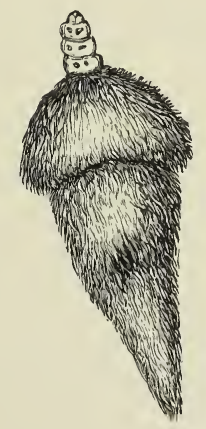

LARVA CASE OF Coleophora lineola. (After Stainton.)

under side of a heath leaf, and the larva bores into the interior of the leaf, devouring all the green pulpy portion, except a very little piece at the tip.

The larva of another Coleophora mines the leaves of several delicate plants in September, and makes whitey-brown, and rather glossy-looking blotches on the leaves. As soon as it has mined a sufficient space, it cuts out the mined place to form a case, and 
from the hairy nature of the leaf and the diamond shape of the excision the case has a very comical appearance.

Some of the dry calyxes of the common Marjoram are often found fastened together lengthwise when the plant is going out of bloom, and a careful examination proves that they have been formed into the case of a caterpillar. The whitish larva of Gelechic subocella may be seen to poke its pale brown head out of the end of this pretty refuge. The larva feeds on the seeds of the plant, and when it has eaten the contents of one flower it bites off the dry calyx, and using it as a case proceeds to another flower, and places the movable calyx in the opening of that which is fixed, the seeds of which

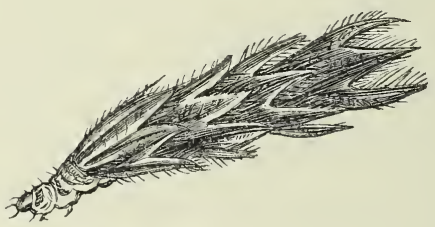

THE LARVA OF Gelechia subocella IN ITS CASE OF ORIGANUM FLOWERS. (After Stainton).

it then demolishes. When the supply is exhausted, the caterpillar bites off the second calyx, and moves off to a third, and thus the flowery case gradually increases in length till it consists of the husks of four or five flowers. When the caterpillar has done with eating and flower-destroying, it attaches this singular home either to the dried flower seed or to the stem of the plant, or to some neighbouring object, and undergoes metamorphosis.*

The yellowish green caterpillar of another Gelechia (Gelechia marmora) injures the roots of the Cerastium, which grows on the sand-hills near the coast, and forms little tubes of sand fastened together with silk. The caterpillar having constructed this peculiar home, attacks the leaves which are trailing on the ground, leaving the case, and returning, before moving off, to plunder some more distant plant. The larva is almost subter-

* Stainton, "Natural History of the Tineina," vol. x., part ii., p. 290. 
ranean in its habits, and may be collected in great quantities in March and April. All the moths of the genus Gelechia are exceedingly quick and active in their movements; at rest one moment, the next they have flown away with extreme rapidity; even without the use of their wings, they run away from the unwary collector. Many species are seen freely on the wing, arising in front, and settling a few paces in advance, and others lead a retired life. Some are met with in the perfect state during a considerable time, and there are two broods in the year of several kinds of the genus. Hybernation occurs but rarely. The larvæ, with sixteen legs, are generally active, and when crawling often raise the head with a peculiar tremulous movement. The greater number of them live in the buds and shoots of plants, or between curled leaves; two species feed in grass leaves rolled into a tubular form; many mine in the leaves of plants, and others eat inside the seeds and stems. The Gelechia of the Origanum mimics the habits of the Coleophora.

The caterpillars of the genus Gracillaria have only fourteen legs, like those of Lithocolletis, and one species undergoes a total change of colour, from pale green to crimson, when about to assume the pupa state. This Gracillaria omissella mines the leaves of the Artemisia vulgaris, loosens large portions of the lower cuticle, and causes them to assume a bladdery appearance. All the larvæ of the genus are miners at first, and some remain so always, whilst a few discontinue this method of life, and proceed to roll up leaves instead. Most of the rollers form conical structures upon leaves; and Gracillaria auroguttella, which feeds upon the Hypericum perforatum, may be taken as an example of a very elaborate cone maker. It commences by mining a narrow strip, which puckers the leaf longitudinally, and then soon quits the mine and constructs its cone. The cone is formed by turning the tip of the leaf downwards, and so applying it to the under surface that the entire leaf is converted into a hollow space, with the edges fitting neatly. The form which the leaf then assumes is nearly that of a double cone (the cones united at their bases), and in it the larva proceeds to devour the under surface. When the interior of the cone is eaten up the caterpillar moves off to another leaf, and thus many rolled 
leaves, each containing a piece of the excrement of the caterpillar, are left upon the tree for a short time. When the caterpillar has attained its full growth it rolls up a leaf longitudinally into a light tube, spins its cocoon, and changes into the pupa. There are two broods in the year.

The pupæ of the genus Nepticula have the parts of the future insect far more conspicuously displayed than is usual in the chrysalides of the Lepidoptera; and Nepticula anomalella may be found in the hollow of the footstalk of the rose leaf which the caterpillar has marked with serpentine tracks in the later weeks of the summer. It is contained in an elliptical reddish silken cocoon.

The perfect insect lays its eggs on the under surface of the rose leaf, close to the mid-rib, and the larva, when hatched, bores into the cellular structures, and commences an irregular wavy gallery. When fully formed the larva splits the upper skin of the leaf, and creeps out; and if it be one of the summer brood it proceeds to the leaf stalk, and there spins an orange coloured cocoon, which is of rather peculiar structure; for the side exposed to the weather has a sort of outer covering which projects beyond the limits of the true cocoon, serving as a protection against the wet. If the larva be of the autumnal brood, it very rarely seeks the foot-stalk, but attaches itself to the main stem of the rose bush, beneath the shelter of some branch or thorn, or else it seeks shelter on the ground amongst leaves. After completing the cocoon, the metamorphosis into the chrysalis takes place, and the second transformation occurs in a fortnight or three weeks in summer, and in six or seven months in winter and spring.

Some of the mining genera of the Tineina undergo very rapid transformations, and the kinds of Lithocolletis which fly in July and September offer examples. They are very small moths, with hairy heads and straight and pendent palpi, and their wings, which are of different colours, are frequently ornamented with spots looking like gold or silver, and have beautiful fringes. Moreover, the antennæ, which are like slender threads of silk, are kept in constant movement. There are at least a hundred species of this genus, and each one lives upon some particular plant; but 
unfortunately very little is known concerning their metamorphosis. The honeysuckle is devoured by two sets of Lithocolletis caterpillars every year, in the spring-time and at the end of summer. A small moth with yellowish brown wings, ornamented with white bands and spots, and bordered with a fine and long silky fringe,

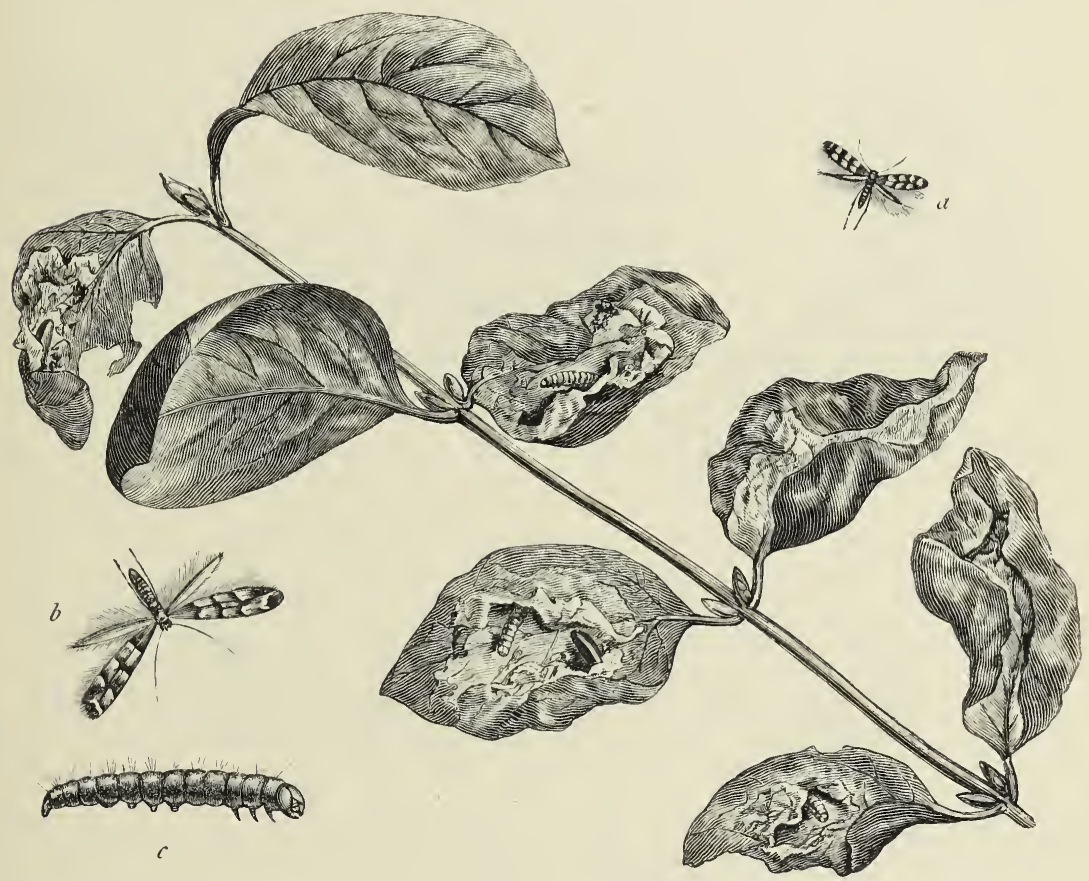

A BRANCH OF HONEYSUCKLE, THE LEAVES OF WHICH ARE OCCUPIED BY THE MINING CATERPILLARS OF Lithocolletis.

Lithocolletis emberizapennella.

$a$. Moth natural size. $b$. Moth magnified. $c$. A caterpillar magnified.

may be seen upon the hedges where the wild honeysuckles grow. About those times of the year the caterpillar of this pretty moth mines the leaves of the honeysuckle from their lower surface, and eats the cellular structures. The leaf very soon begins to twist irregularly, and if it is straightened the skin of it breaks, and the little pale, greenish, semi-transparent caterpillar comes out or recedes, showing great agitation. It is blanched, like many other animals that pass their lives out of 
the light. It does not quit the leaf which nourishes it, but when about to undergo the change into the chrysalis state a thick silken cocoon is spun, which is usually of a dark green colour, and the metamorphosis proceeds.

The tiny caterpillars of this mining insect with such a very long name may be seen in different positions on the leaves of
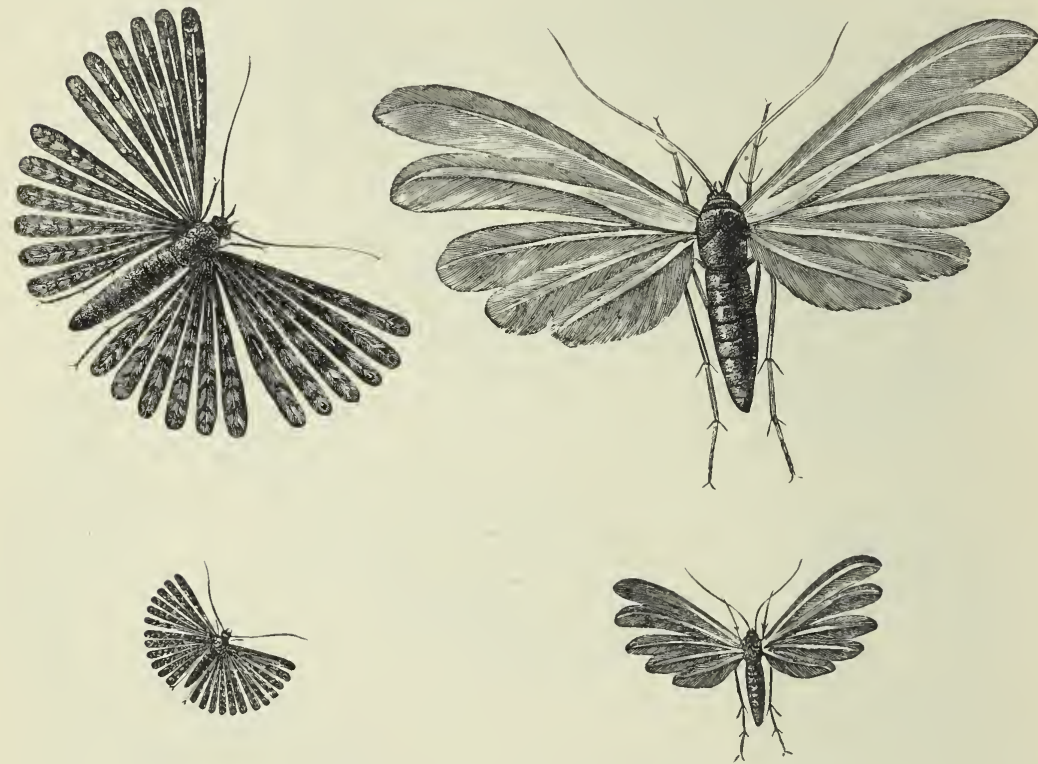

Orneodes hexadactylus. Pterophorus pentadactylus.

(Natural size, and magnified.)

the plant engraved on page I53. The cuticle has been broken so as to show the larvæ and in one leaf the pupa.

Two genera-Pterophons and Orneodes-of the great tribe of the Tincina require to be noticed on account of the singular conformation of their wings. The organs of flight appear to have suffered a singular amount of degradation, so far as their development is concerned, in these little insects, but they are nevertheless exquisitely delicate and peculiar, for the wings are divided longitudinally into several branches, and each of these is furnished with a long fringe of wonderful silkiness, so that the appearance is presented of pretty little plumes of 
feathers of microscopic size. The Pterophora have the first pair of wings divided into two and the second pair into three portions. These insects have also a long trunk and long hind legs, which are furnished with spines. They have a peculiar sort of flight, jerking about here and there, and some of them are called ghosts by country people. The white Pterophorus, which is called pentadactylus, because the wings are in five divisions, is perfectly white in colour, and flies about hedges and banks, with the dark-coloured leaves of which it forms a striking contrast in the eventide. The caterpillar, which is marked with green, white, and yellow rays, lives upon the bindweed, and hangs itself up when about to undergo metamorphosis into a chrysalis by a silken girdle, in the same manner as the cabbage caterpillars.

The Orneodes have their wings, as may be seen in the engraving, very differently arranged to the species of Pteroplorus, for each one presents the appearance of six small but beautifully fringed feathers, and there being twelve on each side the insect really has twenty-four of them. When the moth alights, or is disposed to be quiet, it folds up these pretty feathery wings, just as if they were portions of a fan. The moths have no trunks, and they deposit their eggs here and there upon the flowers of the honeysuckle.

The small caterpillar crawls inside the calyx and eats it from within, and when it has attained its full growth spins a small cocoon.

The silkworm moth's metamorphoses are so well known that they may be conveniently considered as the normal or usual phenomena with which to compare those of all other Chalinoptera. The transformation into the chrysalis state during the summer, and the rapid metamorphosis into the moth, appear necessary, in order that the eggs should be laid so as to be hatched on the first appearance of the leaves in the next spring. The delicate moth could not hybernate, and the chrysalis could not live in its cocoon all through the winter like those of many other genera. So the silkworm embryos in the egg have a long time 
of incubation; but in some species closely allied to the silkworm two or three broods are obtained every year, and the embryonic state is then very short.

How different to this metamorphosis is that of the Sesia apiformis, the caterpillar of which lives for two years, and then changes into a chrysalis which has some power of progression; and how different is the physical condition of the perfect Sesia to the slow-moving Bombyx. The goat moth larva, like its fellow treedweller the Sesia, has a long life, and is metamorphosed into a more or less active chrysalis, and these long-living caterpillars change their skins during growth, but no essential difference is noticed as regards their ornamentation during the successive moults. All the supposed causes of the metamorphosis into the chrysalis state act over and over again upon these long-lived caterpillars, and cold winter, genial spring, and hot summer, succeed each other without the change taking place.

The hybernation of such caterpillars as those of Enectra pilleriana and Lasiocampa quercils, which go into hiding immediately after hatching, proves that there is something more required to produce the metamorphosis besides want of food and heat. The hybernation of well-fed caterpillars, like those of the Anthrocera already mentioned, must be considered with these proofs that metamorphosis is not a condition to be determined by simple physical influences, but that it often refers back to ancestral peculiarities. The cocoon making and burying in the height of the warm weather, when placed in relation with the occurrence of two or more broods during the season, in some closely allied species, the last being hatched late, are incomprehensible on the simple explanation that the silken and stony shelters are absolutely required for the preservation of the insect during its longer or shorter inclusion. The case of the Reapers -which undergo metamorphosis both in summer and in autumn-. is complicated by the fact that the last brood, if it is very late, hybernate as caterpillars, and not in their admirably protected natural shelters. Here is a direct proof that something more than cold and absence of food is required to determine the first metamorphosis of the Lcpidoptera, and that it cannot take place until the development of the caterpillar has advanced to 
a certain and definite stage-that stage being determined by hereditary peculiarities.

The metamorphoses of the Hydrocampide are very interesting, on account of the extraordinary change which occurs in the condition of life between a swimming larva and a gay moth, to which water is almost certain death. The examples of the corresponding transformations of the gaily-coloured flies that lead aquatic existences in the larva state naturally rise up before us, as also do the Zö̈a of the crustaceans, and all these peculiarly allied forms become more strongly than ever united in a common ancestry.
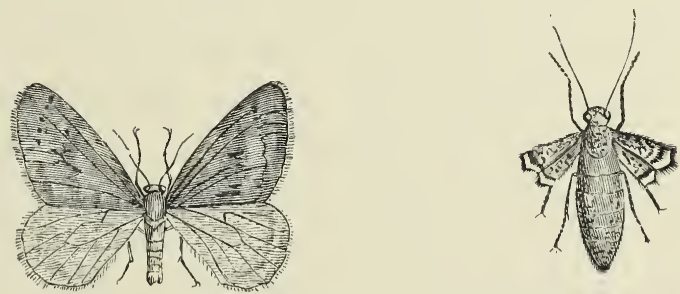

FEMAEE AND MALE MOTHS OF Climatobia brumata.

Retrograde metamorphosis, that is, a transformation which, when completed, leaves the insect less elaborately organised than before, is observed in the females of Psyche and Orgyia, and several other genera. The female of the Winter Moth has no wings developed, that of Climatobia brumata has very small wings, and Psyche is not much more than an egg-bag, not having even the locomotive power of the caterpillar. Why the male should undergo a progressive metamorphosis, and receive additional organs in the usual manner, and why the female, on the contrary, should positively retrograde in its evolution, is impossible of explanation at present. There is no evidence to prove that a difference exists in the caterpillars which turn eventually to the male and female moths, and all of them partake of the same kind of food. The legless and wingless females of Psyche are, perhaps, more retrograde than those of Orgyia. The females of Fumea and Hibernia have legs and antennæ, and, therefore, their development is in excess of that of Psyche.

It has been mentioned that the females of a genus of the 
Tineina have that power of reproduction which dispenses with the male for many generations. The maiden females of Solenobia lay eggs which are fertile, and a succession of broods may occur without a male ever being seen. This method is sometimes called "parthenogenesis."

The celebrated German naturalist, Von Siebold, examined into this question, and his work was translated by W. S. Dallas, in I 857. Von Siebold collected a great number of the cases, or sacs, as he calls them, of Solenobia lichenella and Solenobia triquetrella, and to his great astonishment none but female individuals came out of them, and only a single locality furnished him with a couple of males. He kept these females carefully in little vessels closed with glass lids, and found that they clung to their cases, resting upon the outside of them. These virgin females laid eggs and filled their sacs with them, and did not wait for any fertilising male, for they commenced egg-laying very soon after they escaped from the pupa case, or the chrysalis condition. When the Solenobice were removed from their sacs, they had such a violent impulse to lay, that they pushed their laying-tube about in search of the surface of the sac, and at last let their eggs fall openly. He writes: "If I had wondered at the zeal for oviposition in these husbandless Solenobia, how was I astonished when all the eggs of these females, of whose virgin state I was most positively convinced, gave birth to young caterpillars, which looked about with the greatest assiduity in search of materials for the manufacture of little sacs." He thought that this egg-laying might be a similar phenomena to that of the birth of successive generations of Aphides from the internal budding of sexless individuals; but on examining several of the Solenobice, they proved to be perfectly-developed females. A similar laying of fertile eggs by a virgin of the species Psyche helix is noticed and carefully explained by Von Siebold. He states: "The two species of sacbearers just mentioned are not, however, the only representatives of the true parthenogenesis; an equally striking example of the virgin reproduction of a female insect is presented by Psyche helix. Of this remarkable moth we are at present only certainly acquainted with the female. In the caterpillar state it lives in a sac which in its form resembles a sinistral (turning to the left) 
snail-shell, to which similarity the specific name given by me to this Psyche also refers." The body of the caterpillar which makes this twisted case is also curved spirally, and it leaves an opening in the hinder whorls of the sac. The female moth lays its eggs inside this sac, which it occupied as caterpillar and pupa, and having spun down the front opening, leaves the dwelling by the other opening, which is large enough for its shrivelled, eggless body. Von Siebold proceeds: "These sac-bearers are leafminers, and push their bodies far in between the epidermic plates of the leaves through a round hole which they gnaw in the latter, and devour the green colouring-matter. During this process the sac remains outside, sticking with its aperture to the opening in the epidermis. The leaves, and even the variegated flowers, are in this way often completly decolourised by the sac-bearers." "When these sac-bearers are full-grown-which is the case in the latter part of the summer-they quit the plants they have been feeding upon, like the other caterpillars of the genus, and seek a suitable place for the change into the pupa state. When they find stone walls or rocks in their vicinity, they creep high up on them, and spin down the lower aperture of their dwelling firmly. In passing through the process of moulting, also, these caterpillars, like all other sacbearers, always spin down their habitation temporarily. The evolution of the moth takes place in the same year. If after some time we examine the spun-down sac of a Psyche helix during its chrysalis state, we find the pupa in the lower twist or whorl of the case, with its head directed upwards and its tail-end downwards, towards the last aperture. Between this and the tail-end of the pupa the shrivelled skin of the caterpillar, stripped off in its last change, is always fixed, so that this caterpillar, like all those of the Psychide, turns itself round in the sac before true pupation. In all the sacs of Psyche helix in the pupa state hitherto examined by me, of which I have had the opportunity of observing more than a hundred and fifty in seven years, I never found any but a female pupa. This is of a yellowish brown colour, and with very indistinct segments." "The wingless and almost footless female moth which is evolved from this pupa also appears slightly curved in a spiral. Its colour is grey, with a slight brown tint on the back of the three thoracic segments. The head has no antennæ, 
the rudiments of a mouth are found, and of two eyes without facets. The movements of these admirable examples of retrograde metamorphosis-and how slightly they resemble the well-developed Lepidoptera!-are extremely sluggish, and the six little feet of the thoracic segments, which are in the form of very short conical processes, scarcely take any part in them. A dissection proved these moths to be true females. They deposited their yellowish eggs in the empty pupa case which in Psyche always remains behind in the caterpillar sac; they then shrivelled up to a very small volume, when they generally left the sac by the abovementioned side aperture, and soon afterwards died." Von Siebold proceeds in the description of this strange case as follows:- "The unfertilised eggs concealed in the pupa case are also developed in the same year. If a spun-down sac of Psyche helix be opened in the latter part of the autumn, or in winter, we always find from ten to twenty-four young reddish-grey caterpillars in the interior of the pupa case." No other method of reproduction but by virgin females, and without the influence of the male, was witnessed in this Psyche by Von Siebold.

Heroldt described the changes which go on in the young silkworm within the eggs laid by unfertilised female moths, and found that development proceeded all the same; and Von Siebold acknowledges that the silkworm can be raised occasionally from unfecundated eggs.

Other observers have decided that the tiger and other moths can be thus reproduced, but the above instances must suffice to show the extraordinary method of reproduction amongst the Lcpidoptera, which is of such great importance amongst the bee tribe.

The alterations in the external structures of some genera during successive moultings of the skin have been pointed out. Thus in Hadena oleracea, the caterpiliar has different colours when old to those which ornamented it during the early part of its life, and the "Forked Tail" undergoes alterations in colour during the skin casting process. Attacus cecropice submits to corresponding changes in its tints. It is thus necessary to consider the moulting periods as most important epochs in the evolution of the Lepidoptera, although the marked stages of meta- 
morphoses appear to eclipse everything else which may have to do with the progressive and systematic development. The embryonic life, or that within the egg, the moults, and the first and second metamorphoses, are then the more or less important and marked stages in the evolution of the lepidopterous insects. Some caterpillars do not assume, either at first or at all, a perfect larval condition, and then the embryonic stage has been less complete than usual. Thus the caterpillars of the Cochliopodide are legless; and this state of things is not restricted to that genus. In other instances the larvæ, when hatched, present evidences of advanced development, and in one genus the pupa appears to be far advanced towards the future condition. The extraordinary variety of the shape and colour of the caterpillars of the Noctuina, and the identity of the moths have been noticed; but the study of the phenomena repays, for it adds to our conception of the mysteries of the metamorphosis.

It is interesting to note the structural relations between those Lepidoptera which have a scanty supply of wing scales and the Hymenoptera, and to observe the curious mimicry of shape and tints which then prevails.

The metamorphoses of the Lepidoptera may be classified, for the sake of convenience, as follows: complete, incomplete, and retrograde. The duration of the stages, however, differs, and necessitates a second scheme. The metamorphosis takes place once in the year, and the eggs remain unhatched until the spring, - a long embryonic stage-the other stages being short. The metamorphosis takes place twice or more in the year, and the eggs of the last brood remain through the winter and into spring. Here the embryonic stage differs in length. The metamorphosis may not be completed in the summer and autumn, and the chrysalis lives as such through the winter and into the early summer. The caterpillar may hybernate, and the metamorphosis may take place early in the year; or the caterpillar stage may last more than a year. It is perfectly evident that closely allied Lepidoptera have different forms of metamcrphosis, and that the phenomenon has been acquired in accordance with a law. 


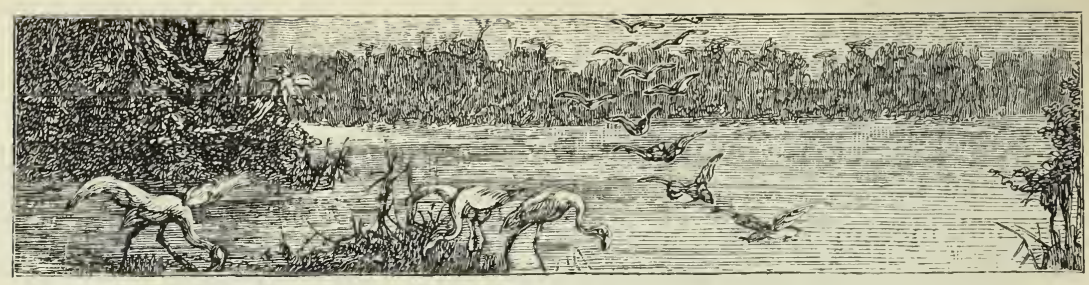

\section{CHAPTER VI.}

THE HY MENOPTER $\Lambda$.

However much we may become interested in the habits, structures, and metamorphoses of other insects, there is always a sense of satisfaction in studying the Hymenoptera. The infinitely numerous insects which are classified under this important order are not celebrated for great elegance of shape, magnificent colours, and elaborate ornamentation, and they are usually small in size, and modest in their decoration. Some, it is true, are brilliant enough, but this is very exceptional, and they never attain a large size.

When the Hymenoptcra are examined no one expects to meet with unusual beauties; but the interest they convey is far higher in its origin than that of simple decoration. The butterfly is admired on account of the richness of its colours, its elegant shape, and the magnificent wings; and a beetle is attractive on account of the dazzling brilliancy of its elytra, which may resemble the most lustrous metals or the finest jewels. But the butterfly and the beetle, which revel in all the decorative wealth of nature, lead useless and apparently purposeless lives, and their external beauty is their sole attraction.

The hymenopterous insect pillages the flowers; it has quiet tints and sombre colours; and its form and shape are simple in the extreme. This insect, which has no very elaborate ornamentation to make it attractive, soon commends itself to the close observer, whose delight in the tiny thing increases to a sense of great admiration, as its agile movements, indefatigable perseverance, and independent spirit gradually unveil themselves. What 
a wonderful contrast there is between the gaudy butterfly or the magnificent Buprestis beetle, and the bee! In the one case there is an existence of decorated idleness, and in the other a modest exterior enhances the charms of a laborious life, in which all the resources of the highest instinct are combined to a common end. Contrasts of this kind are not uncommon in Nature, and are not restricted to families, but are to be noticed in species, and even amongst individuals. There is a great amount of uniformity in the shapes, the physiology, and in the phases of the development of the Lepidoptera, and also in their methods of life and instincts. There are no grand differences, although there is an infinitude of peculiarities.

But the distinctions between the principal types or kinds of the Hymenoptera are most striking. These insects, when perfect, usually feed upon vegetable matters, but during their larval condition some live upon plants, and others remain within excrescences which they produce upon the leaves, roots, and stems of trees. Many larvæ are absolutely carnivorous, and live within the bodies of all kinds of insects; whilst a vast number are provided for by their parents, and receive, as legacies, either a living thing to be fed upon, or a delicacy composed of honey and the pollen of flowers. There is every possible variety of food, and every imaginable method of life.

The hymenopterous larvæ differ amongst themselves in their conformation and in their development. Those of an entire family are hatched sufficiently well developed to take care of themselves; they live in full daylight, and can walk, so that they may be compared to caterpillars. But others pass a hidden existence, beyond the help of the outside world, because they must live in the place where the eggs out of which they have come were deposited, and, indeed, they never care to wander. There are some kinds which are so ill-developed that they have no means of locomotion, and cannot even take their food themselves, so that they require mothers, or a staff of nurses gifted with industry and sufficient intelligence to find a safe place and plenty of proper nourishment for their charges.

Many Hymenoptera-unlike almost all the other insects never abandon their eggs, and the love of their offspring has been 
implanted in them by Nature. This obligation could not exist without bringing with it the necessity for, and the desire of, labour; without exciting maternal love, and many instincts verging upon reason. The smallest amount of intelligence requires a very perfect organisation for its production, and so does a high order of instinct. Mechanical appliances, implements, tools, and industry are requisite to produce good work, and they are only given by Nature to those creatures which are intelligent enough to use them.

The Hymenoptera are the most highly endowed of all insects, yet they often live for a time in apparently most miserable conditions; and parallel instances are not uncommon in the vertebrate animal kingdom-for the most gifted birds can only at first exist, thanks to their parents; but many less favoured kinds, like the gallinaceous birds, for instance, run about and take care of themselves soon after they escape from the egg.

In spite of the great differences which exist between the principal types of the order now under consideration-differences in the shape and external character of the larvæ and the adults ; differences in the internal organisation; differences in the progress of development, in the kind of life, in the diet, and in the condition of existence of the species-all the insects of this great zoological division have common characters, which are readily distinguishable.

The Hymenoptera have four membranous wings (whence their name- $v \mu \eta v$, membrane; $\pi \tau \epsilon \rho o v$, wing), which are free from scales, and they are marked with more or less numerous nervures, which usually do not form a reticulation. The wings, which are rather small in relation to the bulk of the body, are usually perfectly transparent. Sometimes they have a violet hue; but more frequently they are dusky in colour. The wings characterise the Hymenoptera; and the ancients called them-as the moderns do"flies with four wings."

These insects have stoutly formed heads, and very large eyes upon the sides of them. Usually there are three ocelli on the forehead. The antennæ differ in their general structure, even amongst the species of a genus, and, as might be anticipated, in families also. Their mouths are formed for nibbling or crushing, and also for suction. All the structures are free, and are more 
or less well developed. The mandibles are always strong, but differ much in form, according to the habits of the species. The jaws and the lower lip, which are usually rather short, elongate in some kinds which pump up honey, and they then form a kind of trunk, which is doubled up against the thorax when it is not wanted. The thorax is swollen out, as it were, and its integument is solid and dense, like a cuirass; and the muscles which produce the movements of the wings, and which are attached to it within, are very large and strong. The legs have moderate powers; and, although these insects are better able to walk than the Lepidoptera, still they cannot be called, in comparison with others, either walking or jumping insects. Their best means of locomotion are their wings; and the insects fully understand this, for even when they have to walk a short distance the wings assist the legs, and help the not very heavy body to move along. The only Hymenoptera that can be called true walkers are those that have no wings, like the neuter ants, and their agility is very wonderful. The legs are often provided with accessory structures, and are, moreover, modified so as to enable certain species to live particular lives.

Most of these insects have a very movable abdomen attached to the thorax by a very narrow waist, which is notoriously small, in the wasp tribe for instance. The females have a long and slender tube at the end of the abdomen, which is of great importance to them, either as an ovipositor or as a sting. The weapon of offence is invariably formed by the same kind of structures in all insects that possess it, and Lacaze Duthiers has discovered it in a rudimentary condition even amongst the Lepidoptera. These structures are modified in various manners, but the same end is always kept in view, and the resulting organ is of the greatest importance.

The Hymenoptera undergo complete metamorphoses. Some larvæ are usually soft and white, and, as they have no legs, they look like worms; but some exceptional kinds have small fore and hind legs like caterpillars. Almost all the larvæ, when they have attained their full growth, shut themselves up in a cocoon, which they make up with the silken stuff they are able to produce, and then are transformed into pupæ. 
The principal divisions of the Hymenoptera are readily distinguished by characteristic species, so that their classification is comparatively simple, and some remarkable habits which are prevalent amongst some peculiarly constructed kinds appear to have definite relations with their metamorphosis.

\section{THE HYMENOPTERA WITH OVIPOSITORS.}

(Tenthredinide and Siricide.)

The celebrated entomologist Latreille distinguished the $H y$ monoptera which had the abdomen attached to the rest of the body by its entire width from those which had a slender, waistlike junction. This distinction, although not very important, is

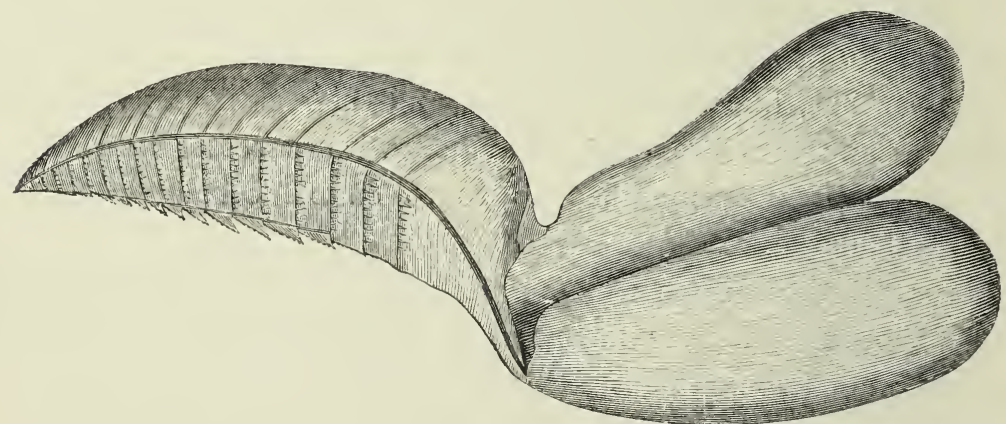

THE OVIPUSITUR OF THE Hylotoma rosea.

very handy. The species with thick waists are collected into two families, one very numerous in species and the other much less so. The principal, or first family, is that of the saw-flies, or Tenthredinida, and the other the Siricida.

The saw-flies are common everywhere, and are to be seen and watched whilst they fly, work, and crawl about in nearly every garden and wood. Once seen, the peculiar habits and odd manners of these active flies are never forgotten. Their body is short and compact, their mandibles are long, flat, and cutting, the jaws are short, feeble, and furnished with six-jointed palpi, and the antennæ are either thread-shaped or are thick at the end or branched. The Tenthredinide are particularly 
distinguishable on account of the movable, dentate, saw-like ovipositor which is attached to the abdomen of the females.

This is a wonderful little instrument. It is in the form of a double saw, the length of which varies according to the species, and there are from fifteen to twenty or more regularly placed teeth added to the cutting edge. But the little saw of the Tenthredo is not always so simple in its construction as that of a carpenter, for the teeth or dentations are covered with others, so that the teeth of the saw are themselves toothed. The perfection of this minute weapon suggests that manufacturers might take a lesson from it and invent a cutting saw with double serrations, which might be of infinite use in the arts.

The double saw corresponds to the stylets of the sting of the wasp and bee. The two valves are kept fixed by being inserted or fixed into a scale which adheres to the sides of the abdomen; and the process that surrounds the stylets of the sting may be noticed in its rudimentary condition as a thin membrane in the saw-flies, but it is of no importance to them.

The Tenthredinide have active dispositions, and are ornamented with various colours, and their bodies are smooth and shining. They do not consume much nourishment in the adult stage, and they then appear to prefer fruit, which they snip in pieces with the aid of their cutting mandibles.

The larvæ resemble caterpillars in their shape and habits, yet it is hardly possible for any one to mistake them for the miniature form of the Lepidoptera. It is true that amateur entomologists have nourished and taken vast pains with the larvæ, believing that they would eventually turn to new and splendid butterflies, and that they have been surprised at the evolution of a saw-fly instead of the expected scale-winged insect. But in spite of the resemblance, the mistake ought never to occur if a careful examination be made.

Caterpillars have never more than five pairs of membranous or hind legs, but the larvæ of the saw-flies have generally seven or eight, and never less than six pairs. The feet have, however, circles of hooks, like the caterpillars. The head is always rounder and more globular, and the eyes are more wide apart and distinct, than in the larva of the butterflies. The saw-fly larvæ have, 
moreover, peculiar movements, and especially that of curling themselves up, and they do this for hours during the great heat of the day; if they are alarmed, they cock up the end of their bodies in a threatening manner, and the attitude doubtless frightens some of their disturbers. The larvæ eat the leaves of most plants, and they collect together in colonies, and often do a great deal of mischief.

When they have attained their full size, the larvæ form cocoons with silk, and glue the threads together so as to make stout and hard cases; and some of them are to be seen stuck between the

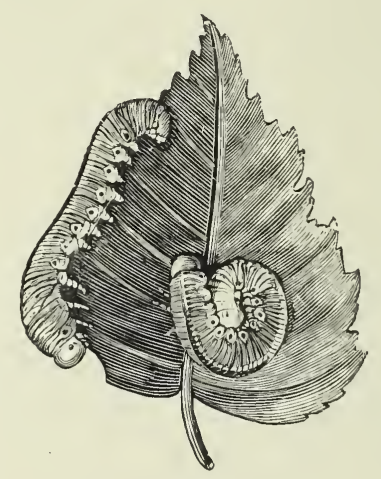

LARVA OF A SAW-FLY.

twigs and leaves or upon the small branches, whilst others are placed in the ground. These ground cocoons, however, contain pieces of stone and dust. Every caterpillar, as soon as its cocoon is made, begins to transform itself into a chrysalis; but the sawfly larvæ remain inert and huddled up for several months after having made their snug and safe hiding-places. The metamorphosis does not take place at once, but occurs some time or other during the winter or early spring; and when it is complete, the fly escapes, usually by cutting the end of the cocoon with its jaws, and, should it be a female, it soon begins to use the ovipositor. It flies to and fro, seeking a proper place to deposit its eggs in, and takes a great deal of pains to select a spot where the nourishment of the future larvæ will be at hand; and it is not simply satisfied, like the butterfly, with laying its eggs on or near the plant upon which the young are to feed. The 
saw-fly places its eggs in the very midst of the food, and protects them with extraordinary care. It makes a series of slits in the stalk of a leaf or in the twig of a shrub with its tiny saw, and deposits an egg at the very bottom of the cut, covering the opening with a secretion that hardens and keeps out the wet and the air. Some saw-flies only attack the petioles of leaves; others like sawing the hard twigs of trees; and each species has its particular method of egg-laying and wood-sawing, and each chooses a particular plant. Some large Tenthredinide only carry a very delicate and small saw, for the eggs are to be laid in the very tissues of the leaves, which must not be torn or pierced through; and others, that are small in size, have great saws which are strong and double-toothed, for they have to cut into hard tissues; so that with a little trouble the naturalist can tell what sort of a saw a tenthredinate insect must have, by observing the habits of the fly; and he can satisfy himself, on the other hand, when he sees the saw, concerning the peculiar habits of its possessor.

All the Tenthredinida are closely allied by their structural peculiarities; and some external characters have caused them to be grouped in two great tribes, which contain many genera.

The tribe, the species of which have short and stout bodies, contains the greatest number of saw-flies, and it is subdivided into four groups-the Cimbicides, the Hylotomites, the Tenthredites, and the Lydites.

The Cimbicides are the largest of the saw-flies. They have thick bodies, and their antennæ are swollen at the end so as to resemble a club, and have never more than eight joints. Their flight is heavy, and they make a great buzzing. Their larvæ have a peculiar tough-looking skin, and have no less than nine pairs of membranous legs. The common German species, the yellow Cimbex (Cimbex lutea) is a large form, and may be considered to be the representative insect of the genus.

The difference between the males and females of this saw-fly is so great that many naturalists considered them to belong to separate species. The male is rather long in shape, and has large legs, its colour is brown, and the insect is marked with a bright yellow spot on the first segment of the abdomen. The female, on the contrary, is plump and rounded in figure, and has a yellow 
colour, the fore parts of the body being blackish. The adult insect flies in the month of May. The females, although they are large insects, have a very small ovipositor saw; but they do not require any other, for, instead of using it upon dense vegetable fibre and hard twigs, they simply incise the stalks of leaves.

The larvæ are of a pretty green colour, and have a black ray down the back; they do not indulge in the threatening posture of lifting up their tails, but curl themselves up just like a sleeping cat.

There are some small saw-flies which are well known, and which belong to the Hylotomites; their antennæ are slightly swollen, and have from three to seven joints. The genus Hylotoma is the most important, and its species are very common in Europe. They usually have the greater part of the body coloured yellow, and the rest black; and the common rose saw-fly is a well-known example, and one that is especially hated by rose fanciers. It is to be found in every garden, and its habits can be watched with ease.

When all is bright and full of sunshine early in the summer morning, and when the rosebuds are longing to open and to display their magnificent colours, then is the time to watch the restless saw-flies that move here and there with great velocity, and rest every now and then on the rose trees. These pretty flies are about one-third of an inch long, and when they fly their wings measure nearly half an inch across. Their bodies are smooth, gleaming, appear highly polished, and have an orange tint, whilst their heads, antennæ, and much of the body, are black, as are the ends of the legs and the pieces of the tarsus or foot. These Hylotoma belong to the species Rosea, but at first nothing unusual is observed respecting their habits. After a while the flies become more numerous, and as the day passes on some begin to think of laying their eggs. The females fly to and fro, and soon several may be recognised, for they are crowded and heavy with eggs. The slow-flying saw-fly may be noticed buzzing about the most succulent and healthiest of the roses, and it is so anxious to lay that it cares little for the spectator. It crawls and runs over the leaves and suckers, and looks here and there, and is evidently intently occupied in some important duty. Finally, the saw-fly finds a delicate succulent 
twig or stem, which it likes, and immediately the insect clasps it with its legs, bends the back, and places its head low. Then the saw suddenly appears under the end of the body, and is dug deeply into the green stem like a knife. Immediately the skin of the twig is pierced, the laminæ which form the double saw are stretched slightly apart, and the gentle saw-like motion cuts deeper and deeper. Each saw cuts so as to separate from its fellow, and to widen the slit, whilst the rough parts of the outside of the saws scrape and enlarge the wound also. In a few seconds or minutes the slit has become large enough for the purpose of the saw-fly, and when this time has arrived the insect rests perfectly still for a short period, and the saws separate sideways and enlarge the slit; at the same time an egg passes down between them slowly but surely. The egg is laid at the bottom of the slit in safety, but more has to be done to ensure the future comfort of the larva and its freedom from danger. If the egg were simply left at the bottom of the wound the vegetable fibrous cells would soon close over and effectually imprison it for ever, and the young larva would be crushed before it was born, or starved. Every care is taken, however, to prevent this misfortune. The egg is hardly laid before a mucus secretion, provided by special glandular structures, escapes from the insect, and enters the wound and covers its sides; it acts as an irritant to the plant, and soon makes itself felt by the vegetable tissues, which it alters and indurates in a remarkable manner. No sooner is it deposited than the fibres become wider apart, and soon blacken, whilst the deeper-seated tissues become thickened and impaired, so far as their growing powers are concerned. The egg thus remains free at the bottom of the slit, and does not suffer from the growth of the surrounding tissues, thanks to the glandular secretion.

Egg after egg is deposited in the same manner, and with the same precautions, and we may often distinguish the twigs where all this has gone on, and which contain a long series of eggs in separate slits. Sometimes only three or four wounds may be counted, but ten or fifteen or more punctures are often made. The operation of laying is by no means easy, and it requires much care; so the female only deposits a few eggs every day, 
and curiously enough it never attacks a second twig on the same tree. Day after day a new plant is chosen, and there is evidently a plan in this. Why should the insect avoid the tempting stems of the same bushes, and seek those of other rose trees? Simply because were it to lay too many eggs on one tree there would not be leaves enough for the progeny. What a wonderful instinct is this, that causes the creature to think for the future, and to reason more wisely than many men! The Hylotoma takes care of all its little ones in the most clever manner possible, and it leaves them enough to live on without starving each other-an example which might be followed by most of the creatures that consider themselves infinitely higher and more able than the tiny insects.

About eight or ten days elapse after the eggs have been fixed into the twigs of the rose, and then the young larvæ are hatched, and they immediately crawl on to the leaves, and begin to eat them.

Their growth is rapid, and they change their skins time after time, but without the general shape of the body or its colours undergoing a decided alteration. The body of the larva is of a more or less dark yellow colour, and the sides are green. It is marked very generally with numerous black and shining tubercles, which are covered with hairs. The head is yellow, and the black eyes are surrounded with spots of the same colour.

These larvæ resemble true caterpillars exceedingly, especially when they move from place to place, but their characteristic attitude is very different from those of the Lepidoptera. They are very prone to adopt the curious and striking posture which has been noticed aiready. Holding on to the plant by their fore legs, they stick up the end of the body, and if they are feeding with the body in the usual horizontal position, and are disturbed suddenly, this threatening attitude is forthwith adopted. Under different circumstances, and when they are at rest, they simply twist the last segments of the body underneath, but do not roll themselves up in a spiral like many other larvæ of saw-flies.

By the end of the month of June the larvæ of this interesting saw-fly have reached their full growth, and most of them walk off the leaves and twigs that have been so serviceable to them, 
and descend to the ground and hide themselves in the soil at a slight depth. Others do not leave the stem of their favourite tree, and not a few stop upon walls or upon the trunks of trees. Wherever they may hide or stop they form an oval-shaped cocoon, which is composed of silk joined together by a very glutinous secretion, but it never contains grains of sand or of earth.

The cocoons of the rose saw-fly are of an earthy yellow colour, and their singular construction was noticed in the last century by Réaumur. On the outside there is an elastic tissue which is able to resist very considerable shocks and knocks, and the microscope shows that it is made up of fibres arranged like the network of a racket mace. This is the first envelope, and the cocoon beneath it is made up of a soft, close, and flexible substance which is not adherent to it.

When the second metamorphosis is complete, and the Hylotoma has changed its pupa skin within the cocoon, it gnaws the soft layers with its mandibles, and cuts the stout outside threads with them, and escapes.

The second generation of the rose saw-flies appears towards the end of July or the beginning of August. They soon lay, and the larvæ may be seen upon the roses during the whole of the autumn. As soon as the temperature of the season begins to decline, and before the fine days are all gone, the larvæ descend to the earth and establish themselves in their cocoons in the soil, and none of them remain on trees or walls. They have the instinct to place themselves out of the danger of frost and cold, for the winter time is full of peril to them. After being snugly housed in their cocoons, where they have to remain until the next spring, they become dull and stupid, and hybernate as larvæ. The long winter passes and the early spring finds the larvæ in much the same state, but a few fine days stimulate their vital processes, and the metamorphosis into the pupa condition proceeds.

The saw-flies are a great pest to horticulturists, and yet a slight knowledge of the method of the metamorphosis of the larva would enable those generally very self-opinionated persons to save many a rose, and prevent much loss to themselves. The habit 
of crawling down the rose stem into the ground on the approach of winter, and of hybernating in the cocoon at the base of the little tree, should suggest the propriety of raking and thoroughly disturbing the superficial mould. By these means the cocoons can be easily seen and destroyed. There is another plan, which is not so ready however, and it is to notice where the eggs are laid, and to paint the twig over with some viscid liquid that will fill the cracks, and seal up the unfortunate larvæ quite hermetically.

The rose saw-flies do not live in common, and each one makes its own cocoon. In the Brazils, however, there is Hylotoma formosa, which, according to Sichel, makes a nest in which many participate.

The Tenthredites are the most numerous of the saw-fly family, and they may be recognised by their antennæ not being swollen and not having less than from nine to fourteen distinct joints. Their habits and metamorphoses resemble those of the Hylotoma, and it is, therefore, only requisite to select a few examples where there is a shade of difference, and where the structures of the insect are evidently modified for a purpose.

The Athalice are small insects, and their colour resembles that of the Hylotome generally speaking, but their antennæ are sufficiently distinct as regards their construction to prevent the genera being confounded. They are finely pectinated in the male Athalia, but they are not composed of more than from nine to ten joints, and this is the case in both sexes.

Athalia centifolice, so well known to English entomologists, from Newport's magnificent descriptions and studies, is one of the commonest species. The larvæ are of a greenish black colour and have eight pairs of membranous legs. They occasionally are to be found in great numbers on culinary vegetables, which they eat and waste remorselessly. United in numerous groups upon each plant, they devour the leaves and even the tenderest twigs. A closely allied species (Athalia spinarum) attacks cruciferous plants, and does a great deal of damage during certain years. The larvæ of these small saw-flies undergo their metamorphoses in the earth, and as they have not much silk at their command they agglutinate earthy particles together, and make a rude sort of cell or cocoon. 
The females lay their eggs by inserting them with their sawovipositor between the skin or cuticle of the turnip leaf and its cellular or parenchymatous structure. The egg is therefore only separated from the atmosphere by a most delicate membrane, so that the heat and moisture soon affect it and hatch the little Athalia contifolice very rapidly. It appears necessary that this egg should be exposed to much heat in order to hasten the birth in time for the turnip to be enjoyed by the larva. Newport states that the cocoon of this insect is lined with silk.

The larvæ of the genus Sclandria are of a somewhat peculiar shape. Their legs are extremely short, and their bodies are lubricated with a viscid secretion which makes them look like small slugs. Réaumur, in fact, called them slug larvæ. The larvæ of Selandria Ethiops often become very injurious to cherry, pear,

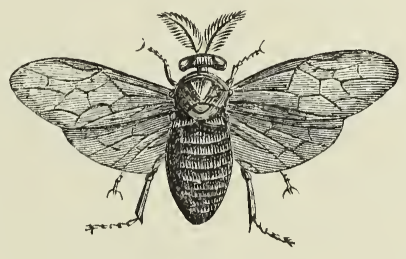

Lophyrus pini.

and other fruit trees. They remain perfectly quiet during the heat of the day, and seem to draw their heads within the first segment of their bodies, and they are then covered over with the slimy moisture so as not to look like insects at all. By night and during the early morning they are lively enough, and they then devour the foliage.

The Lydites form a small group of saw-flies which are characterised by having a great number of joints to their antennæ. They are the saw-flies of the north, and they attack fir trees and pines.

The Lophyri, which belong to this group, have a thick body, and the males have doubly pectinated and feathery antennæ. The species are very difficult to separate, and entomologists have had to take into consideration the disposition of the nervures of the wings, in order to decide upon particular forms with certainty.

The commonest species is Lophyrus pini. The male is quite 
black; the female is almost entirely yellow, and is spotted with black. The adult insect flies during the summer months, and the

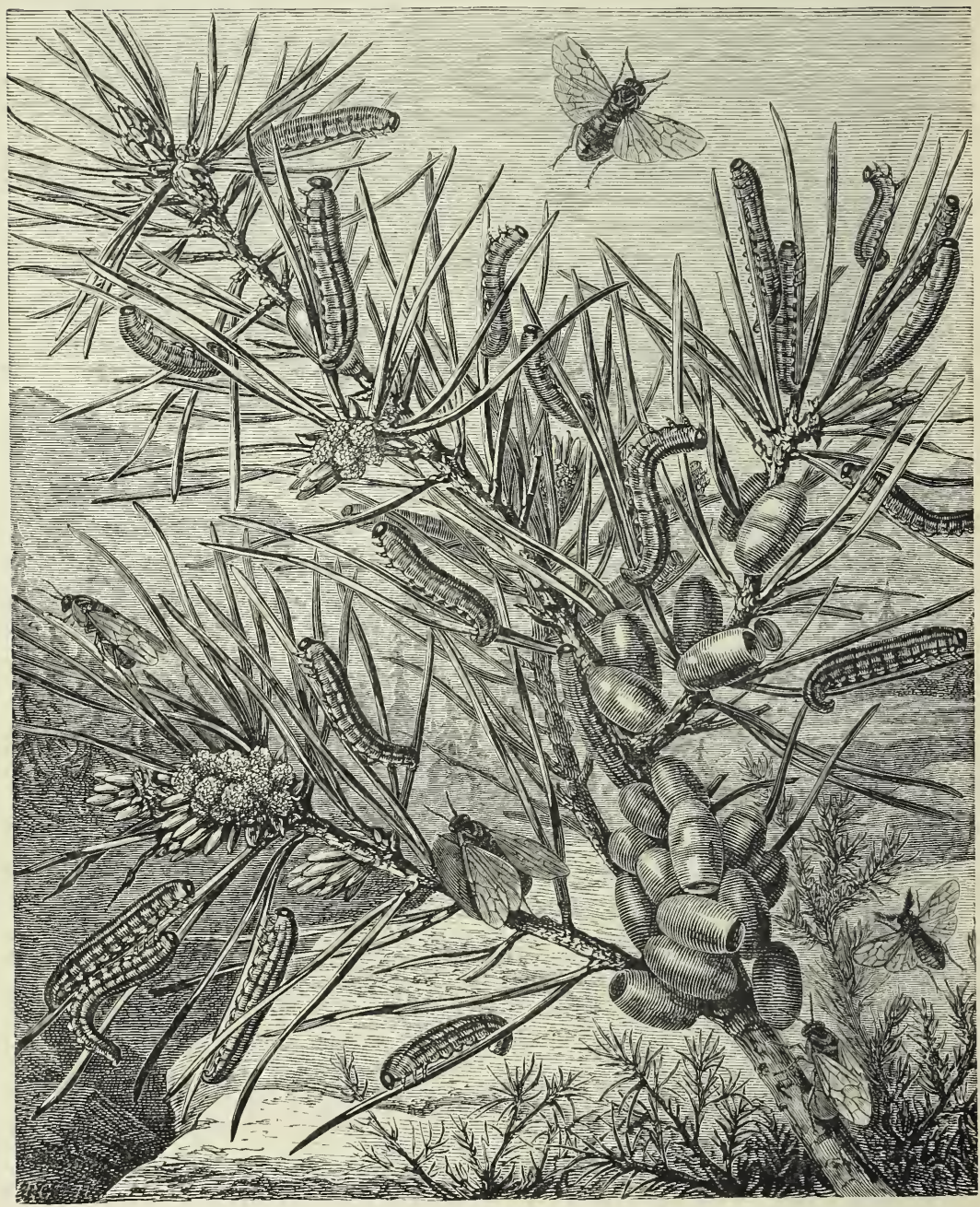

THE METAMORPHOSES OF Lofhymus pini.

temales saw the tissues of the twigs and fine stems of fir-trees, and insert their eggs. The females are so industrious, and are so prolific, that vast numbers of eggs are laid upon a tree, and the parent seems to know that there will be enough and to 
spare for its larvæ. The young larvæ live in groups, and collect in great numbers; they eat first of all the young shoots and buds, and finally do not despise the hardest foliage. Many of the trees they attack are soon terribly despoiled of their leaves, and have their existence endangered, and every now and then large forests of firs and pines are nearly destroyed by the ravages of this insect, which certainly chooses a strong tasting diet.

The larvæ of the Lophyri do not dig into the earth in order to undergo their metamorphosis, like so many of the saw-flies; but they construct their cocoons upon the branches of the tree they have despoiled. The cocoons are grouped together on the stouter twigs of the trees, and are more or less oval in shape. They are often found empty, and one end opens like a trap-door. This is because the saw-fly, when ready to escape, cuts a nearly circular slit in one end, pushes up the flap, and flies off.

The position of the oval shaped cocoons is shown in the engraving, and there are some perfect insects represented. The females are engaged in depositing eggs, whilst a male is flying. The larvæ have the characteristic curl of the tail.

Some larvæ of the genus $L y d d$ live in groups, and like the Lepidoptera under similar circumstances, protect themselves by forming a net-work of silk for the whole colony. The pear-trees are now and then much damaged by Lyda piri, whose larvæ collect in great numbers upon the leaves, and spin a web in common to protect themselves.

The Cephines are the second tribe of the saw-flies, and they have slender bodies. They live in the interior of plants when in the larva form, and thus imitate the peculiar habits of many caterpillars, and, as might be expected, they present similar peculiarities as regards colour and the development of the legs. The Cephincs in fact exhibit so great an arrest of the growth of the membranous legs that they surpass nearly all caterpillars in this respect, and, indeed, they are almost like worms. The species of the genus Cephus have a compressed abdomen, and the ovipositor of the female is hardly visible, whilst the antennæ are swollen at their ends, and composed of twenty-one joints. The commonest kind is Cephus pygmaus - a little insect of a third of an inch in length; it is black, and has a yellow border to its third, fourth, and seventh 
segments. It is very injurious to cereal crops. When the wheat crop is about to ripen, if some white ears are seen elevated above the others which are heavy, green, and somewhat bent, there is a tolerable certainty of not finding the grains but of discovering one or more larvæ of Cophus pygmaus. These small white larvæ may be exposed by breaking the white ears, and they live in the powdery dust which they have produced by gnawing the corn, and by their dejections. These larvæ appear to have a strong impression that the wheat ear is all very well for a temporary home, but that it is dangerous for a permanent one, for before the

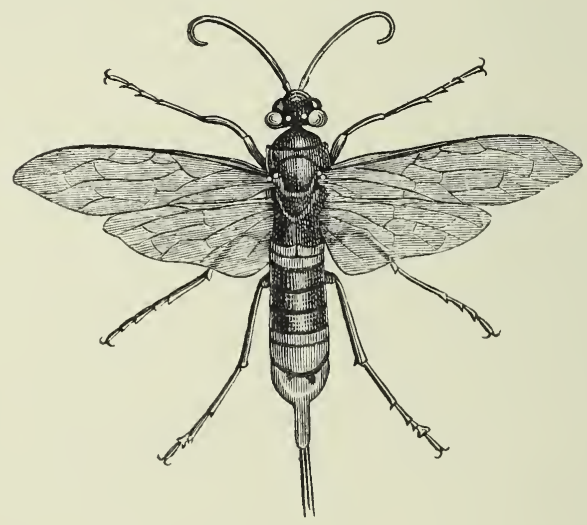

Sirex gigas.

harvest the insect crawls down the stem and buries itself in the ground near the roots. There it makes a cocoon, and hybernates through the winter, out of the way of sickle and scythe.

The Siricide are a more numerous family than the last, and they may be known by their long bodies and short thick mandibles; the antenne being thread-like. The principal genus is Sircx. The females of it have a long, straight saw, which is toothed, for it has to pierce something harder than leaves and rose twigs. The species are more common in Germany, Northern Europe, and North America, than in southern districts; and they frequent the forests of firs and pines. The great SircxSirex gigas-is a splendid insect: the female is black and yellow, 
and attains the length of an inch without reckoning the ovipositor, which is half an inch long. This long instrument is used to perforate the bark of fir trees, and the larva finds itself in the midst of its food.

The genus contains species that have been called by the name of Urocera; and they have, of late years, excited no small astonishment in the minds of many military men, for some of these insects took a fancy to eat lead and gnaw bullets. Marshal Vaillant, a Russian colonel, M. Motschulsky, and the director of the museum at Vienna, M. Kollar, have asserted and proved that the leaden bullets made for the French army during the Crimean war were riddled by Sirex juvencus. These insects certainly got out of the boxes, in the wood of which-green when they were made-the larvæ were included; and they were found in the middle of the bullets, gnawing away, and perforating the lead with their strong mandibles.

Oryssus coronatus is one of the Siricida, and the female has a thin saw, which is folded underneath the abdomen; but, unfortunately, its metamorphoses are unknown.

There is a remarkable saw-fly (Tenthredo Lucorum) which lays its eggs in the hawthorn trees soon after they have pushed forth their tenderest leaves. It is a large fly, and is of a dusky-brown colour, and about the size of a wasp. The female has a small and very thin laying apparatus, and she chooses the upper surface of a leaf, and pokes the edge of the ovipositor just under the cuticle; she then moves the saws gently, and expands them, moving them sideways. As the saws are drawn out of this most delicate wound, an egg is left in their place, and gummed in by a viscid secretion. The female lays several eggs, and they are pale and small. After a while, the leaf grows, and is well nourished with the juices of the plant; and the eggs grow also, being close to the respiratory organs of the leaf, and in the midst of the nutritious fluids. The larva can be seen in the egg, curled up, and turning over and over, after the manner of all embryos. It is hatched after a while, and it crawls upon and devours the leaf. The thorns suffer a great deal from it, and were it not for a fellow hymenopterous insect that lays its eggs in the larva, they would have much more damage done to them. When the larva has attained its full 
growth, it makes a very woody cocoon, and sticks it to the twigs of the tree upon the leaves of which the insect lives. The cocoon is brown and very hard, and the larva hybernates in it, and is transformed in the spring. The fly gnaws off the top of the cocoon from within, and escapes; its jaws, like those of most others, being made solely for this purpose. The Tom-tits get a great many of the larvæ by nibbling the cocoons during hard winters.

\section{THE HYMENOPTERA WHICH PRODUCE GALLS.}

\section{GALL FLIES (Cynipside).}

The Hymenoptera that produce galls, or excrescences upon plants, form a group by themselves. They are small insects, very distinguishable, and they stimulate a great number of different kinds of plants to develop those unusual growths of their tissues which are called gall-nuts, galls, oak-apples, \&c. Everybody has seen these curious and odd-looking excrescences; but very few have noticed the beings that have grown within themand which, when they have attained their perfect form, escape and fly. A winged insect not much more than a tenth or a twelfth of an inch long is not readily observed, especially when amongst the host of little flies that continually move around us.

These small Hymenoptera belong to one family-that of the Cynipsida-which contains the genus Cynips, and others very much like it. The Cynipside have an oblong and very convex body, the abdomen of which is attached to the thorax by a very thin pedicle. The saw ovipositor is very curiously made; it is very long and slender, and is twisted up in a spiral form within the abdomen of the female when it is not required. But when the insect has made up its mind to lay an egg, having chosen the proper spot, the muscles of the abdomen suddenly unfold this spiral, and the ovipositor is straightened, and thrust instantaneously into the plant.

The Cynipside are found everywhere in spring and summer. When about to lay, the females take great trouble to seek a good place on a proper plant: they make a puncture with their long ovipositors in a twig or leaf, and deposit either one or a 


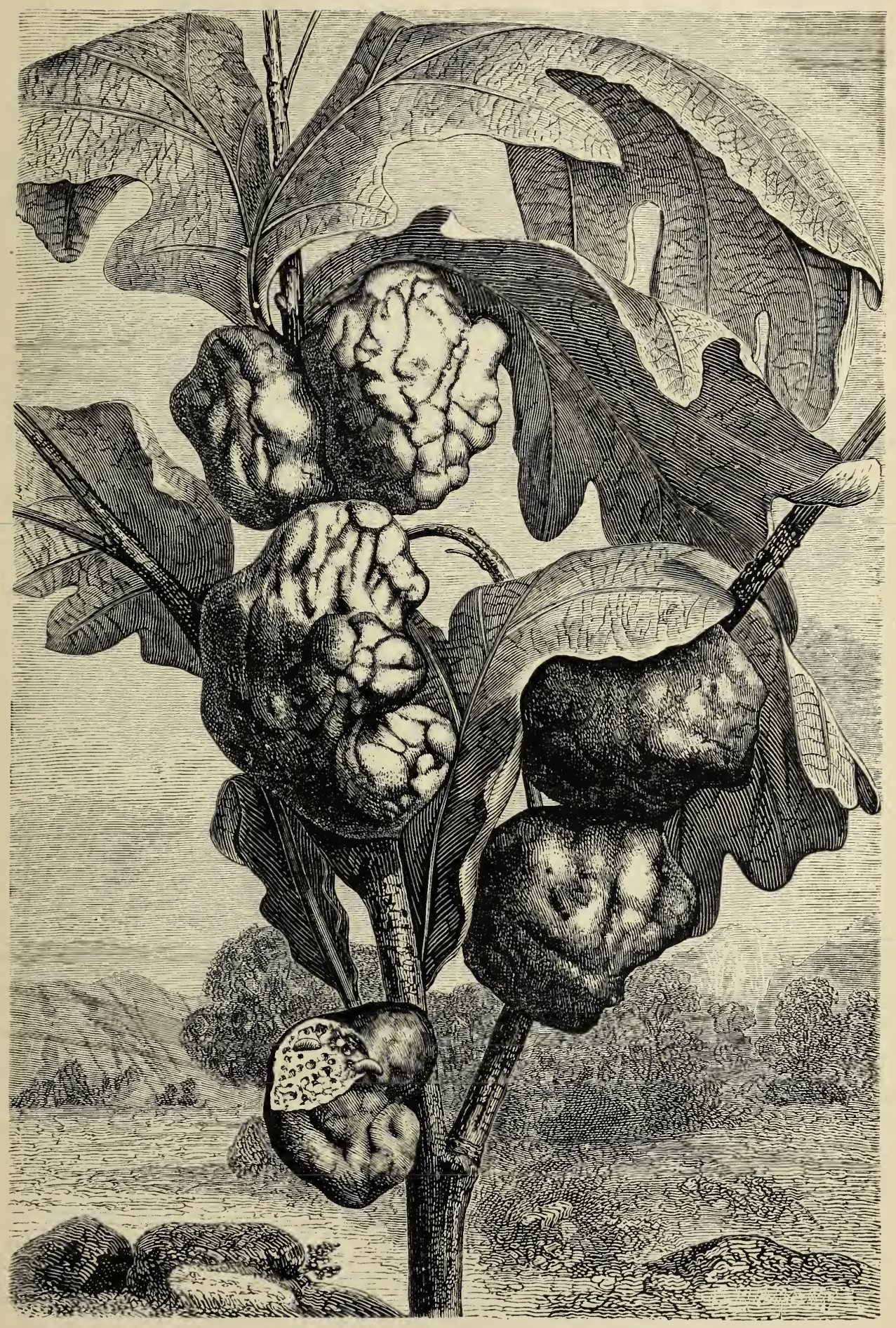



considerable number of eggs. When the puncture is made the insect spreads a secretion over the wound which is of a very irritating character, and it is believed to excite the nutrition of the vegetable tissue to develop irregular masses of its cellular structures. There are multitudes of plants attacked, and generally the shape of the gall differs in each, and is produced by a different insect. Hartig, Westwood, Giraud, and others, have described some very unusual forms. The oak trees afford a refuge for, and nourish many kinds of gall-flies, which do not spare the trunks, the leaves, the twigs, or the roots. Oak-apples, or the rounded masses attached to oaks in the summer, some small and others large, readily attract the attention; they are galls that have been produced by a Cynips. They might be taken to be the fruit of the oak, and they are to the eye miniature apples-oak apples. The largest are always at the base of the leaves, and within them there is a cavity tenanted by one larva; it renains there in a dull and stupid condition during the winter, and is transformed into a pupa in the spring. The adult insect is developed within the cellule, and is obliged to cut its way out into the world with its mandibles. This Cynips is of a bright brown colour, and is called Cynips quercîs baccarum.

The small oak-apples that usually are found in plenty on the lower surface of the leaves are formed by another species-Cynips quercîs folii.

The branches of the oak in the spring-time are often covered with nodules, some of which are very large and irregular in shape. Their surface is smooth, their colour light green, passing into red in some spots, and there are usually several on a twig close to each other. They are constructed on a different plan to those of the gall-leaf insects, for they contain twelve or fifteen cellules, or more, each of which contains a larva. These kinds of Cynips fly in the middle of the summer, and there are probably two generations in each year. They are called Cynips terminalis, on account of the peculiar ornamentation of the female. The sexes differ much in their shape and colour; the male has large transparent wings, and its body is of a uniform bright fawn colour, whilst the female has no wings whatever, and is brownish, the end of the abdomen being of a shiny black tint. 
The large engraving shows the galls of the insect. They are cellular, and are aggregated in masses upon the twigs.

A very common species of Cynips-Cynips aptera-produces great galls upon the roots of the oak, and it is a most remarkable thing that neither the males nor the females should have wings.

The gall nuts of commerce, which are used as dyes, and to make ink and tinctures, and whence gallic acid is derived, are produced by the punctures of Cynips galle tinctoria. These insects affect an Eastern species of oak, Quercus infectoria, and their galls are remarkably hard, round, and tuberculated. They

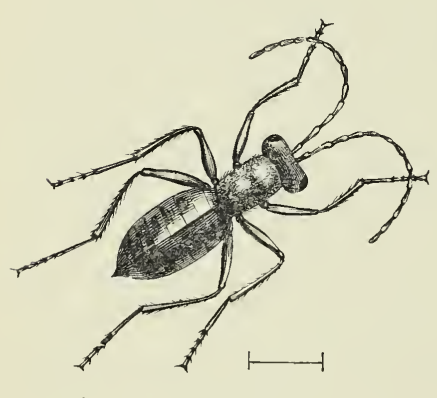

Female.

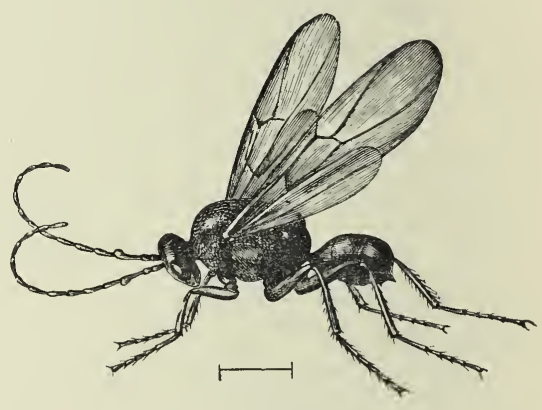

Male.

Cynips terminalis.

only contain one larva. The cellule is moderately capacious, but the walls are very thick; nevertheless, the little Cynips perforates them without much difficulty, in order to come to the light of day.

The rose fungus is one of the most curious galls; it is produced by a Cynips, and is found upon the hedge roses and sweetbriars. The adult insect which produces these excrescences is about the fifth of an inch long. Its transparent wings are slightly clouded, and it is of a glossy black colour. The females lay their eggs towards the end of May or the beginning of June, and the galls soon form, but they grow at first very slowly, and subsequently quickly, so that they attain their full size on the approach of cold weather. Sometimes the galls are round, or flat, at others they are irregular in shape, and resemble medlars, and they are about the same size as those fruits. They are 
moss-like in texture, and appear to be composed of branching filaments, which are placed closely together. Hence their name of "hairy galls." There is a sort of stem or peduncle to the galls, so that when they become variously tinted with green and red colours towards the end of summer they look like pretty fruit. During the winter time these colours disappear, and the galls become uniformly brown.

The mossy surface of the rose fungi is so soft and compressible that it appears at first sight to form the whole of the gall, but this is not the case, for there is a woody texture beneath which is very hard indeed. On cutting the gall across it will be observed that the larvæ inside are admirably protected against injuries from without, for their cells are in the midst of the dense woody tissue, which is covered with the soft moss-like structures. The space in which each larva lives is restricted enough, but it undergoes its metamorphoses in the small cell. The larvæ are whitish, and the only colour about them is in the eyes. When they have attained their full growth, these larvæ remain at rest for a long period; they shorten themselves, as it were, and remain huddled up and quiet from the end of autumn to the beginning of the following spring. Then the metamorphosis into the pupa commences and is perfected. The Cynips does not last more than ten or fifteen days in this form, and then the second metamorphosis takes place. But if the spring is not genial, and if the temperature is low, the perfect insect does not get out of its cell, for it remains within waiting for the fine weather. When the warmth of the season is sufficient for the wellbeing of the Cynips it gnaws its way out of the gall and escapes.

There is a Cynips that undergoes its metamorphosis in the fruit of fig trees in Southern Europe, Africa, and the East, and the perfect insect eats its way out of the fruit when the ovules within are being fertilised with pollen; consequently, this insect brings out with it a quantity of the pollen in the form of dust.

Now this has been taken advantage of by practical men, and figs that are backward and small are stimulated to grow artificially by fixing a fruit containing the Cynips upon them.

The Cynips comes out of the fig covered with pollen, and immediately pushes its way into the ill-developed fruit, the 
ovules of which it fertilises; and then the growth of the fruit proceeds rapidly.

The so-called Dead Sea fruits are galls which have been produced by a Cynips.

\section{THE PARASITIC HYMENOPTERA.}

(Ichneumonida, Chalcidida, Proctotrupida.)

The parasitic Hymenoptera form a little world of themselves, and they have the same habits, instincts, and metamorphoses, although their numbers are enormous. They form the insect array which Nature employs to check the superabundant multiplication of the phytophagous or vegetable-feeding creatures of the class. Every parasite attacks a particular species or some closely allied kinds, in obedience to some mysterious law; and many an unfortunate caterpillar is subject to the violence of several of these dangerous enemies. Nearly every insect has more than one parasite, and this fact enables us to estimate the multitudes of Hymenoptera that are in the world.

These Hymenoptera belong to three very distinct types; but each of them has females which are furnished with a straight, thin, and sharp ovipositor. These parasites are very pretty and elegantly formed insects when in the adult form, and are gifted with great agility and restlessness. But in their early condition they cannot move, having no locomotive organs, and their structures are so soft that they are destroyed with the greatest ease. The larvæ look like worms or maggots, and do not attain a great perfection of development during their growth. The contrast between the lazy and sluggish larva of the active and restless adults of the parasitic Hymenoptera is almost as great as that of the larva and the imago of the industrious Hymenoptera, such as the bees.

All the parasites seek out a caterpillar, a larva, or an insect which suits their purpose, in order to lay an egg within its body. A larva which is born from this egg is nourished by the blood and fat of the victim, whose vital organs it does not touch or injure in any way, for were it to die the parasite would come to 
an end also. It is only when the larva is nearly full grown, and is about to undergo its metamorphosis into a pupa, that it appears to know that the life of the victim is not likely to be of much further use. It then devours the internal organs of the unfortunate insect, and undergoes its transformation. The skin of the victim protects some of the pupæ of its destroyers after all the inside has been eaten.

Nearly all-if not quite all-insects are subject to the attacks of parasitic Hymenoptera. Fine, smooth, and brightly-coloured caterpillars often have a black spot upon their skin, and this is the healed wound of the ovipositor of one of the parasites.

Sooner or later the creature is sure to die, and it never reaches the stage of growth when it can lay eggs or reproduce its kind, for before this time the growing larvæ within destroy it, as it were, by a slow consumption. Some affected caterpillars die soon, others nearly reach their full growth, and a few undergo their transformation into the chrysalis state before death. It is, therefore, not an uncommon thing for a butterfly collector, who hopes to see a fine moth disengage itself from its pupal covering, to be disappointed by the appearance of several little parasitic Hymenoptera that have been living within the chrysalis he has been keeping.

Although we know a great deal about the economy of the parasitic Hymonoptera, still there are some points of the greatest possible interest in it, and which are really very provocative of wonder. When a parasitic insect of this family discovers a caterpillar feeding on a leaf in broad daylight, there is nothing very wonderful about it, because we could do as much ourselves; but when it is evident that the female parasitic Hymenoptera finds out a larva which is situated inside a fruit, and within a branch or trunk of a tree, and perfectly out of sight, we may well wonder how this is done. When one sense fails, another is supposed to supply its place, and the sense of smell of the insect is thought to do what the eyes evidently cannot perform. It is probable that the sense of hearing may assist in the discovery, but it is by no means proved. There is another instinct which is very remarkable, and, indeed, as curious as that just mentioned. A large parasite deposits only one egg under the skin of a caterpillar or other insect, for its larva, as it increases in size, requires all the juices of the 
victim. If two or three eggs had been laid, and larvæ had been born from them, they would have been starved after a while, for the body of the infected insect would have been consumed twice or three times too quickly. But if a moderate sized parasite attacks a tolerably large caterpillar it introduces two or three eggs, and if a very small Ichncumon meets with a fine larva it may lay as many as fifty or sixty eggs in it. There is always enough and to spare in these instances, and it would appear that the insects considered the future. But there is a great sameness in the habits of insects, and these parasites choose their victims upon the same plan generation after generation. If the large parasite came across a new caterpillar three times as big as any it ever saw before, it either would pass it by, or would still only lay one egg. On the other hand, a very small parasite would always lay the same number, whatever the size of the victim might be.

All insects are not equally exposed to the attacks of parasites; for instance, those that know how to form shelters are less so than those which live in broad daylight on leaves, and hairy caterpillars are less liable to suffer than the smooth kinds. It would appear that the long tufts of hairs and the branching spines which cover the bodies of so many larvæ are the structures which protect them, like an armour, from the sudden and eventually fatal stab of the Ichneumons. The peculiar movements given to the hairs by the contraction of the segments of the body evidently prevent the parasites from giving the stab with certainty.

Larvæ are especially subject to the attacks of the parasitic Hymenoptera, and there is no difficulty in understanding why they should be chosen as the homes for the future young of such creatures as the Ichnemmons. The life of adult insects is usually brief, and is cut short by many accidents, so that were the larvæ of the parasites developed within them, their existence would be constantly in danger, and very few of them would come to perfection. It is very wonderful, however, that those insects which do live longer than others in the adult form, should be subject to the attacks of parasites, whilst the others, whose existence is invariably short, should never be pierced by the Hymenoptera. Many Colcoptcra, which are well covered with a hard integument, 
and which, like men in armour, care little for the attacks of their fellows, succumb to the active lancer-like parasitic flies. The weevils, for instance, are long-lived insects, and are encased in armour, but their active enemy finds out the joints, and sticks in its ovipositor between the articulations of the body, and lays the egg, which grows like a canker within.

The parasitic Hymenoptera are of all dimensions; many are of considerable size, but the name of the minute insects is indeed legion. So small are some of their larvæ that several can be accommodated within the body of an Aphis or plant louse, and even in an egg of an insect. The eggs of many Lcpidoptera are destroyed by the larvæ of the parasitic Hymenoptera that have become developed withir them from the eggs introduced by the ovipositor.

Almost all these parasites introduce their eggs under the skin of their victims, so that their larvæ are never seen, but there are some kinds which only lay their eggs on the outside of caterpillars, and other insects. When the larvæ of these last-mentioned parasites are hatched they pinch up the skin with their mandibles, and force the front part of their heads within the victim's body, and remain in that position. They then suck the juices of their prey, and the greater part of their body is exposed to the air.

Since nearly all the parasitic Hymenoptera lead the same sort of life, we might expect not to find any great structural differences amongst them. There is, however, a considerable variety in the length of the ovipositor of the females. The females which deposit their eggs within the bodies of caterpillars or larva that live in the open air have very small ovipositors; those which attack larvæ which are underground, or are protected by some shelter, have longer instruments; and those that have toreach insects which live within the trunks of trees, have very large and greatly developed egg depositors; so that the Ichneumon's habits and prey may be guessed by the length of the ovipositor.

Nature employs these parasites constantly when insect life is too luxuriant; they stop the multiplication of a crowd of creatures that would do an infinitude of injury, and they limit the numbers and the geographical distribution of many species. When the insects which are most injurious to agriculturists are studied, the important 
office of the parasitic Hymenoptera becomes most evident, and they evidently render us most important services, for they check the ravages of the larvæ which destroy cereals, vines, and vegetables of all kinds. The balance of life between the vegetables, the caterpillars, and the parasites is most extraordinary. A few caterpillars come from the egg of one butterfly, perhaps in a newly cultivated district, and they are not noticed. The next year hundreds of caterpillars are found devouring everything, and then one or two stray Iclnemmons come upon the scene. They are so clever that they never miss their aim, and they lay thousands of eggs in as many caterpillars. The year following there are fewer caterpillars, and a great host of Ichncumons, that riddle every insect that comes in their way. Spring comes round again, and there are no caterpillars, vegetation flourishes, and then comes the turn of the parasites. Their office is completed, and they pass away. It is thus that armies of caterpillars suddenly appear and disappear.

There is some difficulty in applying the word parasite to all insects that live in intimate relation with others. The parasite just noticed lives at the expense of the vital juices of its victim or host. It does not devour the body, and then remain glutted. But many insects, like human parasites, only eat the provisions which others have laid up in store for the rainy day, or for their offspring, and these, of course, should be called the true parasites. Others live with their strange companions, and look out for scraps, and what happens to come in their way, these are comrades, and are very common in many families of the Articulata.

The Ichnemmonide have, as a rule, long thin bodies, slender legs, very large wings, which are much veined, and long, slender, vibrating, thread-shaped antennæ. Agility is written in every structure of the Ichntumons; the jaws have long palps; and the slender body, large wings, and the legs, which can be used for running, indicate unusual locomotive powers. The lively appearance of the insects is heightened by their projecting eyes and the long and restless antennæ. They are not to be caught readily, but rush off with wonderful rapidity out of the way of danger, and if a female is seized she endeavours to stick her ovipositor into the fingers of her captor. 
There are two very distinct tribes of Ichneumonida; the Ichneumons proper and the Braconide. The insects of the first tribe have four joints to the palps of their lower lip, and those of the last have only three.

The species contained in the first tribe are usually tolerably large, and the abdomen is rounded at its sides; their ovipositor is very small, and does not project from the hind part of the body when the insect is at rest. They introduce their eggs into the bodies of caterpillars, and other larvæ which live in full daylight. The genus Ichneumon forms part of this tribe, and its species have the abdomen rather thick, and attached to the thorax by a waist. These insects are elongate in form, and are usually decorated with yellow or red bands and spots, which are rendered striking by their black ground. The Pimplite are those Ichneumons which have the abdomen slightly narrowed at its commencement, and very projecting ovipositors; and the females of some kinds, especially of the Ephialte, have them longer than the rest of the body.

The black Ephialtes, a common parasitic Hymenoptera of the centre and north of Europe (Ephialtes manifestator), may be seen during the summer time in the avenues of woods, and resting on flowers, or running upon the trees. The whole of its body is of a shining black colour ; its transparent wings are slightly clouded, its legs are long and slender, and are of a bright red colour, the hind ones being brownish. The male is thin, and rather small, but the female is very robust, and comparatively large. The larvæ of the Buprestis beetles, which live inside the roots of trees, are afflicted by the females of this fine parasite, and there are few things more interesting than the sight of the egg laying. In very fine weather, when the sun is shining in great power, the insect appears full of animation. Its antennæ are perpetually vibrating and moving in different directions; its wings are trembling, and it is constantly running over the trunk of a tree with great rapidity. Every now and then the insect stops, runs to the right hand and to the left, and goes over the ground like a hound that has lost the scent. Then it seeks another locality, and the same vivacious proceeding is repeated a hundred times. Suddenly the insect appears to be satisfied that it has made a discovery, it stops, and 
commences to dig its long and curved ovipositor into the bark; there is a larva of Chalcophora Mariana in the wood, and the

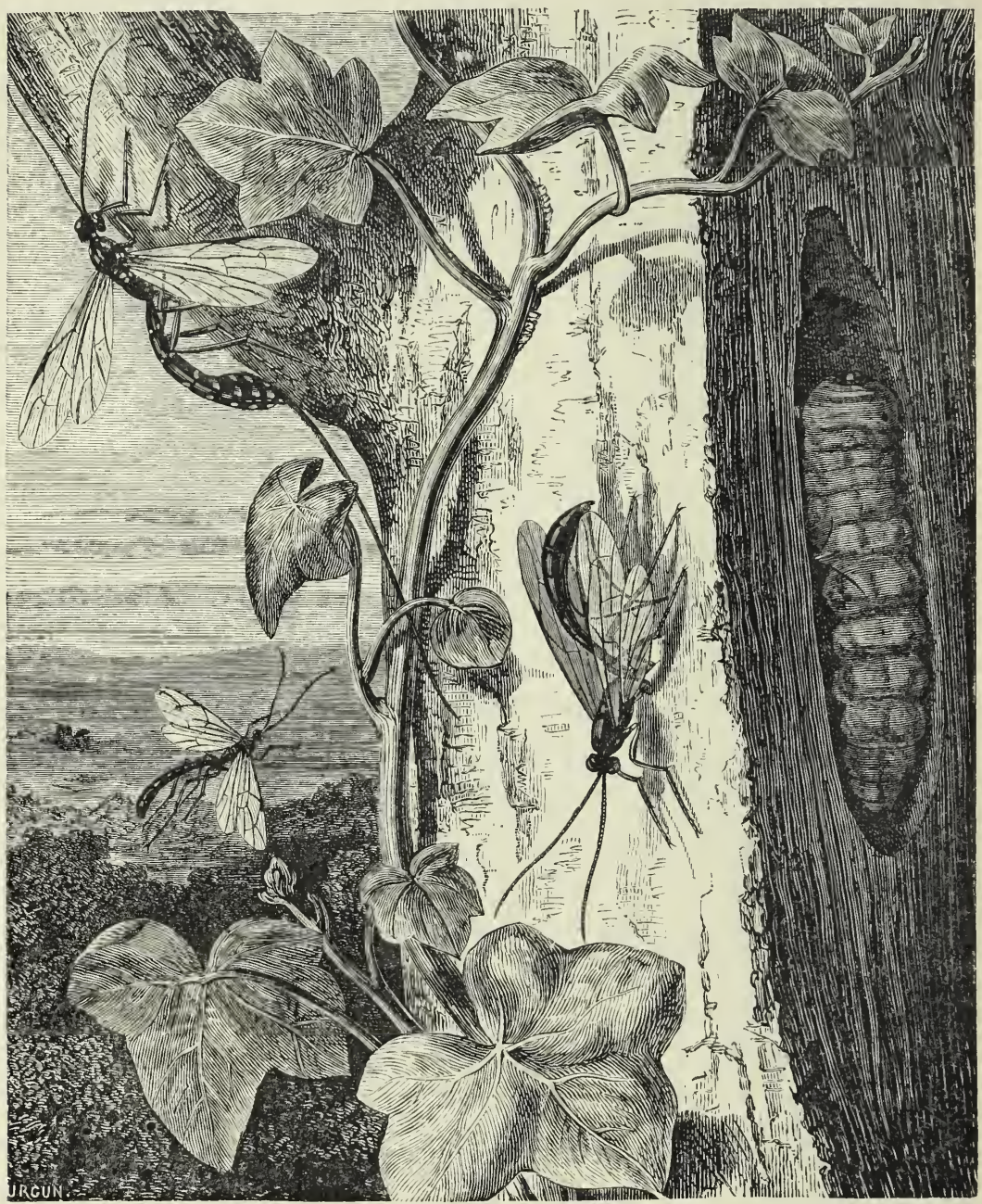

ICHNEUMONS.

Ephialtes manifestator. The male is flying on the left, and the female is introducing an egg into the body of a larva. Another Ephialtes, Rhy'ssa persuasoria, a female, is on the branch to the left hand.

Ephialtes has become aware of it. The insect lowers its head and grasps the bark with its legs ; it then lifts up its abdomen, bring- 
ing the ovipositor beneath, and plunges the point within a narrow fissure, so that it reaches the larva, which is grubbing away, in apparent safety, at the rotten wood. When the stroke is given, the valves of the ovipositor separate, and curve, so that the thrust, when it overcomes the resistance of the wood, penetrates far inside. In the engraving, which is, of course, a diagram, this operation is shown, the wood being removed over the larva. The curve of the ovipositor beneath the abdomen is apparent. All this is very surprising, for the active insect manages to discover the deeply secreted larva, which it cannot see, and to find out a convenient fissure in the wood down which to thurst its ovipositor with certain effect.

The Rlyyssa persuasoria has the same habits as the Ephialtcs, and is a much prettier insect, being marked with little spots, or lines of a yellow colour.

The Ophionide are Ichneumons, which can be distinguished at once by the peculiar shape of the abdomen, for it is bent, and compressed, literally like a sickle. They have a small ovipositor, and deposit their eggs either within caterpillars that feed on leaves in broad daylight and are unsheltered, or upon their skins. The eggs are somewhat remarkable, and have been carefully examined. They are oblong, and have a long and twisted peduncle, and this is fixed on to the skin of the victim. The young larva, on being hatched, breaks its egg shell on the side remote from the peduncle, allows its body still to remain within the pedunculated shell, and thus attacks the caterpillar in safety. Sometimes the female misses the caterpillar, and the egg sticks on her own body, so that when the larva is born it at once attacks its own parent. Most of these kinds are large insects, and Opliion luteus is very common in Europe.

The Braconide are a very large tribe, and are the commonest of the parasitic Iclnueumonida. They multiply at a great rate, and most of them are very small indeed. Many of them frequent flowers during fine weather, and are enemies of the beetles, and the species of the genus Alysia are parasitic upon the great family of the flies Muscida.

The Microgasters belong to a group which differs from that of the Braconites, and are very small insects, being about the 
twelfth of an inch long. They have no less than eighteen joints in their antennæ, and they deposit a quantity of eggs inside many species of caterpillars.

After having lived in the juices of the caterpillars, the larvæ of the Microgasters having attained their full growth, begin to devour the viscera also, and finally they eat through the skin. They then spin silky cocoons, and undergo their metamorphosis. One of the species, Microgaster glomeratus, which is black in colour, and which has fawn coloured legs, can be recognised easily, and its metamorphosis examined. The caterpillars of the cabbage butterfly, Pieris brassica, are frequently killed by this little parasite, and occasionally nearly every one of these destructive vegetable feeders falls a prey. They usually live until about the time of the first metamorphosis, and then they begin to look out for a safe place to hang themselves up, and to undergo the transformation into the chrysalis state. But it is just then that they die, for then the Microgasters which have had enough of the caterpillar, pierce through its skin, and form their cocoons on and around it. They complete their metamorphosis in a few days, and the perfect parasites fly. The cocoons of these Microgasters are usually united in packets, are oval shaped, and being composed of very fine yellow silk, look like those of silkworms in miniature. The smallest of the ichneumons are the species of the genus Hybrizon, and they wage war against the Aphides, one of them laying its egg in the Aphis, which is so common on the delicate stems of roses.

The Proctotmpida are distinguished from the Iclnannonida by their oblong body, the simple condition of the nervures of the wing, the moderately long antennæ, and the long pendant palps. They are such little insects that they must be examined with a good lens or a microscope, if they are to be studied. One tribe of them attacks the maggots of flies, especially of the wheat fly, and another lays its eggs in the larvæ of the Tipula-the daddy longlegs tribe. Some of the parasites of the maggots spin cocoons beneath the skins of their victims. The Teleas ovulorum is a tiny insect of about a fiftieth of an inch long, and it lays its eggs in the eggs of moths, and when its larvæ are developed they enjoy their curious and small habitation. 
The species of a most important family of the Hymenoptera have small palpi, the antenna consist of twelve or thirteen joints, and the nervure of the wing is simple and bifurcate; they are numerous, and the members of them are very common. These Chalcidide are small creatures, and attack all sorts of insects, and do not even spare the other parasites.

The species of the genus Chalcis are common, and the individuals are larger than those of the other kinds. They may be known by the peculiar shape of the antennæ, by the enlargement in the thighs of the hind legs, and by the prominent ovipositor. Chalcis minuta, which is very common in some localities, lays its eggs in the bodies of different kinds of caterpillars, and it is

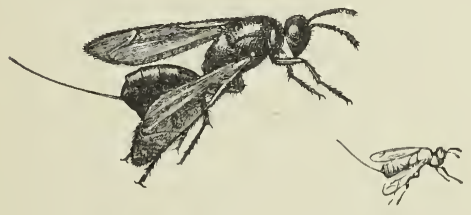

THE ADULT FEMALE (IF Diplolepis bedegzaris.

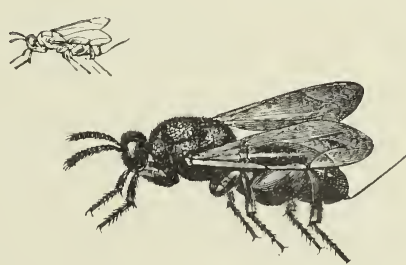

THE ADULT FEMALE OF Chalcis minuta.

especially fond of the Pyralis, which is so troublesome to the vine growers. Nine other species attack this pest also.

The Diplolepide have the body magnificently coloured with golden green tints, and their ovipositor is very long. The females usually seek out the larvæ of the species of Cynips which are enclosed in galls. The larve of the rose fungus upon the sweet briar are frequently attacked by the insect represented above, and a genus of beetles (Anobium) has its members killed and preyed upon by a Perilampis.

A small host of Pteromalide may be seen to issue from the body of a chrysalis of a Vanessa; and the tiny Eulopha, which are perfect insect gems, glowing with golden green and bronze tints, attack caterpillars, maggots, and the eggs of butterflies and moths indiscriminately. 


\section{HYMENOPTERA WITH DENSE INTEGUMENTS.}

\section{(Chrysidide.)}

This family of Hymenoptera cannot be very readily associated with the others. The Chrysidide are commonly called ruby-tail flies or gilded wasps, and they have a close resemblance on account of their peculiar shape to tiny wasp-like flies, but they never attain a third of the size of the common Vespa. The brilliant colours of the Chrysidida strike the observer at once, and their fiery tints look like a blaze of jewels. Some species have the body tinted with a beautiful golden green, others shine in ultramarine, and many have this splendid blue relieved by a scintillating ruby red colour on the abdomen. There are some large spots and chasings upon the thorax, which produce beautiful effects in the light, and thus the Chrysidide are splendid when moving restlessly here and there in the bright sunshine. Had they large bodies they would be prized for their beauty as the humming birds of the insect world, but as they are small creatures, their decorations are therefore less striking.

The integuments of the Chrysidida are very thick and hard; and the insects have the power of rolling themselves up like a ball, by bringing the abdomen against the underneath part of the thorax. This is quite a peculiarity amongst these Hymenoptera; moreover, they differ from others by having a cylindrical body, the abdomen being concave below, and very convex above, and attached to the thorax by a very short waist. The rings of the abdomen appear to shut up more or less within each other, like a telescope slide. The females carry a very sharp sting, which gives great pain. These insects have filiform antennæ, long mandibles; the jaws have palpi, formed of five joints; and the lower lip projects, and is membranous, so that they can suck. The wings are moderately veined, and the legs are slender. These insects exhibit a wonderful amount of activity under a broiling sun, and then they are never still, but are constantly flying here and there, and resting a while upon the flowers. In some spots of central Europe-where these insects are much more common than in the north--they collect in numbers, and afford a mag- 


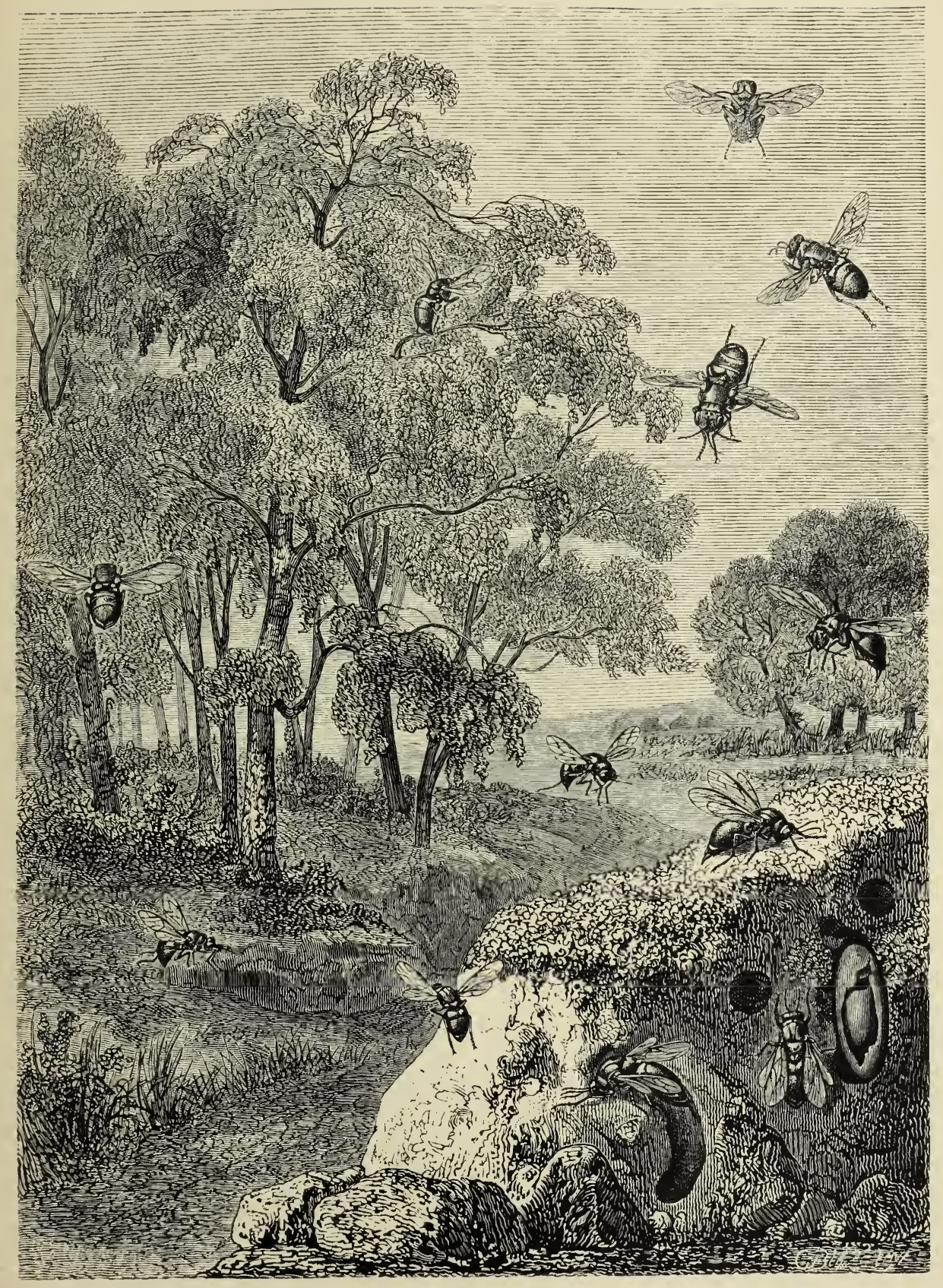

CHRYSIDIDÆ.

Chrysis ignita, Stiloum calens, Parnopes carnea, whose cocoon is to be seen enclosed in the larva of a Bombyx. 

nificent spectacle; and they resemble fiery pearls rushing to and fro. They have no industrial habits, and do not lay eggs within other insects. Their larvæ, liowever, only live upon living prey, and the instinct of the female leads her to lay her eggs where the future offspring will be protected against danger. She has no hesitation about laying them in the nests of the other Hymenoptera, and especially where there is some provision being laid up for the larvæ. She does not care for the solitary bee or a Bembex, for she has a terrible sting and a hard cuirass, which is not to be pierced by ordinary insect weapons.

The female introduces herself into the nest of the bee, for instance, and rolls herself up if attacked, and then, being victorious, lays her eggs on the food which has been stored up. The little parasites are hatched, and live upon this food with the larvæ of the original tenant, and when the store has been devoured they attack the larvæ, and suck their juices. They make a cocoon before undergoing their metamorphosis, but very little is known about their transformations.

The Chrysis ignita is very common in England, and may be seen in constant motion, running upon walls and palings; it lays its eggs in the nests of hornets, sand wasps, and solitary wasps.

Some beautiful insects of the genus Hedychrum have habits like those of the Chrysis just mentioned. Lepeletier de Saint-Fargeau describes the attack of a sand bee upon one of them which had invaded its dwelling in order to lay eggs. The Osmia, a sand bee, discovered the intruder in the act, and immediately proceeded to turn her out by laying hold of her with its mandibles. But the Hcdychrum rolled herself up like a ball, and was invulnerable. The bee carried her out, gave her a good shaking, bit her wings off, and left her. She had her way for all that, and crawled back again into the nest, and laid her egg.

The Stilbi have a very convex abdomen, and are inhabitants of warm climates, but a species is found in Central France. The species of Pamopes are green insects, with flesh-coloured abdomens. Pamopes camci lays its eggs in the nests of the Bembex. 
'THE A N'T FAMILY.

\section{(Formicida.)}

Ants are so common in nearly every part of the globe that they are very well-known insects; nevertheless, they have all sorts of characters given them. They are considered destructive and encroaching, as well as disagreeable things, and they have, as a rule, a very doubtful reputation amongst the public in nearly every country; but naturalists and those who inquire a little more carefully into the mysteries of the insect world, are always ready to admire their wonderful instincts. In fact, the ants possess those marvellous gifts in as great a degree as any other beings. The ancients were struck with their admirable underground works, and from the earliest times imagination has assisted those who look superficially into the natural history of these little creatures, at the expense, however, of truth. The curious ideawhich appears to have commenced in very remote times, and to have been carried down by tradition, and which was assisted by the results of careless observations-concerning the habits of the ants in collecting and storing up provisions, as it were, under the influence of a wise foresight, is evidently incorrect. But although this foresight is not developed in the ants, they still have a few resemblances by which they can be compared with men, so far as social habits are concerned. The same is true for wasps and bees, and many other insects, but when the matter is carefully looked into, the analogy between the insect and human society is much less than might have been supposed. It is evident that all the individuals of a tribe of ants act in concert to carry on a common work, which is invariably effected by means of all, or at least of the greatest possible number of the insects. This is certainly wonderful, but there is nothing like what is observed and which appears to be inevitable in human society, namely, a hierarchy composed of individuals which command, and of others who obey. To all appearance, the most perfect equality exists between all the individuals of insect societies; no one commands and does not work, for they all work, and each insect appears to understand what is required of it, and affords assistance to others 
when it is necessary-being influenced by the instinct of doing a certain definite duty; at least this appears to be consistent with correct observation. Many authors have imagined that the industrious insects that live in communities obey certain chiefs, and have, as it were, a sort of government. The opinion appears to have originated in a very simple manner-because such a state of things exists amongst men, and appears to be necessary; but all the best established facts relating to insects which live in communities, such as ants, wasps, and bees, prove that every one has an equal share in the government of the commonwealth, and that the so-called kings and queens, which are the objects of particular attentions, have no authority, and are in no way concerned with the occupations and labours of the rest of the tribe. The ants, like almost all the Hymenoptera, are born in a very rudimentary condition, for their development within the egg has not progressed much. The larvæ are even incapable of taking the food which is within their reach, for their mouth-pieces are very small and feeble, so that it is necessary that the nourishment should be placed inside their mouths. Thus they may be said to be constant objects of care and anxiety to others of the community. The nursing, which is attended to with wonderful perseverance, is carried out by the workers, who are first-rate nurses, and at the same time admirable architects and builders of spacious and comfortable nurseries.

The united species of ants constitute the family of the Formicide, and are very readily distinguished from other Hymenoptera. They have a triangularly-shaped head, bent antennæ, the first joints of which, always very long, are stalk-like; they have a large upper lip, strong mandibles, and the jaws and lower lip are short; the legs are long and slender, and the abdomen, which is more or less oval, is attached to the thorax by a short and narrow waist. The ants without wings, which are most commonly observed by everybody, and which run about roads and paths, and which have a very narrow thorax, are the workers, or neuters; they crawl over plants and up walls, and are found everywhere. But the males and females are only to be noticed at certain times of the year, and can be distinguished at once from the workers by their possessing wings, and a very broad thorax. There are a 
great number of species of ants, and they may be divided into three groups, which are characterised by some rather important structural differences. These groups are the Formicites, Ponerites, and the Myrmicites. The segment at the base of the abdomen forms a single knot or swelling in the first and second groups, but the females and the workers of the Ponerites have stings, and those of the Formicites have not. The Myrmicites have a sting, but their abdominal segment is formed into two knot-like divisions.

The common genus Formica, the true ants, belongs to the Formicites, and its individuals may be distinguished by their triangular and very dentate mandibles, which are their tools. As every species of ant has peculiar habits, it is best to take one as the type. The ant to which we intend to devote our attention

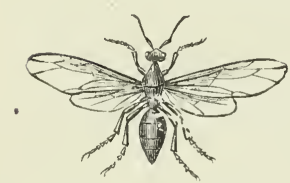

Male.

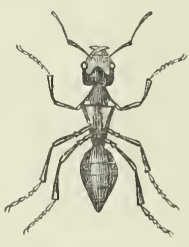

Worker.

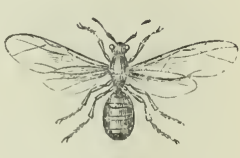

Female.

A. H Y $\Lambda$ N T.

is by no means uncommon, for although it may not be found in woods and copses, yet it is sure to be met with upon nearly every road or path, and very few people that live in Central Europe can say they have never seen a long train or column of the red ant. This ant, Formica mefa, or the Red Ant, is principally known through its workers, which are nearly red, and are very interesting to watch. The workers have a black spot on the head, and sometimes on the thorax, and the abdomen is blackish above, except at the waist. The female, which has the same general tint as the worker, is shining as if it had been polished, and it has the upper parts of the head, the thorax, and the abdomen of a beautiful black colour, and the wings are rather dusky at their bases. The male, which is almost as large as the female, is quite black and hairy.

Now, let us examine the dwelling places of these red ants. 
They may be found in woods where the underwood is not very dense, and they constitute slightly elevated and rounded little patches of earth at the foot of oaks for instance, but sometimes they are of considerable width and length. The surface of the hills is made up of a mass of little pieces of wood, bits of straw, flints, grains of wheat or of oats, and of earth, and it does not require much trouble to become aware that they are all arranged with a purpose, although they appear to be laid about confusedly. If a portion of the roof be broken down a crowd of agitated ants comes to the breach, and begins to repair the mischief at once, working with the most intelligent and persevering determination.

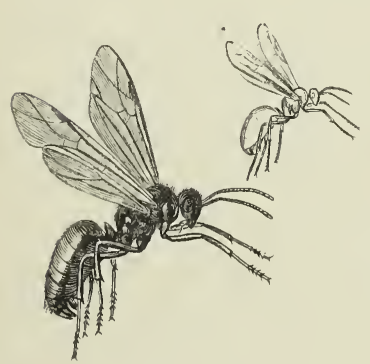

Male.

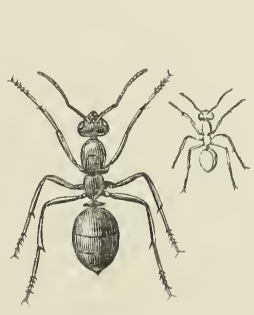

Worker

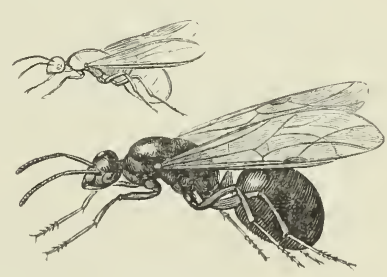

Female.

THE RED A N T.

(Formica mfa.)

A glimpse may be had of the interior of the building whilst the roof is being reconstructed. Sometimes the nest descends to a considerable depth, and it will be noticed that the ants have had to clear out and excavate portions one after the other, as the swarm increased in numbers. It appears to be made up of a tangle of pieces of wood all about the same size, and which appear to be piled up anyhow; but by examining the confused mass with some attention it will be noticed that the morsels of wood are so arranged that they form chambers, galleries, and more or less irregular tracks or runs. Moreover, they are so arranged as to permit a free passage in every part of the nest. In fact, the pieces of wood are disposed after a definite plan, and with much care. Those in the lowest part of the ant's 
nest are stuck into the ground, and are so piled up one upon the other as to prevent the effects of a sudden and violent shock; above all this the tiny beams are laid in stages, one over the other, and in some parts of the nest the intervals between them are filled up with such substances as earth, grains, and dried leaves. It is the presence of these grains-which are used by ants as materials with which to construct their nests-that has given rise to the idea that these insects collect provisions for the rainy day. But ants do not eat wheat or grains of any kind; their nourishment consists of more or less fluid or soft substances, and these supposed wise and economical creatures do not store up, but live from day to day from hand to mouth, and, like most insects, become stupid and hybernate when winter arrives.

If a nest of red ants is examined at different times during the day, a constant succession of alterations will be seen to be going on. Very early in the morning everything seems quiet about the nest, and there are no openings visible, but there are some small cracks which might allow the ants to get out by undergoing a tight squeeze. Then a few of the insects begin to show themselves, and run over the dome of the nest, and they appear to be just awake; gradually they increase in numbers, and then some of them are noticed carrying and bringing little bits of stick, whilst others are clearing out and sweeping the passages to the nest. Should it happen to be fine weather, many large openings, which communicate with the principal galleries, are soon made outside the nest, and then the whole population becomes actively engaged, and each individual appears to have something to do. When the evening comes, the insects shut up the nest, and close the passages, and do everything to enable themselves to pass a quiet night after their labours, by rendering their house secure against violence and invasion. Should heavy rain come on during the daytime, the ants, fearing that water might get inside their nest, hasten to close its openings, and every member of the swarm appears to be impressed with the necessity of doing its best, and all sorts of materials are brought at once to shut the water out, and to place the erection in safety.

Pierre Huber was the first naturalist who made a careful study of these proceedings, which secm to be produced by 


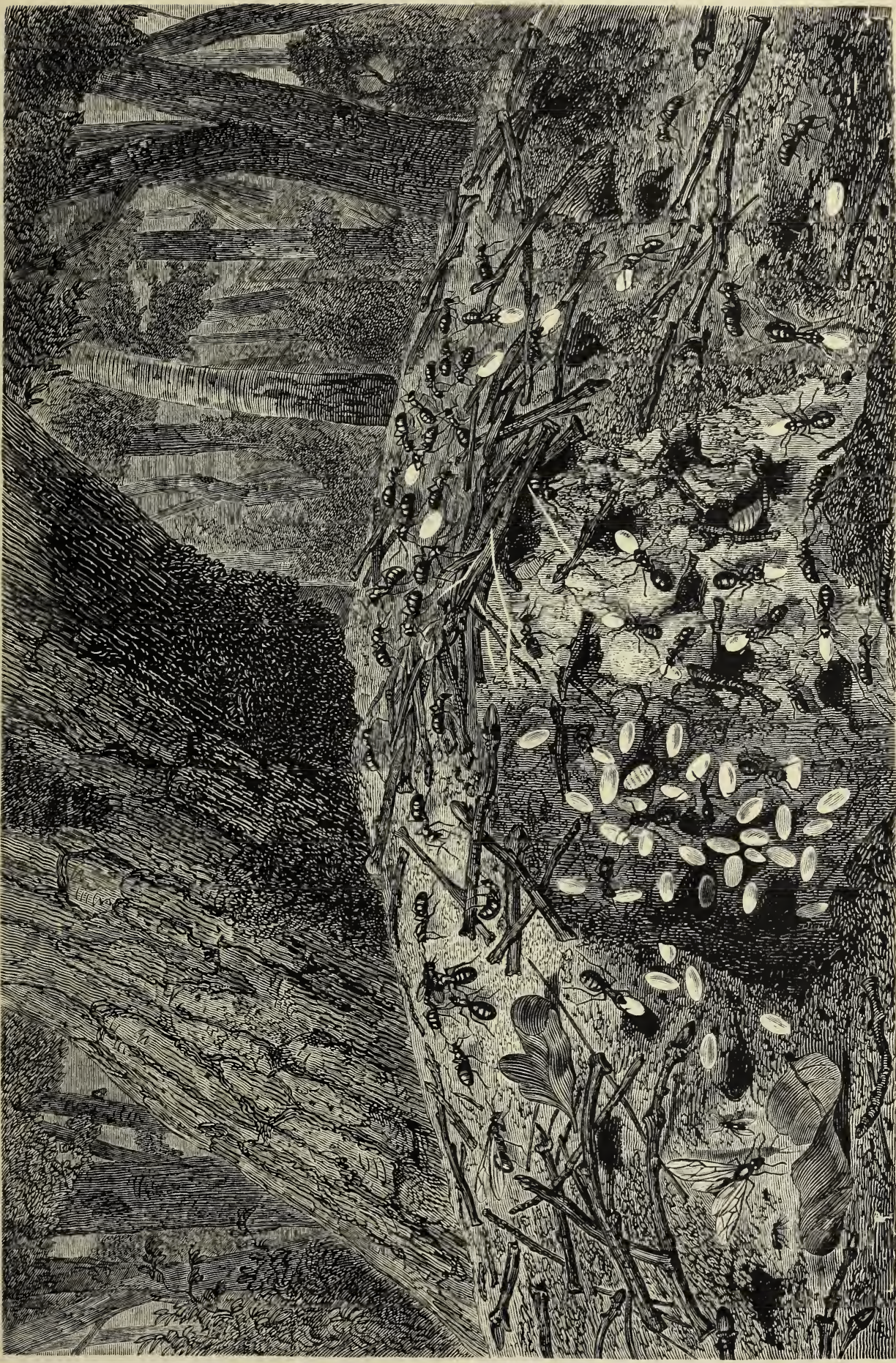



a greater or less reasoning power; moreover, he had the good fortune to witness many proceedings which have not been seen by other observers. Thus, he describes how the ants bring little beams, and place them in front of the galleries, the entry to which they wish to construct, and how they seek for smaller pieces of wood as the operation advances. Having observed these interesting manœuvres, Huber wrote:-“ Is not this the art of our carpenters in miniature? Nature seems to be everywhere in advance of those inventions of which we, as men, are so proud." Huber is correct, for if careful observers of Nature had existed amongst the early races of men, many important branches of knowledge and mechanical ideas, which civilised nations have taken centuries to discover and to complete, would have been found out very soon.

The engraving of the nest of the red ant was drawn from Nature in the forest of d'Aunay, near Paris. The rounded form of the nest is very evident, and there is a great rent in it, which occupies the centre of the mass. The dark holes into which working ants are carrying large oval-shaped cocoons, which are commonly called eggs, are the commencement of galleries, over which small pieces of wood may be noticed fixed in the earth. On the left hand side there are some male and female ants, with wings, and some workers may be seen close to the tree, pulling at a fly which has come within their reach. The whole nest is in a great state of activity in consequence of a portion of it having lately been broken into.

It is very interesting to observe how the ants commence to build their nests, and the beginning of the work may be seen when the overplus of inhabitants of a nest is obliged to leave it in order that a new colony may be founded at the foot of some other tree. First of all the ants have to do mining work, and they dig into the soil with their mandibles, and after prolonged labour they. manage to make a cavity. Then the little bits of wood and the other building materials are sought for, and brought in and stuck into the earth, being crossed one over the other in a most ingenious manner, so that the chambers, the greater or less sized cells, and the galleries, are constructed and strengthened in the lowest part of the nest, and then the upper stories are built. If a large ant's 
nest is opened early in the spring-time, no winged insects will be found, but a multitude of workers, and a few females, which have lost their wings; they are readily distinguishable, however, by their thick thorax and colour. All the female ants are born with wings, and very shortly afterwards they leave home, and fly off with a number of males, but they soon settle down to be careful and steady housekeepers; for whether they stray back to their old nest, or whether they come near to others, they begin to tear off their wings, and should any workers be in the neighbourhood they assist them in completing this extraordinary operation. Nature does not care to perpetuate useless structures, and they generally drop off, or become smaller, but in this instance the
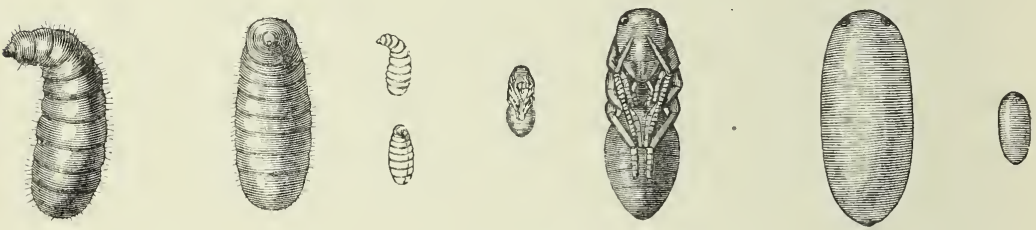

THE LARVA, NYMPH, AND COCOON OF THE RED $\Lambda \mathrm{NT}$.

A larva rnagnified and of the natural size, seen sideways and from above. The nymph seen from below, actual size and magnified. The cocoon of the nymph enlarged, and of the natural size.

ants appear to know that the wings are about to be useless to them, for the females will live a perfectly sedentary life for the future, consequently they act instead of Nature, and destroy their useless organs of flight. The wings of the female ants have nervures which are more or less divided close to their origin, so that they can be cut through very easily, and without the insect suffering any pain. The females begin to lay during the first fine days of the year, and their white and very tiny eggs increase sensibly in size until the larva escape from them. The workers take wonderful care of the eggs; they place them in special chambers, and appear every now and then to lick them, and they carry them alternately to the upper and lower stories of the nest, and manage so that they are never exposed to too great a heat, and that they are kept in a uniform temperature. When the 
larvæ are hatched, more care than ever is required on the part of the laborious insects, for then the ants, which we have noticed as able and industrious architects, have to take their turn in the nursing; and certainly more attentive, vigilant, and devoted servants could not be found.

The little vermiform larvæ cannot move, but they have the instinct to lift up their heads, and to open their mouths, so as to receive their subsistence from the jaws of the nurses, and they are thus fed like little birds lately hatched. It is not for themselves alone that the ants seek honey, sugary liquids, and the juice of fruits, with such avidity, but it is quite as much for the larvæ, to whom these nice things are carried. The particular delights of ants are known to everybody; every one complains in the country of the constant visits of these insects, and they show themselves wherever fruit can be obtained, and where there are syrups and sugar. They may be seen upon flowers, the nectaries of which they visit for the honey, and they are almost always upon the stems of those plants which are crowded with Aphides. Not that they do any harm to them, on the contrary, they rub them gently with their antennæ, and then the Aplides, apparently pleased, cause a little drop of sugary liquid to appear at the end of the small cylindrical tubes, which are situated at the extremity of their bodies. This is what the ants require, and they soon sip it up. The Apliides thus act as cows to the ants, and it is very remarkable that as yet no one has been able to recognise the use that this secretion may be to the Aphides themselves. As soon as an ant discovers a spot where there is some plunder to be had, bands of them will constantly come and visit the place. The ants return to the nest gorged with food, and give up a portion of it, which they have retained in their gullet-pouch, to those which have remained at home, and especially to the larvæ. Hundreds of observations have proved that these industrious insects communicate with and understand each other. Frequently they may be seen to stop and to touch each other with their antennæ, and many naturalists have thought that these appendages are the special organs of a particular insect language. They may be noticed singly or in numbers succouring wounded brethren, and leading them to the nest, and when the inhabitants of 
two nests encroach upon each other, they fight in military array, and with great skill.

It is very interesting to watch the workers in their almost incessant nursing of the larvæ. They clean them by rubbing them with their palpi, they carry them in the early morning up into the higher stories of the nest, so that they may be warmer, and they bring them back again into the depths of the cells when the sun becomes too hot for these frail little creatures. It is very wonderful how the worker ants manage to carry these very soft larvæ in their very sharp mandibles, but accidents never happen, and such a thing is unknown as a wound produced by unusual pressure, or by tumbling up against the walls of the long corridors and chambers of the nest. When the larvæ become full grown they spin a silky cocoon in order that they may undergo their metamorphosis in it. The cocoons are oval in shape, and indeed so much so that they are usually called ant's eggs; and it is certainly curious that a great number of intelligent and highly educated people believe that ants lay eggs much larger than themselves. In fact, it does not strike them as being at all wonderful. Does not nearly every one talk about the ant's eggs, which are collected to feed young pheasants? but these so-called eggs are really cocoons manufactured by larvæ, and which contain them or nymphs. The nymphs are perfectly enclosed in their silky cocoons; they are white, and resemble the adult form swathed up. The workers carry them about as they do the larvæ, and with the same intentions.

When the metamorphosis is completed the perfect ant is absolutely too weak to tear open the silk of its cocoon, and would inevitably perish in this natural prison were it not for the vigilance of the workers, which, like excellent nurses, never let their charges out of their sight. Perceiving that a change has taken place inside the cocoon, these admirable attendants open it with their mandibles, and set free their new companion. But even when thus safely born the lately metamorphosed insects are not in a condition either to take care of themselves, or to take a part in the labours of the community, so their nurses do not leave them, but give them nourishment, and then lead them all over the nest, and thus appear to introduce them to their new life. Fortunately, 
not much education is required, and the young are soon able to participate in the labours of the old. Whenever large numbers of workers are born or are metamorphosed, some males and females come to the light also. The workers love the old house, but the males and females appear to have but one wish, and that is to fly away from home as soon as possible. Some do not fly very far, and when they alight, as has already been noticed, the workers assist the females, and carry them to their nest; most of them, however, fly, or are carried by the wind to great distances, and when they settle they form new colonies. The males appear to die soon after they see their pretty companions remorselessly snipping off their wings, and settling down to a quiet humdrum life.

It was formerly supposed that the females which alighted at a great distance from their old nests returned again, but Huber, having great doubts upon this subject, found that some of them after having left the males, fell on to the ground in out-of-the-way places, whence they could not possibly return to the original nest. It was evident that either they must do something for themselves or else die in obscurity. Huber observed a solitary female go down into a small underground hole, take off her own wings, and become, as it were, a worker ; then she constructed a small nest, laid a few eggs, and brought up the larvæ by acting as mother and nurse at the same time. The larvæ were a generation of workers, and when they grew to adult age, and began to execute all their usual works, from that moment the mother ant became lazy, and did no more. In order to make himself doubly sure upon this point this excellent naturalist imprisoned a single female ant in a little cage, and observed its proceedings. It is quite evident that the greater part of the intelligence and instinct of the ants is devoted to the care of their young before and during metamorphosis, and it is always interesting to notice the agitation of the workers when a hole is made in a nest, and a number of larvæ and nymphs are exposed to daylight, or when they fall from the top to the bottom of the breach. The workers immediately rush to succour these tender little things, and the first care is to carry them off to the deep passages out of sight. This having been done, the reparation of the nest is thought 
about, and the ants, working energetically, will often repair the mischief in the course of an hour. Although most of the species of ants resemble each other in their habits, instincts, and intelligence, each one chooses a particular position for its nest, and establishes it upon a special plan, which has greater or less reference to some peculiar habit. Huber calls those kinds which only use earth as the material for their nests, Mason Ants; there are two kinds of them which are common over a great part of Europe, the Brown Ant, Formica fusca, and the Mining Ant, Formica cunicularia. The neuters or workers of the first species are of a blackish brown colour, and their bodies are covered with fine black hairs, the antennæ and legs being of a reddish tint; the females are of a brilliant black colour, and the males have fawn coloured legs, but are otherwise dark. The workers of the second species are of an iron-red colour, and the females have the same tint, but the males are black. The brown ants, or those of the first species, hollow out the soil and make in the interior of a great cavity cells, galleries, and more or less spacious avenues, all in stories, one over the other, and their nest looks like the dome of a vault outside. The mining ant constructs its divelling very much in the same manner, but the roof never appears above the level of the soil. These insects work the earth with their mandibles, and make pillars, columns, and partitions out of it, and do not neglect to fill up cracks, or to level irregularities, and in fact they act like very able builders. The mason ants cannot work during very dry weather, and they wait patiently, with their buildings half finished, for rain, but should some parts of them which were built up as the weather became very dry show any signs of cracking, the intelligent insects pull them down, and wait for better times. Huber gave some mason ants a good watering from the rose of a waterpot when they were in this somewhat desperate condition, and they set to work immediately, and built up walls and cells, and completed a story in a few hours.

Other ants live in old trunks of trees, and cut and work the wood in a wonderful manner. Of these, Formica fuliginosa, which is of a brilliant black colour, with pale reddish tarsi, is the most common example, and its works almost defy description. It builds many stories, which are almost always horizontal, forms 
platforms and beams of about the thickness of paper, and makes upright partitions of the same delicacy, and these include and partition off rooms and cells, the number of which may be really said to be immense. In some places they make little columns instead of the partitions, which give a miniature palatial aspect to the excavation. Other ants settle down inside the beams of houses, and interfere with the safety of large buildings in consequence of their very intelligent and destructively excavating habits. All these different species, which have such diverse constructive instincts, appear to take care of their larvæ in very much the same way; but there is one kind, Formica sanguinea, which is of an iron-red colour, that settles down in the nests of other species, especially in those of the brown and mining ants, and singularly enough it attacks these kinds in order to carry away their nymphs, so as to make slaves of them. This is an extraordinary fact, but there are other examples of the same kind, which we shall notice presently. We have already mentioned the curious use that some ants make of the Aphides. The red ants visit the plants which are covered by them, but they do not hesitate to look after cochineal insects, scale insects, and several Hcmiptcra; moreover, in those parts of the world where there are no Aphides or scale insects these ants seek the Cicadcllae. But under certain circumstances the ants do not care about passing good food in order to enjoy the tiny drops of aphis liquor, so in order to save time they bring the authors of these little luxuries into the immediate neighbourhood of their nests, and sometimes carry them inside. This is peculiarly the case amongst the ants which lead very sedentary lives, and they select those Apliides which live upon grass and roots. Such species of the genus Formica are always very attentive to the captive Aplides, which they collect together in considerable flocks. Huber says that an ant's nest is all the richer according to the number of its captives; these are the cattle, the cows, and the goats of the ant tribe. Besides these objects of care, many little insects live with the ants, and receive very good treatment from them. Some of them will be noticed in the next chapter, so it must suffice at present to state that the young of the beetles of the genus Clavigera have 
tubular hairs, which the ants are very fond of licking, and they thus appear to have some special secretion which pleases their hosts. It is a very remarkable fact that the larvæ of these beetles cannot take their own nourishment, but they receive it from the mouths of the ants, and these extraordinary little beings thus have the instinct to nourish and to keep alive the beetle larvæ, which afford them some pleasant luxury.

There are some ants with arched mandibles, which are narrow and sharp, and which resemble warlike weapons rather than implements of work. They belong to the genus Polycrgus. The common species of this genus, Polyergus rufescons, is a small insect about a quarter of an inch long, and is a warrior, and does not care for building or any such trouble. It inhabits underground nests, where the brown and mining ants are found, but it does not make its own places of refuge, as it has no structures with which it can work, so it captures the workers of other colonies and employs them as slaves. Huber describes a curious scene in the life history of these ants, which he saw in the neighbourhood of Geneva in I804. He observed a great mass of ants which were red or russet in colour, and of tolerably large size, traversing a road. They marched in a body, and with great rapidity, and they took up a space of from eight to ten feet in length by three or four inches in breadth, and they passed over the road in a very few minutes, penetrated through a thick hedge, and moved on to a grass field, over which they marched in regular array, in spite of numerous obstacles which came in their way. They soon came near a nest of blackish coloured ants, which was situated about twenty paces from the hedge, the dome of it being higher than the grass. Several ants were round about the door of their nest, and immediately that they observed the approaching army they rushed upon the head of the column; the alarm was given within, and a crowd came out from the underground works. The red ants quickened their pace, and soon pushed the black ones into their nest, they then clambered up the dome of the nest, many forcing themselves into the largest avenues, whilst others worked hard with their mandibles, so as to open a breach in the walls. This was soon clone, and the rest of the invading army penetrated 
through the breach. Three or four minutes afterwards the red ants came out again in great haste, each one holding between its mandibles a larva or a nymph. They took the same route homewards, but not in the same military array. This is a clear case of slave making; and after a time the red ants live in peace with and enjoy the results of the labours of their black workers. Under these circumstances the red ant's nest is said to consist of amazons, or legionaries, and workers. It is a wonderful instinct that causes the red Polyergi-which cannot work the soil and construct underground edifices, and which cannot nourish their own larvæ-to select workers from the nests of other species to do all this. They never seek adult workers, for they would never
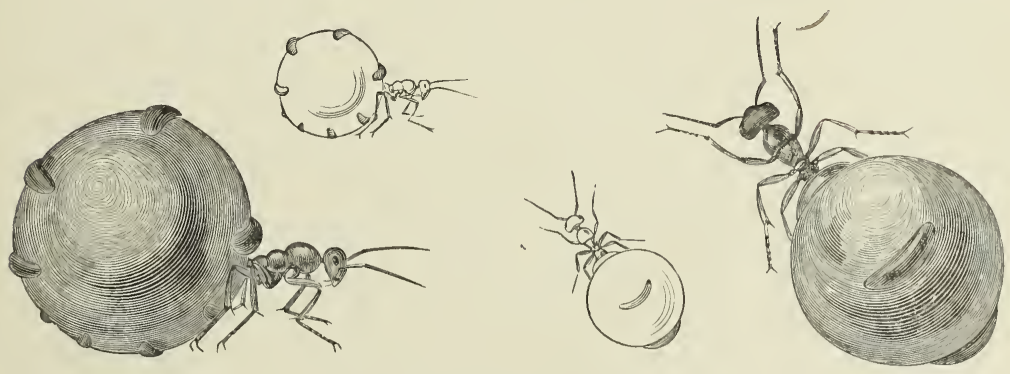

Myrmecocystus Mexicanus.

The ants are represented as seen from above and sideways, natural size and magnified.

stop in a strange home, so they look out for nymphs and larvæ, which never attempt to depart from the nest when they have completed their metamorphosis, but set to work to build cells as well as to feed the larvæ of their captors. A very curious ant is found in Mexico, and was described nearly thirty years since by a Belgian naturalist, M. Wesmaël. The abdomen of this ant (Myrmecocystus Mexicanus) can be distended to a prodigious extent with a sort of honey. They are common near the town of Dolores, and are known there under the name of Busileras, and they live in underground nests, which are not distinguishable from without. These insects do not present any unusual distension of the body in early life, but after a while it is observed in a certain number of individuals. When the accumulation of syrup is very great in the intestines, the body 
becomes so distended that it resembles a transparent bubble. When the ants are thus blown out they cannot walk, but remain fixed or suspended to the floors of the galleries of their nests. The women and children of the country dig them up and enjoy their honey, and it is by no means unusual for these insects to be served at table, the head and the thorax being removed, so that the sweet portions resemble little isolated bladders on a plate. One would almost fancy that this syrupy secretion must collect for some purpose, and probably these very corpulent individuals are the nurses of the establishment.

Many of the ants belonging to tropical countries are classified under the group of the Ponerites, and one of them, Typhlopona Oranicnsis, which is found in Algiers, forms small colonies; it is of a pale red colour, and lives under stones. The males and females are unknown, but the workers all appear to be blind, they never come to the light, and they labour constantly in their dark galleries. How they obtain their food, and of what it may consist, are matters for future observation.

The Mymicites are found in Europe and in America, and the ants of this division are usually very small in temperate climates, but in the inter-tropical regions of America many of the species attain a very considerable bulk, and are also very abundant. There are two forms of workers in the nests of the different kinds of Myrmicites; in one the insects have a small head, and in the other a very large one. This difference in the size of the head has been frequently recognised amongst the workers of the nests in South America, and it appears to be the case also with a European ant. The ants with large heads are called Soldier Ants, in consequence of the expressed opinion of travellers, who assert that they are particularly devoted to the defence of the nest. The supposition that these robust and well-armed individuals might be males has not yet been justified by anatomical investigations. M. Lespès has noticed in the European species that both kinds of these neuter workers do the same sort of work in the interior of the nest. A late discovery made by Professor Schenck has shown that there is a kind of Myrmica whose mandibles are made like those of the Polyergi, and are therefore useless as working instruments. M. Mayr has separated 
these ants into a genus, and asserts that they make slaves of other kinds of Myrmica, and employ them as workers. There appears to be some confusion about the proper name of some of the large ants of America, but nevertheless these insects are known by popular terms; and one, which is called the TravellingAnt, and which lives in Brazil, does some good, and at the same time a great deal of mischief. One kind, Acadona cephalotes, is known by the great size of its workers, which have an enormous head and spine behind, and a tuberculated thorax, the whole insect being of a blackish-brown colour; the female, however, although very large and of a brown colour, has an ordinary sized head. These ants unite in immense numbers, and travel long distances, and suddenly appear in houses, and destroy beetles, rats, and all the disagreeable things that collect in tropical habitations. They make their nests with leaves, and Mr. Lund says he was once passing near to a tree, the foliage of which was perfect, when he was surprised by the leaves falling off it like so much rain, although there was no wind; he went to look at the cause of this strange phenomenon, and found an ant working away with all its energies upon each leaf stalk. The stalk was soon cut through, and the leaf fell to the ground. There was a most curious scene going on, however, at the foot of the tree, for the ground was covered with ants, which were cutting the leaves in little bits as soon as they fell down. In less than an hour the tree was stripped of its foliage, the leaves were cut up, and their pieces carried off.

The Driver Ants of West Africa are stated by Dr. Baird to have no permanent dwellings, as other ants have, but to range about in vast armies in quest of prey. They make their excursions during the night or in very cloudy weather, the hot rays of the sun being fatal to them. If obliged to march during the day they construct underground arches of clay cemented by a fluid secreted from the mouth, and under these arches the pupæ and the prey are carried by the workers. If on their march they are intercepted by a stream of water it is said that they throw across it a bridge of their own bodies, over which the main column marches with freedom and safety. It is to be hoped that if this is true the obliging bridge makers can swim. The community is divided into three classes, soldiers to attack and 
disable their prey, assistants to divide the prey into portable portions, and the labourers or workers. The bite of these insects is very severe, and so intense does it become by accumulation, that large animals, when confined, have been overpowered and destroyed by them. They have been known to kill the Python Natalensis, the largest serpent in that part of the world ; and they are decidedly aggressive in their habits. Their entrance into dwellings is known by a simultaneous movement of all the rats, mice, lizards, and cockroaches with which they may be infested. Even man has to get out of their way, and the driver ant chases him from his home. They are most useful in the economy of Nature; they consume much dead animal and vegetable matter which might otherwise taint the atmosphere ; they tend to keep down the rapid increase of noxious insects and vermin; and they compel the inhabitants to observe habits of comparative cleanliness, as a filthy town or house is sure to be visited by them.

\section{FOSSORIAL HYMENOPTERA.}

The Hymenoptera thus termed belong to several well characterised families. Some resemble the ants both in appearance and in their habits; others have a peculiar look about them, which particularises them, and the rest resemble wasps. But although these fossorial or excavating Hymcnoptcra differ so far as their external characters are concerned, they have many mutual resemblances in their habits and methods of life. They are generally very industrious insects, are gifted with great constructive powers, and are animated with a wonderful amount of instinct and foresight in the preparation for the subsistence of their young. But it must be understood that this last gift only pertains to the females, which are always armed with a sting, for the males do not trouble themselves about their young in any way. These Hymcnoptera excavate the earth and walls, and sometimes penetrate branches of trees and stems of bushes, so as to make safe places and shelters for their larvæ. They are furnished with cutting and toothed mandibles, and their legs are covered with spines, which can act like rakes, and they use these working implements 
with great dexterity. When they are adults their nourishment consists of fluids, such as the honey from flowers and the sap or gum of trees, but when they are larvæ they are carnivorous, and can only exist upon living prey. Consequently the mothers are obliged to chase other insects, and to catch them for their larvæ, and it is therefore a curious and suggestive sight to witness a noncarnivorous insect hunting prey for its carnivorous young, which it is never destined to see. There are only two kinds of individuals amongst these Hymenoptera, namely, males and females, and there are no special workers or neuters, as there are amongst wasps, bees, and ants. The females are always solitary, and work away at the building of their nests, and supply the young with food without any help whatever. Every female chooses an appropriate place, and each species has its particular fancies with regard to the future position of its young; the locality may be chosen in the earth, a cliff, a wall, or in the stump of a bush. They often avail themselves of cavities formed by Nature, or of fissures and cracks, but the proper shaped hole is always formed with great energy and intelligence. The mandibles are the only instruments and tools, though the legs with their spines act as rakes to scrape out and eject the portions of earth detached with the jaws, but the industry and perseverance of the insects are so constant, and their patience is so wonderful, that a small gallery is soon dug out, and an oval shaped cell is made at the bottom of it; sometimes several cells are excavated, but every species has its peculiar arrangement as regards the number of the chambers.

The chamber being formed, the Sphex, the Pompilus, the Crabro, or the Odynerus, as the case may be, must immediately undertake to store up provisions within it, and therefore other insects are hunted, each species having its particular prey. Some like caterpillars, others the larvæ of Colcoptera, and a few even attack spiders; and the Sphex is gifted with that peculiar instinct which has already been noticed in the Icluneumons, for if it obtains a larva belonging to an insect which grows to a considerable size, it only places one in each chamber; but if the larvæ are small, several are introduced, and if they are minute it hunts down a crowd of them. When it seizes its prey, the fossorial Hymenoptera pricks it with its sting, the venom of 
which produces a lethargy, which lasts a long time, and, in fact, the wounded insect never recovers perfectly. There is thus a most interesting series of phenomena of a most remarkable character. The larvæ of these Hymenoptera imperatively require nourishment, which can only be derived from living tissues; they would die close to a dead body, or if they were placed upon an animal which was decomposing, or which had become dry. Thus these larvæ which have no offensive weapons, and which cannot move from place to place, come at last to gnaw and feed upon living insects which cannot do them the least harm. The diffculties which are required to be overcome in order that all this can be consummated would be insurmountable were it not for the bountiful providence of Nature, which causes them to disappear as if by enchantment. These larvæ have nothing to fear from their victims, which have been rendered inert by a proper dose of the venom of the female insect; they cannot offer the least. resistance to any sort of attack, and, condemned to be slowly eaten, they nevertheless live until a large portion of their substance has been consumed. Death can hardly be said to take place until the larva has had enough, and has reached its full growth. The poison of the sting seems to act upon the tissues as a preservative, and caterpillars and the larvæ of beetles which have been stung by Hymenoptera may be kept for several months in pill boxes without showing any alteration, and without undergoing death or decomposition. It is to be hoped that the same Providence that feeds the larve in this extraordinary manner gives the venom a power of subduing pain; if not, Providence is certainly on the side of the Hymenoptera, and a more dreadful fate than that of the living death of the poisoned insects can hardly be imagined.

As soon as one of these fossorial Hymenoptera has collected a stock of provisions within its cell, it lays an egg inside and closes the opening with a portion of the rubbish of the excavation, and alters the outside appearance of the work so completely, and makes it look so much like the neighbouring surfaces, that it is very difficult even for intelligent collectors to find out the nests. The female constructs a great number of these cellular nests; sometimes they are close to each other, and at others they are widely 
apart, but it provisions them all in the same manner, and deposits a single egg in each; then its work is done, and it soon dies. Thus this mother has taken infinite pains, has shown a wonderful foresight, and has laboured without rest for the sake of a progeny which it never can see, and which has habits totally unlike its own. This is the result of instinct, whatever that may be, and it is evidently not the result of reason. Some interesting details bearing upon this subject will be noticed further on, when Bembex vidua is described.

There are some species in all the families of nest-making insects which have the usual organisation and the same method of development, but which have no structures with which they can labour, and which have no maternal instincts for the benefit of the larvæ. We have noticed that some ants make slaves of the individuals of other species who can render proper assistance to the young, and do such work of which they themselves are incapable; and amongst the fossorial Hymenoptera some may be found which cannot chase prey and enclose it in cells, but they manage to introduce their eggs into the galleries and nests which have been well furnished with victims by hunting Hymenoptera. Thus the females which cannot hunt manage that their larvæe live like comrades at the expense of those of the fierce and industrious kinds. They introduce their eggs, and the larvæ are soon hatched, and crawl out of the egg sooner than those to whom the nest really belongs; the consequence is, these parasites-the offspring of lazy parents-eat up a large portion of the provisions laid up in store, to the great detriment of the others. The female Hymonoptera which act in this very human manner have neither mandibles proper to excavate earth, nor legs so spined that they can act as rakes; so not having a mechanical power, they use their wits at the expense of the goods of those insects which are endowed with the means of labouring.

The Mutillide were formerly taken for ants, because the females, having no wings, can only run over the ground, and thus resemble the neuter or worker ants. They are solitary insects, and consist only of males and females, the former having wings. They are found in all parts of the globe, and principally in the tropics. The genus Mutilla is found in Europe and in 
North America. Mutilla Europea is by no means an uncommon insect; the male is of a deep blue colour, has a red thorax, with dusky wings, the margins of the first segments of the abdomen being ornamented with silky hairs of a silver grey. The female is black, its thorax is red, and it has three grey bands on the first three rings of the body. The females are found in woods, walking slowly upon the earth, and they may be seen entering

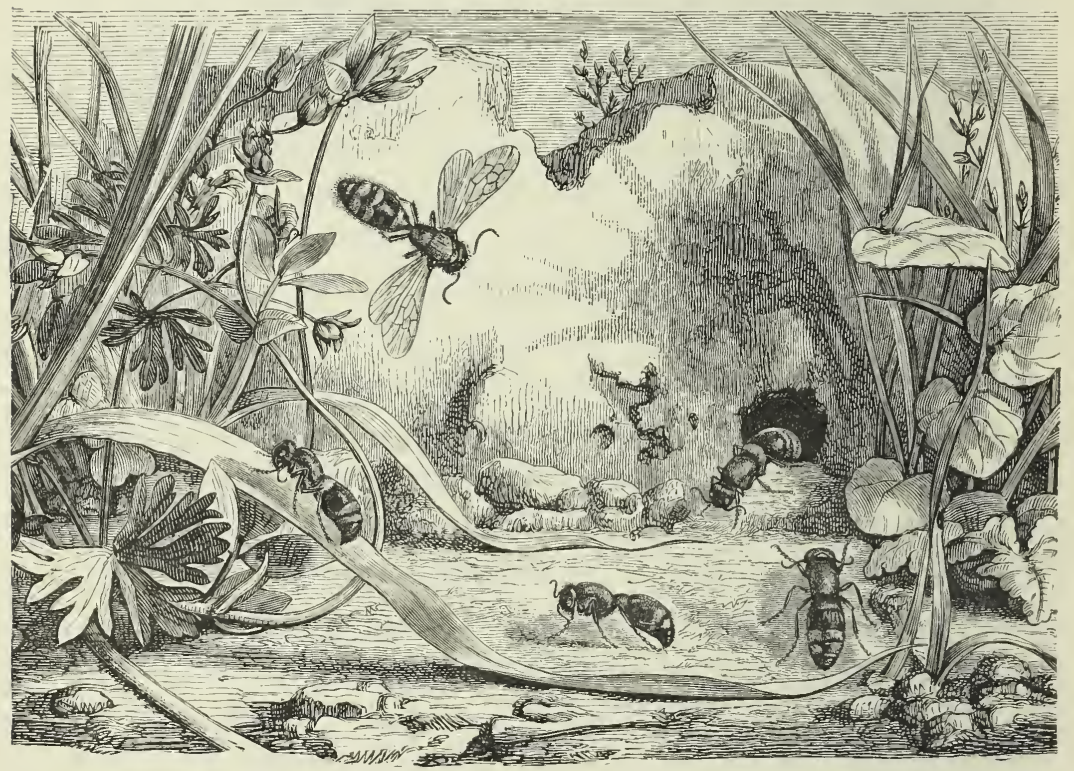

Mutilla Europaca.

holes in the earth, but nothing is satisfactorily known concerning what they do there.

In the engraving the male is represented flying, and the females, which are without wings, are crawling over the ground, coming out of a hole, and crawling upon a leaf.

One author has satisfied himself that the females visit the nests of large humble bees, and this assertion has caused them to be considered the mothers of parasites, but several naturalists have seen them attacking insects, and others have taken them in their holes, where the remains of grasshoppers and of flies were found, and these relics have been considered the leavings of the 
larvæ of the Mutilla. The females have strong and spiny legs, fitted for excavating, and they also have dentated mandibles, so that the implements for forming cells are present, and therefore they are sure to be employed. The females of the North American species have powerful stings and a very acrid venom.

The Australian kinds are arranged under the genus Thynmus, and one of them has a most extraordinary history.

Verreaux states that the males have long bodies, and straight antennæ, but that the females, which are much smaller, have no wings, and twisted antennæ. The male flies about, and carries the female with him, paying her the greatest attention, and placing her on flowers, so that she can obtain her nourishment.

Frequently other males, which have not the happiness of possessing a wingless companion, come near and appear enchanted with her company. Of course they all become jealous, and a fight ensues, and should her protector be unable to conquer the others, in order to disappoint, them he eats her up.

The species of the great genus Scolia have females with strong and arched mandibles, and very spiny legs; some of them include insects of very large size, and the commonest is often noticed in gardens in Central France, Italy, Spain, and North Africa. A Florentine naturalist, Carlo Passerini, studied the natural history of Scolia flavifrons in i840. If old rotten trunks of oaks, or masses of tan, such as are used in gardens and hot-houses, are examined, very large larvæ of a beetle are often found; these larvæ belong to the so-called Rhinoceros Beetle (Oryctes nasicomis). They are usually very quiet, and live in spaces which they have formed within the tan, and they are particularly subject to the attacks of the females of this Scolia.

The Scolia is searching for food for its future larva, and it finds out that the beetle larva is within reach, so it digs down to it, and stings it, so as to produce the curious stupid condition already noticed as invariably following such an attack. As soon as this is done a small egg is laid on the skin of the torpid creature, and is glued to it by a special secretion. A young larva is born from the egg at the end of a few days, and immediately commences to gnaw the skin of its victim with its mandibles; it gradually forces its head into the wound, and 
begins to suck the animal juices. The young Scolia grows rapidly, and day by day the beetle larva becomes smaller and smaller, in consequence of being continually sucked. By the time that it has become completely exhausted, nothing else but the skin remaining, the larva of the Scolia has attained its full growth. It then spins a thick cocoon of a brown colour inside the skin, which is all that is left of the beetle larva; so that this unfortunate creature affords food to the Scolia in the first part of its life, and a certain amount of protection and covering during metamorphosis. The Scolia passes the winter in its cocoon, and undergoes its transformation into a nymph during the spring, but the perfect insect does not break forth until the commencement of June.

In the engraving a male and female Scolia will be noticed, the one on the leaf and the other in flight. Immediately underground in a cell is a larva of the beetle Oryctes nasicomis on its back. The small larva of the Scolia has its head forced into the body of the beetle larva. Below, and on the right hand, is a cocoon which will be seen to rest inside what is left of the beetle larva; and on the left the nymph of the Scolia is shown within its cocoon.

In the Seychelle Islands, and in Madagascar, there are some species of Oryctes the individuals of which attain a great size; they do a great deal of harm to the cocoa-nut trees, and thus cut off one of the most important sources of food in tropical countries. There are two kinds of larvæ of the genus Scolia which eat and destroy the larvæ of these beetles, and which are metamorphosed exactly in the same manner as the European Scolia.

The Sphex is a well-known insect, and belongs to a genus which is closely allied to Scolia, and is commonly called the Sand Wasp. They are generally of considerable size, and their colour is of a brilliant violet blue, more or less deep, and some of them are marked with bands of yellow. Species are found scattered over all parts of the world, especially in warm climates, but only one is found in Great Britain. These Hymenoptera are remarkable for their activity and also for the elegance of their shapes. There is one which has yellowish wings and a red 


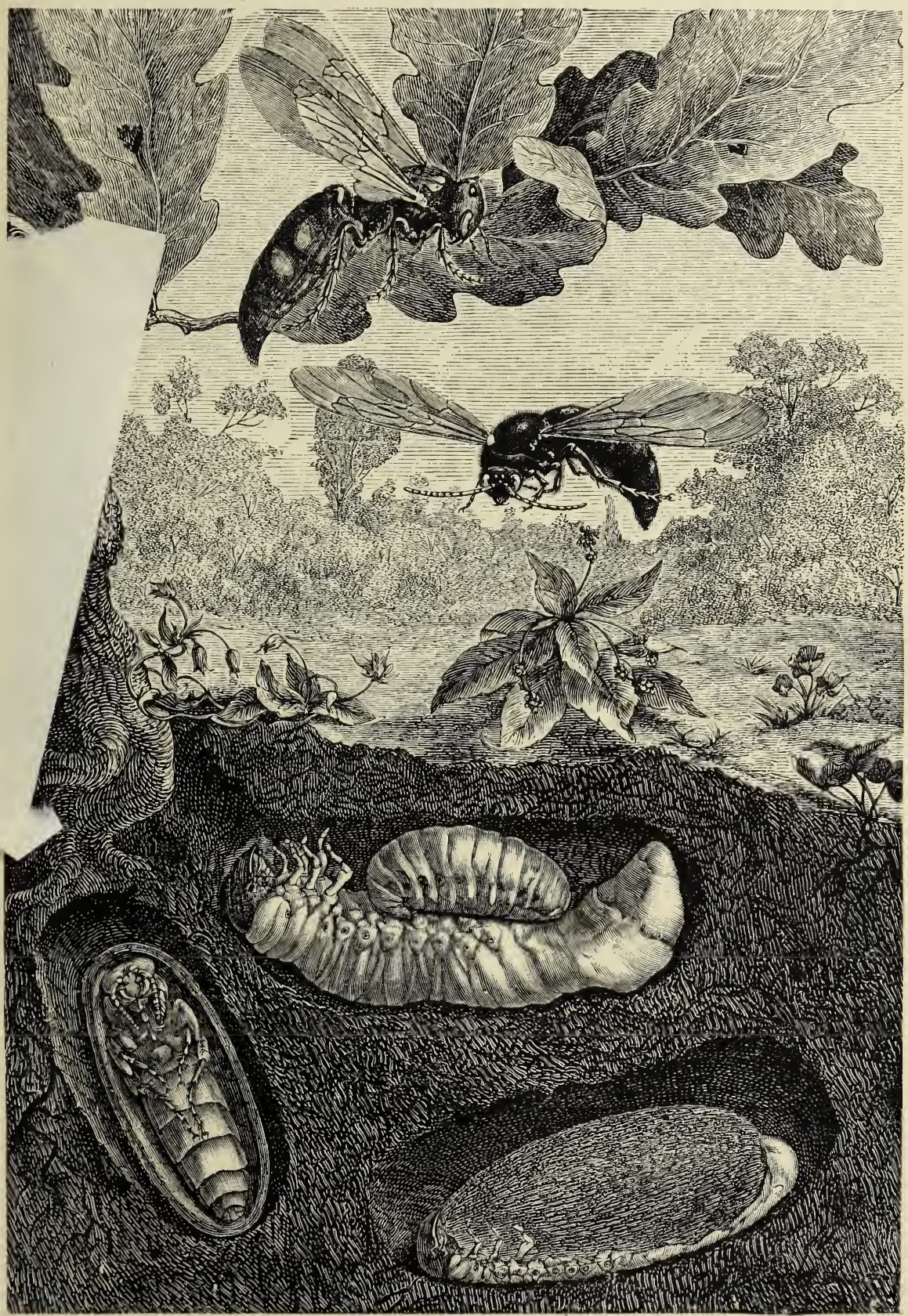

THE METAmorphoses of Scolia flavifrons. 

abdomen (Sphex favipennis), and it makes nests in the sand, in which it lays an egg; then it seeks the larvæ of grasshoppers, and places them in contact with the egg, after having stung them. Another kind, which is found in Languedoc, attacks a very large grasshopper; and it is indeed surprising what very large insects the Sphegide can carry and introduce into their nests. The females of the English species may often be seen in the eastern counties coming out of holes in the banks, and if they are watched, the process of their excavations is not difficult to understand. When the little hole is dug sufficiently deep in the soil, a tiny egg is laid within, the female comes out and stops up the opening with a piece of dust, and flies off in

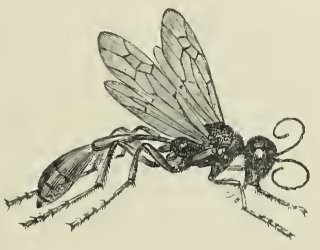

Female.

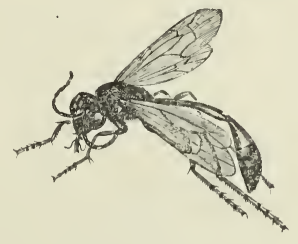

Male.

Ammophila sabulosa.

search of a victim. It pounces upon some small caterpillar or larva, or even small flies, stings one of them, and carries it off bodily to its nest. The female can always discover the hole it has made, and, after rolling away the earth that closes it up, the future food of the young Sphex is pushed into the cavity, which is then closed up from the outside. The activity, energy, and excitement of the insect whilst all this is going on are very great, and it soon dies after the provisioning of the nest is completed.

The genus Ammophila contains one species, the true Sand Wasp, which is very abundant in Europe. It is a slender, elongated insect, with a red band across the lower half of the third, the whole of the fourth, and the upper part of the fifth segment of the abdomen. It has habits like those of the Sphcx just described, but it invariably chooses the caterpillars of certain moths for the prey of its larvæ.

There are some Sphegide in the tropics which have enormnusly 
long waists and very arched mandibles, without teeth on their internal edge. The insects are black, with yellow marks upon them. They are perfect masons, and work in a most intelligent and persevering manner. A species common in Central France

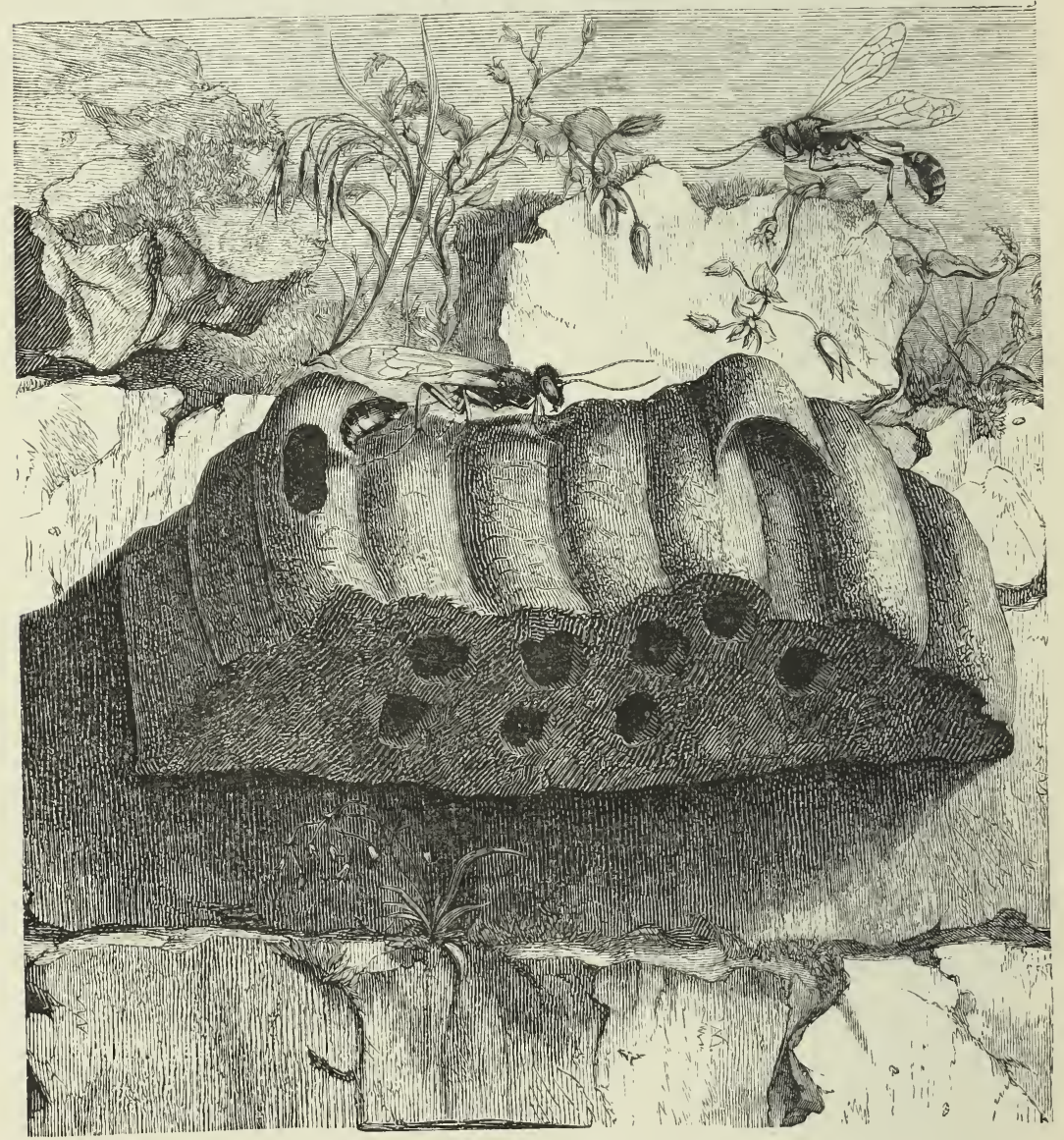

Pelopeus spirifex AND ITS NEST.

(Pclopaus spirifcx) builds its nest in walls, in corners of buildings, and sometimes within barns and houses, but almost always at the height of several yards from the ground. The insect is very slender, and does not seem fitted to carry burdens, but nevertheless it seeks clayey spots, and beats up small portions 
with its mandibles, and carries them off in order to construct its nest.

It begins by forming one chamber, which is hollowed out in the clay brought from a distance and stuck on to a wall, and as soon as it is finished the female goes a hunting, and, curiously enough, selects the most dangerous, bold, and well-armed creatures there are for its prey. It does not hesitate to attack spiders, in fact, it rather enjoys the fight with them. Doubtless, the strong sting of Pelopceus is a terrible weapon, and if it touches the spider there is an end of the combat, but if not, this last insect has its web at hand, threads of which it can throw with great rapidity and exactness.

The Pelopaus is both bold and prudent, and approaches the web flying carefully, and usually it manœuvres so well that the spider is stung before it can do anything; but it sometimes does happen that the spider is prepared for the attack, and the Pelopaus finds its movements paralysed by some fine threads being thrown over it. Then the spider encircles its enemy with layers of web, and devours it.

But it does not often happen that the Pelopens is captured, on the contrary, it usually manages to bring one, two, or three spiders to its nest, according to their size. They are introduced, and an egg is deposited close to them, and then more clay is brought, and all is closed. Thus the first chamber is constructed and victualled, and then the female builds a second one on the side of the first and upon the same horizontal line, and fills it in the same manner, then the third and the fourth cells are added, and sometimes there are six or eight of them. The external surface of the nest is marked with long depressions, which correspond with the intervals between the cells. The lower part of the nest is thinner than the rest, and when the larvæ have become full grown and have undergone their metamorphoses the adult insects come out from this part and leave open holes.

If a nest be detached from a wall before the second metamorphosis has commenced-and this is by no means an easy operation, for the masonry of the Hymenoptera is good-the cells will be noticed to be occupied either by larvæ or by cocoons, which have been made by them after the attainment of their 
full growth. The cocoons are made out of a paper-.like tissue, and are soft and shining, and of a brown tint.

A very beautiful Hymenoptera renders immense service to the inhabitants of the Islands Maurice and Bourbon, and they only regret that the insect is rather uncommon. This Chlorion compressum constructs its nest very much like the Pelopaus, but it does not hunt the same prey. All the seaport towns of those colonies are infested with cockroaches, which do an infinitude of mischief. Fortunately, they have many enemies, and the most terrible of all is the insect just mentioncd. It is by no means an unusual thing for a struggle to be witnessed between one of

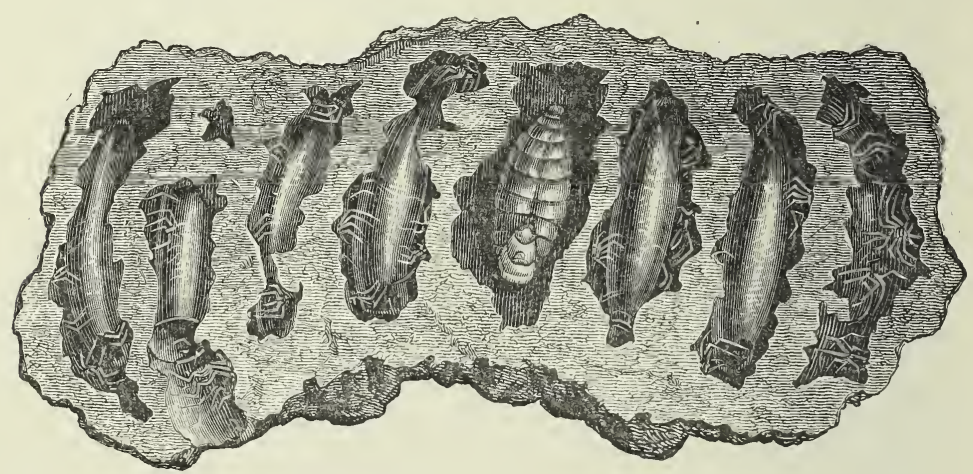

The nest of Pelopaus detached and seen from within.

these agile Sphegida and a cumbersome Blatta or cockroach, but it appears wonderful what use the small insect can possibly make of the larger, and how it can manage to drag such a bulky body into its small nest.

The Chlorion may be seen hunting about here and there, and up and down the roadside and gardens, searching for its favourite prey. It spies out a cockroach, which appears to know intuitively that there is danger at hand, for it shows symptoms of great fright, and seems so confused that it cannot run away. The Chlorion pounces upon the insect, clasps it with its mandibles between the head and the corselct, and stabs it in the body with the sting. Then it flies off for a little distance, and awaits the effects of the poison thus introduced; and when the convulsions of 
the victim have ceased, the clever little insect seizes its stupefied prey, and drags the heavy burden with great efforts to its nest. Usually the opening of the cavity is so narrow that the cockroach cannot be got in, for its legs and wings stick out and prevent its introduction. But the Chlorion sets to work and cuts off the legs and the wings, and having thus lessened the difficulty, it strives hard to push the body into the hole, but as this plan usually fails, the Hymenoptera enters first of all, seizes the cockroach with its mandibles, and drags it in with all its force. As the integuments of the Blatta are more or less soft and flexible, the great insect is at last forced into the gallery, where it never could have been expected to have entered. Such proceedings on the part of the Chlorion almost verge upon the domain of reason; and it is difficult to explain them by the notion of that very indefinite quality called instinct, for the manœuvres vary according to circumstances, and there appears to be an intelligent method of overcoming every difficulty.

The species of the genus Pompilius are fossorial Hymonoptera, which work with the same degree of perfection as the Sphegide, and which hunt with the same bravery and with the same cunning. Those of this country are very small insects, and make their nests in sand or in old trees, for they seem to know that the rotten wood will relieve them from much trouble in the matter of hole-digging. They all provide spiders for the nourishment of their larvæ. Most of them hunt those wandering spiders which scamper about and never make webs, but a few do not hesitate to attack and carry off the great garden spider, even when it is located in the middle of its beautiful web. Some Pompili, which have legs without spines, are incapable of digging, and therefore they act like some of the other insects already mentioned, and which have corresponding structural deficiencies, for they lay their eggs in the nests of other fossorial Hymenoptera, and their larvæ act like parasites.

The Crabronide appear at first sight to resemble the Sphegide, but on examining any of them, it will be observed that the body is only moderately long, their antennæ are straight, the upper lip is hardly projecting, their hind legs are not much longer than the others, and the fore legs end in a broad point. They are common insects all over the world, and their shapes vary 
with their habits and methods of life. There is a sub-family of them called the Bembecide, and they are insects which have a large body, a very distinct lip, and pointed mandibles which have one tooth on their inner margin. The species of the genus Bembex are remarkable for the great length of their jaws, and their lower lip is formed into a sort of trunk, and they may be seen sucking up honey with it from flowers. Bembex rostrata is the commonest of them, and it digs deep, cell-like holes in the sand, and victuals them with flies and Diptera of all kinds; it then lays its eggs, and closes the orifice of its cell with that great care which has already been noticed amongst the Sphegide. The examples we have offered showing the habits of the fossorial Hymenoptera have a certain sameness, for in every instance the female builds the nest, fills each cell with victims for the future larva, lays an egg close by them, and shuts up the habitation, and then dies without ever seeing its progeny.

But M. Fabre, of Avignon, has described the habits of Bembex vidua, which are certainly most remarkable and suggestive, and probably very rare, in the history of the Hymenoptera. In this species the female does not close up the cell, but penetrates into it every day, carrying in a fresh victim for the larva; and it always chooses a fly. Here is a case of a female insect caring for its larva which it sees, and which it notices to eat and care for food, so that the daily visit becomes a pleasure and a duty, according to the usual law of maternity. Of course the larvæ of this species run great risks, for their cells remain unclosed, and carnivorous insects may enter in and destroy them. Moreover, the mother may be taken and killed herself, and then, as no food would be forthcoming, they would die from starvation. There is no doubt that the habits of this species cast a light upon those of the insects which only provide one store of provisions, and then close their nests; for it is not difficult to imagine that if the egg of a former Bcmbcx vidua, the predecessor of all these, should not happen to have hatched at the second visit of the mother, she would have closed the hole and left it uncared for, not seeing the use of troubling herself to no purpose.

Cercoris arcnaria is a species of the tribe of the Crabronide, its members are very common in Europe, and have been 
carefully studied. These insects are very fond of dry ground and sandy soils which are exposed to the noonday sun. They dig deep holes, and it is very remarkable that they should provision them with beetles of the weevil tribe alone. It does not matter what may be the species of the weevil, so that it is one of the family; in fact, ten or twelve species belonging to different genera have been found in the nests of a Cerceris, which certainly appeared to choose the toughest and strongest-skinned beetle it can for the use of its very soft-skinned larva. But the $H y$ menoptera has the instinct to select weevils which have been lately born, and whose integuments, therefore, are not very firm; and,
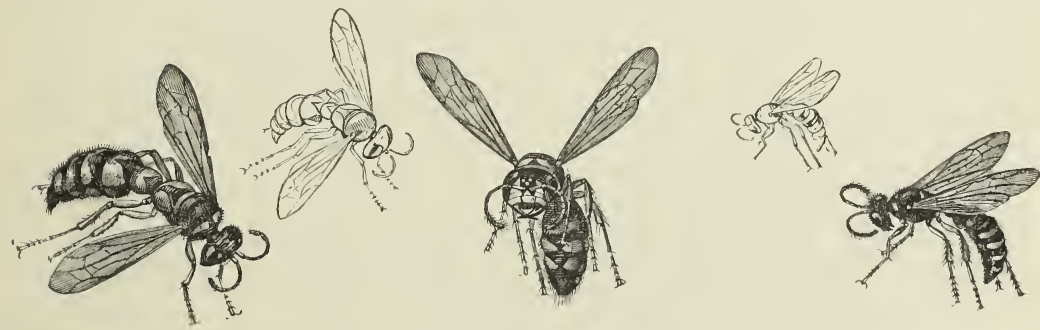

Cerceris arenara.

Females in different attitudes, those shaded darkly being magnified. A male natural size and magnified.

on the other hand, the larvæ appear to have no difficulty in sucking the juices of their prey between the segments of its body.

Cerceris quadricincta, which has been studied by M. Fabre, has a great fancy for weevils, but it does not choose large ones, and selects those of the genus Apion, the smallest of the family, so that it has to collect at least thirty individuals to provision one of its cells. Another Cerceris even attacks those beautiful beetles called Buprestis, many of which glitter like diamonds; and some kinds chase other Hymenoptera, and one beautiful Corceris seizes honey bees, whilst an allied kind selects Ichncumons as its prey.

The genus Philanthus is well known, in consequence of the peculiar habits of one of its species, which is a great bee killer. Philanthus apivorus or triangulum has a black head and body spotted with yellow, and its abdomen is yellow, but there is a triangular black spot on each of its segments, so that it is an insect readily distinguished. It digs galleries in paths in sandy soils, 
and makes them vertical at first, and afterwards horizontal, and carries them on to some depth and distance; indeed, some of the galleries are said to penetrate downwards to the depth of a foot. It is a most audacious insect, and it settles upon flowers, and pulls them about, and plays with them, as if it did not want

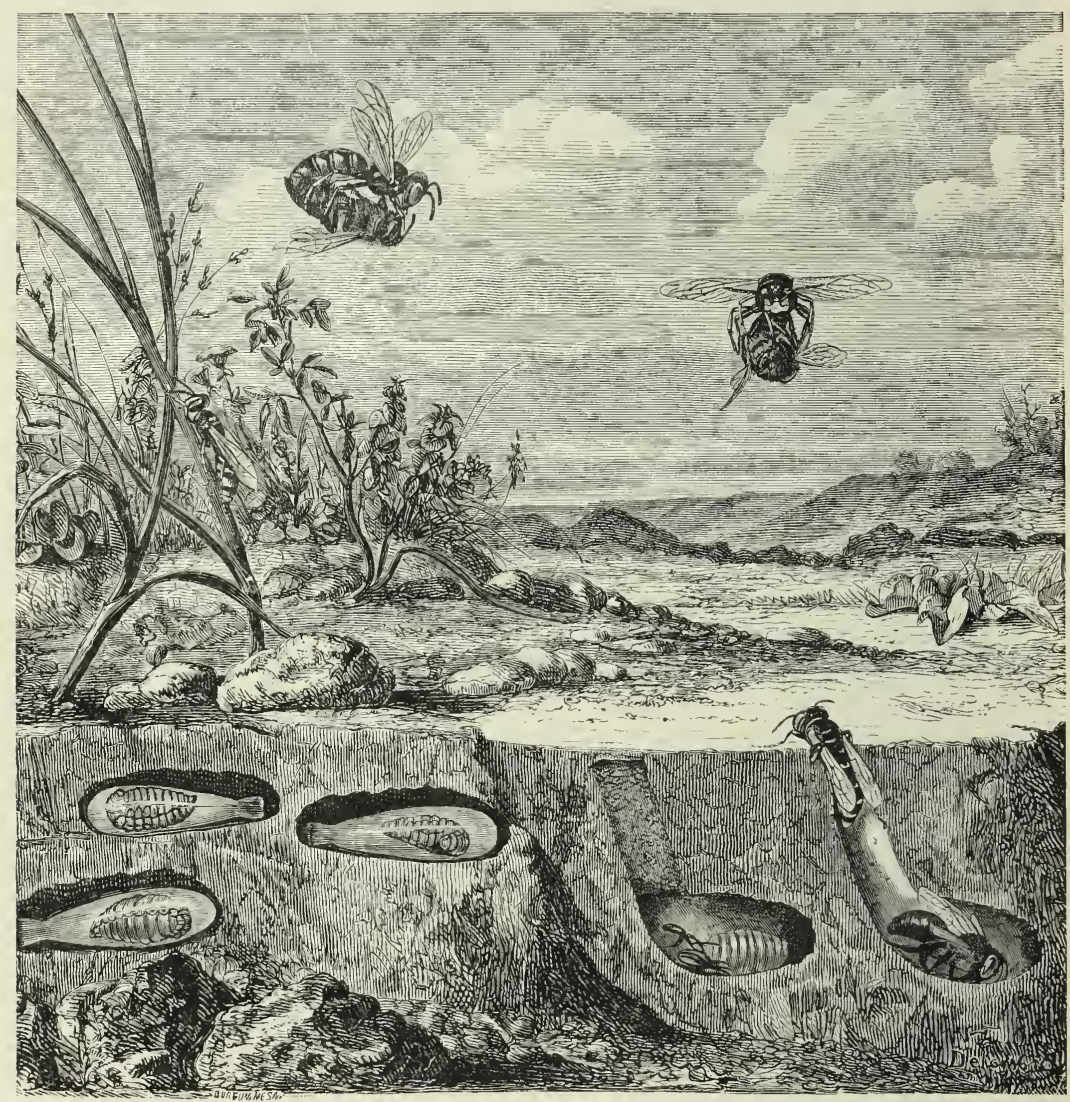

THE METAMORPHOSES OF Philanthus afivorus.

anything to eat, and had no particular cares; but it is on the look out for its prey, and a little patient watching will be rewarded by a very curious scene. Presently a bee comes to the flower to collect honey and pollen in its usual quiet and business-like manner; the sly Philanthus looks at it, and examines it, to see if it is in good condition, and if it is to its taste, rushes upon it with great impetuosity, seizes the bee between the head and 
the corselet, and stings it in the body. The bee, being a brave insect, offers great resistance, but the Philanthus rarely misses its aim, and usually succeeds in imparting some of its venom to the unfortunate victim. The bee becomes convulsed, and thrusts out its sting here and there, but it is of no use, and insensibility soon comes on. Then the attacking insect seizes the bee with its mandibles and legs, and flies off with its burden. As the Philanthus approaches its nest it may often be noticed to stop, as if it feared some hidden danger, but sooner or later it introduces its prey, lays an egg, and closes the gallery.

In the engraving two females may be observed carrying bees which they have stupefied. In the earth, on the right-hand side, a bee has just been introduced into a cell; in the next gallery a large larva has consumed the greater part of its provisions, and in the three other cells the larva may be observed in their cocoons, which have transparent walls.

The Philanthi often frequent particular places in great numbers, and many hundreds of them may be seen working simultaneously, but without taking any notice of each other. Not only do they display indefatigable industry, but very great boldness also, for every now and then they do not hesitate to come near beehives, and to seek their prey in such very dangerous neighbourhoods, for certainly they might easily be destroyed by the efforts of a number of their victims. The larva is rather compact in shape, and attains its full growth when it has eaten its bee; it then constructs a silken cocoon with very thin walls, which are almost transparent. The cocoon is of a very peculiar shape, for it resembles a small long bottle; its bottom is round, and the neck is very visible, and appears to be closed with a black wax; in fact, the cocoons of Plitanthus resemble the tiny bottles in which homoeopaths carry about their remedies. Water renders the cocoons quite transparent.

The Great Crabro (Crabro ceplualotes) makes holes and cells in rotten wood, with the aid of its mandibles, which have a bifid termination, and it victuals its nest with flies.

The small Comonus lugubris constructs regular cells in the stems of briars, and the accompanying engraving represents the curious appearance of the cells in a twig of a wild rose. 
The species of the genus Odynerus, or the False Wasps, are pretty little black insects banded with yellow tints, and they are most interesting on account of their agility, graceful movements, and singular powers of nest constructing. Odynerus parietum is a well-known species, and some years since our attention was directed to a very curious spectacle, which was observable at a short distance from Denain, in the Department du Nord, early in June. The roadside was bordered by a sandy bank of about

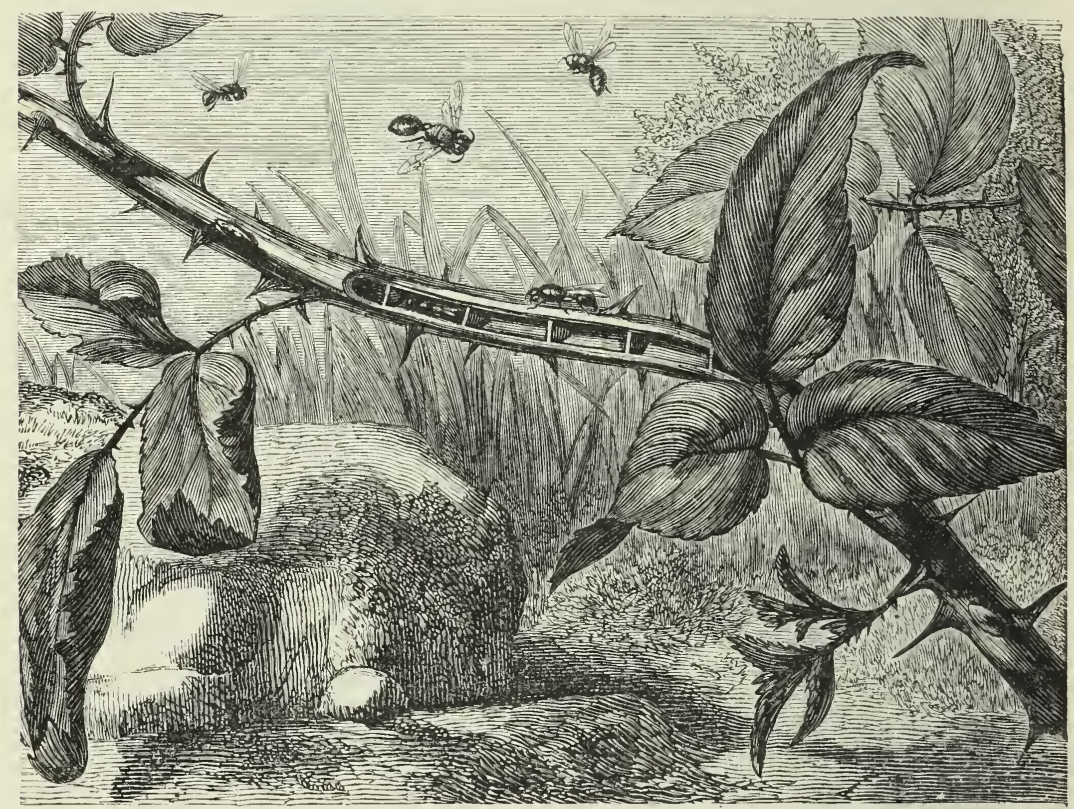

Cemonus lugubris AND ITS NESTS.

seven feet in height, which encircled a great field of lucern. The hedge or bank was formed of a rather dense soil, and was exposed to the full power of the sun; thousands and hundreds of thousands of this Odyncrus were flying about the field and hunting over and upon the plants with wonderful perseverance. They brought little green larva between their mandibles, dug holes in the earth, made little galleries, introduced their prey, and closed up the cells, each one pursuing its particular duty without being in the least disquieted by the thousands that were doing the same thing all around. The liveliness and animation of the scene was 
beyond description. The work was constantly going on, and old and young individuals were occupied either in just commencing to hollow out the soil or in closing up and finishing their labours. In some spots the insects were working hard at victualling their cells, and had completed a curious gallery which projected in front of the soil for more than an inch, like a tube. This tube was slightly curved, and was made up of little flat pieces or cylindrical morsels of earth placed in circles one over and in front of the others; small spaces being left in the walls. of the tube, which gave it a lace-like look, but without admitting the rain. These vestibules are excessively fragile, and fall to pieces when they are touched, but the insects crawl into them without doing any damage. These singular entrances to the galleries and cells last as long as the victualling goes on, but when everything is finished inside, and the eggs are laid, the Odyncrus breaks up its fragile vestibule and thus hides the entrance to its nest most perfectly.

We broke away the earth which formed the bank here and there, and exposed several cells which were just below the soil, and many of them were more or less perfect. In one place a gallery was noticed to form the entry of two, three, or four cells, and in another of only one cell; but all the little chambers were provisioned with the same sort of insect, namely, the green larva of a weevil (Phytomus wariabilis), and there were fifteen or sixteen of them in each cell. The larvæ were intact in most of the cells, but then only the egg of the Odynoms could be found; while in others the provisions had been partly consumed, for the larva had been hatched, and had increased in size at the expense of its victims. The shape of the larva is short and rather oblong.

In the engraving some of the vestibular tubes will be noticed on the right hand, and an Odynerus will be seen crawling into one; other perfect insects may be observed in different positions. On the left hand there are two cells exposed in section, and in each there is a larva with a crowd of its victims upon it. All the Odyneri finish their particular duty by the end of June, and die; and such a bank as we have described presents no external traces of the wonderful insect work that has gone on within; but inside the larvæ are living, eating, and growing, down in the dark and far away from danger. When they have consumed all their 
provisions they will form a silken cocoon, and hybernate in it until the next spring; then they will turn into nymphs, and, after two or three weeks have elapsed, they will fly as perfect insects.

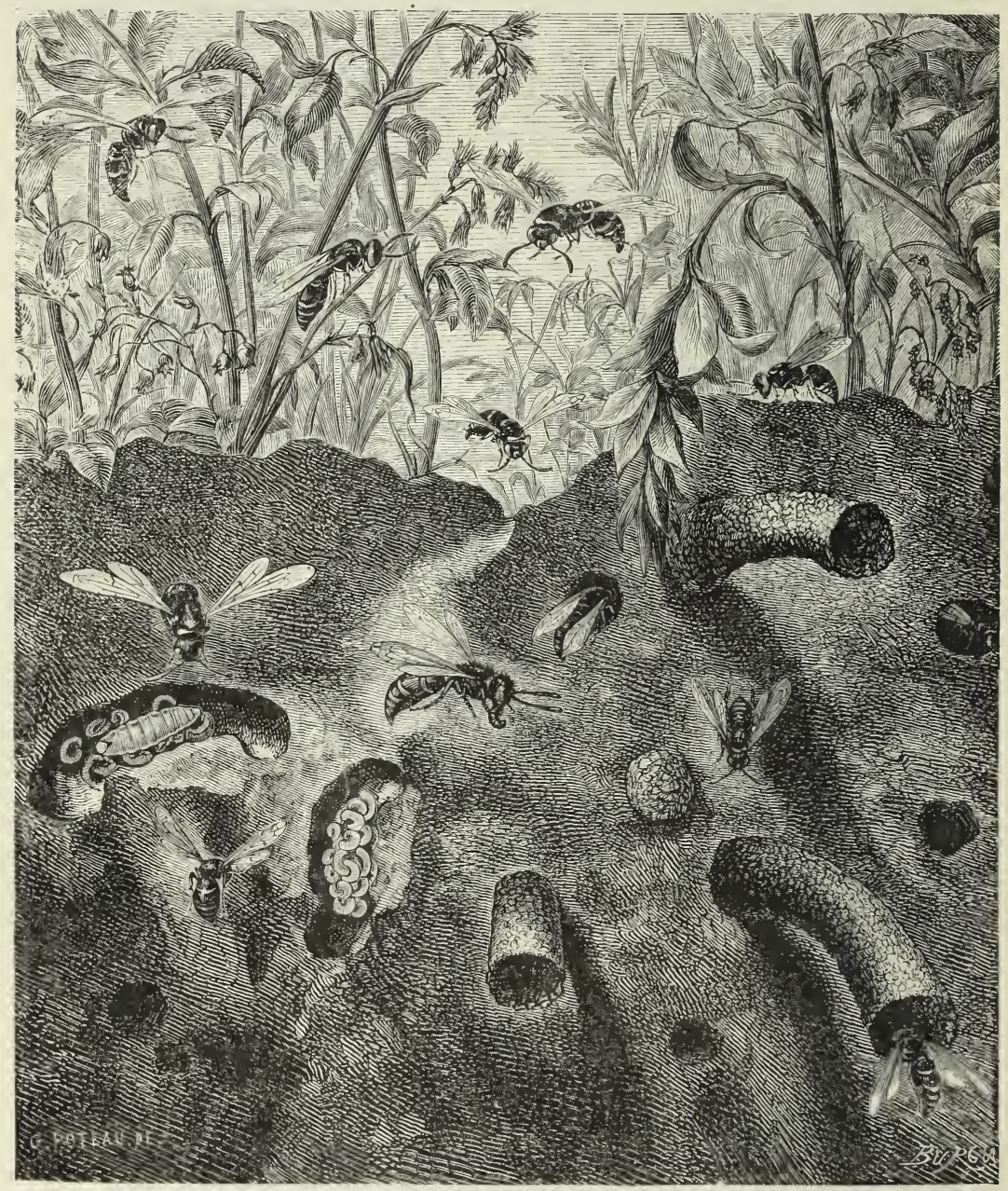

THE METAMORPHOSES OF Odynerus parietum.

The Odyncrus which attacks the briar chooses dry twigs which have a slanting direction, or which are horizontal. The insect sets to work to hollow out a twig by getting rid of the pith, and whon this is completed it goes off to seck earth and 
tiny stones, which it forms into a sort of clay. It then completes a cell and victuals it, and afterwards constructs a second and perhaps a third and fourth. Very often six or ten are to be found. The insect which occupies the cell nearest the opening becomes hatched before any of the others, although this cell was made last

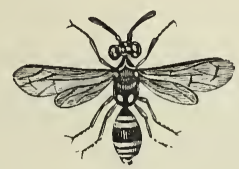

A SPECIES OF Odynerus.

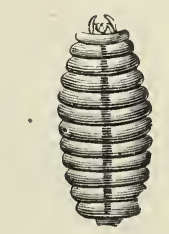

LARVA OF THE Odynerus.

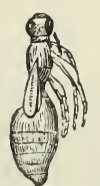

PUPA OF THE

Odynerus.

of all, so that the youngest egg hatches before the others. This is very wonderful, and by thus hatching sooner than the others this youngest Odynerus makes room for the free passage of the insect in the second cell, and so on. The cells open through one passage; and if the insect in the most distant cell, and which was filled first of all, was hatched first, it would force its way through the other chambers to gain the open air, to the great detriment of the included larvæ.

Eumenes pomiformis is a black insect with yellow rings, which builds nests upon walls, and it does not hollow out the earth, but constructs little round capsules out of clay, sticking them to bricks and stones, and making one cell in each. In the engraving on page 232 these little nests are shown, and the mature insects are represented upon the wall.

\section{HYMENOPTERA WHICH MAKE THEIR NESTS OF PAPYRACEOUS SUBSTANCES.}

(Iespida.)

The Hymenoptera which make their nests with papery-looking substances are the Wasps, the true social wasps, and not the solitary wasps which belong to the genera we have just described. These true wasps are arranged in one large family, the Vespidce, which is subdivided into three groups, containing several genera. 
There are three kinds of individuals amongst the wasps, as there are amongst the ants, namely, males, females, and neuters or workers, and these last are really females which never lay eggs, but which are provided with wings, and yet differ much from the perfect females. These insects live in societies, the individuals of which are more or less numerous according to the species. Usually the assemblage only lasts a year, and it breaks up at the

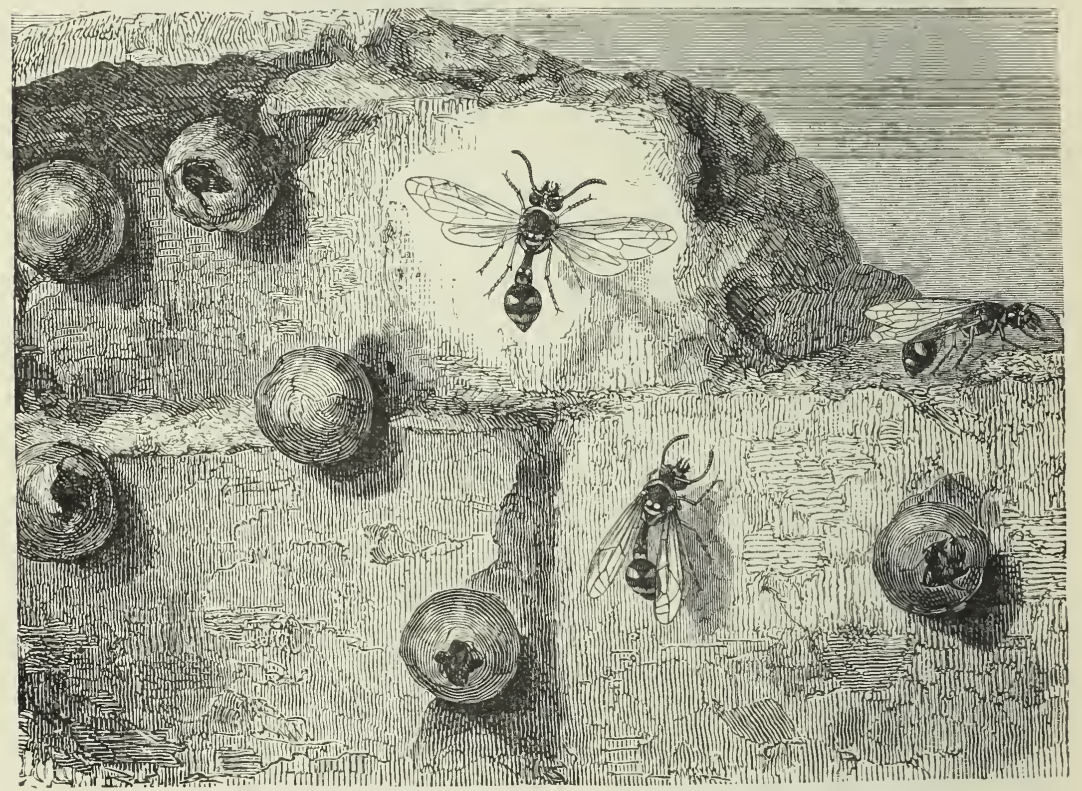

THE NESTS AND ADULT INSECTS OF Eumenes pomiformis.

The capsules with holes in them have been opened by the perfect insects after their metamorphoses, but the others still contain larva or nymphs.

commencement of cold weather; by that time the males are all dead, then the workers begin to die off, and only the true females manage to hybernate by seeking refuge in the holes of walls, cavities of old trees, or wherever they can hide themselves easily and get out of the way of the cold. In the early spring a solitary female, a mother, begins to build a nest; it is small at first, the cells of it are few in number, and an egg is laid in each.

As soon as the larve are born the wasp wanders to and fro for fool for them, and spares no pains in order to provide its 
progeny with sufficient nourishment. The larvæ soon become full-grown, and spin a silken cocoon, which fills up the little cell, and thus enclosed they are transformed into nymphs, the metamorphosis into the adult form occurring shortly. The new wasps thus produced are all workers, or rather workeresses, for they are sterile females, and they are created to take the part of nurses to a progeny which does not belong to them. These workers begin their duties as soon as they become perfect, and from that moment the mother of the nest, who has been so laborious, and who was so industrious when all alone, begins to lead a quiet life, and to do little or nothing, for she has plenty of nurses to take care of the little ones. The workers increase the extent of the nest, and prepare cells for the larvæ, and, when this is done, the mother completes another great batch of egg-laying, and deposits an egg in each cell. The larva which come from these eggs do not turn into workers only, but into male insects and females which are not sterile. It is not known how many egg-layings take place during the year, but they probably vary with the species. Very often the combs of the nests are found to contain larvæ late in the season, and when cold weather suddenly sets in. In this case the wasps appear to understand that the fruits will soon be all gone, and that the means of subsistence will be cut off; but, in order that the larvæe shall not suffer from prolonged starvation, these intelligent creatures kill them at once, so that the nest which was a few days before full of life, activity, and animation, becomes a dreary solitude. The wasps construct their nests out of vegetable matters, such as woody fibres and dead leaves, and they make a sort of paper from these substances. They triturate their building materials between their mandibles, moisten them with their saliva, and mould them into a homogeneous paste, admirably suited for the construction of the cells and the walls of the nests. The nests are made upon different plans, all of which appear to have a distinct reference to some peculiar conformation of the insect. But, although there are many minor differences, still, in the main, all wasps' nests resemble each other. The essential and most important parts of the nests are the cells of the comb, and they are always built upon the same plan. In the commencement the cell is a kind of cylindrical cup, 
and others of the same form are built close together on a horizontal floor, and they are all closed at their summits. The cells of many wasps' nests are always cylindrical in shape, but usually they are hexagonal in outline. When a round cell is in contact with six other cellules which surround it, the walls flatten regularly on account of the equal pressure of the surrounding structures, and a geometrical shape is perfected. The result is that the wall of one cell becomes really a portion or a layer of a partition which is common to two cells, and very soon the double wall is no longer seen to exist, for it is not wanted. By building hexagonal cells there is a great economy of materials, and this is a very important matter when the substances of which some very large nests are composed are scarce.

Everybody respects the wasp, and is aware that the mothers and workers are armed with a very strong sting. The larvæ are feeble creatures; nevertheless, the head of the wasp larva is stronger and larger than that of the other Hymenoptera; even their mouth-pieces are stouter, and this enables them to receive bits of fruit or fragments of insects as nourishment, besides the usual fluid or very soft food. It is supposed by some naturalists that the sterility of the females is more or less due to a difference in the food given to them by the workers; and there is some reason for believing that those larvæ which eventually become mothers are fed upon an animal diet; and the others, which become sterile, and turn into workers, are fed upon vegetable nourishment. There may be some truth in this opinion, but another will be noticed further on.

One of the most common wasps is the Wood or Bush Wasp (Vespa syliestris). It is a little smaller than the common wasp, and it attaches its nest to the branches of trees and bushes, hangs it under roofs, or attaches it to the corners of walls. The little delicate round nests of this species may often be met with in the spring, and a very slight examination of one of them will prove that the covering, or envelope, is made up of a smooth, grey paper, which is slightly shiny and flexible, and perfectly impervious to water. A thick column is found in the middle of the inside of the nest, sustaining a single comb, which is composed of eight, ten, or twelve cells; it is the work of the 


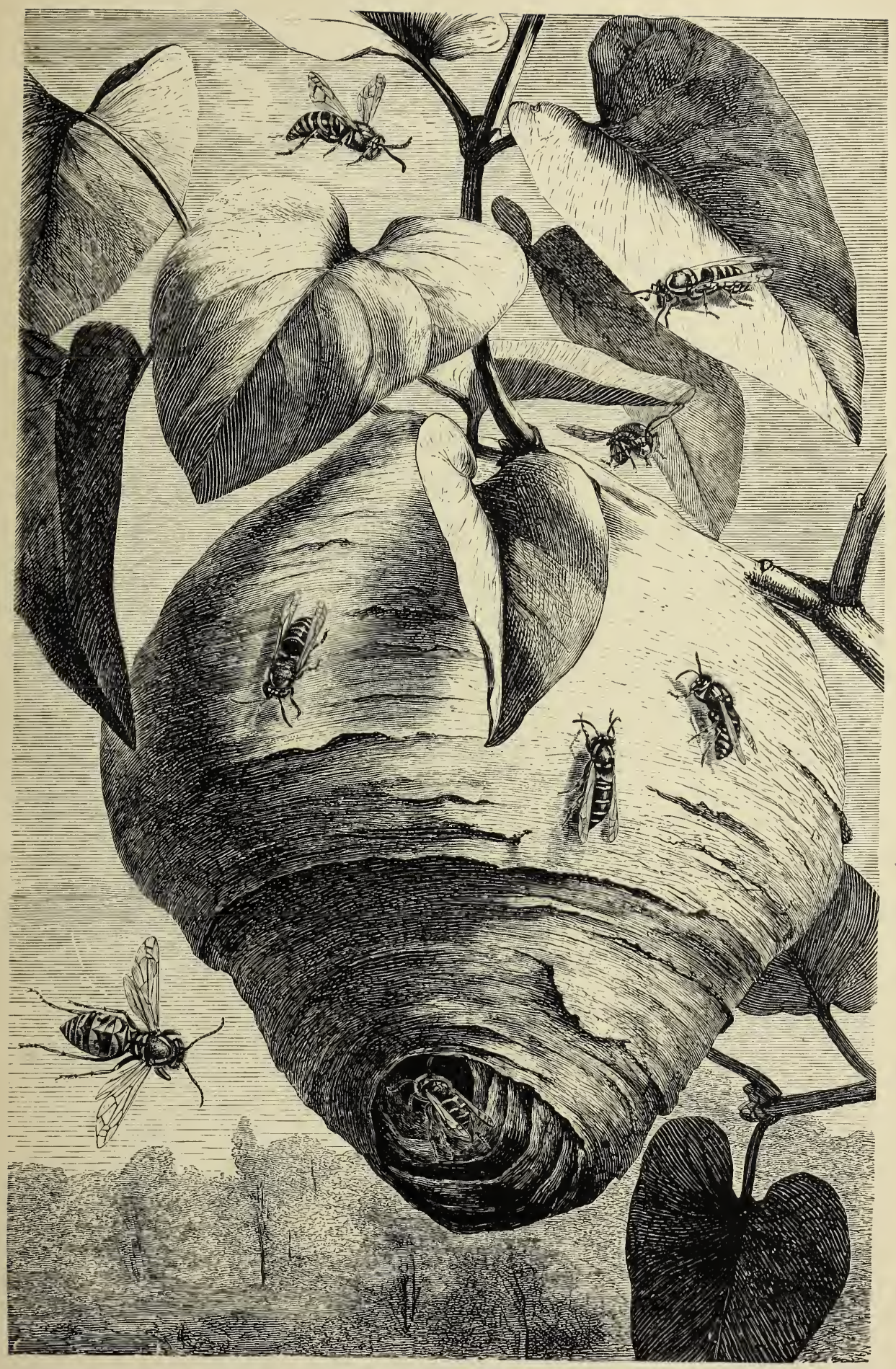

Vespa sylvestris AND NEST. 

mother wasp, which has passed through the winter in a condition of sleepy stupidity. After having built her nest, she deposits an egg in each cell; and when the larvæ are hatched, they become her workers and nurses. They enlarge the first comb by adding new cells around it; then they construct a second comb, and attach it to the first by two or three pillars; then a third is made, and fixed to the second; and so on for a series which may include a fourth, fifth, and a sixth comb. The number of the combs varies according to the increase of the population of the nest. The whole has three papery envelopes, one placed over the other, and they serve to protect the combs, to which, however, they are never attached. The largest nests are sometimes a foot in height; but whether they are large or small, they look very pretty amongst the foliage of beautiful bushes. The opening is situated at the lowest part of the nest, and underneath, and is always sufficiently large to give free ingress and egress to the wasps.

In the accompanying engraving there is a figure of one of these nests, which is suspended from a small branch.

The common wasp ( Vespa vulgaris) makes its home in the earth, and after having found a small cavity somewhere, it brings constructing materials to it, and makes its nest in the dark retreat. When the population of the nest increases, and when the number of the sets of cells has to be augmented, the wasps are obliged to undertake a great deal of labour in order to enlarge the area of their homes. The nests of the common wasps have several papery envelopes, like those of the wasps just mentioned, and they often assume very great size, and contain thousands of individuals. To all appearance, the societies of the common wasp do not perish during the winter; and if one of the localities where wasps are often seen is examined, it will become evident that the wasps never leave it year after year, unless disturbed.

The Hornet (Vespa crabro) is always feared, on account of its great size and fierce appearance; and it may be easily distinguished from all other wasps by the russet colour of the head and front part of the body. Hornets usually make their nests in old trunks of trees which contain large hollow spaces, for they want much room for their great habitation. They attach their first 
comb to the upper part of the cavity by means of a large mass of wax made up in the form of a supporting column. A second comb is added, when required, beneath the first, to which it is fixed by more or less numerous pillars or little columns, and all the combs are attached in this way, one under the other consecutively. When the nest is completed inside some cavity or other, the walls of which protect the whole sufficiently, the insects only make coverings to those parts which are more or less exposed, but under other circunrstances they take great pains to cover up their nest with many envelopes. Some hornets' nests, which are found under the eaves of barns or granaries, attain a very considerable size, and are really very pretty and extraordinary objects. They are wonderfully fragile, and not strongly built, like the nests of the other wasps. Ordinary wasps scrape off woody fibres from living trees, and form a strong tenacious paper, but the hornets content themselves with rotten wood, out of which they manufacture a yellowish or russet-coloured paper, which, although very pretty to the eye, is very friable, and does not possess any lasting properties. The larvæ of these large wasps are fleshy grubs, and are destitute of feet. They have to be fed by the workers, and undergo metamorphoses similar to those of the other wasps.

The wasps which have elongated bodies and the first segment of the abdomen formed into a long pedicle constitute the group of the Polistites. Linnæus, without much regard to the geographical distribution of one of the species, called a very common wasp of this kind Polistes gallica. The French Polistes is a black insect decorated with yellow tints, which are also observed on the antennæ. It frequents open spaces in woods, and there are few prettier sights than that presented in the spring-time by one of the females when it is building its little nest, or is attending to its larvæ. It is not difficult to observe all this, for the Polistes attach their nests to low plants and bushes. The brooms especially furnish them with straight and narrow twigs, which are very convenient for their particular method of nest building. The mother, after having hybernated during the winter, begins to work earnestly and with great perseverance early in May, and commences to construct her nest with materials which resemble those used by the bush wasp. The fibres of bark are reduced into 


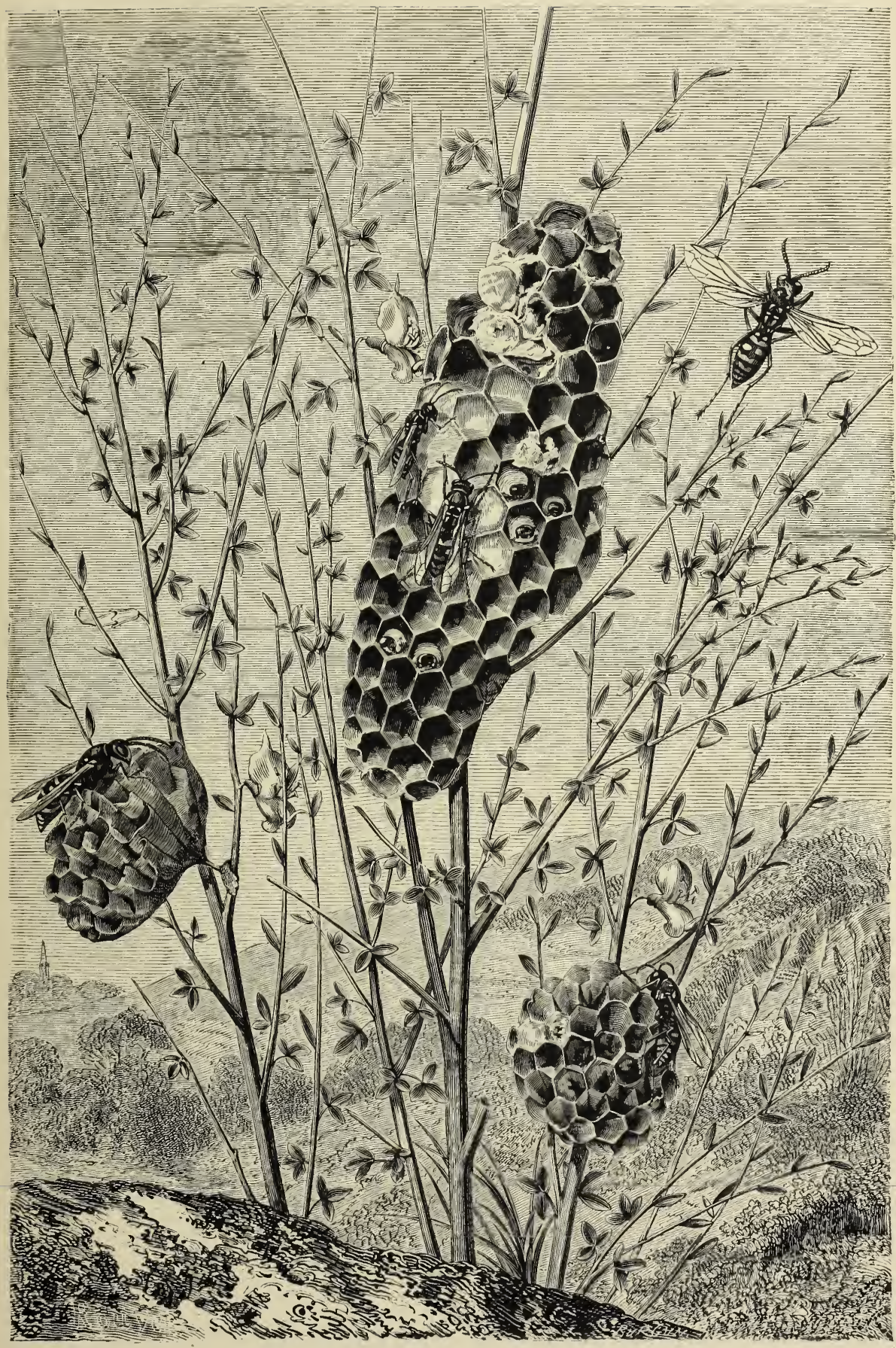

Polistes gallica AKD NESTS. 

a homogeneous paste, which is converted into a strong grey paper. The Polistes first uses a large quantity of this paper to form a solid foundation for the nest, and a strong peduncle, which has to maintain the comb. The comb is very small, and there are not often more than five, six, or eight cells in it. It is never covered up with envelopes, and although it is increased in size subsequently by the addition of new cells, it is never enclosed and protected from the weather. Any one interested in the habits of these industrious Hymenoptera, and who will visit the neighbourhood of their nests daily, can study all the phases of the life of the larvæ, for these pretty nests without envelopes, and unsheltered, offer every opportunity for the investigation; but although apparently so liable to be injured by rain and wind, they are so made that the larvæ are perfectly safe inside. The nests are always placed obliquely, so that the rain falls off them without entering into the cells, or remaining upon them in the least; moreover, they are turned towards the east, and as the bad weather, cold rain, and strong winds usually come from the opposite direction during the summer and autumn months, the inhabitants of them have not much chance of suffering from causes acting from without. The little Polistcs having taken care of its tiny comb, the larvæ are soon transformed into nymphs, and before this occurs they close their cells with a little lid, by forming a silken cocoon. Some observers state that as soon as the adults fly it becomes evident that they are all workers, and that they begin to extend the nest, which, however, never reaches a great size. Fifty or sixty cells constitute a large nest, but it happens sometimes that a second comb is attached to the first by little pillars, as is the case in the nest of wasps.

In the engraving are representations of one large and two small nests of Polistes gallica. That on the left-hand side projects from a peduncle which is attached to a stem. On the right-hand side there is a front view of a small nest, and a Polistes is building the cells. The large nest shows many open cells, a few of which contain larvæ, whose heads are placed outwards, so as to receive food from the workers; there are other cells which appear to be closed in consequence of the larvæ having spun their cocoons within them.

Professor C. T. von Siebold has made most careful examination of the habits and peculiarities of these wasps, and he notices 
that isolated female wasps originate different nests, or colonies, in the spring-time. He has proved that these females were born in the previous summer, and that they lived in the virgin state until the autumn, when they were fertilised just before their sinking into the profound sleep of hybernation. He states that when the female thus fertilised awakens in the spring-time, she lays eggs which turn to females, but not to males. The progeny consists at first of small females, and not of workers or neuters, as stated above. Von Siebold has dissected many of them, and has found that they are not workers-that is to say, females whose reproductive organs are dwarfed and arrested in their growth-but that they are perfectly formed females, full of eggs. This progeny, consisting of virgin females full of eggs, assists the original mother, not in working, but in filling the cells, for the eggs they lay are fertile, although they have never been fecundated. The increase of the nest takes place rapidly, and the larvæ, receiving abundance of nourishment, are transformed into wasps as large as the mother. Towards the end of June or the beginning of July the comb presents a large surface, and is composed of a very great number of cells. At this period some male individuals may be remarked for the first time among the numerous large and small females. Their number soon increases considerably. The observations of these facts suggested to Von Siebold that there might exist in Polistes a division of physiological labour-in this sense, that the fecundated females of the preceding year produce only female eggs, whilst the virgins of the new generation produce male eggs parthenogenetically. Experiment has confirmed this hypothesis in the most striking manner. Von Siebold selected a certain number of nests in the spring, at a period when the mothers had already reared one or two assistants. He removed the mothers from the nests and dissected them, in order to ascertain the condition of their egg-bearing organs. He always found evidences of fertilisation which must have occurred the year before. At the same time he entirely emptied all the cells of those nests which contained eggs, or any small larvæ, preserving only the larvæ of large size. Notwithstanding the disappearance of the mothers, the little virgins continued to take care of the larvæ which had been preserved, and consequently the colonies did not perish. $\mathrm{He}$ 


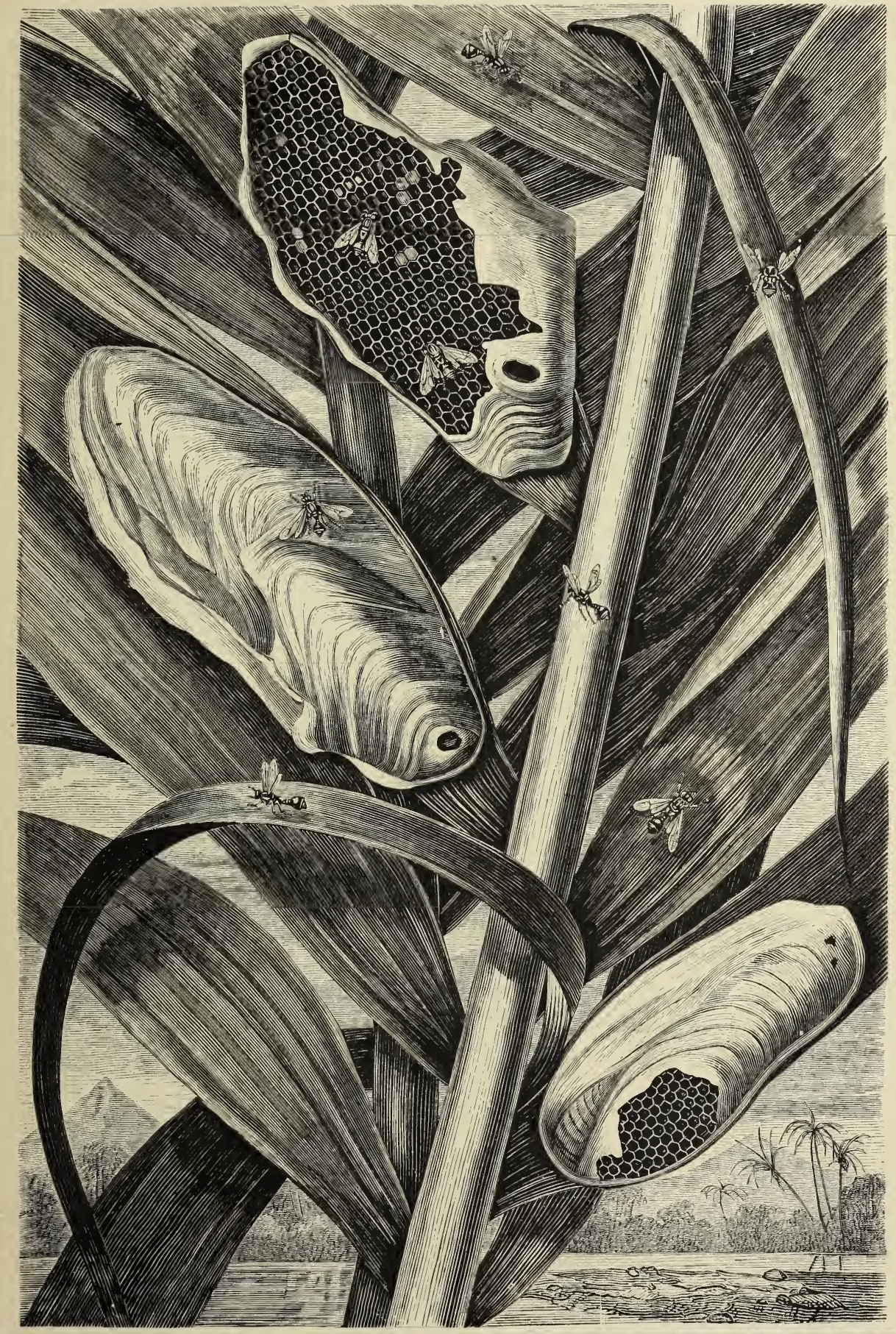

Polybia palmarum AND NESTS. 

took the precaution to mark, in each of the nests experimented upon, the occupied and empty cells. In a few days he perceived that some of the latter contained eggs. Careful examination even enabled him to surprise some of the little virgin wasps at the moment when they were depositing their eggs at the bottom of a cell. These individuals were at once sacrificed and examined. There were eggs within them in abundance, but no evidences of fertilisation by the male. During this time, thanks to the assiduous care of the young virgins, new female individuals-produced from the large larvæ which had not been sacrificed-arrived at their complete development, and at once took part in the labours of the society. The nests were consequently enlarged by new cells, which were speedily occupied by eggs laid by the virgins. All these eggs-and this is an important fact-were developed notwithstanding the absence of fecundation, and gave birth to young larva, which prospered under the care of the virgin society. All these larie, at their final transformation, furnished males, in oppotion to the larvæ which had been previously produced by the original mother, and which had furnished females only. It is therefore evident that in Polistes gallica the male individuals originate by parthenogenesis, from unfecundated eggs. ${ }^{*}$

There are some other wasps, which have very slim bodies, that constitute the genus Polybia. They are not known in Europe, but are very common in tropical America, where they form either enormous nests or tiny and beautifully-formed habitations. One of the species (Polybia liliacea) makes a most wonderful nest, which is often nearly four feet in height, and which contains thousands of cells. It is attached to branches of trees, and its covering, which is almost like cardboard, is rough, and is even attached to the internal combs. Mr. White described a huge Polybia nest from Central America, and noticed that its very thick envelope was covered with large pointed tubercles. On the other hand, some of the small species make their nests on the lower surface of leaves, and one which is here represented, is common in Guatemala.

Polybia palmanum is a very small wasp, about a quarter of an 
inch long, and it constructs its nest on the lower surfaces of palm leaves. The nest does not occupy much space, and the breadth of one leaf suffices. There is only one oval-shaped comb in the nest, and it is clothed in an envelope made of a rather fragile reddishcoloured paper, in which there is a small inferior aperture. The size of the cells of this comb is very minute, and does not reach to more than from the twenty-fifth to the twelfth of an inch. The regularity and the perfection of the construction of the cells are very wonderful, but the insects build so well, that although the palm lcaves move with the wind, and sometimes very strongly so, the larvæ are all safe within the delicate little nest.

Some foreign species of wasps belonging to the genus Chartergus, make their nests of a substance like pasteboard; hence they are called Pasteboard Wasps. The nest of Chartergus nidulans, a native of Brazil, has a beautifully polished white appearance, and is so solid as to be impenetrable to the weather. Réaumur showed some of the substances of which these nests are composed to a cardboard manufacturer, who declared it to be most likely the produce of a particular manufactory at Orleans.

Another wasp, a native of Brazil, which is a honey-making insect, is said to form its nest out of very different materials, for it collects the dried dung of a species of tapir, and moulds it into a rough sort of paper.

A black wasp, which has smoky-coloured wings and a very large head, lives in Guiana, and is called the Armadillo Wasp (Tatua morio). Its nest is perhaps one of the most wonderful examples of intelligent design in insects that can be put forward. These wasps choose the straight and upright branches of a tree which has no lateral twigs, and they make it the axis or the support of the nest. The combs, which are composed only of a few cells, are fixed to the branch by means of a very solid mass of wax. They are separated by a considerable interval, are placed one over the other, and sometimes there are ten of them. In the accompanying engraving their numbers and mutual relations are very well shown. The walls of the nest are formed by a fusiform envelope, made up of a woody paper, and marked with transverse tubings, which are, as it were, goffered. Moreover, this paper, the fibres of which are arranged with wonderful regularity, 


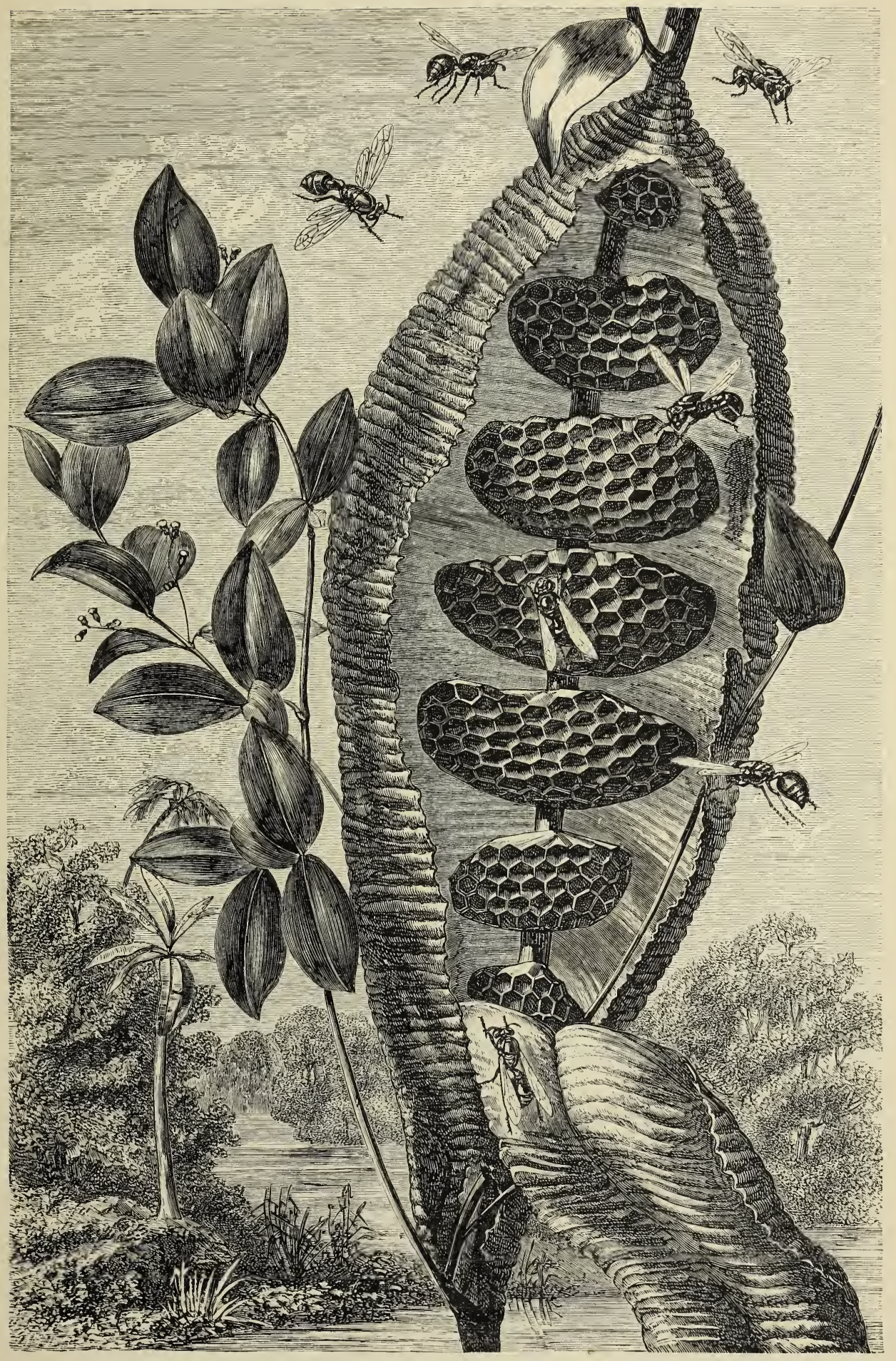

Tatua morio AND NEST. 

is tinted with longitudinal bands of different colours. The envelope is attached closely to the branch above and below the extreme combs, and is perforated low down by a small opening for the insects. Inside there is plenty of room between the combs themselves, and the envelope is not attached to them, so that the wasps can pass up from the bottom to the top of the nest with ease.

\section{B E E S.}

\section{(Apides.)}

The nest-making Hymenoptera, which collect honey and pollen, are more interesting, so far as their organisation is concerned, than any others; and if it were not for the ants, they might also lay claim to possessing greater intelligence and higher instincts than any insects. All the insects which form the family of the Apides - of which the bee is the commonest type-have in fact a higher organisation than any others. The concentration of their nervous system is greater than in any other Hymonoptera; their respiratory apparatus is unusually developed, the tracheæ of their abdomen being transformed into large sacs; and the appendages of the head are especially adapted for particular purposes, their structures being very elaborate. The mandibles are turned into pincers fit to cut wood, or into instruments for digging and working earth, and they are formed to enable the insects to knead cement in moulds to pound their wax in, according to the habits of different species. Among most of the bees the jaws and the lower lip, which are long and delicate, are used as a trunk to suck up honey from the nectaries of flowers; and the hind legs, especially the first joints of the tarsi, are transformed so as to act as pollen collectors.

The bees are vegetarians during the whole of their lives; the adults feed upon honey; and the larvæ, which require more substantial aliment, are supplied with a sort of cake, which is composed of honey and pollen. The larvæ of all these $H y$ menoptera, like those of the wasps and the fossorial kinds, are incapable of moving about, and are destined to live in the narrow cells of the hive, where they are nursed by particular bees. Some bees are solitary, and others live in colonies, which 
are either permanent or only last a year. The solitary species lead a life like that of the fossorial Hymenoptcra; and a single female constructs a nest, makes the cells for its larvæ, and victuals them. The social bees have three kinds of individualsnamely, males, fertile females, and neuters, which are also called workers or sterile females. In those colonies which only last a year some solitary female lays the foundation of the hive, and the workers are gradually born and increase in number; but the fertile females which are found in permanent colonies never do any work, and, indeed, they are incapable of it, for the necessary structures are wanting in them. There are certain species amongst the bees-whose habits are like those of some insects which have already been noticed in treating of the Sphegidawhich have the instinct to enter the nests of industrious kinds, and to deposit their eggs in the cells that have been partly filled with food intended for the larvæ.

The bees we shall first notice differ from all others by not having their hind legs made to collect pollen, and the genus Osmia contains the most important of them. These Hymenoptcra build very elaborate structures, and take almost a fantastic care about the different materials which they use for their cells, each species choosing particular substances. They collect pollen, like other nest-making Hymenoptera, and make a cake of it for their larvæ, but their legs do not assist them in collecting it. But there are some stiff and crowded hairs which cover the lower part of the abdomen of these bees, and they answer the purpose of pollen collectors just as well as the hind legs of the other bees. The Osmia rubs itself against the stamens of flowers, and detaches the pollen, then it collects some grains against the hairy structure, which retains them, and then the insect returns to its nest carrying a greater or less quantity of this important food. Of course the first care of the bee should be to get rid of its burden, but it does not appear, at first sight, how this sticky pollen is to be moved from off the hairs; but a structure is at hand by which this difficulty can be overcome at once, for the Osmia is provided with a kind of brush, which is placed under the first joint of the hind legs, and as these extremities can be moved in all directions, every morsel of pollen is speedily detached from the whole body. 
One of the commonest Osmice is the mason bee of Réaumur (Chalicodoma muraria). This species has a massive body and strong mandibles, which have four small teeth upon them, and its name, which signifies "stone house," is by no means badly chosen. The

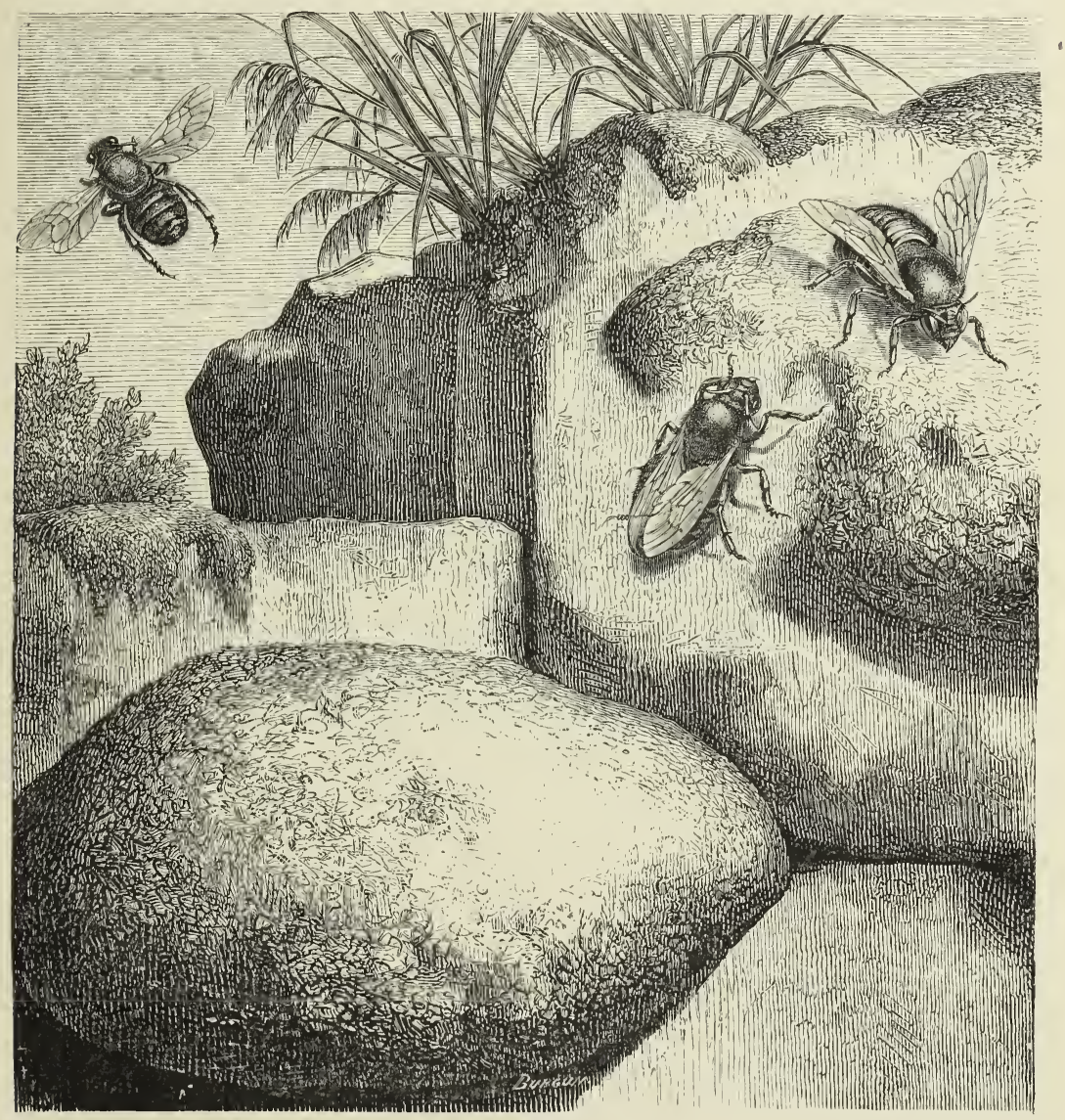

Chaticodoma muraria.

$\Lambda$ male in flight. A female working at her nest. $A$ female seen in front.

$\Lambda$ completer nest.

female mason is of a velvety black colour, and the male, which is always smaller, is clothed with a russet pubescence, the end of the abdomen being black.

Spots of earth may often be seen on walls which have a sunny aspect; they are more or less egg shaped, and look like 
lumps of mud which have been thrown against the wall and become dried up. They are the constructions of this Hymenoptera, and when they are examined closely they will be found to be as hard as Roman cement, and to be made up not with mud, but with a mixture of gravel and earth. The lumps are more or less arched, and it is very evident that their rounded state is not a matter of chance. This mixture of earth and gravel sticks to the wall with the greatest tenacity, and the chisel and hammer are requisite to detach it. Now, these ugly and dirty looking masses have been carefully built up, with a wonderful amount of art, by a single Hymenoptera, which has been the architect and workman at the same time. The labours of the Chalicodoma begin in the month of May, and soon after it is born. The female explores and goes over a wall and chooses a particular spot, and having settled that essential point, she goes off to collect building materials, and if followed, will be noticed to alight upon a sandy and gravelly soil. The insect takes up little masses of sand and small stones, of a certain size, with its mandibles, then it disgorges a little saliva and sticks them to some grains of earth, and thus agglutinates the earth and the sand so as to form the mortar which it is going to use in building. When it has worked up a little piece it flies off with its burden, and returns to its wall to fix on this first quantity of cement. The same trouble is taken over and over again, and then, the mass of mortar appearing sufficient to permit other building operations to be commenced, the bee sets to work to mix all the earth, and usually she labours so well as to complete a little cell in one day. This cell is open to a certain extent, and the bee enters it several times to make the inside walls smooth. Then something else besides building has to be done, for the cell has to be victualled, and the Chalicodoma flies off to collect honey and pollen from the flowers. It makes up a sweet cake from them, which will be the future nourishment of its larva, and then it stuffs the cell nearly full of this food, and lays an egg in the midst. The Hymenoptere walls up the cell and sets to work to construct another close to it, then a third, and sometimes as many as twelve or more. These cells are placed rather irregularly, and are not found to be of the same number in every nest. All the cells are built, filled with 
provisions, and closed perfectly, but yet the labour is not over, for the bee builds up a sort of roof or general covering to the whole, and uses larger sand grains than those which enter into the composition of the cells, and thus the external walls of the nests are found to have great thickness and wonderful hardness. The larvæ will have plenty to live upon, and certainly every care has been taken to place them out of danger. When they are full grown they add to their imprisonment by making a cocoon of a paper-like tissue, which looks as if it were varnished. Their metamorphosis is completed within, and the adult insects fly. But how do they manage to get out of their strong and prison-

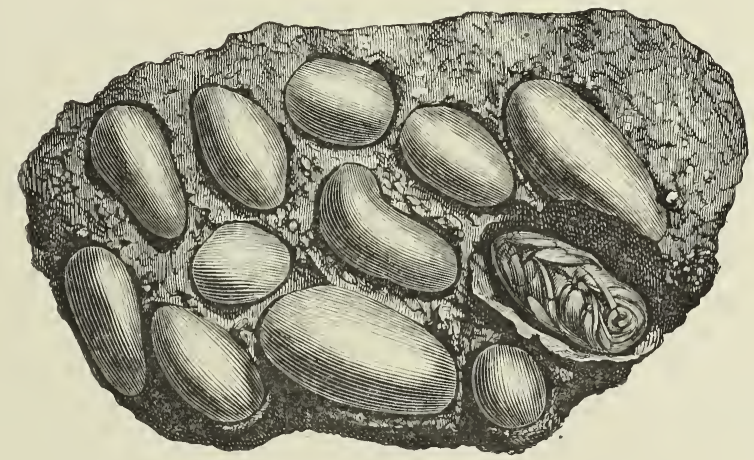

A NEST OF Chalicodoma muraria DETACHED AND SEEN FROM WITHIN.

like home? Do they contrive to pierce the cement, which is as hard as stone, and which resists the blow of a hammer? Every care has been taken not to give too much trouble to the young bees in their first attempt at coming to the light. When the roof and general wall of the nest was constructed, a slit was left low down near each cell, and it forms a kind of door, hidden very carefully by rather soft sand or cement.

It is very remarkable that this insect should not always build up its nest in the same manner, and that it should occasionally use the ruins of last year's nests for the foundation and walls of the new. Old and more or less broken down nests, which contain vacant cells and the skins of the nymphs, frequently remain attached to walls, and the Chalicodoma, when exploring, 
appears to keep a sharp look out for them, and takes care to spare itself all the trouble possible by repairing the broken down cells and making them as good as new. The female cleans out the inside, removes the débris of the cocoons, and brushes out the skins of the larve and nymphs, and all uncleanly matters. Then the holes are repaired, the openings are closed up, and the old nest begins to resemble one of the year. Sometimes the mason bee becomes lazy, and then she penetrates into the nest

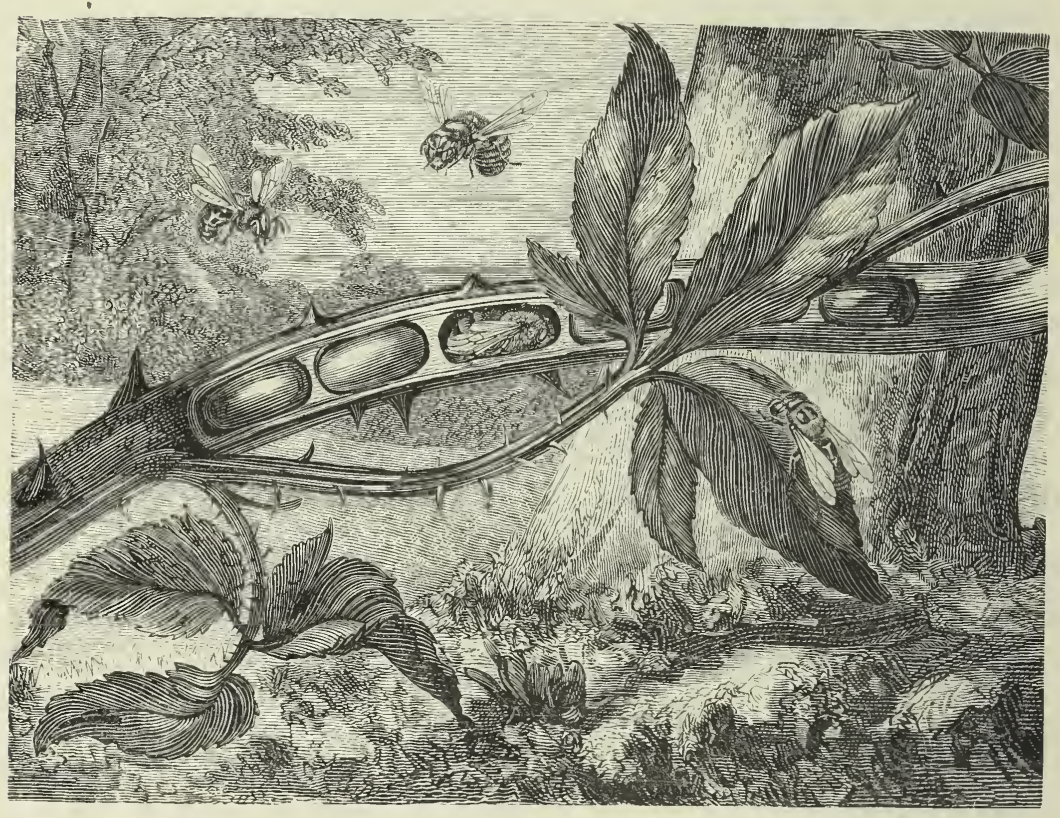

THE Osmia aurulenta AND ITS NEST.

which some other one is making, and, if she likes the position, endeavours to maintain it by force. Réaumur says that when one of these bees was gone to collect some cement wherewith to finish up the cell, M. du Hamel saw another one enter in without any cercmony, crawl all about, and turn everything over, just as if the nest belonged to it. That this was not done out of curiosity was gleaned from the fact that when the true mistress of the nest arrived, laden with building materials, the other one would not allow her to enter, and she was obliged to fight the usurping 
bee in order to obtain her rights, and the new comer was quite ready for the combat. An Osmia which lives in Algiers has the wit to choose snail shells for its nest, and forms cells within them with a mixture of earth and cow-dung. Another wellknown insect (Osmia aurulcuta) seeks for the dried twigs of brambles, clears them out, and constructs cells inside, one after the other, with a small quantity of mortar. Its work is comparatively easy and simple, especially when compared with the labours of the Chalicodoma and other Apides.

In the engraving the perfect insects are seen in flight, and one is crawling upon a leaf. The cells within the bramble are occupied by cocoons, one of which is opened to show a nymph.

Formerly most villages and country houses were covered with thatch, and a stunted vegetation grew over the roofs, in which many insects found very comfortable homes. Many may recollect the pretty villages with their thatched cottages which were so common before slates began to be used, and many naturalists were aware that nearly every straw of those simple roofs was the cradle of many a numerous family of little bees. Now-adays granaries and barns tell the same story, and little Osmice, which have long and notched mandibles, make comfortable galleries in the old straw. These insects are called Chelostomes, and they are so small that the inside of a straw forms a spacious gallery for them. Their strong mandibles are admirably adapted for cutting into the straw, and when this is done the inside is properly cleaned out, and cells are made within witli the aid of a little mortar. It happened, therefore, in the olden time that the labourers inside the cottages protected and gave lodging unintentionally to hundreds of industrious and hard-working little bees.

Some Hymenoptera which belong to the bees are leaf cutters, and have very long mandibles with four teeth upon them, and they are the instruments for perpetrating this clever piece of work. These bees are called Megachilida, and the commonest species, which is well known in every garden, and much dreaded in greenhouses, is Megachile centuncularis.

It is not a remarkable looking insect; in fact no one would believe it to be gifted with so much intelligence by observing its very humble exterior. These bees are smaller than hive bees, are 
black, and have some red hairs on the thorax, and a white down upon the head. A corresponding down ornaments the first three segments of the abdomen in the females, and all the segments of the male insect.

The Megachile makes a perpendicular hole in tolerably solid earth, works it downwards for some inches, and then enlarges it into a horizontal gallery of considerable length. This is to be the future nest, and cells will be made in the side. There is nothing very extraordinary in this, for it is the procedure of most of the Sphegide, Crabronida, and the solitary bees, but something else is about to be done. The insect flies about the rose bushes, and finally selects a nice leaf, upon which it rests either above or below; it then cuts out a large piece with its mandibles, just as if it had been done by a pair of scissors. No time is lost, and the insect cuts quickly and soon detaches the piece of leaf, which does not fall, however, to the ground, heavy as it appears to be in relation to the small insect, for it is taken up between the legs and the mandibles, whilst the wings are strongly agitated, and the bee flies off with it to the nest. The Megachile will thus cut ten or twelve pieces of leaf of different shapes, and will carry them to the bottom of its gallery, and there she twists the different pieces and folds one within the other, so as to form a sort of funnelshaped cone, the end of which is rather narrower than the orifice. The whole looks something like a long sleeve with folds upon it. The pieces of leaf are not sewn or attached to each other, but they are fitted together so perfectly that they retain their shape even when they become dry. This pretty funnel-shaped cell, of from a quarter to a third of an inch long, is destined to be the residence of a larva of the leaf cutter, for it proceeds to make up a cake of honey and pollen, places it inside, and then lays an egg. Nothing more is required but to wall up the nest, and the Megachile goes off to the rose bushes again, where it snips off a circular piece of leaf, of a diameter exactly fitting the opening; it pushes this leaf so that its sides fit into the walls of the funnelshaped roll of leaves which compose the lining of the cell, and endeavours to close it completely. But this intelligent. little worker is not satisfied, for it would appear to be aware that the honey which she has laid up with the egg might flow out 


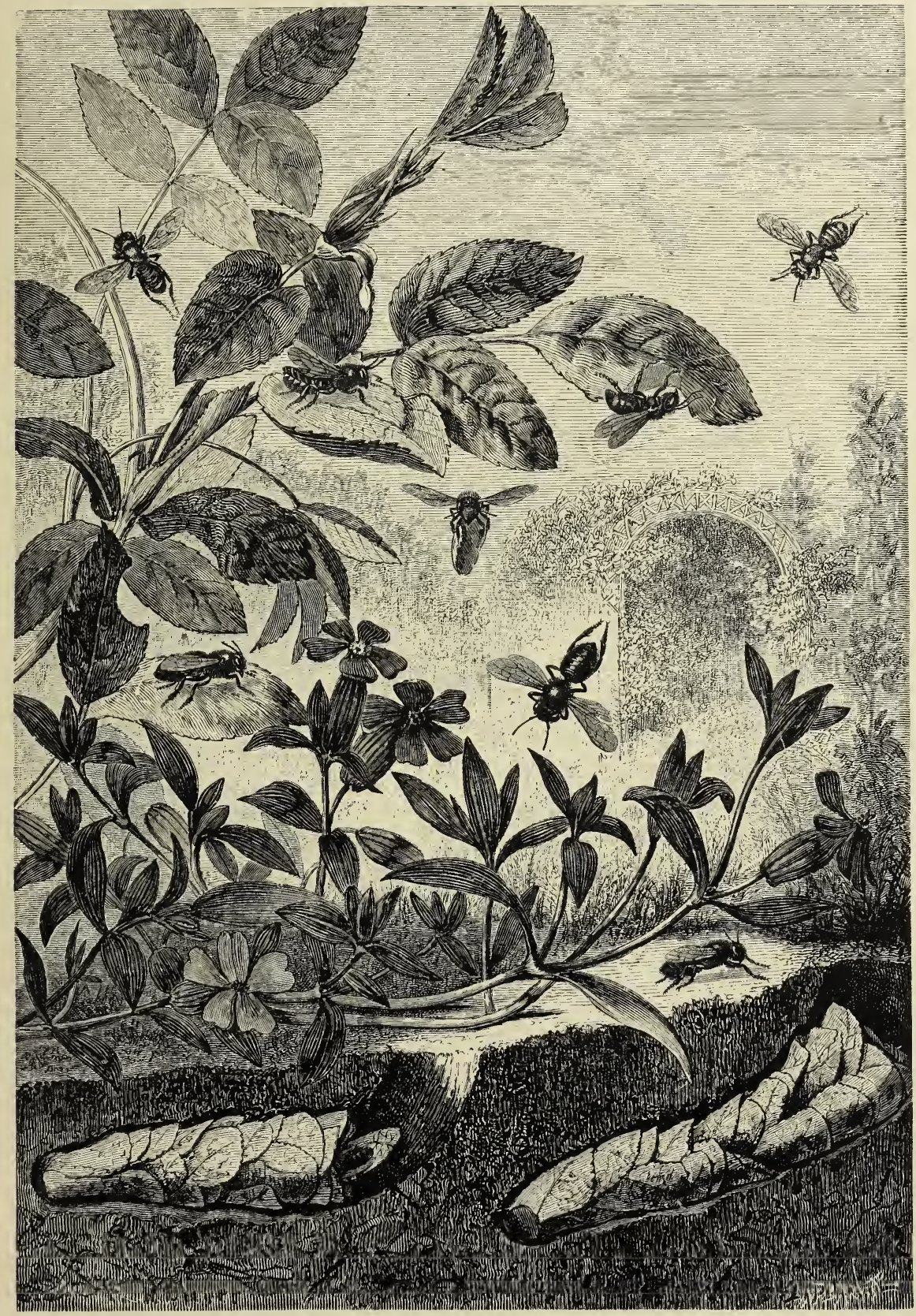



through some narrow slit; so she goes off and cuts two more circular pieces, and uses them as she did the first, and thus the little cells are closed by three layers of leafy covering, and sometimes by a fourth. A second cell is constructed in the same manner, and its end fits into the opening of the first, and thus a series of eight or ten of them is usually found, looking like a long tubular sleeve. When all this is completed, the eggs being laid and the cells victualled, the Megachile closes the hole of its perpendicular shaft with the earth which she dug out in the first instance, and this is done so well that there is no trace of it left.

In the engraving the leaf-cutting bees are depicted either in flight, on the leaves, at work carrying the leaf to their hole, or upon the ground, and one is completing a cell underground, on the left hand side.

There are some other bees which have three teeth to their mandibles, and which, perhaps, are more particular in making up their cells than the leaf cutters. They are called the flower cutters, and one of them, which uses the poppy as its material, is not very uncommon. Anthocopa papaveris, which selects the common scarlet poppy, is a small insect of a velvety black colour, with a white down on the edges of the segments of the abdomen. The female digs perpendicular holes in dry and sandy soils, and pounds their sides so as to make them hard and lasting; then it searches for poppies, and cuts off pieces of their petals, choosing the freshest, youngest, and the most beautiful flowers. The insect flies off with the piece of scarlet stuff, introduces it into the hole, and pushes it down. Of course the delicate tissue is ruffled during this proceeding, but the bee presses it against the sides of the hole, and works away until every fold is removed and the gaudy tissue becomes perfectly smooth. Then three or four pieces are cut off consecutively, and introduced into the hole and made perfectly smooth, and, finally, the honey-cake and egg are placed inside this beautiful little piece of workmanship. Before closing the hole the insect appears to remember the peculiar nature of the soil in which it has made its cell, and in order to prevent any grains of sand from falling upon the honey, the bee folds in the free ends of the lining of the cell, just as a man would fold in the top of a 
sack; this being done, the opening in the earth is filled up, and no trace of it is left.

These bees are represented in the engraving, some flying, some cutting pieces of red poppy, and others are either upon the ground or entering a nest.

The Carpenter Bee (Xylocopa violacea), which is not uncommon,

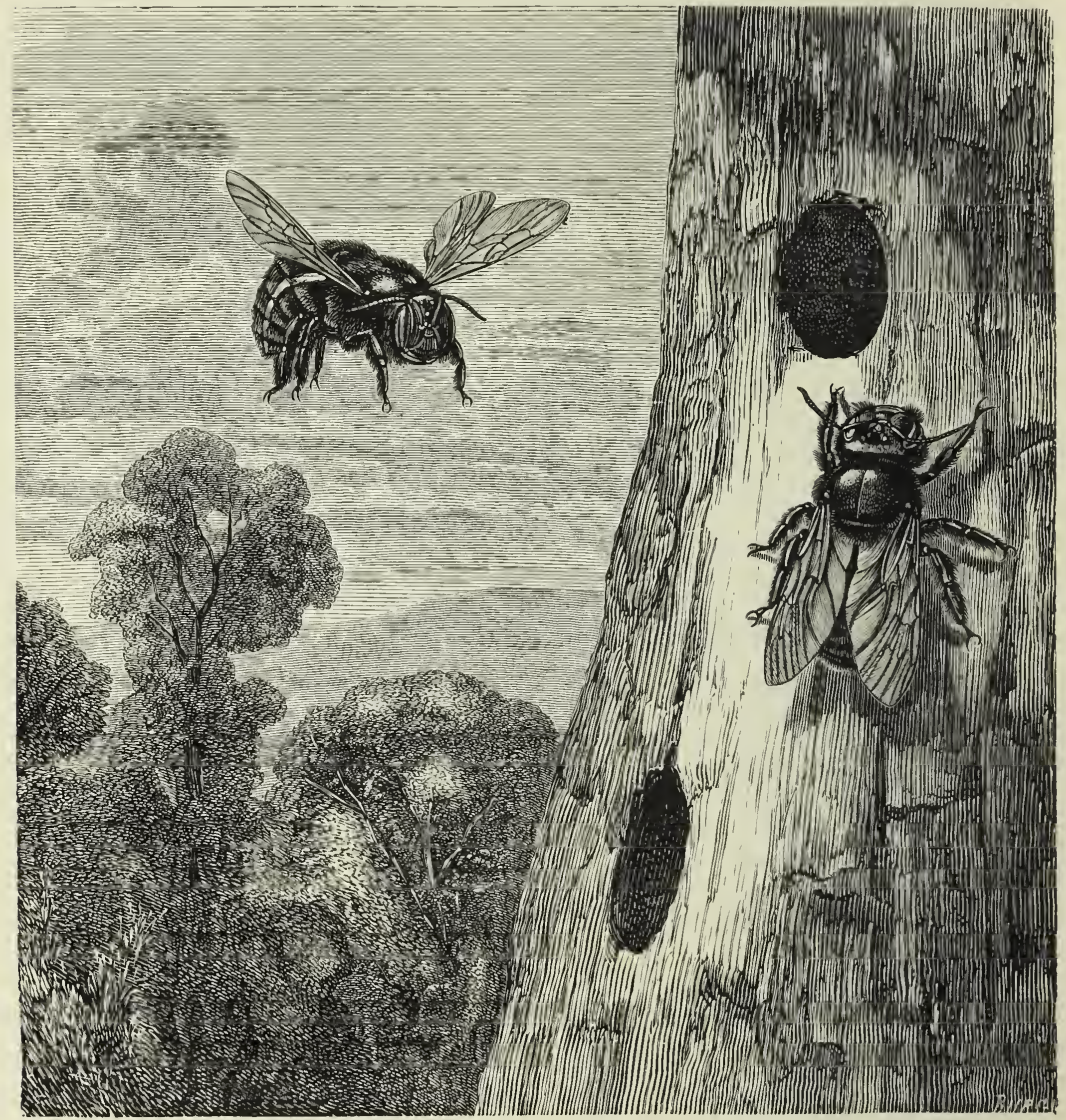

Xylocopa siolacea.

is larger than the largest humble bee, and may be known by its velvety black body and violet-coloured wings. This large bee, when about to construct its nest, searches for pieces of wood which it can pierce without much difficulty; then it sets to work and gnaws away with its mandibles and makes a hole, working indus- 


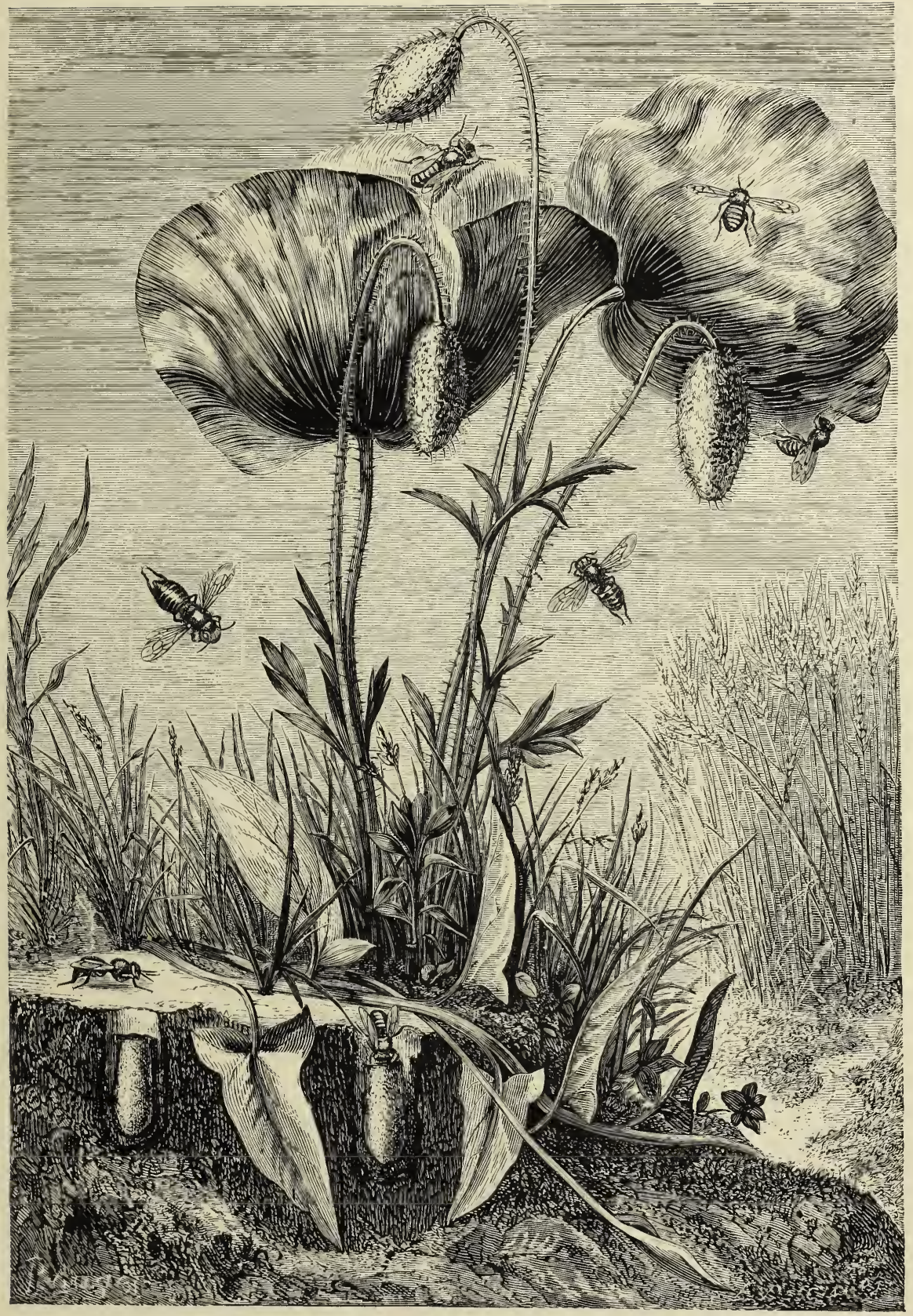

Anthocopa papaveris AND NESTS. 

triously and with no small difficulty. This bit of carpentry may take several weeks, as the hole sometimes reaches to a depth of a foot or more. But if the bee should happen to find an old gallery in a tree, or any tubular holes, she takes possession of them, establishes cells within, and makes their party-walls with sawdust, which she agglutinates with her saliva. The diameter of the holes is often half an inch, and after the sawdust is formed into a paste it is arranged so as to make the floor of the succeeding cell, in which an egg is deposited with the usual supply of pollen paste; this is covered with a layer of the sawdust, and thus the floor of another cell is made; and about a dozen are thus constructed one above the other.

There are some very common bees, which abound in the hot districts of Europe and Africa, which resemble hive bees, but are larger and more hairy. They are solitary bees, and belong to the genus Anthophora. One of them is a black insect, clothed with grey hairs, and having the last segments of the abdomen russet coloured. It digs holes between the stones of old walls, and collects all the sand dug out, agglutinates it with viscid saliva, and fixes it in front of the hole, arranging it in the form of small cylinders. This little vestibule, like that of an insect already described, is destroyed after the nest has been provisioned, and its materials are used to wall up the entrance. Other Anthophora, which make nests in rubbish, do not collect the substances which they have dug out, for they have plenty of materials at hand.

Anthophora personata has fawn-coloured legs, and makes a nest in loose earth, and builds five or six cells which open into a common gallery. When the cells are opened, large larvæ, or nymphs, as the case may be, are found. The larva of this Anthophora remains upon its side, and is a stout and large insect, especially as regards its abdomen, and the creature seems to be content always to remain in this curious position, with the body rather bent in front. In the engraving several of these solitary bees are drawn in flight, and a section of the cells and gallery is drawn on the right hand. Two of the cells contain nymphs, and two others, larvæ.

The bees which act as parasites upon others have been collected in one group called the Nomadina. Some of these 
are parasites of species of Osmia, and others of Anthophora; and these different insects have great resemblances to the kinds they rob. But there are certain peculiarities of structure which distinguish all the parasites, for they invariably have simple hind legs and no masses of hair which enable them to collect pollen readily, for they are not destined to work, and therefore they are not supplied with the necessary implements. Their jaws and lip are very short, and they have no necessity to gorge themselves with honey, for they will never have to supply their young with it. The true Nomadina are slender-shaped Hymenoptera, are almost smooth, and resemble little wasps on account of their black and brown colours variegated with yellow. One species (Prosopis signata) introduces its eggs into the nests of other solitary bees; and the Mclectide, which are called Cuckoo Bees, and which have a large body not unlike that of the Anthophora, are the parasites of these last-mentioned insects.

Everybody knows the Humble Bees, the large velvety $H y$ menoptera, that hum about the garden and make so much noise when they are caught in a room. They form colonies or societies, which commence, enlarge, and end like those of the wasps. A fertile female takes upon herself the duties of a worker early in the spring, after having passed a long hybernation, and lays the foundation of the future swarm. She soon finds herself surrounded by workers, which enlarge the nest. Thus one humble bee (Bombus muscorum) builds nests which are not very easily found, for the female establishes them in little cavities in the middle of fields, and takes care that they are in the immediate neighbourhood of plenty of flowering herbs. Mowers often cut into these nests, and if they are examined they will be found to be composed of a vaulted roof formed of pieces of moss cleverly entangled and fastened together. The opening of the nest, however, is from below. If the covering of moss be removed, a second will be noticed, but it is formed of a thick layer of greyishyellow wax. The moss, although collected in considerable quantities, would permit water to enter into the nest during heavy rains, but the lower roof of wax keeps everything beneath it water-tight. After having removed the waxy covering, the interior of the nest comes into view, and a mass of little round 


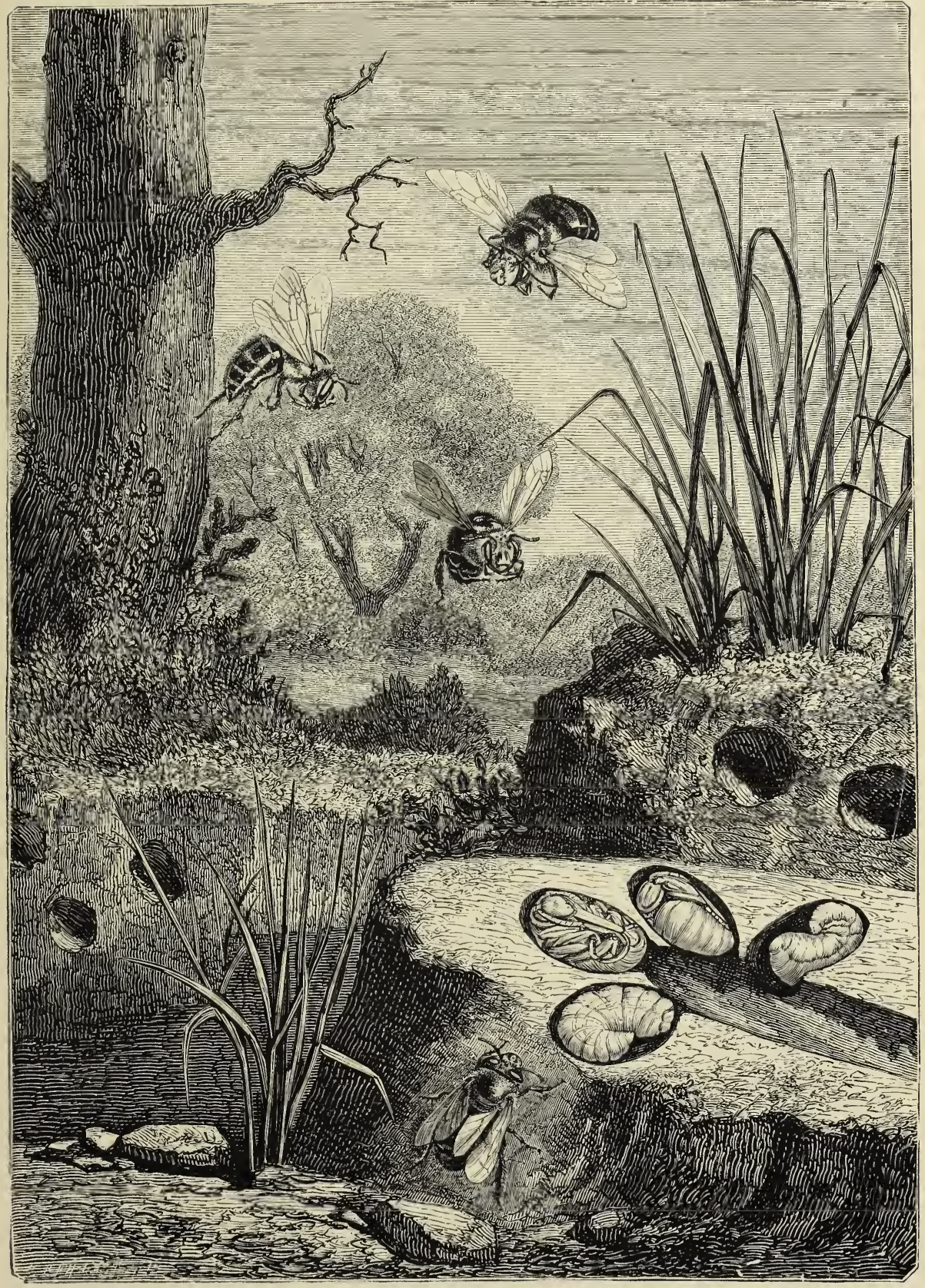

the metamorphoses of Anthophora personata. 

pellets crowded one over the other is observed, and these little things form the paste which is destined to nourish the future larvæ. Mixed with them, and encircled with wax, there are either eggs, larvæ, or cocoons, and at certain times of the year cups of wax, which contain a very pure honey, may be seen on the sides of the nest. The larvæ resemble those of other bees, and they spin themselves cocoons, which are egg-shaped, and which are usually found pressed one against the other. They are of different dimensions - the smallest, always the most numerous, are the cocoons of workers; those of medium size belong to males; and the largest contain fertile females. Before getting out of the cocoons they have to be cut round at one end so that a portion comes off resembling a lid.

In the accompanying engraving there are many workers of this bee, and a large female is represented on the ground on the right hand side. The cocoons are exposed to view.

Another humble bee (Bombus terrestris) is a very large kind, and forms its nests in the earth at a considerable depth. These bees do not use mosses, but make a lining to the roof of their dwelling with layers of wax.

Formerly certain Hymenoptera were classed by all naturalists amongst the humble bees, and, indeed, a superficial examination of them permitted this to be done, for they have the same shape, size, and colours, and look like them; but Lepeletier de SaintFargeau recognised them as parasites, and collected them under the genus Psithyrus. These insects which are so like the humble bees have only two kinds of individuals amongst them, for none of them are workers. There are males and females, and these have, as might be expected, no implements for working. Every species of humble bee has its parasite, its particular Psithyrus; and curiously enough the parasite has the peculiar colouring of the insect it robs, and usually there is no difficulty in telling the habits of a Psithyrus by its shape and tints. There is something in this resemblance more than chance, for it will be found that some flies, not wasps or bees, but Diptera of the genus Volucella, which are parasites in the nests of humble bees and wasps, resemble their unwilling hosts in their colours. One of the commonest species of the genus Psithyrus (Psithyrus vestalis) resembles the common 
humble bee of our gardens. It enters the subterranean nests of this species, lays its eggs, and then returns to the fields.

The habits of the common hive bees, and their methods of cell building, are so well known, that it is not necessary to describe them

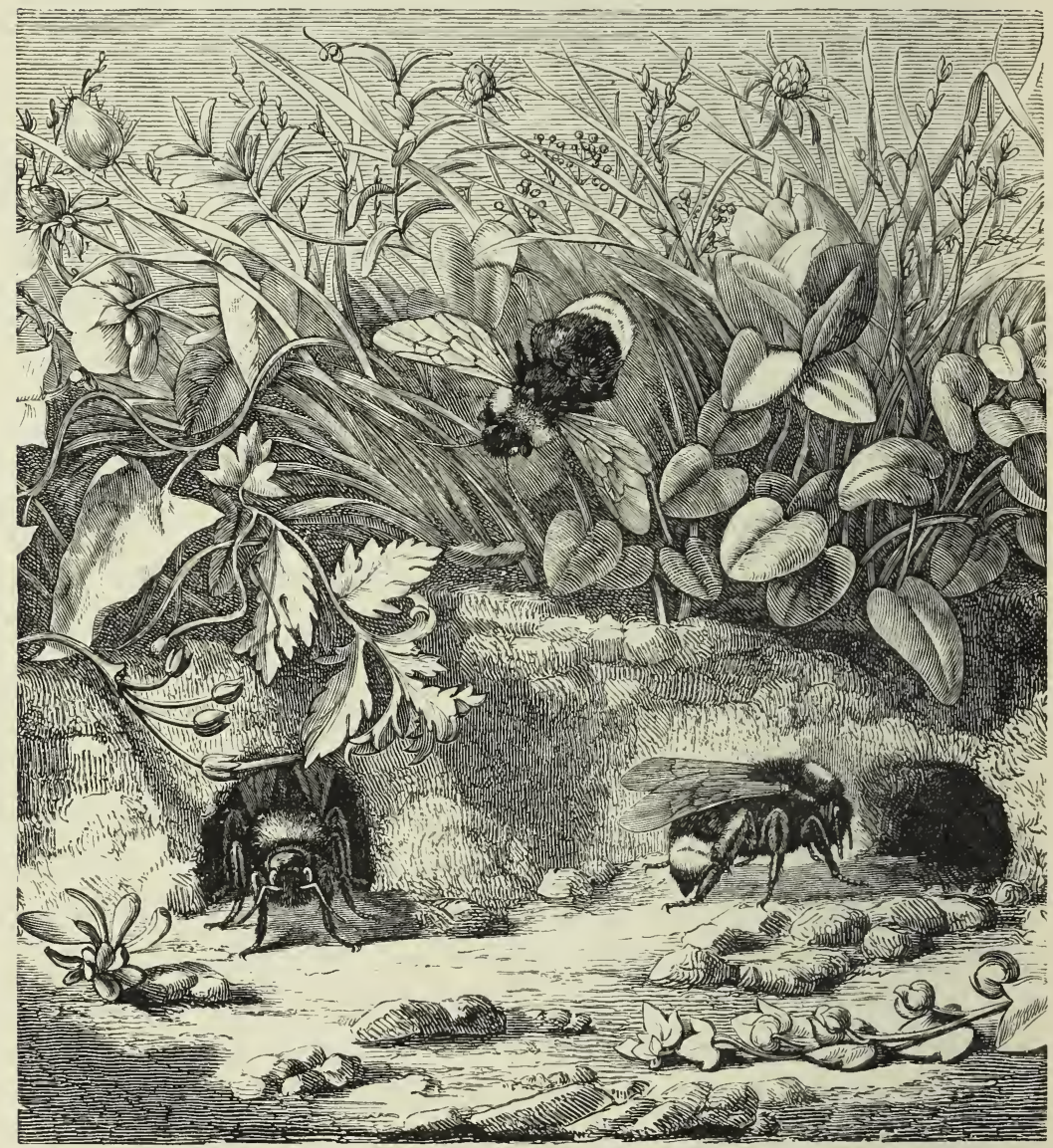

Psithymes a'estalis.

here. It is a curious fact that many virgin bees lay eggs whence male larvæ are always derived, and that this female after fecundation lays other eggs which turn into workers and fertile females. This faculty forms part of the phenomena of parthenogenesis, which have been so carefully studied of late years. Hive bees when wild establish themselves in cavities, such as those 


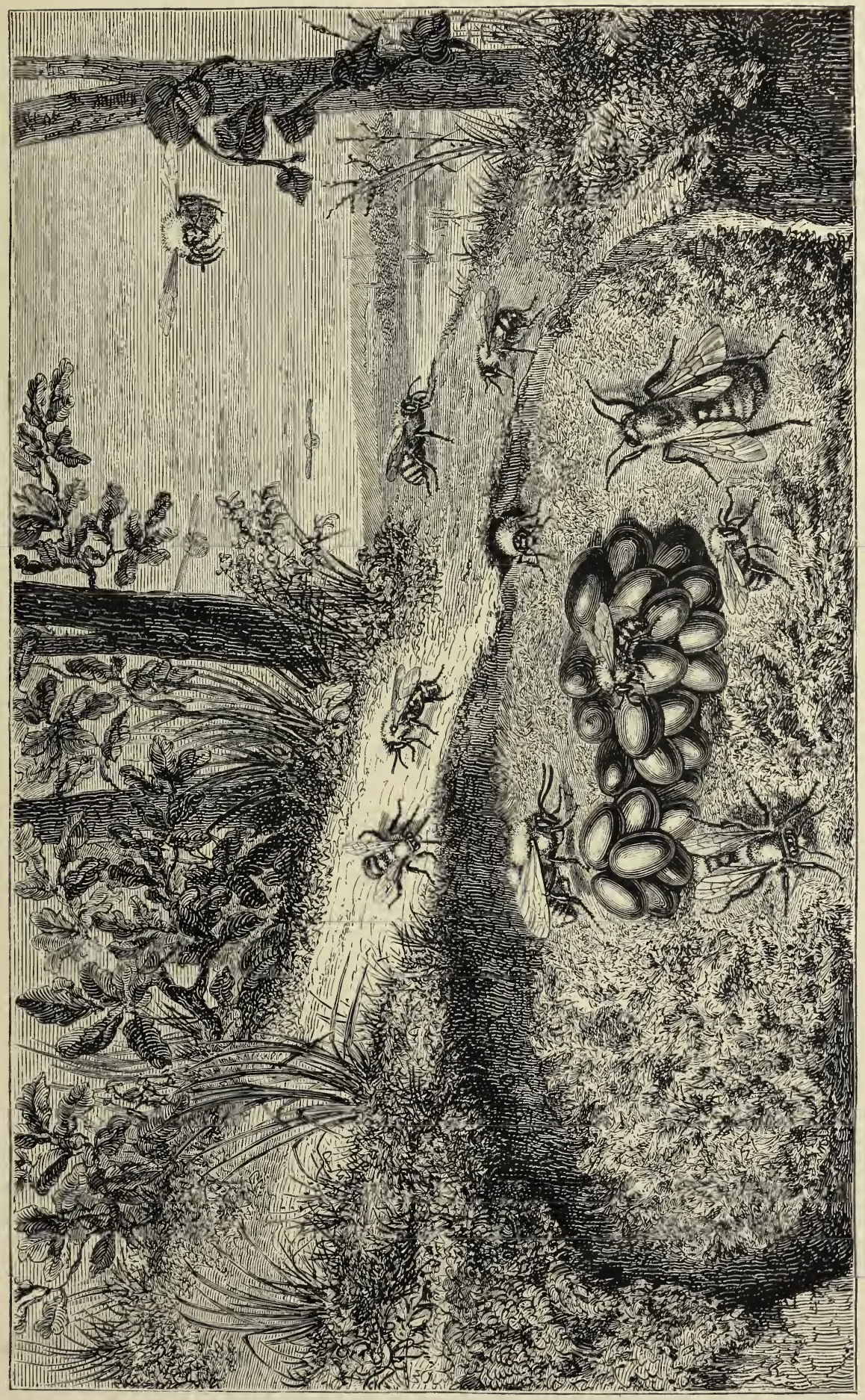



inside old trunks of trees. They make their hive, and their society consists of a crowd of workers and a single female or queen. Cell making goes on, the queen lays, and larvæ are born, and a new generation is thus produced; and thus some hundreds of males may be counted in a hive at one particular period of the year, besides the queen and the workers.

These three kinds of individuals present striking differences. The fertile females and workers of wasps and humble bees are very much alike; the fertile females are only slightly larger than the others-but were they not workers at one period of their existence? The queen bee is incapable of working; the workers or neuters are smaller than she is, and are not so large as the

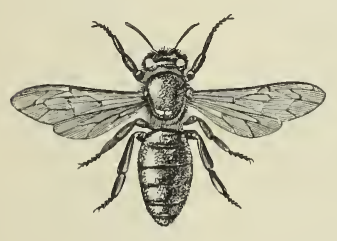

Female.

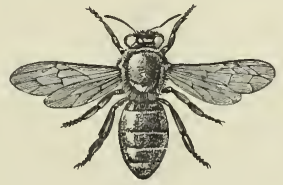

Worker.

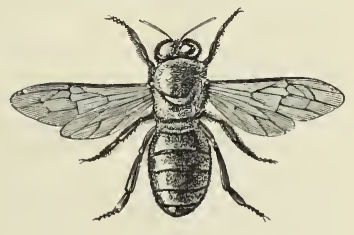

Male.

DOMESTIC BEF.S (Afis mellifica).

drones or males, and it is not necessary to describe them, for they are well known to every one.

The production of wax is one of the most remarkable physiological phenomena of the organisation of these Hymcnoptcra. It was generally thought, formerly, that the bees disgorged their wax from the mouth, and Réaumur certainly held this opinion; but John Hunter discovered the manner in which the wax was formed; and it is now evident that the bees carry within themselves this important building material. The segments of the abdomen of bees overlap from before backwards, but when the margin of one is lifted up, two broad and smooth surfaces will be noticed on the uncovered surface of the next wing; these surfaces maintain during one part of the year two thin, white, and almost transparent laminæ, which are really composed of wax. The wax is really secreted by some small glands which are within the abdomen, and it transudes through the soft and smooth integument between the rings or segments. It would appear that the sugary matters which 
are sucked and digested by the bees are to a great extent transformed into wax, which is to all intents and purposes a sort of fat.

The hind legs of the bees are so important to them in everything relating to the larvæ that it is necessary to notice them briefly. They are very wonderful implements. The leg is much enlarged near its farther end, and resembles a long triangle in outline; a set of sharp points or many strong spines, which are regularly distributed, form a kind of rake towards the extremity, and this implement enables the bee to seize the waxy plates that

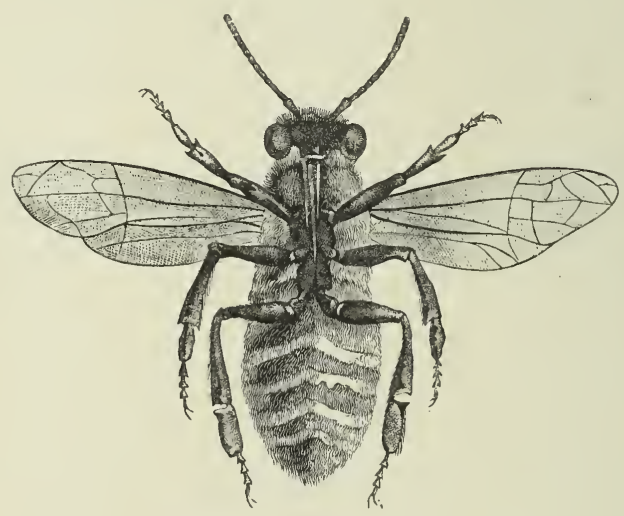

UNDER SURFACE OF A BEE, SHUWING THE WAX BETWEEN THE SEGMENTS.

are between its abdominal segments. The first joint of the tarsus or foot succeeds the leg and attains a great size, when compared with that of the other members of the structure. Being articulated with or jointed to the leg by its internal angle, the free external portion forms, with the leg, a true pair of pincers; moreover, two small spines render the arrangement all the more perfect. This joint is square in outline, and is perfectly smooth on the outside, whilst it is furnished on the inside with many transverse sets of stiff hairs of equal size. The limb acts capitally as a trowel and as a brush. The fertile female, which never works, has the traces of this arrangement, and the males also; but neither of them has the pinching and brushing structures. These are restricted to the workers. The fore legs have a deep notch in the first joint of the 
foot, which is very useful in building, and there are some long and close hairs which form a nice little brush, which can often be placed in contact with the brush behind.

The mouth has some remarkable structures in it. The mandibles enlarge towards their ends, and, as they terminate in a plane surface with a projecting border, they only close together suffi-

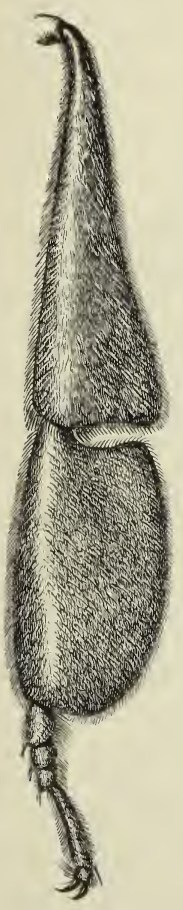

Of a fertile female.

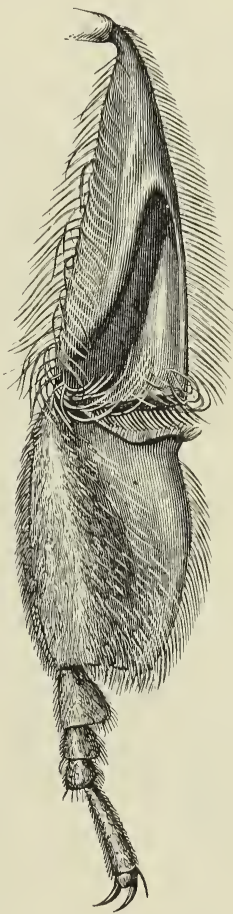

Of a worker, seen from outside.
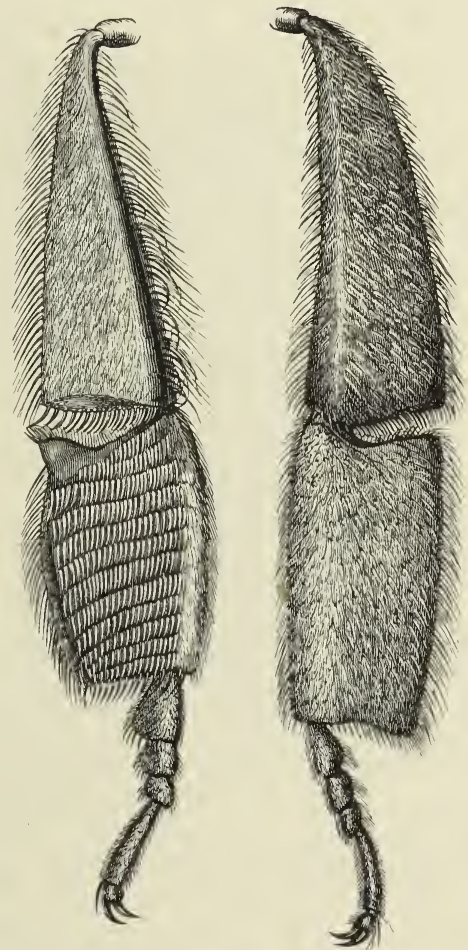

Seen from the inside. The male.

HIND LEGS OF THE BEE.

ciently to permit the proper quantity of wax to rest between them that should be worked at one time. The jaws and lower lip are long and flexible, and constitute a most perfect apparatus for sucking up honey.

The females and workers of nearly all the nest-making Hymcnoptera are armed with defensive weapons, which vary with the type of the insect. The sting of the bee, or rather its effects, are 
well known to most of us. It is made up of two very sharp stylets, which are mounted upon scales attached to the last segment of the abdomen, there being two valve-like sheaths which encase; and

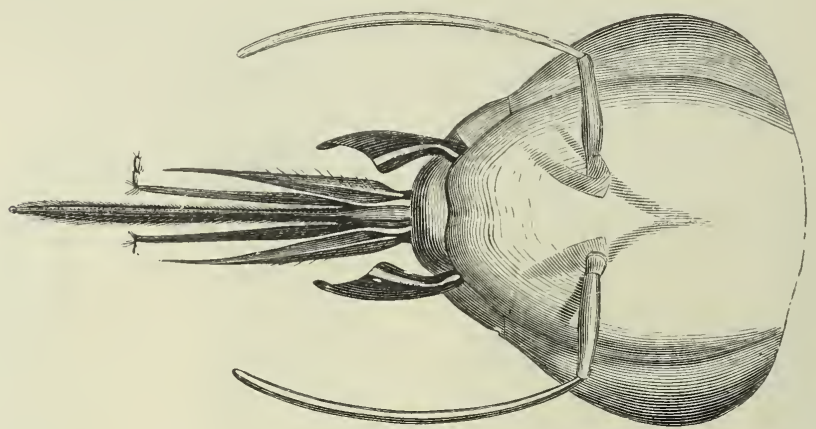

HEAD OF THE HIVE BEE, MAGNIFIED, WITH THE PIECES OF THE MOUTH MUCH SEPARATED FRUM EACH OTHER.

protect them. The poison glands are formed by two twisted tubes which lead into a large reservoir, the small opening of which is in a tube that emerges between the piercing stylets. When the

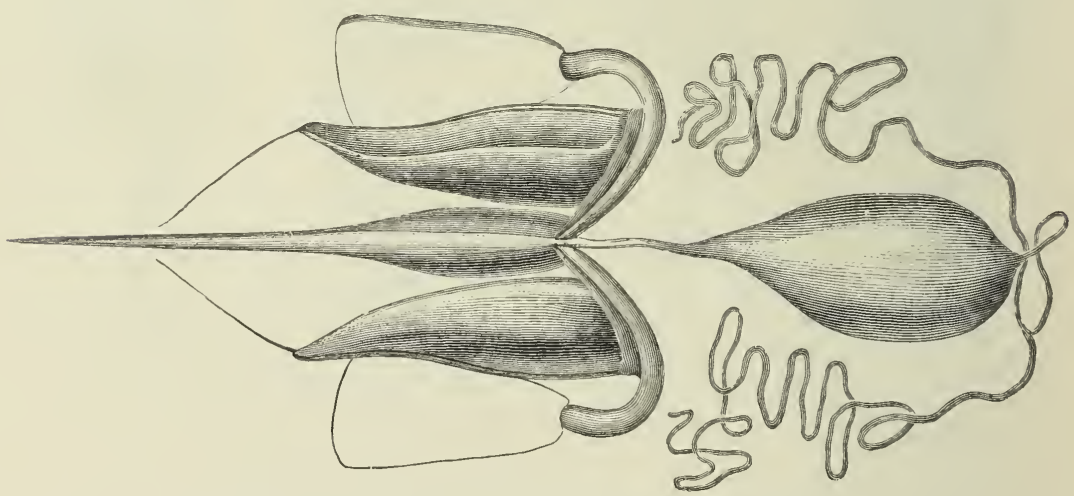

THE STING AND VENOM GLANDS OF THE BEE.

bee is about to sting, it contracts the muscles of its abdomen and forces out the stylets, and the pressure exercised in doing this gives out a drop of venom, which runs along the perforating instruments into the wound inflicted by them.

When a swarm of bees has taken possession of a cavity-of a 
hive, for instance-the workers immediately close all cracks and interstices by using a resinous matter, which is admirably adapted for the purpose, and which is obtained from the buds of poplar and other trees. This substance is called propolis, and is usually found in large quantities in the upper part of the roof of the cavity, where the comb is to be fixed eventually. This is the first part of the labour, and, when it is completed, the bees unite in groups, so

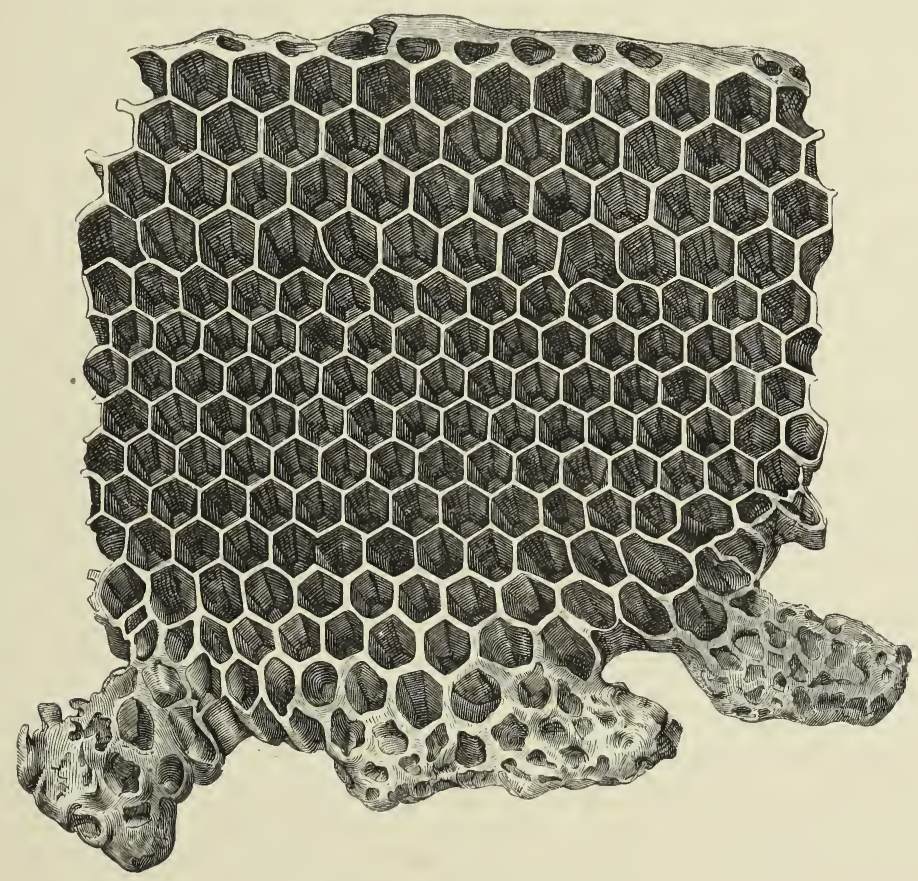

A PORTION OF HONEYCOMB.

as to form the cells of the comb. Each bee seizes a lamella of wax from its own body with the pincer on its hind legs, takes it to its mandibles with the fore-legs, and kneads the mass until a small round piece of proper consistence is formed. This is stuck on to the vault of the hive, and, when a number of such pieces has been collected and placed in their proper position, the cells are hollowed out by the workers, which excavate them side by side, and form them into the regular hexagonal shape by pressure.

The size of the cells varies, but the majority of them are 
small, some are slightly larger, and a few are of considerable size, and are usually at the ends of the combs. The smallest are for the larvæ of workers, the next size will be filled by those of males, and the largest cells will contain queens or fertile females.

As soon as the cells are finished the queen or fertile female of the colony, or sivarm, runs over the surface of the combs and lays an egg in each cavity, and she is attended by a host of workers, who take care that only one egg is dropped into each cell. Should two fall in, one is pulled out and destroyed. When the laying is finished the work of the queen is at an end, and she does not concern herself in any way about the future larvæ, or the attentions of the workers to them.

The larvæ are hatched in three days, and the workers immediately begin to take charge of them. It is possible that the oldest workers (those that cannot build or carry honey so well as others) are particularly the nurses, and they feed the larvæ, as in the case of other Hymonoptera. The larvæ grow rapidly, and make a silken cocoon for themselves before undergoing metamorphosis. The cocoon, as usual, shuts up the cell. The larvæ resemble those of other nest-making Hymenoptera, but they are less developed and weaker, for they cannot seize their own nourishment when it is brought to them, and they have to be fed from the mouth of the nurse.

There are two theories concerning the origin of the female and worker bees. One very doubtful one is as follows; and the other can be best understood by referring to Von Siebold's researches on Polistes gallica, already mentioned.

The bees produce fertile or sterile females (workers), according to their will, and probably the feeding of the larvæ has much to do with the development into egg-bearing or sterile insects. Now and then it happens that the larvæ of workers (sterile bees), which are located in cells near that of a fertile female larva (a future queen) receive, more or less accidentally, some of the particular nourishment intended for their important neighbour. The small quantity of royal food alters the condition of the development of the reproductive organs in the workers, and they become more or less able to lay. When a hive has lost its 


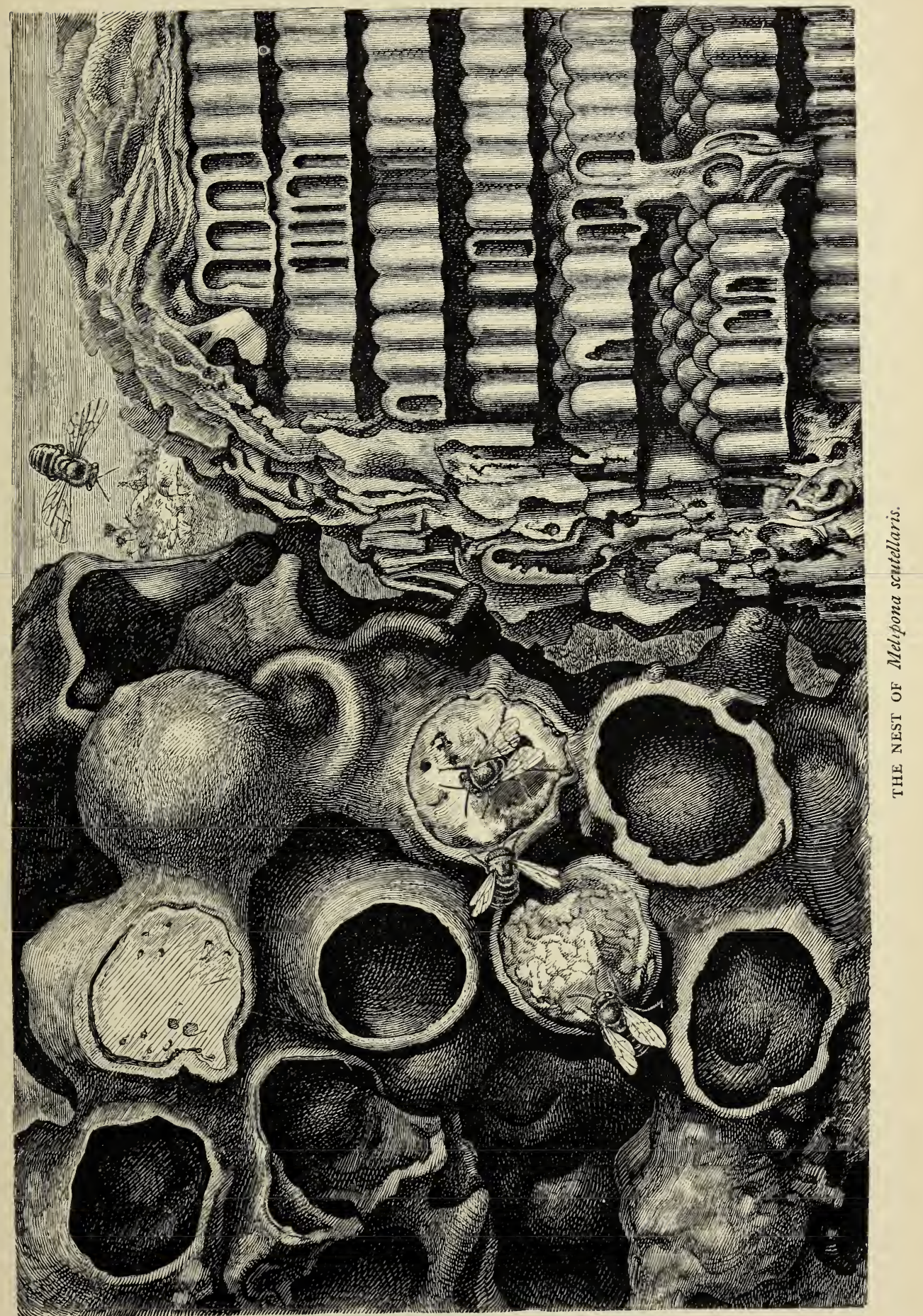



queen the bees produce others by feeding up the larvæ which should be workers.

A larva is chosen for this important position, and its cell is enlarged, the neighbouring insects and their cells being destroyed to make room. Then the larva is fed up royally, and the development of its reproductive system increases, so that finally a change into a fertile female is perfected.

It is perfectly certain that a maiden female can produce a progeny, and that when there are several fertile females associated with males they fight until one is the conqueror, the workers dragging out the dead, and witnessing the combat.

The influence of parasites upon the larvæ is considered elsewhere, as are also the destructive habits of the death's head moth.

There are some short and squat little bees with long legs and very varied colours, which have no sting, and several fertile females are said to live together in harmony amongst them. There may be some doubt about this last statement, but the species lives in South America, where naturalists are rather scarce. There are many species of these Mclipona, and Melipona scutellaris is one of the largest, so far as the bulk of its insects is concerned. These bees make their nests in hollow trees, but are not slow to occupy a box or a basket, and they are soon domesticated. The engraving represents part of a nest only, for these structures are very large, and the Mcliponce are just as prodigal of their wax as the other bees are careful and sparing of it. The centre of the nest is occupied by the cells for the larvæ in the form of a comb of one set of alveoli. The bees hoard up their honey in cells exactly like those in which their larvæ are to live, but the Meliponce make very large vases of wax, in which they collect and store away honey and pollen, and locate them close to the larva cells, and the walls of these great store-houses are very thick and strong.

The single rows of cells in combs placed one over the other are shown in the engraving of the nest of Melipona scutcllaris on the right hand, and close by are the large vesicles of wax, which are being filled by the workers.

All the Hymenopterc we have noticed are terrestrial, and the 
perfect insects either fly in the air or crawl on dry land. Immersion in water is fatal to them after a time. The larve of many Ichnemnons appear to exist surrounded by the juices of their victims, and they must respire either by means of the air passing through the air tubes of the insects they live in, or by the more or less aërated fluids which form their nourishment. But the majority of the hymenopterous larvæ respire by spiracles, and cannot live under water.

A discovery of Sir John Lubbock's is, therefore, very interesting. He observed many specimens of a small hymenopterous insect swimming in pond water with their wings, and quite at their ease. The fly belonged to a genus the larvæ of which are eminently parasitic in the eggs of some Lcpidoptera; and the accomplished naturalist just mentioned considers it highly probable that the slow-flying swimming insect was in search of some aquatic victims for its progeny. He found a second species, which used its legs as oars, but did not swim with its wings; and he noticed that both kinds of these Polyneme were fond of creeping along the sides of the vessel in which they were placed, or on the leaves and stems of aquatic plants. They frequently swam boldly out into open water. The history of the metamorphosis of these aquatic Hymenoptera has yet to be written; and it is evident that its comparison with that of the Hydrocampida amongst the Lepidoptera will form a most interesting inquiry.

The metamorphoses of the Hymenoptcra differ from those of the Lepidoptera, in consequence of the larva remaining for a greater or less period inside a cocoon before transforming into a pupa. Instances of retrograde metamorphosis appear to occur in the genus Cynips, and the wingless condition of the female members of the species of Cynips terminalis, and the absence of wings in Cynips apterc, are usually stated as examples. But the metamorphosis can hardly be said to be retrograde in the strict sense of the term, for the perfect female of Cynips terminalis and the adults of both sexes of Cynips aptora are more fully developed than their larva and nymphs, and possess additional structures. In no sense can they be said to be lower in the insect scale.

The transformations of these insects are not then retrograde, 
and tiey are not incomplete in the usual sense of the term, for there is a marked distinction between the three stages of growth. Tha nymphs have not the same powars and struatures as the adults. The Cynips aptere never has wings; the transformation is imperfect, and the evolution of the insect does not reach the point usually attained by the other Hymenoptera. Wings would be of infinite use to the Cynips, and it does not appear that there is anything relating to the natural history of the species which would account for the loss of wings by disuse during many succeeding generations. The wingless condition and the imperfect metamorphosis probably have a deep signification, and these exceptional Hymenoptera may be the oldest of their order; for it will be shown, in succeeding chapters, that there is great reason for believing that wings have been superadded to the earliest insects during the long geological periods.

Nothing can be more diverse than the development and instinctive powers of the larva of the saw flies, the parasitic Hymenopterc, and of the ants and bees; and it is remarkable that the very imperfect larve of the last two kinds should be transformed into much more intelligent adults than the others. The examination of the structural changes which occur in the nervous system during the transformations of the bee, and which have been noticed in Chapter III., will suggest that the concentration of the nervous masses in the adult has much to do with the development of great power of instinct. The occurrence of parthenogenesis in Cynips, and in some of the wasps and bees, has been proved; and it has been noticed that the workers or wingless adults are probably the result of this process. They are without the power of reproduction, and thus their metamorphosis is a stage more imperfect than that of Cynips aptera.

Very little of the intense activity and instinct of the Hymenopterc appears to be squandered upon the pleasures of the adults, and every unusual gift and habit they may have, with nearly all their restless industry, are employed in one direction-in perpetuating the species and in preserving the young during their transformations. All the honeycomb making, the excavation of nests, and the building-up of subterranean edifices, are for the preservation of the feeble larva and still more helpless pupax. 


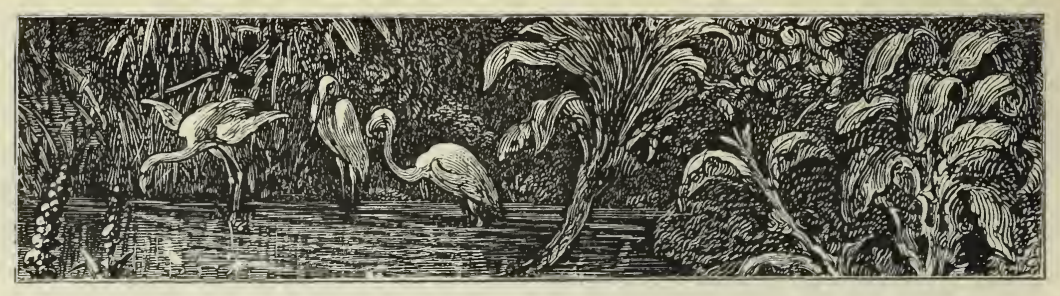

\section{CHAPTER VII.}

THE COLEOPTERA-BEETLES.

THE Coleoptera are those insects which are commonly called beetles. There are great numbers of them, and perhaps they have been more carefully studied, so far as their specific differences are concerned, than any other insects. More pains have been taken to collect them than have been given to the discovery of any other orders, and special collections have been formed by a great number of amateur naturalists, who have searched the whole world over for these objects, which appear to be so very interesting to them. Books which contain simple descriptions of the Coleoptera appear year by year in the different countries of Europe and America, and some treat of one genus of beetles, whilst others refer to the species of a district. The beetles of France are not yet all described, and a distinguished naturalist, M. Mulsant, of Lyons, has been at work at them for more than twenty-five years. This may give us an idea that the species of beetles are tolerably numerous; but really their numbers are legion, and it may be asserted, with a tolerable degree of truth, that I00,000 species have been collected and placed in museums. The greater number of them have been described in large works, in periodicals, and in pamphlets, and it will readily be understood that it is not very easy to find the description of any particular beetle, in consequence of the scattered nature of the literature of the subject. Fortunately, Professor Lacordaire has published a work enumerating the beetles, and giving the names of books which contain their descriptions and drawings.

Considering what charms the Colcopterc have for so large a number of naturalists, one might think that there was something 
unusually interesting about them; but this is not the case. The Coleoptera have no industrial occupations, and their instincts are very limited. In examining into their physiology we do not find any of those remarkable gifts and instincts, almost amounting to reason, that characterise the Hymenoptera, and which are amongst the most instructive and wonderful phenomena of Nature. It would appear that the charms of the Coleoptera, and the interest that they have excited amongst naturalists and collectors, are referable to the beauty of some of them, and to the ease with which they may be preserved, in consequence of the density of their structures and the nature of their wings. There is no difficulty in distinguishing any one of the beetles from all other insects. The most distinctive character is in the wings, which, so far as the beetles are concerned, are four in number, and in two pairs. The fore wings are always of the same hard coriaceous texture as the other parts of the body; they never cross one over the other when the insect is at rest, and they cover the body more or less perfectly. They are sheaths, and act as coverings to the hind pair. The name Colcoptera is taken from this peculiarity ( $\kappa \circ \lambda_{\epsilon} \varsigma$, sheath; $\pi \tau \epsilon \rho a$, wings), and the sheaths are usually called "elytra." These elytra, when the insect is at rest, are joined to each other at their inner margins, and thus form a sort of middle line upon the top of the body. They open at right angles with the body and project straight out from it, and remain fixed in that position when the beetle is flying, and they do not beat the air or vibrate so as to produce motion. The hind wings, which are almost always much larger than the fore wings, are membranous, and are marked with many branching nervures, and these wings, when the insect has done flying, fold themselves up and are hidden underneath the elytra. The membranous wings are strongly vibrated during flight, and do not remain at right angles to the body like the others. The structures of the mouth are usually well developed and strong, and are fashioned for the purposes of mastication.

The Coleoptera undergo complete metamorphoses. They are born as larvæ, like the Lepidoptera and the Hymenoptera, and the larvæ are transformed into immovable or quiet nymphs, which are, like those of the Hymcnoptera, the exact casts or models 
of the perfect insects. The beetle or perfect insect usually passes a short existence.

There is great diversity amongst the Coleoptera, both as regards their anatomy, physiology, development, and the manner in which they live. Many appear to be inferior or lower in the insect scale than others; whilst some are so elaborately constructed that they must be placed in the most perfect class. The most decided anatomical differences, so far as the internal organs are concerned, coincide with striking distinctions in the external conformation of the insect; and in those beetles whose limbs denote superior powers the nervous system is very concentrated; and it is less so in those species the structures of which are more simple. The food of the Coleoptera is of all kinds, so, of course, the modifications of the structures of the digestive organs are very great. Many of the larvæ are leaf-eaters, and certain kinds do a great deal of harm to all sorts of crops and trees. There is much interest attached to the early conditions of the Colcoptera, and there is often a striking resemblance between the larvæ of those families, the adult forms of which differ in the strongest possible manner. In some families of beetles the development of the larvæ is very slight, and they have no legs, so that they look like worms. In other families the larvæ have structures which are intended to act as legs, but they are feebly developed, and locomotion is therefore very imperfect. On the other hand, many larvæ are born so fully formed, that they are very much like the perfect insects, and are more or less active in their habits; and, finally, some on leaving the egg possess the habits and the methods of movement which characterise the perfect forms. They cannot fly, however. All these insects, more or less well organised, must undergo their principal metamorphosis during the period of rest and quietude when they are nymphs. The metamorphoses, the habits, and the instincts of many of the Colcoptera are well known, and those of a considerable number of species in each of the great groups into which these insects may be divided have been carefully studied.

There are at least twenty families of the Coleoptera which can be readily distinguished on account of their members being very characteristically formed ; but it is impossible, from what we know at present, to collect them into groups, and to distinguish one from 
the other by attributing to certain forms higher or lower positions in the insect scale.

Formerly it was attempted, and it was supposed very satisfactorily, to divide all the Coleoptera into four great primary divisions, according to the particular number of the joints of the tarsi. Geoffry, a great entomologist of the last century, invented this method of classification, which, although open to many objections, is very useful, and is generally employed by modern authors.

The divisions are as follow:-I. Pentamera, in which all the tarsi are five-jointed; 2. Hetcromera, in which the four anterior tarsi are five-jointed, and the two posterior four-jointed; 3. The Tetremera, those which have four joints to all the legs; 4. The Trimera, which have never more than three joints to all the tarsi.

It must be understood that this classification is very artificial, for there are many bectles which are very closely allied so far as their general structures are concerned, which have great differences in the numbers of the joints of their legs; and, on the contrary, those whose joints are of the same number, are occasionally noticed to be very different in their other characteristics; so that the number of the joints does not always coincide with the natural affinities of the insects. This ready method must, therefore, give way to one which groups the Coleoptcra by considering the general characters.

The family of the Scarabcide is, perhaps, the most interesting as well as the most numerous of the Colcoptera, and its members present remarkable distinctions in their habits, food, methods of life, and in their general conformation. Nevertheless, although they vary so very much amongst themselves, these beetles constitute a very natural and very characteristic assemblage. They possess antennæ which are short and inserted into a cavity underneath the lateral edges of the head, and which end in a club-shaped mass made up of several leaflets. The antennæ enable us to distinguish most of the Scarabaide at once.

Duméril, who was a good naturalist, called these Colcoptera the Lamellicomes, from the structure of their antennæ; but it should be noticed that all of these organs are not composed of leaflets or lamellæ. Some are in the form of a cone reversed, or are nearly globular towards their ends, the joints being box-like. The tarsi 
are invariably made up of six pieces; the body is always more or less heavy, thick, and stout, and in many of the members of the family the structures of the mouth, and even the mandibles, either remain partly or entirely membranous. This feeble condition of the mouthpieces is generally accounted for by the nature of the diet of the insect.

The Scarabeide are usually large, and some of them attain the greatest size amongst insects. The principal forms of the family are more or less known to everybody, and they are the Scarabaida proper, the Dung Beetles, the Cockchafers, the Rose Beetles, \&c. During the adult stage, the Scarabaida present very notable differences in their external shapes and in their habits, but they resemble each other in a most wonderful manner when they are larvæ. These are the great "white worms," as they are usually called, and they may be the larvæ of any of the family, although they are almost always attributed to the cockchafer. Every one has seen these white fat things, whose bodies are thick and cylindrical, and usually curled up, and whose skin is very thin and furnished here and there with stiff hairs, which give the insect considerable sensibility of touch and may assist in its movenents. The larvæ have a rounded head, which is covered with a fawn-coloured or brownish and very hard skin, and they have strong mandibles, and antennæe that have four or five joints.

The larvæ of the Scarabaide were first carefully studied by a Dutch naturalist, De Haan, in 1836 , and since then other observations have been made upon them. The larvæ are always hidden up either in the ground, in the roots of plants, or in the middle of vegetable or other rubbish. They never come to the light; they are colourless and rather soft, and as they always live in darkness they have no eyes. They are always eating and consuming a large quantity of nourishment, and therefore their digestive organs are very voluminous. They walk with great difficulty, especially as the curvature of their body necessitates their resting on one of their sides. When first born they are rather active, but they soon get lazy and dull, and spend the greater part of their lives in destroying everything in their immediate neighbourhood, and cating it.

After a longer or shorter life, according to their peculiar habits, 
they form a rounded or egg-shaped cocoon, and undergo their metamorphosis into nymphs. In order to make the cocoon, they bring together either grains of the soil or pieces of wood and

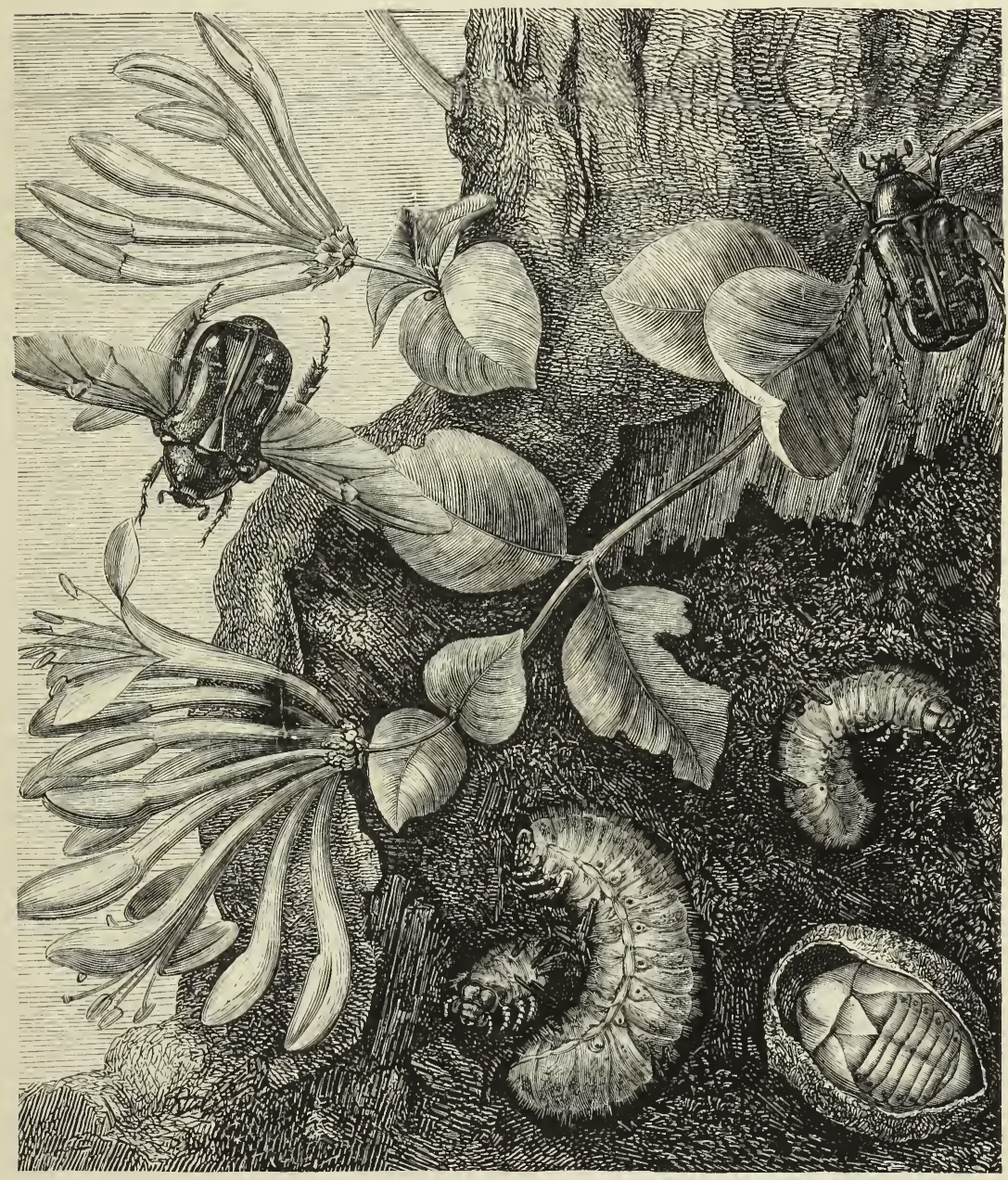

THE METAMORPHOSES OF THE ROSE BeEtle (Cetonia amata).

rubbish, and unite them together with their saliva. The principal types of the family of the Scarabaida, when arranged in different tribes, are the Cetoniida, the Glaphyrida, the Mclolonthida, the 
Scarabaida proper, the Geotrupida, the Coprina, and the Passalina.

The Cetoniide are very beautiful insects, which like the honey they obtain from flowers, and which are distinguished from the other tribes of the family by their membranous mouthpieces and the ten joints which compose the antennit. There are two groups of them; and the first, which consists of the Rose Beetle tribe, properly so called, is well known by its containing the genus Cetonia, the commonest species of which, Cetonia aurata, is so abundant everywhere in Europe. It is to be seen during the whole of the summer, and especially in the months of May and June, flying about gardens or resting upon the flowers. It is a beautiful beetle, whose golden-green tints and delicate linear and white ornamentation strike everybody with admiration, for when it moves in the sunshine, and flies slowly or quickly, the whole of its body looks like a mass of glowing gold-like metal. It is very remarkable that these rose beetles should not fly like most of the others, by extending their elytra at the same time as the membranous wings, for they only lift up the elytra slightly, and never separate them; and this peculiarity is shown in the engraving on the previous page.

On the left-hand side of the engraving one of these beetles may be seen flying downwards with its membranous wings extended, but the elytra still cover the whole of the body, as they do in the insect which may be seen at rest on the upper part of the picture and on the right hand. Low down on the right hand is a nymph in its cocoon, and around it are larvie of different sizes.

This beautiful beetle chooses the most elegant and elaboratelycoloured flowers as its house and food; it likes to dig deep into the hearts of roses and honeysuckles, the petals of which it eats, and, moreover, it sucks their honey. The females usually lay their eggs in decayed wood at the foot of trees or in their trunks, and some have the extraordinary instinct of depositing them in such curious places as ants' nests. They look like the larvæ of cockchafers, but their heads are much smaller, their legs are shorter, and the last segment of their body has a little projection upon it which is not observed in those insects with which we are now comparing them. The larva live together in some 
numbers. At the approach of winter they grub downwards into the earth, even to the distance of one or two feet, and return again in the spring. Probably they live three years in this manner, and then they construct oval-shaped cocoons out of chips of wood and pieces of rubbish, all of which are glued together by the secretion of the salivary glands. They undergo their metamorphoses in the cocoon, and they proceed rather rapidly, for the beetle forces itself out in the early summer. Dr. Baird says that a very pretty species is found in the Philippine Islands, which is of a fine brilliant metallic green colour. The ladies of Manilla keep them as pets in small bamboo cages. The beetles of this family of the Cetoniidce are widely dispersed, but most of them are found in tropical climates, and they vary much in size and in ornamentation in every country.

There are some beetles of a Brazilian species which rest in the morning time in the plantations of maize, where they are found sitting under the leaves; they fly during the day round the lofty trees, upon the leaves of which they feed. They are styled the princes of the beetle tribe, but are inferior in size to the Goliaths (Goliathus), which are peculiar to tropical Africa. The same author informs us that the great Goliathus cacicus is roasted and eaten by the natives. Several species used to fetch very high prices amongst collectors, and as much as $£ 50$ have been given for a single specimen. The larva of this species makes a cocoon of mud, and undergoes its metamorphoses in it.

The Trichiite, which differ from the Cctoniide in not having a particular portion of the mesothorax prominent, have a species which is small and black, and which is often seen running about the ground (Valgus hemipterus). It has five spines on its legs, and the female has a long and straight ovipositor, with which it introduces its eggs into the cracks and holes of decaying wood.

The Melolonthide have a very short lower lip and strong mandibles, which enable them to browse leaves, and the hooks of the legs are constructed in different manners, according to their methods of life. The Cockchafers, or May Bugs, are representative forms of this family. These beetles appear in enormous numbers in some years, and are just as scarce in others; and this depends upon the long duration of their development. If the spring is warm they 
appear in the month of April, but the greatest numbers fly in the month of May; towards the end of June they are almost all gone. They eat the leaves of many trees-such as the oak, the beeches, the maples, and the poplars, and sometimes the elms. Occasionally the trees are completely spoiled and killed by the May bags. They are almost nocturnal in their habits; they dislike the sunshine, and seek the shade during the day under the branches of bushy trees. They wake up in the morning, and are moderately lively then; but during the evening they are particularly active, and fly here and there, making a sonorous buzzing noise. They are heavy and very clumsy in their flight, as most of us know, for when we are walking out in the warm spring evenings there is often some difficulty in escaping these dull and stupid-looking beetles; in fact, they prefer banging against everything, rather than guiding themselves away from obstacles which are hard enough to do them injury.

The May bugs do much mischief when they are beetles, but the ravages they commit in the larva state are of most serious consequence to agriculturalists. The female beetles dig into decaying matter, or light soils, and hide themselves whilst they lay about forty eggs. The larvæ are hatched at the end of four or five weeks, and by this time the tender vegetation of early summer is progressing rapidly. Then these white worms or cockchafer grubs, as they are often called, find themselves surrounded by abundance of food, and, unfortunately, of that kind which is very precious to man. They do not eat the leaves, but the delicate roots which come in their way as they crawl underground; and thus a vast number of plants is destroyed. The larvæ grow very slowly, and do not undergo any metamorphosis until their third year; and then they are transformed into nymphs during the months of March or April. Some weeks afterwards the beetles escape and fly. The long duration of their growth and evolution explains how it is that these beetles usually visit us in great numbers every third year; but it would appear that unusual heat, or seasons of great cold, have something to do with the acceleration or retardation of their development. It is not uncommon for larva to undergo their metamorphosis towards the end of their second year, when the summer has been unusually hot; but even 
then the cold of the autumn may prevent the perfect insect from leaving its cell-so that it does not fly until the spring of the third year. The larvæ are shaped like those of the Scarabaida generally, and they are remarkable for their strong mandibles, which are furnished with a diamond-shaped tooth that enables them to cut across rootlets very easily.

It would appear that the larvæ of the May bugs, found as they are over the whole of Europe, were not formerly such pests to farmers. They were certainly not so common in the olden time, but they appear to have increased their numbers with the spread of agriculture. Farming operations favour these creatures, for they cannot live in undisturbed ground; they cannot move about in solid earth or in old rocks, but they can do so in alluvial soils, or in those which the process of tillage renders light and suitable for vegetation; and, formerly, the acreage of cultivated ground where the May bug larvæ can live was, of course, much less than it is now, and consequently the beetles were not so common. The larvæ must be dug up to be destroyed, and this is a very awkward operation whilst ploughing and spade husbandry are going on. It is much easier to collect the beetles themselves, and if they were well hunted down everywhere simultaneously, there would be no doubt about a rapid diminution in the numbers of the larvæ; but, unfortunately, all the efforts of men who are sufficiently enlightened to advise the farmer rarely meet with success. Thirty years ago, a Prefect in the Department De la Sarthe-M. de Romieu-took great pains, and persevered in urging upon agriculturists to destroy the real originators of the mischief they suffered from; and of late years M. Riset has been studying the amount of mischief these creatures really commit. He found that in two arrondissements in the Department of Seine Inférieure, 360,000 lbs. weight of cockchafer grubs were found; and as a grub only weighs about thirty-one grains, there must have been 8 I,290,322 of them.

With this calculation before us, which refers only to two small districts, it is not difficult to understand the enormous amount of injury that is done to agriculture by these grubs. Very fortunately rooks, jays, magpies, crows, and other birds, eat immense quantities of them, and this fact alone ought to make us careful of 
preventing the wanton destruction of the birds that keep down these insect pests.

The engraving describes the metamorphoses of the cockchafer. The larvæ are seen in different stages, and there is a nymph underground also, whilst the perfect insects are crawling above.

There was at one time a speculation by which people hoped to make money by cxtracting oil from cockchafers, which was supposed to have extraordinary virtues, and to be useful in many ways ; but, unfortunately, the expense of manufacturing the oil was too great, and the effort came to nothing.

The species which most resemble the common cockchafer are not very widely distributed in Nature, and the mischief they perpetrate is not much feared or cared for. One of them may be noticed on account of its great size, and its favourite locality. Melolontha fullo is a fine beetle whose general colour is brownish, and it has little white spots scattered here and there over the whole of its surface, especially on the elytra, on which they produce curious designs. The males of this kind are always admired on account of the great size of the lamellæe of their antennæe, which resemble beautiful feathers. These cockchafers are not found inland, but choose the seaside for their residence, and they may be found on the dunes or sand-hills of Dunkirk and the environs of Ostend, and they have been noticed on different spots by the sides of the Baltic Sca and the ncighbouring ocean, as well as all round the Mecliterrancan. They fly with great velocity, and make much buzzing; and they appcar so fond of noise, that they constantly produce a sharp sound when they are on the ground or amongst the leaves, by rubbing the elytra against the body.

In the engraving the malcs may be seen with their great antennx, and the female on the left-hand side of the picture shows the white markings on the elytra very distinctly.

The Rutclide are beautiful beetles, and are intermediate between the Mclolonthide and the Scarabaide. The species of some of the gencra of this tribe have magnificent colours, which hint at their existence where the sun shines in all its glory, and where the climate is most genial. Some of them live in the hottest countries of the world, others in tropical America, and some in Australia. There are no Colcoptcra in Europe as brilliant as these. The prettiest of 


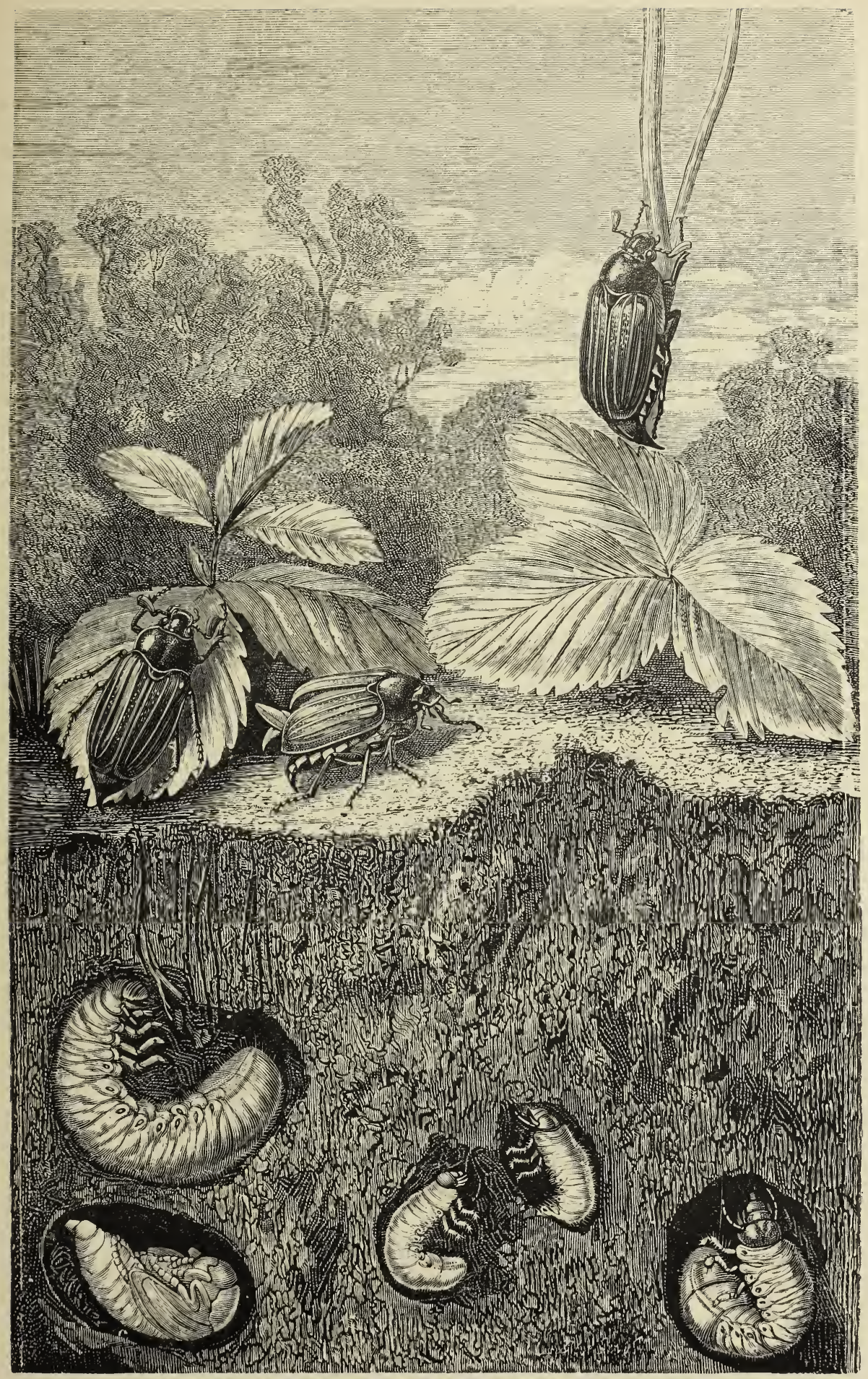

THE METAMORPHOSES OF THE COCKCHAFER, 

these brilliant creatures belong to the genus Euchlora; they are small Coleoptera very much like the cockchafers in shape, and are usually of a beautiful green colour, and their antennæ are made up

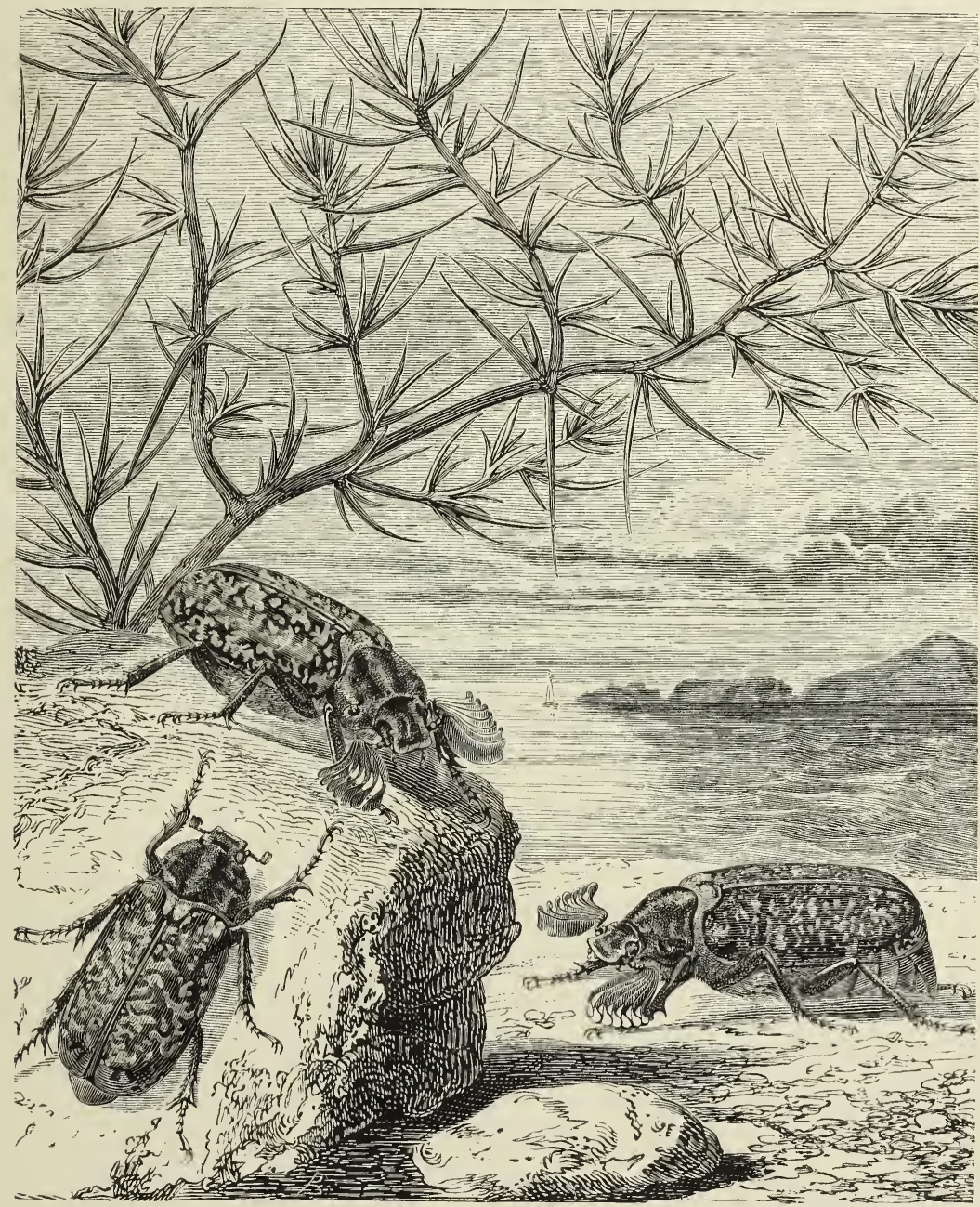

BEETLES OF Melolontha fullo.

of nine joints. One of the commonest species is the vine Euchlora; it is of a beautiful metallic green colour, and its elytra are striated and covered with points. It often does great mischief to vineyards. Another European kind also resembles the cockchafers, and is 
about half an inch long; it is of a dark green colour, and is marked with light brown stripes. It is called Phyllopertha horticola, and every one must have noticed it on trees and bushes during the summer time.

The Scarahaida comprise the giants of the order of the Colcoptcra, and are well known by their heavy and clumsy bodies, which are solidly protected by an integument which acts like a cuirass, by their rudimentary lips, their strong mandibles, and by their head and prothorax being almost always furnished, in the male insects, with prolongations which look like horns. The species of the genus Scarabaus have their jaws furnished with teeth, and the general structure of their mouths indicates that they live upon hard leaves and even upon woody tissues. The horns which the males carry give them a very curious aspect. These horn-like prolongations present great diversities of shape in different species, and the endeavour to find out their uses does not meet with much success. There is nothing which leads to the suspicion that they have any particular function, when the peculiar habits and method of life of these insects are examined; so that, if we take a limited view of the question, we may consider them as decorations or ornaments.

The larger species of the Scarabaida live exclusively in those countries where Nature produces the most luxuriant vegetation, such as the Antilles, South America, and the Moluccas.

The larvæ of these enormous insects live inside the trunks of old trees; and any one can readily believe the mischief they must do, and what a large quantity of vegetable matter they must consume during their growth. The most remarkable of the larger Scarabaide is Scarabcus Hercules; it has a black body and olive elytra, which are very brilliant and spotted with black. The males have the forehead and the prothorax each armed with a prodigiously long horn. Another Scarabaus is as large as this one, it lives in New Granada, and is black in colour; another, which is covered with a fine layer of hairs, is found in the Brazils; and the great Scarabaus Atlas, from the island of Amboyna, has a brilliant bronze tint. The Orycles are the Scarabaide of our part of the world, and may be distinguished from the members of the genus Scarabens by not having tecth in their jaws. 
The finest specimen of these insects is Oryctes nasicornis; it is of a brilliant brown colour, and has a horn upon its forehead like a rhinoceros, whence it has derived its title of "nose-horn." The larva is larger than that of the cockchafer, but has smaller legs, and it lives in the trunks of old and rotten oaks, but it is more readily discovered in those places where tan has been allowed to collect and to remain for some time.

The Geotrupide and the Coprince form other tribes of the Scarabaide. They are essentially the Colcoptera of dung-hills, manure, and of stercoraceous matters in general. The Gcotrupide have weak mandibles and jaws, the first being of a leathery consistence, and the antennæ of ten or eleven joints. The Coprince

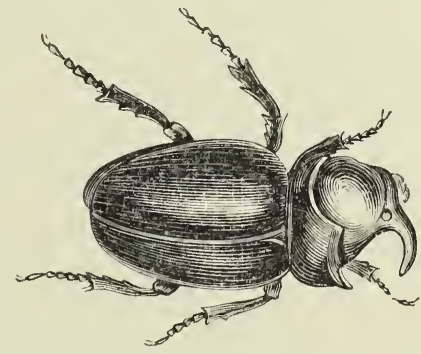

Oryctes nasicomis.

have antennæ which are formed of nine joints, and the mandibles and jaws, which are small and membranous, are suited for the liquid diet in which these insects indulge. The principal genus of the first tribe is Geotrupes, and its members are commonly called dung beetles, as are also the Coprince.

A large bectle, which is of a shining black colour, and whose tints pass from green to blue or to violet, and whose elytra are strongly striated, flies and makes a great buzzing in the fine evenings towards the end of summer and the beginning of autumn, all about the roads and near walls, or wherever filth has been dropped. The female of this beetle takes particular care about laying its eggs. She makes a deepish hole in the earth and a comfortable chamber at the bottom of it; in this retreat she lays an egg and then collects and packs up a quantity of filthy dung, which she 
stores up there, so that when the larva is hatched it will have its natural food at once. The species of another group form the genus Trox, and they have projecting mandibles. These species are small, but are readily distinguished on account of their grey colour and the roughness of their elytra; they like the dust and they are exactly of its colour, and one of them may often be seen on dusty roads (Trox sabulosus). It is a little beetle about a third of an inch long, having the elytra furrowed and ornamented with little tufts of hair. The adults and the larvæ feed on the dead bodies of animals.

There are several well characterised kinds of insects amongst the Coprince (or the Coprophagi of older authors), and their duty is to act as manurers of the soil. The genus Aphodius has many species, which are found very generally over the world. They have oblong bodies, and are about the smallest of the Scarabeide. Aphodius finctarius is to be found on all dung, and its lustrous black colour and red elytra are very marked. Aphodius fossor is found in the same places, and is known by its perfect black colour and larger size.

These dung beetles keep their skins glossy and beautifully shining by secreting an oily fluid, which prevents all the nasty things they live amongst collecting upon them, or staining their skins. This is particularly observable in the sacred beetle of the Egyptians, Ateuchus sacer, which belongs to the group of the Coprince, formerly called Pilulares. The group to which this genus belongs is world-wide, and the American forms are representative of the European. The genus just mentioned, and which may be considered the most important, contains large black Colcoptcra, which are particularly numerous around the Mediterranean. Their great broad and flat bodies attract attention at once.

The sacred beetles have the fore legs enlarged, and furnished with several very strong tooth-like spines, but there is no tarsus at their ends, and they are evidently designed for a special purpose. The heads of the beetles clearly point to the same design, and are admirably adapted for the peculiar habits of the species. The Egyptians represented this beetle-which is now common in Provence and in eastern and northern Europe, as well as in North Africa and Egypt-on their oldest monuments; they 
figured it on amulets, and cut its shape deeply on their tombs. They worshipped the beetle, knowing its habits, for they were an agricultural people; and the title of "sacred" has descended to the present day.

The Ateuchus sacer is quite black, has two tubercles on its head, the elytra are finely striated, there are four spines on the fore legs, and it is scarcely an inch in length.

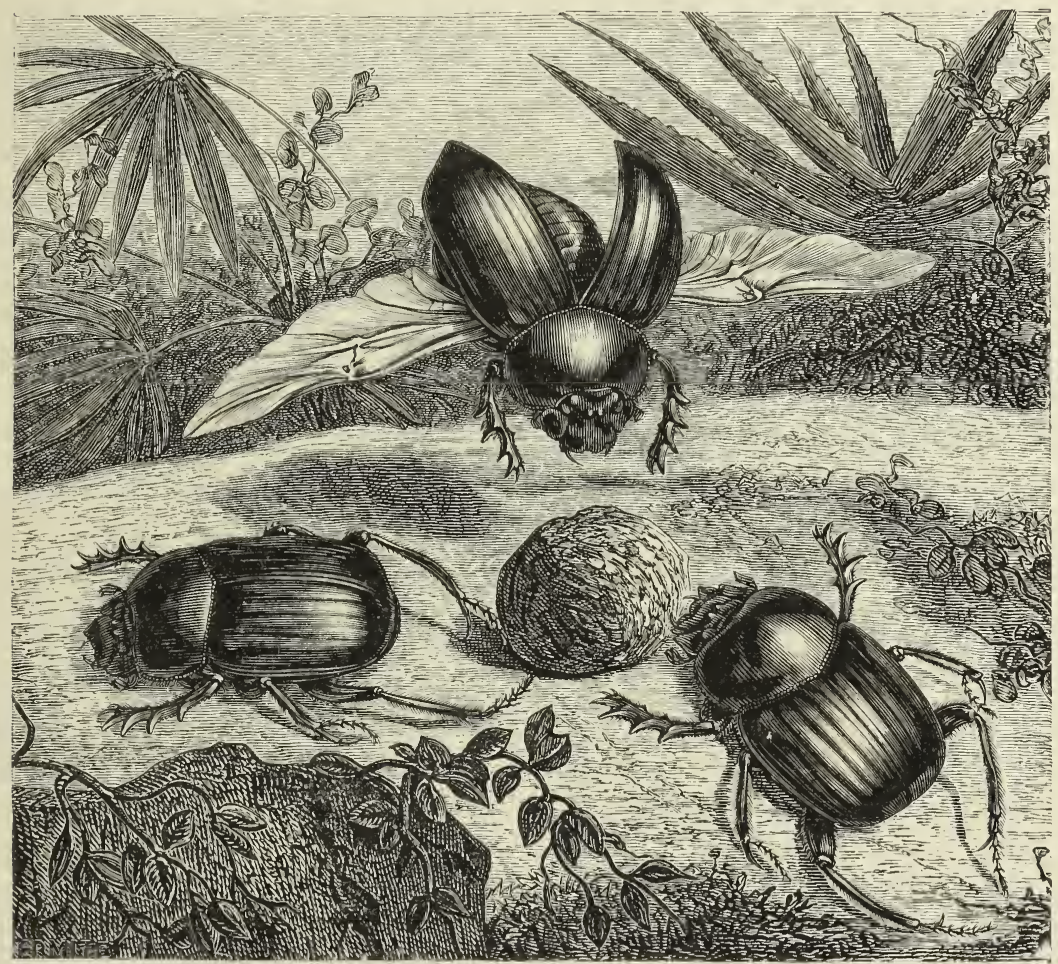

THE SACRED BEETLE (Ateuchus saier).

The instincts of this beetle are very remarkable. It may be found buried in dung, or seen rolling a pill of like substances, which it drags about with its hind legs along the roads and paths. It does not do' all this, or select the offensive matters and roll them up and wheel them off in its peculiar fashion to please mankind, or to fertilise the soil for our benefit. The care for the future offspring, which it will never see, is at the bottom of the 
whole proceeding, and it desires to place its eggs in a safe place. One of the females lays an egg, but instead of being satisfied with allowing it to remain, like other Coprophagi, in the midst of a mass of manure, or in a hole in a dung-heap, it rolls it up in a little mass of refuse in the shape of a pill. The beetle rolls the mass about over the soil with its hind legs, and soon makes it into a round ball. The ball is not left to shift for itself, for the insect is most particular about the place where it is to be put by; it seeks a position in which the future larva can live comfortably and safely, and, in consequence, often has to carry and push the burden for considerable distances. The beetle takes its time, perseveres, and after using much ingenuity, usually succeeds in its endeavours. Should the surface of the soil be very irregular, the beetle places the bundle on its head, the flat shape and tubercles of which are admirably fitted to receive and hold the weight, and carries it over everything until easier ground is reached. Sometimes an impediment is so great that this manouvre is of no use, and the beetle drops the ball, and apparently gives up the labour in disgust at the unexpected difficulty; but this is not really so. The Ateuchus flies off, and soon returns with several others; and it is said that patience will always reward observers with a wonderful sight. The beetles set to work, and push and pull this way and that, and crawl over all sorts of places, mutually assisting each other. When several of them are thus seen rolling a ball, it is a suggestive sight, and very incomprehensible to those who are ignurant of natural history.

As soon as the Ateuclus has rolled the ball to the place where it wishes, the insect begins to dig a hole, and in this it is assisted by its front legs, the large spines of which enable them to dig rapidly and easily. The tarsus is deficient, for it would have been in the way when the legs were digging into hard soil. Having such capital tools, the insect excavates the hole rapidly, and when it is sufficiently spacious and deep, the ball is rolled down to the bottom; then the beetle uses its long hind legs, which are furnished with a sort of brush, to fill in the cavity and smooth the earth over it.

Nany amulets and Egyptian pictures represent an Atcuchus, 
which resembles the shape of Ateuchus sacer, but it has a brilliant golden colour, which was supposed to have been an invention of the artists of the days of the Pyramids, but this is not the case; and the coloured Ateuchus was found, in I8I9, by M. Cailliaud, and it is not rare in Sennaar.

There are some Scarabaida which live in Europe, and are smaller than the sacred beetles, but which have the same habits. One kind, which is very common in France, is named after the pill of dung it carries about, and is called Gymnopleurus pilularius. Another species, which has a thick body and long hind legs, is named after Sisyphus, and is sometimes found in the environs of Paris.

The last tribe of the family of the Scarabaida we have to notice comprehends the genus Passalus, and contains very large beetles, which have long flat bodies, the prothorax separated from the trunk by a waist, antennæ bowed, and spined fore legs. All have a brilliant black colour, and inhabit the American continent, the East Indies, and Australia. They live in the trunks of old trees, and hide beneath the bark, and the flattening of their bodies enables them to do this. The larvæ, which live upon decaying wood, whilst they resemble for the most part those of the Scarabaida, have a peculiar construction, which proves that their development is not far advanced. Their first and second pairs of legs are as long as usual, but those of the third pair only exist as little tubercles.

The Lucanide, or the Stag Beetle family, were formerly included amongst the Scarabaida, but their longer antennæ and peculiar form give them a different aspect. There are also some differences in the larvæ; and it is now proved that the nervous system, which is very centralised in the Scarabaide, is much less so in the Lucanida. The two families are therefore separated by structural differences.

The Lucanida are usually very large insects, whose males are well known on account of the enormous size of their mandibles. These structures, which belong to the mouth, are differently curved and toothed, according to the species, and they look like large pincers, and give the beetles a very formidable appearance. It is impossible, from our present knowledge, to account for the 
use of these great mandibles, the growth and size of which differ in the individuals of the same species. The female beetles do not have these large mandibles, and the structures are of ordinary proportions in them, being furnished with teeth which enable them to be used as leaf-cutters. The Lucanidae are found in many parts of the world, but their species are most abundant in the East Indies, the islands of the Straits of Sunda, and the Moluccas, whence they are occasionally imported into Europe. These insects, which inhabit woods, and only fly in the evening, are difficult to collect in those countries where no one cares to spend a night in the middle of forests; so that these Coleoptera, which are very beautiful, and whose shapes are very remarkable, are much prized by collectors.

The genus Lucanus has been greatly subdivided, but it is not necessary to describe it, because the type of it is so well known under the form of the Great Stag Beetle, Lucanus cervus, our largest beetle. When in the larval condition it lives in the trunks of old decaying oaks, and it is very common in some districts. The beetles fly in the hot evenings of the summer months, and their large mandibles render them very visible. The accompanying engraving of the metamorphoses of the stag beetle represents a large male upon the trunk of a tree; the mandibles are separated, and their dentations are very visible. On the right hand a female beetle is upon a leaf, and her small mandibles make her look like another species, especially as the head is so much narrower than that of the male. Low down in the picture, on the left hand side, there is a nymph in a sort of cocoon hollowed out of the wood. It is a male, and the future mandibles can readily be seen. It is something like the perfect insect, and at the same time resembles the larva. The larva is figured to the right, and its sharp, trenchant jaws are strikingly suited for their purpose. The development of the fore legs is worthy of notice, and so is that of the spiracles which are so very visible on the sides of the body. It is said that these insects are six years in coming to their full growth. Some very natural affinities connect the Lucanide with the Histcride, which are short insects, with broad bodies and antennæe ended by a little solid club-shaped mass; their nervous system is rather less centralised 
than in the Scarabaida. One division of them, the Histeride proper, includes little shining beetles, with truncated elytra which do not cover the whole of the abdomen, angular antennæ, and short legs. The species of the genus Hister are black in colour, the tint being very brilliant, and sometimes spotted with red. They work in manure-heaps and amongst dung, which they eat; and they even enjoy the decomposing flesh of dead animals. Their larvæ, which live in the same way, are soft and white, and have an elongated and compressed shape, and are provided with short legs. Moreover, the end of the abdomen has two doublejointed structures upon it, and a long tubercle also, which has something to do with the progression of the insect. The genus Saprinus contains beetles which are usually of a bronze colour, which may be greenish or bluish in tint; and the heads of the insects are remarkable, for they appear to be sunk into the prothorax. Others, very closely allied to them, live upon decaying wood, and exist generally under the bark. The insects of the other division of the Histeride have not small contractile legs nor angular antennæ. They live upon dead bodies, in mushrooms, in decaying wood, and some frequent flowers. They are usually very small insects, and little is known about their metamorphosis. The commonest species is of a green bronze colour, and is about the twelfth of an inch in length. It is common on flowers.

There are two genera which are well worthy of attention, and they belong to the family of the Silphide. The Silphide have the tarsus formed of six joints, the antennæ ending in a clubshaped mass divided into leaflets, and the mandibles are projecting. They are found principally in Europe and North America.

The members of the genus Nccrophorus, the Sexton Beetles, have a thick body, stout legs, and their hind thighs are more or less enlarged. One species is particularly interesting, on account of its remarkable habits.

Necrophorus vespillo is common throughout the greater part of Europe, and may be readily recognised by its colour. It is black, and is ornamented with yellow hairs on the side of the body; the club end of the antenne are reddish, and the elytra are 
crossed by two broad bands of a light red tint. When the dead body of a mole or a field-mouse is left in the fields, the sexton beetles soon find it out, and begin to collect around in considerable numbers. They are not going to eat the corpse, but they intend to lay their eggs in it. If the body is allowed to remain exposed to the air, it will dry up, or be eaten by other animals,

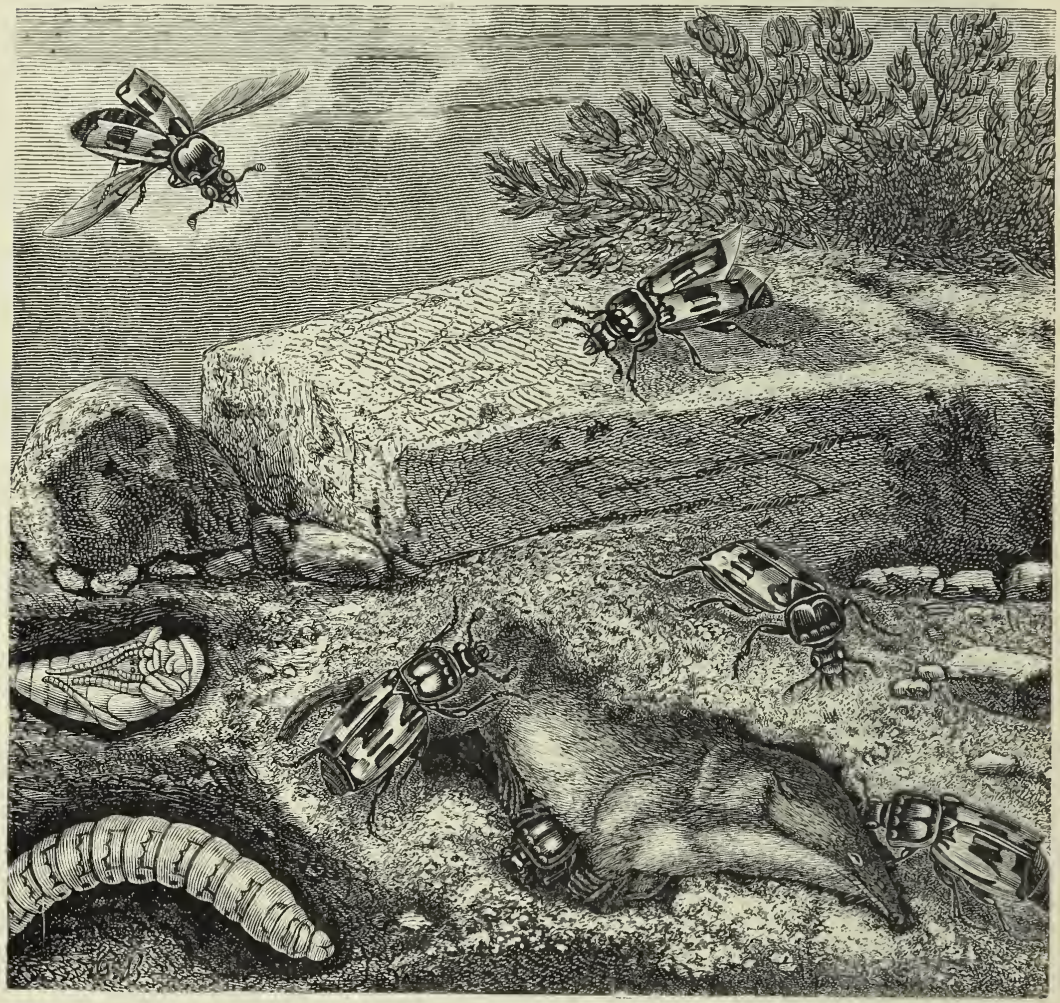

THE METAMORPHOSES OF THE SEXTON BEETLE (Necrophomis vespillo).

so that if any larvæ were therein they would be destroyed, or they would perish for want of food. But the sextons have an instinct which prevents their young from being exposed to such dangers, and they set to work and bury the body, so that their larvæ can nourish themselves upon it without being disturbed. They hollow out the ground beneath the body, and make a tolerably deep hole by throwing out the soil with their large legs; then the animal 
sinks down, and they cover it up with the earth which had collected around the margin of the pit. These beetles are remarkable for the subtle sense of smell they possess. They fly swiftly, and are constantly hunting, with the aid of their acute sense of smelling, for the dead bodies of animals. In Russia, where dead bodies are often buried in shallow graves, the sexton beetles may be seen in hundreds in the churchyards. They dig a hole in the earth over the body, and take up their abode in the substance of the corpse. They generally manage, by dint of hard work, to bury a small animal in twenty-four hours; they then take up their dwelling in the body and feed upon it. The female speedily lays her eggs in the decomposing substances; these soon become larvæ, and feed, like their parents, upon the putrid matter until they acquire their full growth; they then get out of the body and bury themselves in the earth to the depth of several feet, and remain there for three or four weeks, and undergo their metamorphoses. The larvæ make a cell, in which they undergo their transformations. They are oblong in shape, are yellowish in colour, and they have leathery plates on the segments of the thorax and abdomen. They have very small antennæ, powerful mandibles, toothed like a saw, the jaws furnished with little points like those of a comb, and short legs, which enable them to dig. Although they live in darkness, they have two eyes, which are very distinct in young individuals, but which seem to become atrophied as the growth of the adults approaches its maturity.

The engraving represents a small dead animal, which is beginning to disappear in consequence of the beetles having dug beneath it. The perfect insects are figured in different attitudes. On the left, low down, there is a larva, and above it a nymph.

The carrion beetles of the genus Silpha-and which are commonly called Shield Beetles in France, on account of the flattened shape of their body, and from the projection of the prothorax above the head-have ten joints in the antennæ, and the last four pieces form its club-like end. Their elytra are margined off, as it were, and they have long and thin feet. These insects, which are rather small, run with great rapidity, and have very subtle powers of scent, for, like the Necrophori, they soon find out the dead body of any animal which may have been left on the 
soil. They have different methods of life; and the larvæ and beetles differ in their habits. Some seek out and live in putrefying bodies; others exist in living creatures; and a few feed upon vegetable matters. This genus of beetles presents us with a

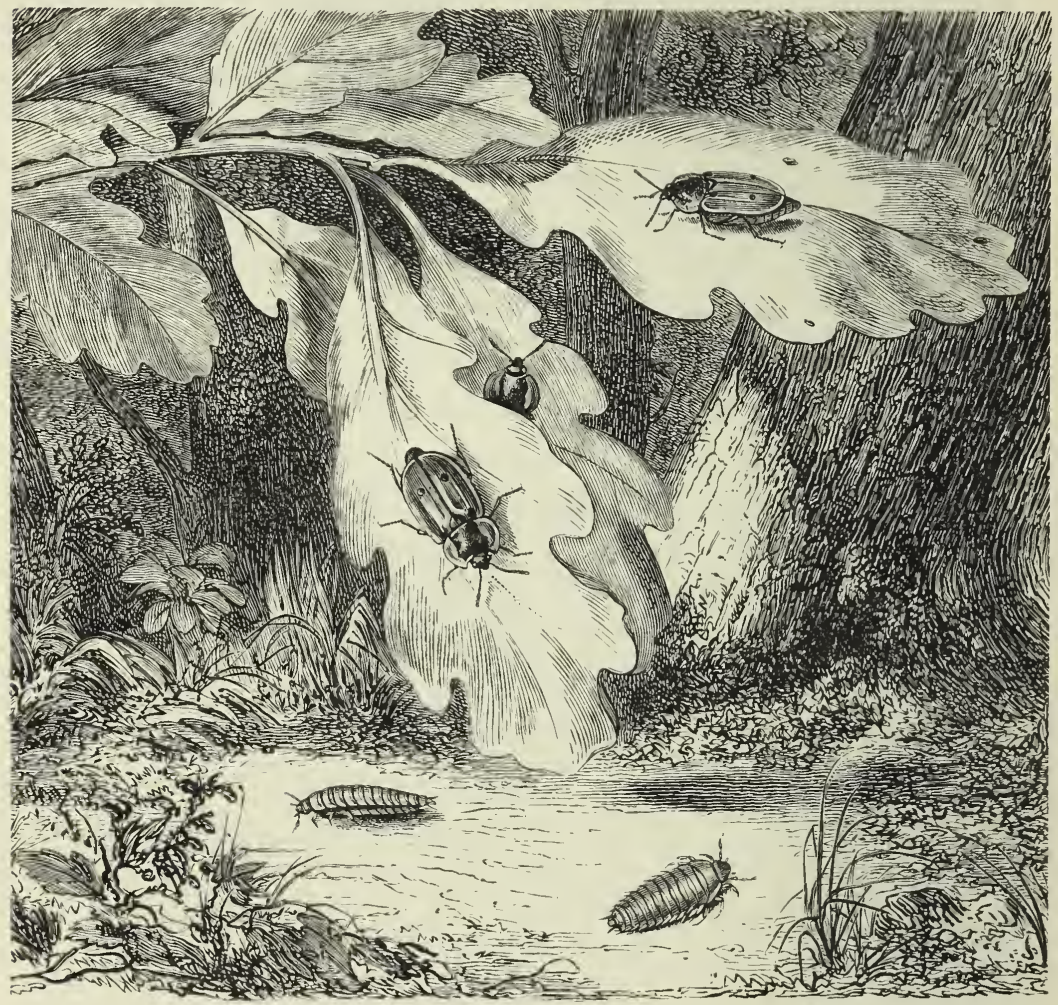

THE METAMORPHOSES OF Silpha quadripunctata.

remarkable example of the existence of very different conditions of life in closely allied species.

The larvæ of the carrion beetles are well advanced in development, and approach the adults in the perfection of their structures. They are very flat, and all the segments of the thorax and of the abdomen are covered with a hard integument. They have six eyes on each side of the head, and long and strong legs, which are furnished with spines, and they move with great ra- 
pidity. These larvæ are represented in the engraving as crawling upon the ground, whilst the full-grown beetles are upon the leaves.

Silpha obscura is the commonest species, and may often be seen running about the roads. It is less than an inch long, is of a black colour, and has three ridges upon the elytra. Its larva lives upon the dead bodies of animals, and is of a brownish colour, and is marked with black lines.

Silpha rugosa is as common as the species just mentioned, and its larvæ, which are perfectly black, are often seen in little groups upon carcases.

Silplia opaca is found in uncultivated lands during the spring, when its larva devours the shoots of young beet-roots. The Silpha represented in the engraving inhabits woods and forests, where it climbs about the oak trees, and chases the caterpillars which frequent the trees in a most active manner. This insect cannot be mistaken, for its body is black, and it has its elytra, which are of a straw colour, ornamented with four black points. The larva remains upon the ground, and, like the perfect insect, is carnivorous, for it attacks any insects which it may come across under the fallen leaves or amongst the grass. Finally, the largest of the carrion beetles, Silpha thoracica, whose prothorax is of a bright red colour, is as carnivorous as the rest of them, and is found amongst underwood, especially in damp places.

The Staphylinide are a family which contain a great number of beetles, some of them being of moderate size, but the generality are very small. They can usually be distinguished from all other Coleoptcra by the shortness of the elytra, which only cover a portion of the abdomen. If the elytra of other beetles were compared to a long coat, those of the Staphylinide would resemble a waistcoat; but, nevertheless, the wings are as large as usual, and are hidden, when the insect is quiet, underneath their cases, being folded up once or twice, so as to be packed away safely. The antennæ are rather long and threadshaped, or more or less beaded.

They are very agile insects, and live under very different conditions of life. Some are absolutely carnivorous, and only feed upon the living prey they catch; others frequent dung- 
hills and manure-heaps; whilst a few are found upon dead bodies. Mushrooms of all kinds are the favourite diet of a number of species, and rotten wood and all sorts of vegetable and animal remains are enjoyed by a great number of them. The Stapliylinide, with their plain legs and antennæ, are

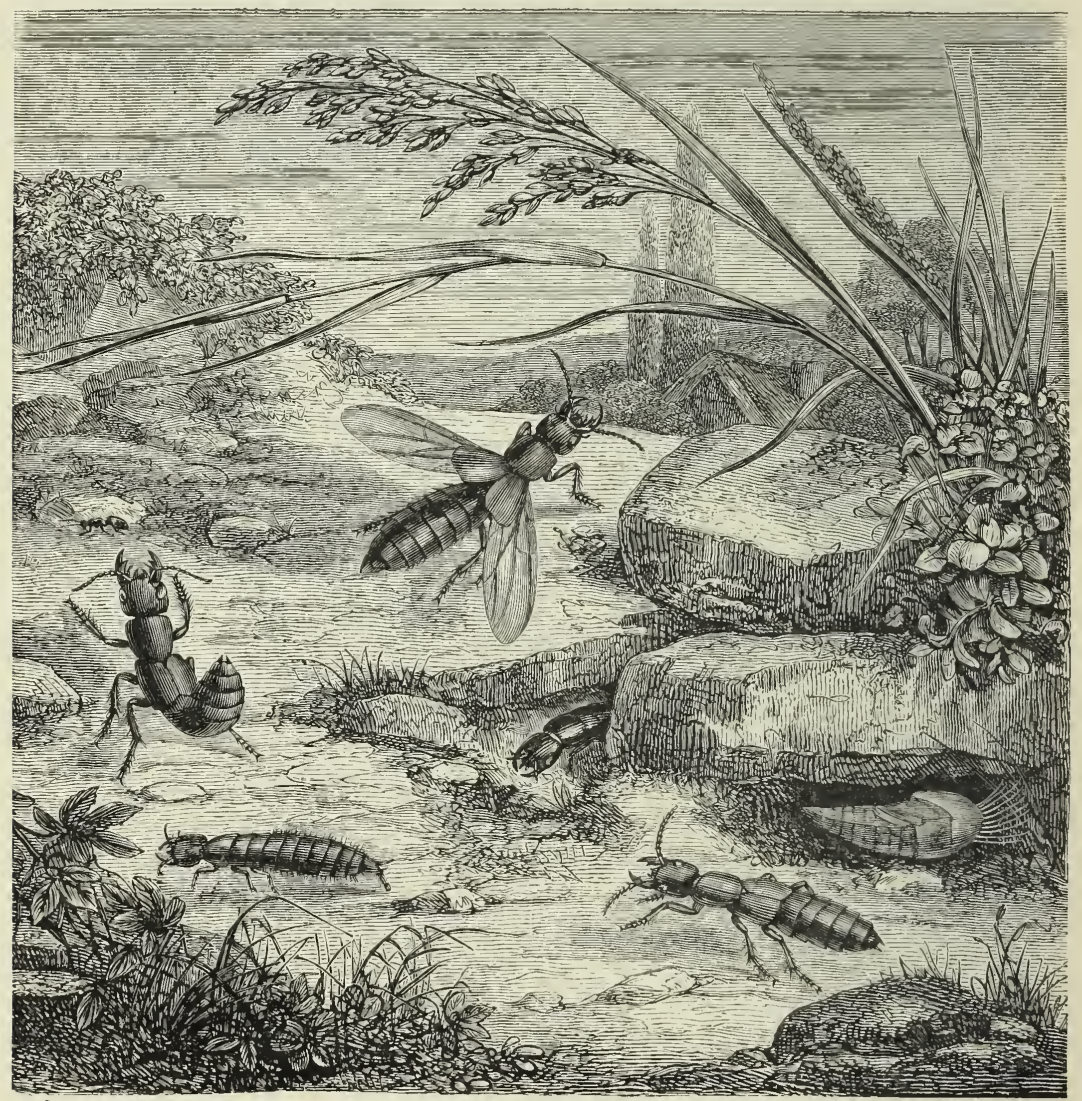

THE METAMORPHOSIS OF Staphylinus olens.

evidently more simply organised than the Silplidice and the Scarabaida; but their larvæ are born much more fully developed than are those of this last family. The larvæ of the Staplyylinida are partly covered with a hard integument, and are very active, and recall the adult forms, not only by their shapes but by their peculiar attitudes. The largest of the Stapliylinida have very 
short elytra, and the last segment of the abdomen is retractile. One of them is very well known, and belongs to the genus Stapluylinus, and it is usually called, in this country, the Devil's Coach-horse. It is a black insect, which is constantly seen on the roads, and emits a very disagreeable smell. It is a carnivorous beetle, and has astonishing impudence and boldness, like many other animals that live by the chase; so that when it is disturbed it does not attempt to run away, but stops, and puts on a menacing attitude. It grasps the ground with its legs, and cocks up its head and tail, snaps its sharp and curved mandibles, and exhales a very disagreeable smell. The larva is quite as carnivorous as the beetle; and its head and thoracic segments are hard, its legs are long, and the abdomen, which is narrow towards the end, is furnished with a sort of tail, which assists in walking. It is very agile, and takes on the habits and methods of progression of the adult.

In the engraving a perfect beetle is represented with its wings expanded, and on the left hand, immediately beneath it, is an adult whose wings are shut up underneath the short elytra, and which is in a menacing attitude. Below it are the larvæ, and under a stone a nymph. The larvæ hide themselves underneath stones or in quiet places, and only go out by night. They hybernate, and when the fine weather returns they make a cell in the ground, where they undergo their metamorphosis. The nymph is of a shining yellow colour, and has a crown of hair on the front of the thorax. Other members of the genus, such as Staphylinus maxillosus, which has prodigious jaws, live upon carcases; others, which have thin and almost linear bodies, are very common in damp woods, and are found underneath fallen leaves and decayed bark, where they chase their prey. The larva of one species lives underneath the bark, and attacks others which feed upon decayed wood. There is a little group of the same tribe, the species of which live, in the larval and adult condition, in decaying vegetables, and especially in mushrooms. An allied form does not care about the mushrooms, but seeks manure heaps, where its larvæ devour the maggots of flies; and another species lives in hornets' nests, where it probably eats the larvæ of those great wasps. 
Some Staplyylinida, which belong to this division, and which are found in the nests of the Termites of Brazil, are distinguished by the enormous development of the abdomen, which is carried in a most peculiar manner, for it is turned up and allowed to rest on the back of the insect. The enormous distension of this part of the body is due to the fact that the beetles do not lay eggs, but produce living larva. This is a very
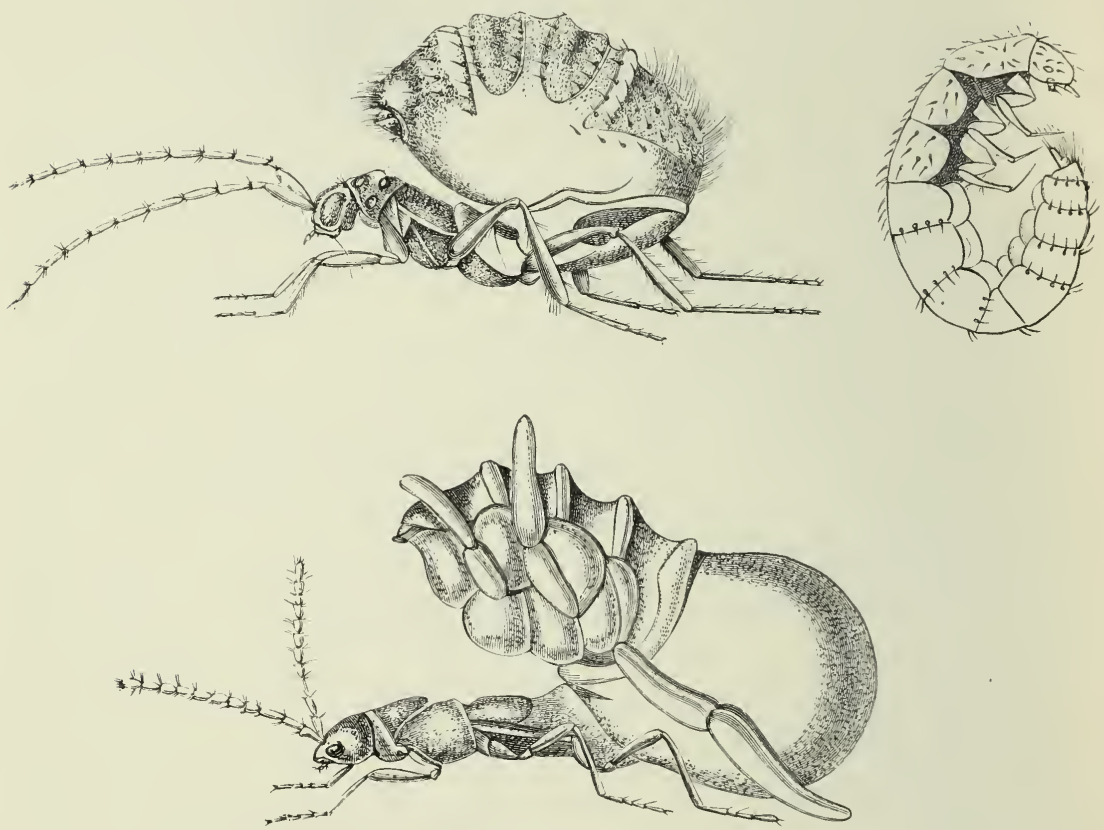

viviparous Staphylinida. (After Schiödte.)

Corotoca melantho and larva.

Spiractha Eurymedusa.

The upper figures are those of Corotoca. The turning up of the hinder parts of the body is very evident in the engraving.

curious and interesting discovery, and it was published by Schiödte in I864. They are the only beetles which do not lay eggs and whose larvæ are born alive, and this is a most remarkable distinction. The insects are about the tenth of an inch long, and their abdomen is soft. It is supposed that the hairs which cover some parts of the abdomen are furnished with a peculiar secretion that is very much liked by the Termites.

There are some other Staphylinide which are very small beetles 
with short elytra, and they are remarkable on account of their antennæ, which are swollen at their ends, and their long palps. Iselaphus and Claviger, genera to which these beetles belong, usually live in ant heaps. The species of the first genus are very active, and hide under stones and about moss, and those of the second really require the attention of ants for their existence, but neither produce larvæ viviparously.

The species of a small family of the Coleoptera do much mischief to manufactured animal substances. They are called Dermestide. These insects are always small, and are of grey, brown, and dusky colours. Their antennæ are short, and terminated by a large, club-shaped end, and their mandibles, which are small, do not project. It is certain that these insects live upon animal matters in the larval state. They attack furs, skins, and leather, animals which are in museums, and the dried flesh of bodies, \&c. Many of them have been transported by shipping from distant countries, and have become acclimatised. They have committed much mischief in nearly every part of the world, and some of the foreign species appear to propagate very rapidly. When they are full grown these insects have slender, contractile feet, and when they are disturbed they fold them under the body and pretend to be dead. The larvæ are clothed in an elastic and thin integument, which is furnished with hairs collected in bundles, in masses, and in slender brushes of great elegance of form. They are gifted with a certain amount of agility; they have little legs, the tarsus ending in a simple hook, and they have small heads, there being usually six eyes on each side. The species of Dermestes are readily known by their long bodies and their antennæ, which consist of ten joints, the last three being formed into a club. They are found in houses, and especially in warehouses. A remarkable species (Dermestes lardarius) is a black insect, and the bases of its elytra are fawn-coloured and marked with three dark points. It consumes very little nourishment in the adult state, but very much the reverse occurs when it is a larva. Then it is a blackish brown insect, covered with long tufts of hairs, which are placed in regular series on the margin of each segment, and it is a perfect pest to furriers and leather-sellers. If it eats lard, as its name indicates, it does not 
hesitate to devour the skins of beasts and of birds that are placed in museums, and it is equally dreaded in shops where anything of the kind is sold.

The Dormestes which frequent hides and stuffed animals are by no means disinclined to enjoy bacon and ham. If they cannot get anything of this sort to eat they have been known to destroy cork, whole cargoes being almost completely ruined by them. They have also been found in asbestos, perforating it in various directions, and undergoing their transformations there. Some other species than those we have noticed have been found in

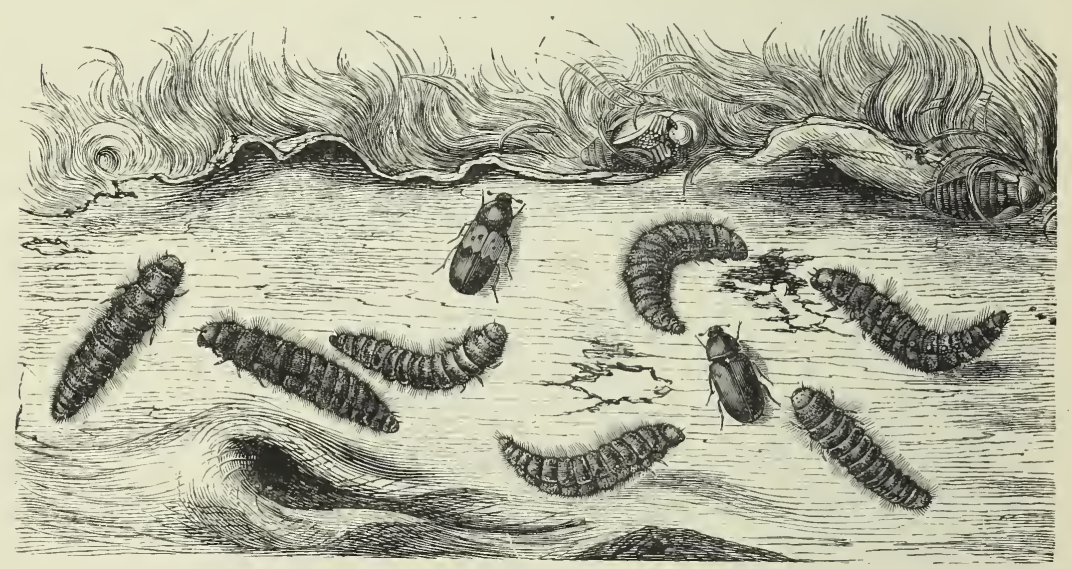

THE METAMORPHoSES OF Dermestes lardarius AND Dermestes mulpinus.

Egyptian mummies. The larvæ of the Dermestes which is so destructive to museums have two strong mandibles, with which they commit their mischief, but usually the perfect insects of these pests do not do much harm.

Another species of the genus, Dermestes antpinus, although not so common over the whole world as the last, is occasionally found in great numbers. The larvæ are found under the same circumstances as those just mentioned, and about twenty-five or thirty years since they caused such great damage in the furriers' warehouses and shops in London that a large reward was offered for a remedy which would destroy them. It is easy to kill them by evaporating benzine, or bisulphicle of carbon, but it is necessary 
to do this several times, and especially when the adult insects have just undergone their metamorphosis, so as to prevent eggs being laid.

The engraving shows on the right hand the black beetle of Dermestes inulpinus and its larva, and on the left hand Dermestes lardarius is represented, the beetle having paler elytra. A Dormestes which has an oval shape and antennæ of eleven joints is readily known by its black colour, and by a white spot on each elytra. It also destroys furs, and is frequently found in houses. Megatoma pellio, as it is called, has a reddish-brown larva, which is covered with long and brilliant hairs, and which has on its end a brush of them looking like a tail, eats all kinds of furs, and even feathers. Some very small kinds, which have short, thick-set, and almost globular bodies, frequent flowers in fine weather. One of them (Anthrenus muscorum) is a beetle about the tenth of an inch long, and is the terror of all collectors of insects. The larvæ do not hesitate to demolish any collection of insects amongst which they may be born, and they commit an infinity of damage in a short time. They get into the interior of the insects, which they eat, and are hardly to be seen except when they undergo their metamorphosis. The nymph is protected by the skin of the larva, underneath which it lives.

Another large family of small insects, allied to those we have just described, are known as Mushroom Eaters. These little beetles have a broad body, and their elytra are often decorated with yellow or red points. Their larve resemble those of $D \mathrm{cr}$. mestes, but they have not so many hairs.

The Hydrophilida are for the most part leaf-eating or herbivorous insects, and they are developed so as to be able to swim and even to live in water. They have short antennæe, which are inserted under the sides of the head, and they have very long palps, which are thread-shaped and pendent. The remarkable size of these appendages to the mouth formerly gave to these beetles the name of Palpicorncs. One of the most notable peculiarities of the structures of these beetles is observed in the females, which have some glands in the abdomen which produce a silky substance that covers their eggs with an impervious cocoon. This is quite unique amongst the Coleoptera; and the 
female Hydroplitida - the extremity of whose abdomen is furnished with two cylindrical appendages or thread drawers-set to work immediately after they have laid their eggs to enclose them in a cocoon, the silken threads of which afford them a safe and secure protection against the multitudes of other insects that are always on the look-out for animal matters. The eggs float in this cocoon until they are hatched. The larvæ are generally oblong, and have rather a projecting head without any neck-like constriction. Tiıey have large mandibles, which are curved near the extremity, and are often dentated. They have coriaceous plates upon the body segments, and the last segment of the abdomen is very small; their legs are rather long, and the tarsi are usually unguiculate. Although they have not the agility of the larvæ of Dytiscus (the true water beetle), they are very active, and care principally for a vegetable diet, but, nevertheless, they are sometimes carnivorous and very voracious, and eat the fry of fishes and small mollusca. Being almost amphibious they may be seen to leave the water and to crawl with some difficulty amongst the grass on the sides of ponds and streams. When about to undergo the first metamorphosis they bury themselves in the earth or in the mud, where they make a cavity, daubing over its inside with their saliva; when the cavity is finished they become nymphs. Although there are not many species in the family, there are some very characteristic forms amongst them.

The genus Hydroplizhs contains large insects of an oval form, having antennæ with nine joints, the last four forming the club. These beetles have two long, very solid, and sharppointed spurs, which, when they are laid hold of incautiously, can inflict a sharp wound. They are found in many parts of the world, but only one kind, Hydroplithus piccus, commonly called Hydrous piccus, inhabits Europe, and it is the largest. It is a well-known beetle, and is an inch and a half in length, being of an olive-black colour. It swims with great facility, on account of its hind legs being flattened, ciliated, and able to be used as oars. It is an interesting inhabitant of fresh-water aquaria. The manner in which it comes to the surface of the water, and the way in which it breathes, when it does so, always excite interest. The IJydrophilus, which is a big beetle, could 
not maintain itself horizontally at the surface of the water, but it pokes out its head above water mark, and folds its antennæ,

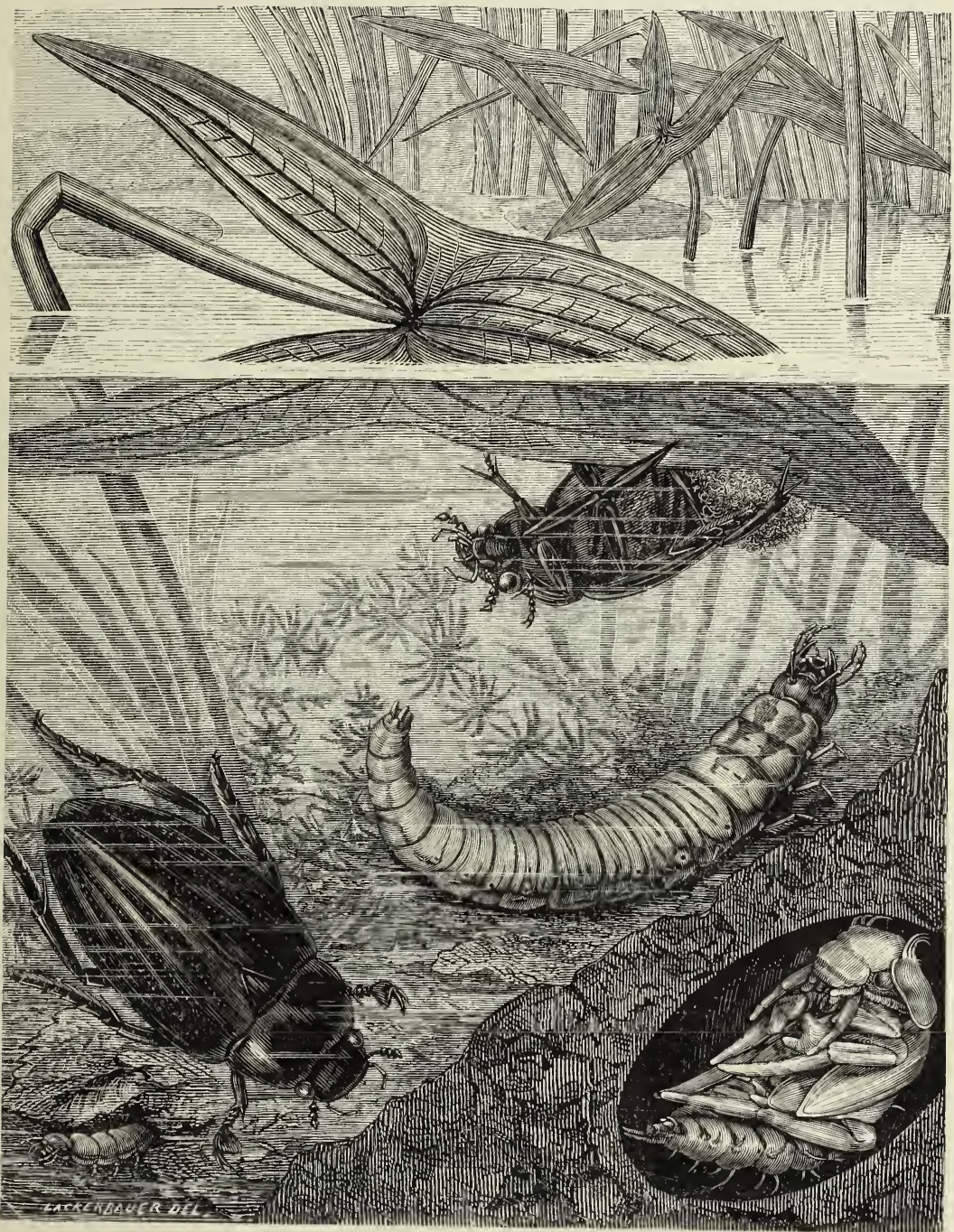

THE METAMORIHOSIS OF Hydrophilus piceus.

the club-shaped ends of which are partly hollowed out; and thus carries downwards a small bubble of air, which is pressed against the sides of the thorax and of the abdomen, and 1 hich then comes 
in contact with the respiratory orifices. The beetle is equally interesting when it is about to lay its eggs, and whilst it is forming its cocoon. Crawling over the aquatic plants head downwards, it lays its eggs and immediately drags its silk-drawers over and around them, and it envelopes them in a cocoon, which it fixes either to a leaf or to a stem. But sometimes the cocoon floats by itself. These cocoons are of a light grey colour, are a short oval in shape, and have a long conical pedicle.

The beetle on the leaf close to the surface of the water, in the engraving on the previous page, is laying its eggs and forming its cocoon. Another beetle is on the ground on the left hand; a nymph is enclosed in its cell on the right, and above it there is a full-grown larva.

As soon as the young larvæ are hatched they begin to feed,
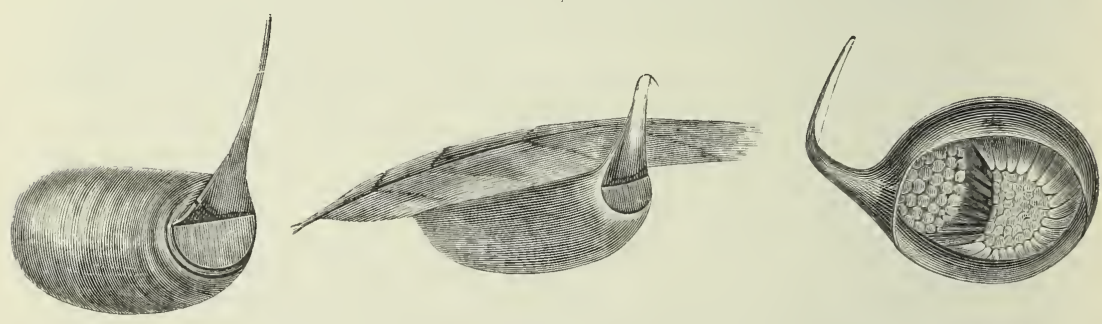

EGG Cocoons of Hydrophilus piceus. (Magnified.)

and grow very rapidly; and when they have attained their full size they are large insects of a dark grey colour, and the hard parts of the head and of the thorax are of a lustrous brown tint. Whilst they are quiet, and even during their progression, the head and the tail are turned up so that the body is always more or less curved. They swim easily with the assistance of ciliated legs and a flexible abdomen. The nymph has some very strong and thick hairs on the thorax and abdomen, but their use is unknown.

The central cocoon represented in the above engraving is attached to a leaf, but that on the left hand is isolated. On the right hand a cocoon has been opened so as to show the position of the eggs in it.

The Dytiscide live in most stagnant waters, and in the little streams which roll slowly along on account of their water weed. These beetles are provided with large wings, with which they can 
fly; and they are frequently noticed to crawl out of the water, and to fly from one pond to another. They thus appear to lead two lives: one, the ordinary sub-aërial existence of beetles; and the other the special life of water insects. They are made like land beetles; and they are therefore obliged to come to the surface every now and then in order to breathe, and a very simple arrangement enables them to obtain a fresh supply of air. The spiracles, or breathing organs, are situated on the upper part of the body, and are protected by the elytra, or wing cases, which fit the upper part and sides of the body, so that no water can get underneath them. When the insect wishes to breathe, it lets itself float to the top of the water, so that the upper part of the back projects above the surface; then the elytra are raised up, expiration takes place, and a supply of fresh air is inspired, and then the beetle shuts down the wing-cases, and includes beneath them a certain quantity of air, which it uses from time to time.

The Dytiscide are carnivorous, and attack all kinds of aquatic insects, which they tear and injure with their strong mandibles. Their larvæ live in the water, and have the same propensities as the adults; and they are constantly chasing a number of insects, mollusca, and even young fish. They are long creatures, narrowed behind, and are clothed in such a hard integument that they may be said to be truly armoured. Their head is large and broad, and the mouthpieces project; their mandibles are arched, and are perforated at the extremity, so that the insect can suck through them; and their legs are long. They are very active, and swim readily by means of a flexible abdomen, which is terminated by two appendages, which are often leaf-shaped.

These insects are provided with spiracles on the sides of all the abdominal segments; nevertheless, when they come to breathe on the surface of the water, they lift up their tails where the last spiracles are, and appear to respire with them in particular. When about to undergo their metamorphosis, they come out of the water, and hide themselves in the mud or sand by its side, and make a cell according to their size, and are transformed into nymphs.

The commonest kind is Dytiscus marginalis, and it abounds in all the stagnant waters of Europe. 
The Gyrinidce are water beetles, and are well known by their peculiar habit of describing circles upon the water with wonderful rapidity. This extraordinary movement has given them their scientific name, which infers that they turn round, and we call them popularly Whirligigs, and the French Tourniquets. They are small beetles, the body is oval, and more or less convex, and the feet are perfectly organised for swimming; the middle and hind ones act as broad oars, and the front legs are used as rudders. They are generálly of a very brilliant metallic bronze colour, and when the sun shines on them they look like pearls dancing on the surface of the water. Sometimes they stop short, appear immovable, and look as if they were easy to be caught, when all at once they disappear with the rapidity of lightning, darting about from place to place, whirling round and round, and finally plunging deep into the water. They pass the greater part of their existence on the surface, and watch for their prey below and look out for dangers above. Moreover, they occasionally snap up a passing fly; so Nature has given them four eyes, or rather their eyes on each side are divided, and the insects appear to have two eyes that look upward and two that look downward. When the whirligigs are caught they exude from their body a milky fluid of an extremely strong and disagreeable odour, which remains for a considerable time afterwards.

The female beetle lays her eggs upon the surface of the leaves of aquatic plants. The adults disappear from the surface of ponds and rivulets when the weather becomes cold, and hide themselves at the bottom, under stones, amongst water weeds, and even in the mud. The larvæ are long, very thin, and white, and the hard parts of their bodies are of a yellow tint. The head is small, and all the segments of the abdomen are furnished upon their sides with long ciliated appendages, which act as swimming organs, and also as gills. The last segment has four movable hooks upon it, which enable the insect to jump. The larvæ, when full grown, are very active and voracious, and they get out of the way of danger by rapid jumping. About this time they leave the water and take up their abode upon the leaves of aquatic plants, spin a cocoon, and undergo their transformations. 


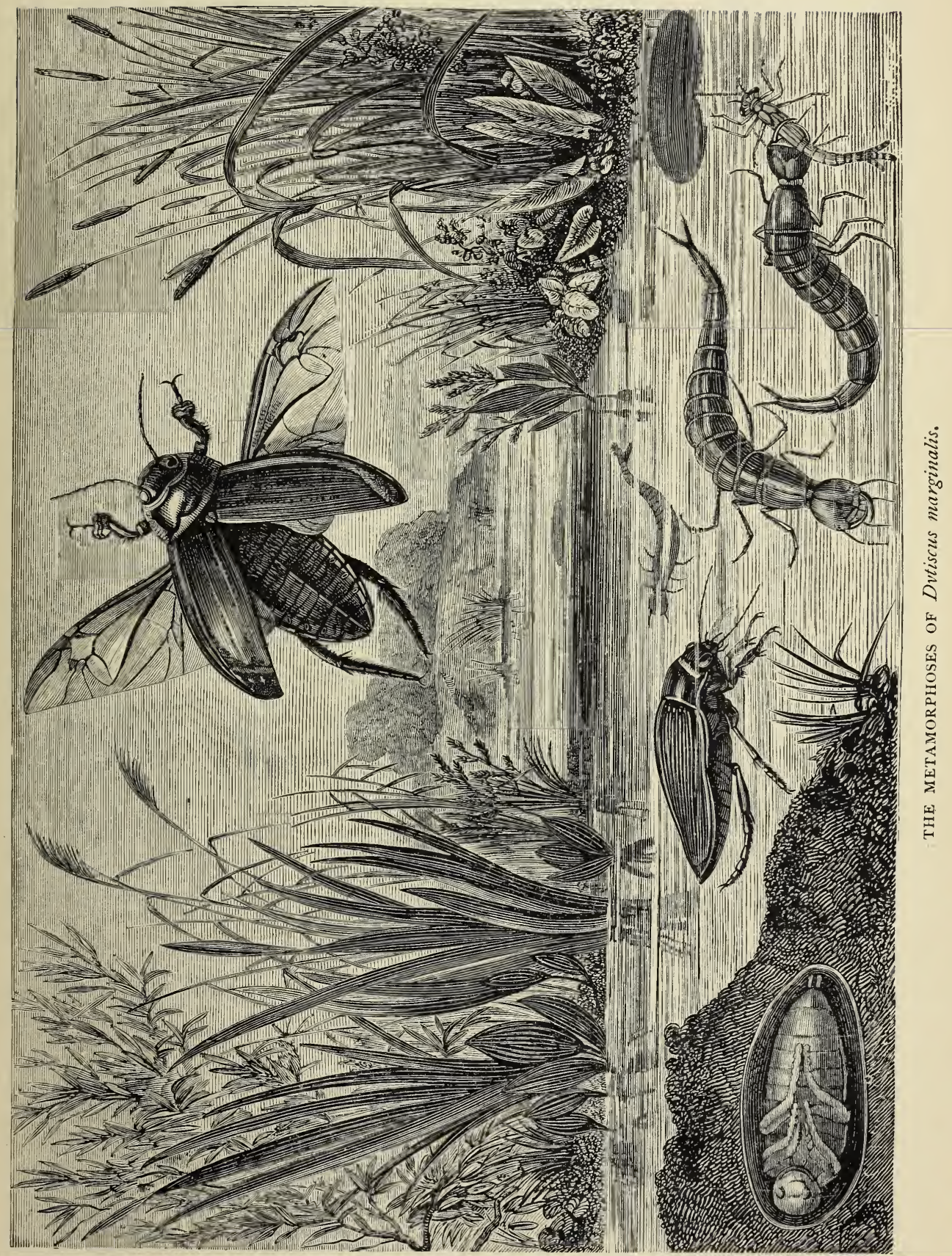



The most ferocious insects of the order of the Coleoptera are the Carabide, and they are essentially carnivorous, being furnished with powerful offensive weapons in the form of cutting mandibles, and being able to run very rapidly. Their bodies are almost always elongated in form; the antennæ are long and cylindrical, like threads, and the legs are admirably adapted for running, but not particularly so for climbing over leaves. But it is the conformation of the jaws that furnishes the most remarkable characteristic of the family. The mouth-pieces have two palpi, the external lobe of the jaw being fashioned into a true palp, which is divided into two or three joints, as is the case in the Dytiscide, which are aquatic carnivorous beetles. This character is not found in other families, and thus becomes important. The males have the front tarsi enlarged, and they hold the females by them when they do not wish to dispense with their company. The larvæ of these Coleoptera are as carnivorous as the adults, and most of them hunt their prey and run it down, so they are encased in more or less solid armour, the head and the segments of the thorax and abdomen being clothed with coriaceous integuments. Their mandibles, which are arched like sickles, have a large tooth at their base, and in some species there are other long and sharp teeth, which give these structures a very terrible appearance. Their bi-lobed jaws have a single palp of four joints ; their legs, which are long, usually end in a tarsus, which consists of two joints; and the end of the abdomen is generally furnished with two jointed appendages and a tubercle, which enable them to walk.

There are two principal forms or types in this family. The Carabide and the Cicindelide, and the genus Carabus is an example of the first. They are for the most part large, brilliantly coloured beetles; and their peculiar shaped heads, their long legs, and their beautifully armoured bodies not only are very elegant, but give them a fierce aspect. They are usually found concealed under stones or amongst moss at the foot of trees; and the common Carabus auratus is constantly seen running about the roads and fields in search of prey. It destroys a great number of insects, which do much mischief to agriculture, but of course country people crush them whenever they 
have an opportunity, instead of preserving them. They are of a beautiful golden green colour, the antennæ and legs are of a russet tint, an 1 the elytra are decorated with three rounded, sculptured ribs. This Carabus, which the French call the Gardener, ard, for some extraordinary reason, the Sempstress, eats caterpillars, snails, and even attacks the May bugs, in spite of

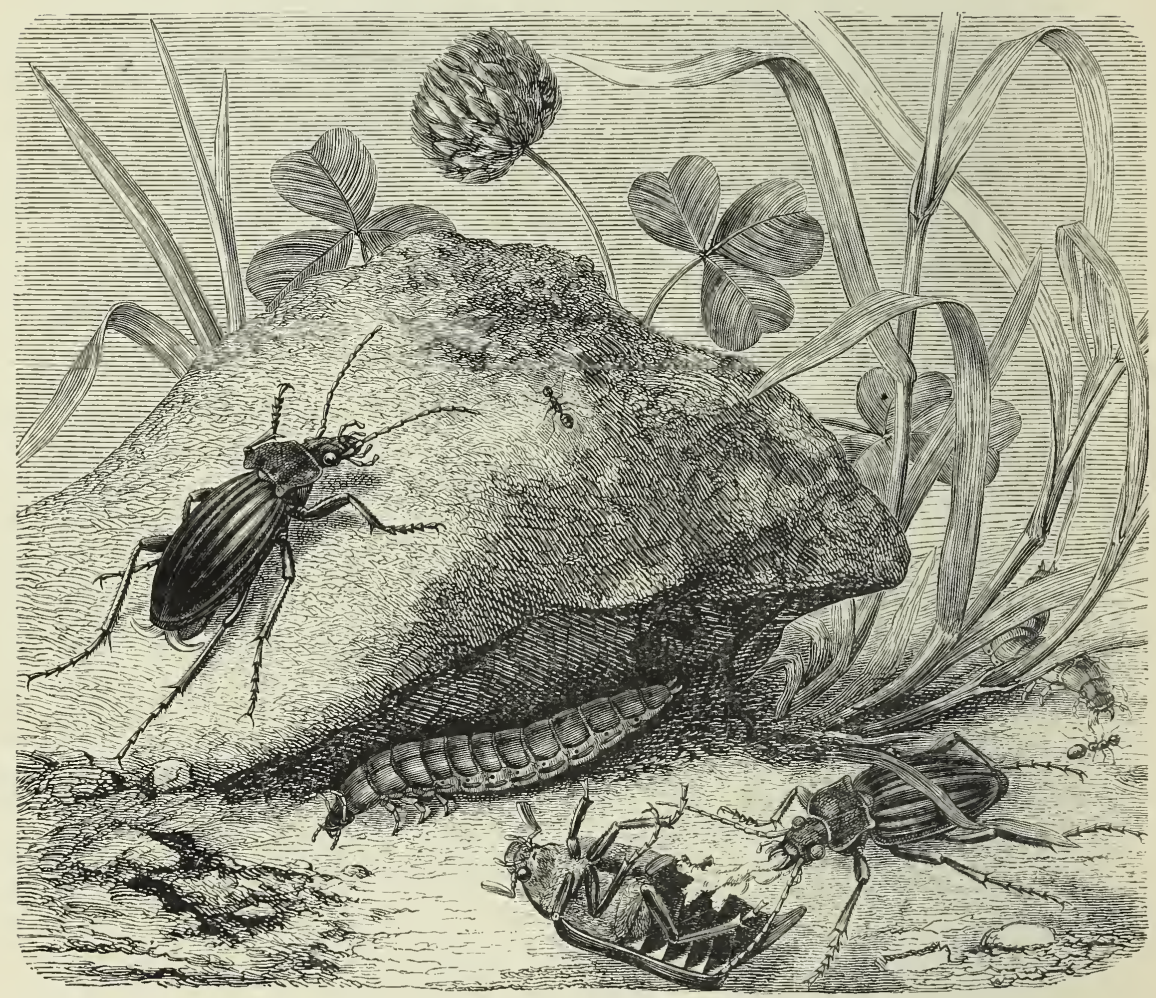

Carabus auratus.

their weight. Sometimes in the spring a very curious massacre may be witnessed, when a May bug bumps against something in its careless flight, and tumbles down on the ground on its back. The Carabus, on the look-out for such eventualities, rushes from a hiding-place, and before the May bug can arise, seizes it with its sharp mandibles and opens its body, tearing its intestines and eating them. The poor May bug wriggles about, and crawls off at a great pace; but to no purpose, for the enemy never 
leaves off the attack; and, finally, it rolls over on its back and becomes an easy prey.

In the engraving a May bug is seen on its back, and a Carabus tearing away at it. Behind the beetle a larva is just pouncing on an ant; and above the May bug a larva is under the shade of a stone, upon which another beetle is about to attack an insect.

The larvæ of Carabus are of a shining black colour, and do not come out in the daytime; they hide themselves up under stones, in holes, or under clods of earth. They cliase their prey like the adults. There are nearly two hundred species of this genus, and they have the wing-cases more or less soldered together; for as the beetles run in search of their prey, their wings are not always required, and, therefore, are imperfect.

The Calosoma sycophanta, which we have already noticed in treating of the Lepidoptera, belongs to this family, and is, perhaps, the most beautiful beetle in Europe. It has wings, although it runs quickly and well; and it has a large body, which is of a deep violet colour, the elytra, which are striated and punctuated, being of a green and gold tint. Its decorations are superb, and its habits are most attractive; and it runs about the trunks of large oaks with incredible rapidity. It attacks by preference the processional caterpillars; and the adult insect and the larva are often seen destroying them together, caring little for the webs, or the dangerous hairs. If the engraving of the metamorphosis of Bombyx processionea is examined, a Calosoma beetle will be seen on the trunk of the tree, about to attack the leader of the caterpillars with its sharp mandibles; and low down on the trunk a Calosoma larva is evidently choosing a fat caterpillar from a nest. In the ground at the base of the tree the nymph of Calosoma may be noticed. The larva resembles those of the genus Carabus, and is larger than they are. When full grown, it grubs into the earth, makes a sort of cell, and is transformed into the nymph, which is decorated with small tufts of hairs, that are very prettily arranged. There are some beetles belonging to this great family whose habits are very different to those of the species just mentioned. The Calosoma and the Carabus enjoy the full sunshine, and pursue their prey like hunters, and scramble over the trunks of trees, and do not like 
water; but there are other beetles which live in caverns, where no light ever penetrates, and they are consequently colourless, almost transparent, and blind; and there are also species which live in those parts of grottoes and caves where the gloom is less dense, and there is some light, and they have imperfect eyes. Blennis areolatus - which was studied by Victor Audouin on the coasts of the island of Noirmontier-passes the greater part of its life at a very considerable depth below the surface of the water, and it is only found at low spring tides, when the sea has retired more than usual. It hides under stones, and in the crevices where a certain quantity of air is apt to remain; and it appears that the long hairs which cover the beetle keep a quantity of air-bubbles between them and the body, for the purposes of respiration.

These beetles are mentioned with the hope that researches will be made at some time or other concerning their metamorphoses.

Another group is that of the Brachinide. They hide themselves under stones and congregate together. They are well known on account of their peculiar manner of repulsing their enemies, for when they are disturbed they elevate their tails and eject a quantity of a vaporous fluid with a considerable noise. There are few things more curious than what happens when a group of these Bombardier beetles is disturbed by the stones which cover them being suddenly removed. Every beetle hastens to get out of the way, and begins by discharging its weapon, and as this goes on the smoky, cloud-like gas which follows the noise is sufficiently remarkable. The fluid which they eject is pungent, acrid, and volatile, so that it becomes a bluish vapour in contact with atmospheric air. Chemical tests prove that it is a strong acid, and it is sufficiently acrid to produce the sensation of burning upon the skin. The apparatus and the secretion are of course superadded during metamorphosis to the usual structures of the larva.

The Cicindelida, or the Tiger Beetle family, is not so numerous in its genera as that of the Carabida. They are very elegant beetles, and their tints are so varied that they are much sought after by naturalists. They have large jaws, long palpi, sharp and toothed mandibles, long and thin legs, so that like the family 
just mentioned they are admirably adapted to act as carnivorous creatures. The common green tiger beetle, Cicindcla campestris, is well known in Europe, North Africa, and in Asia Minor. It is of a beautiful sea-green colour, with copper tints upon the head, the body, and the margins of the elytra, which assume a fiery look when in the full sunlight. These insects are very interesting when they are larvæ, and their habits and artifices resemble those of some very different genera. The larvæ live in the same localities as the adults, and these last are so perfectly covered in by their thick integument, and are so active, that they have no fear of wounds, and can readily escape from too active an enemy. The larvæ have all the desire for slaughter evinced by their parents, but their delicate skins, long bodies, and short legs, not only prevent them from chasing prey, but from attempting a struggle with an insect of any size ; nevertheless, these imperfectly armed creatures manage to obtain their prey without cxposing themselves to much risk. They have short, thick, and spiny legs, which enable them to dig holes in the ground, and they have a flat head, with which they cast forth the pieces of earth they have detached, and furnished with these instruments they construct a vertical tunnel, which curves at a certain depth and becomes a horizontal gallery. The larva has a coriaceous plate on each of the segments of its body, and there are two fleshy tubercles upon the fifth ring of the abdomen, which is larger and more swollen than the others, and which are provided with hooks that curve forwards. The insect crawls in its tunnel with ease, and if it wishes to remain set fast it sticks the back of its body against the sides, and rests safely with the aid of its hooks. In this position it can poke its head out of the ground, and it closes the entrance of its tunnel and waits until some little ant or other insect passes over. The top of the larva's head forms the floor of the cavity down which the insects are expected to fall, and when one of them touches it the larva descends at once and with great precipitation. The prey feels the soil giving way beneath its feet, and falls down the hole, and is forthwith eaten by the larva, which is soon ready for another. When full grown it closes the orifice of its hole, and undergoes the metamorphoses. 
The engraving shows a green tiger beetle flying; beneath it there are two on the ground, and to the right hand there are two galleries or tunnels, each of which contains a larva, hooked on to the side by the peculiar structure of the fifth segment of the abdomen. The habits of this larva resemble those of the ant lion.

The Meal Worm Beetle, whose larva is commonly called the Meal Worm, and which is very injurious to flour and bran, and

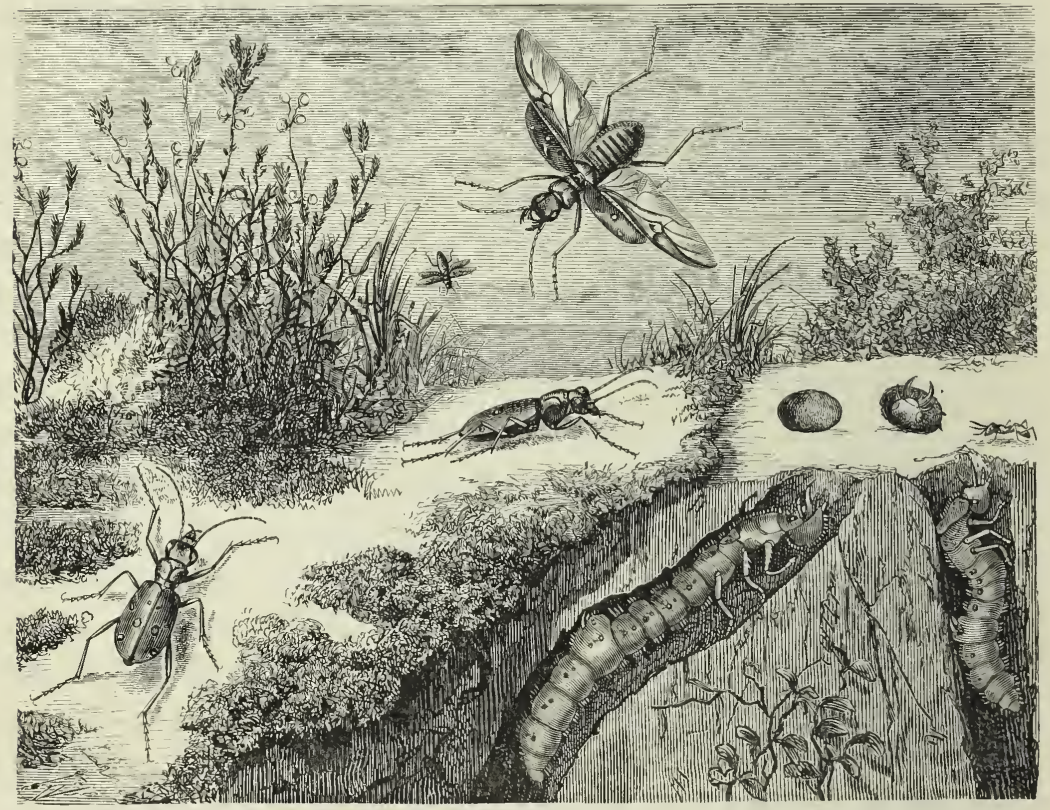

THE METAMORPHOSES OF Cicindella campestris.

which does a great deal of mischief to ships' biscuits, belongs to the family of the Pimclide. It frequents granaries and mills, and especially bakeries, for it likes an elevated temperature. The long, cylindrical, and shining yellow larva passes its life enveloper in the flour, and even makes a cell there, where it can undergo its transformation into a nymph. Its only virtue is that it makes capital bait for fishermen and a good food for pet birds.

The larva are represented in the midst of the flour in the 
engraving, where there is also a nymph on the right hand. The beetles may be seen on the right and on the left side of the engraving.

The beetles of the genus Blaps are closely allied to those just mentioned. Blaps mortisaga, or the Churchyard Beetle, is the best known species in this country. It hates the light, is of a deep black colour, and has the power of producing a very offensive smell. It lives upon rubbish of all kinds, and keeps

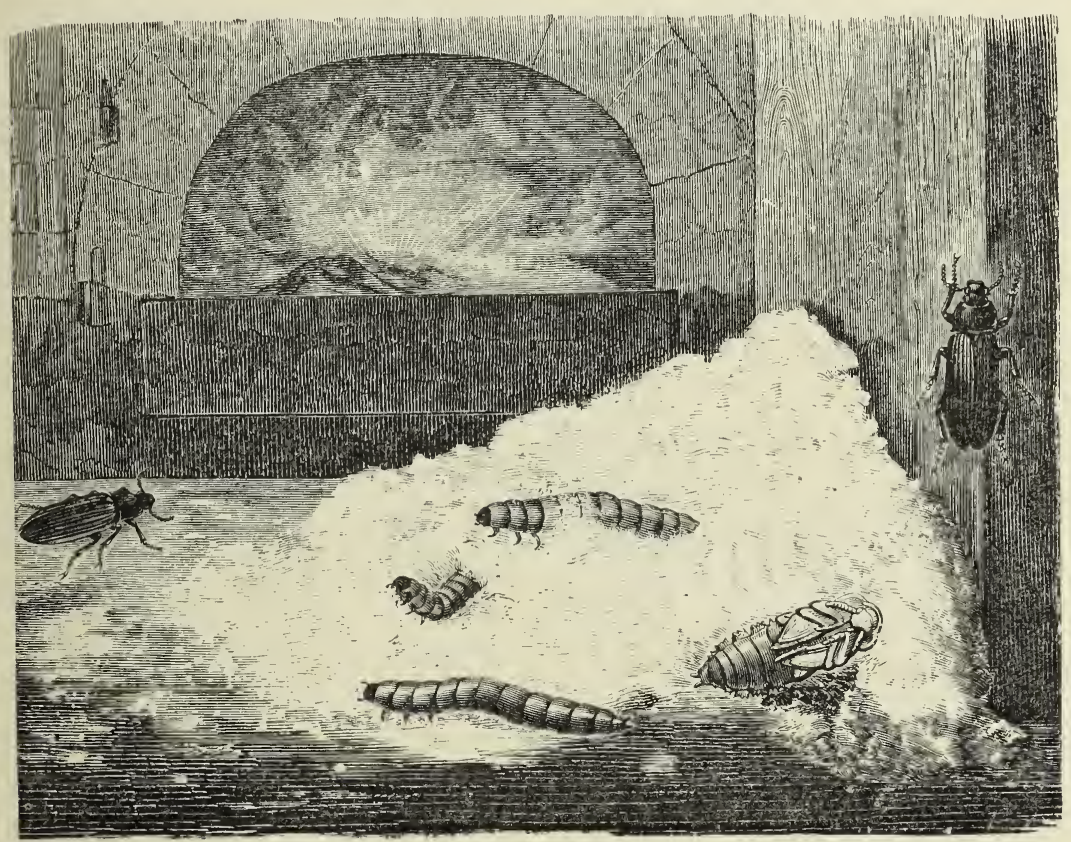

THE Metamorphoses of Tenehrio molitor. (The Meal Worm.)

in damp places, and the darkest and most retired spots of caves and grottoes. Almost all country people look unfavourably upon these beetles, and consider them of evil omen. They are very tenacious of life, and there are instances recorded of their having been kept in spirits of wine for many hours without any ill effect. Curiously enough, the larvæ have been ejected in great numbers from the human stomach, but how they got there we cannot pretend to say.

The Cantharide are well known as the blistering flies, and 
many species of the family have been used in the healing art ever since the time of Hippocrates and Aretæus. The integuments of these insects contain the blistering substance, and as this is so much used a great deal of trouble has been taken to investigate their habits and metamorphoses, but without much success.

The oil beetles belong to this family, although they are apparently very differently formed to the brilliant blistering fly. These oil beetles, which belong to the genus Melö̈, emit an oily liquor like those just mentioned, and it has vesicating properties. The insects do not fly, they have no wings, and their elytra are very short, their bodies being clumsy, heavy, and soft. They crawl over low plants and grasses, and feed upon wild buttercups, and they are apt to be eaten by cattle, whose mouths soon become much affected. The metamorphoses of some of the Cautharide have been very ably investigated by George Newport and other naturalists. Thus, in the year I700, Goedart collected the eggs of some species of Melö̈, and obtained some young larvæ. Later De Geer did the same, but in both cases the larvæe perished immediately after their birth, and the observations of the two authors were forgotten. In I802, Kirby, a celebrated English entomologist, found a small insect which resembled the larvæ described by Goedart and De Geer upon some Hymenoptera related to the bees, and belonging to the genus Andrena, or solitary bees. He thought they were parasites. In I 828 Leon Dufour found an insect which probably belonged to a parasite of the same kind as those just noticed. He considered it to be a new species, and he called it by the name of Triongulinus. Many observers managed to hatch the eggs of Mclö̈, Spanish flies, and of species of the genus Sitaris, which belongs to the same family, but does not possess blistering properties, but they did not get further than the point obtained by Goedart in the year I700. After a time, however, it became evident that the young larva hooked themselves on, whenever they had the opportunity, to other insects provided with wings, and especially to the nest-making Hymcnoptcra; and Victor Audouin found some full grown and adult individuals of species of Sitaris in the nests of the solitary bees. There appeared, 
then, some evidence that these beetles lived during their early age at the expense of the bees. In 1845 George Newport threw a vast amount of light upon the question, which he had exa-

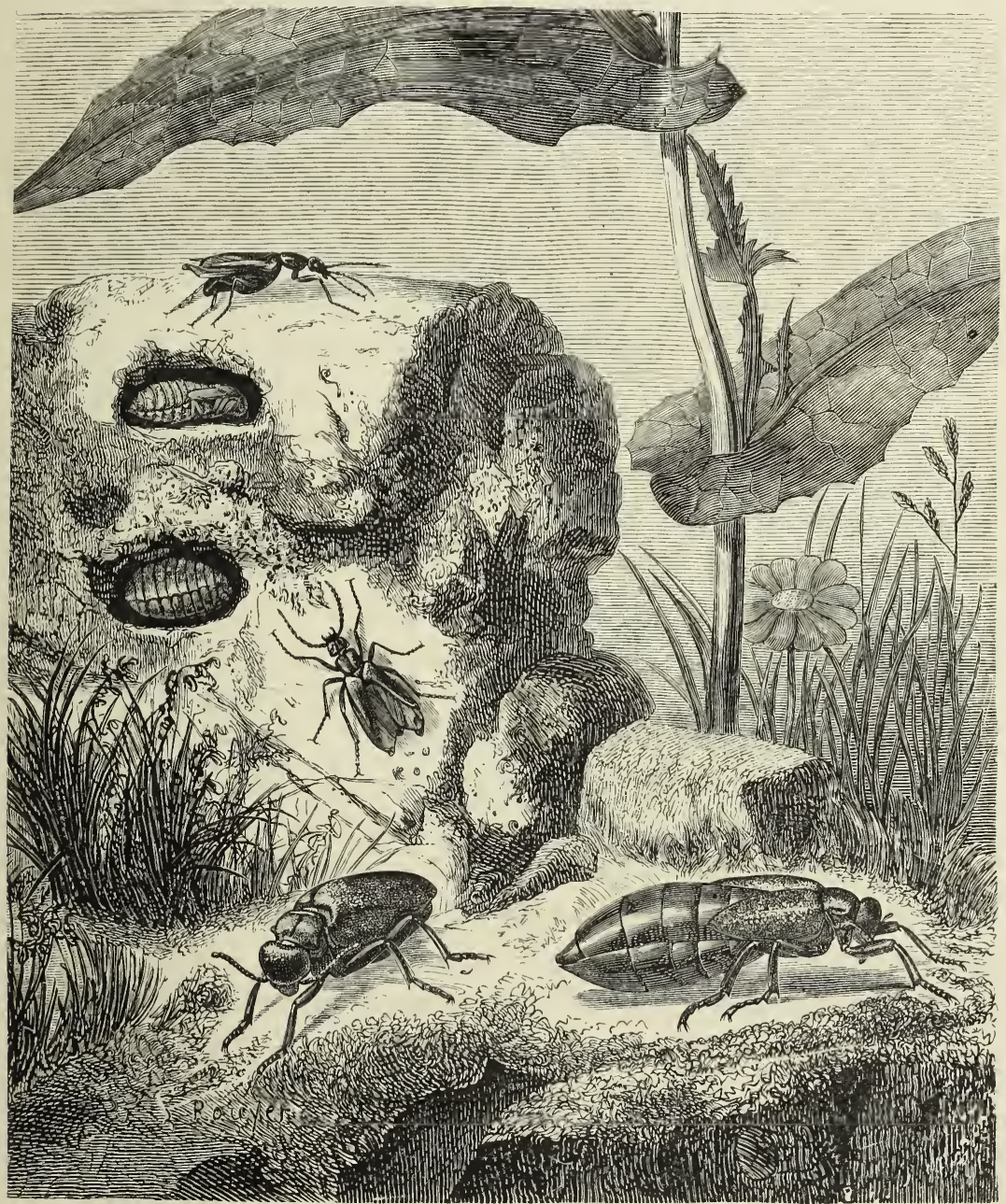

Meloë cicatricosus AND Sitaris humeralis.

mined assiduously for many years. He studied two kinds of Meloë, Meloë proscarabcus and Mcloc cicatricosus, and he satisfied himself that the young larvæ of these beetles attached 
themselves to the hairs of the bees, which carried them to their nests. There the larva underwent their transformations. They nourished themselves with the honey cake of the bee, and when they were full grown they formed for themselves a kind of cell or covering, in which they remained perfectly inactive for some time. They did not become transformed into nymphs at once, but remained as larvæ in this quiet condition. Considering how many accidents might happen to the larva of one of these beetles before it can reach the position which appears to be necessary for its development, it is really wonderful that any one should come to the adult condition. But Nature compensates by giving the females an enormous number of eggs, and Newport counted 4,2 I 8 in one of them. The meloë beetles lay their eggs just below the surface of the ground, and when the little larvæ are hatched they climb upon the plants in their neighbourhood, and should any insects with wings alight near them they do their best to hook themselves on. They do not appear to select bees in particular, although they alone can afford the growing larvæ their nourishment, but choose the first fly that comes, and thus vast numbers are carried about which soon die from starvation.

"According to M. Fabre-the only naturalist who has yet observed these changes in Sitaris-its life-history has eleven events: -I. The egg is laid in the galleries of the Anthophora. 2. A little larva is hatched with six serviceable legs, which remains in its birthplace without food or change of size from October to April. 3. In April it becomes active, and attaches itself to the males of Anthophora when they emerge from their cells, which they do before the females. 4. From the male it passes to the female Anthophora. 5. From the female it passes to its egg, on which it springs as the female lays it on the surface of the honey on which it was to feed, where it sits as on a raft. 6. It then eats up the egg, which takes it eight days. 7. Seated on the empty shell, floating on the honey, it now undergoes a metamorphosis from its previous slim, active, carnivorous form, to a white fleshy grub which is no longer carnivorous, but feeds on honey, and is so organised as to float on the surface of the honey, mouth below, spiracles above. 8. After the honey in the cell is done, it changes its skin, and passes into something under a corneous envelope, like 
the pupa of a fly. 9. It moults again, and once more resembles its second stage (I presume the grub state; but as it is only said to resemble it, not to revert to it, there may be some difference intended: nothing is said as to its food or feeding in this stage.) IO. It then passes into the ordinary pupa state. I Ith and lastly. It becomes the perfect insect." *

These Cantharide thus change their habits of life in the larval condition, and have a succession of alterations of form which has
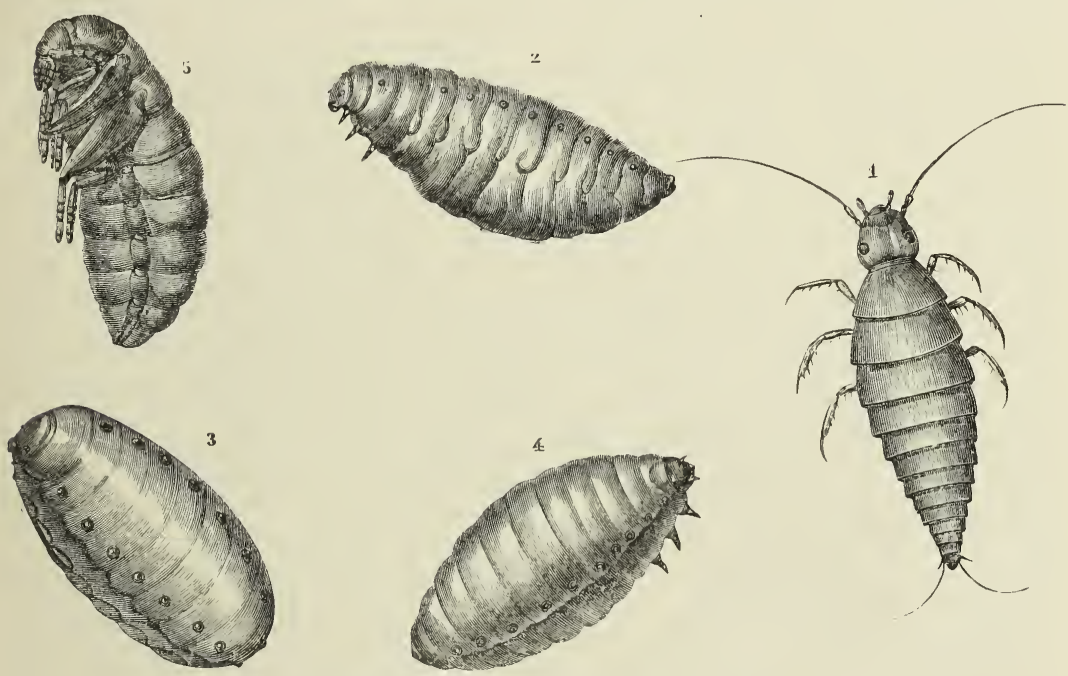

METAMORPHOSES OF Sitaris humeralis.

I. Larva in its earliest form. 2. Larva in the second form. 3. False pupa, or quiet larva. 4. Larva in the fourth stage. 5. Nymph. (All magnified.)

few analogues. Fabre calls the whole proceeding hyper-metamorphosis.

In the engraving, the first figure is that of a very small larva (magnified) which is ready to attach itself to the bee, and to devour the egg of its unwilling host. The second figure represents the larva after its first change of skin, when it has ceased being carnivorous and has become a honey eater. Fig. 3 is the false chrysalis, and Fig. 4 is that of the larva escaped from it. Fig. 5 is that of a nymph.

Glowworms, which are frequently seen in many parts of 
England during the summer nights, are very common in some parts of the Continent, and they sparkle like little gems amongst the grass and dense foliage up the hill sides in Southern Europe. They are beetles, and belong to the genus Lampyris, and they resemble somewhat, but cannot be confounded with, the Cantharida. Their chest pieces, which form a broad mass, project more or less over the head, like a buckler. The males have large wings and long elytra, but the females have only rudi-

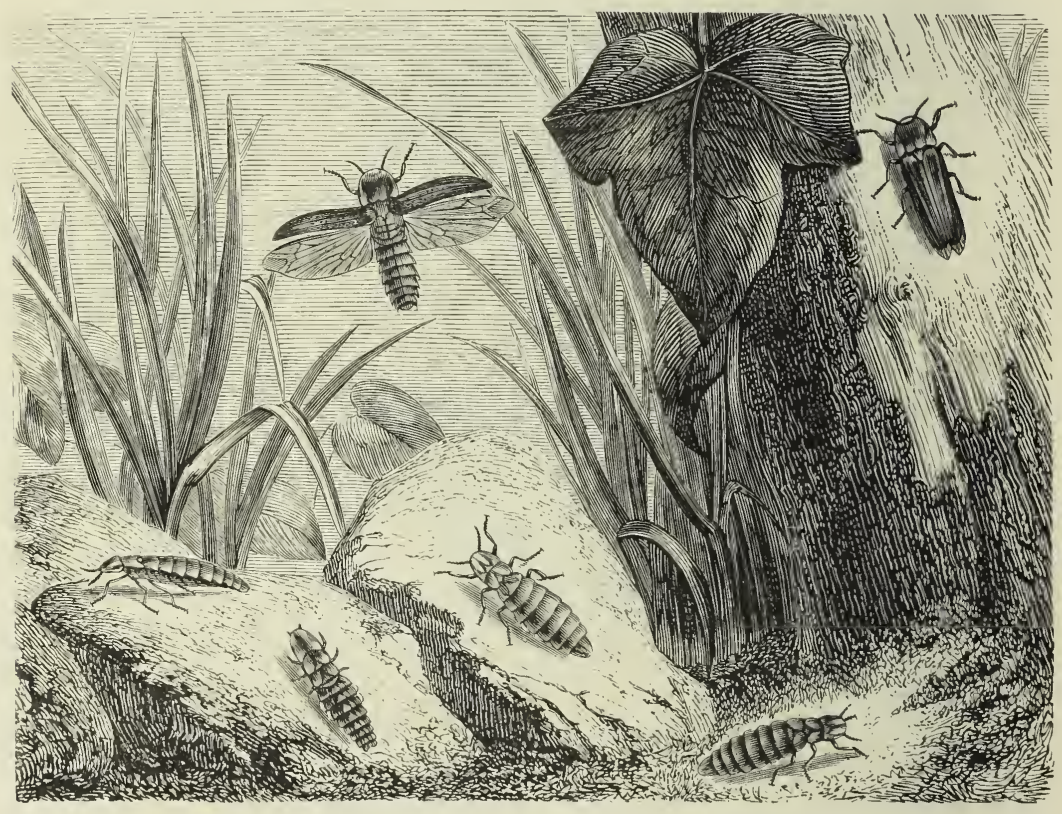

METAMORPhOSES OF THE GLOWWORM (Lampyris splendidula).

mentary wings, and they therefore cannot fly. The females resemble the larve; they are more abundant than the males, and they give out the light which renders them such well known insects. The curious phosphorescent light comes from the under part of the abdomen, near the tip, and is under the control of the animal. It is used to attract the males, which generally conceal themselves during the day-time in the trunks of trees. The larve resemble the females, and are highly developed. They attack and derour snails and other land mollusca, and 
slugs. Other species of the family of the glowworms live in tropical climates, but they are usually small creatures.

There is a male glowworm represented flying in the engraving on page $3 \mathrm{IO}$, and there is one on the tree on the right hand of the

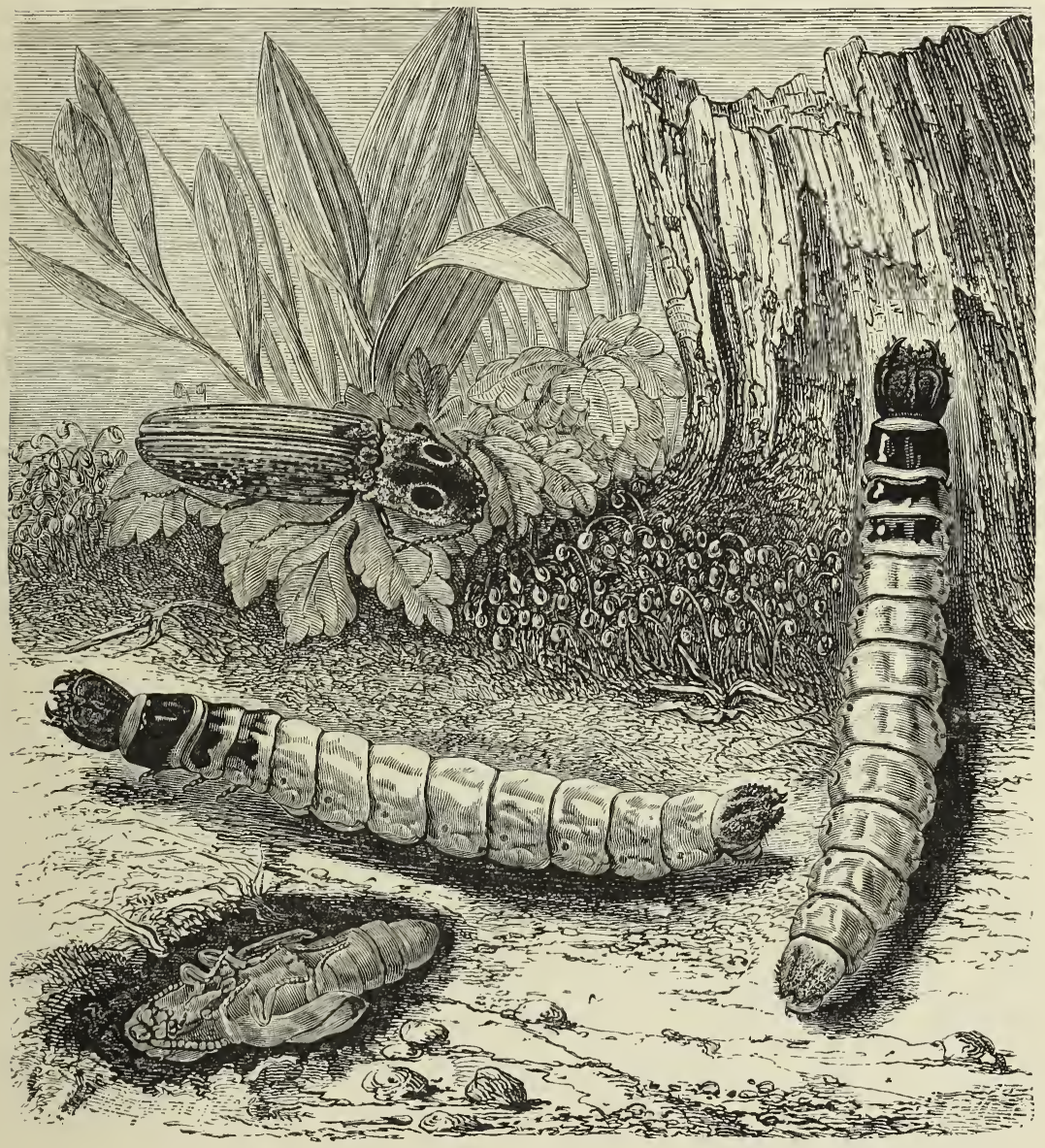

METAMORPHOSES OF Alaus oculatus.

picture. A female is shown beneath the flying male, and there is another on the ground to the right hand. The segmented condition of the body and the want of wings causes the female to resemble the larvæ, and these are represented to the left.

There are some beetles which are very generally known as 
Snaps, or Springing Beetles, or Clip Beetles. They belong to the family of the Elateride, and they are very easily distinguished. They have. solid integuments, the antennæ either cone-shaped or toothed, and the tarsi have five joints, the first being more or less enlarged, and furnished underneath with flexible plates, which enable the insects to walk easily over plants. But the most characteristic structure is a projection of the first piece of the under part of the body, which can be fixed by the will of the insect in a cavity of the second portion. Generally speaking, these insects are of an elliptical or oval form; sometimes they are nearly linear, and are usually flattened. They fly very well, but they cannot run fast. When placed on their back they are able to spring up to a height of ten or twelve times their own length, and this leaping motion is accompanied by a snapping noise, which has given the insects their popular name. Their legs are so short, that when they are on their backs they cannot turn over, but by contracting the body vigorously, the projection of the under part of the body, which we have just noticed, is placed within the cavity in the second part; it remains there, the insect exercising great force to withdraw it. Suddenly, by a sort of trigger motion, the point gives way, the curved body becomes straight, and of course bounds into the air; and should the insect not have the good fortune to come down on its feet, the same process of gymnastics is tried over and over again, until the desired result ensues. One of these beetles is well known in meadows and corn-fields. When in the larval condition it is called the Wire Worm; and as it attacks the roots of grass, it does an infinity of mischief.

Alaus oculatus belongs to this family, and is found in Louisiana. In the engraving on page 3 I I the beetle, with curious eye-shaped markings on the thorax, is upon a leaf; there are two larvæ below it, and the nymph is represented in its underground cell.

The Cleride are very pretty little beetles, which are ornamented with bright and varied colours, and which resemble somewhat the Clicks, and, moreover, they have some likeness to the Dcrmestide. They are of an elongated, nearly cylindrical form, and have club-shaped antenna, the head and thorax roughened with hairs, and the elytra adomed with lively and 
marked colours, disposed in transverse bands. Their integuments are moderately strong, but they are not quite so flexible as those of the glowworms. The adults are very fond of flowers, and run about the trunks of trees. The larvæ are elongated, have small legs, and two projections at the end of the last

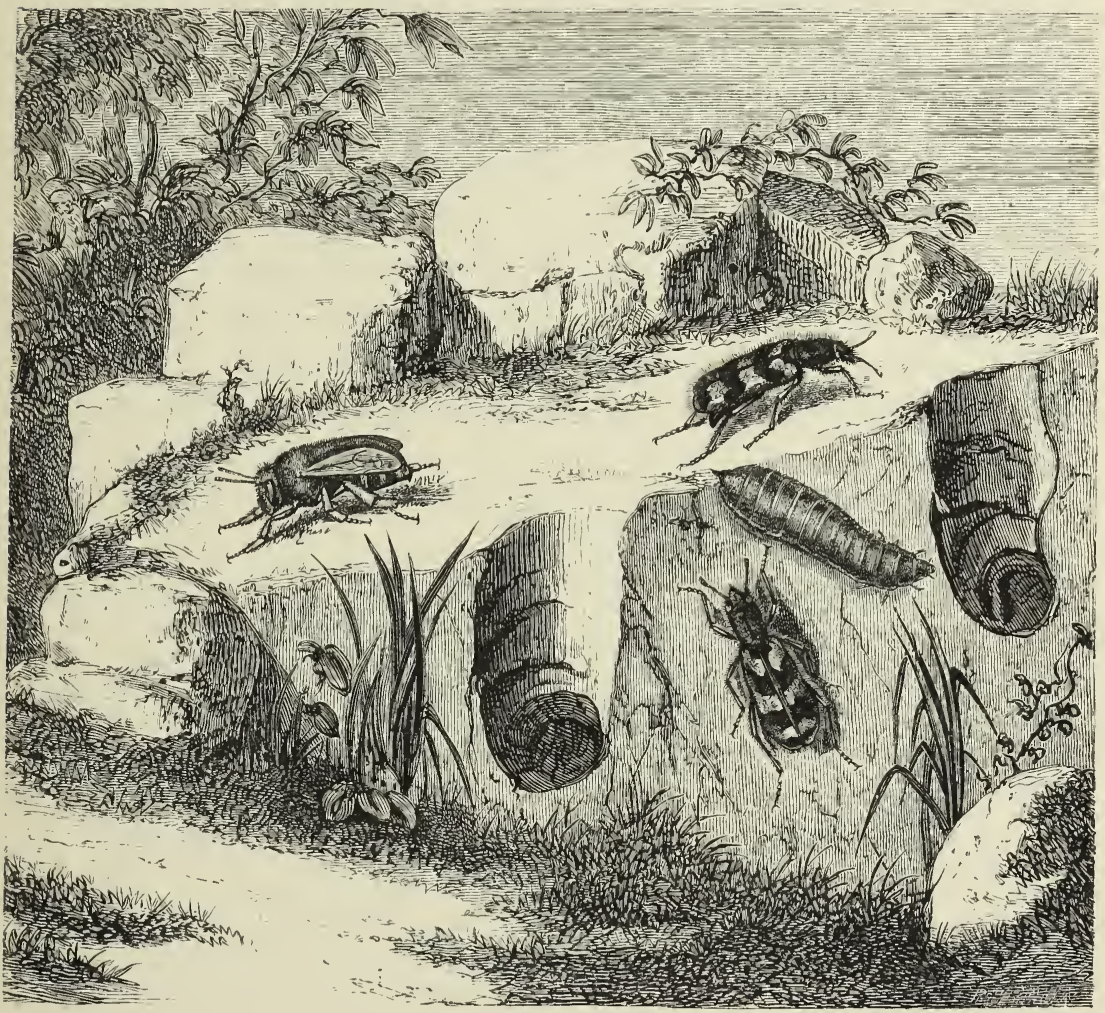

THE METAMORPHOSES OF Trichodes alvearius.

segment of the abdomen. In this stage of their existence they are very carnivorous. One species of the family Trichodes alvearius has very curious habits. The females get into the nests of bees, and lay their eggs there. The larva, as soon as they are able, begin to eat the larve of the bees, and very likely they enjoy some of the comb also. The beetle has bluish black elytra, marked with three red bands, and may be noticed to enter the nests of 
solitary bees. Another species selects the hive bee, and lays its eggs in the cells with the larvæ of the bees. The larvæ of the beetles, when they have destroyed those of the bees in one part of the hive, search out the others, and proceed from cell to cell devouring the inhabitants of each.

In the engraving on page 313 the nests of the bee are seen in section, and the larva of the beetle is drawn between two adults.

Another species (Clenus formicarius) is a little red insect, which is rather common, and its larvæ live under the bark of old trees, where they chase and devour many wood-eating insects, especially larvæ. Others, belonging to the genus Necrobia, feed, both in the perfect and larval state, upon carrion and dead animal matter, such as dried skins and old bones. They are very common in houses, and one species frequents prisons and other gloomy places. Some of the larva of the genus Anobium live in old wood, which they eat, and they undergo their metamorphosis in a small cell, which they form within planks and beams in old furniture, and when they become beetles they eat their way out by drilling small round holes, which every one has seen in old houses. The beetles are nocturnal in their habits, and call each other by striking their mandibles against wood, and they answer each other in the same manner. The blow produces a little tick, and it is repeated at intervals. The beetle being invisible, superstitious people have a nervous dread of it, and many old women, especially nurses, call it the death tick, and prophesy a fatal issue of the complaints of the sufferers they are watching if the beetle calls its love in this very disagreeable manner.

Elm trees are very often noticed to be scored beneath the bark by radiating lines, which are arranged in a very regular manner. This is the work of a most destructive beetle, which is called Scolytus destructor. It is worthy of its name, for many large trees and whole forests finally succumb to its attacks. They have small and projecting heads, club-shaped antennæ, and very strong mandibles. In the adult form they nibble the bark of trees, and suck the sap, and the females lay their eggs on the trees the sap of which does not circulate very actively. The female penetrates underneath the bark, and screws herself in between it and the woody tissue. She makes a gallery, into 
which her body fits exactly, and bores little side alleys on either side and at regular distances, and lays an egg in each. As soon as the larvæ are born they set to work to gnaw the wood,

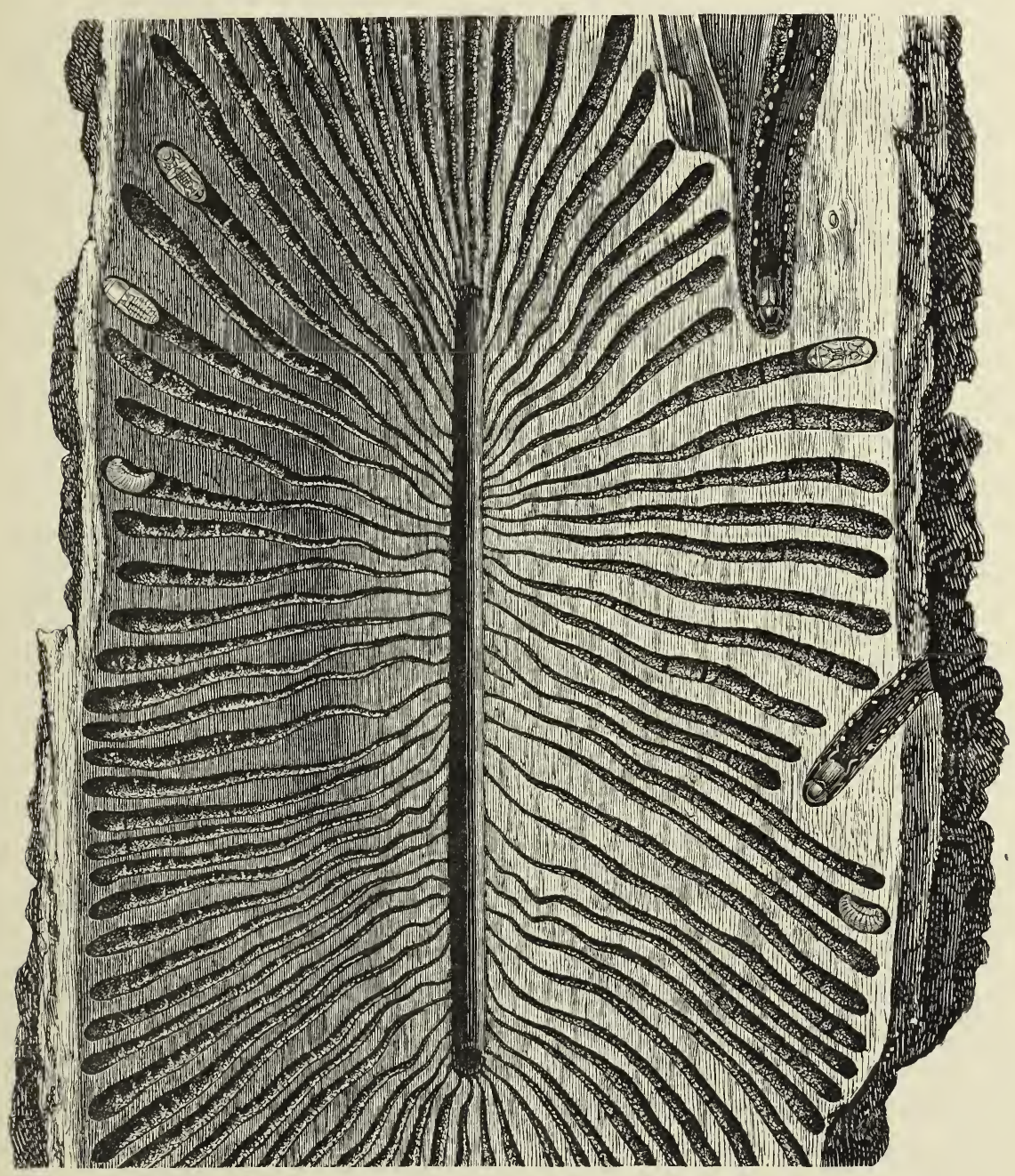

THE BARK OF AN ELM PIERCED AND MARKED BY Scolytus destructor.

doing this so as to enlarge and lengthen their side alleys, and they always eat away in a determinate direction. The bark and the wood of the trees which have been attacked by the Scolytus are marked with regular designs, which are peculiar 
to certain species, and some of them resemble tattooings when they are done on hard wood, and really look like works of art. The large elms are destroyed by this beetle in particular, and a smaller one does a great amount of mischief to oaks.

In the centre of the engraving on page 3 I 5 the long gallery made in the first instance by the female is seen to be surrounded by the radiating alleys, which have been gnawed out by the larvæ. At the end of some of them nymphs may be observed, and in others larvæ may be noticed. On the right hand side there are two perforations from without, and a female beetle may be seen at the end of each making its gallery. They have already laid some eggs which resemble white points within little niches on the sides of the gallery. These little niches will be enlarged
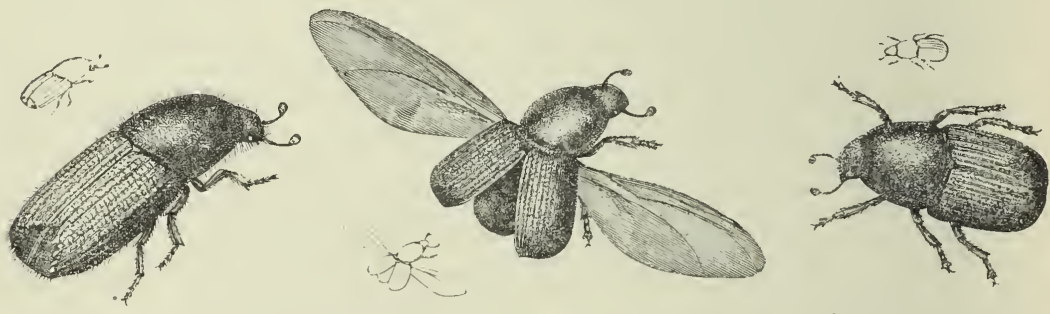

Tomicus typographus.

Scolytus destructor.

The beetles of these destructive species are represented in their natural size, and magnified.

in a radiating direction by the larvæ, which, as they grow larger and larger, make wider and longer alleys. A closely allied genus has a species which does much mischief to fir trees, marking them just as if plans or maps had been cut upon them. It is called Tomicus typograpluus.

The most numerous family of the order of the Colcoptera is that of the Curculionide, and many species are known as Weevils and Hog Beetles.

The larvæ of the Curculionide are almost always thick, massive, and slightly curled, like the larvæ of the Scarabaida; they are colourless, white or yellow, and they have flexible skins. These insects live hidden up in the trunks of trees, and in twigs or in grains. They have no legs, or they only possess the rudiments of them, in the form of small tubercles, which may be distinguished 
in a great number of species. The head is strong, and is clothed with a leathery integument; their antennæ are very small, their mandibles are strong, and often dentated; and-as a rule, there being a few exceptions to it-they have no eyes.

The larvæ are, therefore, very embryonic in appearance, and can be contrasted with those of many other Colcoptera which are much more developed.

Three principal forms may be distinguished in this great family-the Bruchide, whose beaks are short and broad; the Attclabine, whose beaks are long and almost cylindrical; and the Curculionida, which have beaks of greater or less length, or whose antennæ are bent after the first joint.

The Bruchida are well known, on account of the mischief committed by the commonest genus, Bruchus. Almost every one has seen dried peas pierced by a perfectly circular little hole; and some may have noticed a small beetle, about the eighth of an inch long, coming out of them; it is a blackish insect, marked with white lines or spots. It is called Bruchus pisi, and is a very common beetle. The mature insect lays its eggs when the peas begin to ripen. As soon as the larvæ are hatched, they make their way into the substance of the pea from without, and devour the inside. When the larva is about to undergo its metamorphosis, it gnaws in such a manner as to come so close to the outside skin that it only leaves a delicate layer between it and the world. When the adult has undergone its transformations it has only to break through this thin partition in order to come into the light. In some instances the larvæ remain within beans and peas during the whole of the winter, and undergo their transformations before it is time to sow the peas next year. Their ravages were at one time so universal in North America, as to put an end in some places to the cultivation of peas altogether.

Brucus granarius is another species which is very destructive to the same plants in this country; and in tropical countries other species attack plants with seeds like peas, and some are even found in the cocoa-nut. Dr. Baird writes that the species of Anthribus which belong to this family are most frequently found amongst old wood, and some of them appear to live as parasites upon the Cocci; one species, which lives through the 
winter in the pine-forests of Germany, destroys the Cocci in great numbers. The genus Attelabus has a very pretty species, with red elytra and corselet; its habits have been very carefully observed by M. Goureau. The female deposits an egg at the end of an oak-leaf, then she splits the large median nervure across several times close together, then she folds the leaf and rolls it up, and thus makes a safe home for her larva, which she never sees, and of whose habits she can form no conception. The larvæ live in leaves and flowers; they only eat the tissue between the outside skin. They change their skin several times before they attain their full growth; and having spun a cocoon of silk, or of glutinous matter, they shut themselves up and undergo their

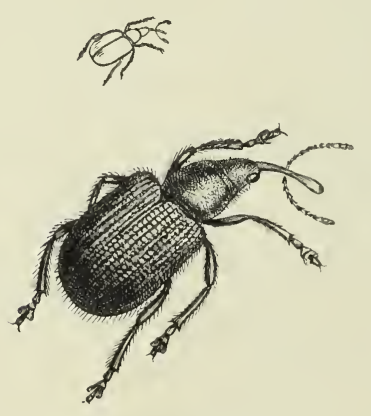

Rhynchites Bacchus.

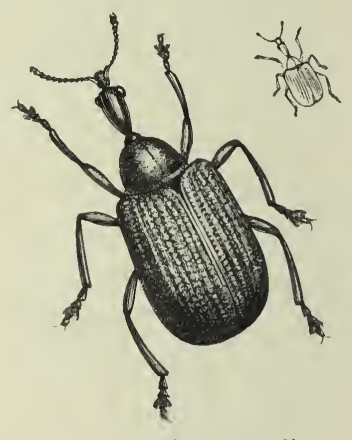

Apoderus coryli.

transformations. The larvæ of other species live either in the stems of plants or in fruits, which serve them as a shelter and as food. They do great mischief to the plants upon which they live, but they are perfectly harmless as beetles. The species of the genus Apoderus and Rhynclites - the last being characterised by a long and thin beak-have the instinct of cutting the stems of leaves or the ends of twigs, and of laying their eggs just inside ; and their larvæ, which can only live upon fading leaves, have thus to thank their parent for giving them life, and their peculiar means of subsistence also.

In the engraving above the real and magnified sizes of two common beetles, whose long beaks are very visible, are shown.

Many of the species are very hurtful to fruit trees, and it appears that the male insect, in some instances, helps the female 


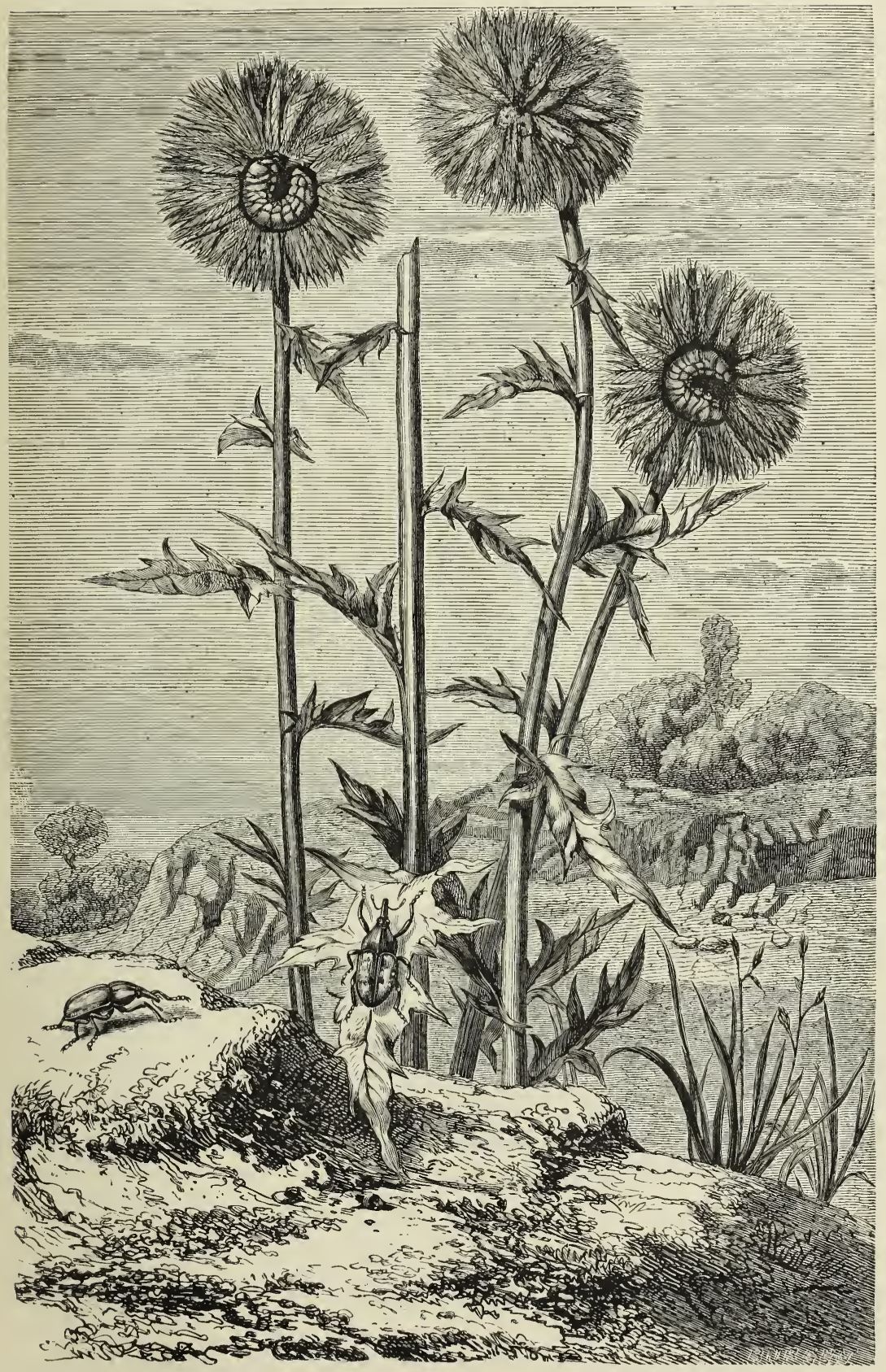

BEETLES AND LARVA OF Larinus maculosus. 
to find a shelter for the egg. One kind attacks the vine and the pear tree. The female insect selects a leaf, cuts the stalk with her beak almost half through, and then rolls the leaf together, and in doing this she is assisted by the male. Having made a symmetrical roll, she cuts into and pierces it with the beak and lays an egg in the opening, and then she pushes in the egg in such a manner that it remains on the inner side of the leaf. Five or six eggs are thus introduced, and the leaf is rolled up in such a way that it is impossible to discover from the outward appearance how the eggs were deposited.

The Apodcrus in the engraving on page 318 is a pretty red insect with a black head, and it rolls up the leaves of nut trees. The Rynchites in the same engraving has a violet red tint, and looks very silky, and it twists up vine leaves.

The little Apion is scarcely a line in length, lives in its larval condition in seeds and grains, and is very injurious. It is a true weevil, in spite of its size.

The Larini frequent the shores of the Mediterranean. They are well known by their elytra, which are covered with a sort of efflorescence, which imitates spots and cloudy markings. Their larvæ live in the fleshy part of the receptacle or eye of composite flowers. The engraving represents the larva of Larinus maculosus in the centre of the receptacle of Echinops ritro. The adults are on the ground and on a leaf.

Very large species of the genus Calandra are found in the tropical parts of the globe; and in Guiana the palm trees are more or less riddled by one. The adult Calandra palmarum is a large velvety black beetle, and is nearly two inches in length; its larva is a great worm-shaped creature, and lives in the pith of the trunk of the trees, boring large cavities in the wood itself. When full-grown it forms a cocoon with the woody fibres which surround the pith, and undergoes its transformations therein. This species and another, Calandra sacchari, are equally destructive to the sugar-cane in the West Indies. The natives of Guiana and Surinam consider these larvæ as great dainties, and eat them boiled.

Calandra grcinaria, or the Corn Weevil, is notorious for the ravages it commits upon the corn in granarics. It is a slender 


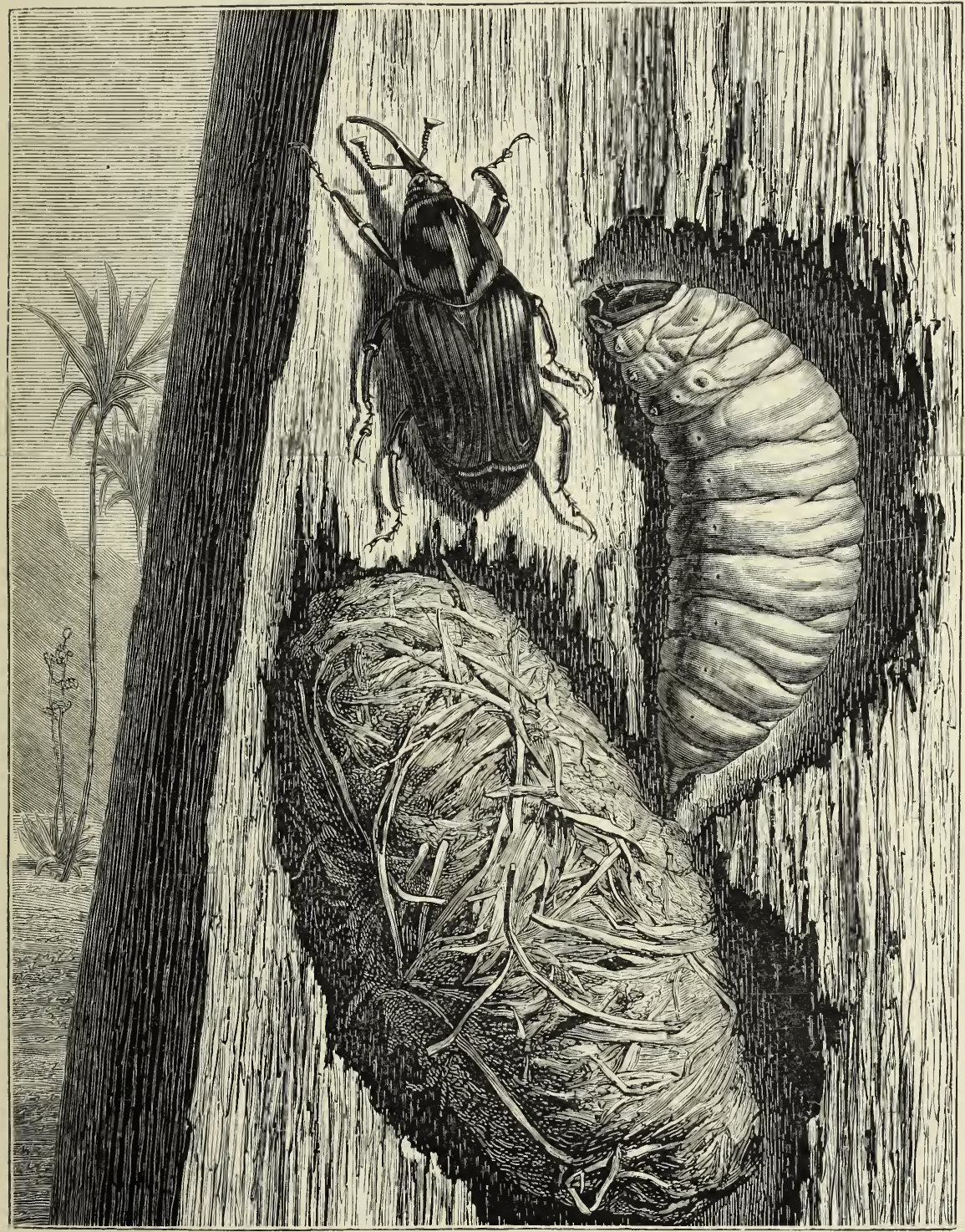

THE METAMORPHOSES OF Calandra palmarum.

The beetle is seen on the wood of the palm, and its beak is a very prominent part of its structure; the larva is gnawing the wood, and there is a large cocoon in a cavity below.

beetle, about one-eighth of an inch in length, and is of a pitchy red colour. The female deposits her eggs upon the corn after 
it is stored, and the young grubs burrow into the wheat as soon as they are hatched, each individual occupying a single grain: they eat the whole of it, and only leave the husks. They then undergo their metamorphosis, and at the appointed time come out perfect beetles, to lay their eggs for a second brood. Unfortunately, the mischief is generally unperceived until it is too late to remedy it ; but kiln-drying the grain appears to be the only effective means of destroying these injurious insects. The rice and Indian corn are destroyed by the Rice Weevil, in a similar manner, in the countries where these grains are cultivated.

When naturalists dilate upon the most beautiful of the Colcoptera, and upon those which possess the most marvellous richness of colours, and extremely polished and shining bodies,

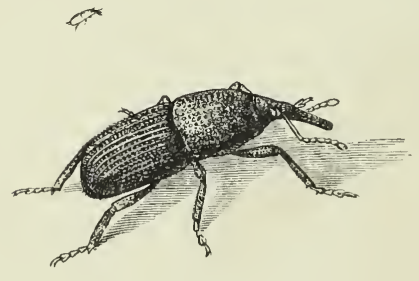

Calandra oryza.

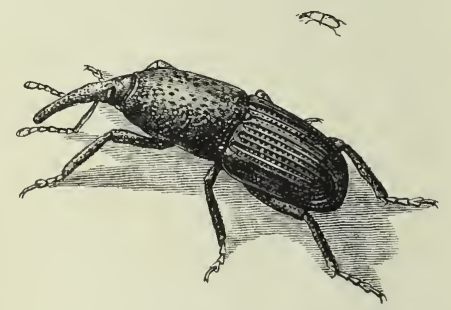

Calandra granciria.

The figures of these weevils are magnified in the illustration, but the natural size of the insects is shown above.

they refer especially to the Buprestide; it is an immense family; containing no less than forty-two genera and I,5Co species. (Dr. Baird). But those that are found in France and in England have very plain decorations, and are very different in their external appearance to their magnificent brethren in the tropics. They are sometimes called Gold-beaters, but doubtless have many other familiar names.

The brilliant species are not very elegantly shaped; their bodies are long, the prothorax broad, and their legs are short; and they have a character which distinguishes them at once amongst the beetles, for their wings are not longer than the elytra.

The illustration shows one of the Buprestida, with its wings expanded, and it will be observed that they only equal in length 
the dense elytra. The larvæ live in the trunks of trees and in woody tissues, twigs, and stems, and they are somewhat remarkable. They are white insects, without legs, or having only vestiges of them, in the form of tubercles; they have a retractile head, the front part of which alone is thick and leathery, but the prothoracic segment is very large and broad, and is clothed with a coriaceous plate that is either granulated or tuberculated. This arrangement enables the larvæ to use much force and tearing power when they are perforating trees, to which they do, in the tropics, a great deal of harm. Fortunately, however, our trees do not suffer from them.

The beetles of the genus Chalcophora are amongst the largest of

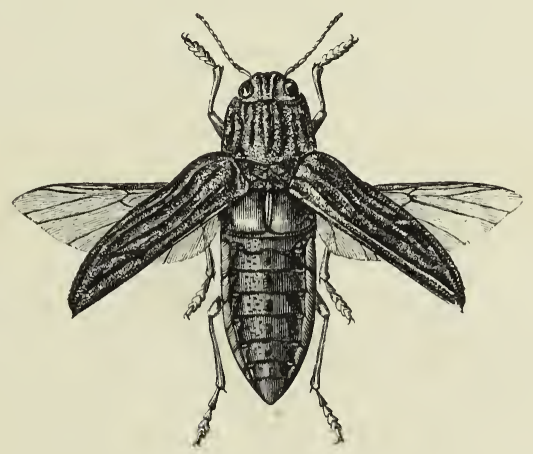

Chalcophora Mariana.

the family; and the species Mariana, whose metamorphoses are illustrated in the engraving on page 324 , is a prettily-sculptured and bronzed beetle, which is common in the pine forests of the south of France, Italy, and Germany. Its larva hollows out large galleries and holes in the trunks of the trees.

In the same engraving the larva which has done part of this mischief is shown in its gallery, and its small head and enormously developed first thoracic segment may be noticed, the rest of the body being rather slender. It undergoes the metamorphoses in one of the galleries, and in one of them a pupa may be observed, whose structures foreshadow those of the adult form very distinctly.

The Longicorn Beetles, or the Goat Beetles, as they are sometimes called, on account of their long, cylindrical antennæ, 
which look like horns, belong to the family of the Cerambycida. The adults are made for walking well, and they have usually

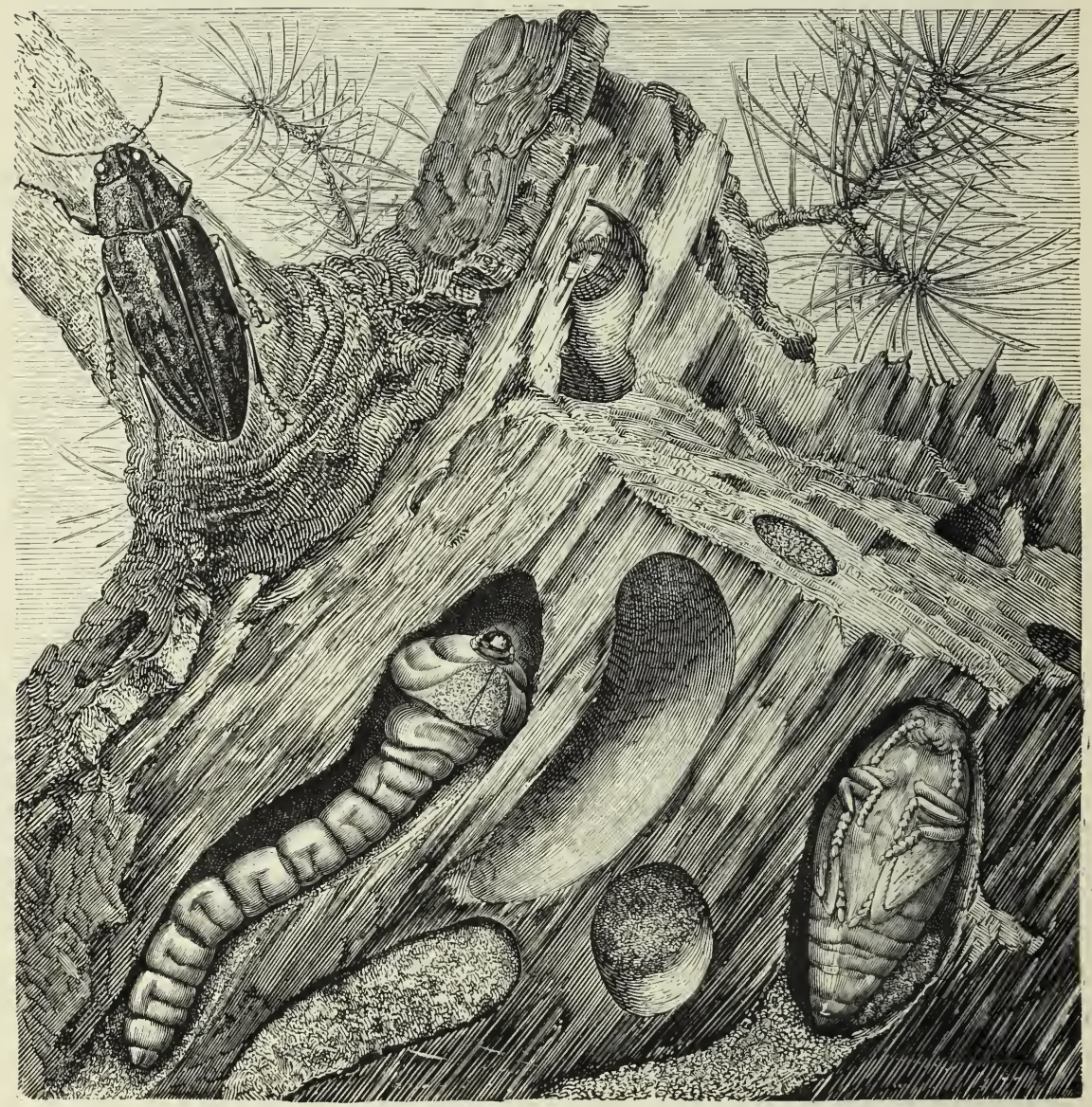

THE METAMORPHOSES OF Chalcophora Mariana.

The adult insect is represented as crawling upon a branch of a fir-tree, which is more or less ricdled and hollowed into tunnels or galleries. The larva and chrysalis are also shown.

very strong, and indeed occasionally enormous, mandibles, differently toothed according to the species, and the jaws of the lower lip present many decided modifications of form, according to the peculiar habits of the insccts. The beetles are leaf-eaters, 


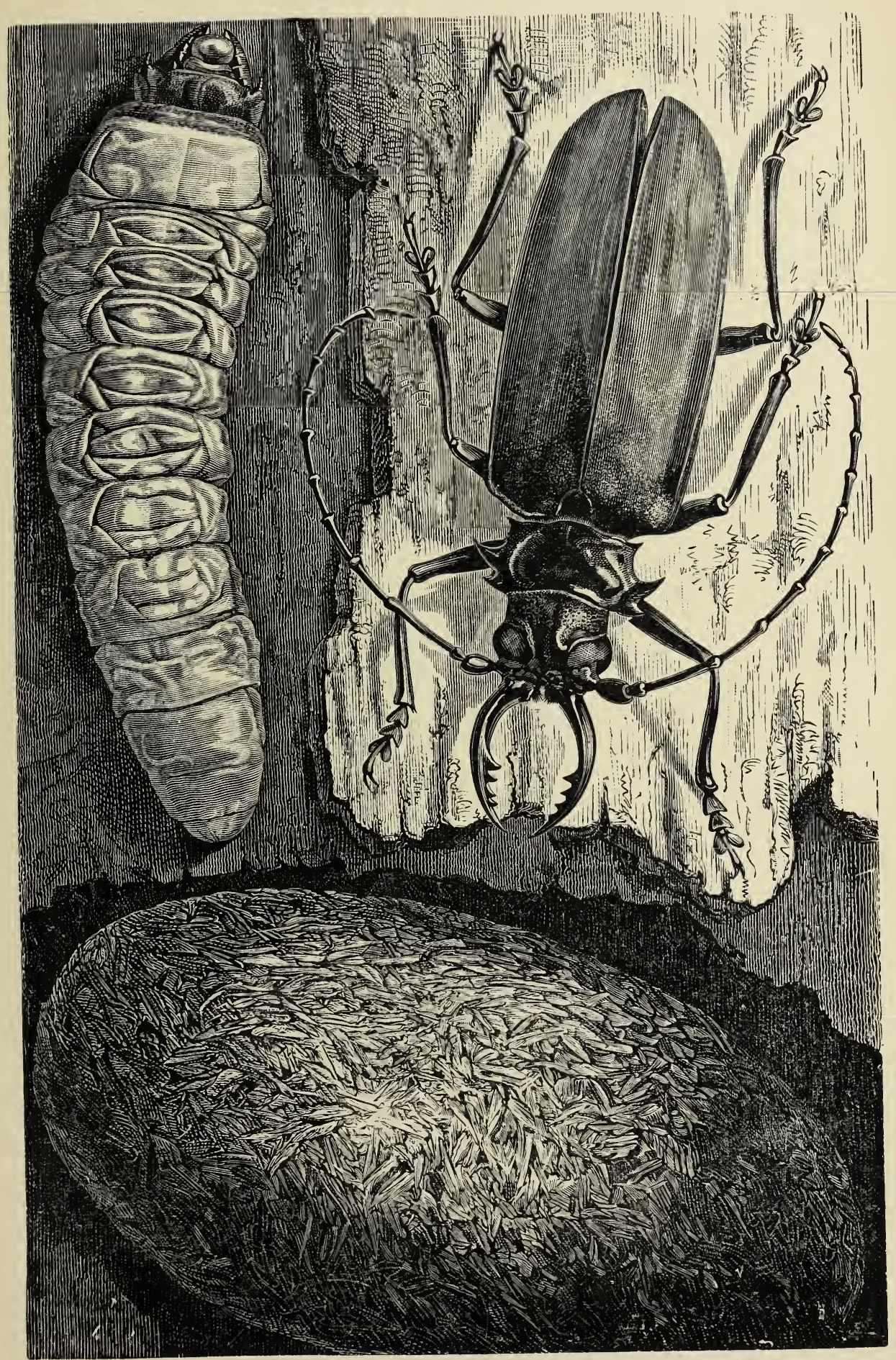

THE METAMORPHOSIS OF Acanthophorus serraticomis. 

and the diversity in the structure of their mouths depends upon the nature of the vegetable matters upon which they feed. The species are world-wide, but their abundance is in distinct relation with the richness of the vegetation of different countries, so that South America, India, Ceylon, and the Islands of Sunda, and the Moluccas contain a great number of the most beautiful and largest Capricorns. It is impossible to confound a beetle belonging to this family with that of any other. There is the greatest resemblance amongst the larvæ of the whole family, and they look like stout elongated white worms, and the segments of their bodies are very much alike in all. All the segments are a little swollen, the first, however, being the largest, and being covered above and below with a leathery plate. They have rudimentary antennæ. These larvæ live in the trunks and branches of trees, and in the cellular structures of some herbaceous plants. As they never come to the light they are colourless, and have soft integuments, but as they feed upon the wood out of which they form galleries, they have very strong jaws and a very stout head. As they do not want to walk much in a narrow gallery, they have no legs, or else they are in a most rudimentary condition, but their swollen segments enable them to climb. This history of the peculiar structures of the larva presents striking analogies with that of the wood-eating larvæ of the Lepidoptera and Hymenoptcra; and the existence of similar adaptations in very different insects in order to enable them to live under the same conditions of existence is very remarkable. But the weak jaws of Chalcophora Mariana, which are presumed to do the same kind of work as those of the Ccrambycida, must be remembered in considering such generalisations. The strength of the jaws of the larvæ of the Cerambycide differs according to the density of the tissue of the plant in which the particular species live. The abdomen of the female beetles of some genera is provided with an ovipositor of considerable length, by means of which they can insert their eggs into the crevices of trees or plants, in the interior of which their larvæ live and are hatched. The larvæ make a cocoon by joining together fragments of wood and little bits of vegetable tissue with their saliva, and are transformed into nymphs. Some of the beetles are remarkable for 
the emission of a fragrant odour not unlike that of otto of roses.

The exuberant vegetation of tropical countries can well afford to be checked by the ravages of insects, and some of the largest trees, which require much heat and damp for their growth, are more or less destroyed by some of the largest larvæ which are known. Thus in Guiana there is an immense beetle called the Titan (Titanus giganteus), whose larva gnaws and makes galleries in the largest trees, and its size almost appears to bear some relation to the magnitude of its food. Again, in India, there are beetles with long mandibles which make them look almost like stag beetles, but the antennæ are enormously long and spined at each joint, and they have very large larvæ. The larva of Acanthophorus serraticornis lives under the bark of large trees in the neighibourhood of Pondicherry. It does not come into the light, and, like many other wood-borers, it forms galleries within the wood, and finally makes a cocoon of enormous dimensions out of the vegetable tissue. The engraving exhibits the beetle upon the outside of a tree, the larva being under the bark, and a great cocoon in a kind of gallery.

The mimosa trees in the West Indies suffer greatly from a beetle which is called Lamia amputator. The larva bores and excavates the branches and delicate saplings of the trees, and undergoes its metamorphosis in them. This mischief having been done, the coup de grâce is given by the perfect insect, for the beetle has a fancy for gnawing round the branches in a circular line, so as to cut them off completely. An allied species (Oncideres vomicosa) does very much the same sort of thing. M. Houllet, now the head gardener of the tropical department of the Musée d'Histoire Naturelle in Paris, once lived in the environs of Rio Janeiro, and every night he heard the sound of falling branches of trees belonging to the Acacia lcbbck. He found on examination that these branches were sawn all round in a circular direction, but their central part, or pith, was not touched, so that the branches broke by their own weight or by the simple force of the wind. The mischief was put down to the evil dispositions of the slaves of the house, but M. Houllet discovered a beetle upon a branch which had been thus cut, and it soon became evident that this 


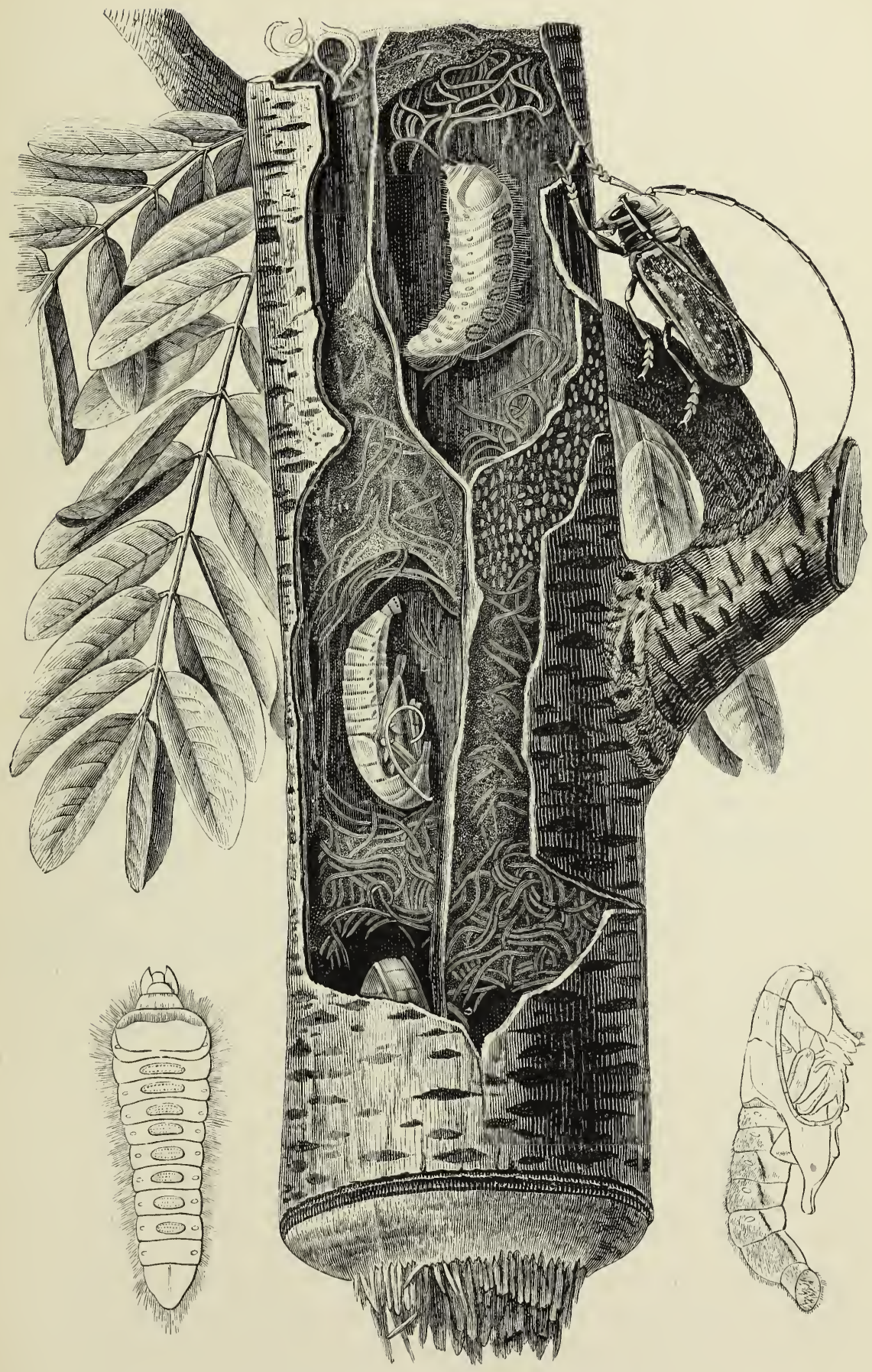

THE METAMORPHOSES OF Oncideres vomicosus. 
insect was the author of the destruction of the trees, for when a branch was carefully opened it was found to contain the living larvæ and nymphs of the Onideres.

In the engraving on page 327 a beetle may be noticed with very long horns upon a little twig close to the main branch. Quite low down the fractured end of the branch shows in the centre the ragged pith, but between this and the bark the tissues are perfectly smooth, the bark being cut through in a circular manner. The smoothness of the tissues has been produced by the gnawing of the beetle, which does not touch the pith. Within the branch, and on a level with the beetle, there is a larva which has made an excavation. A larva is also represented on the left hand side of the plate. Below, a nymph may be seen in a cavity, and there is one represented outside the branch on the right-hand side. Now, what is the reason that the beetle should cut away the branch? If it is that which is usually considered to be true by naturalists, it is a most wonderful instance of superior instinct. It is supposed that the branch is cut off in order to prevent an unusual supply of sap flowing into it, or with a view of diminishing the amount of sap circulating generally in the branch. Were the incision not made through the bark and the flow of the sap not checked, the larvæ would suffer from too great abundance of liquid in their immediate neighbourhood; and the diminution of the sap is necessary for the perfection of the metamorphoses.

The Chrysomclide are leaf-eating insects, and attack all kinds of plants. Many of them are ornamented with most beautiful colours of gold, red, copper, bronze, metallic green, deep blue, azure violet, and silver, and very few of them are of a sombre hue. Unlike those just described, the larvæ of these beetles generally live in the open air, fixed upon the leaves of plants or trees. They are stout, thick-set, and having very small legs, they walk but very slowly, and many of them, on account of their having soft integuments, protect themselves from danger in most interesting and curious manners. The beetles of the genus Crioceris are oblong creatures, with very narrow heads and fore-parts of the body, and they may be constantly seen upon the twigs and leaves of the beautiful white lilies which are grown in gardens. They may be recognised by their brilliant black colour, which is 
set off by the beautiful vermilion tint of the corselet and elytra. The larva is certainly not beautiful, but it is interesting in consequence of its extraordinary instinct of self-preservation.

The larvæ, some of which may be seen on the left hand leaves in the engraving below, have soft integuments, and, there-

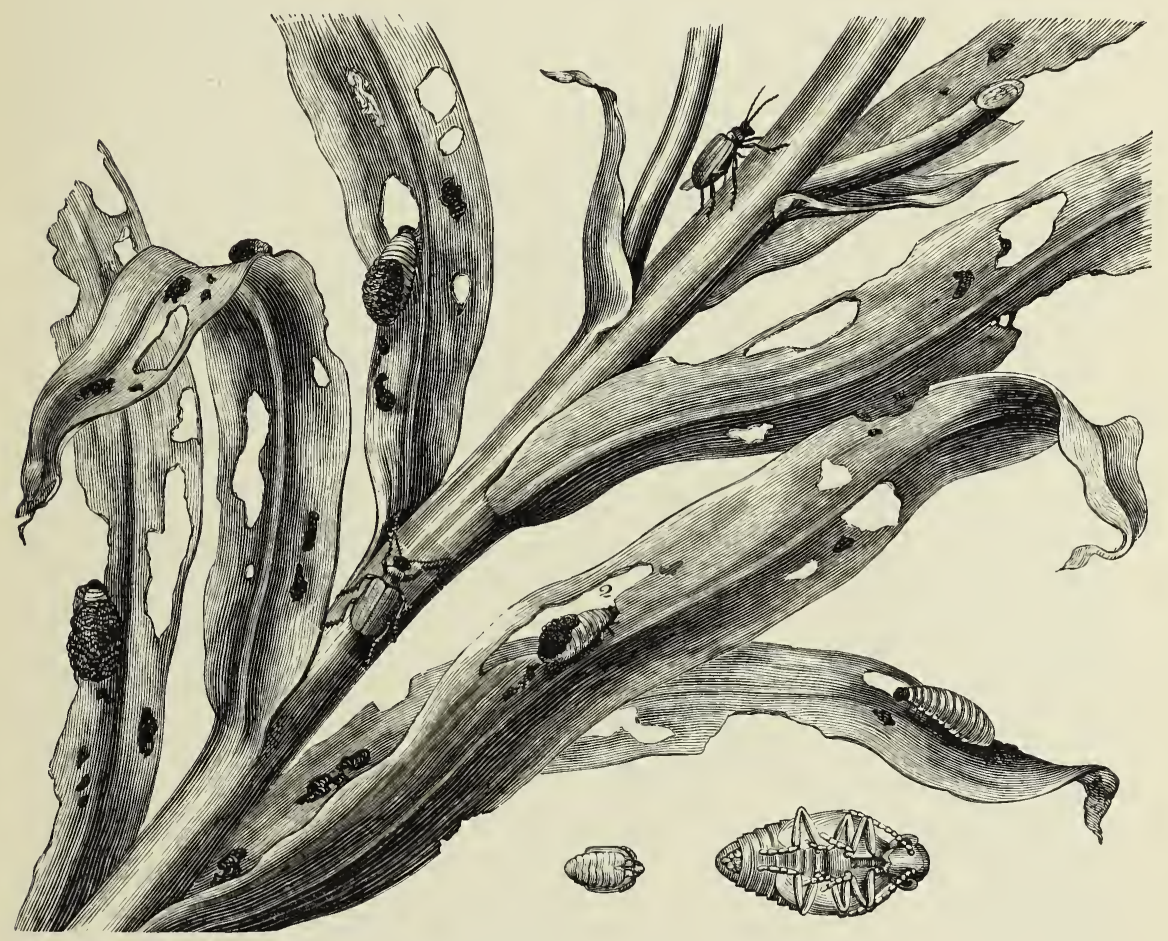

THE METAMORPHOSES OF Crioceris merdigera.

A nymph seen from above. A nymph (magnified) seen from below.

fore, some extraordinary protection must be had against the at. tacks of other insects and the weather. The vent of the larva is nearly on a level with its back, so that all digested matters which pass from the intestines slide over or collect upon the body. The larva of Crioceris merdigera thus lives under most miserable clothing, but which is safely and easily replaced, and the insect appears to know this, for if disturbed and cleansed, it sets to work and eats as quickly as it can, knowing that Nature will soon 
provide another coat. The perfect insects are represented upon the stem of the lily.

The larva of another beetle, which is closely allied to the species just described, has almost as curious a protection. It may be seen on artichokes and large thistles. It is broad, flat, and has long, pointed, or spiny hairs fixed to its sides, and a fork-shaped

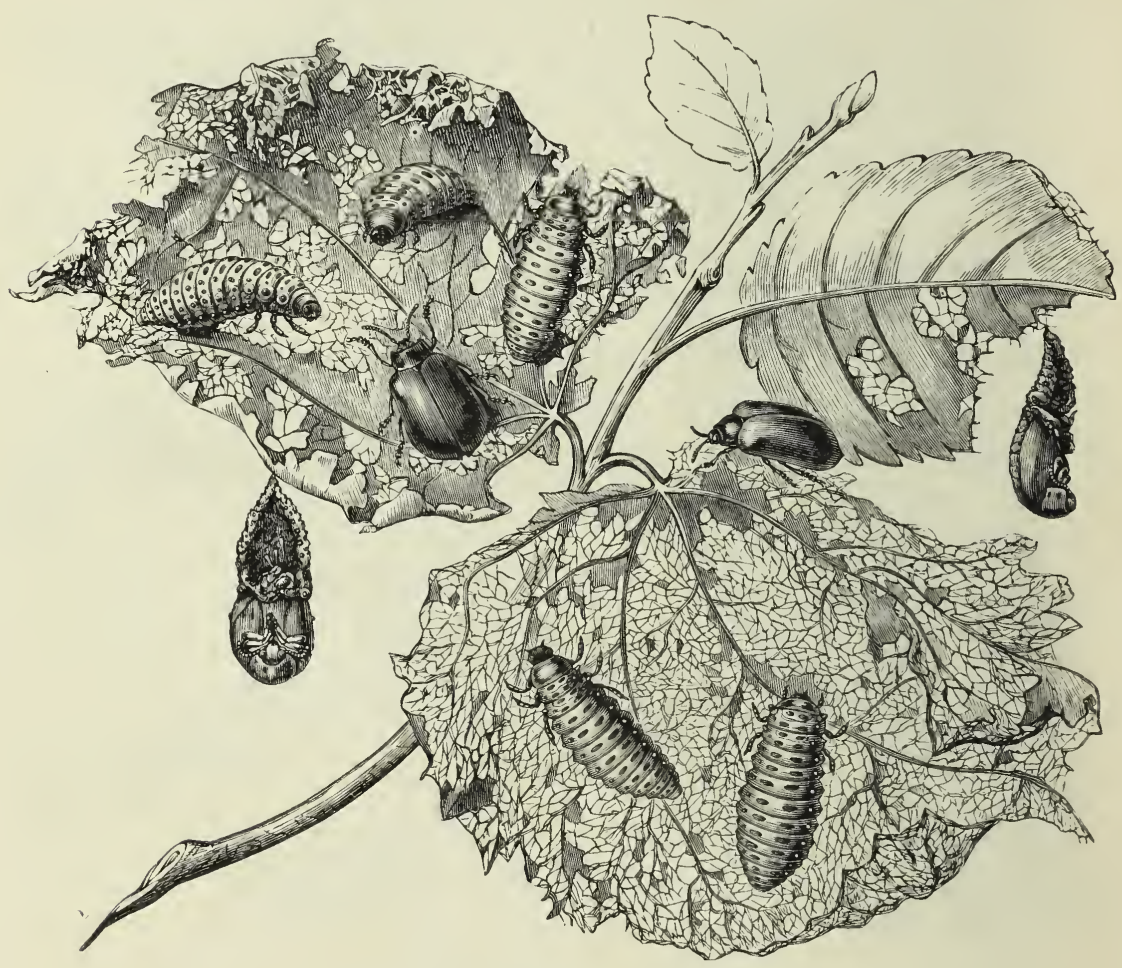

THE METAMORPHOSES OF Lina populi.

appendage, which is attached to the end of the body and curved forwards above the insect. The vent is situated at the base of this appendage, and the matters coming from it stick on to the fork which is hoisted up above the body with the lump of dirt upon it like a parasol.

The poplar trees are frequently much damaged by some species of the genus Lina. The adult beetle is of a green bronze colour, and has red elytra, but the larva is yellow and is 
spotted with brilliant black. The larva destroys the foliage, and eats the cellular tissue of the leaves, but does not touch the nervures, so that they look very much like lace work. When

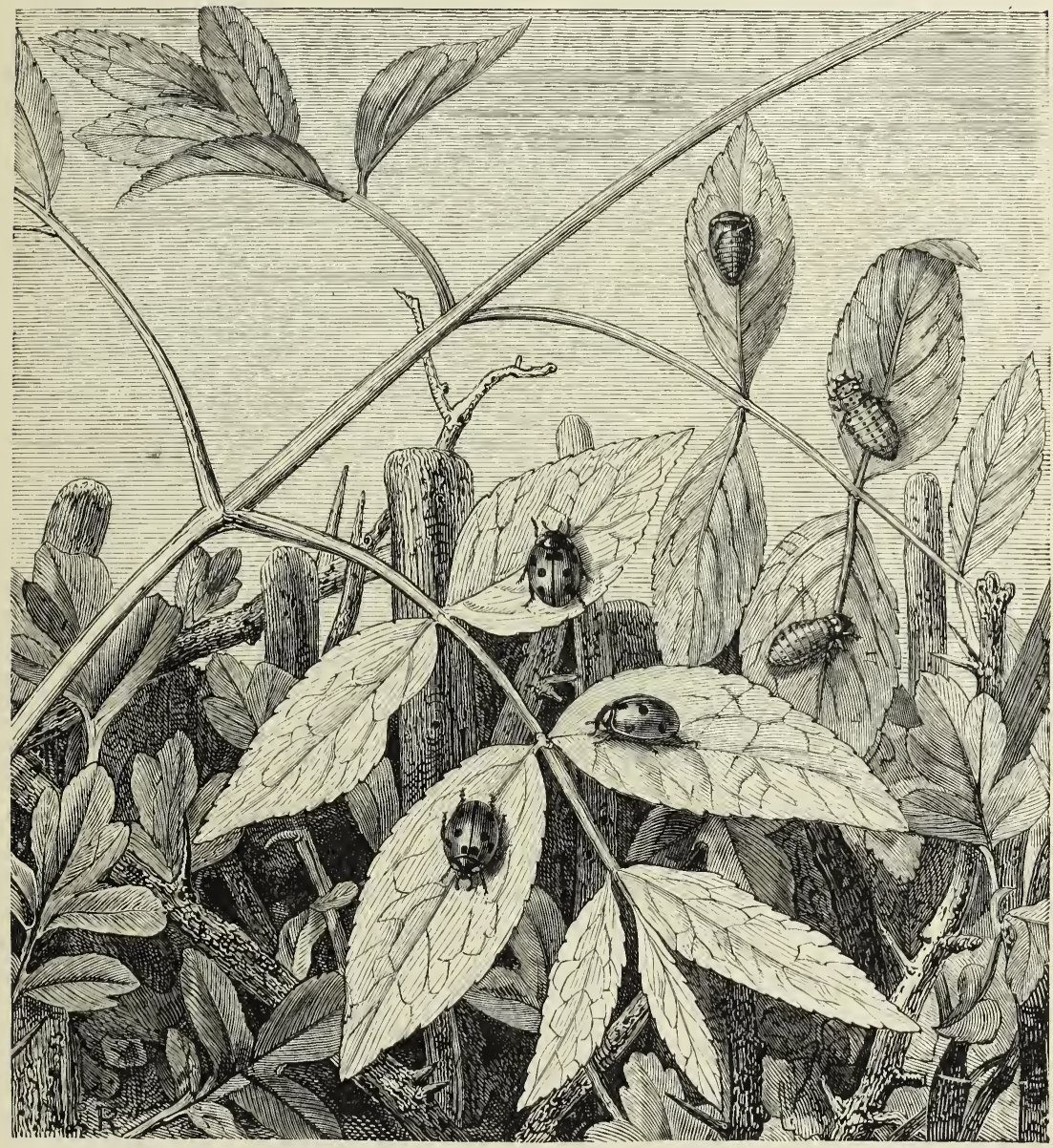

THE METAMORIHOSIS OF THE LADY BIRD.

(Coccinclla septempunetata.)

about to undergo its metamorphosis the larva hangs itself to a leaf by its tail, and after a time the skin cracks and the nymph may be seen underneath, but it remains thus protected until it is transformed into the beetle.

The nymph is represented hanging from a leaf, the larva 
are making lace work of the leaves, and the beetles are crawling upon the plants. This hanging up of the nymph resembles the favourite position of many chrysalides of the Lcpidoftcra, and it is somewhat remarkable that another genus of these beetles las larvæ which construct movable tubes, in which they live, and which they carry about after the fashion of many caterpillars.

The last family of the order of the Colcoptera that comes under our notice is that of the Coccinellide, or the Lady Birds. These are great favourites with children, and even with collectors; and popular sympathy is extended towards them, and certainly very properly, for they do much good by preventing the excessive multiplication of plant lice, and, moreover, they are very pretty things. The lady birds with seven spots (Coccinella septempunctati) are very common in Europe, and, indeed, in Asia, Africa, and America. They are small insects, which are so well known that they need not be described, but it may be often noticed that when they are alarmed or laid hold of they fold up their limbs and ejest from the joints a yellow mucilaginous fluid, which has a very disagreeable odour. Immense swarms of these insects are sometimes observed, especially on the south-eastern coasts of England, and they have been described as extending in dense masses for miles. The adult insects do not eat much, but the larvæ consume enormous quantities of the little insects which are so injurious to vegetation, and they may be seen chasing, or rather creeping up to, the plant lice, and eating one after the other, taking the whole set on a leaf or stem in regular order. The larva is of a lead grey colour, and has a broad yellow spot in front of the head, three little red spots on the sides, besides black spots and little bunches of hairs. When about to undergo its transformation the insect attaches itself to a leaf just like the caterpillar of a butterfly.

In the engraving on page 33 I the lady birds are seen upon the leaves in the centre. There are two larvæ on the right hand, and a nymph on a solitary leaf above the others. 


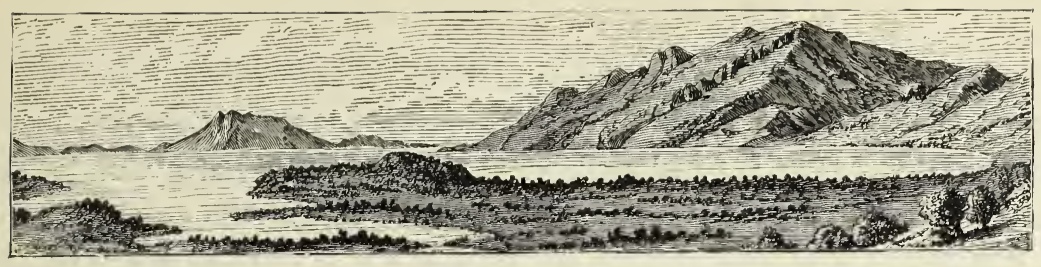

\section{CHAPTER VIII.}

THE OR T H O P T E R A.

THERE are not many typical forms amongst the Orthoptcra. Most of them are well known, and the Earwigs, the Crickets, the Grasshoppers and the Locusts, are the familiar examples.

If we institute a comparison between the Orthoptera and the Coleoptera some very interesting results may be obtained. So far as their structures are concerned there is a great general likeness between the two groups, but there are enormous dif. ferences as regards the progress of their development. The Orthoptcra are insects that bite and browse like the Coleoptcra, and the structures of their mouths are not more unlike than they usually are in families belonging to the same order. The organs of flight, however, distinguish the Orthoptcra from all other insects. The anterior wings differ in their texture and general form from the posterior, they are of almost leathery consistence, and with one exception they cross each other when the insect is quiet. The hind wings are very characteristic. They are membranous, much veined, and their large nervures are almost like straight sticks. These wings fold themselves up longitudinally, like a fan, hence the name of Orthoptcra (o $\rho \theta$ os, straight; $\pi \tau \epsilon \rho a$, wings).

If we only find moderate differences between the adult Orthoptera and Coleoptcra, there are nevertheless very great differences between them in the early part of their existence. The earwigs, the crickets, and the grasshoppers, on leaving the egg have the form, the appearance, and almost all the characteristics of the adults whose method of life they also follow. Whilst the 
Lepidoptera, the Hymenoptera, and the Colcoptera are born in a very embryonic or immature state, the Orthoptera spring into life almost as well developed as the adults, and hardly undergo any changes before attaining the perfect form. These changes consist of the development of the organs of flight and reproduction. There are many Orthoptera, however, which never obtain their organs of flight, and they become adults without having acquired the same perfection which is common to the rest of the group. They may be said to have had their development arrested, or, perhaps, they are the oldest forms of insect life, metamorphosis and wings having been superadded to the original kinds. Most of the Orthoptera change their skin or moult at certain periods of their growth. Some of the insects moult three times successively, and still resemble the creature that first came from the egg; a fourth moult takes place, and then the rudiments of crumpled wings may be observed; then a fifth change of the skin happens, and it leaves the insects with their great wings perfectly finished. The Orthoptera which never obtain organs of flight only undergo the first three moultings, and those which only have the rudiments of wings do not change their skin after the fourth time. They never have any period of inactivity; and in consequence of this and of the peculiarities of their growth just mentioned they are called insects whose metamorphoses are incomplete; but it is customary to call those which have no vestiges of wings, larvæ, and those which have them in a rudimentary state, nymphs. The larvæ, nymphs, and the perfect insects are active and lead the same kind of life.

The species of Orthoptera are spread over the whole surface of the world, and are particularly abundant in those tropical climates where vegetation is in excess. There the herbivorous Orthoptera, which are the most numerous, revel amongst plants of all kinds, which they consume in great quantity. Usually they are beautiful insects, embellished with lively and light colours, the shading of which is very pleasant to the eye; but this is not always the case, as some of them are remarkably ugly and dark.

The Forficulida, which everybody calls the Earwigs, are much more remarkable-especially in their habits-than most of us have any idea of. They have the credit of crawling into the ears and 
doing some mischief to the brain; but really the only lives they ever endanger are those of the plants and pot-herbs in the garden. Their nippers, as they are familiarly called, and their great activity, appear to have given them a bad character; but they

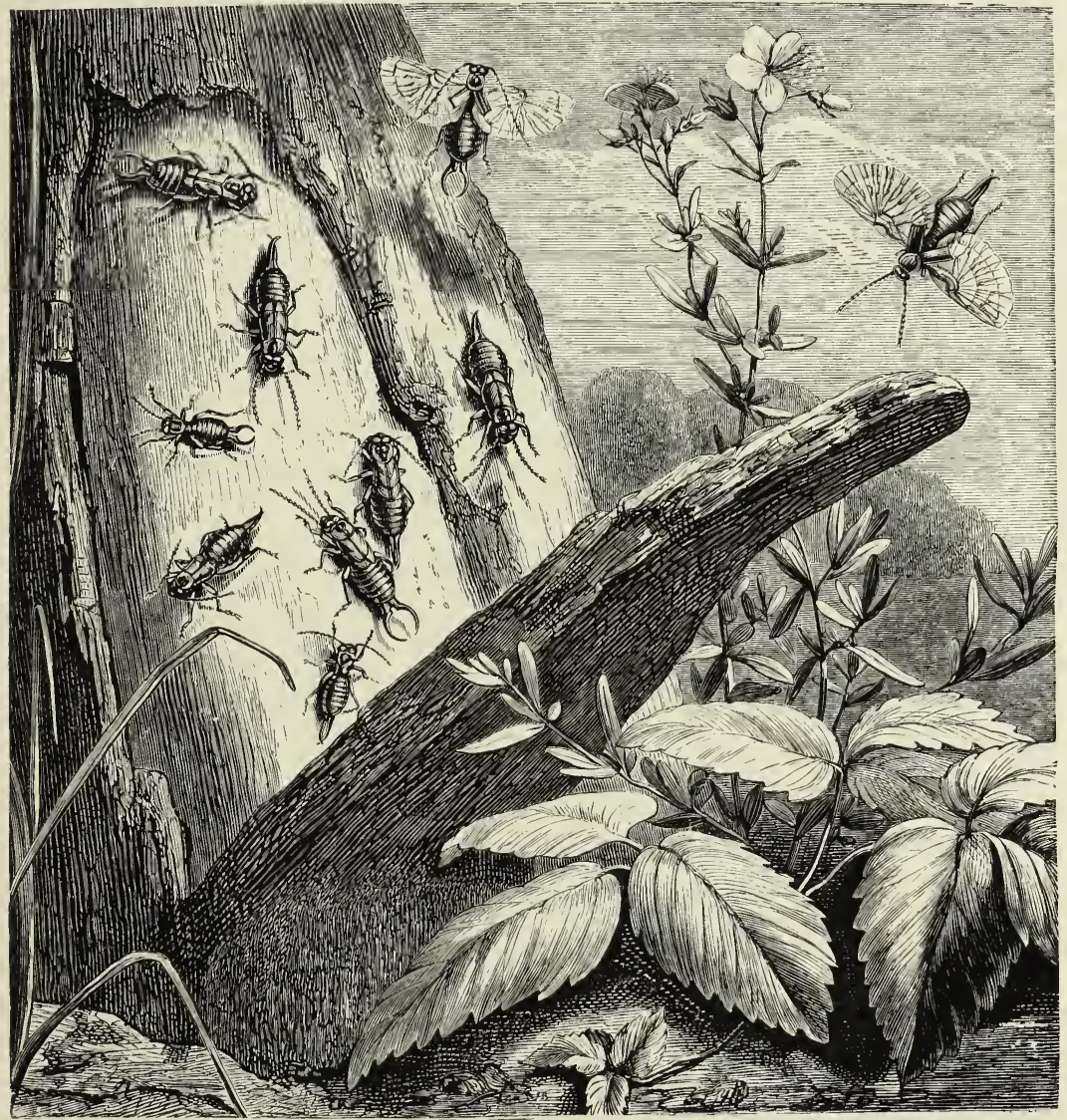

EARWIGS. (Forficula auricularia.)

are much to be admired for some things, for they are amongst the few insects that care for their young, and an old earwig may often be seen acting like an old hen.

The wings of the earwigs are well worth examining. The anterior wings are short, like those of the Staphylinide amongst the beetles, and they do not cross each other as those of the 
other Orthoptera do. The posterior wings are large, and are very pretty when they are extended; the insect folds them first of all like a fan, and then turns them up, and doubles them transversely, so that they fit underneath the front ones.

There is only one genus in this family, and there are several species of it in Europe; but the Forficula auricularia is the best known. The earwigs are nocturnal in their habits, and are rarely seen in the day-time, unless disturbed. Sometimes they hide themselves by lying flatly under leaves; but they are more frequently found hidden up. under stones, under the bark of old trees which has become rather detached, and in the interior of all sorts of dark hollow places. There a perfect family of them will keep quiet in safety during the day, and it will be found to consist of little ones without wings, those a little advanced in age with rudiments of them, and of the fathers and mothers who know how to fly. They are not industrial in their habits, but the females watch over their eggs, and carry them off to a safe place if they are threatened with any danger. These insects attack all sorts of vegetable tissues, and the most beautiful flowers are no more to them than the humblest weeds. Unfortunately, however, they seem to prefer spoiling the flowers whose petals are most elaborate.

The Blattide are generally considered very disagreeable insects. They are not pleasant to look at; they are offensive to our sense of smell, on account of their very fetid odour, and they excite our antipathy on account of the waste and destruction they cause. Possessing great agility, and being able to run with extraordinary rapidity, they have something very peculiar in their aspect and habits; generally the body is large, broad, flat, and clothed with very flexible coriaceous integuments. The head is almost hidden under the prothorax, and its antennæ are very long and as delicate as threads. They are common in some places, especially on board ship and in seaport towns; but commerce has carried them more or less over the whole world. They are called by all sorts of names, but we know them as black beetles and cock-roaches. Such they are, in fact, as regards their colour, but they are true Orthoptcra. They manage to hide themselves up very easily; and from their having flat bodies and very com- 


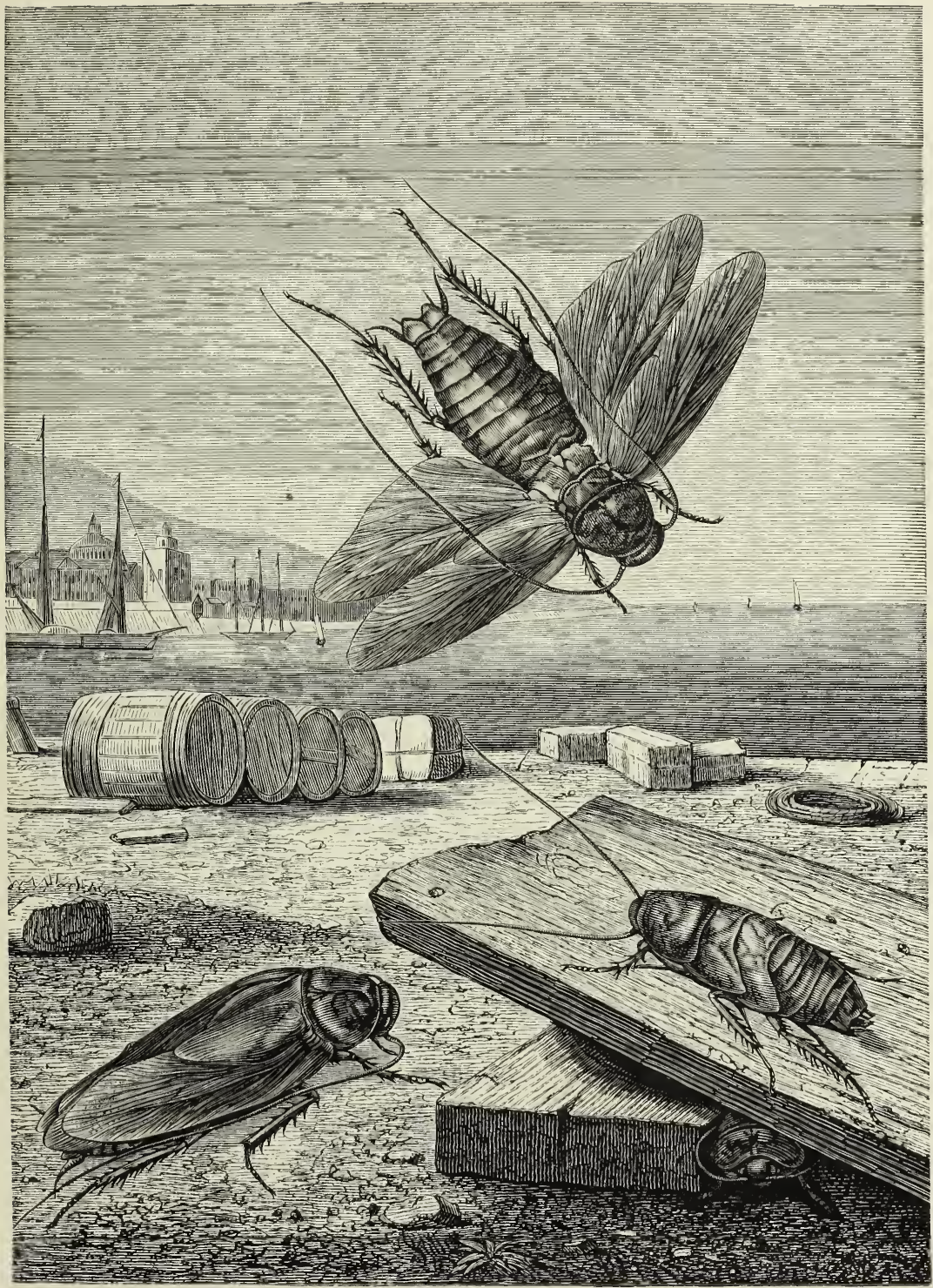

Blatta Americana.

pressible skins, they can squeeze themselves into very narrow places. Being omnivorous they attack everything that comes in their way which can possibly be consumed; nothing is amiss to 
them; and they inflict great losses upon merchants, as well as upon householders. They do not lay their eggs one by one in different places, but they shut them up in a sort of capsule, which is rather leathery, and they carry it about with them until the young are about to escape; they then help the little ones to get out of this bag, and at first are very attentive to them.

The Blatta Americana is very common, and may be frequently noticed in the cargoes of ships. The engraving on page 337 represents the larva and two adults of this kind.

Blatta Orientalis, which is not so large as that just noticed, has its wings very badly developed. It is common in towns, and is particularly fond of hiding up in the cracks of chimneys, and of only appearing at night time. The larvæ when first born are quite white, and resemble their parents in form, but change their skins six times before they become perfect.

There is one great family of the Orthoptera the species of which are all carnivorous, and there are no insects which have such an extraordinary appearance as these Mantide. Their strange attitudes, their great and strong limbs and leaf-like shapes, combined with the great slowness of their movements, do not make them look at all like bloodthirsty creatures. They have a narrow body, a very long prothorax, and a very movable head, which has large eyes and sharp and trenchant mandibles. They have large wings, front legs admirably adapted for seizing their prey, and the others are slender. The Mantide are generally large and fresh-coloured, and sometimes the posterior wings, which are always more or less transparent, are very prettily ornamented and coloured. They crawl on bushes, where they remain perfectly immobile hour after hour with the front of the body erect and with their front legs folded. This perfect quietude does not raise any suspicions in the insects which are flying about, but if an unfortunate fly comes too close the Mantis extends its foot rapidly and too surely. The Mantide cover their eggs with a kind of capsule, which they hang on plants.

The eggs are laid towards the end of summer, and the young larvæ escape and grow like all the other Orthoptera. The species of this family inhabit the hot parts of Europe and the tropics, and wherever they are seen, their positions, apparently so medi- 


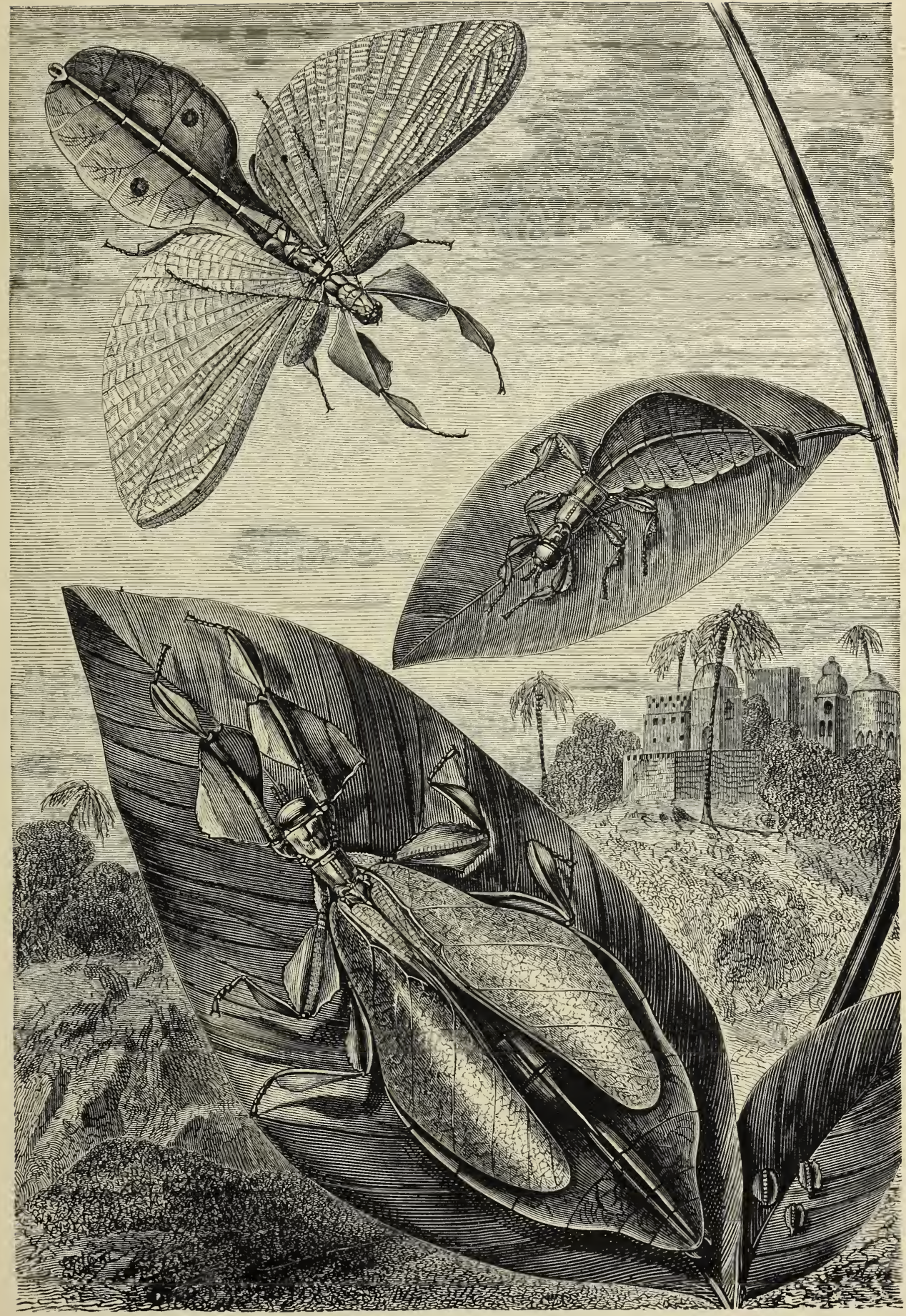

THE EGGS AND mMATURE AND ADILT FORMS OF Phyllium siccifolinm. 

tative, have inspired observers with some amount of veneration for them. People are often deceived by appearances, and nothing leads very well disposed persons astray so much as the belief that certain actions represent goodness of disposition. Persons

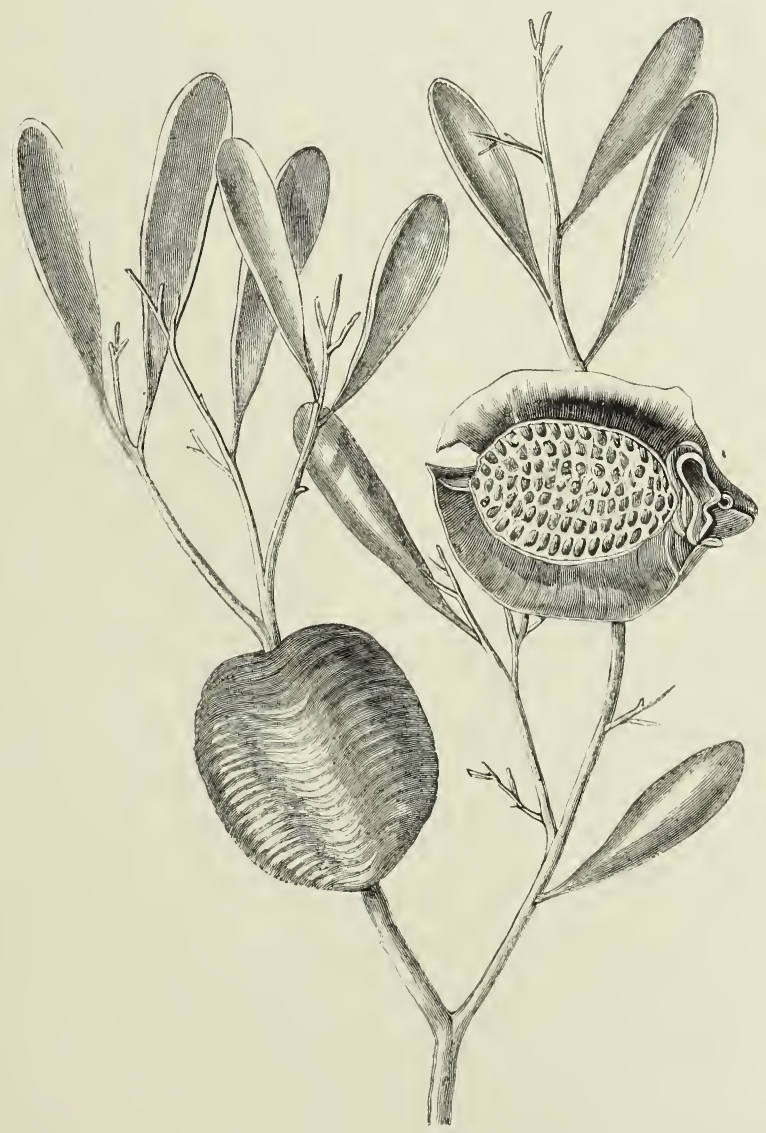

EGG CAPSUles of Mantis religiosa.

A capsule attached to a twig and a section of a capsule.

who want to deceive others have only to pretend to be very sanctified, and to pray in the corners of the streets, and act the hypocrite persistently. Success will attend them in an exact relation to their endeavours to deceive. All this holds good for insects, and there is no more respectable and saintly-looking preacher than the Mantis religiosa, or the praying Mantis. Any 
unfortunate moths that may admire it on account of its attitudes of supplication soon find out that instead of saying "Let us pray," it says "Let us prey."

The Empuse are much handsomer than the insects of the

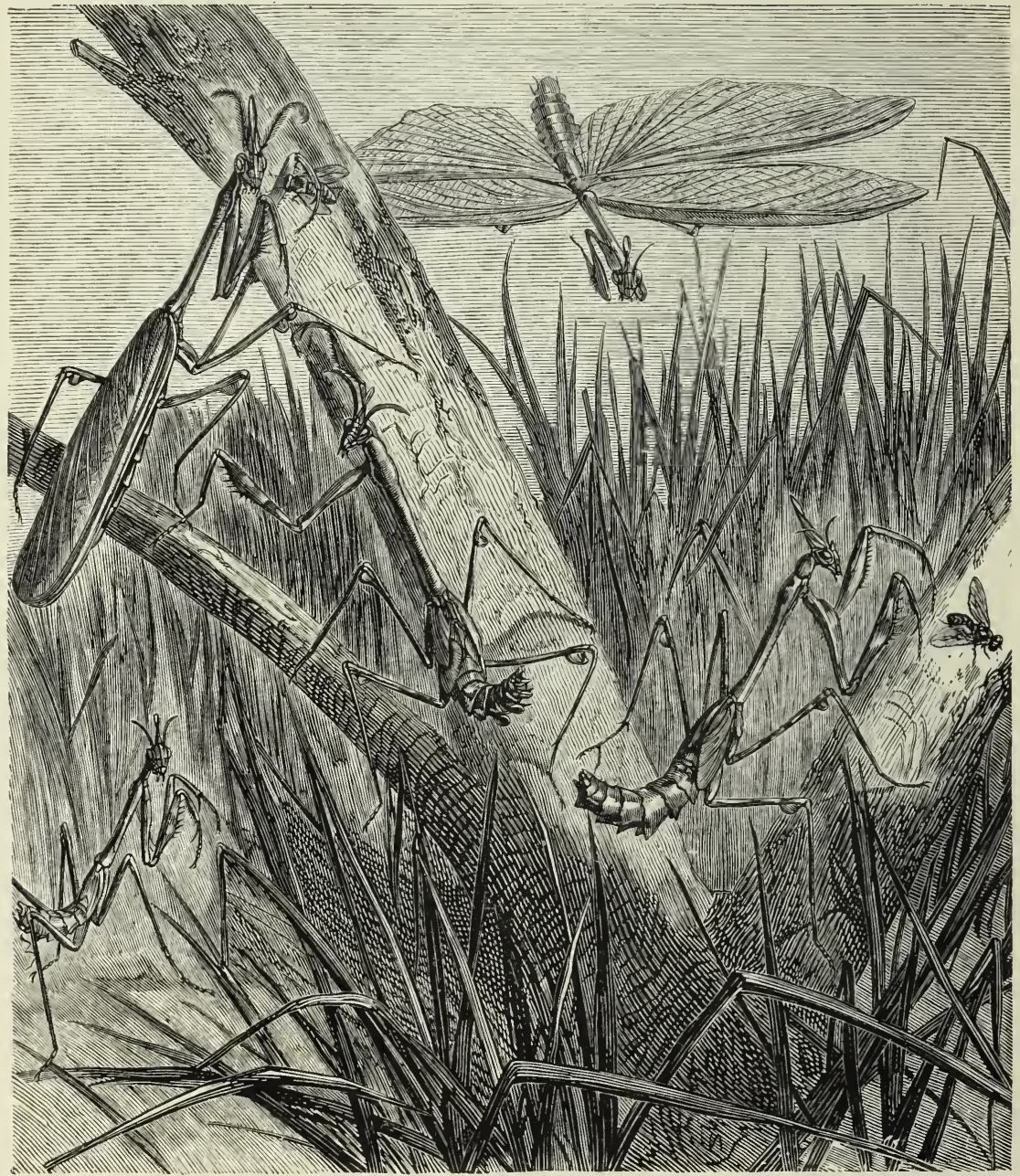

METAMORPHOSES OF Empusa pauperata.

genus Mantis. They have a long, leaf-shaped projection on their heads, short antennæ, a very thin thorax, and their legs are ornamented with curious leaf-like expansions. There is a very pretty Empusa, which lives in the Maritime Alps, and which is 


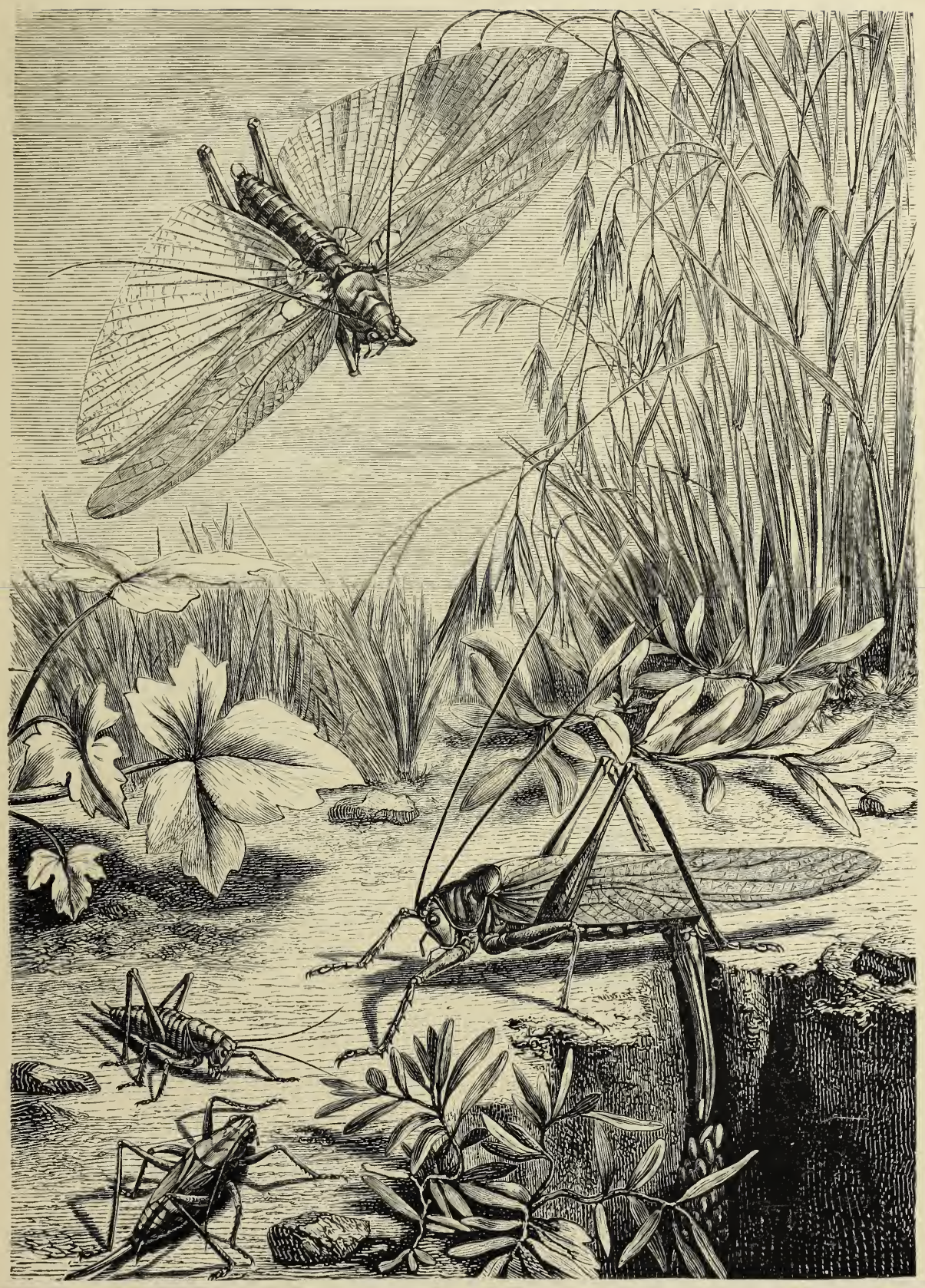

THE METAMORPHOSES OF THE GREAT GREEN GRASSHOPPER. 

represented in the engraving on the opposite page. The body of the Empusa is decorated with a mixture of most delicate grey, green, white, and violet tints, and the wings of the adults are of a clear sea-green colour, the borders and the nervures being lilac.

The Phasmiace are, however, the most curious of all insects. They approach the Mantide in general appearance, but are distinguished by their fore legs being of the ordinary form, and suited, like the rest, for walking. Unfortunately their incomplete metamorphosis has not been studied carefully.

All the Orthoptera which we have hitherto noticed may be called walkers or runners; but those which we are now about to describe are termed jumpers or leapers.

The grasshoppers are true jumpers, and have their hind legs so formed that they can lift themselves from the ground and jump considerable distances; the females have a long and stout ovipositor, which has a sabre shape, and is attached to the hind part of the body. Nearly all the "jumpers" have well-developed wings; the front ones, or the elytra, are long, and the posterior are of considerable size; but there are some species whose wings are always in a rudimentary state. In every instance the first pair of wings of the male insects are so formed that they can produce musical sounds. At the base of the elytra there is a greater or less space, which is covered by a thin, transparent, and very tense membrane, and it is situated between some twisted and enlarged nervures. When the insects are anxious for a little female society at eventide, they elevate their wings, and rub them one upon the other, and produce a sound which is rendered intense, sharp, and chirping by the vibration of the membrane. The grasshoppers fly easily, in spite of their heavy bodies; but they walk with difficulty, in consequence of the disproportion which exists between their front and hind legs; so they usually move from place to place by a series of jumps. The jumping is produced by the action of the large muscles of the thighs acting upon the long legs and feet. These insects use their ovipositor for the purpose of burying their eggs in the soil ; and it is interesting to observe that several species which live almost in the same manner have different modes of egg-laying, and their ovipositors are therefore variously fashioned. The spccies of the grasshopper 
genus have a tubercular projection on their foreheads, and their elytra are longer than the hind wings; and the largest kind, Locusta viridissima, which people in central and northern Europe very improperly call the Cigala, is well known to everybody.

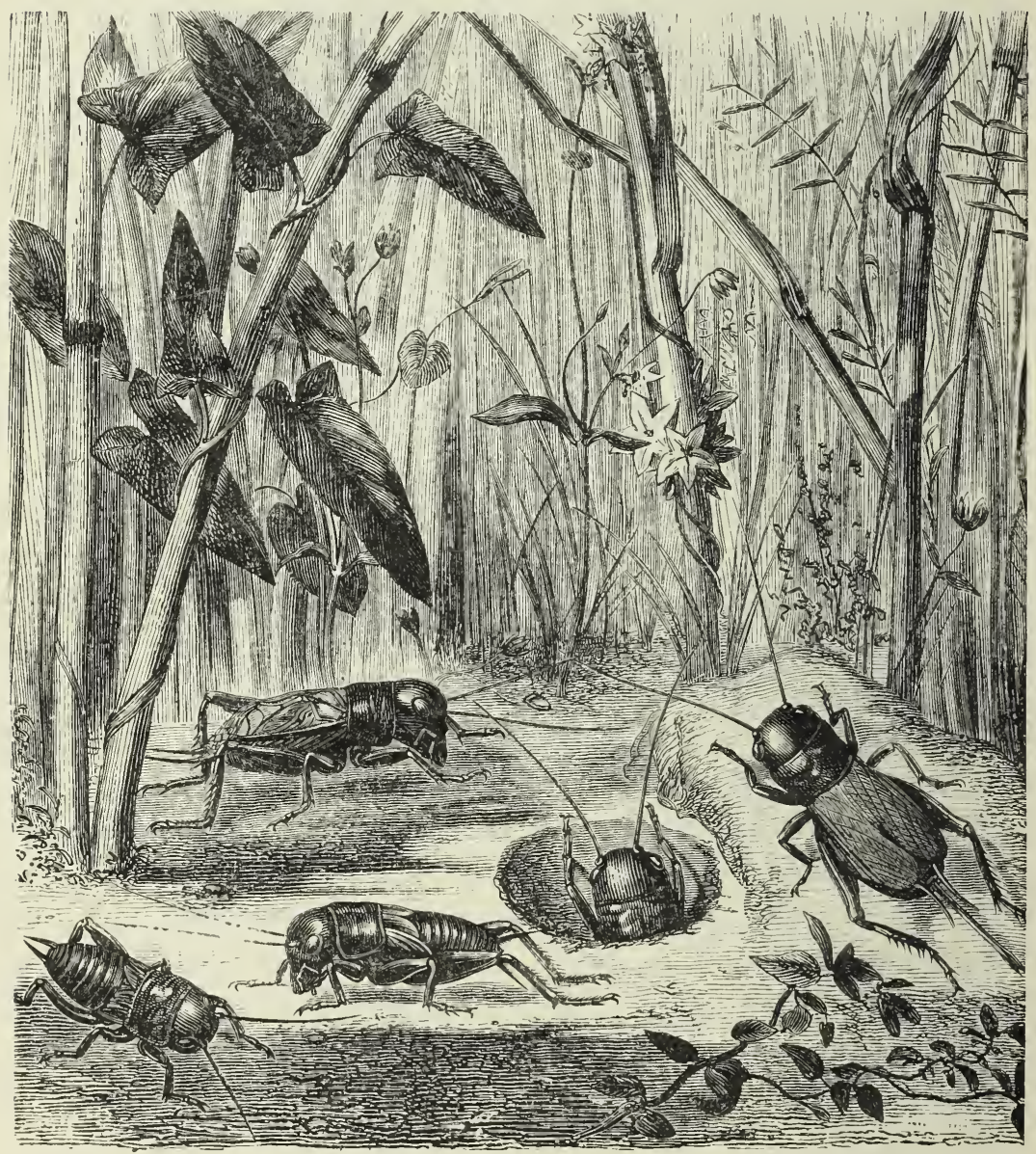

METAMIORPHOSIS OF THE FIEI.D CRICKET.

In the accompanying engraving the female of this green grasshopper is laying her eggs in a hole in the ground, and one is just escaping from the ovipositor. A male is flying about, and it will be observed that he has no ovipositor, but that he has very long front wings, with spaces in them just where they join the body, 


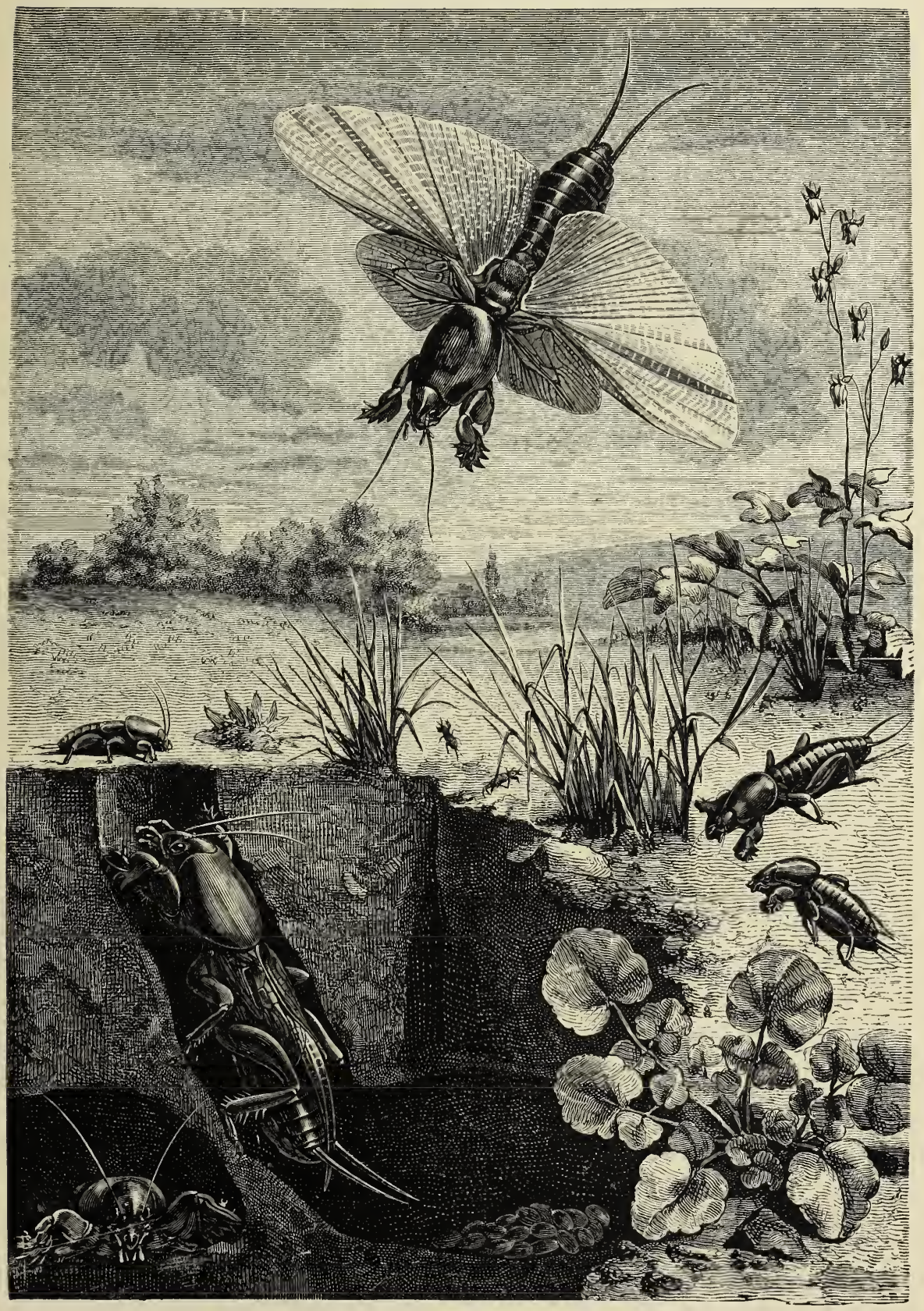

THE METAMORPHOSES OF THE MOLE CRICKET. (Gryllotalpa vulgaris.) 

for his musical apparatus. A male and female are on the ground, and have not yet completed their full growth.

Everybody knows and can recognise a cricket, but naturalists appear to have done their best to make ordinary mortals confound crickets with grasshoppers, and both with locusts. Thus the French call crickets Grillide, and the grasshoppers Locustes. The English call the grasshoppers Grillide and Achetide. There are Field Crickets, and House Crickets, and Mole Crickets, and they have great resemblances to the grasshoppers.

The crickets are nocturnal insects, whose colours are dark and of brown and grey tints, but the grasshoppers and locusts like the light. They have all long and slender antennæ, and legs adapted for jumping, and the elytra of the males have a large musical apparatus, and the females possess an elongated ovipositor.

There are two principal types in this family-the crickets whose front legs and feet are simple in their structure, and the mole crickets, which have flattened fore legs. The musical sound of the crickets has given them their name, and we hear it by night in the fields and in houses hour after hour. These insects live very solitary existences, except when they are disposed for that society which they suppose they can obtain by their everlasting chirp. Each one of them digs a hole, and does not leave it except during the night, and children in the fields, who know this, can often catch a field cricket by poking straws down cracks in the ground. The house cricket, which is of a yellow grey colour, and more or less marked with brown tints, is smaller than the other, and hides itself in holes and cracks in old walls and chimneys. It is a chilly insect, and it seeks its nourishment and delights to live in warm places. In towns it prefers bakeries and the neighbourhood, of ovens, and in the country the most humble kitchens are favoured by its merry chirp.

The engraving on the opposite page shows a cricket emerging from its hole, and a female on the bank above it; the imperfect insects are on the ground in front.

The mole crickets are large insects, and are wonderfully adapted for their particular method of life. They live under ground, and very rarely leave their holes. Their body is almost cylindrical, their feet are thick and short; their front legs, which are also 
short and wonderfully enlarged, and, as it were, fingered, enable them to grub in the earth very effectually. They are the true moles of the insect class, and they choose made soils, like those of gardens and vineyards, for their dwelling places. They make galleries, destroying everything which comes in their way, cutting through roots and eating the fine underground twigs as well as the worms and the grubs which they come across during their excavations. Some authors have asserted that the mole cricket is truly carnivorous, but this is a mistake. They will eat worms and insects which come in their way, but their nourishment is principally of a vegetable character; and it can be readily imagined that they are very destructive. Their excavations consist of vertical shafts more or less deep, and of long horizontal galleries which lead from them; the insect is, in fact, a regular miner, and the female lays its eggs in the remotest part of the mine.

In the accompanying engraving a mole cricket is seen coming out of its shaft, another is in a gallery, a male is flying, and the immature insects are crawling over the soil.

One tribe of the Orthoptera still remains to be noticed, and its members are the true locusts, and belong to the Acridide.

The Acridide have short and thick antennæ, but they have not the same kind of musical apparatus as the tribes already described, nor ovipositors; but if they have not this particular musical apparatus they are none the less good musicians-that is to say if the stridulous noise they make can be called music. They produce it in this manner: there are very prominent nervures on the elytra, and the thighs of the hind legs are furnished with ridges on their internal surface; the insect rubs the thigh sharply against the elytra, and produces on this natural fiddle a sharp vibrating sound. We may not admire it, but it is quite certain that the lady crickets do, and doubtless they constitute a very critical audience. The accompanying engraving exhibits the metamorphosis of the locust (Acridium percgrinum).

The locusts deposit their eggs in the earth, and close them up in a kind of tunnel, and the young ones are born without wings, which become developed as they grow older.

Some remarks on the metamorphoses of the Orthoptera will be found in the chapter on the Crustacca. 


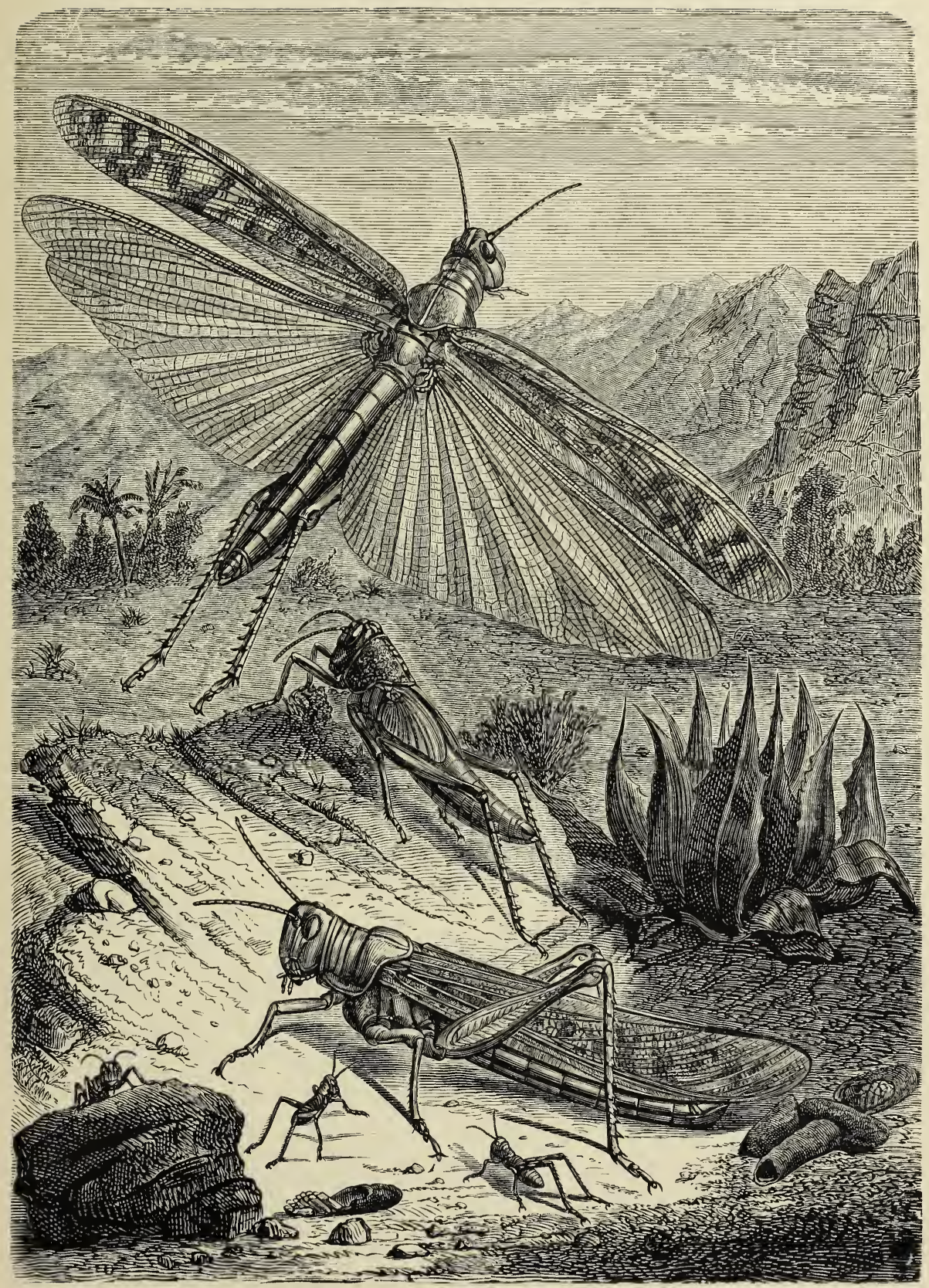

THE METAMORPHOSES OF Locusts. (Acridium peregrimum.) 



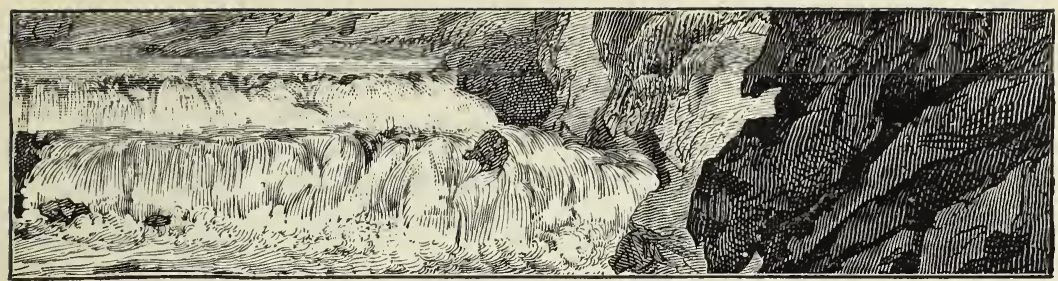

CHAPTER IX.

THE THYSA NOPTERA.

THE very small black flies which are such a source of annoyance to travellers in the summer-time, and which fly into our eyes and crawl over our faces during the prevalence of warm windy weather, principally belong to a kind of insect which is characterised by having very remarkable wings when in the adult condition. These insects exist by myriads, and there are several species of them;

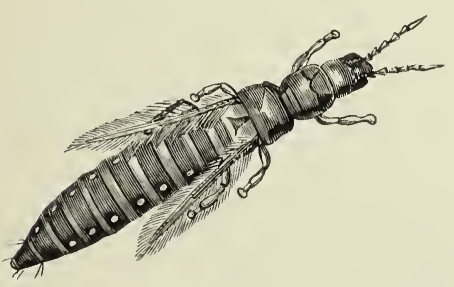

The adult insect.

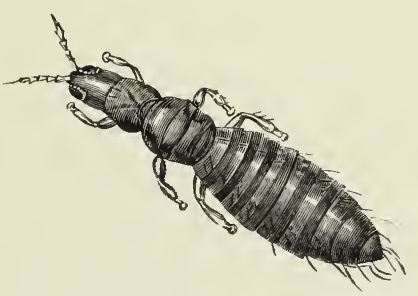

The larva.

(Magnified.)

THE INCOMPLETE METAMORPHOSIS OF Thrips cerealium.

and they are all exceedingly destructive to flowers, and especially to the bloom of cereal plants. The little black insects are to be seen on almost every flower, and they devour the delicate cellular tissue of the petals. Thrips cercalium is very destructive when it occurs in multitudes upon the wheat, barley, and oats, for it interferes with the proper nutrition of the grain, by nibbling the protecting envelopes and the tissue which connects it to the stalk.

All the members of the genus Thrips-and they alone con- 
stitute the order now under consideration-possess four very narrow membranous wings, without any folds or network upon them, but furnished and decorated with beautiful fringes upon the edges. These fringes characterise the order, which in other respects is closely allied to the Orthoptera, and they give the name

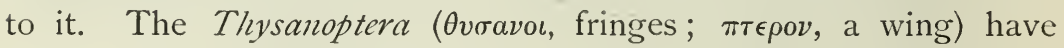
filiform antennæ and very large eyes, and the different species of the genus Thrips have a great diversity of wing fringing. The structure of the wings is somewhat analogous to that observed in the Lepidoptera, in the Pterophorina, and the Alucitina.

The metamorphoses of the Thysanoptera have not received much attention, but they are known to be of the incomplete kind. The quiet chrysalis condition is not observed, and the larvæ are born from the egg, greatly resembling the adults. The absence of wings is the great distinction between the larval and the imago state, as it is in the closely-allied order of the Orthoptera. The larva moults several times, and the wings are gradually added. the colour of the insect altering also.

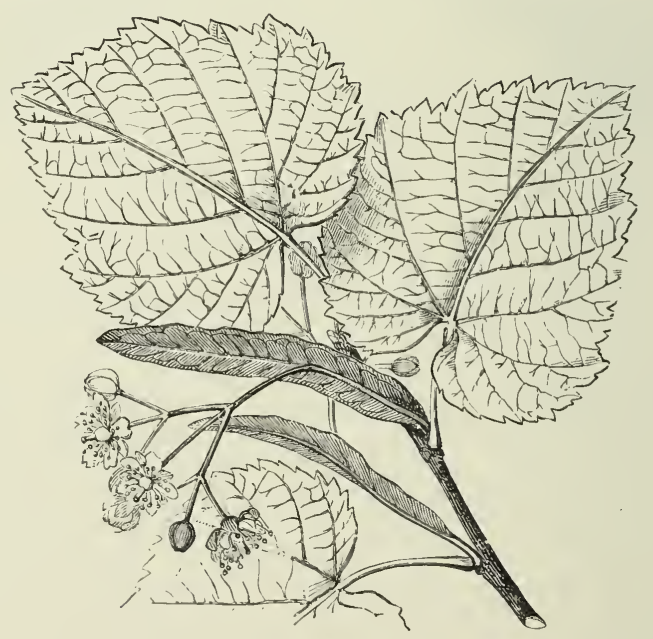




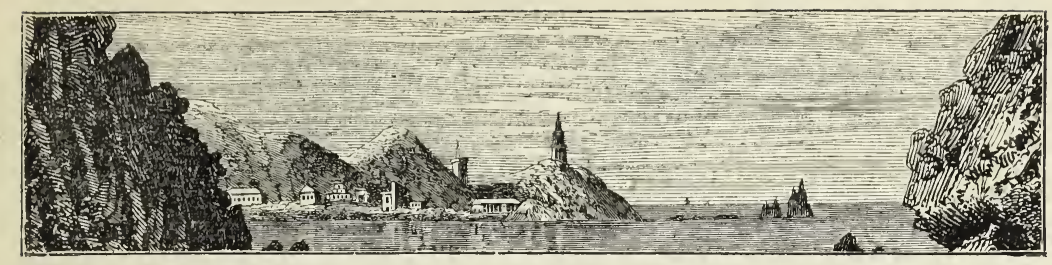

\section{CHAPTER $X$.}

THE NEUROPTERA.

ALL the varieties of metamorphosis may be observed amongst the Neuroptera. Some of these insects never have a period of inactivity, and do not undergo greater transformations than the Orthoptera. But others have to submit to two metamorphoses before they become perfect, and the transformations are as sharply defined as they are in the Lepidoptera. These last undergo complete, and those just mentioned pass through incomplete, metamorphoses.

Other Neuroptera remain in a condition of inaction for a very short time, and their nymphs lose their activity and undergo a rapid metamorphosis, as it were, at the very moment when the adult insects escape from the pupa case. It is very remarkable that such varied metamorphoses should occur amongst insects which have great structural affinities, and which belong to a very natural order.

The Neuroptera are known at once by their peculiar wings. They have four, which are membranous and naked-that is to say not covered with scales-and they are marked with membranous nervures so arranged as to look like net-work. They are insects whose wings are therefore much veined and reticulate, their legs are delicate, and their bodies are almost always long and slender. The jaws and the structures of the mouth concerned in feeding are separate, and do not form a sucking apparatus. There are many different forms amongst the Neuroptera, and some have exceptional structures. Thus there are Ncuroptera whose transparent wings have nervures placed across them, and there are 
others which have hairy wings without any cross-marking, and the nervures branch off. Now, there are many amongst the first kind which greatly resemble the Orthoptera. They unite, there-

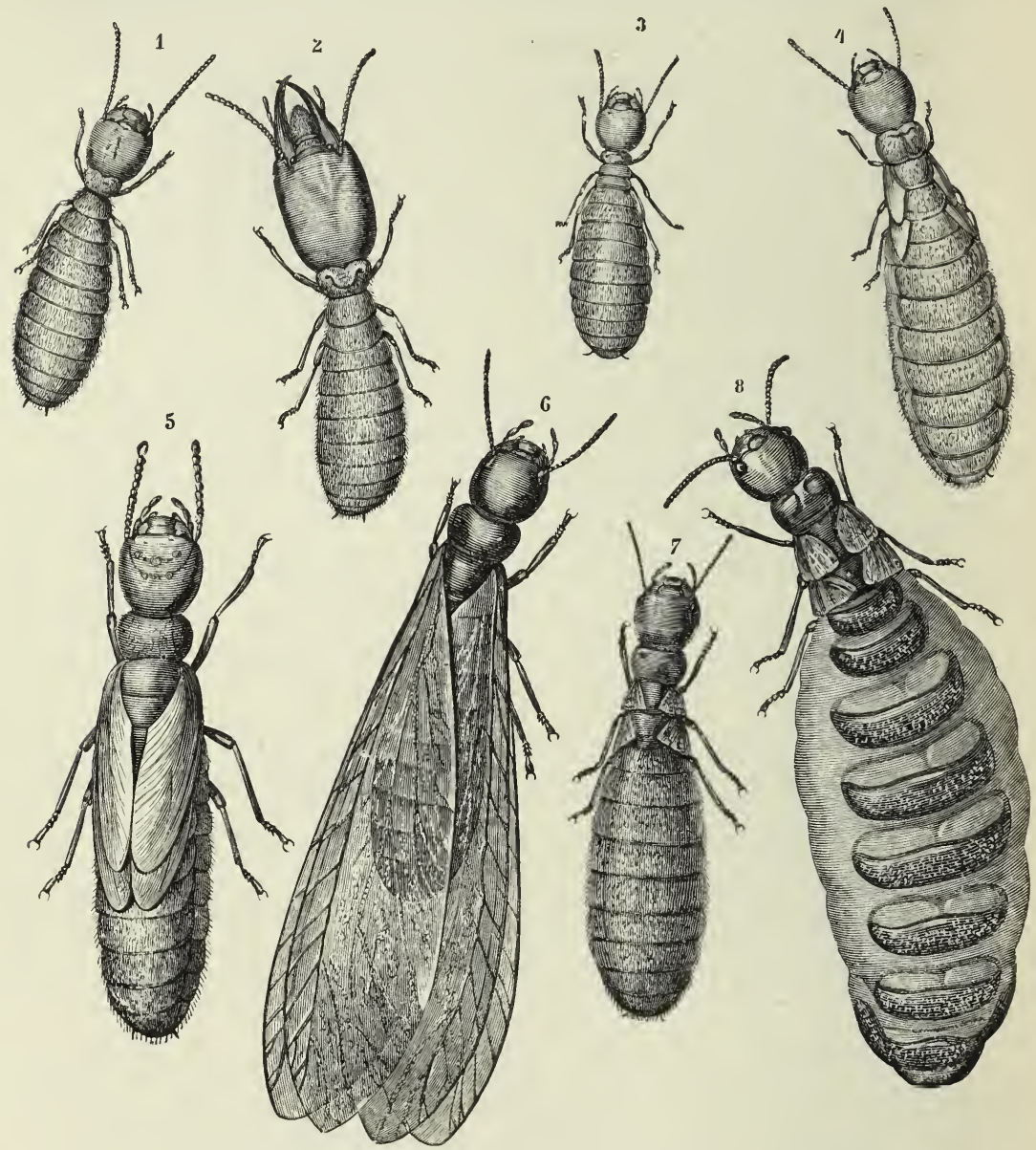

DIFFERENT INSECTS IN AN ANT-HILL. (Termes hucifugum.)

1. Workman. 2. Soldier. 3. Larva. 4. Nymph with small wings. 5. Nymph with long wings. 6. Male. 7. Little female. 8. Large female. (All magnified.)

fore, these two divisions of the insect world, and at the same time are more or less separable from the characteristic Neuroptera.

The Ncuroptera live in different manners. Some of them are very industrious, are fond of society, and build large homes, whilst 
others - and these are the most numerous - do not appear to possess either remarkable talents or instincts, but they are interesting, in consequence of their leading such very different lives in the larva and adult stages. One of the most interesting families -not only of this order but of the whole class of insects-is that of the White Ant, the Termitida. These insects are gregarious, and form numerous societies, in which may be found males and females, several kinds of neuters, and active larvæ and nymphs. They build very large dwellings, containing multitudes of chambers and galleries, and they always work in the dark. If they wish to move from one locality to another, they can construct first-rate tunnels; and their habits, especially those of construction, have caused them to be compared with the true ants; and they are well known in all tropical climates, where they commit frightful damage, as white ants. The males and females of Termes lucifugum have large wings, the cross or transverse nervures of which can hardly be seen, and they are rudimentary; their heads are large and strong, and there are three ocelli placed between the larger pair of eyes. The neuters, which never have wings, are of two kinds-first, the workers, with a round head and short mandibles, and second, the soldiers, with long heads and large and strong jaws.

M. Lespès has discovered that there exist in the dwellings of Termes lucifugum in France, besides the larvæ of the neuters and of the males and females, and besides the neuters, workmen, and soldiers, two sorts of nymphs, some very small, with rudiments of very short wings, and others larger, with longer wings ; and evenand this is a very inexplicable fact-two kinds of males and females, one small, and appearing in May, and the other, much larger, not being observable till the month of August. M. Lespès calls the first little kings and little queens; and the second, the great kings and great queens. When the eggs are about to be laid, ordinarily a single couple is found in the interior of the nest, and the individuals composing it have lost their wings, and indeed they always appear to fall off at this time. The bodies of the great females are often distended with eggs.

It is of course in hot climates that the Termites attain their greatest size and numbers. It is stated that a third of the flat 
country in Ceylon is undermined by them. In Western Africa they resemble the common or ants proper in their habits. Like them they are composed of three kinds of individuals, males, females, and neuters or workers. They erect dwellings in the form of pyramids or cones; and Termes bellicosus builds them up to a height of three or four yards, and flanks the edifices with little towers, and constructs them so solidly that several men may stand upon them without falling through. The neuters or soldiers, which are very large and have great jaws, are always ready to attack anybody molesting their habitations. Each house or community consists of a king and queen and labourers and the soldiers, and there are about a hundred of the labourers to each soldier. The military Tcrmes appear to be labourers in a further state

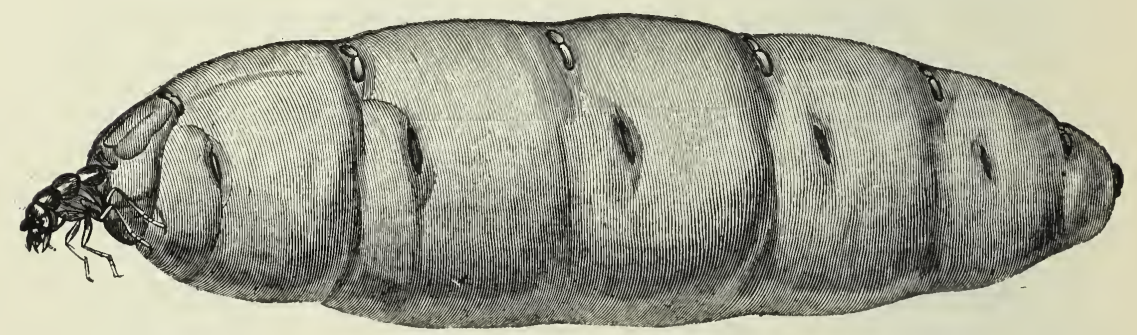

A FEMALE Termes FROM THE AFRICAN COAST.

of development. The males and females are possessed of wings, and at the proper time they issue forth from the nest in immense numbers and take their flight. They begin to emigrate at the commencement of the rainy season, and as their wings are not strong, and are only calculated to carry them for a few hours, the number that perish by the heavy rains is enormous. It is said that perhaps not more than one pair out of many thousands reach a place of safety. The fortunate pair which do succeed are generally found by some of the labouring insects - which are continually running over the surface of the ground in the neighbourhood of their covered galleries-and are immediately elected king and queen of a new colony. The queen lays about sixty eggs in a minute, or 80,000 or upwards in the course of twentyfour hours, and they are instantly taken away by the others 
and carried to a. part of the ant hill, where they are hatched and the larvæ are attended to and nursed until they are able to shift for themselves. The engraving on the opposite page shows a fullsized queen. The metamorphosis is very incomplete, and the larvæ resemble the adults except in not having full-grown wings, but there are other arrests of development, and the limitation of the power of reproduction is very definite. The pupæ hardly differ from the larvæ and the adult forms.

There are some small Neuroptera which resemble the Termes somewhat, but their habits are comparatively uninteresting. They are the Psocida. They have wings which are slightly veined, large heads, with three ocelli on the forehead, setiform antennæ, and very slender legs. These insects are found on mosses and upon the trunks of trees and old walls, and a very small species inhabits houses, and is particularly fond of crawling amongst old and damp papers. The wings of the females never become developed, and they therefore remain, as it were, in a larval condition. It looks something like a little louse, and as it is said to make a noise by clashing its jaws together, it has been called Psocus pulsatorius.

The Perlide are very distinct as a family. They are moderately-sized Neuroptera, with large hind wings, which are folded near their attachment. They have setiform or thread-shaped antennæ and well-developed jaws. Moreover, they present manifest resemblances to the Orthoptera, as do the Termites and the Psocida. Pictet of Geneva has paid great attention to the European species of this family. The Perlide undergo incomplete metamorphoses. The larvæ are aquatic, carnivorous, active, and are often provided with external respiratory organs or gills, which consist of small tufts of filaments that are attached to the lower part of the segments of the thorax. The nymphs or pupæ, which are always active, differ from the larvæ in having the rudiments of wings.

When the nymphs have attained their full size they leave the water and settle upon the stones or plants on the bank; their skin soon dries and splits along the back, and then the adult or perfect insect scrambles out and takes to flight. The larvæ appear to prefer running streams, and they pass the winter at 
the bottom of the water, and shed their skins several times, and undergo their first metamorphosis during the spring. The fly does not make much use of its wings during the day, but is lively in the evening, and the females carry their bag of eggs suspended to their bodies. Some of the species are found in high northern latitudes, and appear over the snow at the very first approach of spring. Perla marginata, whose aquatic and perfect conditions are shown in the accompanying engraving, has two long articu-

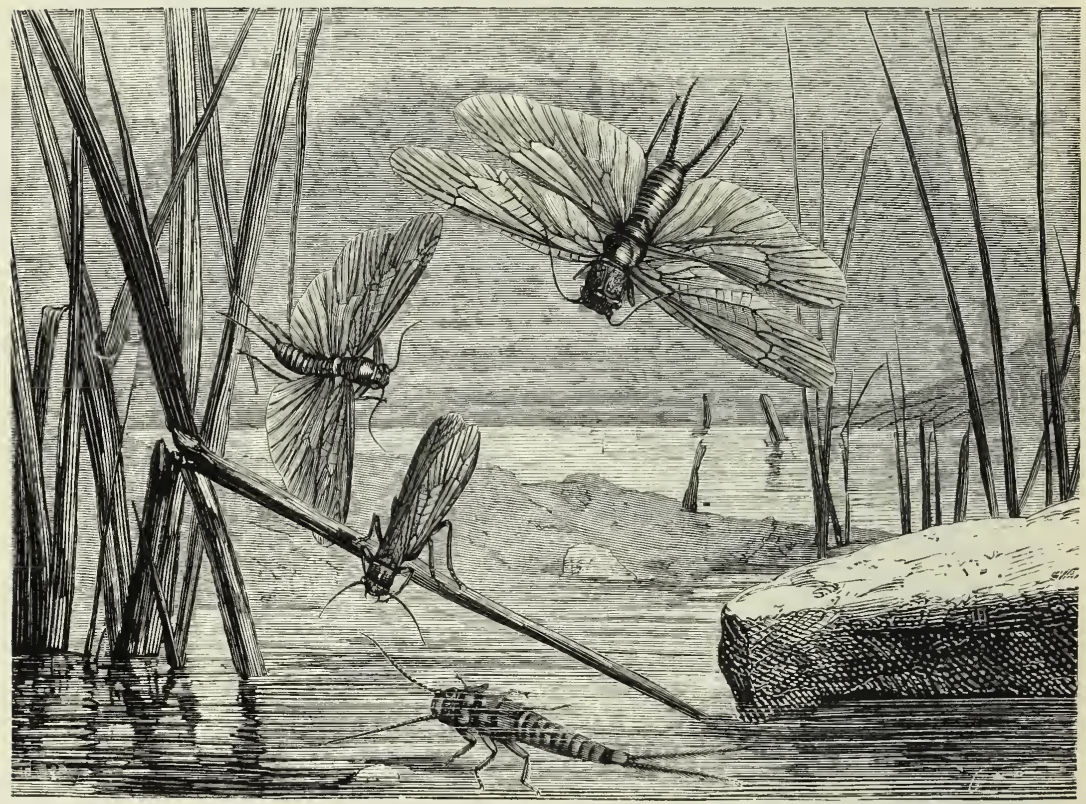

THE METAMORPHOSES OF Perla marginata.

lated processes, something like those of the earwig. It is a common insect, and its larva, which is of a yellow citron colour spotted with black, is found in running streams and swiftlyflowing brooks. A closely allied species, the Nomoura, lives exactly in the same way as the Perla, but they are smaller insects. When young they have curious processes sticking out from the body, like those of the Perla, but they disappear in the perfect insect. The wings are always perfectly developed in the females, but they are short and rudimentary in the males 
This is curious enough, for it is not often that the degraded condition so commonly observable in the wings of female insects is to be found in the males, and it is very interesting that such closely-allied insects should have such remarkable differences of structure.

The Ephemeride exist in enormous numbers, and last for the shortest time imaginable in their perfect state. They are the lightest, the most fragile, and the most delicate creatures in the world. They float away in the air from off the water, in which they have lived during the early stages of their existence, flutter in the sunshine, dance about with every breeze, and they grow faint as the sun gets low, and sink and die with the night. They are truly ephemeral beings. They can be easily distinguished. They have very short antennæ, ending with an extremely delicate silk-like thread; their wings are very fine, the front ones are the largest, the hind ones being very small; the body is terminated by two or three long-jointed bristles; the structures of the mouth are soft, and cannot receive food, and indeed the perfect insects, living as they do only a few hours, never think of wasting their lives in cating and drinking. They all exist for love, and they spend their short day in a constant and active courtship. The eggs are laid in little packets upon the water. As soon as the larvæ escape from the egg they take to the water, and grow more or less rapidly, according to the species. These larva are essentially aquatic insects, and are organised so that they can respire in water, for there are gills, or delicate folds of skin, which are traversed by numerous trachex fixed on to their bodies. The larvx of all the species of the genus Ephomera are very similar, and they are believed to live two or three years before they begin their transformations. They reside beneath stones or in burrows at the bottom of running streams, and they undergo an incomplete metamorphosis. They have very strong jaws covered with spines, and mandibles with sharp points to them. They begin to be nymphs when the rudiments of wings appear. When the nymph is full grown, it crawls out of the water on to plants or stones, and its skin cracks down the back and the adult emerges from it into the air. But this perfect insect is covered over and entirely enclosed in a 
beautiful and most delicate membrane, which it has to escape from before it takes to flight. When thus enclosed it is called the pseud-imago, in contradistinction to the imago or the perfect insect.

The engraving represents the metamorphoses of the May fly. In the water, amongst the weeds, there are larvæ and a large nymph, on a leaf at the side one is escaping from its covering, and the perfect insects are flying over the lake.

The European Ephemeride have been carefully studied by
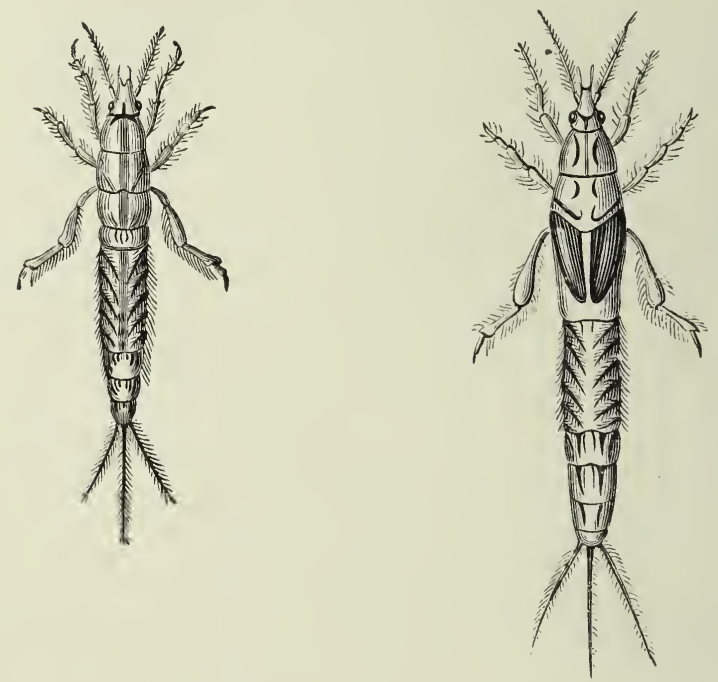

LARVA ANI PUPA OF AN Ephemera.

Pictet, and the kinds which can properly be united together, on account of their having numerous transverse nervures on their wings, and their abdomens being terminated by three bristleshaped hairs, are called Ephemera. The commonest are the May flies, which appear in early summer in such enormous quantities. The adults have a short life, which only lasts a few hours; they never take any nourishment; and their beautiful wings, which are exquisitely made, and delicately marked with brown spots, appear almost to be wasted, so short is their time of flight. Their larva and nymphs, like those of the species which are allied to them, are long and cylindrical, and have projecting jaws and 


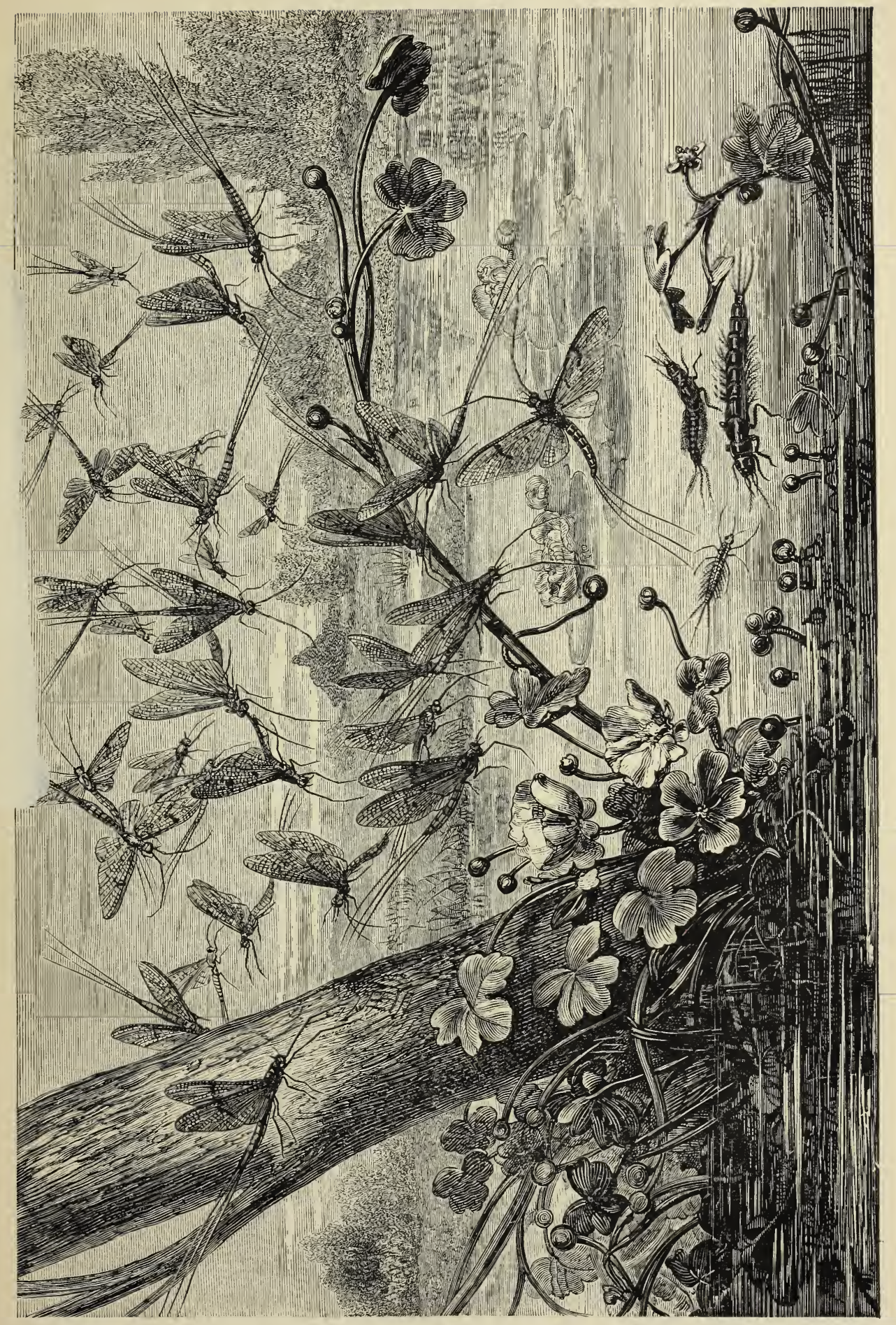



large claws, which enable them to dig in the mud at the bottom of the streams, where they make galleries, into which they retire out of the way of danger. They breathe with. their gills or branchiæ situated on the abdomen, and which are narrow, finely divided, and covered with delicate hairs. The nymph is quite as active as the larva.

The insects which are united in the genus Cloe have very pretty larvæ, which are slender, excessively delicate, almost transparent, and provided with leaf-shaped branchiæ, which they vibrate incessantly and with great rapidity. They have tiny legs, and are provided with broad fringes to the body, which act as oars.

These little larvæ, so exquisitely elegant, live in the open water, swim with ease, and catch their prey and elude their enemies by the rapidity of their movements. When in the adult state they have their wings veined, and are furnished with only two bristle-shaped projections on the abdomen. The males have very extraordinary eyes, and each appears to be surmounted by a second, so that this insect with double eyes, transparent wings, and a fawn-coloured thorax, is called Cloe bioculata.

The most important family of the order of the Ncuroptcra is that of the Libcllulida, and its members present the characteristics of the group in the highest degree. They are those insects which are constantly flying during the summer by the river side and over ponds and lakes, and which in England are called Dragon Flies; but which, on account of their gauzy wings, brilliant colours, their thin and exquisite shapes, and their elegant motions, are named Demoiselles by the French. This difference in the names is very significant of the national thought. In England we appreciate people for their intrinsic merits; but in France it is too common to be guided by externals. With all their admiration for the beauty of the fair sex, no Frenchman would compare these beautiful and aërial insects with the ladies, if their habits were known; for under this fine exterior there exists a terrible amount of destructive will and power; and they are, perhaps, the most bloodthirsty things in creation. We have not been misguided, for we know that from their very birth, and in every stage of their development, they are worthy of the name of dragon flies. The wings of these insects are nearly equal in 
length, and they are beautifully reticulated by interlacing nervures; they have a large head and great eyes, and small antennæ. They have a quick sight, and fly with great rapidity, backwards, forwards, sideways, upwards, and downwards, and without turning; their mouth is strengthened to the utmost; their jaws are strong, and end in sharp points. The mandibles are provided with keen teeth, and the lower lip is very large, and its palps are short and thick. Thus armed, they chase and pull down every fly, moth, or butterfly which they come across. They rend these delicate creatures, and eat them; but frequently they appear to kill for killing's sake. These Neuroptera, especially the males, have a curious pincer at the extremity of the body. The lady dragon flies are as sanguinary as the males, from whom they do not appear to receive the most polite treatment; and the courtship is a scene of general bad behaviour and violence. They all undergo incomplete metamorphoses. The eggs are laid upon the water, and the larvæ take very kindly to that element. As the larvæ grow their body becomes larger, their head flatter, and their eyes wider apart than those of the perfect insect. They are not less bloodthirsty than the adults, but they are very slow in their movements, and they do not appear to have the instinct to hide themselves in order to catch their prey. Nevertheless, they have no difficulty in seizing very active insects which come swimming along, for the larvæ and nymphs have a most remarkable weapon in their lower lip. The lip is very long, and has palps formed in the shape of pincers. It is attached to the chin, which is also very long, by a sort of hinge, which allows it to rest against the under part of the body when the insect is quiet. Suppose the larva is looking out for prey; it remains perfectly quict until some small insect passes by at what might be considered a safe distance, but the victim has not calculated upon the hidden weapon which is suddenly straightened and poked forward and which clasps the unfortunate with its pincers. The larvæ and the nymphs, althougin they live under water and must respire, have no branchix or any external organs by which they can breathe. Their method of respiration is unique; they breathe with their intestines. The large intestine is covered with numerous trachea, and when the animal wishes to breathe it opens the orifice of 


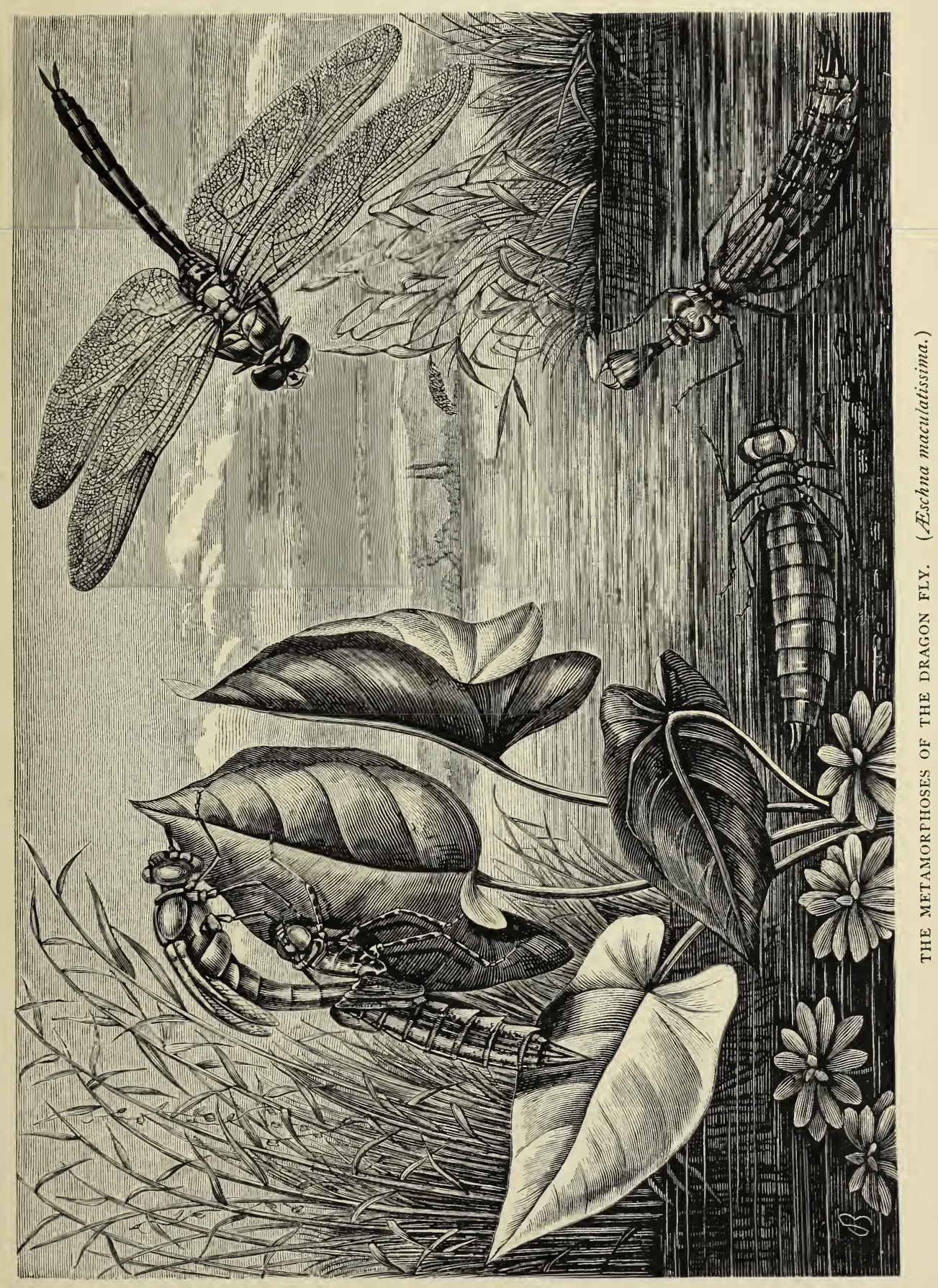



the intestine and admits a quantity of water. This, of course, contains air mechanically suspended, which is taken up the trachex just mentioned. Curiously enough, these insects, which walk very slowly, manage to get out of the way of enemies by expelling the water in their intestine with considerable violence, and this projects them to some distance.

When about to undergo its transformation the nymph leaves the water and crawls upon plants by the side. Then the skin dries, splits, and sets the perfect insect free. The larve live

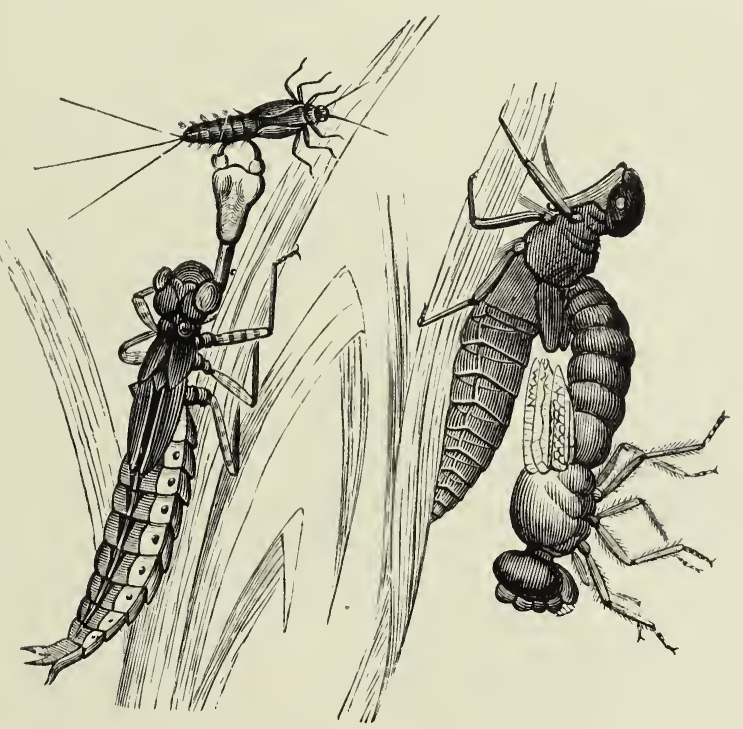

NYMPH OF THE Libellula AND THE PERFECT INSECT EMERGING.

about a year before acquiring their full growth, and the nymph is very active, and has the rudiments of wings.

The Asclunite have a rounded and robust body, and three articulations to their lip. Some have enormous eyes, set close together, so that they nearly touch each other in the middle line, and others have their eyes set wide apart.

The engraving shows the metamorphosis of Eschna maculatissima. On the right one of them is flying; immediately below, in the water, a nymph may be seen projecting her long under lip with its pincers; by its side is a larva in a quiet condition, 
and above it, on the leaves, a perfect insect may be seen crawling out of the skin of the nymph preparatory to taking flight.

The Agrionida have slender bodies, and the abdomen is cylindrical, and in the shape of a rod. They are usually very small dragon flies, and there is a very common one whose males are of a beautiful blue metallic colour, with a greenish-blue band on the wings, and whose females are of a most brilliant green colour.

When we compare some of the members of the family of the

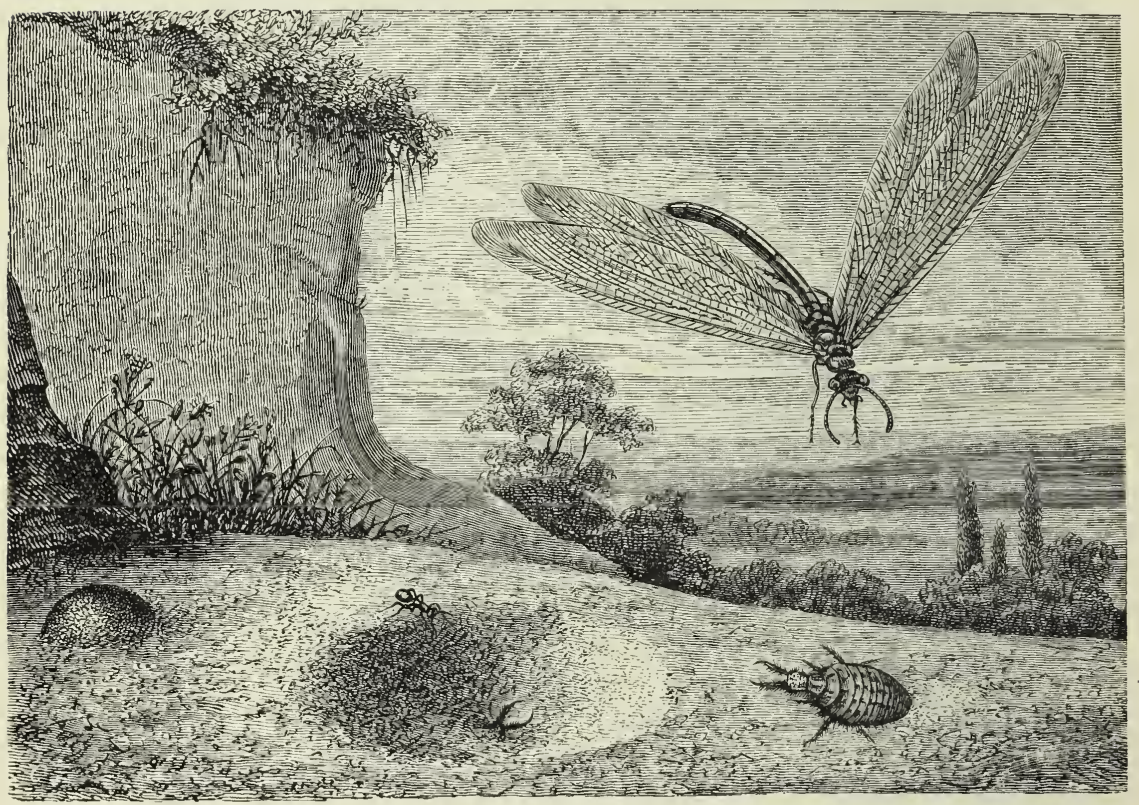

METAMORPHOSES OF THE COMMON ANT LION. (Myrmeleon formicarium.)

Myrmclconide, or Ant Lions, with the dragon flies, there does not appear to be much difference between them, and there are really very close affinities between the two families, so far as their adults or perfect insects are concerned. But there are very considerable distinctions to be noticed in the nature of the metamorphosis and the habits of the larvæ. The Myrmalconide live on dry land in their early conditions of life. They undergo complete metamorphoses, and their larva, which are short, squat, and always carnivorous, are not in the least like the perfect insects. 
Moreover, they usually construct a cocoon when they have attained their full growth, and are transformed into quiet and inactive nymphs. The perfect insects have their wings less reticulate than the dragon flies, their eyes are smaller, and the antennæ have many articulations. The mandibles are sharp, and the jaws and lip, which are rather narrowed, have long palps upon them. There are two divisions in the family.

The ant lions which form the genus Myrmeleon have very remarkable habits in the larval condition.

In some sandy places on little hills which have a sunny aspect it is not uncommon to notice small cavities which have a funnel shape. They are made by the larvæ of the ant lion, which are insects of a greyish-red colour having on their sides little collections of black hairs; the front and middle sets of legs project forwards, and the hind ones, which are stronger and not so movable, are kept backwards against the body. These larvæ can only walk backwards. In burying themselves in the sand they turn round and round, and throw the grains out from the funnelshaped hole they make by their twistings, using their large and flat heads like a shovel. The sand as it is thrown over the sides of the hole forms a margin to it, and when all is completed, the ant lion sinks itself at the bottom of the trap in the sand, and only shows its long mandibles. The spot which it chooses for its dangerous dwelling is usually in the neighbourhood of the dwellings of ants and other insects. The unfortunate ant which happens to tread on the margin of the hole sets some sand off rolling, and it immediately begins to struggle against falling down, but the larva of the ant lion throws some sand upon it, and it soon comes tumbling down to the bottom of the funnel. The ant is immediately seized between the sharp mandibles of the ant lion, which are perforated by tubes, and which allow the bloodthirsty insect to suck the juices of its prey. This perforation of the mandibles is one of the remarkable peculiarities of the organisation of these insects. When the larva becomes fully grown it winds a silken cocoon from a silk gland which, unlike those of the Lepidoptera, is situated at the extremity of the body; there is not much silk to spare, so a quantity of sand is glued into its walls. The larva lives for about two years, and the 
chrysalis becomes transformed into the perfect insect in about three weeks. The adults are of a dark grey colour, with yellow spots, and they have large transparent wings, which are orna-

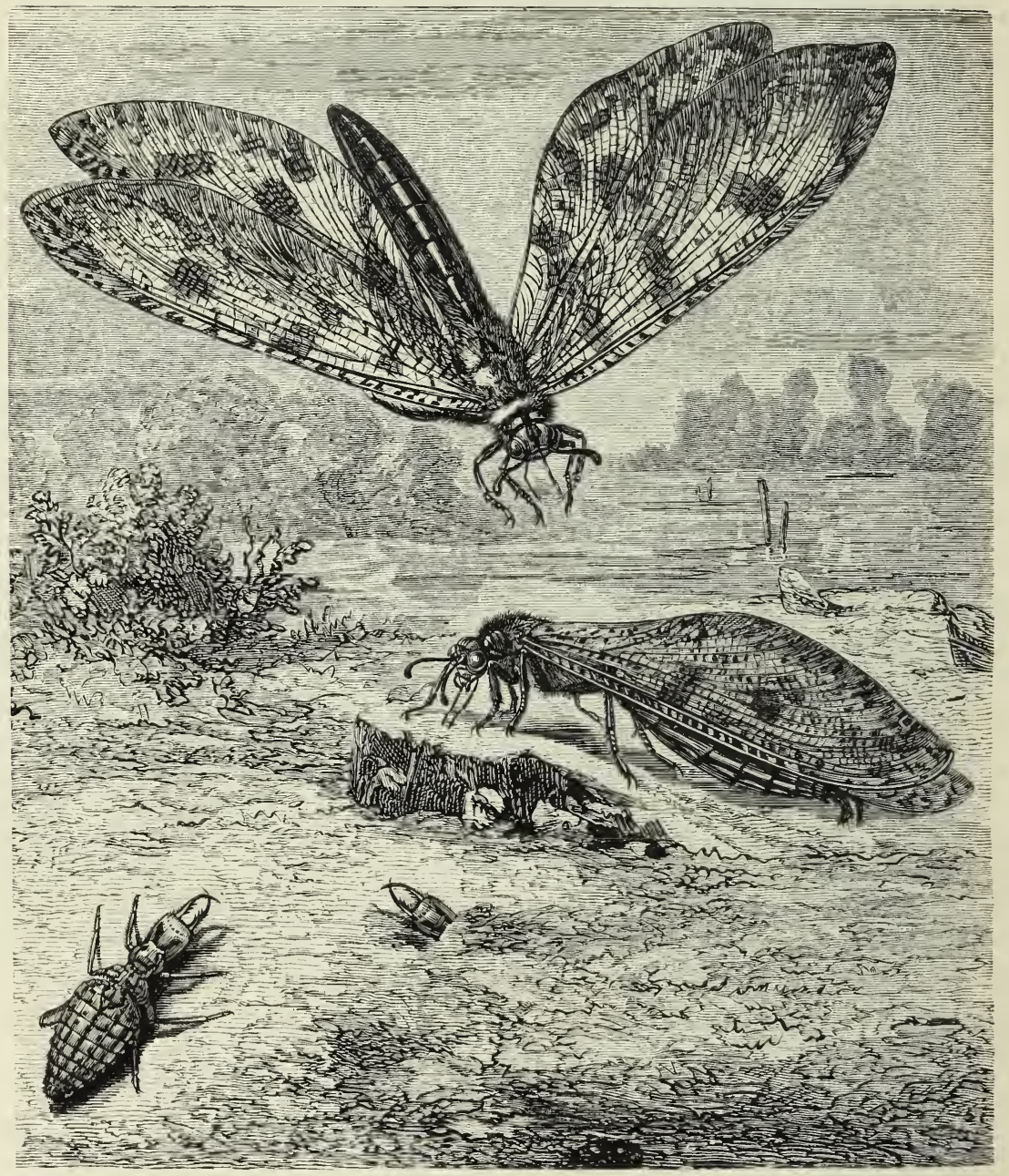

THE MÉTAMORPHOSIS OF THE DRAGON FLY ANT LION. (Palfares libelluloides.)

mented with little black marks. In the tropical regions of the globe there are large ant lions, whose great wings are spotted with brown and black, belonging to the genus Palparcs. One of these is also found in Provence, and is called the Dragon Fly Ant 
Lion (Palpares libclluloides), and it is represented in the engraving on the opposite page. One perfect insect is about to come to the ground, a second is on the ground and is looking at a larva which

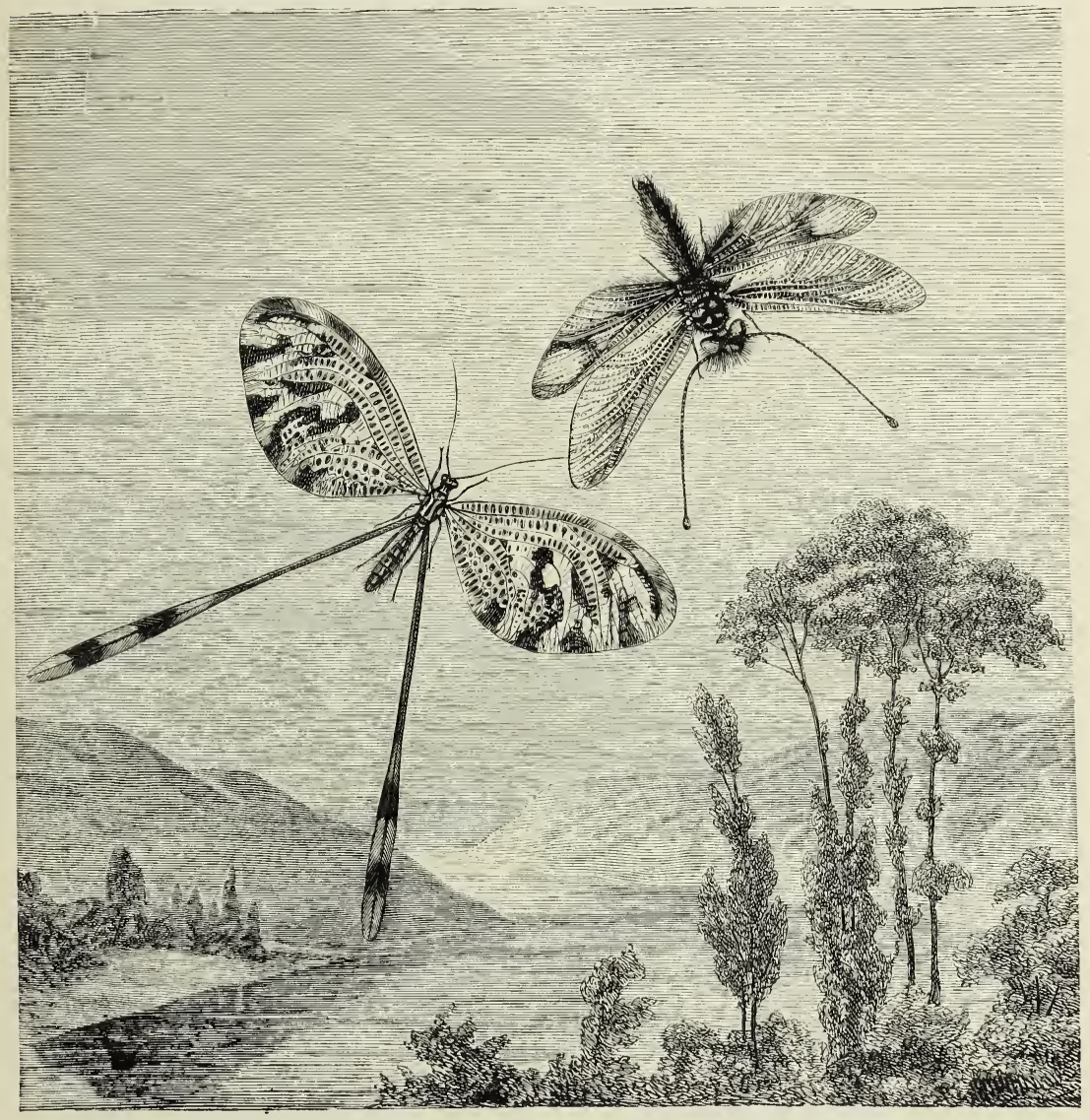

Nemoptera cua AND Ascalaphus longicomis.

is nearly completely hidden in the sand, whilst another larva is upon the sand.

It is very remarkable that the larva of this kind should not, like the others, make a funnel-shaped trap in the sand, and that it should simply bury itself anyhow, leaving, however, its mandibles in the open air.

There is a little group of Neuroptera belonging to the tribe 
of which the ant lions are characteristic forms; they constitute the genus Ascalaphus, aad they are very pretty insects, which are not unlike some of the Lepidoptera. They have long antennæ, which terminate in a large club-shaped end, like those of the genus Argynnis; their wings are very prettily tinted, and are usually of a bright yellow colour, with black markings. Many of them are to be found in Southern Europe, and their larvæ, whose habits are unknown, resembie those of the ant lions. In the engraving on page $36 \mathrm{I}$ one of these perfect insects is represented on the right hand of the picture, above the trees.

The Nemopterce are remarkable for the great beauty of their forms. They inhabit the shores of the Mediterranean, but unfortunately very little is known about them. A perfect insect of Ncmoptera coa is represented in the engraving on page $36 \mathrm{I}$, and its silken antennæ are very fine and thread-like, whilst the hind wings are very long, slender, and oar-shaped. The front wings are broad and large, and are of a yellow sulphury colour, spotted and figured with black. It is one of the prettiest of insects.

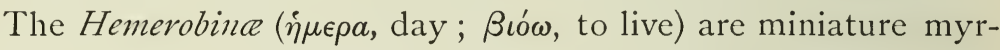
meleons, and have long and slender antennæ, and large and wellveined wings. We may often notice these beautiful flies upon rose and elder trees, and they can be recognised easily, on account of their small heads being furnished with prominent, rounded, brilliant eyes, which look like polished gold. The body of the fly is of a delicate green colour, and the large wings, so beautifully reticulated, reflect all the colours of the rainbow.

These pretty insects are sluggish in their motions, and prefer to fly by twilight. They lay their eggs upon plants, attaching them by a long and narrow foot-stalk, which gives them the look of a fungus. The larvæ, more slender than those of the ant lions, and destined to crawl and run over leaves and twigs, have a peculiar structure on the foot to enable them to do this safely. They live a life of constant warfare against the Aplides, or plant lice, killing and eating them day after day, so that they are called Aphis Lions. When they have attained their full growth they spin a small cocoon of pure silk, and are transformed into pupx. They live in this condition for fifteen days, and then the perfect insect flies. These pretty Ncuroptera have 
a most disgusting scent, as any one that handles them will soon discover.

The Scorpion Flies, Panorpa communis, are common in some

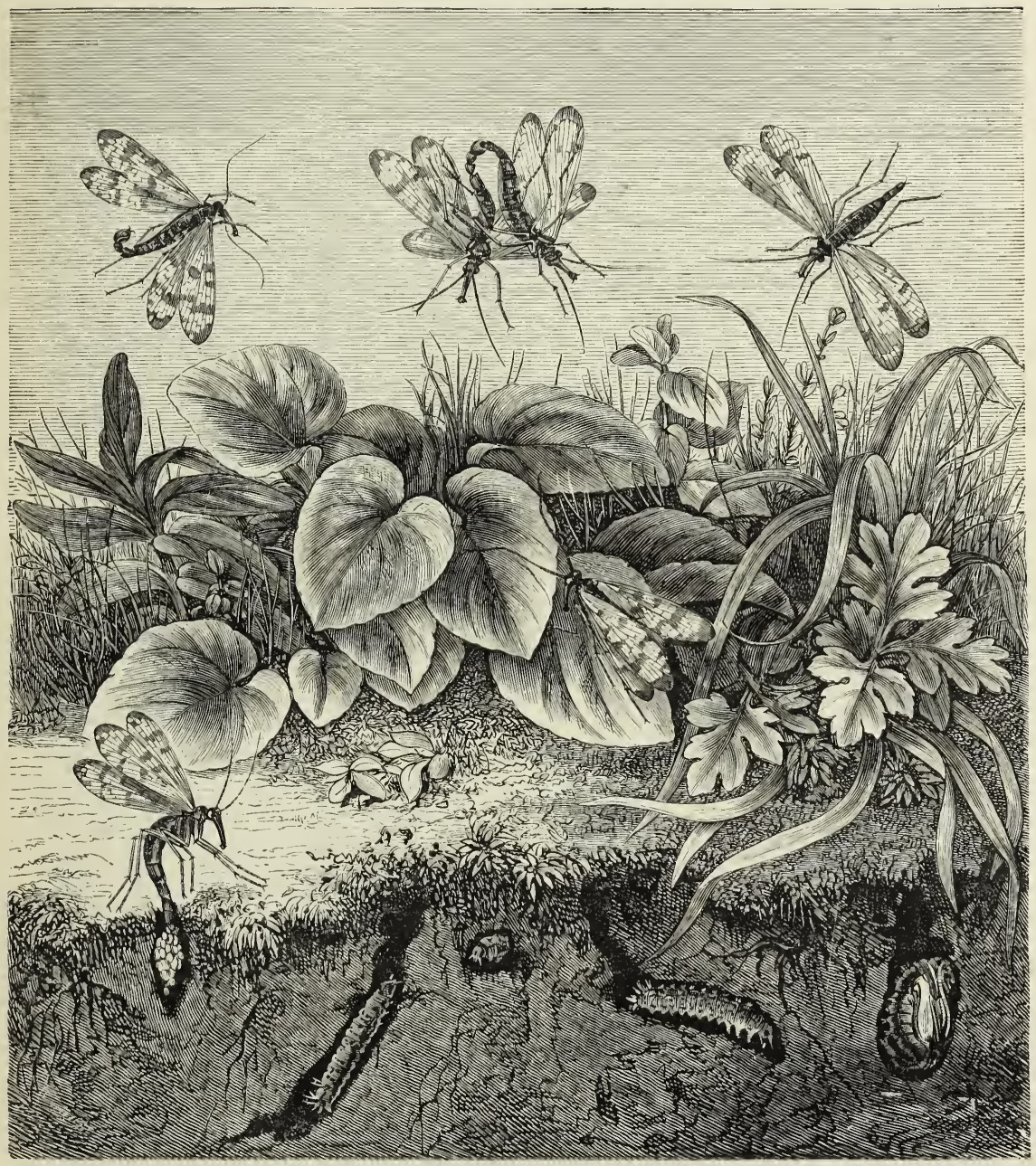

THE METAMORPhoses of Panorpa communis.

parts of Europe, in damp places. The adults have a curiously long muzzle, and rather small wings, which are transparent, and spotted with brown colours; the males have the same sort of body-pincers as the dragon flies, and the females have a longish 
egg tube or ovipositor, which she pokes into the moist ground, and then lays her eggs.

The larvæ are almost cylindrical in shape, and have small

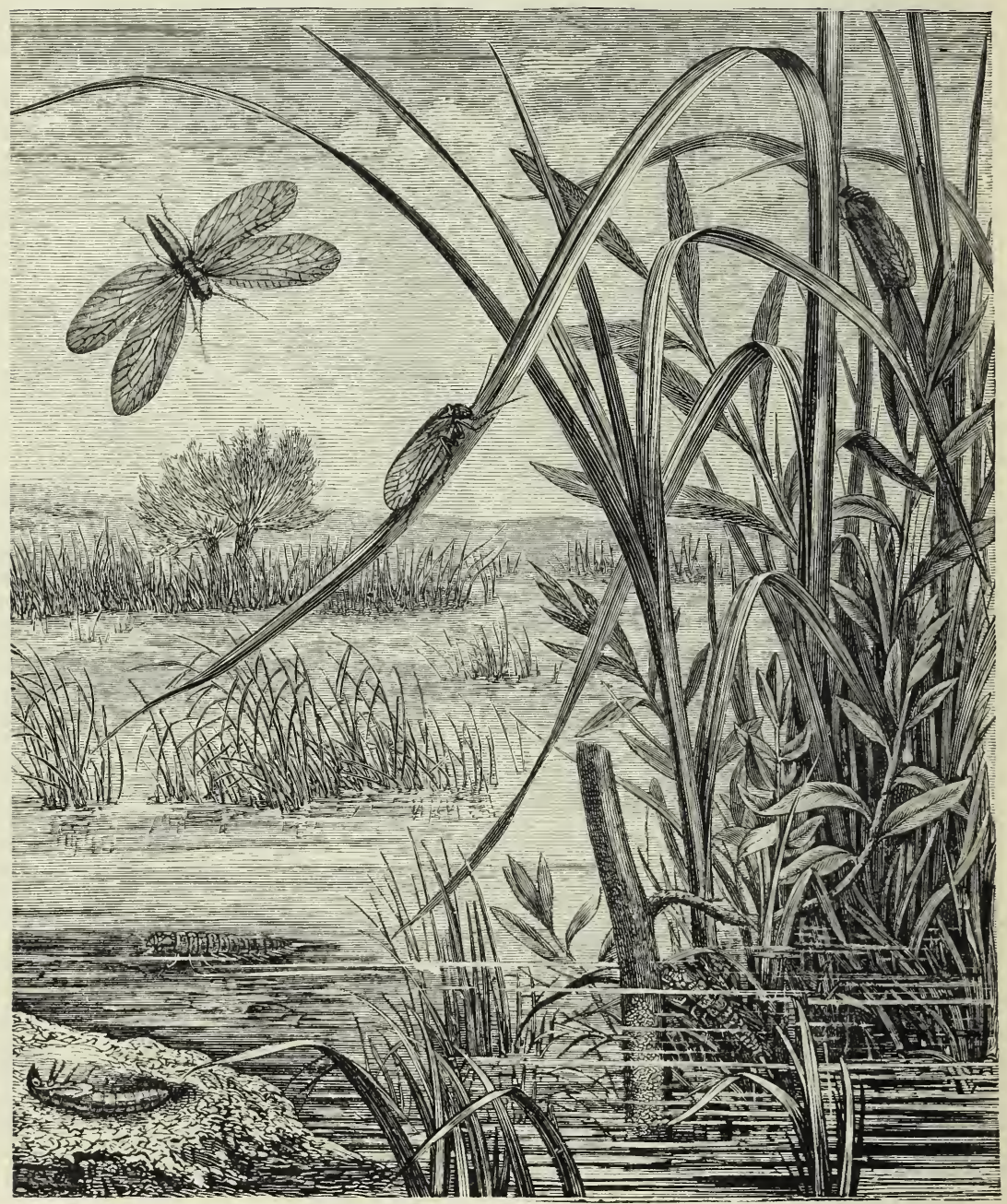

THE METAMORPHOSES OF Semblis lutaria.

fore legs, and little tubercles which act as hind legs; they are of a grey red colour, and have a few hairs. They live at a depth of a few lines, or an inch, in moist ground, and make tunnels 
and galleries amongst the decaying vegetation upon which they feed. They undergo complete metamorphoses, and the nymph remains in one of the underground passages. The engraving represents a female imago of Panorpa communis laying her eggs in a hole she has made with her ovipositor. The perfect insects are flying over head, and the larvæ and a nymph are in their galleries.

There are some other Nouroptrex that undergo complete metamorphoses-the Semblida. The perfect insects of the genus Semblis have wings with only a few transverse nervures; their prothorax is rather long, and their antennæ are thread-like. The wings are of a dusky colour, and the mandibles are very short. The perfect insect may often be seen on the borders of ponds and marshes, and it lays its eggs on the tissues of plants. The larva go down into the water, and spend their time in chasing other water insects, or in hiding up in the mud. They have respiratory membranes joined on to the sides of the body in the form of gills.

When the larvæ have attained their full growth they proceed to act differently to those of the other Neuroptera, for they come out of the water when their time for metamorphosis is at hand, and make a hole in the damp earth, within which they are transformed into nymphs.

The last division of the Neuroptera is often separated from the others in a distinct family, for its genera have their wings very peculiarly marked and constructed. The Caddis Flies, or Phrysanide, undergo complete metamorphoses, and present some resemblance to the Lepidoptcra. Their wings have no cross reticulations, and are peculiarised by the presence of small hairs, which are stuck on after the manner of the scales in the butter fly's wing. The mouth is useless, and its structures are soft and impervious. The antenne are thick, long, and pointed. The caddis flies are numerous in species in temperate climates, and they are usually greyish-brown or yellowish in colour. The adults fly in the evening in the marshes and by the side of rivers, streams, and brooks. The females deposit their eggs in the water, and envelop them in a glutinous mass, so that the bunches stick to stones or aquatic plants. 
The caddis flies, or rather the caddis worms, are particularly interesting in their aquatic condition. They are then very carnivorous, but have soft skins; consequently they form tubes and

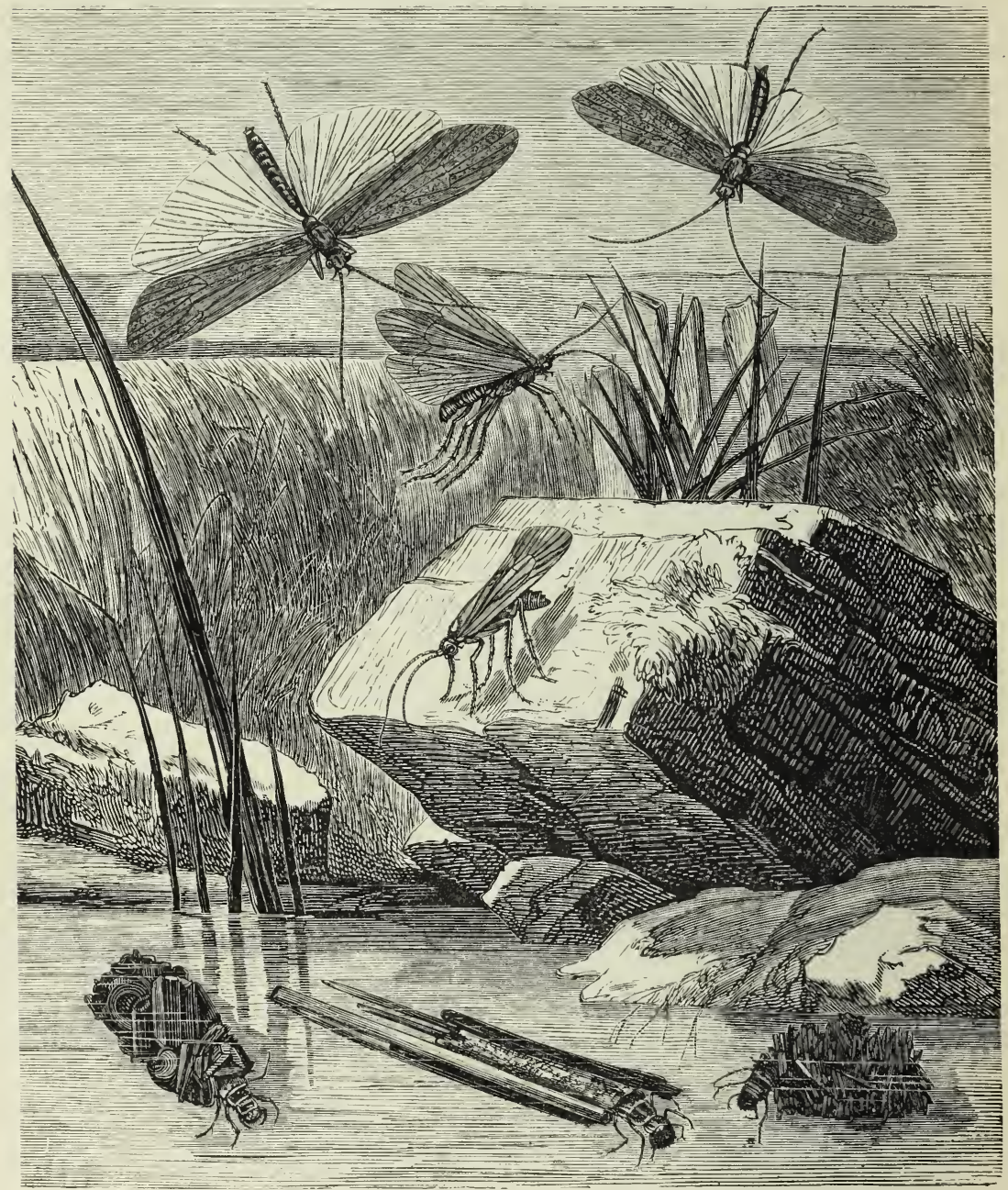

THE METAMORPHOSES OF THE CADIIS FLIES.

(Phryganea flavicornis, Phryganea rhombica, and Phrysanea fusca.)

cases out of all kinds of objects, and stick them together with a little silk, like some caterpillars, the Psyclicle, for instance. They carry their houses, for such are their tubes, about with 


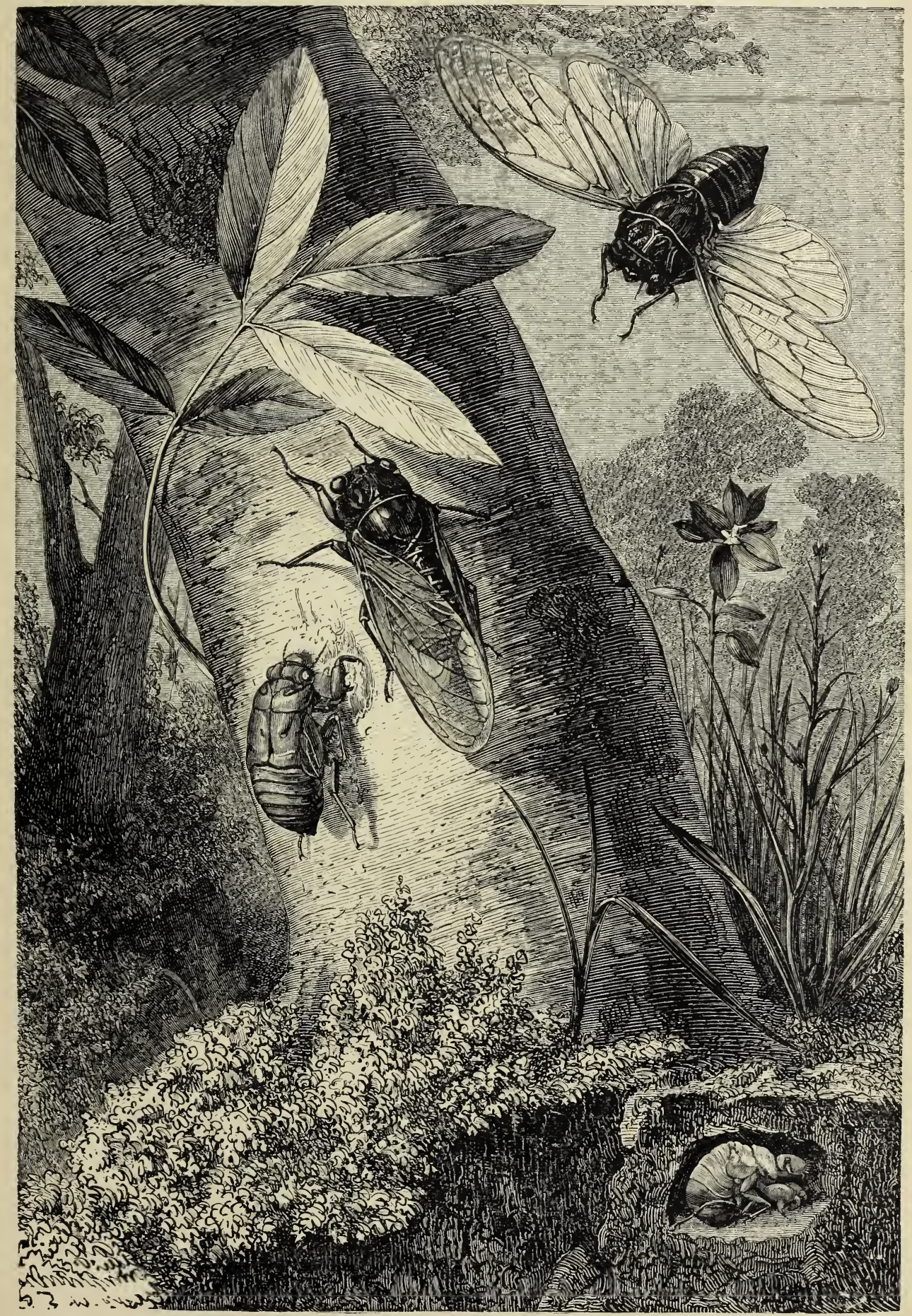



them, and only project the front part of their bodies. Should any danger threaten them, or should they be alarmed, they retract their bodies within the case immediately. Each species makes its case in a different manner, and employs different materials. Some of the larvæ of caddis flies invariably use gravel or very small stones for their cases, and others the small fresh-water snail and other shells, which they glue together. Many use bits of stick or morsels of plants, so that each species
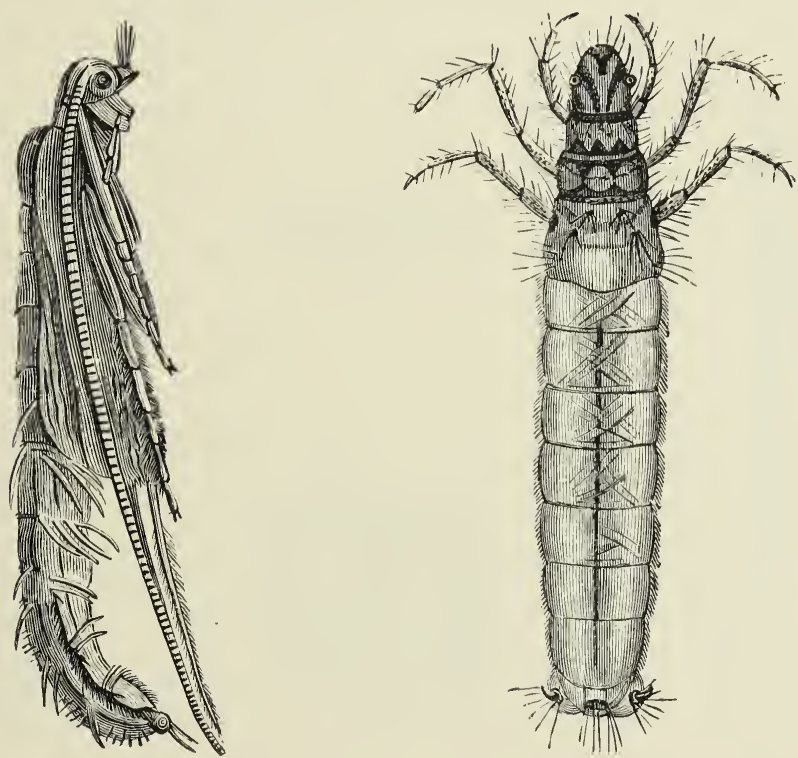

THE NYMPH AND LARVA OF SPEClES OF THE GENUS Phryganed. (Magnified.)

may be known by its tube. Some live in fixed habitations, which are made in the same manner as the others, but which are not to be moved.

So numerous were the caddis worms in the olden time that a very thick limestone in the Auvergne is made up of the tubes or indusix of them.

The larvæ always live in water, and they have respiratory filaments fitted for aquatic breathing upon the sides of the abdomen. They have a scaly head, and the thoracic segments are clothed with leathery plates. The legs are long, and the 
soft skin of the abdomen is terminated by two hooks, which anchor the insect in its dwelling.

When about to undergo their metamorphosis the larvæ fix their tube or case upon something and close up the ends. The nymphs have the same kind of respiratory organs as the larvæ, and in order to enable its successor to breathe, the larva closes the tube with a sort of open-work fence, which, whilst it prevents any intrusions, allows the water to flow in and out.

The nymph has rudimentary wings, and resembles the larva more than the imago.
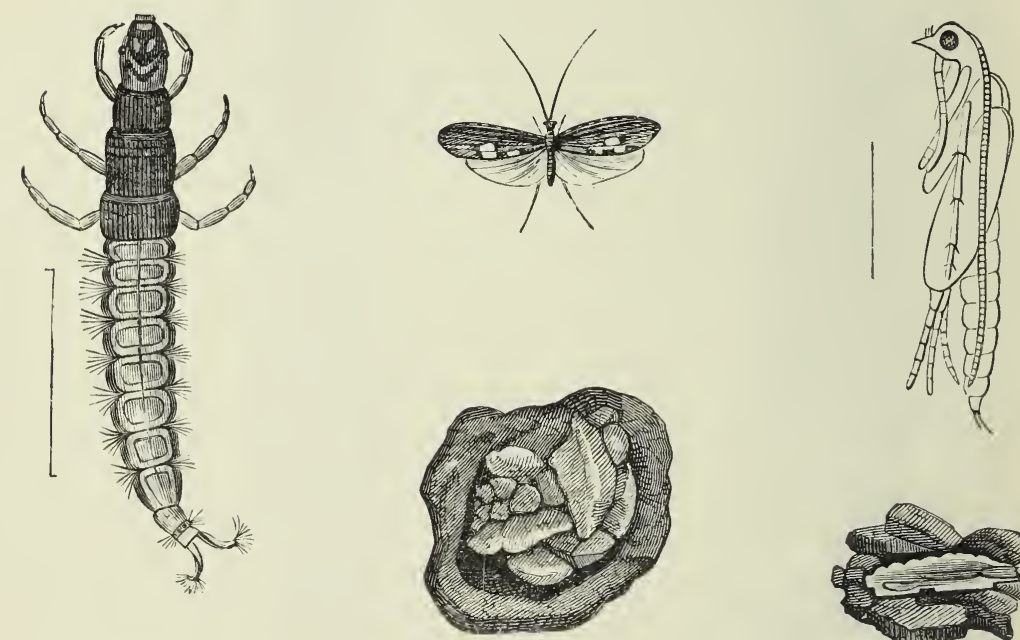

IIydropsyche atomaria. I ARVA, IMArO, SHELTER, PIPA, AND CASE.

The caddis fly, with yellow or. fawn-coloured antennæ (Pliryganea flavicornis), when in the larva state, forms its case with large bits of wood. Ploryganca rhombica chooses the sprigs of aquatic plants, and Pliryganca fusca makes a central tube of tiny pieces of stone, and adds long straws and shreds to the outside.

The tubes of these species are represented in the engraving.

Some caddis flics, when in the larval state, form shelters which are not movable, and which afford homes to several individuals. The species of Hydropsyche have larva with branchial filaments or gills attached to the abdomen, and their metamorphosis into the pupa is complete. 
The genus Rhyacophilus has a species, the larvæ of which spin a cocoon in the interior of the shelter before undergoing metamorphosis.

The importance of the moulting or skin shedding in relation to metamorphosis has been treated of by Sir John Lubbock with his usual care and intelligence. He has investigated the larvæ of an Ephemera (Chlö̈on dinidiatum), which is common in the ponds of the county of Kent, and has shown that their growth takes place step by step during a series of moults. There are no less than seventeen tolerably well pronounced grades of development before the larvæ attain maturity, and the wingless creatures obtain the simplest rudiments of the organs of flight during the eighth stage of their growth. During five other stages the rudimentary wings increase so as to cover three-quarters of the metathorax; and by the time the insects have passed through the whole of the stages, the wing-cases cover more than half of the first segment of the abdomen.

At first the larvæ had legs adapted for walking, but not for swimming, nor could they support the body out of the water. The abdomen consisted of ten segments, and no trachex were visible, so that respiration took place by the outer surface of the body. In moulting, the skin on the upper part of the head splits, and the larva comes through the minute crack. After a third moult, branchiæ or gills appeared, but still no tracheæ were visible within them; but during the next stage the respiratory organs began to vibrate and to contain tracheæ; moreover, the circulation of the blood and the beating of the heart were visible. The insect thus undergoes a progressive development in the larva state until the time comes for a more decided change into the state of the nymph, and in fact a metamorphosis has gone on from birth until the maturity of the larva. When the nature of the growth within the egg is ascertained in this Ephonera the immature condition of the young larva will be more evident than ever. 


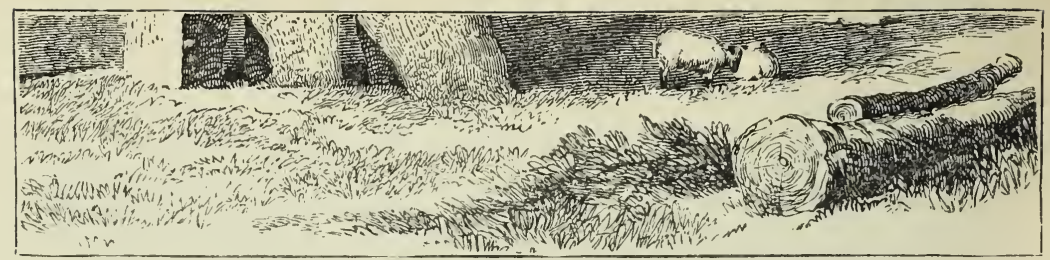

CHAPTER XI.

T H E HE M I P T E R A.

IF we state that the order of the Hemiptera contains Bugs, that is to say, domestic Bugs and the Shielded Bugs, the Cigala, the Plant Lice, and the Cochineal Insects, every one can pretty well understand the general nature of the assemblage of creatures which is classified in it.

The Hcmiptcra undergo an incomplete metamorphosis like the Orthoptcra, and are born nearly in the same shape as the perfect insects, and, therefore, they do not suffer any very great external changes during their development. The larvæ are, generally speaking, only distinguished from the adults by the want of any appearance of wings. They undergo several changes of their skin, and after a particular one they appear with the rudiments of wings. The insects are then considered to be nymphs. After a last change of the skin the wings appear in their perfect state, and then the insect is considered to be adult. Their eggs are often very pretty, being variously ornamented and chamfered; and those of some kinds are in the shape of little barrels or tubs, with a sort of coverlid. Those of the plant-sucking kinds are usually deposited in layers upon the leaves and trees.

Many naturalists have divided the Hemiptcra into two principal divisions, although all these insects are allied by very evident and natural affinities; but it is, pehraps, as well to admit that there are two sections of them. In the first-the Hctcroptera-the wings are coriaceous in that half which is attached to the body, and transparent in the rest, and the suckers spring from the lower 
part of the head. In the second-the Homoptera - the wings are entirely membranous and transparent, and the sucker is attached to the frontal region of the head.

There are four families in the section of the Heteroptera-the Scutelleride, the Lygcida, the Reduviine, and the Nepida; and there are also four in the section of Homoptcra-the Cicadida, the Fulgoride, the Aphide, and the Coccide.

The Scutelleride contain a great number of species, and are commonly called Land Bugs, or Shielded Bugs, or Wood Bugs. They are distinguished by having long antennæ, and a scutellum that covers the whole of the wings and the abdomen. The body is generally rather short and oval, and the insects are often remarkable for the brilliancy of their colours, and for the red, green, and metallic hues which adorn the greater part of their surface. One set of these insects has the scutellum covering the whole of the body behind the prothorax, and another has a triangular scutellum, which leaves a large part uncovered. The first is rarely seen in Europe; but the genus Tetyra has some kinds which are injurious to our wheat crops. The second set is represented by Pentatoma grisea, which is found on many common plants and on walls, in groups; and another kind, which frequents the cabbage, is well known on account of its black and red colouring. Hundreds of these are sometimes found upon cabbages and upon other cruciferous plants, which they injure very much. They have a very characteristic smell, which is similar to that of the ordinary bug.

In the engraving on page 372 a full-grown adult is flying, and it will be noticed that the front wings are not membranous near the body, and the triangular scutellum behind the chest is very readily observed. These insects may be noticed in a state of rest on the leaves; and one on the left-hand side shows how the wings are folded, and are half covered by the scutellum. Several larvæ are crawling over the plants.

The Lygeide have rather elongated bodies, and their scutellum is always very small. One of them, which belongs to the genus Astemma, whose species, Astemma aptera, has no ocelli, is found everywhere during summer-time, especially in the fields and gardens; but it often runs about on the ground on roads 
and paths. This hemipterous, insect is very peculiarly made about the wings, which are usually imperfectly developed, for their membranous part remains in a rudimentary condition; how-

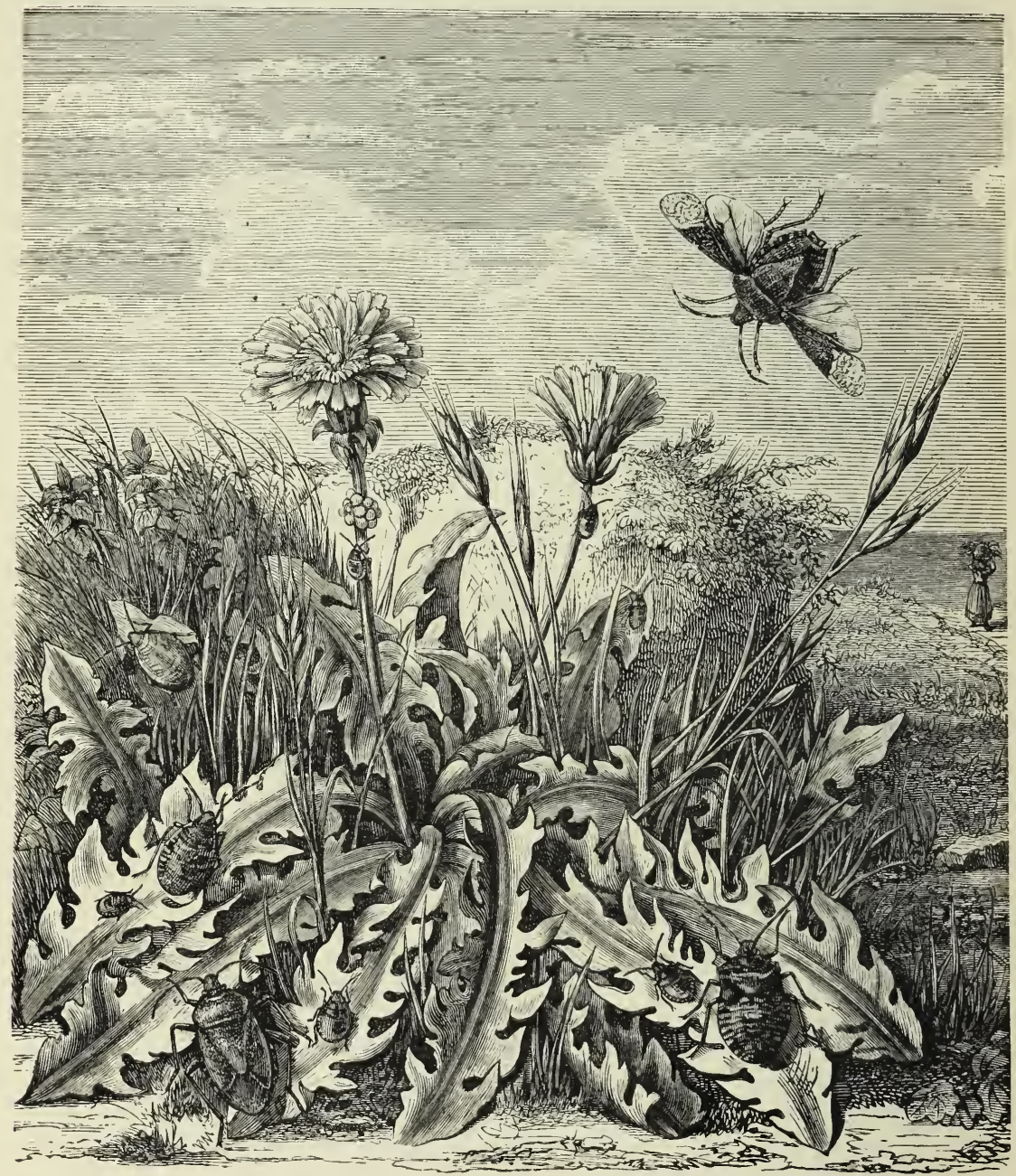

THE METAMORPHOSIS OF Pentatoma grisea.

ever, it happens every now and then that some individuals have their wings full grown and perfect in every respect.

The engraving shows one of these insects with fully developed wings, and others which have them in a rudimentary 
condition. There are some insects of this set, however, which have ocelli on the forehead; they are very common, and children call them "soldiers and sailors," and they are always scrambling and crawling over each other on the twigs of plants. They are red and black in colour, or they may be of a general lead colour, with red spaces toned down with black spots.

The name of Bugs (Cincx), which was applied by ancient

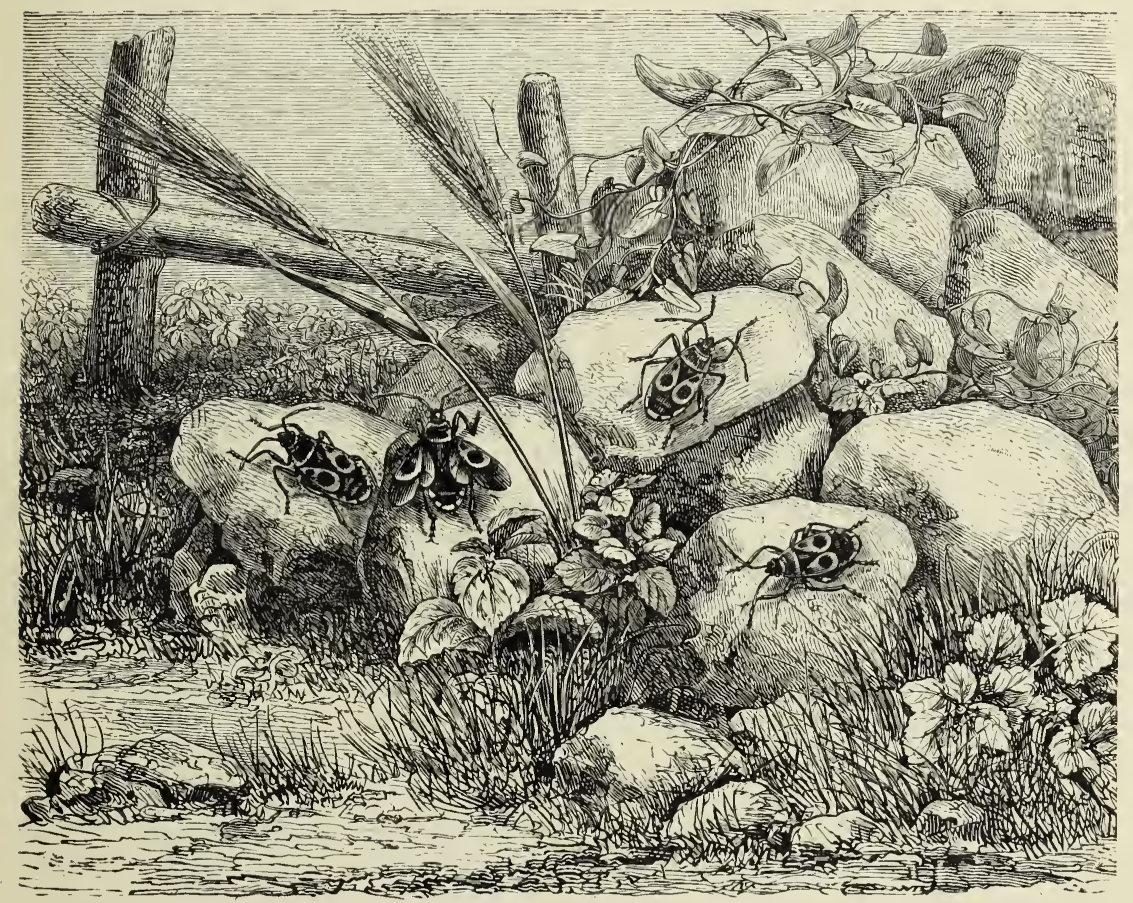

Astemma aptera.

authors to almost the whole of this division of the Hcmiptera, is now only given to those species with more or less egg-shaped bodies, antennæ very delicate towards the end, and heads slightly narrowed behind. The type of this family is unfortunately well known to almost everybody, and it is the common Bed Bug (Cimex lectularius). This insect nourishes itself almost exclusively with the blood of man. Who does not know its habits? During the day-time it remains hidden amongst the bed hangings, and in the wood, in cracks in the walls, behind the wall paper, 
and in any dark and narrow crevices; and it starts forth at night time to look for its victims, and displays a surprising amount of instinct and perseverance. Some people remove their beds away from the walls with the notion that they are beyond the reach of such very intimate visitors, but the bugs crawl up on to the ceiling, and when they come immediately over the sleepers they let themselves fall, and proceed to enjoy themselves forthwith. They lay their eggs in hidden places, and when they are hatched the young ones grow with greater or less rapidity, according to the temperature of the room and the corpulency of its inhabitants. They change their skins very often, and the husks we see are not dead insects, but those of vigorous ones which are only a little way off. They undergo a very incomplete metamorphosis, and the adult insects never have any wings, and they thus resemble the larvæ and nymphs of the other Hemipterd. We may thank Providence that they have no wings. They have, as everybody knows, a peculiar smell. The female bug lays her eggs at the beginning of summer, and the larvæ; when hatched, are small, white, and semi-transparent, of a slightly different form from the parent, and they take eleven weeks to attain their full size.

The Reduviince have rather slender bodies, and are essentially carnivorous in their habits. They run swiftly over the ground, and chase other insects, which they kill and eat. Curiously enough, they are especially fond of the bed bug, but, unfortunately, they are rather scarce, so that it does not seem possible to keep them in houses and to train them up to indulge in this very important peculiarity. They have a sharp and elongated beak, which is strong enough to pierce the skins of the animals upon which they live, and its bite produces much pain. The species are scattered all over the globe, but are much more numerous in warm than in cold countries, only a few being found in Europe. The largest and finest are natives of India and America. The common species, however, is the European Redurius porsonatus. It is generally found inside houses living amongst the dust and fluff. It is then in the condition of a larva or nymph, and it hides itself by covering its body with those evidences of uncleanly habits. When it becomes an adult it obtains its wings and 
flies about the fields, returning, however, to houses in order to lay its eggs.

A larva may be seen in the engraving on the ground, close to the basket on the right hand side; the perfect insect is entering the house, and immediately beneath it, on the ground, is a nymph.

The Hydrometride are aquatic Reduriine. They are insects which are commonly observable during the summer upon the

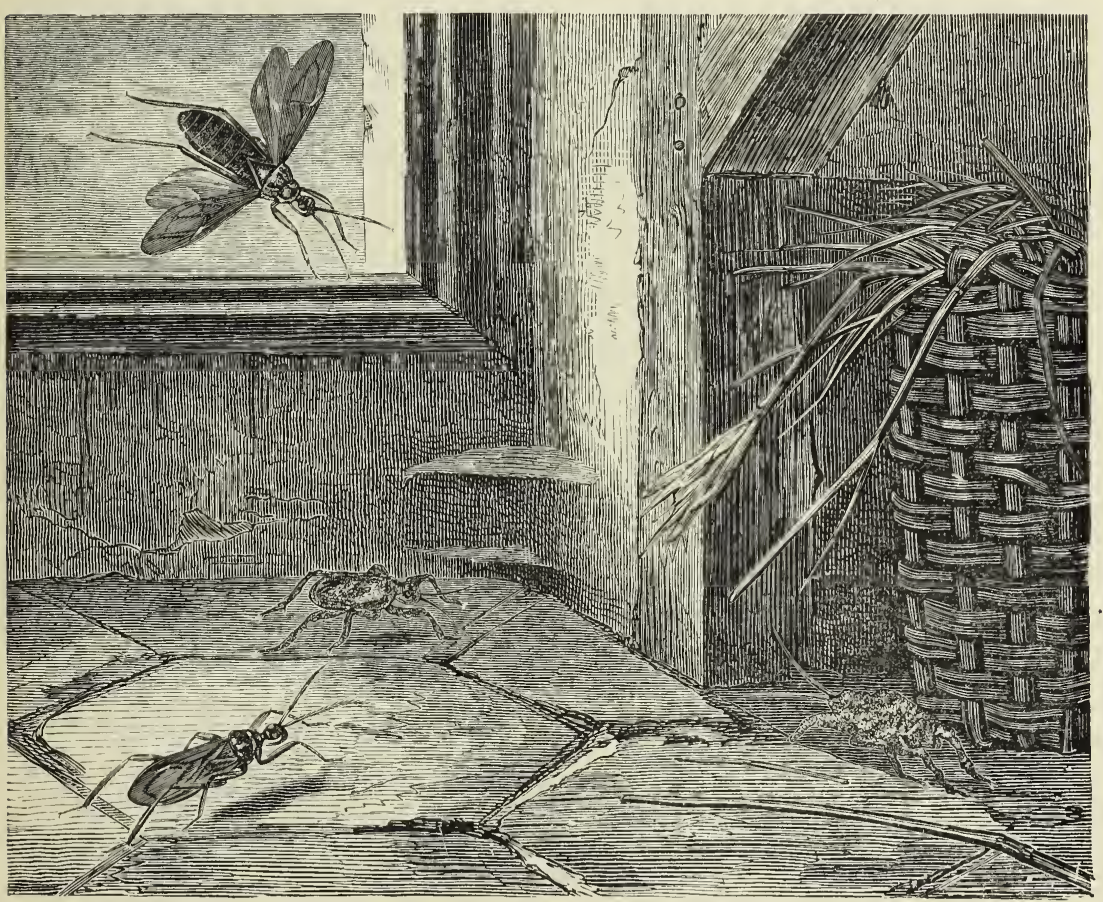

THE METAMORPHOSES OF Reduvius personatus.

surface of running or standing waters. Some have long narrow legs, with which they appear to be taking the measure of the top of the water. They are called Hydrometra stagnomum. The species of the genus Gerris, which are very numerous, are also very common, and some others belonging to the genus Halobates have been found walking over the waves of the tropical seas as easily as the first twirl and twist about on our ponds. In order to enable a Gerris to live on the surface of stagnant water, and to skim upon 
it with great velocity, Nature has given it a body somewhat like that of a wherry in shape. The long middle feet, which are covered with a fine close down like the rest of the body, glide on the water, and even remain motionless without becoming wet. Their food consists of other insects, and they are able in the adult stage to fly from pond to pond. It is very remarkable that the larvæ of many species which differ only from the perfect insects by wanting wings, should be able to produce their kind without becoming full grown.

The Ncpide, or Water Scorpions, are carnivorous, like the Reduvinae; they may be known by their very short antennæ, which seem to be hidden in cavities below the eyes, and by two long bristle-shaped processes, which project from the end of their tail, and by which they breathe.

There are many groups of them. For instance the Nepe, or true Water Scorpions, which have slender legs, the front ones being used to seize their prey, the leg being folded on the thigh, as in the Mantida. These insects lay their eggs in packets upon stones or aquatic plants, but some kinds carry them on their back. They swim slowly, often immerse themselves in the mud, and live upon small aquatic animals. The Ranetrce have long, thin, and slender bodies, with immensely long legs; but the Nepe we have just mentioned have large and flat bodies.

The Notonectide are the true swimmers of this great division of the insects. They have a large liead, short fore legs, and very long hind ones, which act as oars. All undergo incomplete metamorphoses.

In the engraving on the opposite page Notonecta glauca, or the Boatman, may be seen low down. On the right are two water scorpions, Nepa cincrea, the smaller one being a larva. On the left hand the great sprawling Ranatra is on the top of the water.

The Cicada family introduce us to the Homoptcra, and form a well-characterised group, the kinds of which do not differ much amongst themselves, one Cicad $a$ being very much like another. In Southern Europe the Cigala (Cicade) are known to every one, and have been celebrated since the time of the highest antiquity; but they do not live in the centre and north of Europe. The perfect insects live upon trees, sucking the juice of the leaves, and the females deposit their eggs, from 500 to 700 in number, in 
the dead or dried branches, in holes which they bore by means of a very curious ovipositor, which is something like that of the saw flies. They make little slits upon the branches, and drop an egg into each one of them.

The metamorphoses of the Cigala are rather more advanced than those of the Hemiptcra, and are like those of the dragon flies. As soon as the larvæ are born-and they look very much

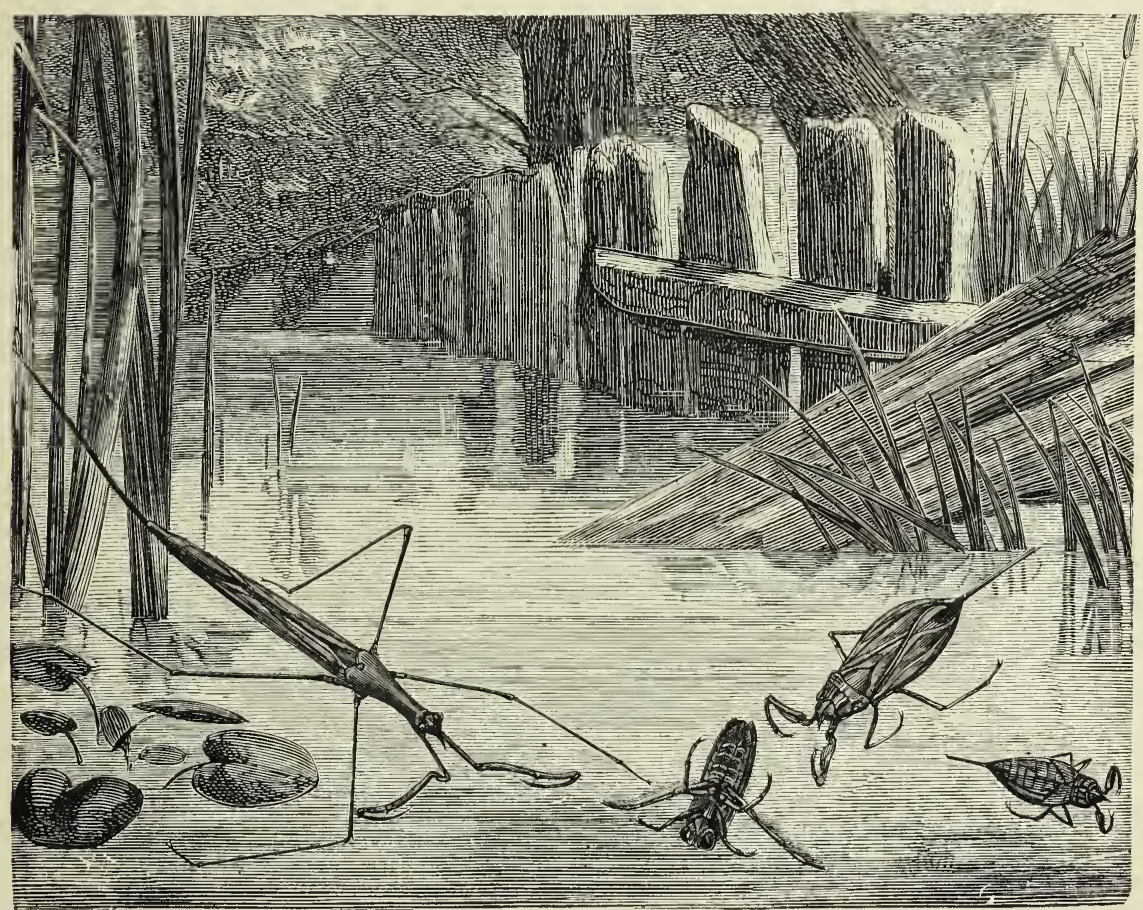

THE Nepiace.

like fleas in the first instance-they descend the tree and hide themselves in the earth, and suck the roots in their neighbourhood. They are furnished with spiny legs and large and strong thighs, and these are capital instruments for digging. The nymphs crawl out of the earth and live upon the trunks of trees, or on the plants close by. After remaining perfectly quict as nymphs for a short time only, their skin cracks down the back, and the perfect insect leaves its covering and takes flight. The Cigala of the ash and of the elm are common in the south of 
France, and their wings are transparent and without any colour, but this is not the case with the species of India and southern Africa, for they have their wings magnificently tinted. The song of some of the Brazilian species is said to be heard for the distance of a mile; and one American species, which is called the Seventeen Years' Locust, does a great deal of mischief. Ever since the year I7 I5, when its visit was first recorded at Philadelphia, no causes have affected the regularity of its return at intervals of seventeen years, even to the very month.

It is very common to notice on the leaves of willows and sallows by the river side little spots which look like saliva; if this matter is removed a larva or a nymph may be detected. It is called in England the Cuckoo Spit, or Frog Hopper, and is commonly found frequenting garden plants. The insect is called Aphrophora spumaria. The larva and pupa invest themselves with this frothy secretion, in which they lic hid until they complete their transformations. The frothy matter is vulgarly supposed to be really the spittle of the cuckoo. The larvæ are quite destitute of any wings, and they are only rudimentary in the nymphs. The adults have legs fitted for leaping, and they suck the juices of plants with the aid of their suckers.

Some of the Aplida or the Plant Lice have wings which are always more transparent than those of the little Cicadclla just mentioned; they have also long antennæ, which are composed of seven pieces. They are provided with two small tubelike projections, which stick up from the end of the abdomen, and which communicate with each other, and with a gland that secretes the sugary liquor of which the ants are so fond, and which is said by some naturalists to nourish the newly-born Aphida. There is no doubt about the ants milking the plant lice by tapping them on the end of the tubes, but it is a matter of doubt whether the young Aphida have the sense or the power to avail themselves of what certainly might be very nourishing to them. The males of the plant lice have large wings, but almost all the females are deficient in these organs of flight.

It was formerly a great puzzle to understand or to account for the rapid increase of plant lice, and the question has been carefully entertained by some of the most distinguished 
naturalists and physiologists of the world. It was evident to all, and in fact everybody can observe it, that perfect male and

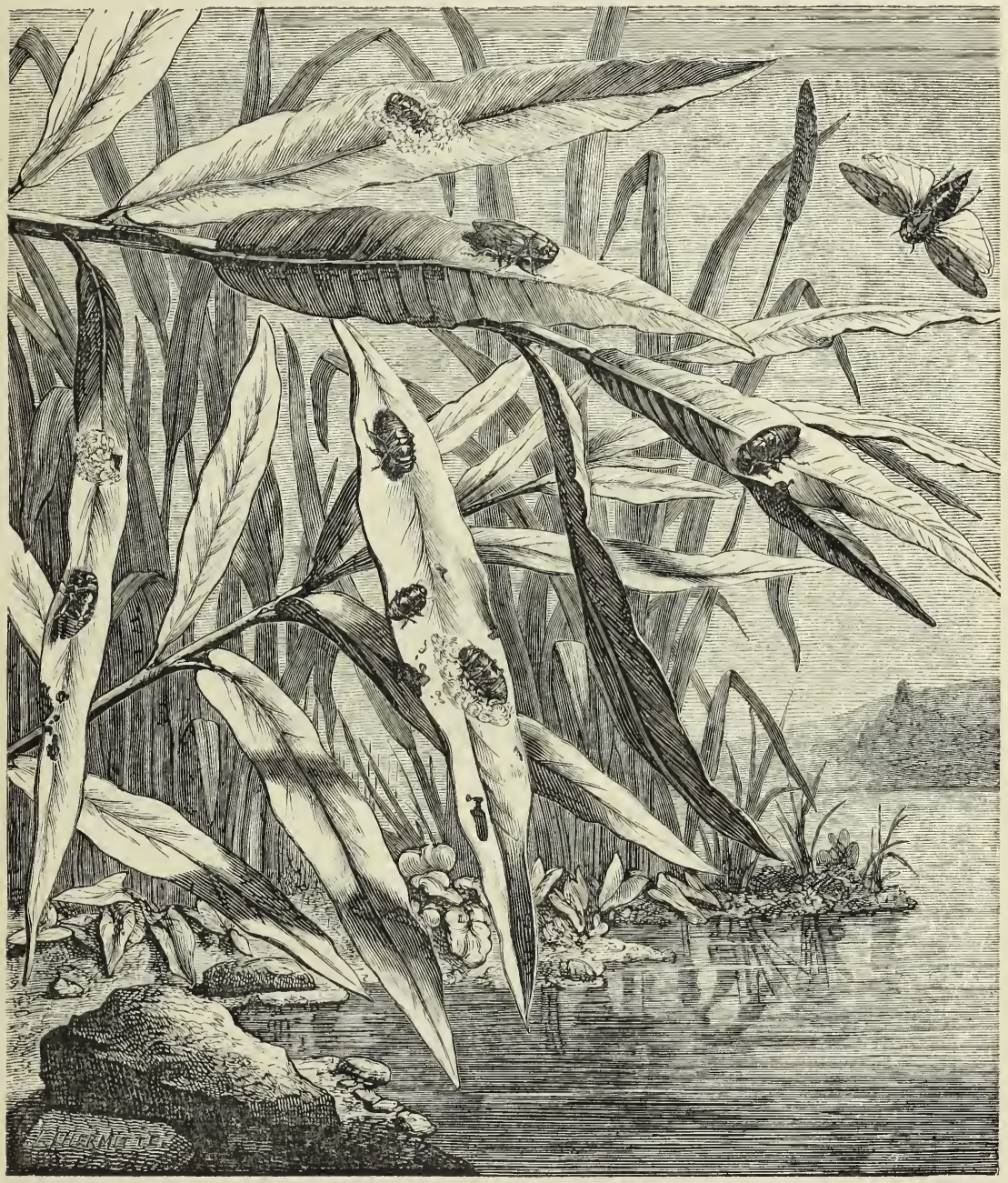

METAMORPHOSES OF THE CUCKOO SPIT. (Aphrophora spumaria.)

female Aphide, all with wings, fly about in great quantities in the autumn season. A little care will prove that the eggs are laid at this time on plants, and that they are covered up with a sort of mucus which the female places over them to protect 
them. Now in the spring these eggs are hatched, but they do not produce caterpillars or grubs, but imperfect Aphida, which have no wings, and which are all females. So far as is known, all the males die in the autumn, and the females also as soon as they have laid their eggs, so that in the early spring there are no other Aphida in the world except these imperfect females. Now these, as everybody knows, are the mothers of millions and millions of plant lice, which are exactly like them - that is to say, imperfect because they are wingless. These children are produced time after time, each set giving birth to others, and sometimes there are nine or ten successive generations. The last generation

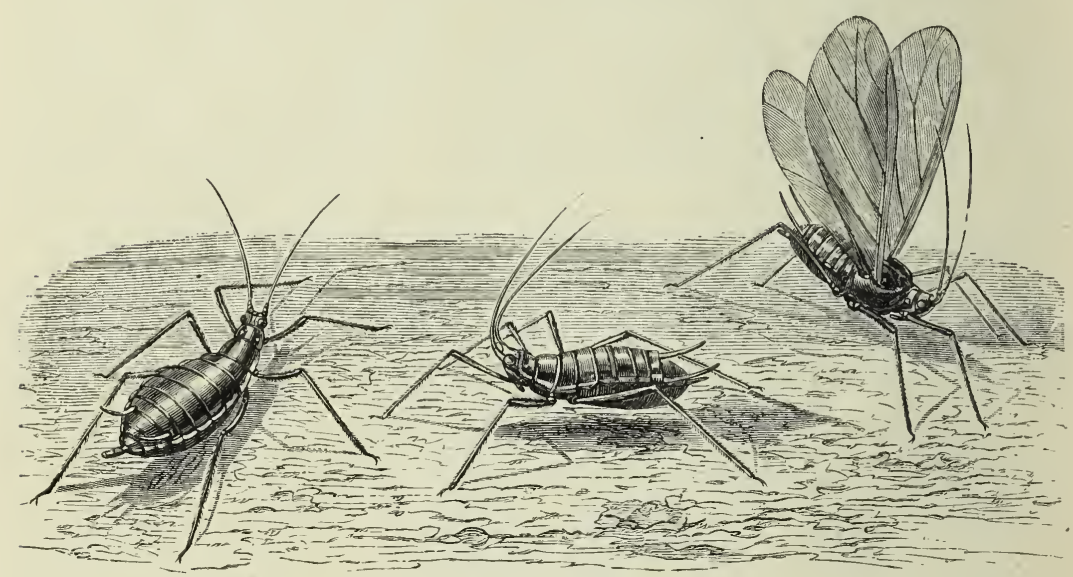

THE ROSE Aphis.

of Aphida does not produce those like unto itself, but perfect male and female individuals with wings. All the generations of imperfect females are not born from eggs, but they are born alive, and they may be traced with the microscope like little buds within the old ones. Bonnet, Réaumur, Owen, Huxley, Carus, Leydig, and Balbiani especially have studied these interesting insects. As soon as they are hatched the imperfect females begin to grow and increase in size, and they attain their full dimensions in ten or twelve days; and then these curious little inside buds are born at the rate of three, four, or seven a day. When they are born they are miniatures of their mother, and in ten days they begin to produce others. The second generation does 
the same, and so on until the ninth or tenth. Then the imperfect females have inside buds, which, when born, are not miniatures of their mother, but resemble the parents which laid the eggs the year

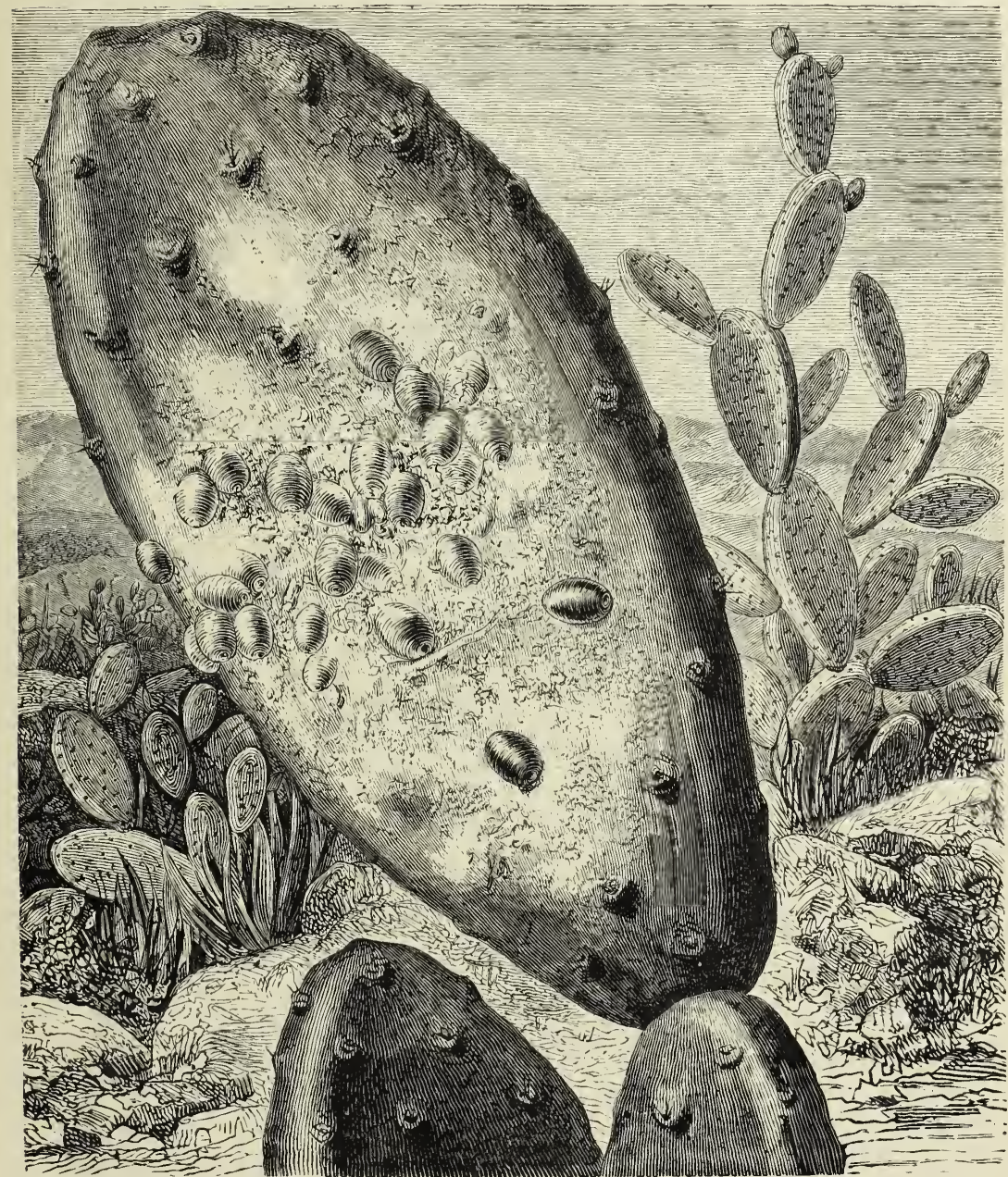

COCHINEAL inseCt. (Coccus cacti.)

before. These grow rapidly, and soon fly, and lay eggs in their turn. It is very evident that simple arithmetic can show that one plant louse might produce a quintillion during one year. It is easy then to understand the occurrence of enormous multitudes 
and the sudden appearance of thousands of these insects upon different plants. Fortunately they have a crowd of enemies, otherwise they would do a vast amount of harm to vegetation. They are found on almost every kind of plant, and upwards of three hundred species have been described. The hop Apliis sometimes nearly ruins the crop, and the rose Aphis, and that which is found on the scented geranium also do much mischief. The

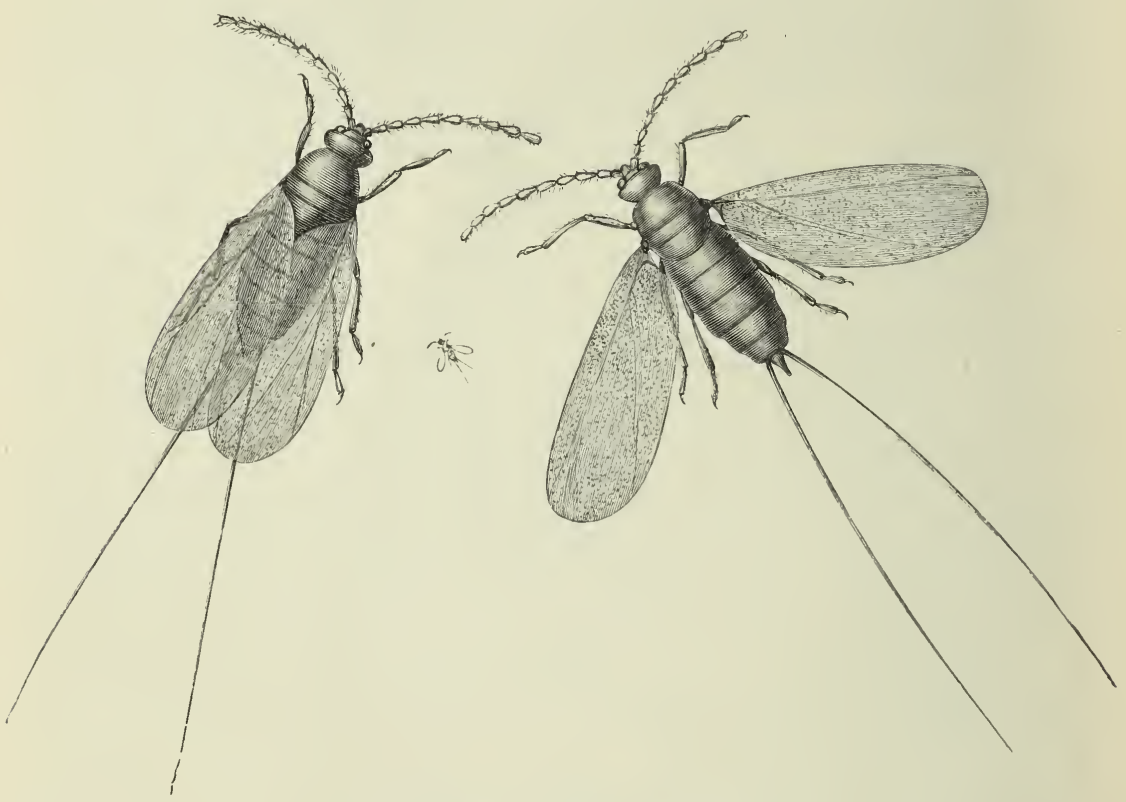

COCHINEAL INSECT. (Magnified.)

larvæ of the Cocinclla, or lady birds, and several Icluncumons, devour and kill great numbers.

The engraving on page 380 shows two immature females and a male which has wings.

The mischief done by these insects is produced by their tapping the delicate tissues of the plants with their suckers, and by their extracting the richest sap. They congregate in groups on the stems and leaves, but in the autumn the last generations emigrate from plant to plant.

Some of the Aplides which belong to the genus Lachinus do a great deal of harm to apple trees; they are well known from the 
curious white cottony stuff which encircles them and protects them from the air. When we crush this white mass the Aphis within it bursts, and a red stain is produced like blood. Some others live in groups, which are enclosed in the galls which they produce by irritating the structures of certain plants.

The family of the Coccide are very closely allied to the Aphide, and are frequently called scale insects or mealy bugs. They are very interesting, and may be easily distinguished from the plant lice. The development of the Coccide does not progress so regularly as it does in the Aphides, and it stops short, and even retrogrades in most remarkable manners. They do a great deal of harm to vegetation; but some, such as the cochineal insects, are most useful to man, on account of their furnishing magnificent colouring matters and inducing commerce.

In the engraving on page 38 I the rounded scale-like insects on the cactus are females. The female Cocci possess a certain amount of activity when they are born, and they search out leaves and twigs or stems upon which they intend to feed. Having made up their minds they stick their sucker into the tissue of the plant, and can never take it out again. They are found firmly attached to it, and it will be noticed that they gradually lose all trace of the articulalations of the body, that they become motionless and apparently senseless, so that they resemble vegetable excrescences. They are always sucking, and even their courtship is spent whilst they are imbibing the juices of the plant beneath them. They lay a large quantity of eggs, and produce a greater or less abundance of a cottony matter. The egg laying goes on without any movement on the part of the mother, and when she dies her body dries up and often forms a shelter for the newly born creatures. The larvæ, as soon as they are born, spread over the branches and leaves, and remain there during the warm weather. They are usually very small, but they increase to such an extent that the death of the plant becomes almost certain. It appears that they are reproduced somewhat like the Apliida, but only the males have wings.

The engraving on page 382 represents the males of the cochineal insect highly magnified. 


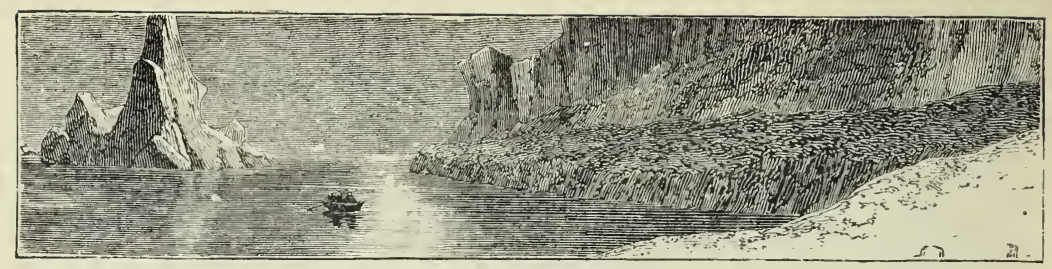

CHAPTER XII.

THE APHANIPTERA. - THE STREPSIPTERA.

THE Aphaniptera are insects which are known to everybody; but the Strepsiptera have never been seen except by a few naturalists. The first are Fleas, and are admitted to be particularly interesting insects, quite as much as regards their structures, their instincts, and metamorphoses, as on account of their well-known habits. The adult fleas are suckers, like the Hemiptera, but their mouths are constructed very differently, for the lip is a sharp tissue; the mandibles are long flattened blades finely denticulated on their margins; the jaws are small triangular pieces; and the lower lip is a membranous lamina supporting large palpi. The eyes are situated on the sides of the head, and appear to be simple; the antennæe are very small, and the wings only exist in the form of scales, as small vestiges of those important organs-hence the name of Aphaniptera. The legs are strong and spiny, and the hind ones, which are longer than the others, have their thigh pieces enlarged, and are admirably suited for jumping. These insects undergo complete metamorphoses, and the larvæ are worm-shaped, and the nymphs are inactive, but the last transformation is imperfect, for the organs of flight are rudimentary. There is only one family in this order, and it has only one genus, that of the fleas (Pulex). Each species attacks one animal in particular, and one kind selects man as the object of its attentions. This last is readily recognised by its smooth head, and by the stiff hairs upon the segments of the thorax and the abdomen.

It is not necessary to explain how fleas live; they multiply prodigiously in hot climates, and grow to a very unusual size under certain conditions. For instance, immense fleas, which are 
sometimes twice or three times larger than usual, are found upon the shores frequented by bathers, but they are of the same kind as that which attacks the human race. Fleas lay their eggs in cracks, in cushions, and in boards, or in the midst of dust, and their larvæ, which have no legs, and which, therefore, must live where they have been born, can only exist in consequence of the nourishment brought to them by the adults. Were they abandoned they would perish, but they have excellent mothers who never leave them; for after a flea, should it be a mother, has gorged itself with blood it seeks its young and disgorges a small quantity so as to keep them alive.

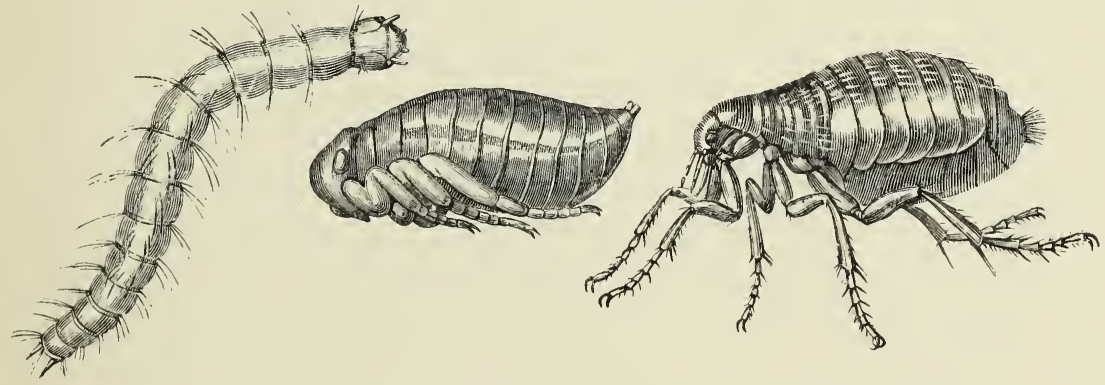

THE Metamorphoses OF THE COMMON FLEA. (Pulex irritans.)

The larvæ shut themselves up in silken cocoons when they have attained their full size, and undergo their metamorphosis into the condition of nymphs. In the engraving the long, legless, vermiform larva may be seen close to an inactive nymph, which resembles somewhat the perfect insect, which has long legs and the peculiar hairiness of the segments. The dog's flea (Pulex canis) is smaller than the species which attacks man, and is distinct from it, nevertheless it sometimes interferes with human beings. The Jigger, or Pulex penetrans, which lives in the hot districts of America, introduces itself under the skin of men and animals, and grows there to a surprising size; it is very small when it is born. The male always retains its tiny size, and does not shut itself up for life; but the female attains an immense size when underneath the skin, growing sometimes as large as a nut, on account of the dilatation of the abdomen by the abundance 
of the eggs within. These jiggers produce deep ulcerations, which give a great deal of trouble before they can be healed.

Packard considers the flea in the light of a wingless fly, and agrees with Baron Osten Säcken, that it is a degraded genus of the family to which belong some small Mycetophila, that live in mushrooms and toadstools during their larval condition. The metamorphoses of the flea agree closely with those of these small insects. He states: "In its adult condition the flea combines the characters of the Diptera with certain features of the grasshoppers and cockroaches and the bugs (Hemiptera)." No wonder, then, that this aggregation of unpleasant characteristics is fierce, bloodthirsty, and agile. The same author states that "there are minute wing-pads instead of wings present in some 'species."

The Strcpsiptera are very singular insects, being remarkable from their peculiar method of life and the nature of their growth. Towards the end of the last century Professor Rossi, of Pisa, discovered a species which was parasitic on wasps, and he thought that it belonged to the Iclmeumons, and lately Dr. Peck, an American naturalist, has discovered another species (Xcnos Peckii), which lives in the body of wasps, like the most interesting insect we are about to notice. Kirby discovered an insect many years since which had most extraordinary structural characteristics and habits, and he described it as the type of the Strepsiptera. These insects have the front wings rudimentary, and only existing in the shape of long and narrow offshoots or balancers; but the posterior wings, on the contrary, are very much developed, and are membranous, being capable of folding up like a fan. The eyes are globular and prominent, the antennæ are short, and the structures of the mouth are free. It soon became evident that only the males of the insect were known.

Siebold, in I843, having obtained some eggs, was able to observe the larvæ, and he soon discovered that the females of Stylops, one of the Strepsiptera, were blind, had no legs, and always retained the appearance of larvæ, and that they never quitted the bodies of those insects in which they pass a parasitic existence. George Newport paid great attention to the history of these "curious insects, and when he wrote his article "Insecta" in the Cyclopadia of Anatomy and Physiology, four distinct genera 
of these minute parasites had already been discovered. One of the largest species (Stylops Spencii) is scarcely more than two lines in length, while the smallest species yet known is not more than two-thirds of a line, or scarcely a line in breadth with its wings expanded. They undergo metamorphosis, and the males, when they have become perfect insects, fly and roam about, but the females are condemned to a perfectly quiet life. The head and the thoracic segments of the bodies of these last are united completely, but the abdomen, which is very large, always remains very soft, so that the whole of the body only appears to be formed

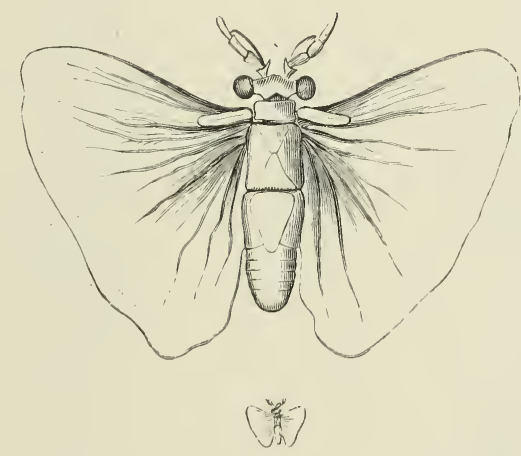

Stylops aterrimus. THE MALE. (Natural size and magnified.)

of two portions. They are ovo-viviparous insects, and the young larvæ escape as such from the body of the mother. They are active creatures, and, being furnished with long legs, crawl over the hairs and skin of the hymenopterous insect they are parasitic upon. They behave like the larvæ of Mclö and Sitaris, whose peculiar methods of life have been noticed in our description of the Colcoptera. Clinging on to a wasp or a bee they are carried off and finally arrive in the nest or hive, as the case may be, and there they attack the larvæ. When once fixed upon the hymenopterous larvæ they undergo a change of skin, and their shape then becomes totally different, and their legs are atrophied. But these parasites, being exceedingly small, do not kill the larvæ; they suck their juices after the manner of the Iilneumons, and do not interfere with the metamorphoses of the insects upon which they are parasitic. 
On the right-hand, in the accompanying engraving, there is a larva much magnified, lately born, and climbing upon the hair of one of the Hymenoptera, and on the left hand there is a perfect
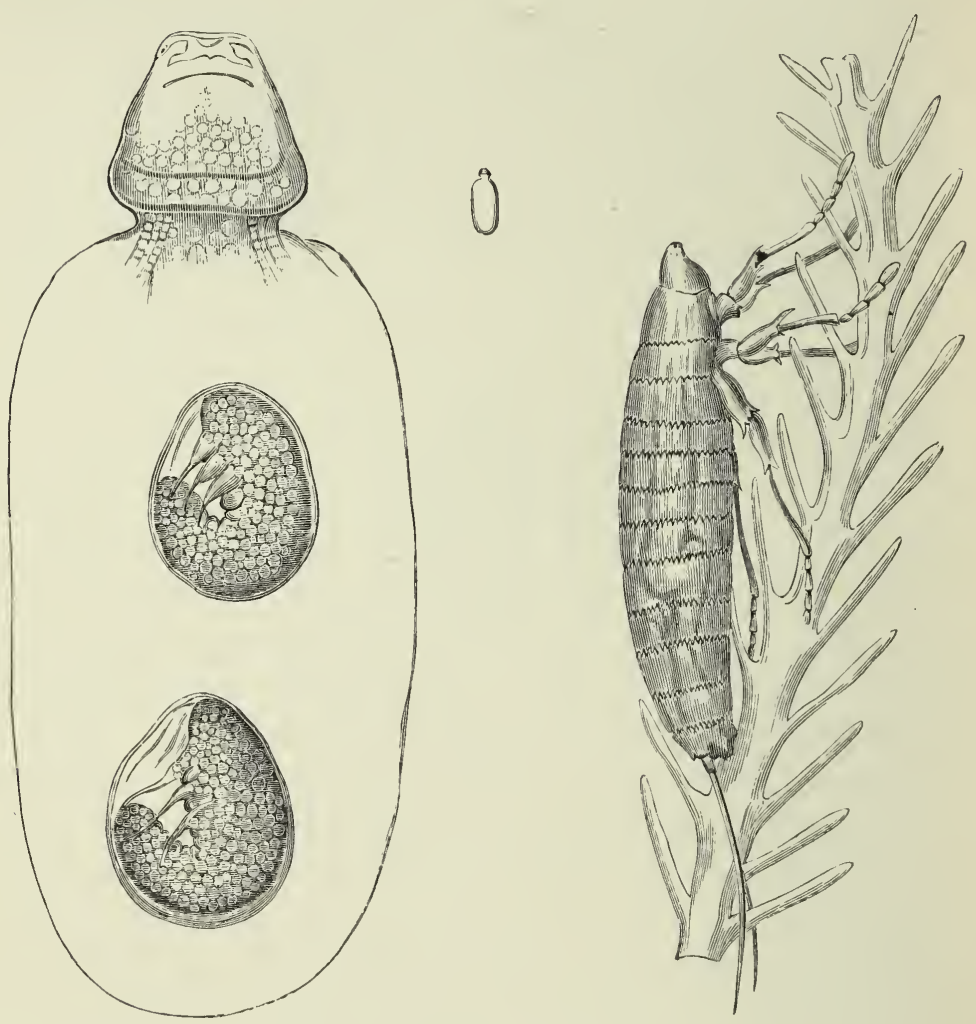

FEMALE AND LARVA OF Stylops aterrimus.

female insect very much magnified, with ovo-viviparous larvæ within its abdomen, and between the two figures there is a representation of a larva of the natural size. It is evident, however, that ova may be expelled from the mother before they are hatched.

Packard describes the curious history of the female Stylops which he found parasitic on one of the bees. He caught the bee, and on examining it he noticed a pale reddish brown triangular mark on the abdomen, and this was the flattened head and thorax of a female Stylops. The creature is included in the 
body of the bee, and is nourished by its juices. The head and thorax of the parasite were noticed to be soldered into a single flattened mass, the baggy hind body being greatly enlarged like that of the female white ant. On carefully drawing out the whole body from the bee the mass was found to be very extensible, soft, and baggy, and on examining it under a high power of the microscope, multitudes of very minute larvæ were observed, and they began to issue out from the body of the parent all alive, and not as eggs. The male of this Stylops childreni is totally unlike its partner, having large hind wings, and being able to fly, as has already been noticed. It appears, then, that the larvæ are hatched or crawl out of the body of the mother on to the body of the bee, and are then transported to its nest. Then they enter the body of the bee larva, and live upon its fatty matter. The male Stylops is turned into a pupa within the bee, and so is the female; but after the second metamorphosis the male flies off, leaving his wingless partner imprisoned for life, and she usually dies immediately after giving birth to her myriad offspring (Packard). The female respires by peculiarly arranged tracheæ, and absorbs nourishment through her skin as well as by means of an alimentary canal which ends in a blind sac. All the beauties of the female, so far as they are visible to the male, consist in the tiny patch which appears just without the body of the unfortunate bee, and the ova collect in a space which opens between the united head and body and the abdomen. The front wings of the male are analogous to the elytra of beetles, and the correct zoological position of the insect is probably close to Melö and Sitaris amongst the Coleopterd.

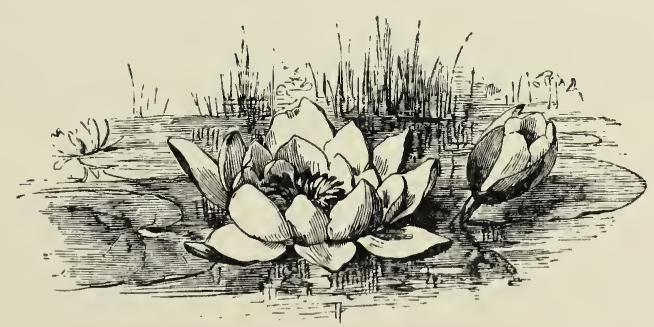




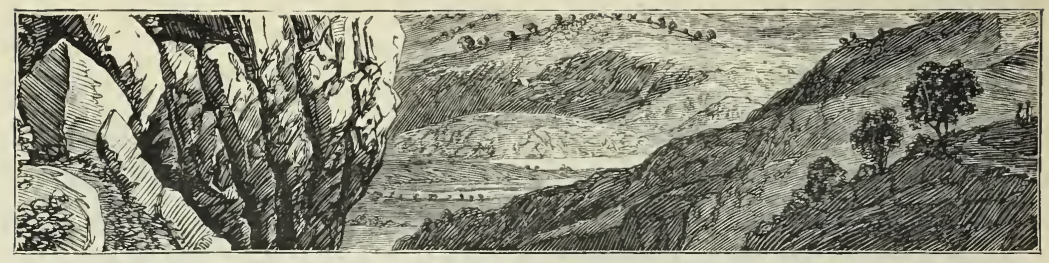

\section{CHAPTER XIII.}

THE DIPTERA-FLIES.

THERE are only two large and well developed wings, which are membranous and without scales, in the Diptera; the second pair are quite rudimentary, and form small projections of wingmembrane, which are called balancers or poisers. In the common gnat these poisers are like simple foot-stalks surmounted by a round knob, and are attached one on each side to that segment of the body which ought to sustain a large hind wing. This is their form in the house fly. They are generally more or less concealed beneath the winglets, which are little appendages to the fore wings. The excessive size of that segment of the body which bears the great proper wings of the Diptera, the front pair, appears to render a diminution in the size of the segment which ought to maintain the hind wings inevitable.

The Diptcra are sucking insects, but their suckers are formed differently to those of the Hemiptera or the Aphaniptera. Moreover these important organs of the mouth differ greatly in many genera of the flies themselves. These insects undergo complete metamorphoses; the larvæ are ordinarily vermiform and legless, are known as maggots, and usually possess considerable activity, and can crawl backwards and forwards. They do not require maternal assistance, and are usually placed so that their food is close at hand. The nymphs of the Diptcra differ greatly; some of them are active, although they take no nourishment; some are inactive, and quite as much so as the chrysalides of the Lcpidoptera or the nymphs of Colcoptcra, and others which are perfectly immobile, do not lose the skin belonging to the larvæ; these 
are well shown in the case of the common house fly. The metamorphoses differ, therefore, considerably in this very natural group. There are two great divisions in the order of the Diptcra

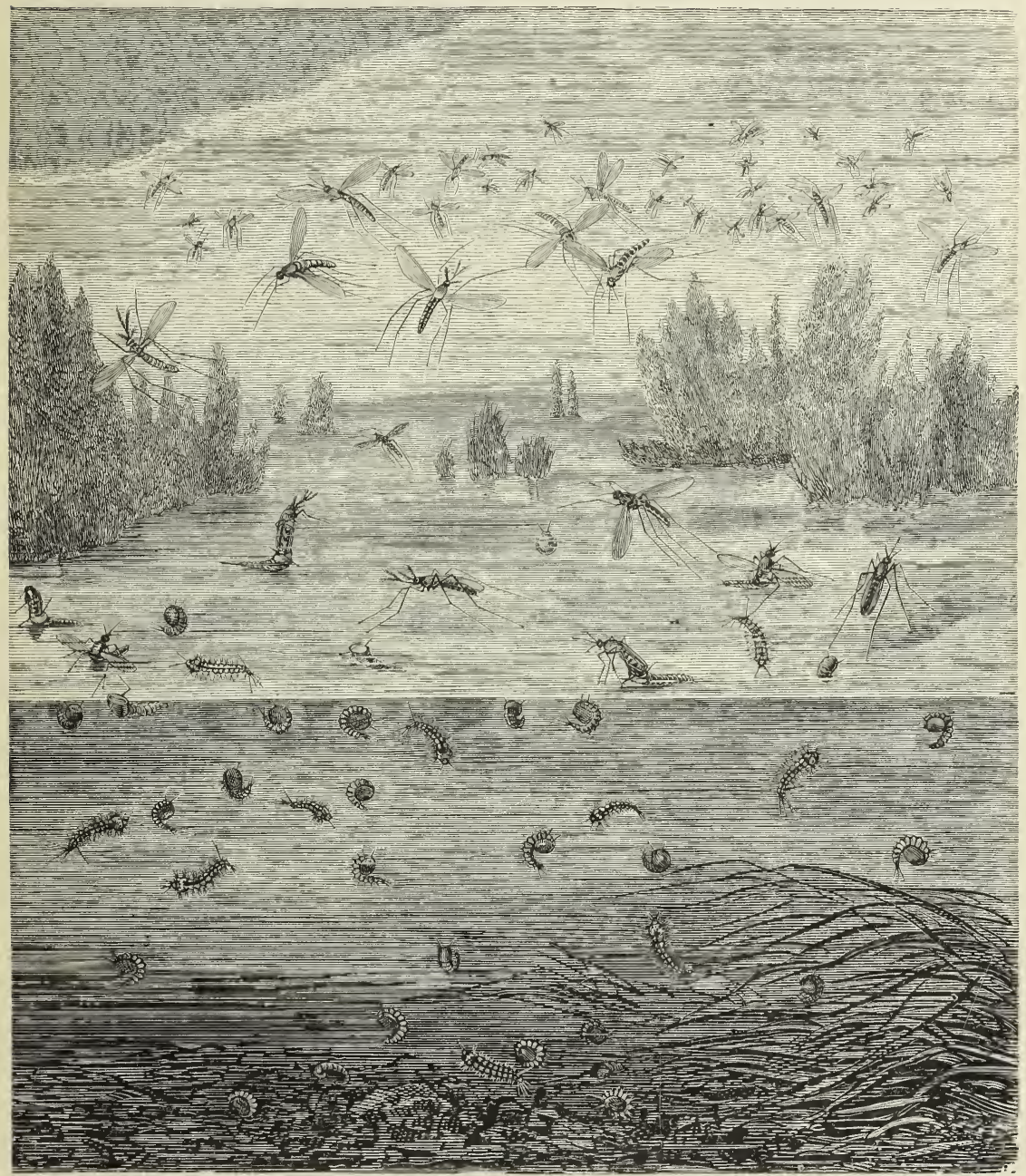

THE METAMORPHOSES OF THE GNAT.

characterised by distinctions in the antennæ; the first section have thread-shaped and the second very short antennæ, consisting of three very distinct joints, and a slender thread which is called a style. The first section, the Nemocera, have long and 
slender bodies, long wings, and great legs, which are excessively thin and delicate. The Gnats and the Daddy Long Legs are the types.

The natural history of the gnats is full of interest, and even the common gnat, Culcx pipicns, is well worthy of study; and we may almost wonder at finding such a bloodthirsty and annoying being in so delicate and fragile a body. The gnat has a very elaborately constructed offensive weapon in its mouth, the structures of which, although excessively delicate, can do their perforating duty perfectly. All the pieces of the mouth are free, and the mandibles are in the shape of sharp blades, toothed on their margins. Gnats abound in marshy districts and where there is stagnant water, for their larvæ are aquatic, but cannot live in running streams. They are very fond of such places as water tubs in gardens, and it does not much matter if the water is not quite fresh.

The male gnats have pretty hairy antennæ like little feathers, and the females have antennæ which are almost plain; it is, therefore, not difficult to distinguish one from the other, and it is rather important, for the females are the blood-suckers. When about to lay their eggs they seek the water, and, with the assistance of their long hind legs, collect and agglutinate them together, and place the little boat-shaped mass upon the surface and leave it to its fate. The larvæ are soon hatched, and grow with great rapidity. They swim with great agility, and may be noticed to be constantly ascending and descending, and rushing about in search of prey. The transparence of their tissues, the delicacy of the hairs which cover them here and there, and the extreme mobility of the segments of their bodies, render them very interesting objects for the microscope. They are almost always seen with their heads downwards and their tails towards the surface of the water. There are two antennæ on the head, which is also furnished with hairs that direct the food towards the mouth. The first segment of the body is large and broad, and then the others diminish gradually to the last, which carries tufts of hairs, and the last but one is provided with a tube, the extremity of which is perforated for a respiratory orifice. After the larva have grown to a certain size they undergo a change of their skin, and become nymphs, which, although active and 
full of life, are, as it were, swathed up and incapable of taking nourishment. They swim with the aid of two large lamellæe, which resemble a tail somewhat; and it may be noticed that when the nymphs come up to the surface of the water they do not present their tails, like the larvæ, so as to obtain air, but allow their backs to touch the surface just where there are two little respiratory tubes.

When the perfect insect is about to emerge from the nymph this last floats on the surface of the water, perfectly at rest, and then the skin of the back, which is exposed to the air, dries and splits open. Then the perfectly-formed gnat begins to come out; first of all it protrudes its head, then a portion of its body, and, after a short time, one long leg after another is disengaged from the nymph's skin. But all is not over yet, and the gnat has to take great pains so as not to capsize the frail little boat-like skin which separates it from the water. Very gradually this little creature rises up and extends its wings, which are still moist and limp, but soon, especially if the weather is warm, they become crisp and movable, and then the gnat gives a downward stroke with them and flies off in safety. There is no pseud-imago state, as in the Neuroptcra. When there is no wind this is not a very difficult operation, but during stormy weather thousands of gnats are drowned, for, if their wings are once wetted, there is an end to the insect's existence within a very short time.

The species of the genus Tipula, known commonly as Daddy Long Legs, from their immensely elongated thin legs, frequent grass lands and marshy districts, and very frequently commit great havoc upon the turf. The females have a long ovipositor, and penetrate the earth with it and leave their eggs underground, and the larvæ eat the fine roots of all the delicate plants which come in their way. The Tipula olcracea, or the Cabbage Crane Fly, is very common, and the perfect insect is of a tawny colour, and its wings are rather dusky. The larva has a black head, and the rest of its body is of an earthy colour, and the last segment of the body is perforated by the respiratory orifices, and has four tubercles upon it. The nymph is more compact than the larva, and is usually motionless, but it can move with the aid of some spines which are upon the body, so as to approach the surface of the soil when about to undergo the second metamorphosis. 
The Cccidomyide are very small Diptera which, like the Cynips, produce galls on plants in which their larvæ live. Nevertheless, there are exceptions to this gall-making peculiarity, for the wheat fly, Cecidomyia tritici, lays its eggs in the centre of the flower of the wheat plant, and when its larvæ are hatched they eat the pollen, and thus prevent the formation of the corn. An American species, which is known by the name of the Hessian Fly, attacks the lower part of the stem of the wheat plant, and the larva
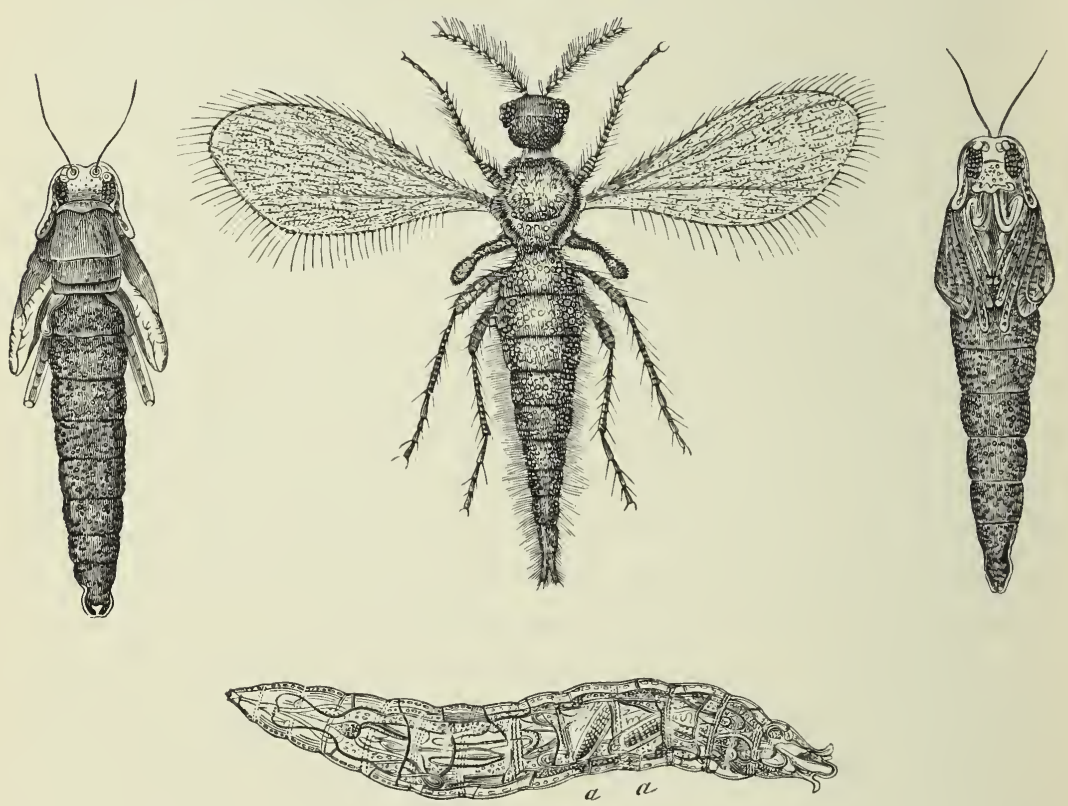

Cecidomyia WITH VIVIPAROUS LARVA.

nourishes itself with the sap, which it appears to take by suction, and causes the stem to wither and die.

A very interesting discovery has been made by Nicholas Wagner, a professor at Kazan, to the effect that the larvæ of some species of Cecidomyia which live underneath the bark of trees have the power of producing creatures like unto themselves. In the centre of the engraving there is a representation of the adult insect, and on either side of it drawings of the nymph, and below the larva is depicted, and it will be seen to contain at $a a$ 
living larvæ within it (after Wagner). In the spring-time the little perfect insect lays its eggs, and by-and-by the larvæ are hatched from them. If these larvæ are examined, smaller ones will be noticed inside them, and eventually they tear open the body of their mother and escape. They reproduce others in the same fashion, and a succession of these extraordinary generations takes place during the whole of the fine weather. The increase of these larvæ progresses at a great ratio, and finally metamorphosis takes place when the cold weather is at hand. This curious parthenogenesis (from the larva, not from the perfect insect) has been carefully studied by excellent observers, and is an established fact. An equally interesting development from immature insects occurs in the case of the larvæ of Chironomus, which have been proved by a Russian naturalist to contain eggs which are subsequently laid by the pupæ. The gall-making species are usually very small as regards their individuals, and the females deposit their eggs in the young shoots, leaves, or flowers, which they pierce by means of their sharp-pointed ovipositor. Where this puncture is made a gall or excrescence takes place, which grows sometimes to a large size, serving often as a nest and food to the young larvæ.

The Asilide belong to the second division of the Diptera, and are very active insects, which have a very formidable sucker, for the two mandibles being completely soldered together form a very sharp and piercing blade. The species are very numerous, and are strong predatory insects, living upon live flies, and even upon bees, which they chase and soon kill. Their flight is strong, and they make a loud buzzing noise when on the wing. Some, which have elongated bodies, a short trunk, and a formidable sucker, attack horses and cattle, and sometimes man, and they pierce the skin and suck the blood. One of the commonest European species, Asilus crabroniformis, is decorated like some of the Hymonoptera, and when it begins to suck produces the same pain as that inflicted by a sharp lancet. It often attacks large animals, but usually it sucks the blood of insects, and especially of caterpillars.

This insect, which is so bloodthirsty in adult age, appears to be a vegetarian when in the condition of a larva. The larvæ are found underground, where they gnaw roots, and eventually 
construct a cell, in which metamorphosis takes place into the nymph.

The Tabanida, or Breeze Flies, are generally larger and more

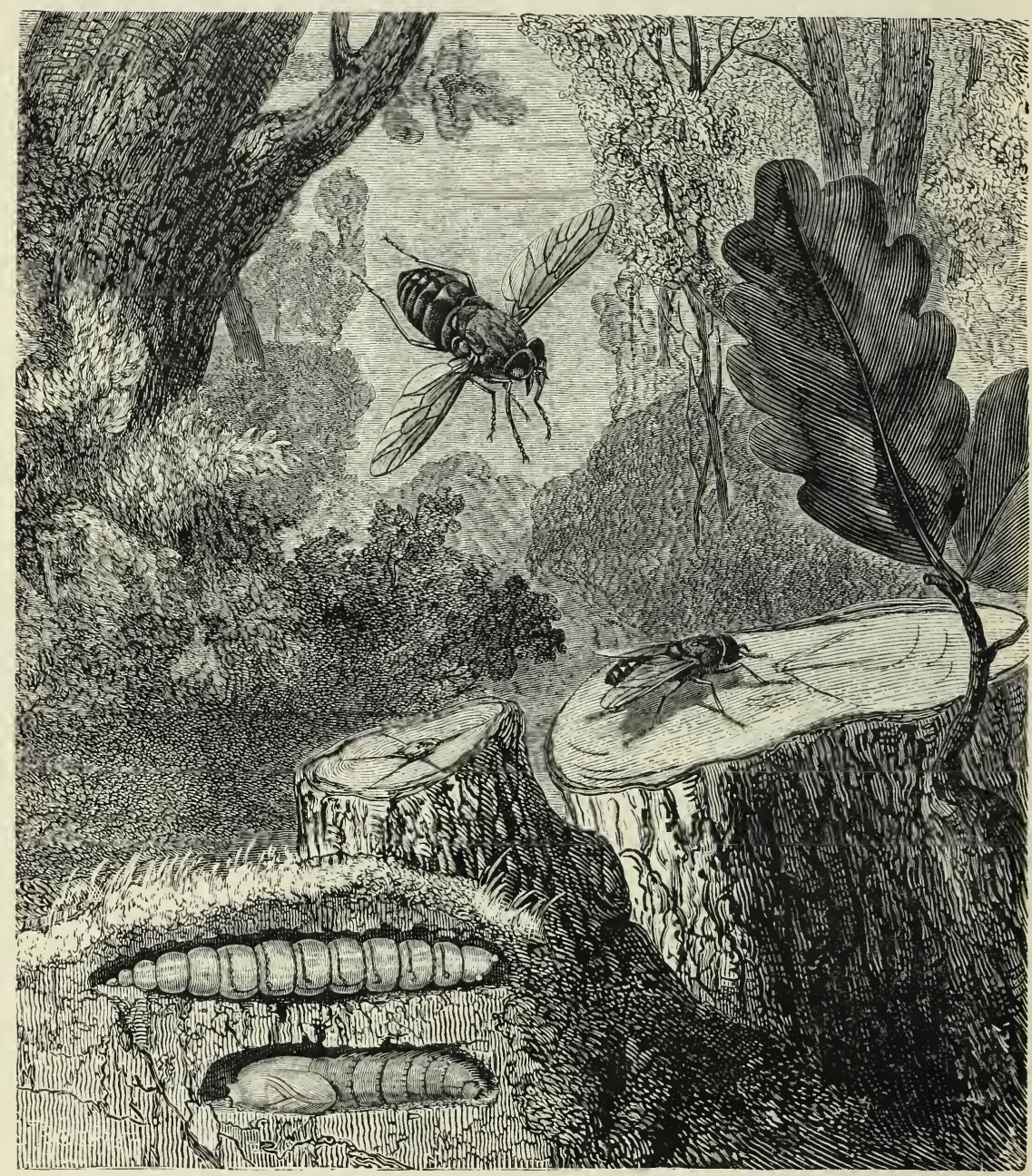

TIE METAMORPHOSES OF Tabanus bovinus.

powerful than the rest of the Diptera; they have a large body, with a depressed head, and their sucker or proboscis is very different to that of the kinds just mentioned. They have a large trunk, which is sometimes longer than the whole body, and their 
piercing mandibles are not joined together, but are separated. Their wings are provided with a greater number of nervures than any others of the order. They live chiefly by sucking the blood of animals, especially of horses, and even of man; but the males are by no means so sanguinary as the females. These pierce the skin of their victims with great facility by means of the lancets of their proboscis, while the former live partially from the juices of flowers. The breeze flies are met with chiefly in woods and pastures, in the middle of summer, and during the heat of the day. When flying they make a loud buzzing noise, and that of Tabanus bovinus is well known to cattle and horses, for they become very restive at the sound. This insect is a large palebrown fly, marked on the back by a series of whitish spots, and the larva is a large, dusky yellowish, cylindrical worm, marked by transverse black rings. The larva know nothing about the love of blood, but live underground, and have no legs, but they manage to feed upon vegetable matters. They are metamorphosed into immobile nymphs, which may be recognised by their having six spines at the end of their bodies.

The perfect insects, one upon a tree and the other in flight, are shown in the engraving on the opposite page, and the protruding proboscis, extended wings, and long legs of these must be compared with the legless condition of the immobile nymph and legless larva which are represented underground in order that the extent of the metamorphosis should be appreciated.*

The metamorphoses of Strationys chamcleo are, perhaps, as interesting as those of any other of the Diptera. It is a common fly, and, being bloodthirsty, it frequents flowers in order to meet with other insects whose juices it can suck. The larva lives in stagnant waters, and is a long creature with coriaceous integuments, and its head is small, and is furnished with two hooks which are really its mandibles. The terminal segments of its body are thin, delicate, and are so narrowed that they can enter slightly one within the other like the slides of a telescope, or can elongate by being projected backwards; they form a long

* It would appear that some species of these flies have larvæ which live in water and in damp places, under stones and pieces of wood. Mr. Walsh found an aquatic larva of this genus, which within a short time devoured eleven water snails (Packard). 
tube, which is pierced at its extremity by two orifices, which are surrounded by a crown of small hairs. The larva chooses shallow waters to swim about in, and when it requires air and a supply

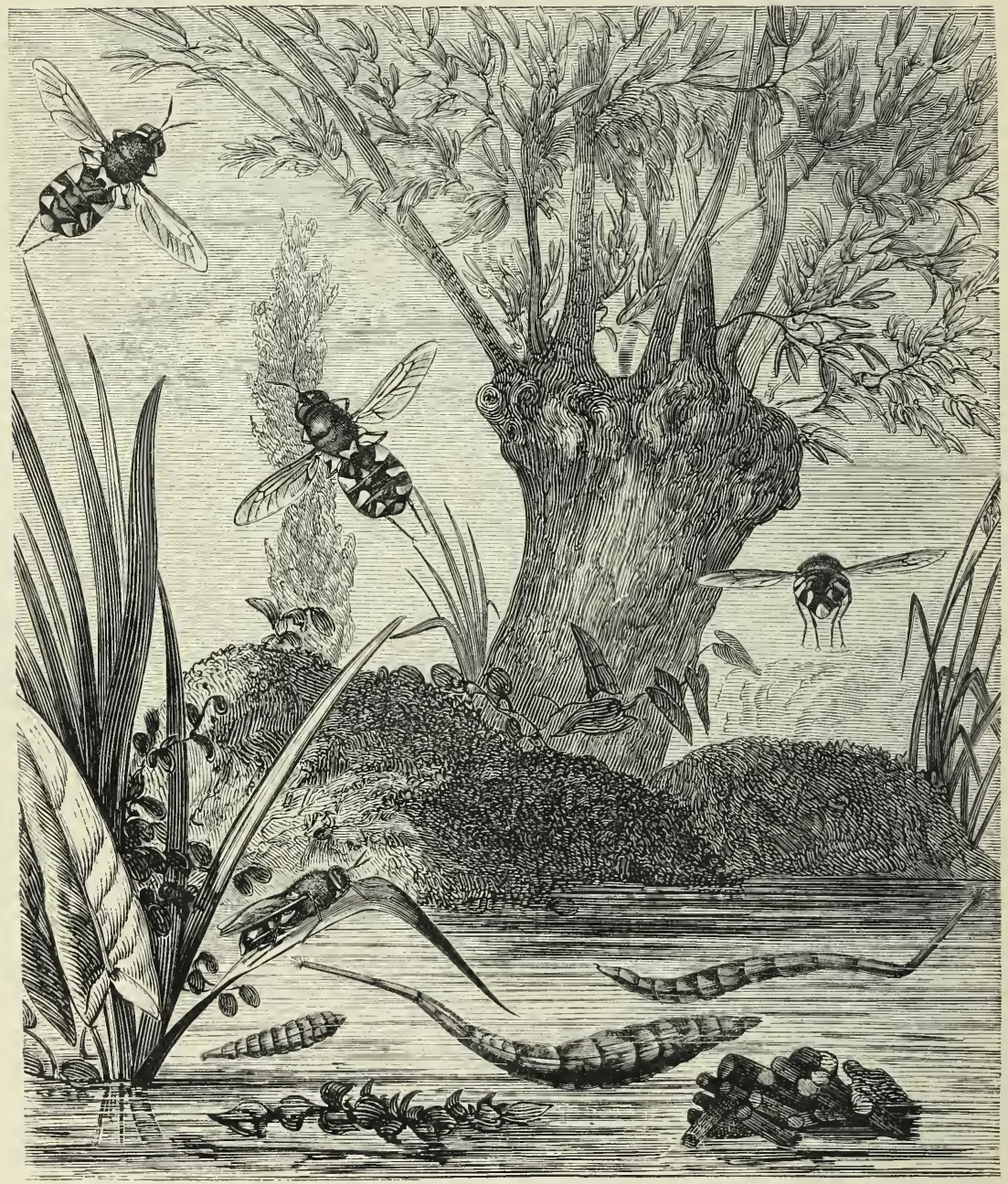

THE METAMORPHOSES OF Stratiomys chamaleo.

of breath, it sticks up the end of its body and elongates the last segments, and respires through the two holes just mentioned. After a longer or shorter larva life, the insect comes up to the surface of the water and floats; it does not change its shape, but 
evidently a change has taken place, for the larval condition is at an end. If one of these floating creatures be taken up and cut open, the pupa will be seen within the skin, which acts as the cocoon, and also as a boat for the fly which will spring into life in a short time. The fly, which has two perfect wings, a flat body, long antennæ, and which is decorated with beautiful colours, is about as different an insect from the long-tailed, dull-coloured swimming larvæ as can well be imagined. In the engraving opposite the perfect insects are seen in flight, and one is upon a rush ; two larvæ are shown, one on the right hand side has its tail erect, and is breathing in air, and beneath the insect on the leaf, is a nymph.

The Diptera with a short and thick trunk, mandibles united to form a single blade, and with a broad and very flexible lip, which makes a good sucker, are distinguished as Syrphide. Their proboscis is thus long and membranous, and they like honey. There are several very interesting genera in this family. The Volucelle are large flies, which have black, yellow, and russet colours upon them, and they choose the nests of social bees for their larvæ. The female deposits its eggs in the combs, and particular species have their favourite bee-hive or wasp nest, as the case may be. Thus Volucella bombylans visits the humble bees, and Volucella zonaria attacks the wasps, and curiously enough wears the livery of those dangerous insects, amongst which she leaves her eggs. The larvæ of Volucella are of a dirty white colour, are covered with small spines, and the last segment of the body is rounded off, and is pierced for the organs of respiration. The membranous legs are furnished with little hooks. The egg is laid in the cell which contains the wasp larva, and when it is hatched the Volucella eats its way into its victim, and gradually intrudes the whole of its body except the last segment, which being in contact with the external air, and having the respiratory orifices in it, is the only portion of the body by which the parasite can be distinguished, and through which it can take in air to oxygenate its blood.

When the Volucella larvæ attain their full growth they are transformed into nymphs, which have two small open tubes placed upon the prothoracic region, and which communicate internally with the tracheæ. This apparatus is like that of the gnat. 
The bees are often attacked, according to A. S. Packard, by a fly which belongs to the genus Phora. "It is a small insect, about one line and a half long, which is found in Europe during the summer and autumn flying slowly about flowers and windows, and in the vicinity of bee-hives. Its white transparent larva is cylindrical, a little pointed before, but broader behind. The head is small and rounded, and at the posterior end of the body are several slender spines. The pupa case which encloses the delicate chrysalis is oval, consisting of eight segments, flattened above, and with two large spines near the head and four on the extremity of the body. When impelled by instinct to provide for the continuance of its species, the Phora enters the bee-hive, and gains admission to a cell; then it bores with its ovipositor through the

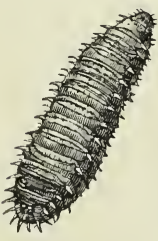

Larva.

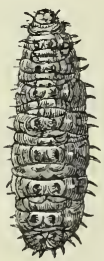

Nymph.

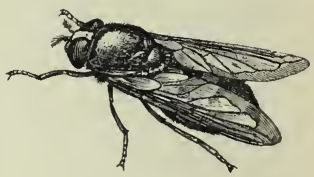

Adult.

METAMORPHOSES OF Volucella zonaria.

skin of the bee larva, laying its long oval egg in a horizontal position just under the skin. The embryo of the Phora is already well developed, so that three hours after the egg is inserted in the body of its unsuspecting and helpless host the egg is nearly ready to hatch. In about two hours more the larva actually breaks off the larger end of the egg shell, and at once begins to eat the fatty tissues of its victim, its posterior half remaining in the shell. In an hour more the larva leaves the egg entirely, and buries itself completely in the fatty portion of the young bee. The maggot moults three times. In twelve hours after the last moult it turns round with its head towards the posterior end of the body of its host, and in another twelve hours, having become full fed, it bores through the skin of the bee larva, eats its way through the brood covering of the cell, and falls to the bottom of the hive, where it changes to a pupa in the dust and dirt, or else it 
creeps out of the door, and transforms in the earth. Twelve days after the fly appears."

The habits and metamorphoses of the insects included in the

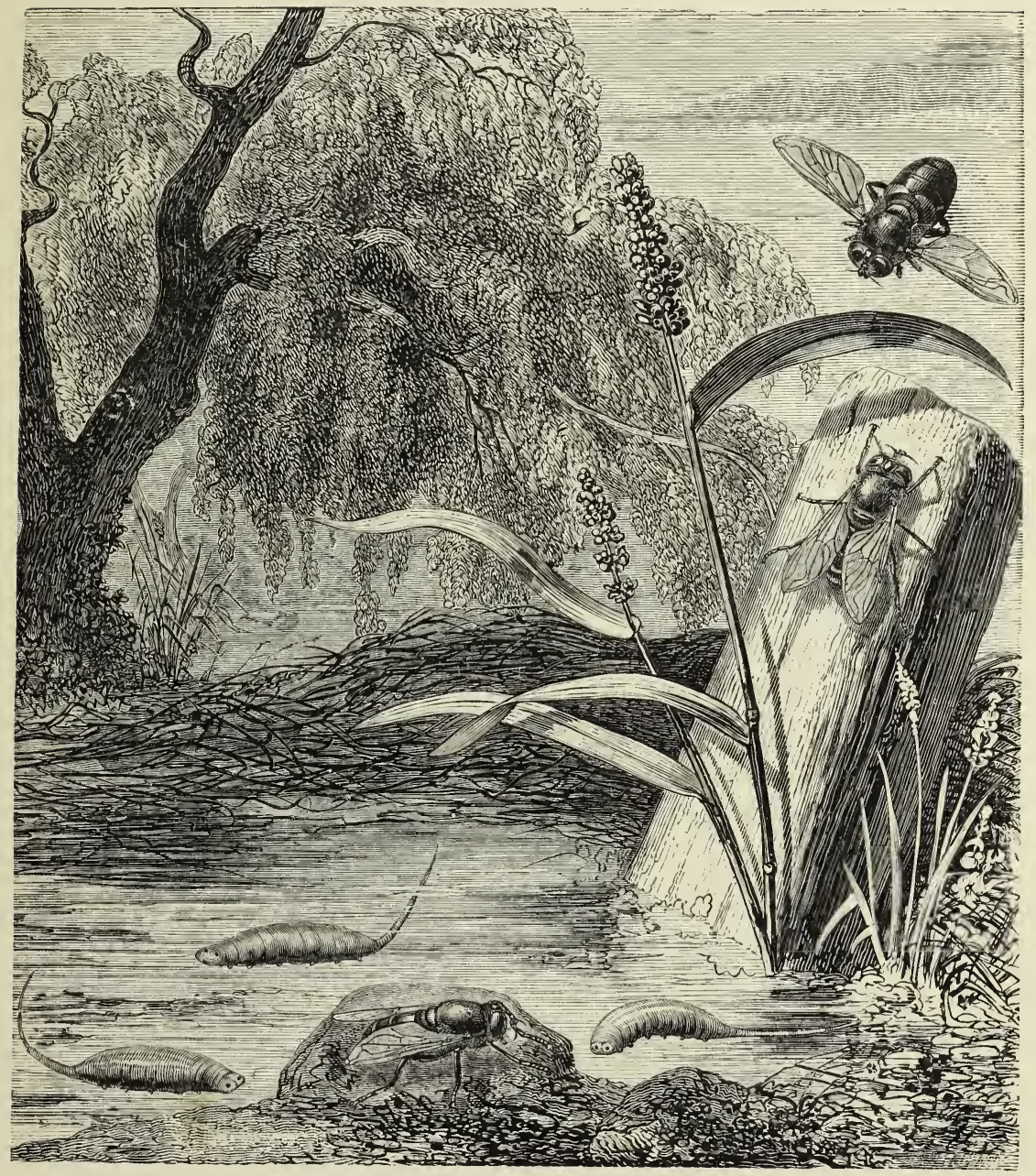

THE METAMORPHOSES OF THE RAT-TAILED FLY. (Eristalis tenax.)

genus Eristalis resemble those of Strationys. The larvæ have the same kind of tail-like appendage, which can be elongated when required; they live in shallow water, and move slowly on the bottom by means of very small legs, which are attached to the 
thorax and to the abdominal segments. The bodies of the larvæ are not supplied with any respiratory apparatus on their sides, so that the insects can only breathe by elongating and sticking up their tails, which are perforated, and can act as breathing organs. The larvæ are found in very briny waters, and even in the water of salt works, and besides in stinking pools. The perfect insect of this rat-tailed creature has a large black body, with russet spots upon the abdomen.

In the engraving on page $40 \mathrm{I}$ the larvæ may be seen having two large eyes, a stoutish body, and a long tail.

If one of them be placed in pure water it will live for a short time, and by just covering the insect at first, and adding water gradually, the tail will be noticed to become erect, and to elongate gradually, so as to keep pace with the flow of water, and always to remain above the surface. After having developed its tail to the utmost, should any more water be added the insect is drowned.

The Syrphus Fly, or Aphis Eater, is gaily spotted and banded with yellow, so that it resembles a small wasp. They may be seen upon flowers in fine weather, and they lay their eggs upon bushes and plants. The larvæ are very small creatures, and are very slender in front, and they walk, or rather crawl over the foliage, principally with the aid of their mandibles.

They are of a pale green colour, and may often be observed upon rose trees, where they feed upon the plant lice, which they suck and destroy with great rapidity. The larvæ of other Syrplide even attack caterpillars, and manage to eat their way into the bodies of their victims, but they always leave the last segment of the body in the open air, so as to breathe, for the respiratory orifices are situated at the end.

The true flies, or Muscida, are a great puzzle to those naturalists who indulge in classification. They have a distinct proboscis, which is thick, membranous, and terminated by two large lobes. It is formed by the united mouth-pieces, and especially by the large lower lip, and the mandibles, which are partly united together, form a sharp blade. These Diptcra, which differ so much in the adult stage, resemble each other in the larval condition. The white maggots are so well known that it is not necessary to 
describe them, but it must be observed that they do not moult or change their skin during their growth, and that when the time for metamorphosis is at hand, the body shortens, the skin becomes hard, and of a brown colour, and the chrysalis or pupa forms within. Many of the larvæ live as parasites within other insects.

In the accompanying engraving the larva of Gymmosoma rotundata is shown within the body of one of the Hemiptera. It has a long hooked-shaped tube, which is attached to its last segment,
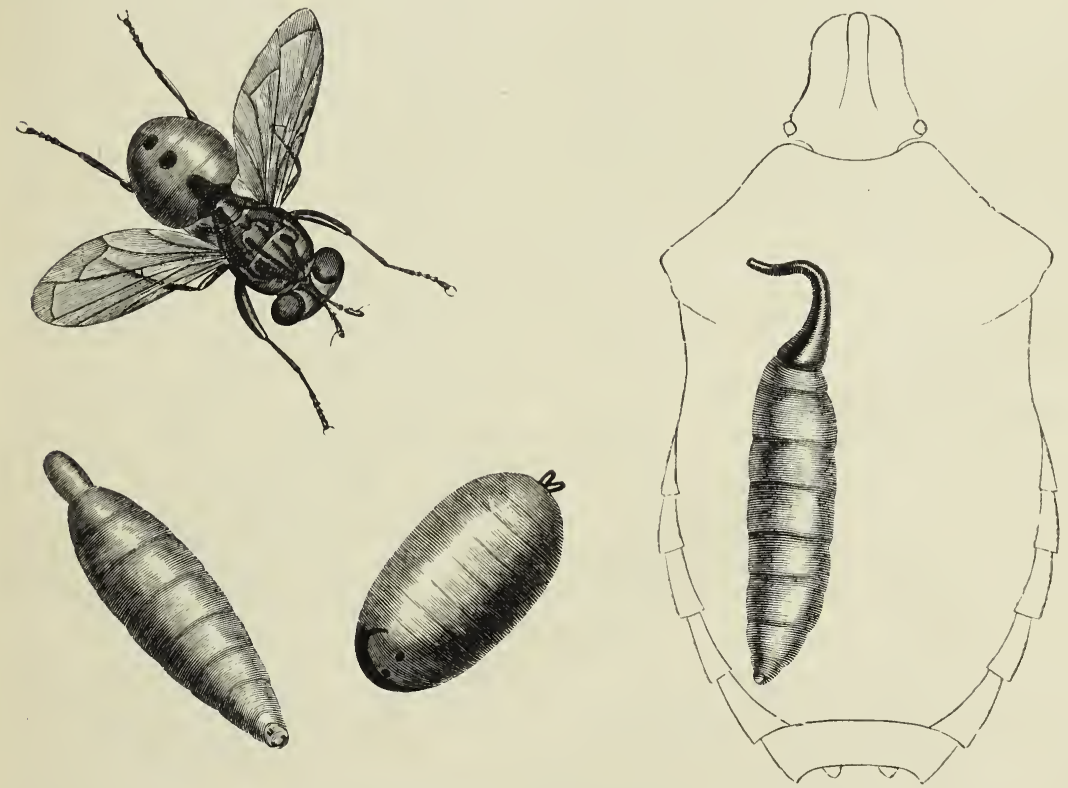

THE METAMORPHOSES oF Gymnosoma rotundata.

and this tube is protruded through one of the spiracles or respiratory orifices of its victim, so that it eats the juices and fat, and breathes through the body of the creature or "host" upon which it is parasitic. The perfect insect and the pupa are also depicted.

The Flesh Fly and the Blue Bottle are very useful as larvæ, or, as they are called, Gentles, for they devour dead bodies of all kinds, and many species, belonging to the genus Sarcoplaga, live upon stercoraceous matter.

The curious legless larvæ are very well known, and so are the egg-shaped, dark-brown pupæ. The larvæ, which at first 
are called "fly blows," increase in size with very great rapidity if they have sufficient food; and there is some truth in the

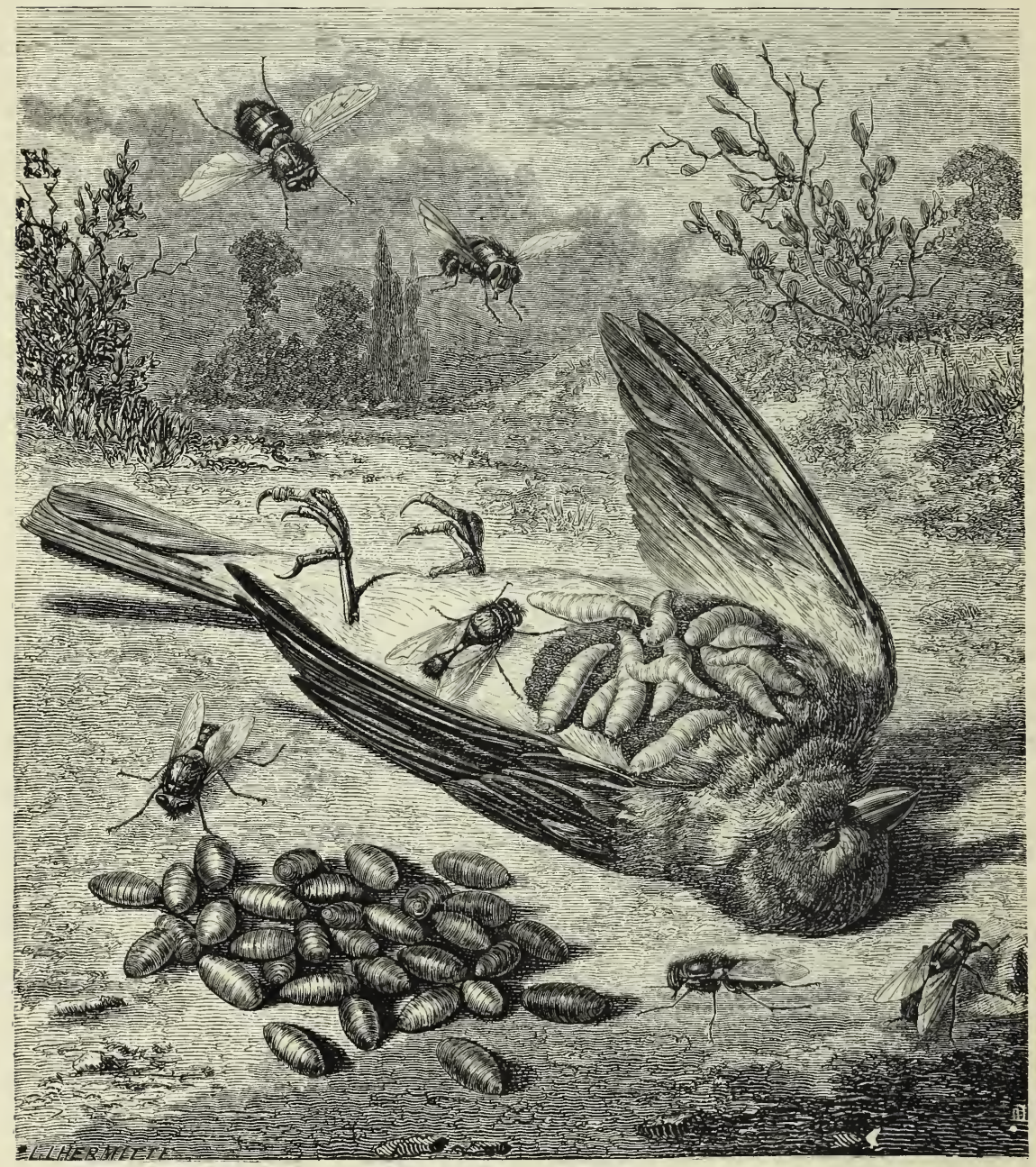

THE METAMORPHOSES OF THE MEAT FLIES.

(Calliphora romitoriu and Sarcophaga camaria.)

saying that a pair of maggots will eat up a carcase as soon as a lion, for the reproductive powers of the female are enormous.

The Bot Flies are very extraordinary creatures. They are large velvety flies, which have very small antennæe and a rudi- 
mentary trunk. When in the imago or perfect condition they do not take any nourishment; but inasmuch as they chase horses, oxen, and sheep, and all kinds of ruminants, and frighten them with their buzzing, they are generally supposed to sting the animals, but really they are incapable of doing anything of the kind.

The Gad Flies, or Tabani, chase the animals in order to suck their blood, but the bot flies seek them in order to lay their eggs, for their larvæ live as parasites upon the domestic animals, and ruminating Mammalia generally. The adult fly lays its eggs on the skin of some particular animal, and in some instances they are licked off the skin and are conveyed into the stomach, where they hatch, and the larvæ live by sucking the juices of the animal or the matter which their presence produces. Some larvæ are hatched on the surface of the skin, and they then bore into the body underneath, and feed there. The larvæ are thick, fleshy bots, without feet, and they are covered with rows of spines and tubercles, by which they move about, and they breathe through spiracles, which open at the end of the body. They moult twice, and just before attaining the pupa state they leave the bodies of the creatures they have lived in, and reach the ground, where they undergo their metamorphoses, the pupa being protected by the dried skin of the larva. The bot fly of the horse buzzes about horses and lays its eggs rapidly, and attaches them with a sticky substance to the hair about those parts of the body which the animal is in the habit of licking. The eggs are hatched, and the horse swallows the larvæ and they pass down into the stomach, to which they become fixed by means of their hooked mandibles. After a certain time they are passed out with the excrement and undergo their metamorphoses in cracks under the ground. The bot which affects sheep is an object of great terror to them. It lives in its larval state up the passages which lead from the nose amongst the front bones of the head, and produces much suffering. The larvæ of some bots, especially those which attack oxen, deer, and goats, dig themselves under the skin of those animals, and produce little tumours; and this is well known to some birds, for the starlings may be constantly seen at certain seasons of the year looking out for them on the backs and flanks of deer. 
There are several well-authenticated instances of bot flies attacking men, but it is probable that this is an accidental occurrence, and that they are the parasites of the monkey or dog.

There are some very extraordinary flies which inhabit the sea, and Packard describes the larva of a species living on floating sea grass. He noticed that they were transformed into pupæ, and that in nineteen days the second metamorphosis into the fly was perfected. He also describes an Ephydra whose larva lives in the strong salt works of Illinois and under the sea-weed on the shores of Narragansett Bay.

The Ticks are Diptera without wings, or which have them in a

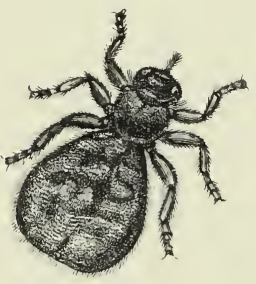

Melophagus ovis.
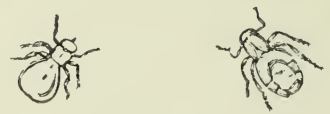

Leptatana cervi.

rudimentary condition. They have a sucker, and live parasitically upon all sorts of creatures.

The Sheep Tick, Melophagus ovis, has a wingless and hairy body and a long proboscis. The young are developed within the body of the parent until they attain the pupa state, and then the pupa in its case, which is nearly as large as the whole insect, is cast forth. Packard notices the Bat Tick, which has a small body and enormous legs, and it is either blind or provided with four simple eyes. These insects are of small size, being only a line or two in length.

The Stag Tick, Leptotona cervi, like the Sheep Tick, has no wings, and remains attached to the animal; but some Bird Ticks have very small wings, which enable them to leave one animal for another. These degraded Diptera are the connecting links between the true insects and the spider and mite families. 
The Bee Louse or Tick may be compared to a spider fly, and is about two-thirds of a line long. It is pupiparous, like the sheep tick, and the very day it is hatched it sheds its skin and changes to an oval pupa of a dark brown colour. Packard states that its habits resemble those of the flea, and that it is evidently a connecting link between the flea and the two-winged flies. Like the former, it lives and brings forth its young on the body of its victim or host, and draws its food by plunging its stout beak into the skin of the bee; and sometimes one of these industrious insects may be seen to be weighed down by as many as a hundred of these bloodthirsty creatures.

The varieties of metamorphosis in the Diptera are thus very considerable, and it must strike every observer that the most decided transformations are those of the parasitic flies. This is one of the proofs that the metamorphosis has been gradually added to the evolution of the insect, and that it is preservative of the species.

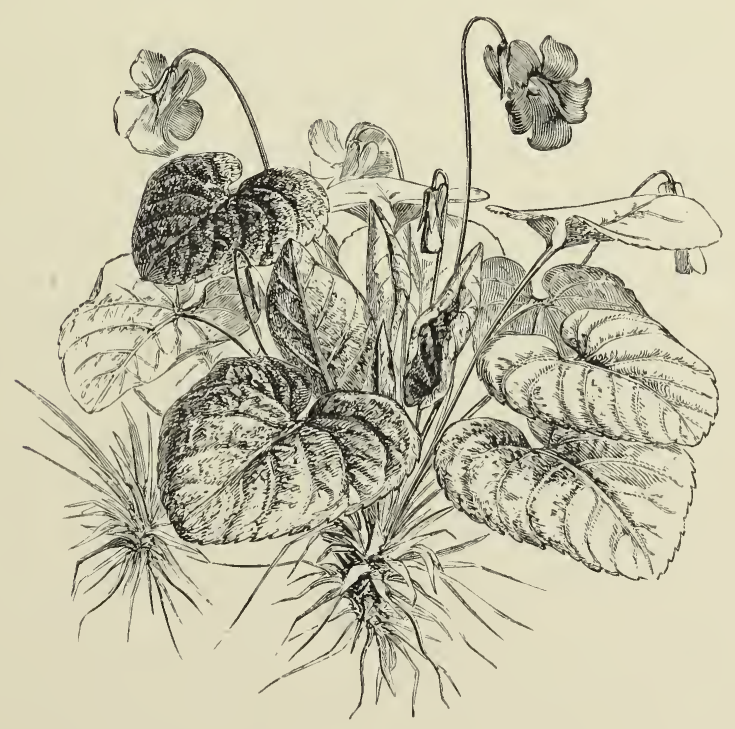




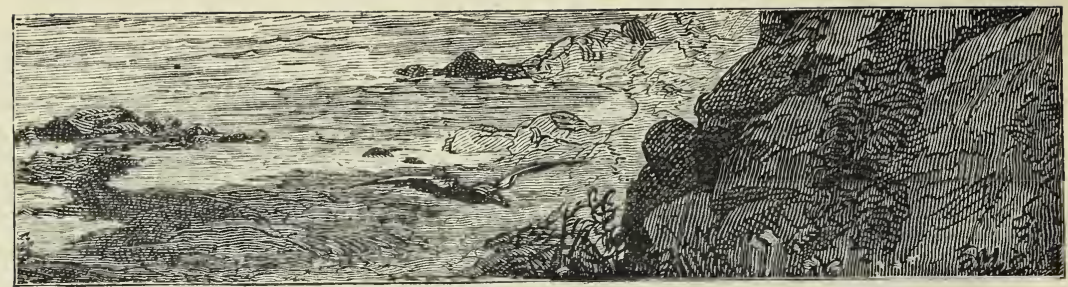

\section{CHAPTER XIV.}

THE ANOPLURA-THE THYSANURA.

THEsE are the most degraded forms of insects, and they never obtain, during any time of their lives, those elaborate structures which are usually considered to be characteristic of the class. The members of the species of Anoplura and Thysanura are invariably wingless, and their young are hatched almost as fully developed as the adults. They do not undergo metamorphosis, but their growth and development are accompanied by the phenomena of skin changing.

It appears that when the parasitic lice or Pcdiculi-which constitute an important portion of the class Anoplura-are hatched from the egg, they have not much subsequent alteration to submit to, as they are nearly perfect. Moreover, the young louse is not more perfect than the adult, and, therefore, no retrograde metamorphosis takes place. The caterpillars of Psyche and Orgyia turn either into male moths with beautiful wings or into females with the most rudimentary organs of flight, and this occurs because these last submit to a retrograde metamorphosis. The adult female Orgyia is absolutely lower in organisation than the caterpillar. But, although there is some resemblance between these female moths and the Anoplura, it must be remembered that the lice retain their larval condition through life. There are some proofs, however, that there is a retrograde development in the louse before it is hatched. Until late in its life within the egg the louse grows, and is formed like the embryos of other insects, and then, just before hatching, takes on its peculiar degraded aspect and essential 
structural details. Then the parasite is born closely resembling its parents.

There are two great divisions of the Anoplura; in one, the true lice, the insects have suckers; and in the other, the bird lice, there are jaws. The Pcdiculi which are parasitic upon the hair and clothes of man are, of course, disgusting on account of their association with dirt and disease, but nevertheless they are interesting creatures to the naturalist, on account of their wingless and degraded condition, as well as from their not undergoing metamorphosis. Moreover, there is much interest accompanying their birth, for the females preponderate, and they can lay fertile eggs time after time without the help of the male, and generations of

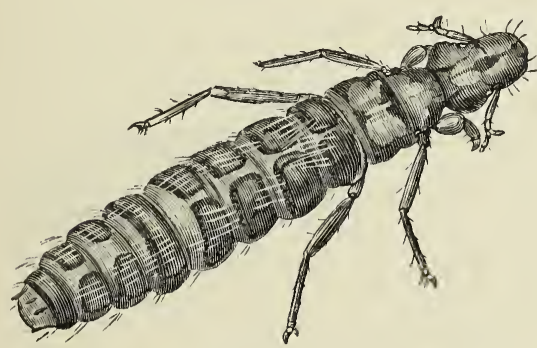

Philoptcrus selcifrons.

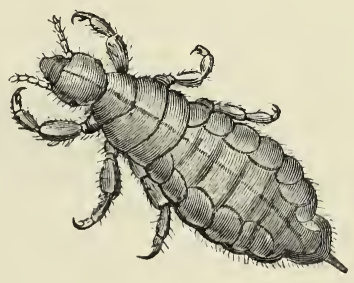

Pediculus capitis.

females succeed each other and produce fertile eggs under the same exceptional circumstances.

The Head Louse, drawn above, is not very unlike a long bedbug (Cincx) in its early stage.

The lice without suckers, and with jaws that can bite through the skin, afflict most domestic mammals and all sorts of birds. In tracing their development within the egg it becomes evident that some of the earlier characters of the embryo are retained persistently; thus the permanently enlarged forehead of the bird louse can be recognised during very early egg life, but this structure disappears very soon in the embryos of the true lice with suckers.

The legs and claws of the different species of Philopterous or bird lice vary much in structure, on account of the peculiar conditions in which the parasites are placed and live. One genus, which has a species parasitic on the porpoise-the only marine 
parasitic true insect-is very degraded in its structures and development; and the forms classified as Goniodes are also remarkable for their defective organisation, as well as for the presence of a claw upon the antennæ of the males. The philosophical naturalist may ponder with interest upon the absence of the metamorphoses in these parasitic creatures, and consider their evident anatomical, and therefore classificatory relation with those spiders which have tracheæ as their respiratory organs; and he must be struck with the anatomical relations of these groups with the other insects that undergo incomplete or imperfect metamorphoses.

The Thysanura or skip tail tribe are small insects which are

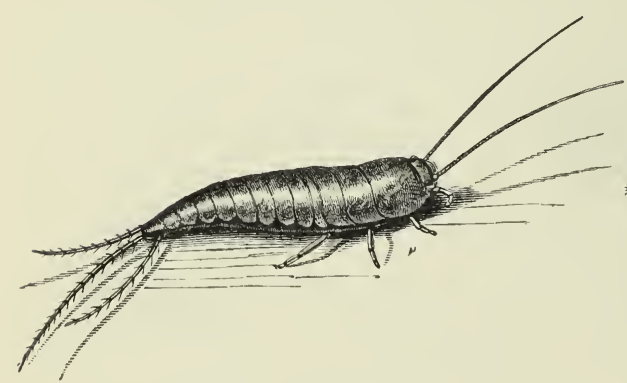

THE FISH SCALE.

(Lepisma saccharina.)

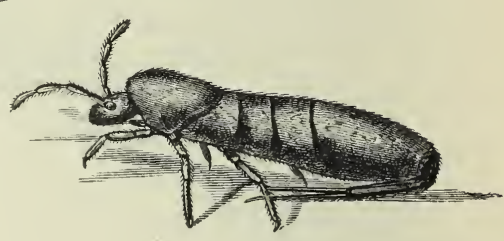

TIE SKIP TAIL.

(Podura plumbea.)

better known on account of the beauty of their microscopic body scales than for any interesting habits or instincts. They do not undergo metamorphosis, and are wingless.

Sir John Lubbock's careful researches have resulted in his being satisfied that in the genus Smynthurus there are tracheæ for respiratory purposes, and that they communicate with the external air by means of spiracles, which are not situated along the margins of the thorax, but in the head, where it is attached to the body. 


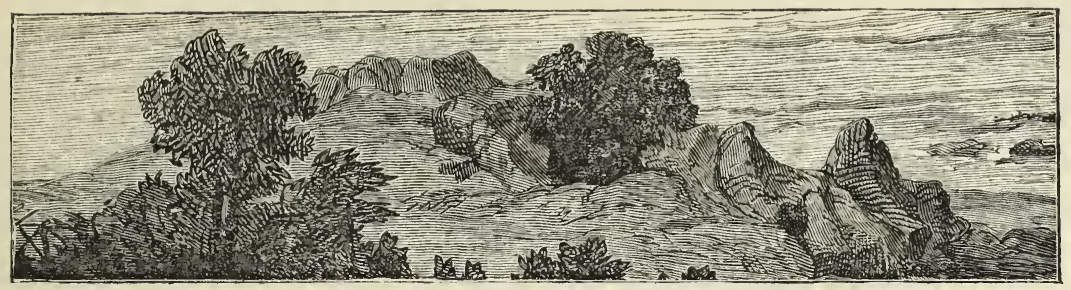

\section{CHAPTER X V.}

THE MYRIAPODA.

THE Myriapods, familiarly known as the Hundred Legs, or Centipedes, were formerly classified with the true insects, but of late years they have been separated from them, and arranged in a class by themselves. A very superficial examination of the characteristics of the Myriapods will be sufficient to explain the necessity for this separation, and it is rendered absolute after the study of the early development and growth of these many-legged creatures. The aspect of the perfect Myriapod does not give the least insight into the interesting series of developments which produced it; and yet their early structures are those which ally them to the larva of the insect classes already described.

Common observation decides at once that the Myriapods have a great number of legs all very much alike, and that they have a head; but the division of the body into the thorax and abdomen, as in true insects, is not apparent, for the head is followed by a long series of segments or rings, each giving attachment to one or two pairs of legs. The distinction between the thorax and abdomen, as hitherto applied, is therefore impossible, for instead of the locomotive organs being restricted to the segments of the thorax, and being absent in the abdomen, all the segments or rings of the Myriapoda are supplied with them.

The mouth of the Myriapod has much in common with that of the insect, and is composed of a labrum, two mandibles, two jaws, and a lower lip, or second pair of jaws ; but the first two or three pairs of legs enter into the category of mouth organs also, 
and it would appear, according to Savigny, that they correspond with the three thoracic legs of insects which have very different functions, however.

The Myriapoda are divided into two great orders, which can be distinguished very readily. The "Thousand Legs," which have two pairs of legs to each segment of the body, and antennæ with seven joints, constitute the first order, or that of the Chilognatha; and the "Hundred Legs," which have one pair of legs to each segment, and also long tapering antennæ, with fourteen or more joints, form the second order, or that of the Chilopoda.

The Chilognatha are fond of hiding up under stones, in damp, dark places, and they live upon decaying vegetable matter and
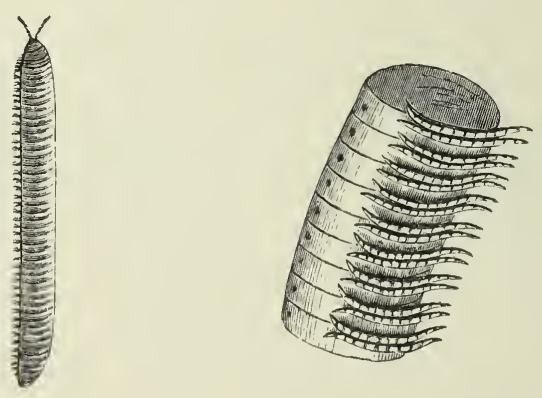

Segments (Magnified).

THE MYRIAPOD. (Fulus terrestris.)

the tender rootlets and buds of plants. They have not very formidable jaws, and the common genus, Fulus, which is to be found everywhere in gardens and fields when the upper soil is disturbed, may be considered the type. The Fulide have not really a thousand legs, but several hundred pairs may exist upon the long and cylindrical body, whose twistings and serpentine motions impress observers very unfavourably concerning the habits and intentions of the creature.

The Chilopoda, on the contrary, are insects of prey, and chase and kill all sorts of small living things, upon which they feed with their strong jaws. The Scolopendra is the type of this division, and is a very formidable hunter. Its head appears to consist of two parts-one a circular shield-like plate, into which are fixed the antennae and the eyes, and the other a large and strong segment, 
which is horny, and supports a pair of sharp hooked fangs resembling jaws, that move sideways, like the so-called mandibles of the spider. These jaws are, however, only modifications of the first fect, which are converted into instruments for killing prey, instead of moving their possessor from place to place, and each is perforated near its sharp termination with a long oval slit, through which venom is said to be instilled into the wound inflicted by this formidable weapon.

The texture of the segments of the body of Fulus is hard and brittle, but the rings of the Scolopondra are flattened, and covered above and below with tough and leathery scales. Each segment, as has been stated above, in the Chilognatha, supports two pair of legs on each side on its under surface, but the first three segments only support a single pair. The last two segments are also without legs. The legs are short, feeble, and have several joints.

In the Scolopcndra, however, the legs are long, strong, and very active; they have five joints, and terminate in a claw. Those attached to the segments near the head are small, but as they approach the hinder part of the body they increase in size and strength, the last pair being turned backwards. The number of the segments and legs appears to be constant in the adult Myriapod, but subject to important and remarkable increase during the progress of growth and development.

A drawing of the alimentary canal of a Myriapod reminds us of that of the lepidopterous larvæ. The osophagus or gullet of Fulus tcrestris is capacious, the stomach is long and straight, and ends where the liver tubes enter, and an intestine straight and short succeeds. The salivary glands are folded up at the sides of the gullet, and the liver tubes pursue a tortuous course, and terminate at the end of the stomach. In fact, the resemblance is very great indeed. The respiratory organs are also similar as regards their arrangement in the two classes. The Myriapoda respire in the same manner as insects, by means of lateral spiracles and tracheal tubes. The spiracles are as visible on the sides of some Scolopendride as they are on the flanks of caterpillars, and the tracheæ pass inwards in both instances, to be distributed over and amongst the internal organs. Moreover, the minute structures of the trachere are identical in the two classes, and the spiral 
fibre which keeps the tubes open is found in both. The true insects resemble the Myriapods in their vascular system, and in their nervous system also. The nervous system of the Myriapoda, as in all the Articulata, exhibits a double series of ganglia, connected by cords of intercommunication. The ganglia above the œesophagus in the Myriapods is situated within the head, and corresponds with the structure as seen in the larvæ of insects.

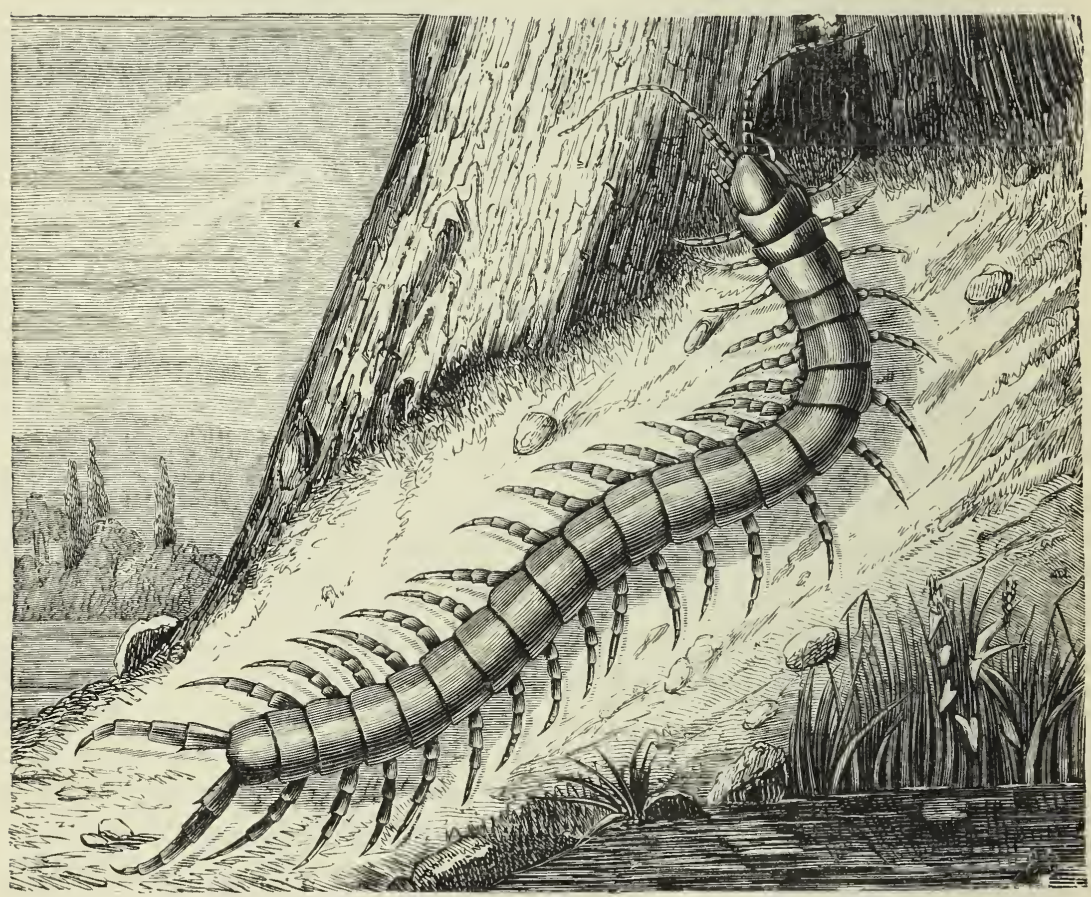

Scolopendra morsitans.

The ganglia of the nervous chain which runs down the body, as in insects, are numerous, in proportion to the number of segments; and they are well developed in Scolopendra, whose legs are long and powerful, and but feebly so in Fulus, whose locomotive organs are small and weak. The organs of the senses of the Myriapoda resemble those of insect larva, but the most perfect Scoloncndra does not present the complicated compound eye which characterises the perfect butterfly or beetle.

Wings are never met with amongst the class now under con- 
sideration, but the powers of locomotion are increased over those of a simple insect larva, by the multiplication of the segments of the body and their legs. There is no consolidation of the anterior segments into a thorax, as is the case in insects, and instead of this concentration during development, the reverse takes place, and the growing Myriapod increases by the production of new rings.

No metamorphosis takes place in the Myriapoda; but the absence of the distinct phases which characterise the phenomenon is compensated for by a succession of changes of skin and accessions of structures.

Sir John Lubbock has described a curious little Myriapod, which he has named Pauropus, and it was found by him amongst dead leaves and in other accumulations of decaying organic substances, in company with species of Thysanura, mites, worms, and other living things that frequent similar situations. Pauropus Huxlcyi is a bustling, active, neat, and cleanly little creature, and Sir John Lubbock says it has a look of cheerful intelligence which forms a great contrast to the dull stupidity of the Fulida, or the melancholy ferocity of most Chilopods. It lives throughout the year among dead leaves, and is continually running about, and it sometimes gives a rush of surprising velocity. He found it during the winter in the warmer days, and he noticed that it cleans its feet and antennæ with its mouth.

The animal is tolerably transparent, and the digestive organs are plainly visible, but there are no tracheæ. Lubbock supposes that it respires through its delicate skin, as no traces of respiratory organs were to be seen; and, if this is the case, it forms a separate family, for all the other Myriapods respire through the agency of tracheæ. The growth of these insects is very remarkable.

The smallest specimens observed by Lubbock were about $\frac{1}{72}$ of an inch in length, and possessed three pairs of legs only. The first pair was attached to the third segment (the one which succeeds the head), the other two to the following one. Beyond the legs were two other segments, making six in all, as seen from above, and counting the head as two. The first of the six-legged insects was found in September, and they were in company with their parents. They moult, and there appears to be great 
wriggling and much trouble to get out of the old skin. When the skin has been got rid of, the singular fact comes to light that another large segment and two more pairs of legs are added, so that the Pauropus becomes a ten-legged animal. After a while the insect moults again, and at each change of skin obtains a fresh pair of legs, and at last nine pairs are developed.

The three pairs of primitive legs so characteristic of the true insects are speedily added to during the growth of the young Fulus, and that this is the case will be gleaned from Newport's description of the Myriapod from its earliest observable state.

The development of the young Fulus is divided by Newport* into several distinct and well-marked periods. The first period extends from the deposition of the egg to the gradual bursting of the shell and the exposure of the embryo within, occupying the space of twenty-five entire days, during which the egg acquires a sensible increase of bulk.

On the nineteenth day there was a complete alteration in the form of the egg. It was more obtuse at both ends, and had become much larger, and the outline of the embryo, coiled up within the shell and nearly filling the whole interior, was very distinct, although as yet there were no rudiments of limbs or even of a division of the body into distinct segments. On the following day (the twentieth) the outline of the embryo was more apparent, and on its concave or ventral surface there were faint traces of a division of the body into six segments. Up to this time Newport was unable to detect an umbilical cord attached to the embryo. From this time the egg became larger every day, until the twenty-fifth day, when it was greatly distended, and began to assume a kidney-shaped appearance, and commenced bursting along the back, the back of the white embryo gradually passing through the opening (Fig. I).

In the second period of development the embryo is exposed to a new medium, and perhaps derives the means of its further growth from external sources, although it is still enveloped in the foetal membranes, and retains its connection with the shell.

\footnotetext{
* Quoted from Rymer Jones' article "Myriapoda," in the "Cyclopædia of Anatomy and Physiology."
} 
The liberation of the embryo is a remarkably slow process as compared with the escape of other animals from the egg. In Mr. Newport's observations from ten to twelve hours elapsed before the body of the young Myriapod was so far liberated as to remain only partially enclosed between the two halves of
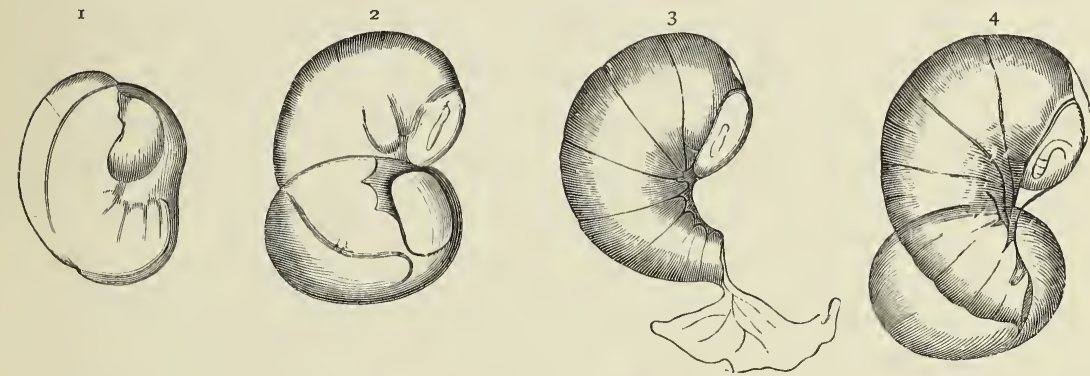

6

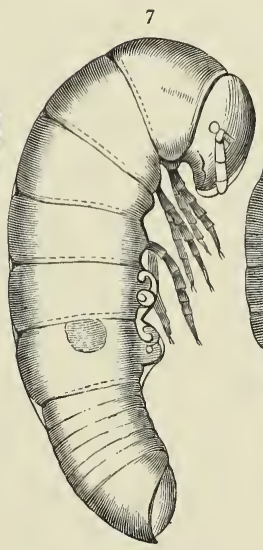

8
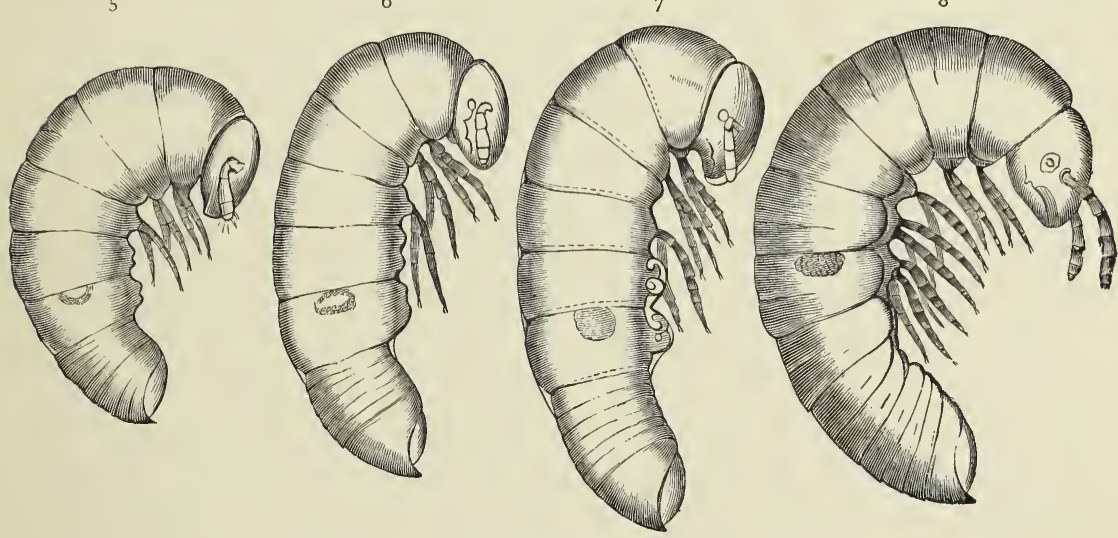

THE DEVELOPMENT OF Fulus terrestris. (After Newport.)

I. The embryo on the rupture of the egg. 2, 3. Newly born Fulus at the end of the first day. 4. A nine days' old Julus. 5. Fulus on the seventeenth day. 6. On the nineteenth day. 7. On the twentieth day. 8. On the twenty-sixth day.

the shell, being still attached to its interior by a cord (Fig. 2). So remarkable is its condition at this period that it strongly resembles the expansion of the germ in the seed of a plant rather than the evolution of a living animal. The embryo is perfectly motionless, and the bursting of its shell appears to be effected not by any direct effort of its own, since up to this time it has only acquired the form and cxternal semblance of a living 
animal, but by the force of expansion of the growing body, the development of which being greatest along the line of the back, exerts in consequence a greater degree of force against the middle of the dorsal than the corresponding part of the ventral surface. The head and tail of the embryo act as a fulcrum against the ventral surface only at the ends of the shell, and thus bend it into the kidney-shaped form it assumes while the dorsal surface of the embryo is gradually pressed through the opening. From the comparative rapidity of its enlargement immediately after the shell is fissured it seems as if the stimulus given to it by exposure to a new medium-atmospheric air-were the great means of exciting its evolution.

The embryo is now formed of eight distinct segments (Fig. 3), including the head, the ninth or anal ring being still indistinct. The head is more defined in its outline, and exhibits at its sides a faint trace of the future antennæ. The four thoracic segments also exhibit on their ventral surface little nipple-shaped extensions, three of which on each side are the rudiments of future legs. Mr. Newport was unable to detect any separate internal organs, the whole embryo being made up of a mass of cells, in the midst of which there appeared to be some traces of the commencement of the alimentary canal. On the third day the embryo had increased considerably in size, but was still perfectly motionless. The rudiments of the legs were more developed, and, indeed, the creature is then apodal, or legless, for several days after bursting its shell, the future limbs being in a very rudimentary state.

Some faint traces of a single eye or ocellus on each side of the head were discerned on the fourth day, and there were traces of the formation of the internal organs. Internally the body was still formed of cells, aggregated together, but differing more in size than at any previous period, as if they were becoming fused into separate tissues, and in the midst of them, and closely surrounded on all sides, was the newly-formed alimentary canal. Around the sides of the body muscular structure was also in course of development, but as yet was exceedingly indistinct. The legs had become larger and more obtuse, and the embryo was still motionless and incompetent to take on spontaneous movements. On the third day the posterior part of the body is less distinctly 
divided into segments than the anterior, the first five segments being most distinctly marked. On the fourth day the sixth and seventh segments are more defined. New segments are formed gradually in the membrane which connects the seventh with the eighth segment, and this last is always the last segment but one throughout the life of the Myriapod (Fig. 4). On the ninth day the changes have advanced much farther. Not only have the future new segments become more distinct, but transverse depressions are also seen on the dorsal surface of the original segments, showing their division into double ones, as in the perfect animal. The rudiments of legs are now further developed, and their transparent further extremities are seen to be applied closely together and extended along the ventral surface of the body as in the nymphs or pupæ of true insects. The antennæ and ocelli are more apparent, and the embryo itself has increased at least one-third of its original dimensions. It has thus continued to grow through nine succeeding days since the bursting of its shell without any visible means of nourishment, the nutriment supplied by the yolk having been exhausted before that occurrence. It becomes a matter of inquiry, then, from whence is it nourished? whether it has already sufficient materials derived from the egg and stored up within itself for its future development, or whether the external enclosing meinbrane may not still contribute to the function of nutrition by absorbing fluid condensed from the air of the humid locality in which it resides? "The probability of this last supposition," writes Mr. Newport, "is somewhat countenanced by the fact that I have constantly observed the membranes of the embryo at this period covered with microscopic drops of fluid, but whether this is fluid condensed on the membranes from the atmosphere of the dwelling, or whether it results from the transudation of that which was once contained within the membrane, remains for future inquiry." It is to be observed, however, that the weight of the embryo was not determined repeatedly by Mr. Newport, and this is to be regretted, because it would have settled the matter at issue. With regard to the internal construction of the body at this period, it was observed that the alimentary canal was nearly complete, some liver ducts were seen, and the great divisions of the digestive organs also. 
On the tenth day the organ of circulation was noticed for the first time, and the great dorsal vessel was seen to pulsate. The head of the embryo had now begun to assume the peculiar corneous appearance common to the larvæ of insects, and its body had much increased in size. On the eleventh day the head was more distinct, and the antennæ appeared at its sides like short crescent-shaped clubs with their terminations directed forward. Above them the single ocelli were distinctly seen. On the morning of the seventeenth day Mr. Newport found all the embryos ready to leave their investing membrane. Some of them were already detached from the shell; others were still connected with it. Their increase of bulk had been very great within the last few hours. The body was more straightened, the head less inflected under the thorax, and the eye was a dark-coloured spot above and behind the antennæ. The greater length was produced by the growth of the posterior segments, more especially of those in the space before the last segment but one. This last segment but one is called the penultimate, and the space the antepenultimate and germinal space, and the faint divisions of future segments were seen in it. The seven anterior or front segments were much enlarged.

The third period of development was now entered by the animals divesting themselves of their membranous coverings (Fig. 5). This was the first spontaneous act of the Myriapod, which curled itself up and appeared exhausted, and life was only proved to exist by occasional movements of the antennæ. It possessed three pairs of legs, like the true insects, and yet no great physical change was observed to mark the line between the condition of an inert embryo and one capable of spontaneous movement. This gift characterises the beginning of the third period, and the vegetative life ends with it, for the Myriapods gradually acquire voluntary and instinctive faculties, both as regards the means of procuring nourishment and of preserving themselves from injury. In about an hour after leaving the membranes, the young Fulus cxhibited a marked change. Its head was elongated on the prothorax, the parts of the mouth were distinctly movable, and the cyc, a single ocellus on each side of the head, acquired a darker colour. The whole body had increased a fourth in bulk. It now 
measured about a line in length, and exhibited the nine original segments, the first seven being strongly marked. In the space we have called the antepenultimate, six new segments were now developed; these were still very small, the length of the whole being equal to that of one of the others. At that time they did not form independent divisions of the body, but were covered by the common skin or tegument. The last segment of the body and the penultimate are permanent, and are not divided off into the segments which make theị appearance from time to time, and these are really new growths.

The skin covering the whole body is thrown off, and then the Fulus appears with the six new segments mentioned above, and ready for food. It will be observed that additional legs have begun to grow. Hitherto the Fulus has had three pairs, but four additional pairs are in course of formation, and they exist at this period as nipple-shaped prominences on the under surface of the sixth and seventh segments, four on each, and covered by the common skin or tegument which is beginning to fall off. The three pairs of legs that now exist are attached as follows:-One pair to the prothorax or second segment, one to the third, and one to the fifth segment. The general appearance of the animal has now become less delicate, the head has acquired a darker colour, and a faint broad patch is making its appearance at the anterior part of the seventh segment. This patch (Figs. 5, 6, 7) is permanent through all the earlier changes, and is of the greatest utility in determining how new segments are produced. Such was the condition of the young Fulus an hour after leaving the membranes. It soon began to exhibit its animal powers, to show the instincts peculiar to its species, and to be sensibly affected by external causes. In less than six hours the little creature was in motion. At first the antennæ were the organs employed, and they were moved slowly to and fro, and appeared to gain power by use. In a short time the limbs began to be extended, and the animal slowly raised itself upon them for the first time. Its first efforts at locomotion were exceedingly feeble, but it gradually gained strength. At the end of twelve hours the Fulus crawled about slowly, but moved its antennæ briskly. On exposing the insect to a strong light, a marked effect was produced 
in their movements. They evidently were greatly affected by it, and seemed to shun it instinctively. This was the first marked exhibition of instinct, and then locomotion was performed with the same instinctive care. The end or anal segment was expanded like the same part in a caterpillar; and, being first attached, like a true pro-leg, and its steps, as it were, measured, its body was carried forward by an effort that extended, as in insects, from segment to segment.

At twenty-four hours after escaping from the membrane the young animals were lying together in a heap, but when disturbed seemed to have acquired more power of moving; they remained quiet except when roused, and had not yet taken food. The only marked difference in their appearance, excepting that they had still further increased in size, was in the nipple-shaped protuberances on the sixth and seventh segments, the rudiments of future legs. These were now more distinct and more uniform. Ten hours later in the day they assumed still more the appearance of nipples projecting from the under surface of the segments. When examined in specimens that had been placed in spirits of wine it became evident that these projections were occasioned by the development under the deciduous (cast skin) integument of four new but exceedingly minute legs, complete in all their parts, each covered by its proper skin. The claws to the legs were also more strongly marked. The new segments were more grown.

Mr. Newport found that the Myriapods had assumed a darker colour on the nineteenth day, but they had not as yet taken food. The double pair of legs to the sixth and seventh segments were distinct through the external tegument, which had begun to be separated from the surface of the old segments, to which up to this period it had closely adhered (Fig. 6). The patch on the side of the seventh segment had become darker, and the new segments were further advanced. On the twenty-first day the young Fulides still remained coiled up and perfectly quiescent, with their legs placed side by side along the under surface of the body, like the pupæ of lepidopterous insects. The new legs had increased in size as well as the whole animal, although it had not taken food. The animal was still partly coiled up, but the skin that covered its body was greatly distended, more 
especially along the ventral surface. It was less able to move than before, the period of throwing off the skin being fast approaching; the double legs of the sixth and seventh segments, enclosed in their proper skin, were now more elongated, and very much enlarged; and the new segments were further developed, and the germinal membrane also. Up to this period the young Fulus is still essentially in an embryonic condition, and it does not acquire the peculiarities of a true larva until the approaching change of skin. This took place by the twenty-sixth day, and the Myriapod was found to have seven pairs of legs and fifteen segments to its body. The antennæ had become elongated by at least one-third of their original length, and exhibited at least six distinct joints. The eye still consisted of a single ocellus, but this was now surrounded by a darker-coloured portion of the tegument. The new legs were equal in size and length to the original ones, and were evidently more feeble. The transverse markings on the seven anterior segments were very distinct, and the large brown patch on the seventh ring was darker in colour (Figs. 7 and 8). The whole body was considerably elongated, and this was produced chiefly by the extension of the new segments formed by the germinal membrane. The penultimate and the anal segments, of course, had undergone no change, and they never possess legs.

By the forty-fifth day more segments were added, and the Fulus began to be torpid, and lay coiled up in a spiral form. The tegument of the body began to assume a whitish, crustaceous appearance, and the animals secreted themselves beneath any dry covering, but avoided parts which were too wet. The principal changes in their general appearance were in the eyes, each ocellus being much more distinct, and in the germinal space, which was developed to its greatest extent; the six new segments were defined.

The change of skin is effected in the following manner:The young Fulus, when about to cast its integument, bends its body in a semicircular form, with its head inflected against the under surface of the second segment. In this condition it remains for several hours, with its legs widely separated and the dorsal (back) surface of the segments extended. The head is then bent more forcibly on the chest, and a longitudinal fissure takes place on the top of the head, and extends outwards behind 
the antennæ. The head is carefully withdrawn through the opening in its covering, and with it the antennæ and parts of the mouth, and afterwards the anterior segments and single pair of legs. The first and apparently most difficult part of the shedding of the skin is its detachment from the posterior segments of the body, and from the interior of the large intestine. To effect this the animal, which has been previously lying coiled up in a circular form, first straightens its whole body; it then forcibly contracts and shortens itself, especially at the posterior part, and by this means becomes greatly enlarged in bulk at its middle portion, but smaller at its extremities. During these efforts, which are some of the most powerful it is able to make, the skin becomes loosened from its posterior parts, and while still contracting its segments, the anal extremities, and with it the entire lining of the large intestine, become completely detached, and from these it gently withdraws itself within the old skin, in which the body is encased, as from the finger of a glove. This is precisely what takes place in the shedding of the skin in true insects. Having effected this part of its labour, all the posterior segments are again shortened; the animal once more disposes itself in a circular form, and after repeated exertions, succeeds in bursting the tegument of the head in the part just described. As in the case of the true insects, the young Fulus entirely empties its alimentary canal and ceases to eat for one or two days preceding each skin shedding. When examined immediately before the change there are no other symptoms of new legs than slight eievations of the skin, and this perhaps accounts for the length of time occupied in the change, the new legs requiring time for further development before the old skin is thrown off.

Having cast its skin, and thus attained the fifth period of development, the young Fulus has three ocelli on each side of the head, seven joints to the antennæ, thirty-four legs, and twentyone segments to its body.

The Fulus changed its skin again on the sixty-third day, and entered its sixth period of development. It then had acquired twenty-seven segments to its body, which had greatly increased in size, and was of a brown tint. There were six distinct ocelli on each side of the head, and there were altogether fifty-eight legs.

The Chilopoda, which have less numerous legs, appear to 
undergo changes somewhat like the Fulide before attaining the adult stage. The species of the genus Crytops, when full grown, have inconspicuous eyes, seventeen joints to the antennæ, and twenty-one pairs of feet. But when they are young they have no mouth, and nothing like it is to be seen when the microscope is used; there is, however, a rounded aperture at the back of the head, and fringed at its margin. It is remarkable that one of the species of the genus, Crytops Savigni, should have no less than twenty-nine joints to its antennæ in its imperfect state, but only seventeen in the adult form, so that there is a retrograde development during the successive moultings and the corresponding structural changes.

One genus, Scutigera, has a slim body, but very great legs and antennæ; and the growth of Scutigcra araneoidcs is very remarkable, according to Fabre, especially with reference to the front and hind parts of the body. The young are furnished with only seven pairs of feet; but during development the number of the segments, legs, and ocelli, besides the number of the joints of the antennæ and tarsi, increases. The segments which bear the first seven pairs of feet, and which exist at the moment of birth, form the half of the body which contains the organs of the senses and the essential parts of the digestive apparatus; whilst the other half, which lodges the reproductive apparatus, is developed subsequently. Fabre appears to consider that the first part represents the larva, which only manifests the life of the individual, and the posterior portion the perfect insect, in which resides the life of the species. This fancy may be of course applice to the case of the Fulus; but it only testifies to the vivid imagination of an able naturalist. The same author has observed the phases in the development of Lithobius forficatus. It is born with ten segments, seven pairs of feet, seven joints on its antennæ, and two ocelli. Two months elapse, and the Myriapod is observed to have seventeen segments, fifteen pairs of feet, six ocelli on each side of the head, and twenty-six joints to its antennæ.

The Myriapoda are very ancient creatures, and doubtless the Fulus that was found in a tree stump in a coal seam in Nova Scotia by Dr. Dawson took as long to mature during a series of moults, which imitated metamorphosis, as its modern descendants. 


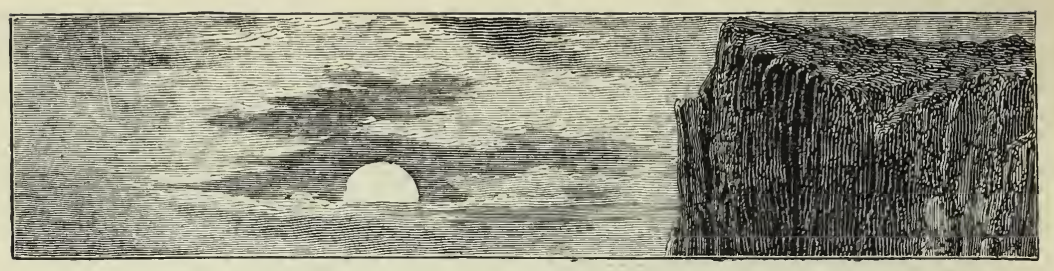

CHAPTER XVI.

A R A C H N I D A - S P I D E R S.

If the question, Do spiders undergo metamorphoses? were asked of the ordinary observers of Nature, probably an answer in the negative would almost invariably follow. Whoever saw a spider in the form of a grub transform into a pupa, and then spring into web-spinning life ? might be a question asked as an answer to the demand just made, which savours to a certain extent of absurdity. But as a matter of fact, many Arachnida do pass through the stage of larva, nymph, and perfect insect, and those of one great order of the class are almost invariably transformed. A metamorphosis is very decided in some, and a further change even is superadded in certain genera.

The majority of the Arachinida that do not undergo metamorphosis shed their skins from time to time, or moult, and internal changes go on before and during these external alterations, which are very considerable and impertant. Moult after moult produces fresh changes and the appearance of new structures, so that the sum of these alterations may almost equal in amount those which occur at stated periods in the spiders which undergo metamorphoses. Nevertheless, the moulting spiders are born from the egg much more fully developed than those which suffer metamorphosis. These last are hatched when only three pairs of legs are observable, but the others present the rudiments of four pairs long before they are sufficiently developed to crawl from the egg. Nothing like the slow growth of the Fulus is witnessed amongst the moulting spiders, but they are born fecble, and their limbs are not strong, and they pass through an infancy, as it were, and moult several 


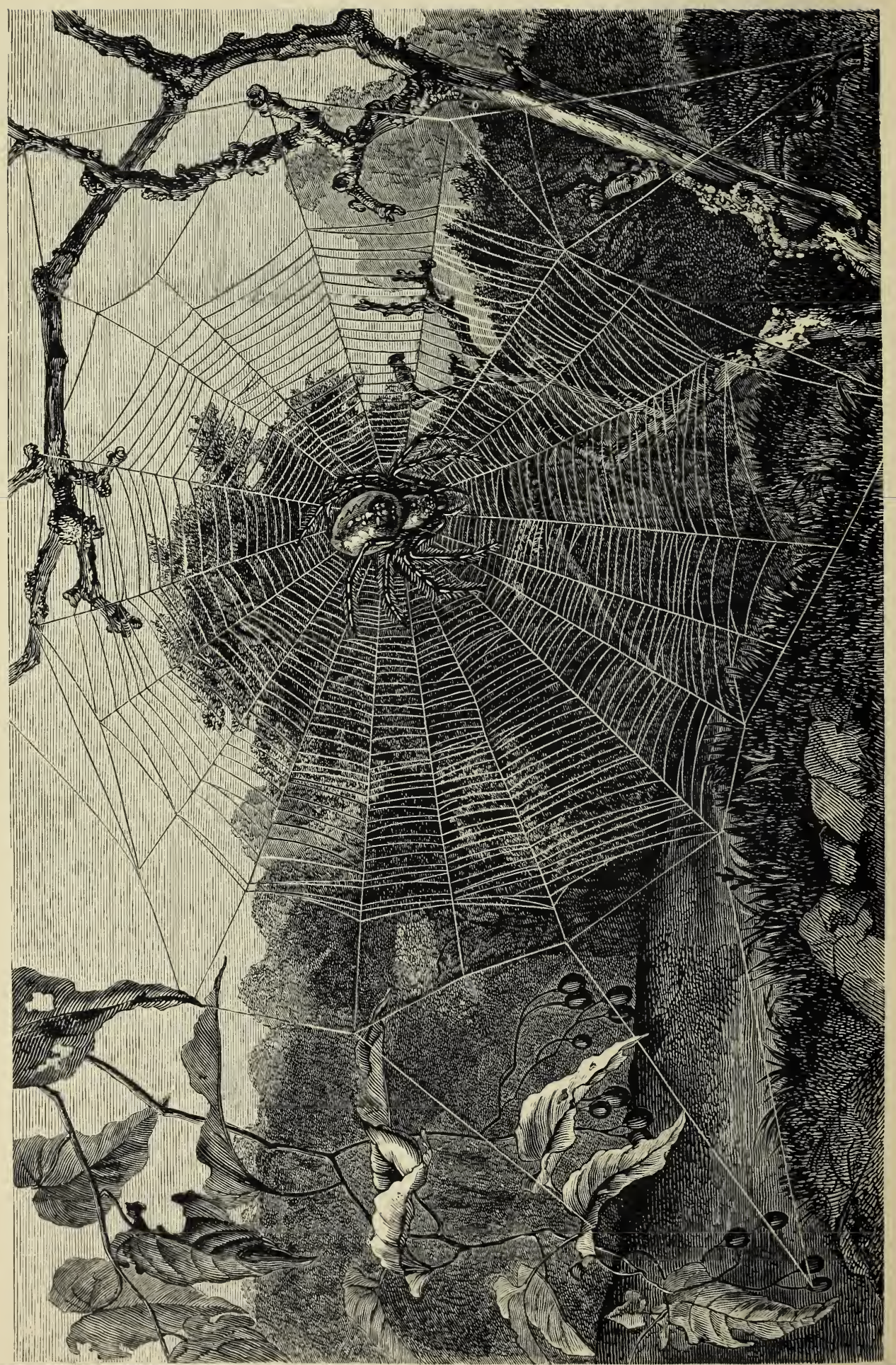


times before adult age and all its powers are perfected. The moulting may, therefore, be considered in the light of an incomplete metamorphosis. A great deal of careful observation is still required before any decided assertions can be made satisfactorily concerning even the habitual moultings of all the spiders that do not undergo metamorphosis. Some genera do not even appear to moult, and the incompleteness and deficiency of any metamorphoses have been stated in others, so that our present knowledge permits us to say that the Arachnida very closely allied by habits, instincts, and structural peculiarities, differ materially in their method of evolution after leaving the egg; moulting and metamorphosis being apparent or absent in spiders which resemble each other very much.

The relation of the metamorphoses to the classification of the spiders is, therefore, very interesting to the philosophical naturalist, but unsatisfactory to the species maker and to those who only classify.

The Arachnida are divided into two great orders. In the first, which includes the true spiders and scorpions, the respiration is carried on by means of sac-like depressions in the body, and in the second the creatures breathe like the true insects and Myriapoda, by means of tracheæ. The true insects are thus connected with the second order of tracheary spiders by a similarity of construction; and the Crustacea or crab tribe, to be noticed hereafter, are allied to the pulmonary Arachnida with the respiratory sacs, and by the general arrangement of the segments of the body and limbs. The Arachinida thus form a link between the insects and the Crustaced.

How the Arachnida are to be distinguished from these classes may be understood by examining their peculiar conformation. Thus, the Arachnida may be said to have the body divided into a chest or thorax and an abdomen. Wings are never present, and not even their rudiments. The legs are eight in number in the adult ; the eyes are smooth; and the head is soldered into and continuous with the chest.

If the Mygale fodiens - which is represented in the middle of its curious nest in the accompanying engraving-be examined, it will be found to consist of a swollen abdomen, which is attached to the 
thorax by a broad base, the hinder legs being joined on to the thorax close to it. Four legs are supported by the thorax on either side, and the ocelli mark the front of the upper part of the head, which is also joined by fusion, and not by a neck to the thorax. In front of the rounded margin of the head, before the eyes, are the long and stout jaws, one on each side, and they look like the ends of a stout pair of scissor blades. A palp projects

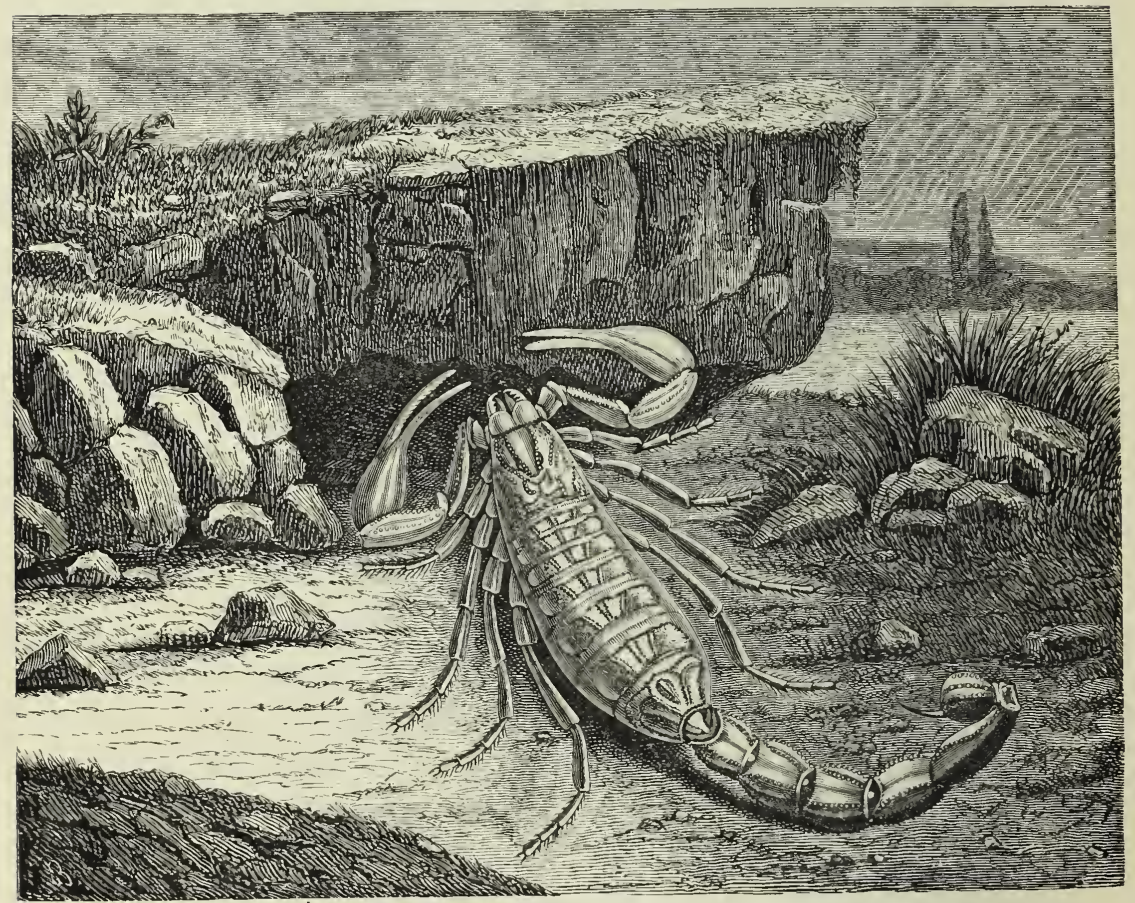

THE SCORPION. (Scorpio occitanus.)

from either side of the base of the jaws, and looks like a leg, but it ends in a peculiar structure, and is not a locomotive organ.

The abdomen is not jointed and has no visible segments; the web spinning apparatus exists; and this spider does not breathe by trachere but by pulmonary sacs.

The integument of the spiders is precisely analogous to that of the true insects, and has the same chemical constitution. In the order of the pulmonary (sac breathing) Arachnida it may be 


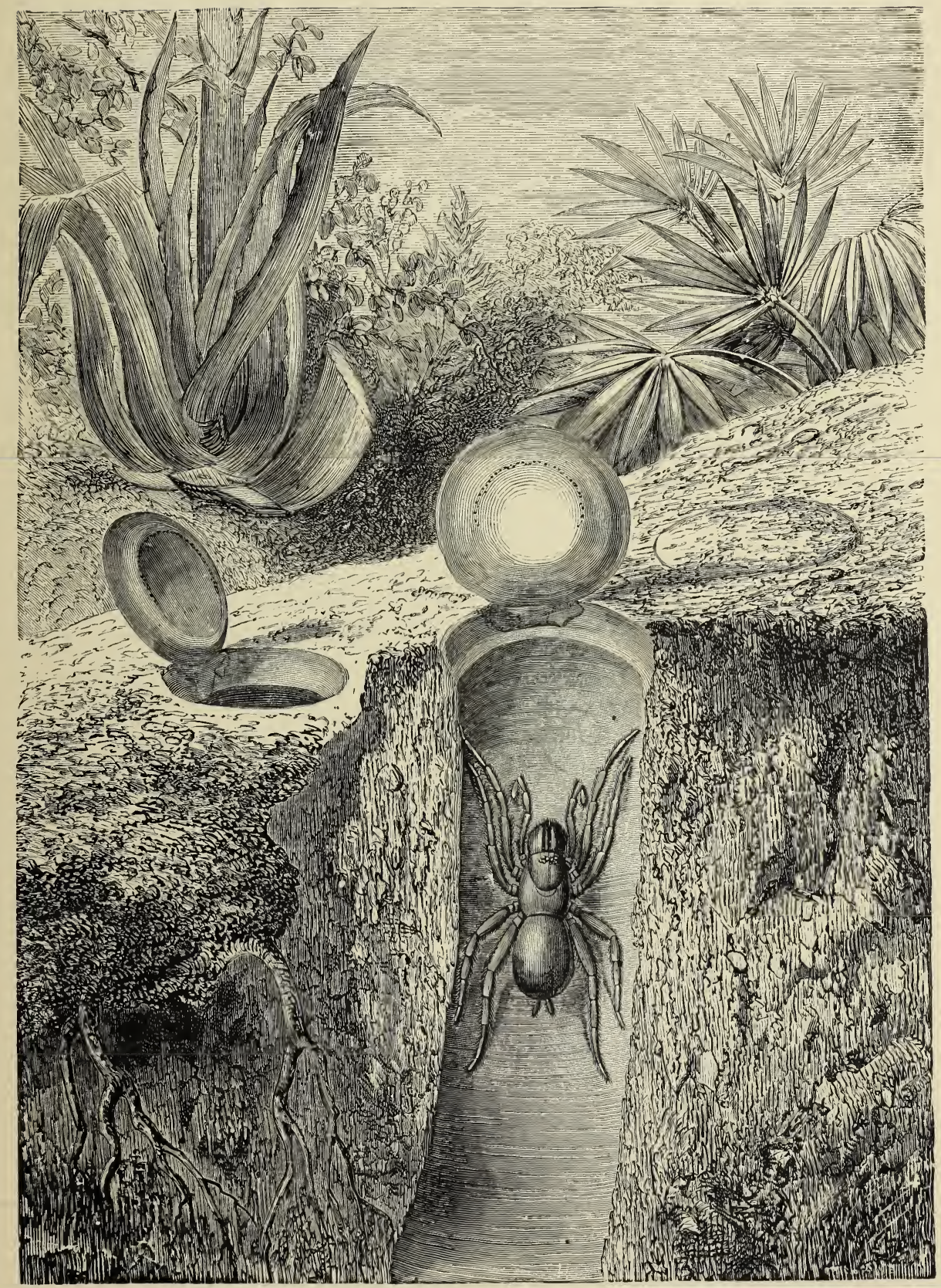

Mygale fodiens AND ITS NEST. 

soft, leathery, and even transparent in texture, and capable of great extension, and this is the case in the true spiders whose abdomens are not in segments; but in the other family of the order, which includes the scorpions, and which have the abdomen articulated and formed of many segments, the skin, especially of the abdomen, is hard and solid. This last family allies the spiders to the Crustacea, and its members have not any spinning apparatus. The palpi are terminated by a pincer-shaped weapon, and the last segment of the abdomen is turned into a poisonbearing claw. The respiratory structures of the scorpion are much more elaborate than those of the ordinary pulmoniferous spiders, and a number of folds or laminæ, attached above to a common tissue, are suspended side by side, like the leaves of a book, form the pulmonary branchia. Müller says they can be distended with air, but probably it is necessary that they should always be kept slightly moist. These structures resemble somewhat those by which the land crabs and other terrestrial Crustacca breathe. The scorpions give birth to eggs which are hatched whilst passing from the mother, or shortly afterwards, and the little ones are frequently carried about by her until they have gained their full strength. The history of the growth and development of these ovo-viviparous Arachnida has, however, yet to be written.

The common spider (Tegenaria civilis) is remarkable for the number of its moults, and Mr. Blackwell has discovered that both sexes change their integument nine times before they arrive at maturity, once in the cocoon, and eight times after quitting it. He states that the life of the spiders lasts four years, and hints at the probability of the occurrence of parthenogenesis.

Theridion lineatum, also a common spider, deposits about i 70 eggs, and leaves them in a silken cocoon, in which the young remain long after they are hatched, and are supplied with food by the mother; and Thcridion riparium watches over its young in the same manner, and feeds them with ants.

Considering that the pulmoniferous spiders do not undergo any metamorphosis, and that the tracheary ones do, it is important to settle the question whether anything like a progressive development resembling a metamorphosis goes on in the eggs of the first order. 
In I 824 Heroldt described the changes which occur in the eggs of the spider (pulmoniferous) before it was hatched, and his investigations are a wonderful piece of intelligent and patient research. He divides the growth of the spider within the eggfrom its first appearance as a shapeless and structureless germ to the perfect condition when hatching took place-into eleven stages, but there is not a strict line of division between the stages, only different organs are formed, and various appearances are presented gradually.

Up to the period which Heroldt terms the seventh, the body of the spider looks like an opaque structureless mass, but when this commences, traces of rings, four in number on either side, may be noticed. These are the rudiments of the legs. They occupy the side of the front part of the egg, and they are extended downwards also. The end of the first leg is close to that of the opposite side; but the three others, though of greater length, are separated by a space which is filled with a cloudy and somewhat transparent matter. This space is subsequently occupied by the trunk and much of the abdomen. The future head is in front, but is not yet rounded like in the perfect spider, but is flattened forwards, and there is a ring on its sides which forms the palpi of the jaws, and portions of the mandibles may be distinguished in a very rudimentary condition. It is probable that all the parts which appertain to the head, as the eyes, the hooks or the mandibles, and the maxillæ or jaws, have their limits well defined at this period. In the preceding period, or the sixth, only the general outlines of the head and body could be distinguished. With respect to the head, it is nearly separated from the chest (as in insects), and this fact is of importance, since in all the full-grown spiders the confluence of the head and chest is most intimate, and their original separation only indicated by a groove of greater or less depth.

The integument or skin of the fœtal spider begins to be seen at this time, and can be detected in the form of furrows or arched folds.

During the eighth period the feet, mandibles, and the head become more definite as structures, and the whole ovum diminishes in size in front, and is somewhat constricted so as to 
mark off the cephalo-thoracic from the abdominal region. The integument may be seen to be forming in the abdomen, and the rudiments of the heart or dorsal blood vessel are noticed. The eyes begin to be distinguished. The diminution of bulk in front continues during the ninth period, and the division into two parts also. The chest and abdomen become more defined and elongated. The legs now present slight traces of a division into joints, and have increased greatly in size and length.

Tenth period. The small end of the ovum, which is still more elongated, is now found to be distinguished from the large one by a true constriction dividing the ovum into two parts, denominated in the perfect spider, thorax and abdomen. The visible parts of the thorax are the mandibles, the palpi, and the legs. These latter appendages are folded upon the chest, and have grown so long as to cross the middle line of the body, and they are locked together like the fingers when the hands are clasped. The abdomen presents nothing remarkable except an elongated opaque streak, which exists along the middle of the under surface from the feet to the end of the belly. Heroldt considers this to be an indication of the development of the internal parts of the abdomen, of the intestinal canal, and the secreting organs. In proportion as the young spider increases, the external membrane or covering of the egg is applied more exactly to its body, and seems to represent an exterior skin, of which the young creature soon divests itself almost in the same manner as the caterpillar sheds the skin in which it is enveloped.

By the increase of the young creature during this last stage of all, the membrane of the egg becomes so stretched, and is applied so exactly to the surface of the body, that the different parts of the body can be seen through it like the nymph or chrysalis of certain insects. The essential parts of the thorax are the head and feet. The head is of a white colour, and is surmounted by eight brown streaks; the legs, which are also white, are closely applied to the chest, with their extremities alternating with each other. One may distinguish in each a hip, a thigh, a leg, and a tarsus. The articulations of the palpi and mandibles are also visible through the general envelope of the egg. The streak upon the abdomen has divided, and part of 
it corresponds to the vent. At this stage of the development the young spider gives no sign of motion, but at length, when all is completed, it bursts the egg by tearing through the outer membrane.

According to De Geer this outer membrane becomes fissured along the chest-piece of the spider, which protrudes its head, the mandibles, thorax, and abdomen; after which there remains the more difficult operation of extricating the legs and maxillary palpi from that part of the external membrane with which these parts are as it were enveloped.

This is at length effected, though slowly, by alternately dilating and contracting the body and legs, upon which the spider is liberated and soon becomes capable of progression. As the parts are disengaged from the skin-like membrane it is pushed towards the ends of the legs, and is reduced to a little white bag, which is all that remains. Sometimes the pellicle is found still slightly adherent to the abdomen, but the spider soon frees itself entirely from it. This is the mode in which the young spiders of every species disembarrass themselves of the egg covering, and the operation is analogous to that of moulting. This is, however, only the first birth; all the parts of the spider, the head, jaws, legs, and abdomen, are still enveloped in a membrane which furnishes a sort of sheath to each.

The spider is embarrassed in all its movements; it changes its situation with apparent pain, and is unable to construct a web and seize its prey. It seems, indeed, to be stupid and indisposed to action. To this end, and in order to be fit for moving about, it is necessary that the spider should free itself of this other covering, and then only it can be said to see the light. This last operation, or, as it may be called, the first moult, takes place after a period varying according to the degrees of atmospheric heat and moisture. Sometimes it is observed within the first week, at others it is not effected before the end of several, for in every instance the moult takes place in the woolly net or general covering of all the eggs, and the young spider does not quit this common nest, except in fine weather, until generally in the months of May and June.

Before arriving at the adult stage the spider changes its skin 
many times, and even after that period it is still subject to moults, which occur every year-in the spring and after the egg laying.* There is no phase in this progressive development like a metamorphosis, but nevertheless the unfavourable condition of the lately-born spider is very different to that of the adult, and the perfection of all the organs and the strengthening of the tissues keeps pace with the consecutive changes of skin.

The spiders which undergo metamorphosis, and to which the Acarida or mite tribe, and the Hydrachnide or water mites belong, breathe by means of trachex, and there are no segments in and on the abdomen. All these last-mentioned Arachnida undergo metamorphosis, and their larval condition brings them in close relationship with the true insects with six legs. There are some exceptions to the invariable occurrence of metamorphosis, but this should be expected when it is remembered that the phenomenon is not constant even amongst the insects, and that it was probably added to their evolution in consequence of the influence of external conditions acting under some law of life.

The unsegmented condition of the abdomen in the tracheary Arachnida belonging to the genera which undergo metamorphosis is invariable, and this part of the body is united without the intervention of a depression even, to the segments which support the legs, and it is often found that the head, thorax, and abdomen are all fused together to form one indivisible mass. The mouth in these is always provided with a lower lip which is spoon or sheath-shaped, and which envelopes for the most part the other portions of the mouth, and does not allow them to be free as in the other Arachnida. The palpi which are attached to the mandibles vary greatly in size, length, and function, and their peculiar construction and different uses have formed the basis for the classification of these small creatures.

M. Dugès has given some most interesting details concerning the structures and metamorphoses of the tracheary Arachnida in the "Annales des Sciences Naturelles," I 834.

He found many small eggs sprinkled over stones in shady places like so many tiny white points, and, on examining them 
with a magnifying glass, he discovered that each resembled a round cupola of a chalky consistence, and that they were shut by a coverlid which was conical in shape and ornamented with radiating grooves like the marks on a parasol. When the egg was broken a red pulp came forth, but when it was allowed to hatch a small spider partly lifted off the lid with its back and entered the world. The newly born creature was red, and was a larva; it had six legs only, and crawled slowly, and did not increase in size. Dugès noticed that after a while the larva seeks some crack in the ground near by, and becomes motionless. Then its skin comes off and forms a transparent shelter for the nymph or pupa, just as is the case in many insects.

During the nymph condition the second metamorphosis takes place, and, after a lapse of a few days, an eight-legged spider bursts forth. The little Raphignathus is not much larger in the adult than in the larval condition, but its long legs enable it to move rapidly. It has an oval-shaped body with a projecting head, or rather, mouth, which looks like the head. There is a small eye of a dark red colour on either side of the front of the body. The spider lives upon the elder trees and sucks their sap.

It is evident that there is a complete metamorphosis in this genus, and that the nymph or immobile pupa is quite as good an evidence of it as a chrysalis would be.

Some species of Tetranychus, which resemble somewhat the spiders just noticed, do much mischief to lime trees, roses, acacias, and even to oaks, by irritating the leaves and destroying their powers of respiration. The spiders live on the under surface, and spread a very delicate web over the leaf, so as to form a shelter for a numerous colony. They are very small creatures, with ovalshaped bodies covered with long hairs, and their eight legs are not long; they secrete a very fine web, which cannot be detected with the naked eye, and when it is finished they may be observed digging their suckers into the cellular tissue of the leaf and pumping up the liquid sap. The females may be observed laying large eggs, and a larva soon comes forth with six legs and a pellucid body. As soon as the leaves begin to fall, the larvæ hide themselves under stones, and undergo their first metamorphosis into immobile pupx, probably during the spring-time. Another 
mite belonging to the genus Dermanyssus lives upon it as a parasite, and also undergoes a metamorphosis, and the larva is six-legged.

Another spider with tracheæ and an unsegmented abdomen appears to have a metamorphosis after having attained adult age, besides those which occur previously. Rhyncholophus cenercus is common in the environs of Montpellier, where numerous colonies of it may be found in shady places by the roadside. It is a small spider not more than a line in length, but its long legs give it an important appearance, and enable it to run and spring actively. There are four red eyes in two groups, one on each side of the front of the body, which is more or less square shaped, and the dingy colour of the delicate but closely-set hairs gives the specific name. It has a long and sharp beak-shaped mouth, and lives upon the juices of other insects.

After having obtained its eight legs, and apparently its adult stage, a metamorphosis takes place, for immobile nymphs are found in holes and under stones, clothed with the exuviæ of the supposed mature spider, and the eight legs and hairy tissues can be readily examined.

Small creatures come forth from this second nymph condition, which resemble those just noticed; but they are less round in shape, less red, and are able to reproduce their kind by egrgs.

The garden mites belonging to the genus Trombidion are often of a fine red colour, and one of them chooses such a dangerous host to be parasitic upon as the active running wall spider. The mite frequents the female spiders especially, and fixes itself upon the hind thighs; for, unlike the males, they have short palpi, which cannot reach these parts, so that the parasites live there in security. The males soon pull the mites off if they settle upon them. When full-grown these mites are as large as a mustard seed, and they have oval-shaped bodies, which are swollen, slightly hairy; and have two eyes. But there are only six legs, which are short, but nevertheless useful and sufficiently strong to enable the mite to change its position.

When the larva-for such is the mite-detaches itself from its spider host, it seeks the ground, and hides up in small dark holes, becomes motionless, and remains so for twenty days. 
Dugès saw the eight legs of the perfect insect forming beneath the transparent skin of the nymph, whose body was smooth, oval, and just like a little yellow egg. After a while a tiny brilliant red Trombidion came forth, small, but with eight legs, and it was a perfect spider with tracheæ. These mites die if left for a short period in water; and they live by sucking the juices of the creatures upon which they are parasitic, such as the spider just mentioned, the daddy-long-legs fly, and others.

The Hydrachinide, or water ticks or mites, are spiders with tracheæ and unsegmented bodies that undergo metamorphosis, the larvæ being very unlike the perfect insect, and only having six legs. All the water ticks may be recognised by their hairy legs, so well adapted for swimming, and by the peculiar shape of their palpi, which enable them to cling on to plants and stones as if with anchors. These mites have a sort of plastron, which is formed by their flat, broad, and adherent haunches.

The Harlequin, Atar histrionicus, lays its transparent eggs in layers, which look like so much gum, and the larvæ which are hatched from them are aquatic. The larvæ have six legs, a flat almond-shaped body, with two large eyes, and the belly is reddish in colour, whilst the legs are blue. The adult has eight legs, and also numerous little points on the back, which secrete a viscous matter that forms into a web, in which the creature can live and breathe air whilst pursuing its usual life under water.

The males of the genus Diplodontus are very sociable, and so are the females; and little swarms of them may be noticed enjoying the warmth of the shallows. When thus disposed they often run great risks, for instead of watching the fall of the water on the mud, they allow it to take place suddenly, without their moving off, and then many a happy coterie is dried up and destroyed. The larvæ, like all the others, have six legs, and turn into immobile nymphs, which are watched with amusing politeness by the adult males. Wives appear to be at a premium amongst these spiders, and the males make up their minds about their future courtship before the nymphs are transformed; hence the funny hugging and constant squeezing which are bestowed by the amorous eight-legged set upon the quiet and totally unconscious ladies in futuro. When the egg-laying is going on the 
mothers associate together very familiarly upon the smooth leaves of the water plants. The eggs are red, ovoid in shape, and are in myriads; they are placed side by side, and are covered over with a mucous secretion, which protects them. It is not unusual to see one female after another choose the same spot for egglaying, and to observe the number of egg-layers increasing hour after hour, so that a thick crust is formed at last on the plant. After a fortnight the young larvæ are hatched; they are excessively small, and are of a brilliant red colour. They are hairy, and have six long legs, terminating in claws. These larvæ swim with great rapidity, and often seek the surface of the water, and allow themselves to become dry; then they run over the pond as quickly as if it were a solid surface. It is very probable that these six-legged larvæ live as parasites upon the larvæ and nymphs of dragon flies, May flies, and gnats; and it is by no means certain that the adults of these flying insects are not attacked also. M. Dugès believes that a second metamorphosis takes place during the adult stage, as in the genus noticed above.

Some of the water mites do not swim, but are able to fix themselves on to other insects, and to crawl. Limnocharis aquaticus is one of them; and it may be recognised in the adult state by its irregularly oval body, which is rather conical in front, very soft and capable of being altered in shape spontaneously. The skin is reddish in colour, and the tints are brightest when the insect is young. There are no hairs, except on the legs, where they are not very commonly seen; the eyes are large, close together, triangular in shape, and of a deep red colour, and they appear to be fixed on to a special scale-like piece of the body. The claws of the legs are large, retractile, and are made to hold on with, and not for swimming.

The eggs are laid on the mud at the bottom of ponds, and look like a whitish incrustation tinted with red; and small red larvæ, with six long legs, oval bodies, and snout-like heads, come forth from them. These larvæ run upon the surface of the water, or swim in the midst of it; but they soon give up that sort of life, and select a host to be parasitic upon. Gerris lacustris is their favourite insect. It is one of the Hemiptera, and lives on the surface of stagnant waters, skimming over them with great 
rapidity, with the aid of the long middle feet, which act like oars. The Limnocharis attaches itself in the larval condition to the body of the Gerris, selecting the neighbourhood of the head in preference to any other spot for its point of attack. This takes place before and during the month of July, and then the small bright red larvæ, with great movable suckers, looking like heads, may be seen hanging on with their six legs, terminating in strong claws. When the larvæ are fixed they dig their suckers into the Gerris, and live at its expense, and are moved about from place to place by their restless and unwilling entertainer. Having attained at last the size of a pin's head, the larvæ detach themselves, and sink down through the water, and crawl over the

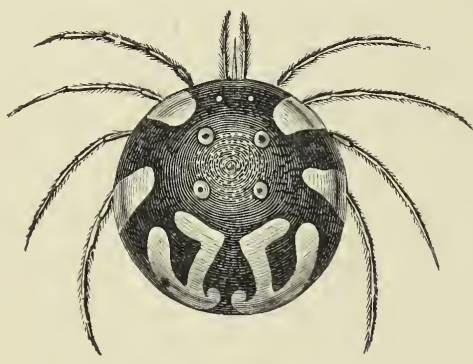

Adult.

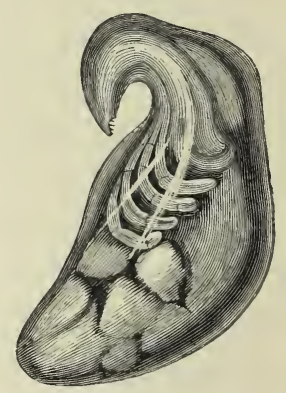

Larva.

Hydrachna geographica. (Magnified.)

weeds and bottom slowly, and seek a hole or a crevice, down which they plunge. There the metamorphosis takes place, and the six-legged larvæ become motionless nymphs. The nymph stage lasts fifteen days, and then a small brilliant red eight-legged adult Limnocharis emerges.

The globular water mite called Hydrachna gcographica may be taken as the type of the genus Hydrachna; but M. Dugès has given such interesting details respecting a closely-allied species, Hydrachua globula (Hermann), that we do not hesitate to take advantage of them, especially as they convey most correct impressions concerning the metamorphosis.*

The true Hydrachna are distinguished by their beaks being as 
long as their palpi, their having the third joint of the palpi the longest, and by the presence of sharp blades for mandibles. A full-grown female of Hydrachua globula measures two lines and a quarter in diameter; and her shape, although apparently globular, is really ovoid. The body is smooth, red, and maddercoloured, and is marked by some muscular impressions on the back. When it is moderately grown, the skin has a satin-like look, on account of the ramifications beneath it of the myriads of tracheæ, the white and shining appearance of which is seen through the transparent cuticle. The same transparency of the skin allows the intestinal canal to be distinguished, as well as the granules and cells of the tissue itself.

There is a double sub-triangular rough and thick plate on the skin, in the front of the body, which supports the muscles of the palpi and of the other parts of the mouth. The eyes are external to these plates, and they are red and kidney-shaped; and in front of each of them there is a small hole, out of which water comes when the insect is allowed to become slightly dry. These are spiracles, and there are others behind the hind legs. M. Dugès saw tracheæ springing from these spiracles, and forming a dense layer under the skin; and he noticed that the tubes did not contain a spiral fibre like those of insects, and that they were excessively delicate and silky. It is an interesting question whether or not the water in which the Hydrachne live is absorbed or taken into the tracheæ; some may be, but there are evidences that the air which is contained in the water is the essential principle for respiration for these insects, as it really is for all other aquatic beings. When the Hydrachnce are quiet under the shade of the leaves of water plants, they constantly move their hind legs about, in order to maintain a current of water around the body. If the water becomes stagnant, they come up to the surface or the edge, and permit the greater part of the body to remain in the air, moistening it from time to time, and washing the back with the long hind legs. They take care not to become too dry, for three quarters of an hour's drought kills them. M. Dugès found, moreover, that if one of these spiders was placed in spirits of wine, it swam about, and continued to do so for half an hour; then, on being replaced in water, it became as lively as ever in a few 
minutes. It would appear, then, that the aërated fluid is not taken into the tracheæ.

The mouth of this spider is a very important organ, and has to do with much besides sucking and piercing. It is formed like a beak, large, and elongated into the shape of a gutter; and it encloses part of the two piercing blades or mandibles, which can unite to form a second sucker-shaped projection. The palpi are hooked at the end, and enable the insect to hold on to the potamogetons and other water-weeds, whence it derives part of its nourishment by the aid of its piercing suckers. It eats other matters, however, for the spider may be seen feasting upon the flocculi, which contain myriads of animalcules and microscopic plants, and which float in the water.

Eight legs exist, and the three hinder pairs are the longest and are suited for swimming, whilst the others are shorter. All are furnished with two long hooked claws, which are retractile.

M. Dugès saw the females making pin-like holes in the soft central tissues of the potamogetons with their beaks, and then placing their eggs within, so that an opaque appearance was given to the plants. The eggs are deposited in great numbers, and hundreds of these oblong and reddish-brown ova are laid by each female. The employment of the mouth-pieces as instruments for ovipositing is very interesting. The female dies soon after laying, and her body becomes flaccid first of all. She does not cover up the punctures in the plant with any secretion, but leaves the eggs to be protected by the cells of the plant. The larvæ of insects and many worms devour the eggs, but some always remain to become hatched. The egg-laying takes place towards the end of May, and six weeks elapse before the larvæ are hatched; and during this time the potamogeton leaves and stems die and undergo decomposition, so that the newly-born spiders escape without difficulty from the surrounding tissues.

The larvæ have six legs, which are placed very closely together, and each leg is hairy and adapted for swimming, and, moreover, it is clawed. The feet are red in colour, and so is the body, which is oval, flat beneath, and convex above. In front are the two great eyes on each side, and between them, and projecting backwards, is a kind of scale. The beak looks exactly 
like a great head, more or less angular in shape, and stuck on in front of the eyes, and it terminates in a narrow mouth. How long these larvæ swim freely in the water is not known, but they cannot go out of the element without perishing by becoming dried up; but when they become nymphs they are carried about in the water and in the air also, by the insects they are attached to as parasites. Towards the end of the summer and during the autumn the nymphs are to be found attached to the bodies or limbs and elytra of such Hemiptera as Nepa, and they are slung on to their hosts by tail-like threads. When the nymph is found attached to the hard parts of Nepe minute perforations in them will be noticed with a magnifying glass. The water beetles are preyed upon by these nymphs, and in return some of the Dytiscide demolish the spiders.

The Hydrachna larva, immediately after it is hatched, has a globular body, but the hinder part soon begins to elongate, and becomes more or less pointed after a while, and the little spider larva is noticed to be flat and spindle-shaped. In a short time the shape alters to that of an elongated ellipse, and when it has attained its full growth the larva becomes pear-shaped, and is curved beneath and tinted of a red violet colour. The young Hydrachne only attain this size and shape during the winter time, and then they are about a line in length. It is remarkable that although the the body increases so much in bulk, the sucker, legs, and scale do not grow larger, but are always of the same size, and are situated invariably at the front of the animal. When the larva has attained the greatest possible size the sucker appears to constitute the head, the scale is present with the remains of eyes, and six thighs; but it frequently happens that the palpi and even the legs have disappeared partly or entirely, especially if the larva living as parasite has been attached to a vigorous and actively swimming water beetle. In this case the membranous space which unites the sucker to the body is really elongated like a neck. This is most remarkable, and the manner in which the retrogade development is accomplished is well worthy of study. Early in the larval life, and before the body begins to elongate, the legs and palpi appear to retreat within the animal and to leave their outside skin attached to their prey. This skin continues to act as 
a protecting mantle, and is liable to all sorts of accidents, from the shocks received during the swimming of the beetle to and fro. The Hydrachna, with its membranes thus retracted, is really a nymph, and not a quiescent one, but an active creature, which nourishes itself and grows. The gullet of the nymph still traverses
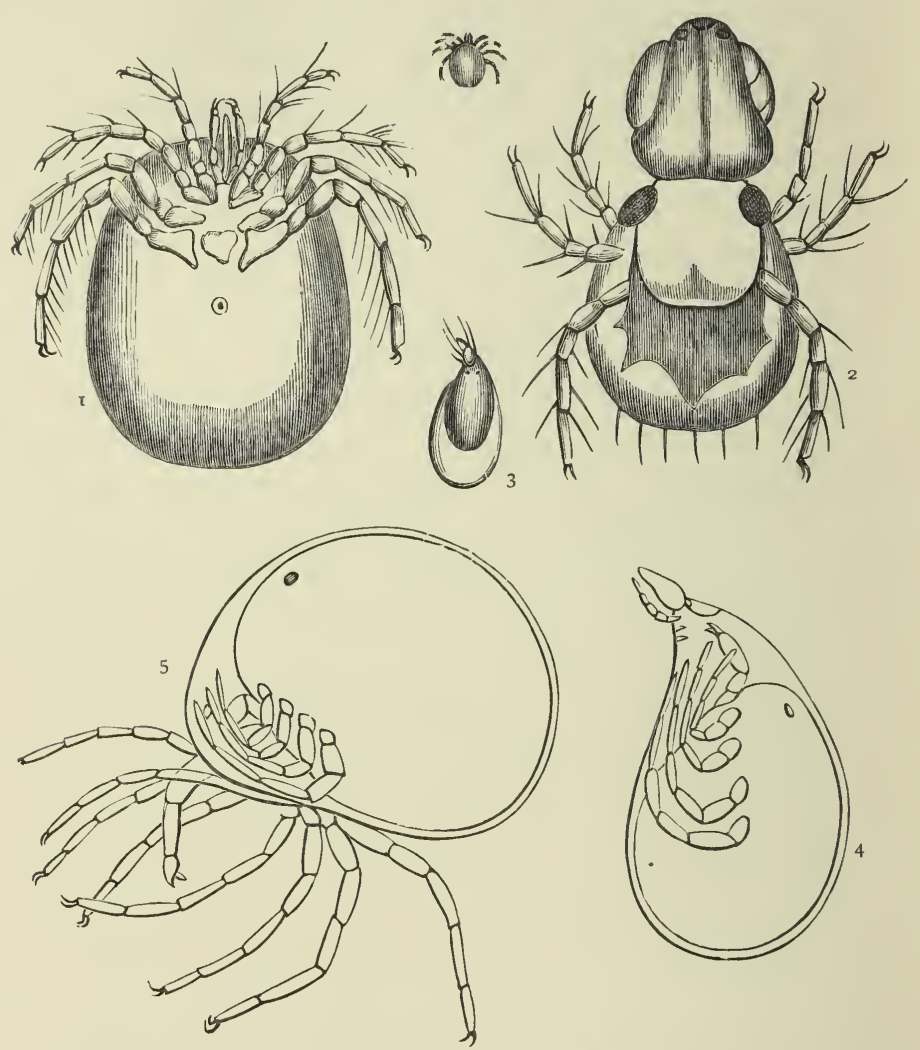

THE METAMORPHOSES OF Hydrachna globula.

I. The perfect spider (natural size and magnified). 2. The larva (magnified). 3. A nymph. 4. A nymph magnified, showing the eight-legged spider within. 5. The last form of nymph (magnified).

the sucker, which is plunged into the body of the host, and a membranous prolongation of it has penetrated the flesh of the victim, and retains the sucker so tightly in contact with the muscles and juicy tissues that it remains in that position after the nymph has left its skin altogether. 
When the mass produced in the body of the Hydracluna by the retractation of the legs and palpi is examined after a short interval, ten white-looking objects, arranged in two lines or series, are to be seen, the hinder ones being the largest. Of these ten, eight are destined to be the future legs of the perfect insect, and two will be palpi. A white spot indicates the future egg organs, and the intestinal canal is observed curved behind and swollen near its lower end, where it communicates with a narrow vent. It is full of a white substance, which is surrounded by a red pulp. After a while the ten white objects elongate, curve, and direct their thin free ends forward, and assume the appearance of limbs as they grow. The beak is formed at the same time, and this and all the structures take on a red tint. The eyes of the future perfect spider may be seen under the skin of the nymph. The old membranes covering the eyes or corneæ are still to be seen. All the old skin is furrowed, but it is still strong enough to preserve its shape. In due time the new animal splits the skin transversely, and comes forth and begins to swim with great activity.

The species of the genus Ncpa and Ranetra of the Hemipterc are so frequently covered with these nymphs as parasites, that it is very strange that they had escaped careful description before M. Dugès examined them. Most observers took the pear-shaped bodies for eggs, and nearly all the great entomologists considered them to be anything but what they really are. The presence of six legs in the nymph led Audouin to consider them to belong to a special genus of the Araclmida, gifted like the true insects with six legs only.

But it is evident that the Hydrachna passes through a larva state and then has six legs, and then becomes a more or less physiologically active but probably an immobile nymph-many thanks to its host. It then assumes the condition of a free swimming spider, whose eight limbs have been developed during the end of the nymph stage. These metamorphoses are perfect, and the three stages are characterised by different modes of life, and by differently looking creatures. But the free swimming spider which springs from out of the pupa-like nymph skin is not the adult insect, although it has passed through the regular 
metamorphosis, for it has to undergo a moult and a structural change, which, however, is not of great magnitude. These little oval pear-shaped Hydrachnce are not capable of reproducing their kind, so they live a life of childhood for a while, and then after the lapse of several weeks, their growth having been considerable, they settle down upon a potamogeton leaf, and stick their beaks into its cellular tissues, and hang on by their legs. This anchoring and sticking in of the beak is not done for the reception of food, but is otherwise a direct imitation of the procedure of the larva which did the same to the water beetle. In a short time the soft parts of the legs are seen to retract, just as they did in the nymph, and to leave the outside skin, which still adheres to the plant, and to collect en masse in the body. There they undergo a second elaboration; they assume gradually the shape of the limbs of the perfect Hydrachna, elongate, become thin, and harden little by little. The hairs and all the details of the future skin form within the old skin, which finally cracks and gives passage to the perfect Hydraclna, which swims off to lead a life of courtship and maternal care after its wonderful evolution.

The skin left behind is very curious, for it is really the covering of the former legs, jaws, eyes, and body. Dugès managed to cut off one or two legs from some Hydrachna before they began to moult in the last stage of their existence, and he found that the mutilation was not cured during the moult, or rather the fourth metamorphosis, for the limbs came out truncated and conical in shape.

The common red spider of hothouses and gardens makes a delicate web on the under surface of leaves, and sticks its sucker into them when thus protected, and lives upon the vegetable juices. Its history is not known, but another kind, belonging to the same division of the spiders without segments on the abdomen, leads the same kind of life and undergoes metamorphosis.

Scheuten described* Typhlodromus pyri, one of the Gamasei which lives upon the leaves of the common pear tree. The mature spider is blind, yet it keeps in very rapid motion; and the larva is also eyeless, but the front pair of legs appear to replace the organs of sight to a certain extent, for they are kept in constant motion, 
feeling here and there. The larva perforates the pear leaves from beneath, and lives under them, forming gall-like excrescences, but which are not true galls; it has only four legs. After its metamorphosis a perfect insect with eight legs comes forth.

The Itch Insect, of which a representation is given, is one of the Acarida or spiders with unsegmented bodies and palpi, which enable them to adhere. It undergoes metamorphoses, and the larva has six legs. The female burrows under the skin, and the male lives upon the surface of the human body.

M. Robin states that the mites pass through a series of metamorphoses; a six-legged larva issuing from the egg becoming

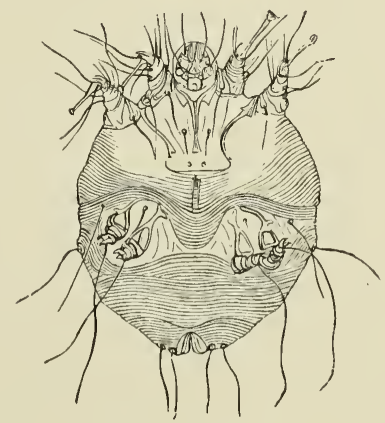

ITCH INSECT.

converted into a nymph, from which the adult mite proceeds. $\mathrm{He}$ has observed in the mites which attack birds in cages (Sarcoptide) a more complicated series of phenomena. In them the males pass through four and the females five stages. The egg in issuing from the animal has the form of a hexapod larva (six-legged) and is followed by a stage of a nymph with eight legs, but without any organs of reproduction. These turn into sexual males, which moult once, and become perfect, or into females. These are like the nymphs, and moult, and produce the perfect female which lays eggs.

The ticks which stick to so many animals and suck their blood are spiders, but in their early life they have some of the characteristics of true insects. Thus, the moose tick collects upon those fine deer when they are in the forests, and irritate them greatly. The eggs of this tick, when they are hatched, open like the valves of a clam shell, and a six-legged creature comes forth from each. 
The editors of the American Natural History Miscellany, I869, state that the six-footed young one has enormous legs, and that the head is separated from the hind body. The young tick has terrible jaws, with which it buries its head and fore-part of the body within the tissues of the deer. The perfect tick has eight legs, which are short, and a large body.

When considering the strong structural relation between the spiders and true insects, the history of the development of the first mentioned creatures within the egg and that of the metamorphoses of the tracheary order should never be forgotten. The early condition of the spider within the egg has a strong resemblance to that of the insect, for the head is not then forced into the chest, and there are traces of segments on the body; moreover, the sixlegged condition of the water mites and some ticks in their larva condition refers back, like the other facts, to a common ancestry with the Insecta.

The water mites, although they rarely care to quit the depths of the streams and ponds, do so at their pleasure, and run over the surface, and it is evident that they are not so perfectly adapted for aquatic life as many insects. Their tracheæ are not arranged as branchiæ, and this consideration, amongst many others, leads to the belief that their present mode of life was not original. In a note to the admirable article by Audouin in the "Encyclopedia of Anatomy and Physiology," Dr. Todd writes :"Mr. Blackwell has related an accidental discovery of the power of some spiders to abstract respirable air from water. Several individuals have preserved an active state of existence under water for six, fourteen, or twenty-eight days, spinning their lines and exercising their functions as if in air, while others have not survived a single hour."

The case of the water spider, Argyroneta aquatica, whose divingbell shaped nests under water, and whose method of carrying down air to fill them with, are so well known and so constantly referred to in all the books on natural history, loses much of its strangeness and uniqueness when the above-mentioned facts are considered. It does not undergo a metamorphosis, however, so that there is no necessary connection between an amphibious Arachnidan existence and a sequence of the larval, nymph, and adult condition. 
The engraving represents some of the spiders on the floating leaves, and one has made its plunge into the water. The cephalothorax is white, because the fine silky covering of web which encases the body contains air; and the whole of the spiders

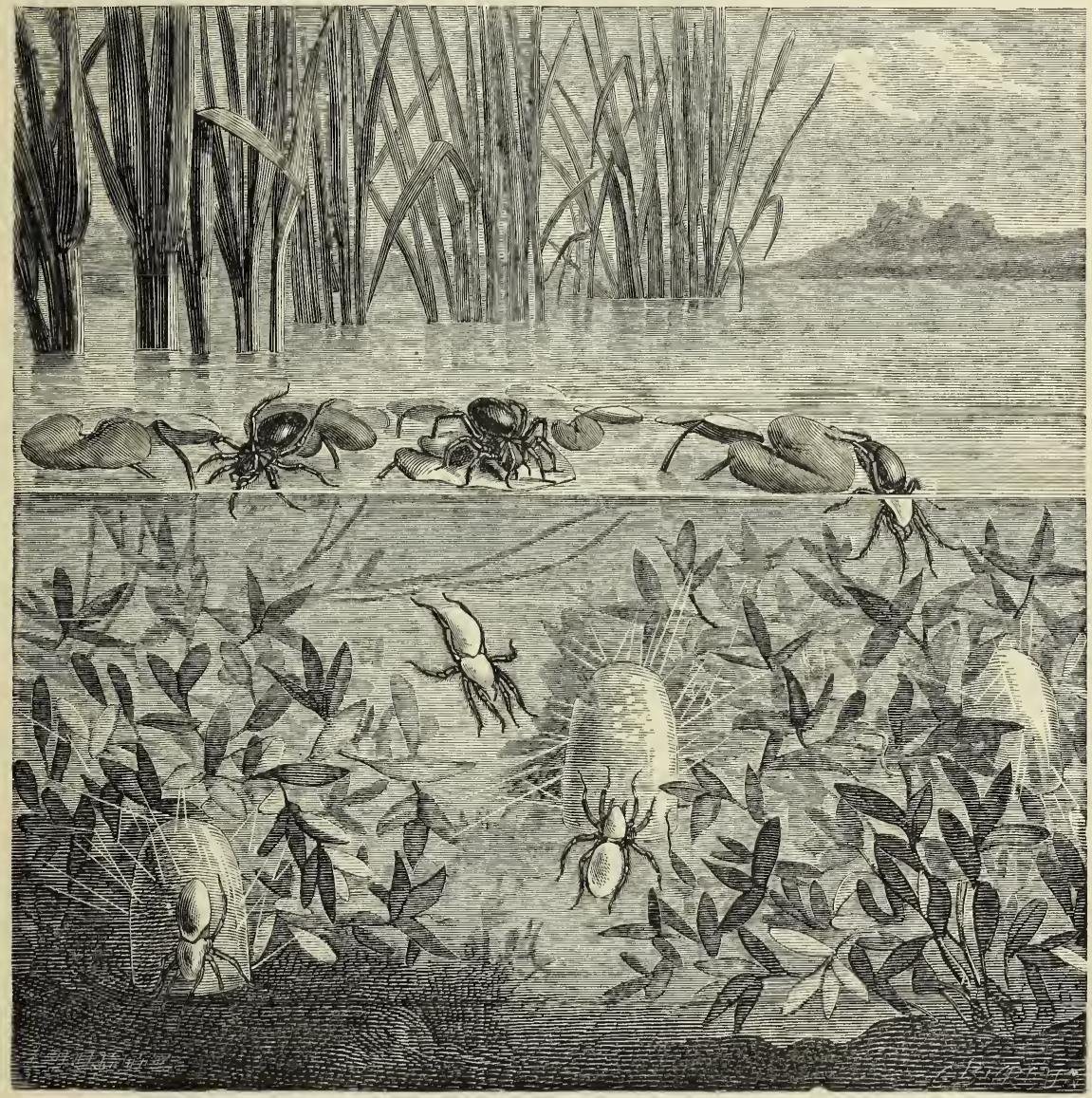

THE NESTS OF THE WATER SPIDER. (Argyroncta aquatica.)

which are seen deep in the water are of the same colour, because air is mechanically entangled in the tissue covering the whole of their bodies. This air is rubbed off with the aid of the legs when the spider enters its bell-shaped nest, and its globules replace the water, and at last, after successive ascents and descents, the dome is full of air. 


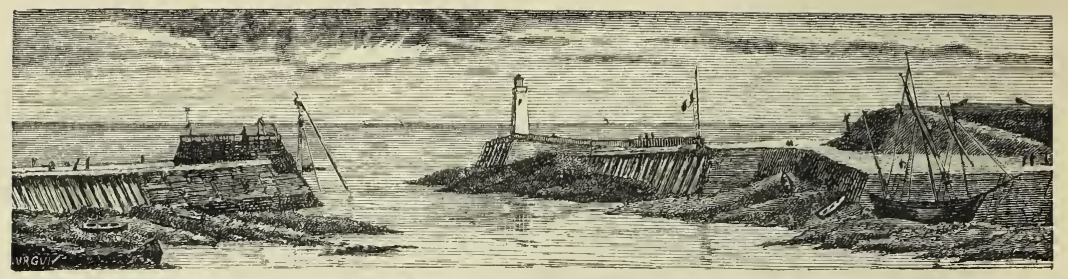

\section{CHAPTER XVII.}

\section{THE CRUSTACEA.}

A VERY slight acquaintance with the common objects of the sea-shore, and the inhabitants of marine aquaria, suffices to render us familiar with the varieties of the articulate creatures which are classified as the Crustacea. Lobsters, spiny lobsters, cray fish, prawns, shrimps, crabs, spider crabs, hermit crabs, sand hoppers, wood lice, water fleas, king crabs, and last, but not the least interesting, the barnacles, are readily recognised and distinguished by all who take the commonest interest in natural history.

The bodies of these animals are divided into segments; the skin is hard, calcareous, or horny, and the limbs are jointed, attached to special rings, and are arranged in a double series. The limbs, or rather the articulated extremities, are the antennæ, jaws, and mouth pieces, and the walking, swimming, and prehensile legs. The nervous system is ganglionic, and is situated below the digestive organs, and above and in front of them. The respiration is almost invariably aquatic, and, although some species can exist on dry land, still moisture is required for their peculiar lung cavities. Some Crustacca have no special breathing organs, but respire by means of their skin. These statements recall to the mind the organisation of the true insects and the spiders. The tracheæ are wanting in the Crustacea, but nevertheless the classificatory anatomist combines these classes, otherwise so united by their common structures, and with much truth, for it is by no means improbable that they all had a common parentage soon after articulate life commenced on the globe. 
What appeared most unreasonable to the imperfectly informed naturalist of a quarter of a century since is commending itself to those who are now most qualified to judge of such questions. For instance, what could be more distinct than the prawn and any insect in the thoughts of the older anatomists; the one has more legs than the other, the respiratory apparatus differs, and the physiology is not the same. The progress of science, and the researches of Thomson, Spence Bate, Goodsir, and many others, opened up the investigation by discovering and describing the metamorphoses of the crab class, phenomena which were at once stoutly denied. It was proved that some Crustacca left the egg totally unlike the adult form, and that a transformation occurred into a creature more like the perfect animal, the process of evolution being unaccompanied by any immobile state like that of the chrysalis, and being assisted by repeated skin sheddings. In some Crustacea the first stage was shown to be absent, and that in others the animal left the egg not so very unlike the parent, and it was soon discovered that closely allied members of the class were subject to one or other of these incomplete metamorphoses, or to no transformation at all. The transformation is not invariable in the evolution of the class, nor is it in the true insects; and similarity of structure, and great general resemblances of shape, organisation, and habit, evidently do not necessitate the same method of arriving at maturity in either class. It is most probable, then, that the transformations were superadded in both classes to kinds the destinies of which required such phases in order to maintain the life of the species. The creature which comes from the egg in the Crustacea is called the Nauplius; it develops into the Zö̈a, and this usually turns into the adult form, but there may be an intermediate stage. The three phases are often as different as regards the method of life and shape of the creature as are the larvæ, mobile nymphs, and perfect forms of such insects as the Orthoptera.

The earliest stage of crustacean life, subsequent to the embryonic state, presents a Nauplius whose anatomy is as different from that of the mature prawn, for instance, as that of the larva is from the butterfly. The Nauplius has not the number of the extremities which characterises the Crustaced as a class, nor has 
the $Z$ ö̈ $a$, which succeeds. Like the larvæ of those spiders which undergo metamorphosis they have six legs-the three pairs of extremities which characterise the true insects as a class. Moreover, the mouthpieces of the immature representatives of the different classes are of the same number. Fritz Müller points this out with great force, when arguing respecting the interesting question of the origin of the classes included under the Articulata from a common ancestry, and remarks, moreover, that the true insects, like the Zö̈e of Crustacea have no appendages to the abdomen, and that both have mandibles without palpi. When the habits, transformations, and structures of the water insects are considered, and especially those of the wonderful water larvæ of the Hydrocampa moth and the Ephemera larva, there is no difficulty in believing in the descent of the more complicated terrestrial forms of insects from the Nauplii or Zö̈e of early fresh water Crustacea.

Fritz Müller has pointed out that the Orthoptera with larvæ which have eleven segments in the abdomen (and not nine as in the Lcpidoptcra larvæ) agree with the rudimentary prawns - the Zö̈e, and with the higher Crustacca, in the number of their body segments. He notices, moreover, that in the Orthoptera and the Crustacea the egg orifice and the vent are placed on different segments, and not on one particular ring.

The oldest known insects are Orthoptera, or the closely allied Ncuroptera and Colcoptcra. It is, therefore, important to remember that the majority of the Orthoptera leave the egg not in a more or less embryonic condition, but as larvæ which resemble greatly and have the same habits as the adult forms. The development of wings proceeds, and the generative processes are adopted, and that is nearly all that takes place between birth and adult age, except simple growth. The growth progresses without distinct states, and is accompanied by no marked phases of transformation. All this hints at the complete metamorphosis of other insects being an acquired gift during the struggle for existence; and when the structural relations between the Orthoptcra and the Zö̈e of the Crustacca are considered, the origin of the two articulate or insect forms from some older kind of Crustaced commends itself to 
our belief, and as much might be said for the ancestry of the Arachinida through the Acarida.

The Crustacea with ten legs, and eyes which are placed on the ends of short movable stalks, or peduncles, or the Decapods, were the first that were found to undergo transformations. In this order the head and the thorax are fused together so as to form a carapace, and the branchiæe or gills are attached to the legs and hidden beneath it. Those decapod Crustacea which have a long segmented abdomen ending in a fan-like tail, such as the lobster, shrimp, and prawn, are called Macroura, and the short-tailed tribe, such as the crabs, are termed Brachynra. A third order, containing the Hermit Crabs, which have a small fifth pair of legs, and the abdomen more or less soft and peculiarly formed, are the Anomoura.

An English naturalist, Mr. Vaughan Thomson, was the first to recognise that the decapod Crustacea passed through a kind of transformation before reaching their maturity. His observations were sharply criticised, but they stood the test of careful examination, and some years afterwards Spence Bate's celebrated essay in the "Philosophical Transactions," I857, confirmed their accuracy, and added much to the knowledge of the subject. Mr. Bate remarked that previous observers and writers, including Mr. Thomson, agreed that two remarkable metamorphoses take place during the progressive development of the crab to the adult stage. The rule holds good for most of the Crustacer, the land crabs and fresh water cray-fish forming an exception. These are the only Crustacea which do not undergo very decided changes of form during their evolution after the escape from the egg.

The following is a brief analysis of Mr. Bate's communication. He commences by asserting that nothing like an immobile chrysalis stage occurs in the Crustacea, and that the transformations are due to the more unimportant structures of one stage of life becoming very important in the succeeding. The larvæ of Carcimus mcenas, a common crab, were obtained: those in the earliest stages of growth were procured direct from the animal, and were hatched whilst in Mr. Bate's possession, and those of a later date were derived from Plymouth Sound. With these specimens before him, Mr. Bate traced the progressive development of the respective 
parts of the crab, from their simplest to their adult and most elaborate condition.

The embryo, when it first quits the egg, is enclosed within a general tunic, which embraces each individual member, and is conformable to the whole animal. The tunic is exceedingly transparent, and the hairs of the young immature crab and the hornlike processes which characterise the carapace, are folded down and compressed. The crab swims about for a few hours in this state, and then liberates itself by throwing off the portion of tunic which covers the head and the part of the body which gives off the long legs. The tunic upon the jointed tail-like end is cast off some hours afterwards. (Page 454, Fig. I.)

The following terms are used to distinguish the portions of the body of the Crustacca. The tail-like long body is called the plcon, from $\pi \lambda \epsilon^{\prime} \omega$, to navigate, being that part of the animal which supports the limbs by which it swims about; and the swimming limbs are called pleopoda. The tail end is the telson. The portion which supports the walking legs is called the pereion, from $\pi \epsilon \rho a \imath$, $\omega$, to walk about; and the legs are termed percipoda. This portion is hidden by the carapace in the young state, and this last-named part is what is familiarly considered to be the head.

When freed from the tunic, the animal sports and gambols in the water partly by the action of the entire pleon, and partly by the great feeler legs attached to the pereion. The carapace is seen to be armed with a long projecting beak or rostrum, and a spinelike portion projects from the back. (Fig. on page 453.) In this early stage the dorsal spine or that on the back, is no mere ornament, but possesses a specific use in supporting the heart in its position. The carapace is attached to the pleon by a membrane, and there is an opening in it on either side, so as to admit a stream of water into the branchial cavities. The carapace is compressed in front, and the eyes are prominent, and are fixed upon a short stalk.

In the youngest stage, and in the crab when escaped from the tunic (Zö̈a-for the crabs, unlike many other Crustacea, do not go through the nauplins form) there is a pair of appendages in front which represent the antennx, and there are some hairs upon them, which become gradually developed into the organ of hearing. 
Next come the mandibles, and then the maxillæ, and these are followed from before backwards by swimming legs and the germs of five pairs of true walking legs, and of the branchiæ. The pleon consists at this stage of six segments, five upon one plan, and the last different. The first five are simple articulations, but the germ of the future true swimming legs-pleopoda-are noticed upon

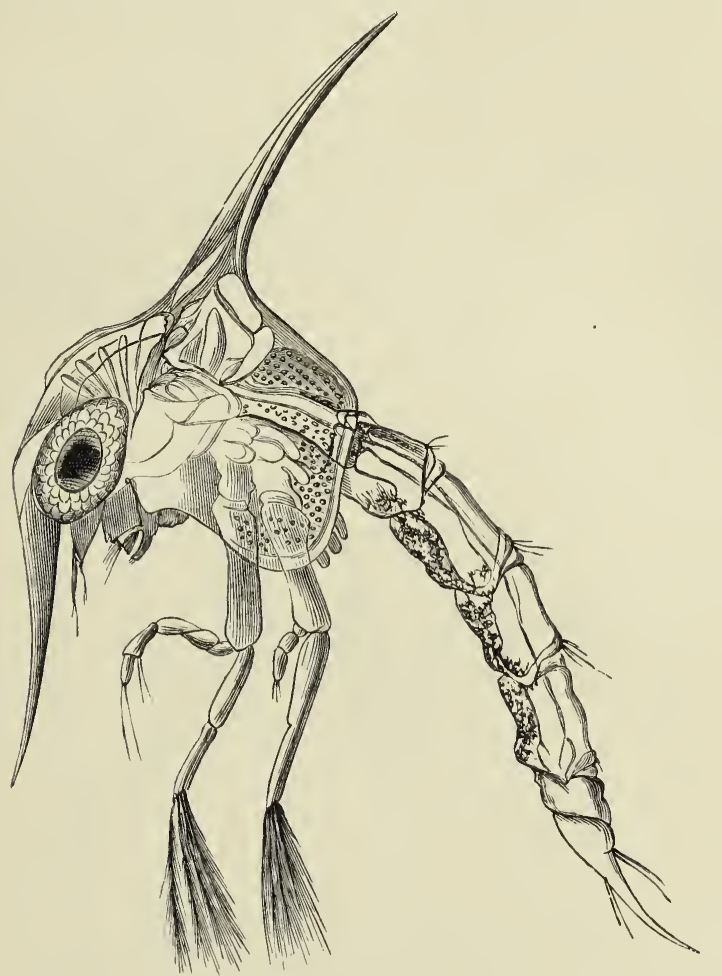

Carcinus manas.

A zoëa after the rupture of the tunic.

one or two of them. The last appendage of the pleon is the future telson of the adult crab.

Repeated moults of the skin, probably at intervals of seven or eight days, succeed each other, producing at each stage but little change to the eye but that of size. At the expiration of a month there is not very much alteration in the Zö̈a except that of bulk.

The examination of individual parts will, however, exhibit some progress in the development of each member in relation to 
the whole. The eye has become more pedunculated, and appears to be movable. The auditory hairs have increased in number. The sac-like vesicles, the germs of the pereipoda, have increased in length at the rate of a joint at every moult, and seven of these legs are visible. The future branchiæ may be detected in the form of simple sacs. The chelæ, or pincers, are seen on the first pair of legs. The pleon now has the seven segments proper to the
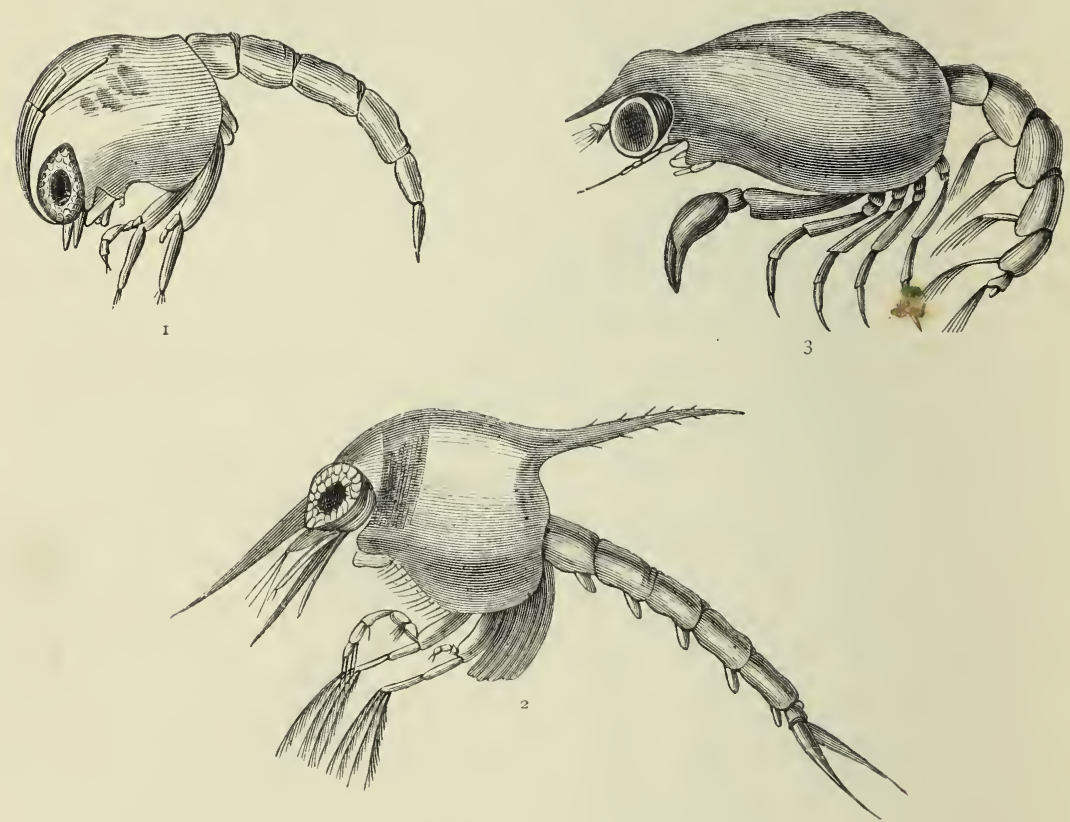

THE METAMORPHOSES OF Carcinus manas.

I. A zoéa within the transparent tunic.

2. Zoëa after several moults.

3. Zoëa still older, and without spines, and with walking legs.

adult, and the three central rings have undeveloped pleopoda upon them.

If we examine the growing animal after a few more moults, and when it has increased to about three lines in length, we shall find its outline still holding a resemblance, though a less close one, to the previous appearance. The form of the carapace scarcely differs except in the shorter relative length of the antennæe and dorsal spines, and the whole animal appears stouter and more 
robust. The long legs on the pereion cease to be used as swimming legs; the pereipoda are more fully developed, and assist in their proper capacity; and the pleon has lost its forked extremity. The antennæ scarcely differ from those of the adult, and the olfactory organ is present in an immature form. The true swimming legs, or pleopoda, have branches and hairs, and have become useful organs, and the telson has lost its appendages. Some other moults deprive the animal of the spine on the back (dorsal), the carapace becomes much altered in shape, especially near the eyes; the auditory organ has become further developed; the walking legs have increased in size, and the claws also.

When the young crab becomes a little larger, though still of the same form, the segments of the pleon in the male commence a a fusion together. The eyes are prominent, and resemble more and more those of the adult stage; but the most striking alteration is the gradual extension of the carapace behind the eyes. The telson gradually assumes the shape of a blunt point fringed with hairs.

Gradually the successive moultings are accompanied by the approach to the adult form, and this is finally reached, evidently, without any distinct stage of quiescence.

Mr. Spence Bate sums up the result of his observations as follows:- "In contemplating the development of the decapod Crustacea, from the youngest and most anomalous form to that of the adult, we perceive that the greatest amount of change, both in appearance and the development of parts, takes place in the Brachyura; but that even here the change is no sudden transformation of one form into another, but a gradual and persistent growth following each successive moult. Every part that is present in the larva, though not permanent in itself, is to be found in a permanent condition in one or other form of adult Crustacea; and, moreover, those appendages which play the most important parts in the larva fulfil only secondary conditions in relation to the aciult. Thus the large natatory limbs in the larva become the palps of the adult Gnathiopoda, and the appendages of the second antennæe either represent unimportant parts of the same organ or are altozether wanting. Again, we perceive that certain parts which contiune present with but a small amount of alteration, 
such as the mandibles and the maxillæ, bear a close resemblance of form to the same organs in adult Crustacea, of an order lower than the parent of these." (Spence Bate.)

Many years since, Erdl stated that the young lobster was of the same shape as the adult, and the metamorphosis of these common Crustacea has therefore been denied. This opinion was strengthened by the observation that the European fresh-water cray-fish and the West Indian land crab quit the egg with the full number of jointed limbs, and, indeed, in the likeness of their parents. All these are stalk-eyed Crustacea; and what could be more natural than that they should all have the same method of evolution? It is most remarkable how dangerous it is to reason by analogy in natural history, and to indulge the imagination in science. Gerbe, Spence Bate, and Couch, however, have proved that the statement of Erdl is not consistent with facts. Spence Bate noticed, in one of his reports to the British Association for the Advancement of Science, that "common as the European lobster (Homarus marimus) is, it is very remarkable that a very young specimen has, as far as I know, never been met with." He offered a reward for a very small specimen, but never received one less than three inches long from the tip of the spine over the head (rostrum) to the end of the tail-piece (telson). By hatching the eggs, however, he obtained the first stage of lobster life, but could not keep the young alive until their metamorphosis into the second. Having obtained also a young lobster, eight days old, from the Hamburg aquarium, he was able to state that not only is the young hatched in a form distinct from that of the parent, but that it retains that form for some time after its birth.

The figures on the next page are by M. Gerbe, and the descriptions of Spence Bate prove that they are tolerably correct.

The egg is about one-tenth of an inch in diameter, and contains a yolk of a dark, almost black, green colour. The central dark eye of the embryo is distinctly seen in the earlier days of development, but it is lost when the animal escapes from the egg. At this period the young Zö̈a has a short pointed (Fig. 2) rostrum that is at first bent back, two large eyes situated under the front part of the head, and two antennæ. It has mandibles without joints, two pairs of maxillæ, the third not being yet developed, and 


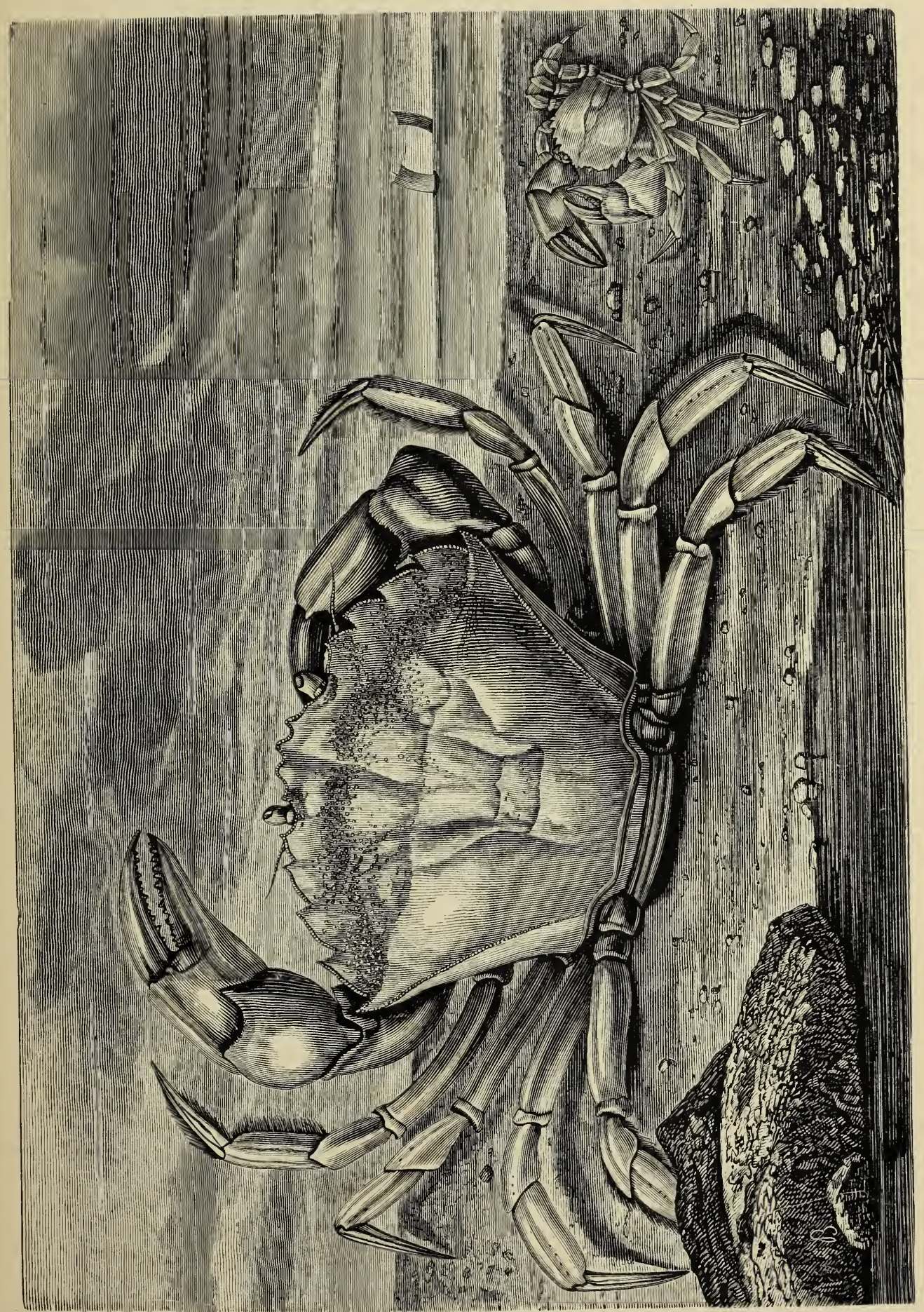



seven pairs of legs, which are furnished with an oar-like branch on the third joint. The abdomen has six segments only, and no appendages; and the tail or telson is flat and pointed, with a strong projecting central spine. In Fig. 3 M. Gerbe shows that the resemblance to the adult has become greater, but the great antennæ, rostrum, and chelate extremities, and the appendages of the abdomen, are not yet developed.

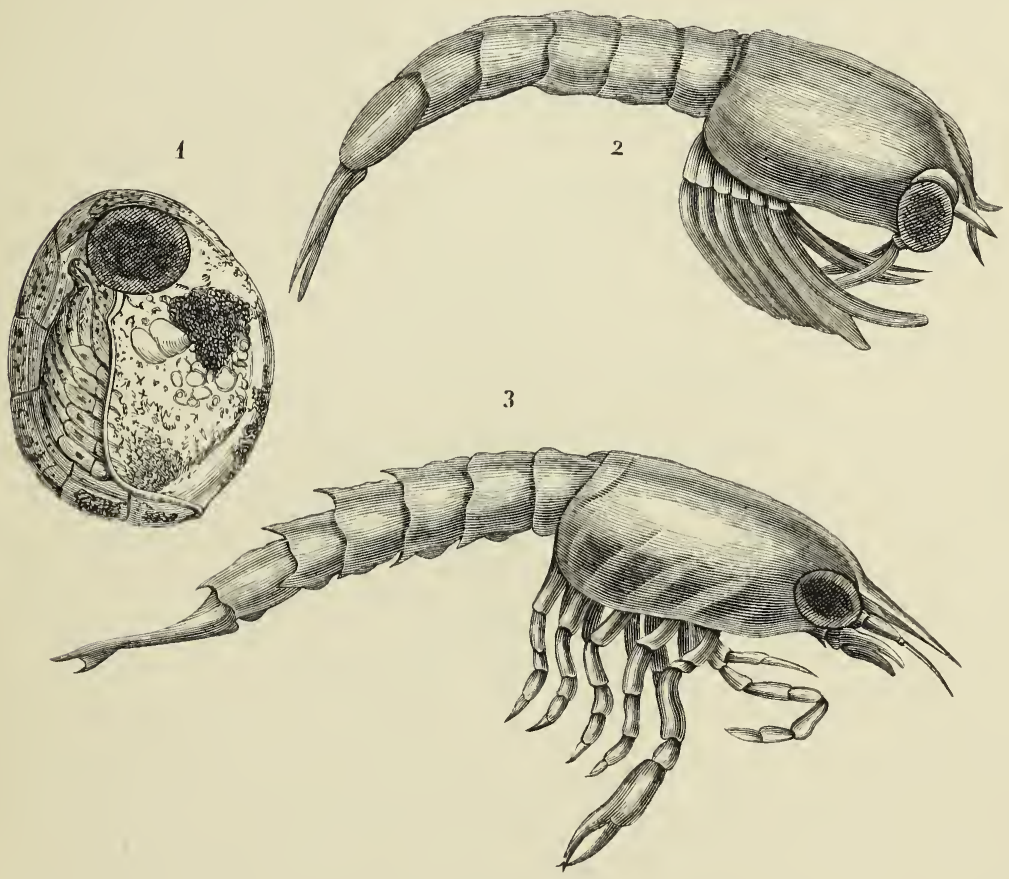

YOUNG LOBSTERS.

1. Embryo in the egg. 2. Zoëa just born. 3. After the first moult.

Let us examine Fritz Müller's description of the metamorphoses of a prawn, which is a stalk-eyed Crustacean, and closely allied to the lobster (from W. S. Dallas's admirable translation of "Facts for Darwin"). The young of the genus Peneus quit the egg totally unlike the adults, and the extent of the metamorphosis is as great as in any of the true Insecta. The youngest forms have, when they quit the egg, an ovate body without any segments; they have a solitary frontal eye, and three pairs of swimming feet, of which 
the anterior are simple, and the other two branched (biramose). These Nauplii have no carapace, no paired eyes, no masticating organs, and the mouth is over-arched by a helmet-like hood.

This rudimentary larva or Nauplius soon alters in shape, moults, and a fold of skin grows across the back behind the third pair of feet, and four pairs of stout processes (rudiments of new limbs) sprout forth on the ventral surface. Within the third pair of feet powerful mandibles are developed. In a subsequent moult the new

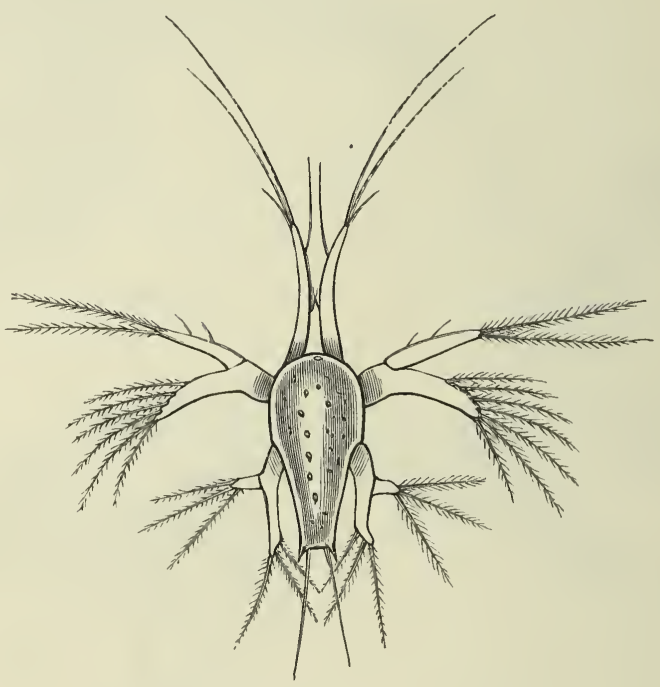

YOUNGEST NAUPLIUS OF A PRAWN.

Magnified 25 diameters (after F. Müller).

limbs (maxillæ and antennæ and intermediate maxilipedes-foot jaws) come into action, and the Nauplius becomes a Zoëa, agreeing perfectly with the $Z o \ddot{e} a$ of the crabs in the number of the appendages of the body, although very different in form and mode of locomotion, and even in many particulars of internal structure. The chief organs of motion are still the two anterior pairs of feet which are slender, and furnished with long setæ or hair-like spines. The third pair of feet loses its branches, and becomes converted into mandibles destitute of palpi.

The labrum acquires a spine directed forwards, and of considerable size, and the two-branched foot jaws appear to assist but 
slightly in locomotion. The forked tail is remarkable, and is unlike the flat apparatus of many other Crustacea. The heart possesses only one pair of fissures, and has no muscles traversing its interior, whilst in other zoёa two pairs of fissures and an interior apparatus are always recognisable.

During the next zoëal period the paired eyes, the segments of the middle body and abdomen, the hind foot jaws, the sides of the

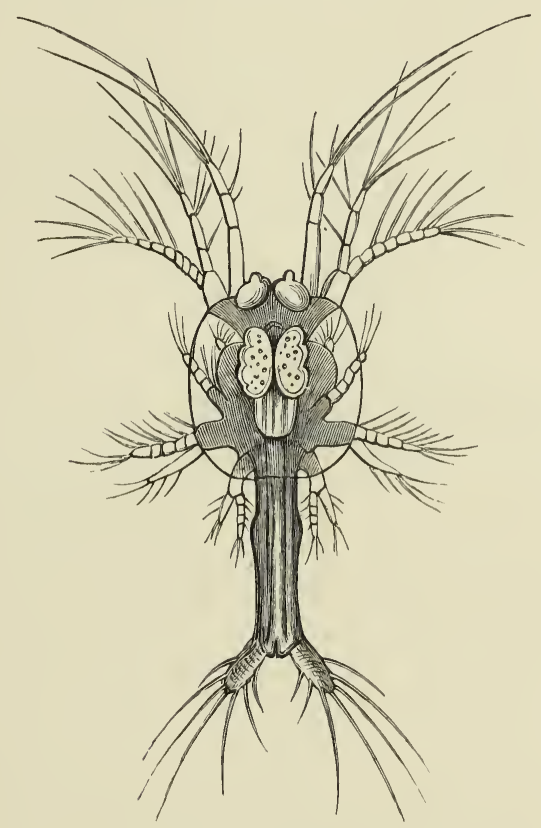

YOUNG ZOËA OF THE SAME PRAWN.

Nagnified 45 diameters (after F. Müller).

tail, and the stump-like rudiments of the feet of the middle body are formed.

The appendages of the tail-piece sprout forth like other limbs freely on the ventral surface.

As the feet of the middle body come into action simultaneous with other profound changes, the zoëa passes into the "mysis form." The antennæ cease to serve for locomotion, their place is taken by the thoracic feet, furnished with long hair-like spines (setæ), and by the abdomen, which just before was laboriously dragged along as a useless burden, but now, with its powerful 
muscles, jerks the animal through the water in a series of lively jumps. The anterior antennæ have lost the long setæ, and by the

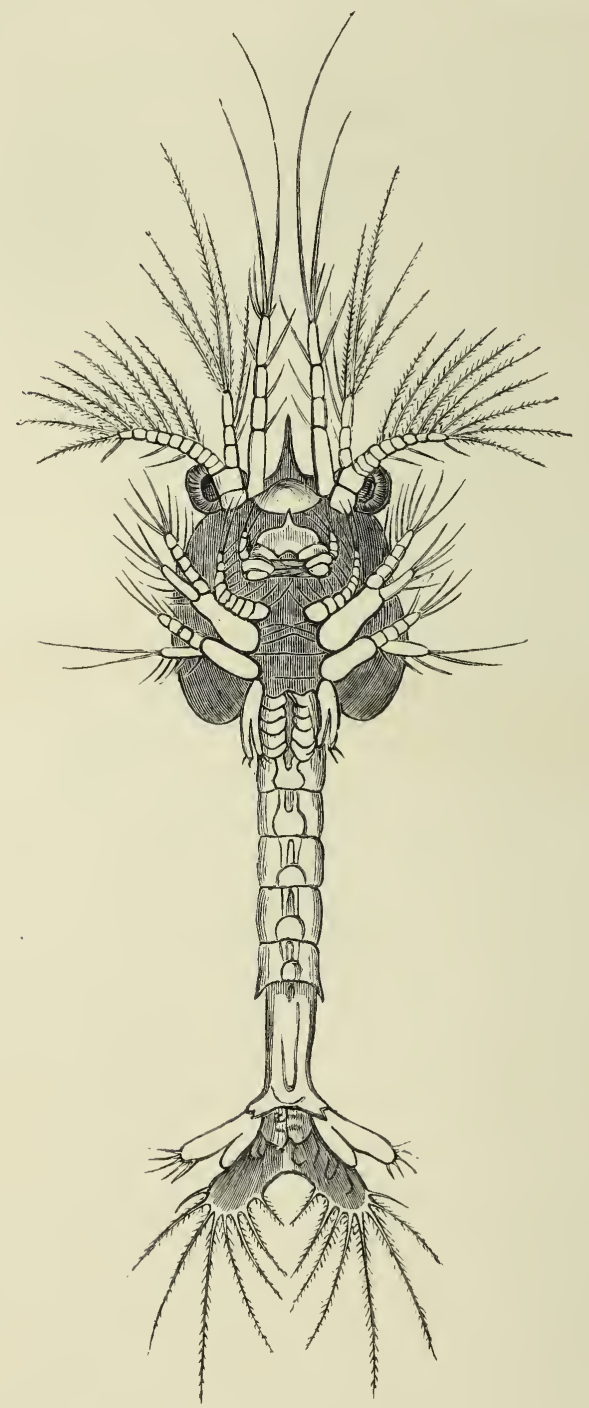

OLDER ZOËA OF THE SAME PRAWN.

Magnified 45 diameters (after F. Müller).

side of the last or fourth joint, endowed with olfactory filaments (smellers), there appears a second branch, which is at first of a single joint. The five new pairs of feet are biramose, the inner 
branch short and simple, the outer one longer, annulated at the end, furnished with long setæ, and kept, as in the genus Mysis, in constant whirling motion.

During this Mysis period the hearing organs are formed in the base joint of the anterior antennæ; the inner branches of the first three pairs of feet are developed into chelæ, or pincers, and the two hinder pairs into walking feet; palpi sprout from the mandibles, branchiæ on the thorax, and swimming feet on the abdomen. The spine on the labrum becomes reduced in size.

In this way the animal gradually approaches the prawn form, in which the median eye has become indistinct; the spine of the labrum and the outer branches of the cheliferous, pincer-bearing, and walking feet have been lost, the mandibular palpi and the

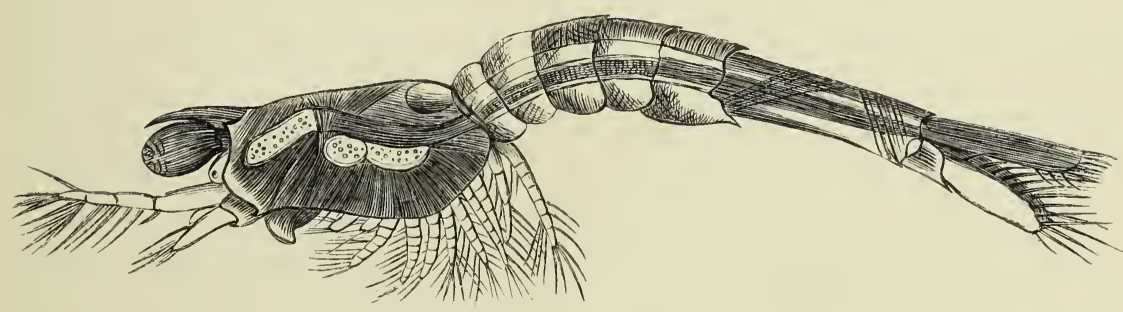

MYSIS FORM OF THE SAME PRAWN.

Magnified 45 diameters (after F. Müller).

abdominal feet have acquired distinct joints and setæ, and the branchiæ come into action. In noticing the development of the genus Myris, F. Müller states that the first organ which shows itself in the embryo within the egg is the tail; then more appendages on the other end, and the rudiments of antennæ and mandibles appear; but the egg membrane bursts, and the animal is set free, before any internal organ, or even any tissue, except the cells of the skin, is formed. The Mysis is developed within this skin bag.

The Spiny Lobsters (the Palinurida) are not only well-known articles of food, but are exceedingly interesting on account of their strange transformations during development-transformations much greater than those of the ordinary lobsters. There is one species in the European seas, and its metamorphosis has been 
studied especially by Gerbe and Spence Bate. The young of the spiny lobster are remarkable on account of their great resemblance to those of another genus, Phyllosoma. M. Gerbe has no doubt of the identity of the young forms of these two genera, the adults of which are very different; but Spence Bate, after weighing

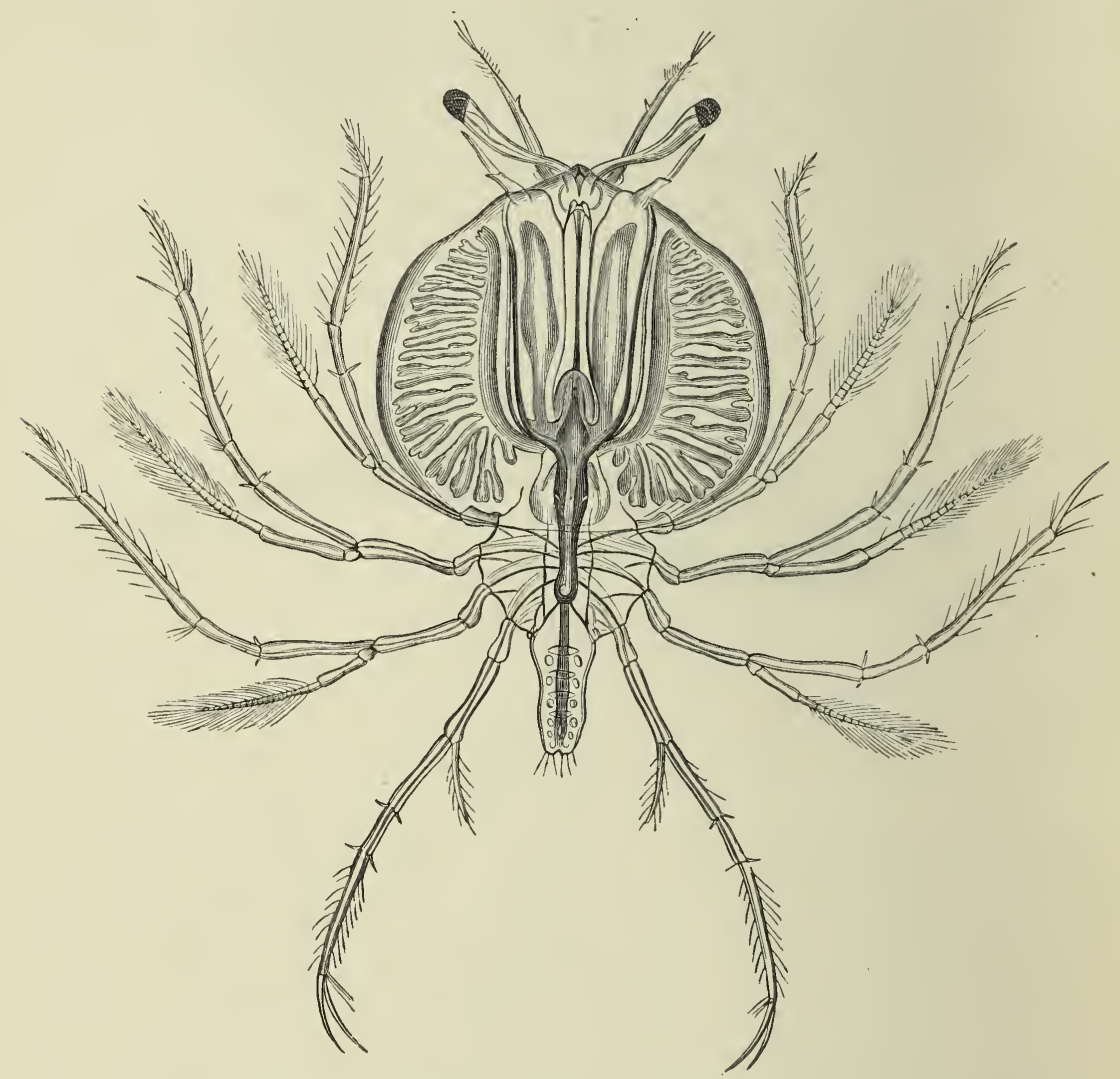

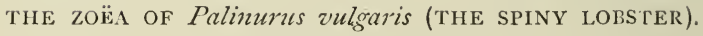

(After M. Gerbe.)

the evidence on both sides of the question, determines that the zoëa are not identical. The great difference between the miniature and the perfect spiny lobster can be appreciated by comparing the engraving of the zoëa with that of the adult form.

The outside figures belong to species of the genus Praniza, and are small $I$ sopoda, the variations in colour of which are very remark- 


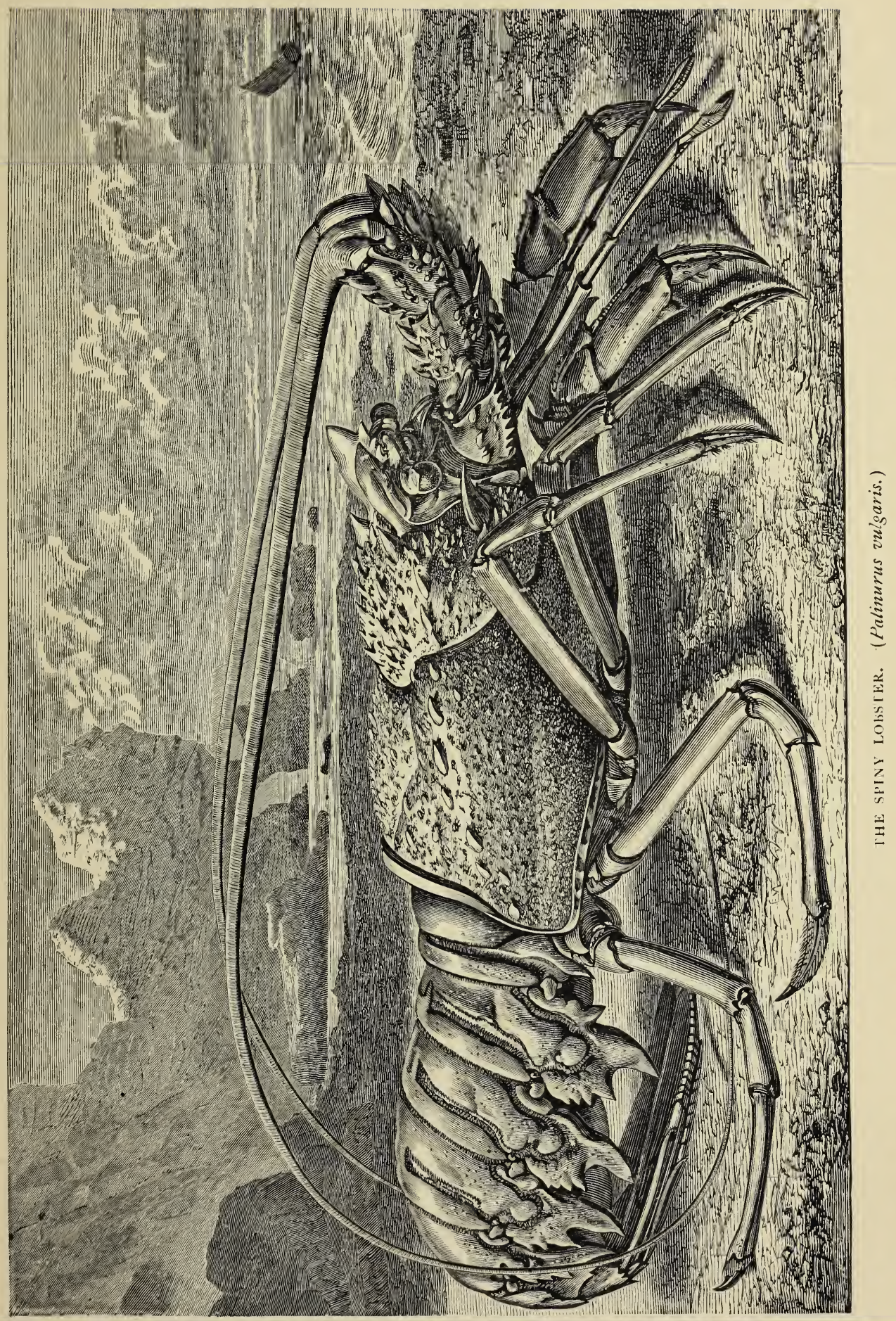



able. Sometimes they are of a grass-green colour, or blue or ashgrey; and they are often transparent and dirty white. A variety of the common British kind is of a reddish-brown colour. Not only are they interesting on account of this peculiarity, but they have also afforded much discussion concerning their relation to the creature represented in the central figure, which belongs to the genus Anceus. M. Hesse, a distinguished French naturalist, made a great sensation amongst carcinologists some years since by asserting
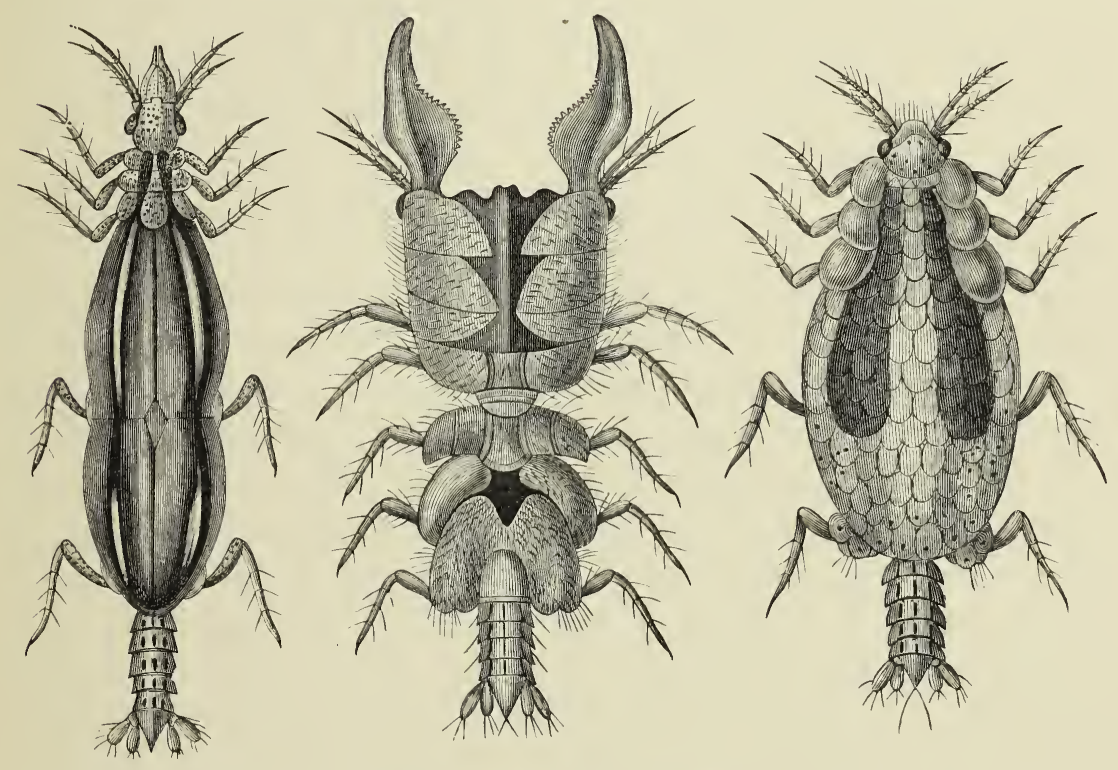

SPECIES of Praniza AND Anceus.

that his researches had led him to be certain that the Anccus was the mature form of Praniza, and that the female Ancens's eggs were developed into creatures like those represented above. Whilst he was pursuing his investigations, Spence Bate was completing some very careful researches upon this very subject, and the English naturalist arrived at very different conclusions. He showed that the young Praniza was not quite like its adult form, but that the resemblance was great, and that the young of Praniza caruleata was more like Anceus than the lately-hatched of the other Praniza. The distinctions in the anatomy of the genus Praniza and Anceus 
were carefully pointed out by the same accurate observer, and then he proved that Praniza had eggs' of different shape to the last-mentioned genus. Praniza, to have eggs, must be an adult form, and therefore could not be the immature zoёa of Anceus.

Whilst accepting Spence Bate's proofs of the distinctness of the two-forms; it must be remarked that M. Hesse had some warrant for his idea that the supposed change from the Praniza stage to that of Ancens took place very late in the life of the creature, for a correspondingly great alteration does occur in other Isopoda, such as Tanais, the males of which receive a very considerable access of abdominal feet simultaneously with the last pair of feet of the thorax, and alter greatly before attaining sexual maturity.

There are some examples of great retrograde metamorphosis amongst this order of the Crustacea, as a consequence of a parasitic mode of life. The young of the Fish Lice (Cymothoa) are lively swimmers, and the adults stiff, stupid, heavy fellows, whose short, clinging feet are capable of but little movement. Some, which are parasitic upon crabs and lobsters, take up their abode chiefly in the branchial cavity, and then it is found that the adult females are usually quite destitute of eyes. The antennæ are rudimentary, the segments of the body are more or less amalgamated with each other, the feet are stunted, and the swimming appendages are transformed into leaf-shaped branchix. In the males, which are dwarfed, the eyes, antennæ, and feet are usually better preserved than in the females; but, on the other hand, all the appendages and every trace of segmentation have not unfrequently disappeared. In the females of Entoniscus, which are found in the body cavity of crabs, the eyes, antennæ, mouth-organs, the segmentation, and the whole of the limbs (in one species) disappear without leaving a trace. One species would almost be regarded as a flat worm rather than an Isopod, if its eggs and young did not betray its crustacean nature.*

Metamorphosis appears to be absent in the common woodlouse, which may be taken as the type of the Isopoda.

The small water fleas, or Daphniide, are well known to those 


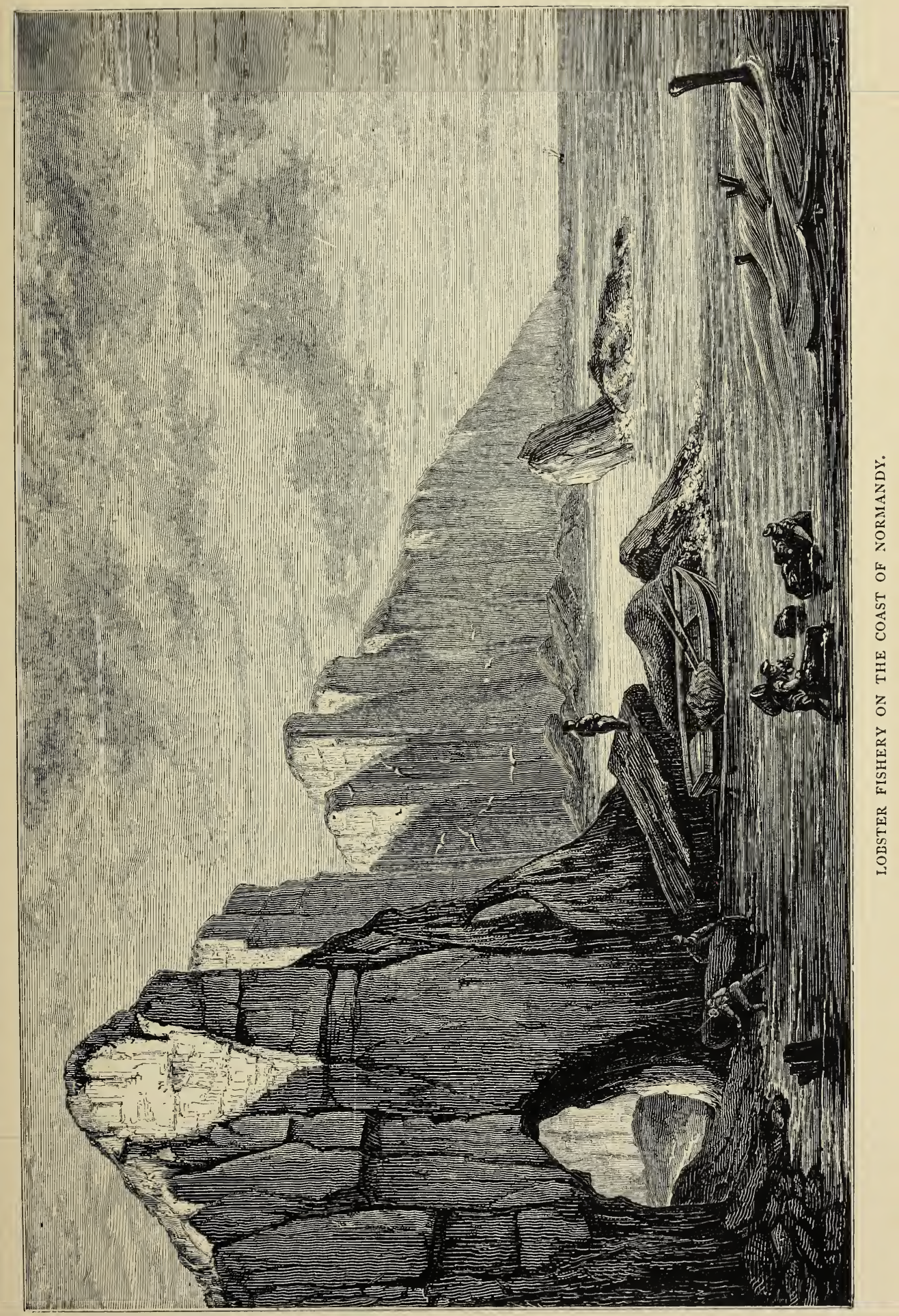



who keep fresh-water aquaria. The Daphnia pulex is very abundant in ditches and ponds, and it is recognised by the carapace consisting of two shell-like valves, which enclose the body, and allow the large antennæ to protrude externally. It is the type of an order, and is only interesting to us because it does not undergo metamorphosis. The young Daphniide are born from the egg with ten legs and with the external appearance of the adults. Shell moulting occurs several tinies, and there is much that is interesting in the creature's having two kinds of

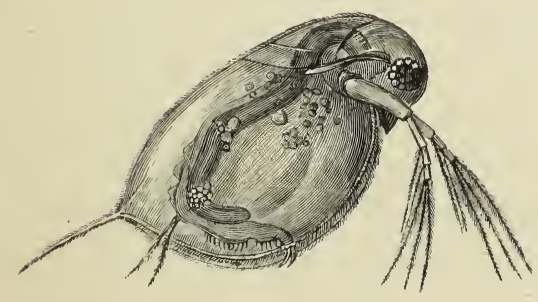

Diaplinia pulcx.

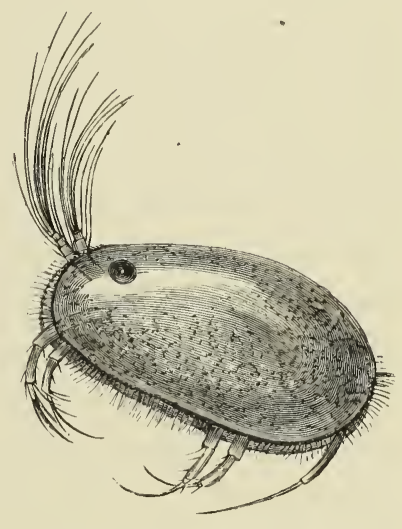

Cypris fusca.

eggs, but the absence of transformation is the most remarkable part of its cconomy.

The Daplniza is classified with certain other Crustacea on account of the absence of true branchiæ and the presence of foliaceous feet, which act as respiratory organs; but the Phyllopoda, which are thus associated with the water fleas by a common physiology, have a different method of evolution. They undergo transformations, and one genus (Nebalica), a species of which lives in the sea, are born as Nauplii and become Zö̈a before arriving at maturity. The Phyllopoda have very numerous segments and limbs, and these are added to the bodies of the Nauplii, one after the other, from before backwards, and there is no sharp line of division between the different regions of the body, such as the thorax and abdomen. Fritz Müller considers them as zö̈ $a$ which 
have never attained that maturity which is observable in the Decapoda.

The subdivision of the Crustacea called Entomostraca, the members of which have no branchiæ, or any modification of other structures, for the purposes of respiration, the sessile eyes being generally united in one great mass, contains two orders. The first, the Copepoda, of which the genus Cyclops is well known, has the body divided into distinct rings, and has only a rudimentary carapace; and the second, the Ostropoda, has a large shield-like carapace, as in the genus Cypris. All these minute Crustacca undergo metamorphosis, and they have been especially studied by Claus, and commented upon by Fritz Müller.

The Copepoda (oar-footed) are very small, and the males and females differ, the latter carrying their eggs in a bag which hangs externally from the hind end of the body. These one-eyed creatures vary much amongst themselves, and have been classified under many genera. They occur in myriads, both in salt and fresh water; and Cyclops quadricornis is perhaps the most abundant British species, and may be found in ponds and ditches in great multitudes. One genus (Cetochilus) supplies the whale with food; and the Sapphirince are luminous at night in the South Sea. The Copepoda are born from the egg in the Nauplius form, and are totally unlike the adults. They have, at the earliest period, three pairs of limbs, which become eventually, and after metamorphosis, antennæ and mandibles. A single eye, the labrum, and mouth, already occupy their permanent positions. The hind part of the body is usually short and destitute of limbs, and has two terminal setæ or bristles, and the shape of the whole creature is very diverse in the different species. The changes which the first larval stages (Nauplii) undergo during the progress of growth consist essentially in an extension of the body and the sprouting forth of new limbs. The following stage finds the Cyclops with a fourth pair of limbs, which are the future maxillæ or jaws; then follow at once three new pairs of limbs, the jaw feet and the two anterior pairs of swimming feet. The larva still continues like a Nauplius, as the three fore pairs of limbs represent rowing feet; at the next moult, it is converted into the youngest cyclops-like state, when it resembles the adult animal in the structure of the antennæ and mouth-pieces, 
although the number of limbs and body segments is still much less. For only the rudiments of the third and fourth pairs of natatory feet have made their appearance in the form of cushions fringed with setæ, and the body consists of an oval cephalo-thorax (head and thorax combined), the second, third, and fourth thoracic segments, and an elongated terminal joint. Many forms of the Crustacca which are parasitic upon other creatures do not attain a further development than this, although they can reproduce their kind, and some do not even reach this stage of, comparatively speaking, "under" development. But all the rest, and most of the parasites, pass through a longer or shorter series of stages of development, in which the limbs acquire a higher stage of division into joints. The posterior pairs of feet are developed, and the last thoracic and the different abdominal segments are successively separated from the common terminal portion. (Claus and Fritz Müller.)

Very little is known as yet concerning the systematic growth of the Ostracoda. The genus Cypris, a species of which (Cypris fusca) is represented on page 465 , is found in fresh water, and nearly all of the members of the genus Cythera frequent the sea. All have a horny cretaceous covering of two valves exactly resembling a minute mussel shell (Baird). Claus has shown that the eggs produce Nauplius forms, which are, however, shell bearing, and that, after many moultings, the adult shape is attained. The eye, the two pairs of limbs, the antennæ, and the tail-end of the Cypris fusca, represented in the engraving, belong to a full-grown adult. The general shape of these Entromostraca should be kept in mind, for it will be referred to when considering the metamorphosis of the Cirripedes.

Many Crustacea have the mouth prolonged in the shape of a sucker, and one order of these (Haustellata) not only has kinds classified under it which are very unusual and extraordinary in shape, but the limbs even are more or less rudimentary.

The metamorphoses of the sucking and parasitic Crustacea belonging to this order, which frequent salt and fresh water fish of all kinds, are very remarkable, not only because the change of external appearance is great during the successive phases of Nanplius, Zö̈a, and adult life, but because there is a manifest retrograde transformation; the structurcs of the active larva being 
more elaborate and complicated than those of the full-grown males and females.

The central figure represents a newly-born larva or Nauplius form; that on the left is of a $Z o \ddot{c} a$, after a moult, and the perfect female is shown upon the right hand side of the engraving.

These creatures may be found in the adult form upon the eyes, skins, and gills of many fish and Crustacea, and adhere by the matter which is formed upon the arched ends of the projections in front of the straight part of the head, which is surmounted by two small antennæ. The head, body, and abdomen are united, but there are constrictions which divide them to a
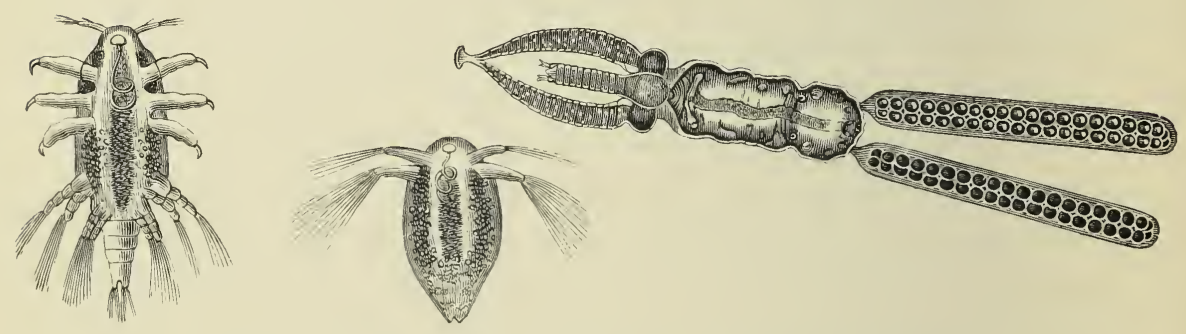

THE METAMORPHOSES OF A Lernean (7racheliastes polycolpus).

certain extent, and the intestinal canal may be noticed running down the midst. The female, at certain times of the year, has two long ovisacs at the end of the abdomen, for the reception of eggs which are developed within the body, but the limbs do not exist. The only exception to this statement is the arched structure ended by the sucker in front of the head, and probably this is formed by a pair of altered extremities. The Lernaa lives upon the juices of the fish, to which it adheres, and it produces ova which in due time escape.

The egg consists of an outer and inner membrane; and the embryo, which before hatching is more or less globular, is furnished with an eye and two pairs of oar-like legs, the second pair being subdivided, and all ended with bristle-shaped hairs. The embryo bursts forth, and a Nauplius or early larva, like that figured in the engraving, results. The legs are more fully 
developed, but not increased in number; the eye is distinct, and there is a peculiar tortuous tube running from it downwards besides a digestive sac. In the course of a very short time a metamorphosis occurs; the outer integument is loosened by the formation of a second beneath it, which encloses a body altered in its shape and in the number and nature of its appendages. The body of the new form has six legs (five if the double one is counted as one), an elongated abdomen, antennæ, and the eye; and the first three extremities are furnished with prehensile organs, whilst the last are natatory.

Owen, quoting Nordmann, states that in the parasite of the perch the antennæ probably seem to indicate to the freely swimming creature its appropriate object, to which it then proceeds to attach itself. The second pair of legs increase in size, and their terminal hook enlarges; the third pair lengthen and unite together to form a circular cartilaginous sucker. The first pair of feet form the mandibles. This is the last metamorphosis, and the Lernaa becomes stationary. The two sexes are alike in their young and locomotive state; the male has shorter and thicker second legs, and is not hung up for life, as he has to seek his mate, but the hind natatory legs disappear in both.

The metamorphoses of the barnacle tribe (the Cirripedia) are quite as decided and as extraordinary as those of the other Crustacea. They have been specially studied by Spence Bate, by that most accurate and philosophical observer, Charles Darwin, and by Martin St. Auge and other foreign naturalists. The engraving of Lepas anatifera on the next page gives an idea of the shape of one great division of the Cirripedia - the stalked. This class is divided into pedunculated or stalked, and sessile or unstalked kinds; the first are represented hanging on to pieces of wood, and the last may be seen encrusting nearly every rock and piece of timber on most parts of the sea-coast, and are something like acorns in shape. Neither the pedunculated nor the sessile kinds ever move from their fixed position, and the only evidence of life presented by them to the ordinary observer is the occasional projection from the end of the shell of delicate fringed "cirri," which thresh the water in one direction. The cirri are represented in the large engraving like so many feathers projecting from the side of the shell of the 


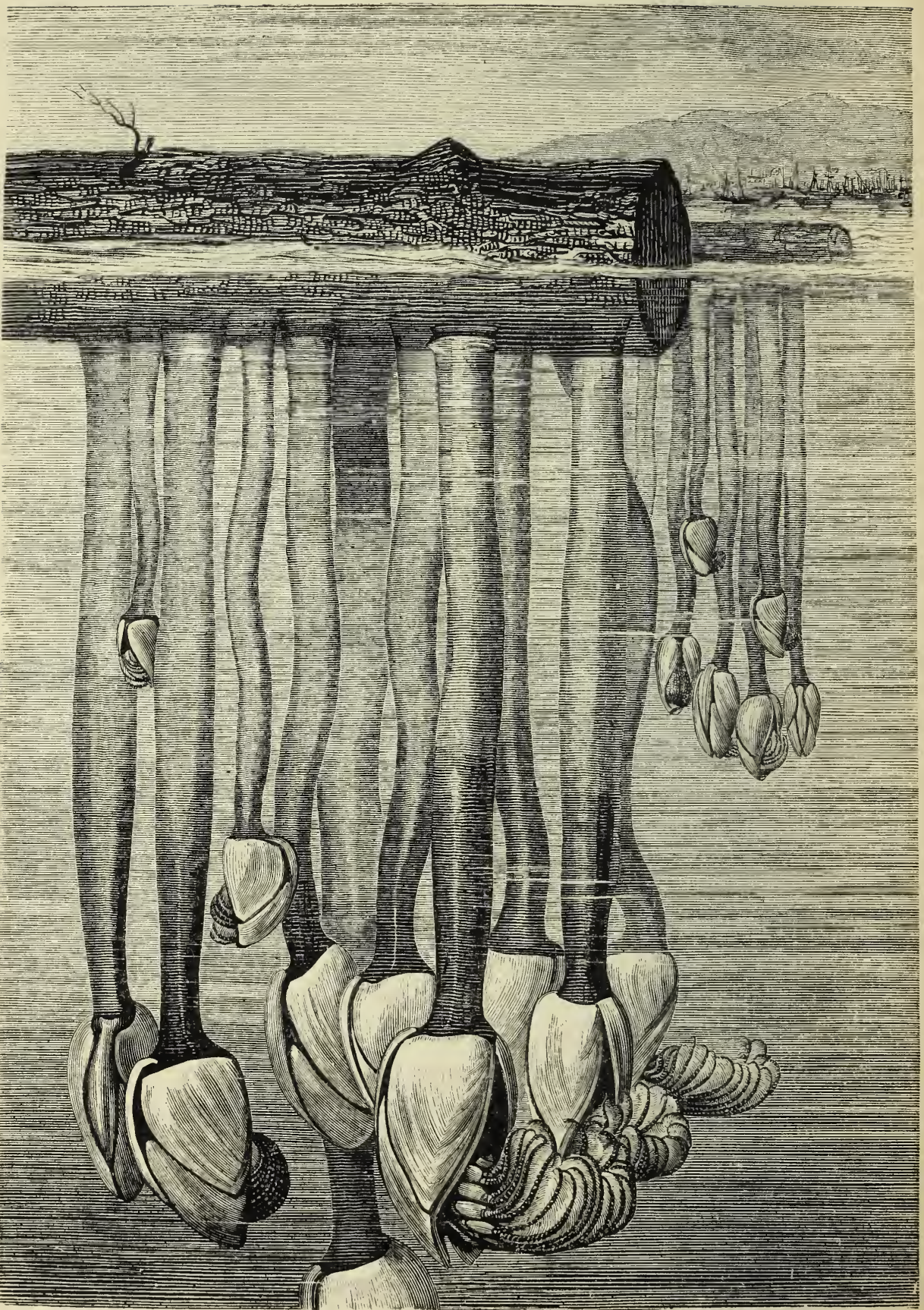


Lepas, and their absence may be remarked in many instances. They are enclosed within the cavity formed by the white looking shell, which, however, in Nature is occasionally coloured with a blue and even purple tint. When a sessile barnacle is examined-and they can readily be kept in the aquarium - the cirri will be seen to project through a trap-door apparatus called the "operculum," or lid of the shell. The shell is made up of five or more side pieces connected together with strips of membrane, which are often brilliantly coloured. The pieces or valves are composed of carbonate of lime; but in some kinds of Cirripedia they are formed, like

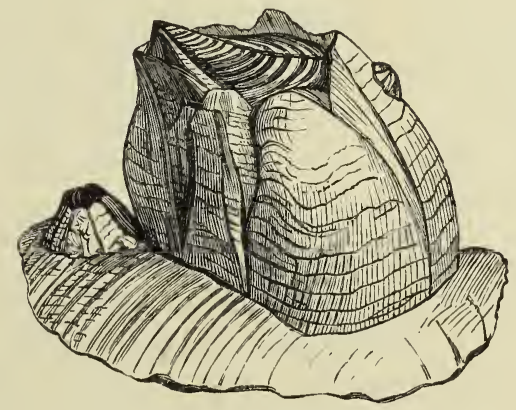

AN ADUlt SESSille BARNACle. (Balanus.)

the membranes, of chitine, and the whole is lined internally by the sac which contains the living barnacle. When there is a peduncle one end forms the base of the shell, and the other is stuck fast to timber, stones, and sea-weeds, and the living animal is continued down into this long neck like attachment. This peduncle varies in length in different kinds; it is usually flattened, but often quite cylindrical, and is composed of very strong, thick, transparent membrane, which covers a thick true skin, which is often coloured in long bands. The outside membrane is either naked or clothed with minute pointed spines, or it is penetrated by scales frequently of carbonate of lime, which are more or less symmetrically placed over parts or the whole structure. The peduncle is lined within by three layers of muscles, longitudinal, transverse, and oblique, and they produce a gentle swaying movement, which is beyond the will of the animal, for the muscular fibres are not of that class which is within the influence of volition. The interior 
of the peduncle is filled up with a great mass of the egg-producing apparatus of the Cirripede; the ovarian tubes and the body of some kinds extend down into it also. On examining the attachment of the peduncle to the rock or timber to which it adheres, one of the secrets of the evolution of the Cirripede is at once discovered; and the same thing occurs in investigating the adhesion of the sessile barnacles or acorn shells, which are so very tightly stuck on to stones by their shells without a peduncle. The relics of a former condition of life become evident, and the remains of antennæ are discovered, which are traversed by tubes or ducts containing the same lind of cement which attaches the base of the peduncle to its supporting stone. These ducts can be followed along the muscles of the peduncle till they expand into the small glands called by Darwin-from whose admirable monograph on the Cirripede this description is taken-cement glands. But the ovarian tubes fill the peduncle more or less, and the cement glands are in contact with them, and the structures of the tubes and the glands run one into the other, and the last are, in fact, ovarian tubes specially modified. The cellular matter which serves for the development of the ova in the ovarian tubes is, by the special action of the walls of the gland, changed into the opaque cellular matter of the gland ducts, and this again subsequently into that tissue or substance which cements the Cirripede to its surface of attachment. The cement removed from the outside of a Cirripede consists of a thin layer of very tough, bright. brown, transparent structureless substance, and is of the nature of chitine. It flowed out of the tubes traversing the antennæ, and glued them and the neighbouring parts of the head of the Cirripede to the surface of the timber or stone. It becomes evident from this discovery that there was a previous condition of Cirripede life when antennæ were required, and that the animal is attached by its head and not by a tail, and that the cirri are therefore not parts of the mouth or head, but are legs. A free swimming creature, with antennæ and legs, and certainly not provided with a heavy shell, must have chosen a satisfactory spot whereon to spend the rest of its days under a very different external configuration, and must have become permanently adherent by its cement bearing antenne.

A very remarkable metamorphosis en- 
sued. The perfect or fully-developed barnacle or sessile Cirripede has a mouth almost in the shape of a proboscis, and it is surrounded by the usual structures noticed in the Crustacea, but they have been more or less modified in their growth. There is a swollen lip, and palpi are soldered to it; and there are mandibles, maxillæ, and outer maxillæ, which serve as a lower lip. The opening into the gullet is situated between the mandibles, and the œsophagus - or tube leading down to the stomach-is capable of violent swallowing movements, and the small creatures brought within the range of the mouth by the whip-like motion of the fine, hairy, and branched cirri are prevented from escaping by the palpi just mentioned. The mandibles have strong teeth, and their duty appears to be to crush and force anything down the œsophagus after it has been guided towards them by the spiny maxillæ. The numerous cirri are jointed, spined, and hairy, and act as arms, although they are legs, so to determine currents in the water, which wash multitudes of small creatures within range of the mouth, and which supply the respiratory appendages with abundance of well aërated fluid. The stomach is curved and bent up, and is provided with glands and branching liver tubes, and is lined with an epithelium; and small Crustacea, minute Mollusca, and larvæ of all kinds are digested by it. When the food has been digested, the internal epithelial coat of the stomach covers it like a bag, and is forced out with it. The eyes in the. pedunculated Cirripedia are apparently united; but two lenses exist, and this double eye is situated deep within the body. It is attached to a muscle at the lowest part of the œsophagus, and lies actually on the upper part of the stomach, so that a ray of light has to pass through many tissues, and to dip down into the body before it can be felt by the optic nerve. Yet these creatures are probably sensitive to light.

The Lepas and barnacle are bi-sexual, and the eggs, when excluded from the body, and to all intents and purposes laid, are collected in leaf-like masses within the sac which lines the shell, and they remain there to be hatched. The leaves of eggs are fertilised when they first enter the sac, and are kept from being washed out by a number of bead-like bodies mounted on stalks, which retain them within a reduplication or fold of the 
skin of the sac. By this arrangement the eggs are placed between new and inner and old and outer integuments, and as the retaining structures are cast during the moults which the perfect Cirripede undergoes, the ova are then liable to be set free. The moults are restricted to the outside of the membranes, uniting the valves of the shell in the young adult form, and to the lid-membrane in the sessile Balani. In the others the surface of the peduncle disintegrates, and is removed, and the scales upon it are served in the same manner, and the delicate membrane lining the sac and the skin of the whole body are regularly shed, and also the membranes of the mouth, œsophagus, and the horny jaws. The new spines of the cirri are formed within the old ones. The growth of these creatures is often very rapid, and the skin sheddings numerous, on account of their being necessary for the enlargement of the body and the expansion of the shell.

The pedunculated Cirripedic are found in nearly every sea, and are fixed to stationary and floating objects. Some are attached to the shells of Mollusca which live on the shore, and others to timber and weed, but a great many live fixed upon and even partly within the skin of whales and sharks. In these last instances the peduncle is sunk into the skin of the large marine creatures, and the cement glands produce the adhesion. The range of the sessile barnacles is immense, and they frequent coral reefs and all shores where there is rock and clear water free from much mud and sand. Some frequent turtles, sea snakes, others Crustacea, whales, manatees, and shells.

Before I835 Mr. Vaughan Thompson discovered the larva when about to become metamorphosed into a barnacle, and Burmeister recognised that the larval condition was divided into two stages, the early and later creatures being as different from each other as they both are from the mature Cirripede. Goodsir drew the larva of Balanus in the first stage, and Spence Bate has made observations and drawings of those of several species. The following description of the larvæ and of their metamorphoses is abstracted from Charles Darwin's monograph (Ray Society).

The ova of the Lcpadida (pedunculated Cirripedes) are hatched whilst within the sac of the parent, and the young larva of the first stage is nearly globular in shape (in Scalpcllum sulgare, an English 
species, with a short flattened peduncle, with calcareous scales), and depressed. The larva has a shell in the form of a carapace, which is cut short or truncated in front, where it has a horn on each side. The under surface of the larva is flat and broad, and is formed of thinner membrane than the back or dorsal surface. The horns just alluded to are long in the larva of Lepas anatifera, and short in the species Scalpellum, now being described, and their ends are either rounded and excessively transparent, or furnished in other kinds with an abrupt minute sharp point.
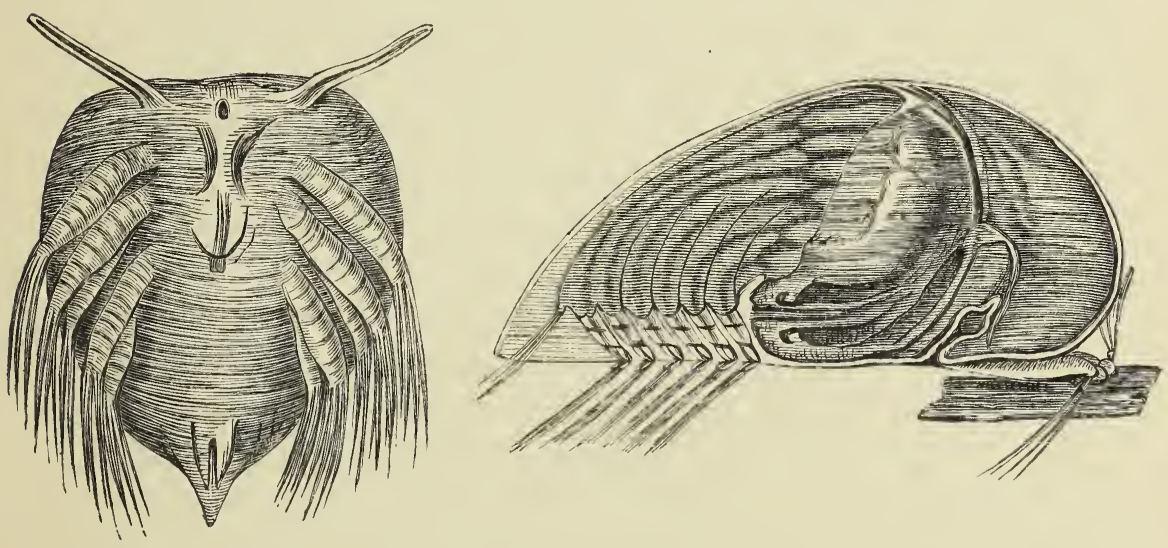

LARVA OF Scalpellum vulgare (from below.) LARVA, SECond STAGE. (After Darwin.)

Mr. Darwin saw distinctly a long thread-shaped organ bearing excessively fine hairs in lines so exactly like the long plumose spines on the antennæ of the larva of the last stage (and by which the mature Balanus adheres to surfaces) that he had not the least doubt that these horns were the cores in which antennx were in process of formation. Behind these horns, and near each other on the lower surface (sternal) of the body, there are two other minute doubly curved horns, and within each of them there is a most delicate and jointed thread-shaped structure on a thicker base. There are thus at first two sets of antennæ in the larva. Anterior to the points of origin of the smaller antennæ is seated a heart-shaped eye, but in some species this eye is not perfectly developed when they are born. There are three pairs of limbs seated close together; each leg of the first pair always con- 
sists of a spiny ramus, or oar-shaped limb, not jointed in the Scalpellum, but many-jointed in other genera. The other pairs have each two rami, supported on a common stem or upper leg, and they are jointed, and the longer spines upon them are beautifully feathery. The end of the body or abdomen ends a little beyond the posterior end of the carapace in a slightly upturned horny point, and a short distance in front of this there is a strong forked projection.

Between the points whence the three pairs of legs start from the body, there is a mouth, in the shape of a proboscis, and an œsophagus, which loses itself internally amidst the cellular and oily matter filling the animal. There are some spines on the hinder legs close to the body, and in the immediate neighbourhood of the mouth (which is thus far back), which appear to come for the purposes of prehension; they grow rapidly, and act like the mandibles and maxilla of mature Cirripedes for seizing the prey. The first pair of legs answers to the outer pair of jaw legs (maxillopoda) of the higher Crustaced, and the other four legs to the first two thoracic limbs in the same animals; the mouth, in the larva, being between the bases of the hind legs.

The young larva swims actively by means of its oar-like legs, and in a day or two changes its skin, and after that proceeding the end of the carapace is seen to be elongated into a point, and the end of the abdomen becomes developed in Lepas into a single, tapering, spinose projection. In other genera there are different methods of growth, so far as these endings are concerned.

The first skin shedding or moult may take place within the sac of the parent. The carapace or shell covers the dorsal or back surface, and in the larva of the first stage is not marked with joints or segmentations. Some kinds gain the eye after the first moult, and others, which had a single eye at birth, begin to show a double organ after the skin shedding. The antennæ increase in length after the first moult, and before that period there are no traces of jaws or other legs behind the three pair.

The larva of Lepas in the second stage was described by Burmeister, and great changes must have occurred during its metamorphosis. The carapace has greatly aitered in its character, and two fleshy projections from the front of it, by which the creature adheres to 
sea-weed and other objects, are in reality the altered large antennæ of the larva of the first stage ; but the smaller antennæ have wasted away. The eye has commenced becoming double, but is not as yet compound in structure. The mouth is still in the form of a proboscis, and does not differ much from its former condition. But no jaws or mouth-pieces are present. The legs are still in three pairs, the mouth bears the same relation to them as before, and the abdomen has become short.

Considerable increase in size takes place during the development of the Cirripede up to the time when it is about to enter the third larval state, which, from its having some peculiarities, that will be noticed hereafter, is more or less correctly termed the pupal condition.

On comparing the larva of the second stage and the pupa, no very great external changes can be discovered; but the great antennæ have come out of their surrounding cases, the carapace has extended so as to enclose the whole body, the eyes have become further apart, and three other pairs of legs have been developed behind the others. Moreover, a small abdomen has become slightly separated from the thorax. The mouth, formerly a proboscis, and active enough in swallowing and seizing, is now closed and functionless ; but its position is marked by a sort of lip, the old shrivelled œosphagus, and the commencing jaws and new gullet. This mouthless pupa can swim rapidly, but it does not appear to have much, if any, power of steering itself, and it differs in these peculiarities from the larva, for that could swim where it chose, and with considerable energy. The pupa of one species of Lepas can walk tolerably over sea-weed with the aid of its large antennæ ; and these are formed of four segments, those nearest the body supporting the eyes. The position of the cement tubes with respect to the antennæ of the perfect Balamus has been already noticed. They may be traced in the pupa to end in a third and disc-shaped segment, which is used as a climbing structure. The cement constantly exudes from the outside of the disc, and finally it causes the antennæ to adhere permanently.

Whilst the pupa remains a free swimmer, the eyes, the position of which to the antennæ has been noticed above, are included within the carapace or shell, but they are within the skin lining it. But 
when the pupa adheres by its antennæ to its future resting-place, the skin is absorbed, and the new one does not include these organs of vision. It thus happens that they are very visible through the transparent shell before the last metamorphosis, which occurs at the close of the pupal condition. Soon, however, these eyes lose their powers; their nerve becomes absorbed, and after a while the carapace and all are moulted and cast off.

"The eyes of Cirripedes," writes Mr. Darwin, "certainly undergo a remarkable series of changes. In the first larva there is a single eye, perhaps formed by the confluence of two, occupying the normal position in the front of the head; in the second stage the eye has become double, but the two are as yet simple-they are now situated posteriorly to the second pair of antennæ; in the third or pupal stage, they remain in the same situation, but have become compound, of great size, and are attached to the bases of the antennæ; in the mature or fourth stage, they have moved away posteriorly, and again have become simple, of minute size, and are either confluent, as in Lepas, or tolerably perfect, as in Balanus."

It must not be supposed that the eye of the mature Cirripede is metąmorphosed from the eye of the pupa, for such is not the case, the new eyes and the old eyes are formed some way apart, and frequently both can be seen within the pupa at the same time.

The future mature young Cirripede is gradually perfected within the pupa. The mouth is formed under the rudimentary and useless mouth of the pupa, and a new wesophagus is elaborated around the old one. After the casting of the outer parts of the pupa, many old markings are retained by the perfect creature, and it is observed that the extremities of the cirri, which are so important in the mature barnacle, are formed within the old legs; moreover, it is evident that the body (thorax) of the young Cirripede is not formed within that of the pupa, but within a portion anterior or in front of $i t$. The position of the body becomes changed in consequence, the alimentary canal is shortened to half its former length, and the space which formerly existed between the mouth and the first pair of legs is lost by coalescence. When the due time for the act of metamorphosis has arrived, the carapace of the pupa splits along the back, and is cast off, together with some of the segments of the antennæ of the eyes and some other structures. The three 
terminal joints of the antennæ invariably remain cemented to the surface of attachment. The carapace separates all round the orifice, but the delicate tunic lining the sac and investing the body and legs of the pupa is not shed for a considerable time afterwards. At this period the Cirripede is more or less horizontally disposed with regard to the surface upon which it adheres, but immediately after the moult a most important change of position occurs. The Cirripede turns up and remains at right angles to its attachment, so that the tail end is upwards, and the cirri-the legs-being upwards also. A moult of the membranes just noticed occurs, and the traces of the valves of the complicated shell are seen forming. The valves or pieces of the permanent shell are at first membranous, but calcareous structures soon become formed under them.

Small parasitic and very strange-looking creatures were noticed by Mr. Darwin upon and within the shells of mature Cirripedes, and after much patient research he discovered that they were the males of the shelly females or bi-sexual barnacles. Many kinds of these males are without mouth or thorax, and have very defective cirri. Some have rudiments of valves, and all lead a life at the expense of the protecting female. It is probable that the larvæ of these imperfect creatures are of the same shape as those of the fully developed females, but the retrograde metamorphosis has been greater in their case than in that of the latter.

Some of the pedunculated Cirripedes, which are parasitic upon large marine animals, have their structures modified and altered from the original form to meet the emergencies of their condition. Thus, an Anelasma lives upon the outsides of sharks in the northern seas, and its peduncle is immersed in their skins; and Mr. Darwin could find no cement glands or cement. The surface of the peduncle is beset with much-ramified hollow filaments, which penetrate the shark's flesh like roots. Now the cirri and mouth organs of these Cirripedes are very defective in their structure, and the presence of the hollow filaments of the antennæ explains why, for they suck up the juices of the shark, and replace the functions of the food-catching and digesting apparatus. Mr. Darwin found the stomach empty in the specimen examined by him, and the palpi and external maxillæ were nearly absent. 
Now the pupæ of the Cirripedes resemble greatly those of some Crustacea which are called Rhizocephala. In both the mouth is closed and useless, and the prehensile antennæ are developed; but in the Cirripedes there are eyes and some other proofs of a higher organisation. The pupæ of the Cirripedes attach themselves, as has been explained, and those of the Rhizoccphala fix themselves to the abdomen of common and hermit crabs. The future of the Rhizocephalous pupæ is wonderful, and would be perfectly unique were it not for the notice given above of the Anelasma. They remain through life without mouth or any digestive apparatus; they lose all their limbs completely after their metamorphosis from the pupa, and appear (writes Fritz Müller) as sausage-like sac-shaped or discoidal excrescences upon their victim or " host," filled with ova. From the point of attachment closed tubes-ramified-like rootssink into the interior of the "host," twisting round its intestines even, or becoming diffused amongst the sac-like tubes of its liver. The only manifestations of life which persist in these non plus ultras in the series of retrogressively metamorphosed Crustacea are powerful contractions of the roots, and an alternate expansion and contraction of the body, in consequence of which water flows into the blood cavity, and is again expelled through a wide orifice. There is a close resemblance between the early larvæ or Nauplii of the Rhizocephala and the Cirripedia, and the likeness of the pupæ to each other has been noticed; but then the retrograde metamorphosis causes an extreme divergence of character, the Anclasma linking, however, the two orders Rhizocephala and Cirripedia together, and offering a strong evidence of their former common origin. (Fritz Müller, translated by W. S. Dallas.)

Thus the Crustacea, like some of the other great divisions of the Articulata, have some kinds which do not undergo any metamorphosis, and others in which the transformation is very great and progressive; whilst a few forms positively retrograde in their development during their wonderful evolution. 


\section{LIST OF WORKS}

PUBLISHED BY

\section{CASSELL, PETTER, AND GALPIN.}

\section{ZBibles and Religious $\mathfrak{Z l}$ iterature.}

Bible, Cassell's Illustrated Family. Complete in One Volume, royal 4to, gilt edges, I, 7 Io pp., 960 Illustrations, and Family Register. Calf, $\AA^{2}$ Ios.; morocco antique, $£ 3$ Ios.

* * Cassell's "Illustrated Family Bible" has attained a circulation of nearly Half a Million.

Bible, Cassell's Illustrated Family. Toned Paper Edition. Half morocco, gilt edges, $£ 2$ Ios. ; full morocco antique, $£ 3$ Ios. ; best full morocco elegant, $£ 3$ I $5 \mathrm{~s}$.

Bible, Cassell's Illustrated Family. Large Paper Edition. I,494 pp., and Family Register. Cloth gilt, $\Varangle^{2}$ IOs. ; flexible morocco antique, $£ 4$; full gilt morocco elegant, $£ 5$.

Bible, The Child's. 830 pp.; 220 Illustrations. Demy 4to. Being a Selection from the Holy Bible, in the words of the Authorised Version. Cloth elegant, gilt edges, $\ell_{I}$ Is. ; flexible leather binding, hand-tooled, gilt edges, $£$ I IOs.; best morocco elegant or antique, $£_{2} 2$ s.

** Nearly 60,000 copies of "The Child's Bible" have been already sold.
Bible, The Doré. Illustrated by Gustave DORE. Complete in Two very handsome Vols. Bound in cloth gilt, $£ 8$; morocco, gilt edges, $£ 12$; best polished morocco antique extra, $£$ I5.

Bible Dictionary, Cassell's. Complete in One or Two Vols., strongly bound in cloth, 2 Is.; in One Vol., strongly bound in russia or morocco, 40s. I, I59 pp., and nearly 600 Illustrations. Imp. 8vo.

Commentary, Matthew Henry's. Complete in Three Volumes. Cloth, lettered, $f^{2}$ 12s. 6d. Demy 4to, 3,308 pp.; numerous Illustrations and Maps.

Family Prayer Book, Cassell's. Cloth, 7 s. 6 d. ; with gilt edges, 9s.; morocco antique, 2 Is. 398 pp., demy 4 to.

Mission Life. A Record of Mission Work in all Parts of the Globe. Volume for I870, containing about 800 pages letterpress, and numerous Engravings. Cloth, $5 \mathrm{~s}$.

Quiver, The. Volume for I870. 840 pages letterpress, and numerous Engravings. Cloth, lettered, 7s. 6d.; gilt edges, 8s. 6d.

\section{Ufhiluren's Zooks.}

Shilling Story Books. 96 pp., fcap. 8 vo, cloth, lettered. With Illustrations in each Vol. Lottie's White Frock, and other Stories.

Helpful Nellie, and other Stories.

Only Just Once, and other Stories.

The Boot on the Wrong Foot, and other Stories. Iittle Content, and other Stories. By EDITH WALFORD.

Iittle Iizzie. By Mary Gillies. And other Tales. Luke Barnicott. By William Howitt. And other Tales.

My First Cruise. By W. H. Kingston. And other Tales.

The Boat Club. By Oliver Optic. And other Tales.

The Delft Jug. By Silverpen. And other Tales. The Elchester College Boys. By Mrs. Henry Wood. And other Tales.

The Little Peacemaker. By Mary Howitt. And other Tales.

Jonas on a Farm. Ву Јасов Аввотт. And other Tales.

Shilling Toy Books. In demy 4to, stiff covers. With full-page Illustrations printed in Colours by KRONHEIM.

1. How Cock Sparrow Spent his Christmas.

2. The Adventures of Robinson Crusoe.

3. Queer Creatures. Drawn by One of Themselves.

4. \#sop's Frables. (2I Plates.)

\section{Shilling Reading Books.}

Evenings at Home. In Words of One Syllable. Cloth, limp.

सtsop's Fables. In Words of One Syllable. Cloth, limp.
Eighteenpenny Series of New and Original

Works. Bound in best cloth, gilt edges, with Four Coloured Plates by KRONHEIM in each

Book. 128 pp., fcap. 8vo.

Iittle Blackcap. And other Stories.

Tommy and his Broom. And other Stories.

Little Red Shoes. And other Stories.

Charlie's Lessons about Animals.

The Broken Promise. And other Stories. By the Hon. Mrs. GreENE.

The Holidays at Ilandudno.

The Hop Garden: A Story of Town and Country

Life.
Algy's Lesson. By S. E. DE Morgan.

Hid in a Cave; or, The Lost Child.

Ashfield Farm; or, Ellen and Robert's First Journey from Home.

Grandmamma's Spectacles, By the Author of "A Trap to Catch a Sunbeam."

Little Fables for Little Folks.

Flora Selwyn: A Story for Girls.

Two Shilling Series of New and Original

Works. Bound in cloth gilt, gilt edges, with Illus-

trations printed in Colours, I6o pp., fcap. 8vo.

Dr. Savory's Tongs. By Two Sisters.

The Golden Gate. By H. G. B. Hunt.

Love and Duty. By AnNa J. BuckLand.

Brave Lisette. And other Stories. By Miss Carless.

Beatrice Iangton; or, The Spirit of Obedience.

Owen Carstone: A Story of School Life.

The Boy who Wondered.

New Stories and Old Legends. By Mrs. T. K. HERVEY.

The Iittle Orphan.

The Story of Arthur Hunter and his First Shilling.

The Story of the Hamiltons.

The Hillside Farm.

BELLE SAUVAGE YARD, LONDON; \& 596, BROADWAY, NEW YORK. 


\section{Chilloren's liooks-continued.}

Half-Crown Library. I6o pp., extra fcap. 8 vo, handsomely bound in cloth gilt, with Illustrations and Ornamental Chapter Heads.

Labour Stands on Golden Feet. A Holiday Story for the Industrial Classes. Translated from the German of HEINRICH ZschokKe, by Dr. JoHN Yeats.

Stories of the Olden Time. Selected and arranged by M. JONES, Author of "The Story of Captain Cook," \&c.

One Trip More. And other Stories. By the Author of "Mary Powell."

Truly Noble:A Story. By Madame De Chatelain.

Autobiographies of a Lump of Coal and a Grain of Salt, \&c. By ANNIE CAREY.

Love and Life in Norway. By BJornstjerne BJORNSEN. Translated from the Norwegian by the Hon. Augusta Bethell and A. Plesner.

The Fishing Girl. By Bjornstjerne Bjornsen. Translated from the Norwegian by F. RICHARDSON and A. Plesner.

\section{The Children's Library. A Series of}

Volumes specially prepared for Children. Beautifully Illustrated, and handsomely bound in cloth gilt, uniform in size and price.

The Children's Sunday Album. By the Author of "A Trap to Catch a Sunbeam." With upwards of roo Engravings. A companion volume to "The Children's Album," by UNCLE JOHN. Cloth gilt, $35.6 \mathrm{~d}$.

The Story of Robin Hood. Illustrated with Eight Plates printed in Colours. Cloth, 3s. 6d.

The True Robinson Crusoes. A Series of Stirring Adventures. Edited by Chas. Russell. Cloth gilt, $3 \mathrm{~s}$. $6 \mathrm{~d}$.

Off to Sea. By W. H. G. Kingston. With Eight Coloured Plates by KRONHEIM. Cloth gilt, $3 \mathrm{~s}$. 6d.

The Children's Album. Containing Coloured Frontispiece and nearly 200 Engravings, with Short Stories, by UNCLE JOHN. With several Pieces of Music. Twenty-sixth Thousand. 3s. $6 \mathrm{~d}$.

Old Burchell's Pocket: A Book for the Young Folks. By Elihu Burritt. 3s. 6d.

Peggy, and other Tales ; including the History OF A THREEPENNY Bit, and THE STORY OF A Sovereign. By the Author of "Misunderstood." 3s. $6 \mathrm{~d}$.

Mince-Pie Island: A Christmas Story for Young Readers. By R. St. JOHN CORBET. 3s. $6 \mathrm{~d}$.

Cloudland and Shadowland; or, Rambles into Fairy Land with Uncle White Cloud. 3s. 6d.

The Queen of the Tournament, and Butterfy Ball at Maperley Hall. By the Author of "Mince-Pie Island." 3s. 6d.

Lily and Nannie at School: A Story for Girls. By the Author of "The Little Warringtons." 3s. 6d.

The Magic of Kindness; or, The Wondrous Story of the Good Huan. By the Brothers MAYHEw. With Eight Plates by Walter Crane. Cloth gilt, 3s. 6d.

On a Coral Reef: A Sea Story for Boys. By ArThur Locker. Cloth gilt, 3s. 6d.

King Gab's Story Bag; and the Wondrous Tales it contained. By Heraclitus Grey. With Eight Plates by Walter Crane. 3s. 6d.

Crocker the Clown: A Tale for Boys. By B. Clarke. $3 \mathrm{~s}$. $6 \mathrm{~d}$.

Hours of Sunshine: A Series of Poems for Children. By MatThias BARR, Author of "Little Willie," \&c. With Sixteen Coloured Plates from Designs by Oscar Pletsch. 3s. 6d.

Playing Trades. By Heraclitus Grey, Author of "King Gab," \&c. With Sixteen Coloured Plates from Designs by J. BARFOOT. 3s. 6d.

The Happy Nursery. By Ellis A. Davidson. Containing Designs for Toys, New Games, \&c. Cloth gilt, $3 \mathrm{~s} .6 \mathrm{~d}$.

Picture 'Teaching for Young and Old. A Series of Object Lessons Progressively Arranged, so as to teach the meaning of every term employed. With more than 200 Illustrations.

Picture Natural History. A Series of Plates numbering upwards of 600 in which the Animal, Vegetable, and Mineral Kingdoms are classified in Families. With Descriptive Letterpress. Edited by the Rev. C. Boutell, M.A.

\section{The Children's Library-continued.}

The Angel of the Iceberg. And other Stories. By JoHN TodD, D.D. (New Edition.) 3s. 6d.

Drawing-Room Plays. Gilt edges, 3s. 6d.

Famous Regiments of the British Army. By William H. Davenport Adams. $320 \mathrm{pp}$. Four Illustrations and Coloured Frontispiece. 3s. 6d.

Will Adams: The Adventures of the First Englishman in Japan. By William Dalton. 3s. 6d.

Working Women of this Century: The Lesson of their Lives. By Clara Lucas Balfour. 436 pp. 3s. $6 \mathrm{~d}$.

\section{ONE SYLLABLE SERIES.}

Uniform with the Children's Library.

Assop's Fables, in Words of One Syllable. With Eight Illustrations printed in Colours by KRONHEIM. 3s. $6 \mathrm{~d}$.

Sandford and Merton, in Words of One Syllable. With Eight Illustrations printed in Colours by KRONHEIM. $3 \mathrm{~s} .6 \mathrm{~d}$.

Reynard the Fox; the Rare Romance of, and the Shifts of his Son Reynardine. In Words of One Syllable. By Samuel Phillips Day. With Eight Coloured Illustrations by KroNheim, from Designs by ERNEST GRISET. 3s. 6 d.

The Pilgrim's Progress, Written in Words of One Syllable by S. Phillips Day. With Eight Coloured Illustrations by KRONHEIM. 3s. $6 \mathrm{~d}$.

The Swiss Family Robinson, in Words of One Syllable. By the Author of "The Boy's First Reader." Eight Coloured Illustrations from Designs by Griset, Crane, \&cc. 3s. 6d.

Evenings at Home, in Words of One Syllable. By the Author of "The Children's Album." Eight Coloured Illustrations from the Designs of DOWNARD, BAYES, \&c. 3s. $6 \mathrm{~d}$.

\section{Five Shilling Books.}

Home Chat with Our Young Folks. By Clara Matéaux, Author of "The Story of Don Quixote," \&c. \&c. With 200 Illustrations.

The Story of Don Quixote. By Clara MatÉaux. Re-narrated in a familiar manner, especially adapted for Younger Readers, and Illustrated with numerous Engravings. Fcap. 4to.

A Voyage to the South Pole. A New Story. By W. H. G. Kingston. Profusely Illustrated.

Robinson Crusoe, Life and Adventures of New Edition. Cloth plain, 5s.; full gilt, 6s. $6 \mathrm{~d}$.

Swiss Family Robinson. New Edition, complete. Cloth plain, 5s.; full gilt, 6s. $6 \mathrm{~d}$.

Old Friends and New Faces. Demy 4 to. Twenty-four Coloured Plates by KRONHEIM.

\section{Six Shilling Books.}

Esther West. By IsA CRAIG-KNox. With Twenty-four full-page Illustrations.

Peoples of the World. By Bessie ParkesBeLLOC. With about Fifty Engravings. Cloth gilt,

Little Songs for Me to Sing. Illustrated by J. E. Millais, R.A. ; with Music composed expressly for the work by HenRY Leslie. Dedicated to Her Royal Highness the Princess of W Ales, by Special Permission.

The Story of Captain Cook. By M. Jones. With a bout Fifty Engravings. Cloth gilt.

\section{Seven and Sixpenny Books.}

Bright Thoughts for the Little Ones. Twenty-seven Original Drawings by PROCTER. With Prose and Verse by Grandmamma. Cloth gilt, gilt edges.

The Child's Garland of Little Poems: Rhymes for Little People. With exquisite Illustrative Borders by Giacomelli. Cloth gilt, too pp. fcap. 4 to.

Favourite Poems by Gifted Bards. Illus. trated, cloth gilt.

Beauties of Poetry and Gems of Art. With 32 Illustrations, cloth gilt.

Jewels Gathered from Yainter and Poet. Cloth gilt, gilt edges. 


\section{㚼irtionaries.}

Bible Dictionary, Cassell's. With 600 Illustrations. One or Two Volumes, 2Is. ; bound in morocco, 40 .

Biographical Dictionary, Cassell's. I, I6o pages, imp. 8vo. Illustrated with Portraits. Cloth, 2Is.; half morocco or calf, $35 \mathrm{~s}$.

Brewer's Dictionary of Phrase and Fable; giving the Derivation, Source, or Origin of Common Phrases, Allusions, and Words that have a Tale to Tell. By the Rev. Dr. Brewer. Demy 8vo, I,ooo pp., cloth, IOs. 6d.

Dictionary of the English Language, 16th Edition. 3s. 6d.

French and English Pronouncing Dictionary. Crown 8vo, 956 pp., cloth, 3s. 6d.
German-English and English-German Pronouncing Dictionary. Crown 8vo, cloth, 864 pp., 3s. 6 d.

Latin-English and English-Latin Dictionary. By J. R. BEARD, D.D., and C. BEard, B.A. Cloth, 9I4 pp., 3s. 6d.

Illustrated National Dictionary, The, on the basis of Webster. With 250 Engravings. Crown $16 \mathrm{mo}$, Is.

\section{Webster's Etymological Dictionary.} 3s. $6 \mathrm{~d}$.

Dictionary of Derivations, The. By Professor Sullivan, LL.D. IIth Edition. 2s.

\section{CẼurational ratork.}

Algebra, Elements of. Paper covers, Is.; cloth, Is. 6d.

Anatomical Atlas, The. Designed and Printed in Colours from Nature. Royal folio, with Index, IOs. $6 \mathrm{~d}$.

\section{Arithmetic.}

Hudson's Arithmetic for School and College Use. With a copious Collection of Exercises, and KEY. Is. 6 d.

Wallace's Arithmetic. Cloth, is. 6d.

Arithmetic for the Young. Cloth, rs.

Elementary Arithmetic. Simple Rules. 4d. Key to Ditto, 3d.

Elementary Arithmetic. Compound Rules. 6d. Key to Ditto, 3d.

Book-Keeping, by Single and Double Entry. Is. Ruled Account Books to Ditto, extra, Is. 6d. each Set.

Book-Keeping for the Million. By Theodore Jones. Cloth, 3 s.

Book-Keeping for Schools. The English System. By Theodore Jones. 2s. ; cloth, 3s. Book-Keeping for Schools, The Key to. 2s. ; cloth, 3s.

Books for Jones's System, Ruled Sets of. $2 \mathrm{~s}$.

Brewer's Series of First Books. Price 6d. each.

Reading and spelling. Bible History. History of bingland. Geography.

Common Things.

$$
\begin{aligned}
& \text { French History. } \\
& \text { Astronomy. } \\
& \text { Chemistry. } \\
& \text { Facts and Discoveries. } \\
& \text { Grecian History. }
\end{aligned}
$$

Brewer's, The Young Tutor. First Series. Being the First Six Books in this Series, bound in One Volume. Cloth, 3s. 6d.

Brewer's, The Young Tutor. Second Series. Being the latter Six Books in this Series, bound in One Volume. Cloth, 3s. 6d.

Brewer's Guide to Every-Day Knowledge. 284 pp., 2s. 6 d.
Cassell's Technical Manuals, for Joiners, Carpenters, Machinists, Builders, CabiNET MaKers, Stonemasons, Tin-PLATE Workers, Plumbers, and Artisans geneRALLY.

Linear Drawing. By E. A. Davidson. With ${ }_{50}$ Illustrations. 128 pp., extra fcap. 8vo, cloth limp, 2s.

Orthographic and Isometrical Projection. By the same Author. With 40 whole-page Diagrams. $128 \mathrm{pp}$., extra fcap. 8vo, cloth limp, 2s.

Linear Drawing and Projection. The Two Volumes in One. Cloth, lettered, 3s. $6 \mathrm{~d}$.

Building Construction, the Elements of, and Architectural Drawing. By Ellis A. Davidson. With I 30 Illustrations. Extra fcap. 8vo, 128 pp., cloth limp, 25 .

Systematic Drawing and Shading. By Charles Ryan, Head Master, Leamington School of Art. With numerous Illustrations and Drawing Copies. 20 pp., extra fcap. 8vo, cloth limp. 2S.

Drawing for Carpenters and Joiners. By ElLIS A. DAvidson. With 253 Illustrations and Drawing Copies. I04 pp., extra fcap. 8vo, cloth, 3s. $6 \mathrm{~d}$.

Practical Perspective. By Ellis A. Davidson. With ${ }^{6}$ double-page Illustrations. 90 pp., cloth, $3 \mathrm{~s}$.

Drawing for Machinists. By Ellis A. DavidSON. With nearly 200 Illustrations and Diagrams.
Extra fcap. 8vo, cloth, 4s. 6d.

Cassell's Elementary Atlas. 16 Coloured Maps. Fcap. 4to, 6d.

Cassell's Preparatory Atlas. 16 Coloured Maps. Crown 4to, 6d.

Cassell's First School Atlas. Coloured Maps. Crown 4to, Is.

Cassell's Handy Atlas. 24 Coloured Maps, and Index. Crown 8vo, cloth, 2s. 6d.

Cassell's Beginner's Atlas. 24 Coloured Maps, and Index. Crown 4to, cloth, 2s. 6d.

Cassell's Introductory Atlas. I8 Coloured Maps, and Index. Cloth, 3s. 6d.

Cassell's Select Atlas. 23 Coloured Maps, and Index. Imperial 8vo, cloth, 5s.

Cassell's Comprehensive Atlas. $4^{2}$ Coloured Maps, and Index. Ios. $6 \mathrm{~d}$.

Chemistry. Specially adapted for the use or Self-Students. Cloth, Is. 


\section{JEsucatiomal oltorks-continued.}

Chemistry, Elementary. By the Rev. H. Martyn Hart. 290 pp., crown 8vo, cloth, 35. $6 \mathrm{~d}$.

Copy-Books for Schools, Cassell's. With Set Copies on every page. Price $2 \mathrm{~d}$. each.
1. Initiatory Exer-
9. Small Hand. cises.

2. Letters and Combinations.

3. Short Words.

4. Capitals.

5. Text Hand.

6. Text and Round.

7. Round Hand.

8. Round and Small Hands.

10. Text, Round, and Small Hands.

11. Introduction to Iuadies' Hand.

12. Ladies' Hand.

13. Commereial Sen. tences.

14. Figures.

*** These Books are now very largely used in Schools, and have been described as the cheapest and best ever published.

Drawing Copies, Cassell's Popular.

Series A. Flor al and Vegetable Forms. Twelve Parts, 6d. each. Twelve Packets, on Cardboard, is. each.

Series B. Model Drawing. Twelve Parts, 6d. each. Twelve Packets, on Cardboard, is. each.

Series C. Landscape Drawing. Twelve Parts, 6d. each. T'welve Packsts, on Cardboard, is. each.

Series D. Figure Drawing. Twelve Parts, 6d. each. Twelve Packets, on Cardboard, rs. each.

Series E. Animal Drawing. Twelve Parts, 6d. each. Twelve Packets, on Cardboard, Is, each.

The Drawing Copies, in $6 d$. Parts, and 1 s. Packets on Cardboard, may be had in separate Parts or Packets.

\section{Drawing Copies.}

Gregory's First Grade Self-teaching Freehand Outline Drawing Examples. By ChARLES GREGory, Wolverhampton (Master of the Art Classes at the Willenhall Literary Institute, \&c. \&c.). In Two Packets, each containing Twenty-four Examples, on Card, price is. per Packet. Enlarged for black-board, 2s. 6d. per Packet.

Gregory's Outlines from Models used in Schools, on Twelve Cards, Is.; and enlarged for black-board, $2 \mathrm{~s}$.

Gregory's Outlines from Flowers. Twelve large Cards, in Packet, is. $6 \mathrm{~d}$.

Gregory's Easy Drawing Examples. Twentyfour Cards, in Packet, is. ; enlarged for blackboard, 2s. $6 \mathrm{~d}$.

First Fxamples in Freehand Drawing. By Walter Smith. Price 25 .

The School of Art Model and Object Drawing Book. By WALTER SaItTh, Head Master of the Leeds School of Art and Science. Price 3 s.

English Grammar. By Prof. Sullivan,

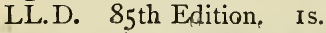

Etymology, a Manual of. By Professor Sullivan, LL.D. 3rd Edition. Iod.

English Spelling and Reading Book. With upwards of I60 Illustrations, cloth, Is.

Euclid, Cassell's. Edited by Professor WaL. LACE, A.M., of the Glasgow University. Is. ; cloth, Is. 6d. Key to Ditto, 4d.

French, Cassell's Lessons in. By Professor FAsquelle. New Edition, Revised and Improved. By Professor DE Lolme. Parts I. and II, in paper, 2s. ; cloth, each 2s. $6 \mathrm{~d}$. Complete in One Volume, I 88 pp., 4s. 6 d.

French, Key to the Exercises in Cassell's Lessons in. Is.; cloth, Is. $6 \mathrm{~d}$. French, Shilling Lessons in. By Professor DE Lolme. Is. ; cloth, Is. 6 d.
French, Sixpenny Lessons in. 6d.

French Manual. By Professor De Lolme. Cloth, 3 s.

French and English Correspondence for Boys. 2s. $6 \mathrm{~d}$.

French and English Correspondence for Young Ladies. 2s. 6d.

French and English Commercial Correspondence. $2 \mathrm{~s} .6 \mathrm{~d}$.

French Reader, The. New Edition. By Professor De Lolme. Paper, 2s. ; cloth, 2s. 6d.

Galbraith and Haughton's Scientific Manuals. Cloth, red edges.

Arithmetic. Cloth, 3s. 6d.

Plane Trigonometry, 2s. $6 \mathrm{~d}$.

Fuclid. Elements I., II., III. 2s. 6d.

Euclid. Bosks IV., V., VI. 2s. 6d.

Mathematical Tables. $3 \mathrm{~s}$. $6 \mathrm{~d}$.

Mechanics. Cloth, lettered. 3s. $6 \mathrm{~d}$.

Optics. 2s. 6 d.

Hydrostatics. 3s. $6 \mathrm{~d}$.

Astronomy. 5s.

Steam Engine. 3s. 6d.

Algebra. Third Edition. Part I., 2s. 6d. ; complete, 7 s. 6 d.

Tides and Tidal Currents. New Edition, with Tidal Cards. 3 s.

Natural Philosophy. With r6o Illustrations.

The Three Kingdoms of Nature. With 230 Illustrations. $5 \mathrm{~s}$.

Geography, Ancient, Modern, and Sacred. By Professor Sullivan, LL.D. Is.

Geography Generalised; with Maps and Illustrations. By Prof. Sullivin, LL.D. 2s.

German Reader, The International, for the Use of Colleges and Schools. By EDWARD A. OpPen, of Haileybury College. 4s. 6 d.

German, Lessons in. By W. H. WoodBURY. Parts I. and II., 2s. ; cloth, each 2s. 6 d. Complete in One Volume, cloth, 4s. 6d.

German, Key to Lessons in. Is.; cloth, Is. $6 \mathrm{~d}$.

German, Sixpenny Lessons in. By E. A. OpPen, of Haileybury College. 6d.

The Literary Class Book, By Professor Sullivan, LL.D. I Ith Edition. 2s. 6 d.

Natural History of Commerce, The. By J. YEATS, LL.D. Intended for the study of Young Merchants, Manufacturers, and Business Men. $45^{2}$ pp., crown 8vo, cloth, $5 \mathrm{~s}$.

Natural Philosophy, the Elements of. For the use of Schools. By the Rev. SAMUeL Haughton, M.D., F.R.S., Fellow of Trinity College, Dublin. With I6o Illustrations. Cloth, 3s. $6 \mathrm{~d}$.

Natural Philosophy, in Easy Lessons. By Professor TyNDALL, F.R.S. Illustrated. New Edition, 2s. 6d.

Natural Philosophy, Hand-book of. Cloth, Is. 


\section{IEvurational rellorks-continued.}

Popular Education \& School-keeping. By Professor Sullivan, LL.D. Second Edition. 2s.

\section{Popular Educator, Cassell's New.} Revised to the Present Date, with numerous Additions. Now complete, in Six Vols., best cloth gilt, 6s. each; or in Three Vols., halfcalf, $\AA^{2}$ ios.

Primary Series. An entirely new and original Series of Volumes, specially prepared for the use of Elementary, National, and other Schools, written by men of practical experience.

Elementary Arithmetic: Simple Rules. Key to ditto, $3 \mathrm{~d}$.

Elementary Arithmetic. Compound Rules. $6 \mathrm{~d}$. Key to ditto, $3 \mathrm{~d}$.

Elementary British History. 6d.

Elementary Geography. Illustrated. $4 \mathrm{~d}$.

A Handy-book on Health, and How to Preserve it. Cloth, gd.

England at Home: An Elementary Text-Book of Geography, Manufacture, Trade, and Commerce. Is.

Our Bodies: An Elementary T'ext-Book of Human Physiology. is.

Our Houses, and what they are Made of. Is.

Our Frod. Supplying Elementary Lessons in Domestic Economy. Is.

Our First Grammar: an Elementary Text-Book. Is.

The Uses of Plants in Food, Arts, and Commerce. With Illustrations. Is.

Right: Lines in their Right Places; or, Geometry without Instruments. With Drawings on Wood by the Author. Is.

\section{ffine Art}

Essop's Fables. With numerous Illustrations from Original Designs by ERNEST GRISET. Imperial 8vo, $236 \mathrm{pp}$, cloth, 7s. 6d. ; full gilt, gilt edges, Ios. $6 \mathrm{~d}$.

After Ophir. By Captain A. F. Lindeey. Illustrated with about Sixty Engravings. Cloth gilt, 7s. 6d.

Arms and Armour. By Charles Boutell, M.A., Author of "English Heraldry." With numerous Engravings. 7s. 6d.

Beauties of Poetry and Gems of Art. With Thirty-two Illustrations by J. C. HorsLEY, R.A., J. Tenxiel, C. W. Cope, R.A., Pickersgill, \&c. With Ornamental Borders, \&.c. $7 \mathrm{~s} .6 \mathrm{~d}$.

Book of Historical Costumes, The. With 96 full-page Coloured Engravings. 503.

British Army, The History of the. By Sir Sibiald David Scott, Bart. Dedicated, by special permission, to the Queen. Two Vols., I, I 78 pp., demy $8 \mathrm{vo}$, cloth, £2 2 s.

Bunyan. The Pilgrim's Progress. Cloth, 7s. 6d.; gilt edges, Ios. 6d.; morocco antique, 2 Is.

Bunyan. The Holy War. Uniform with above, and same price.

Chefs-d'œuvre of the Industrial Arts. With 200 Illustrations. By PHILIPPE BURTy. Edited by W. Chaffers, F.S.A. Cloth, I6s.; extra cloth gilt, 2 Is.

Crusoe, Life and Adventures of. With IOO Illustrations by MATT MORGAN, Harrison WeIr, R. P. LEITCH, \&c. Cloth, 7s. 6d.; full gilt, IOs. 6d. ; morocco, 2 Is.
Primary Series-continued.

Vegetable Physiology, in Easy Lessons, with numerous Illustrations. Is. $6 \mathrm{~d}$.

The Animal Kingdom. With abundant Illustrations. Double Vol., cloth, lettered, 200 pp. 25 .

CASSELL'S STANDARD READERS.

Adapted to the Requirements of the Revised Code.

The Boy's First Reader. Standard I. With easy Spelling Exercises. Illustrated. 4d.

The Boy's Reader. Standard II. Containing Lessons in Reading and Spelling. With many Illustrations. $4 \mathrm{~d}$.

The Girl's First Reader. Standard I. With easy Spelling Exercises. Illustrated.' 4 d.

The Girl's Reader. Standard II. Containing Lessons in Reading and Spelling. Illustrated. 4d.

The Boy's and Girı's Reader. Standard III. Cloth, $7 \mathrm{~d}$.

The Boy's and Girl's Reader. Standard IV. gd.

The Poetical Reader. Standard V. 208 pp., fcap. 8vo., cloth. Is.

The Explanatory Reader. Standard VI. Cloth, Is.

Science Popularly Explained. Cloth, 3s. 6 d.

The Spelling-Book Superseded. By Professor Sullivan, LL.D. Is. $4 \mathrm{~d}$.

Upwards of Four Hundred Words, Spelled in Two or More Ways; with an Attempt to Settle their Orthography. By Professor Sullivan, LL.D. Iod.

\section{Yolumes.}

Doxé Gallery, The, Containing 250 of the finest Drawings of Gustave DORE. Letterpress and Memoir by Edmund Ollier. Cloth gilt, $£ 55$ s. ; full morocco elegant, $£$ ro.

Doré Bible (see Bibles).

Doré's Milton's Paradise Lost. Illustrated with full-page Drawings by Gustave DORE. Cloth, $£ 5$; best polished morocco, gilt extra, $£$ Io.

Doré's Dante's Inferno. Cloth, £2 1os.; morocco antique, with gilt edges, $£ 44$ s. ; full -morocco, £6 6s.

Dorés Dante's Purgatory \& Paradise. Uniform with the INFERNO, and same price.

Doré's Don Quixote. with 400 Illustrations. Cloth, $£$ I IOs. ; half morocco, $£^{2} 5$ s. ; full morocco antique, $\Varangle 3$ Ios.

Dorés Atala. By Chateaubriand. Cloth, $£ 2$ 2s. ; morocco gilt, $£ 44$ s.

Doré's La Fontaine's Fables. With 86 full-page and many other Engravings. Cloth, $£^{\mathrm{I}}$ 10S.; half morocco, $£^{2} 5 \mathrm{~s}$.; full morocco antique, $£ 3$ Ios.

Doré's Fairy Realm. Illustrated with 25 full-page Engravings by Gustave Doré. Cloth gilt, gilt edges, $\Varangle \mathbf{I}$ Is.

Dore's, The History of Croquemitaine, and the Times of Charlemagne. With nearly 200 Engravings. Cloth, Ios. 6d.

Dorés, The Adventures of Munchausen. With 3 I full-page Engravings. Cloth, Ios. 6d. 


\section{ffine Art Wolumes-continued.}

Dore's, The Legend of the Wandering Jew. Folio, I 5s. ; extra gilt, 2 Is.

English Heraldry. By Charles Boutell, M.A., Author of "Arms and Armour," \&c. With 46o Engravings. Cloth, gilt top, 7s. 6d.

Favourite Poems by Gifted Bards. Illustrated with 24 Engravings by CORBOULD, Thomas, Selous, and other eminent Artists. Cloth, gilt edges, 7s. $6 \mathrm{~d}$.

Foxe's Book of Martyrs. Illustrated with I 8 I Engravings. Plain cloth, I2s. ; full gilt cloth, gilt edges, I $5 \mathrm{~s}$.

Goethe Gallery. A Series of beautiful Photographs from KAULBACH's Drawings of the Heroines of Goethe. Handsomely bound in morocco, $42 \mathrm{~s}$.

Goethe's Heroines. A Series of 21 exquisite Engravings on Steel. Cloth, lettered, $£ 77 \mathrm{~s}$.

Greece, The Scenery of. By W. Linton. Fifty exquisitely beautiful full-page Steel Engravings. Cloth, lettered, gilt edges, $42 \mathrm{~s}$.

Gulliver's Travels. By Dean Swift. Illustrated with 88 Engravings by MORTEN. With an Introduction, Annotations, and a LIFE of SwiFT, by J. F. WALLER, LL.D., M.R.I.A. Imperial 8vo, 400 pp., plain cloth, 7s. 6d. ; full gilt cloth, gilt edges, Ios. 6d. ; full morocco antique, 2 Is.

Illustrated Readings. Vol. I., cloth gilt, 7s. 6d. ; full gilt, gilt edges, Ios. 6d. Vol. II., cloth, 7s. $6 \mathrm{~d}$.; full gilt, gilt edges, Ios. $6 \mathrm{~d}$. Or the Two Vols. in One, cl., I2s. 6d.; hf. morocco, I $5 \mathrm{~s}$.

Illustrated Travels : a Record of Discovery, Geography, and Adventure. Edited by H. W. BATES, Assistant-Secretary of the Royal Geographical Society. Vols. I. and II., each, cloth, I5s. ; cloth, extra gilt, gilt edges, I8s. Or, the Two Vols. in One, cloth, 25s.; best cloth, gilt edges, 3 Is. $6 \mathrm{~d}$.

Insect World, The. From the French of LOUIS FIGUIER. With 570 Illustrations. Edited by E. W. JAnsen, Lib.E.S. Cloth, lettered, I6s. ; extra cloth gilt, 2 Is.

Jewels Gathered from Painter and Poet. Cloth, gilt edges, 7s. 6d.

Log of the Fortuna, The. By Capt. A. F. LiNDLEY. With Fifty Engravings. Fcap. 4to, 256 pp., cloth gilt, $7 \mathrm{~s}$. $6 \mathrm{~d}$.

Millais' Illustrations. A Collection of 80 Drawings on Wood by JoHn EveretT Millais, R.A. Cloth, gilt edges, I $6 \mathrm{~s}$.

\section{称and=3Books}

Bacon's Guide to America and the Colonies. With Maps, \&c. Cloth, 2s. 6d.

Civil Service, Guide to Employment in the. Revised to the Present Time. Cl., 2s. 6d. Civil Service, Guide to the Indian. By A. C. Ewald, F.S.A. Cloth, 4s. 6d.

Guide to America for the Capitalist, Tourist, or Emigrant. By G. W. BACON, F.R.S. With Coloured Map, Is.

Hand-Books, Cassell's Popular. Cloth, Is. each ; free by post for I 3 stamps.

Art of Conversation.|Business.

Book - Keeping, by Chemistry. Single and Double Entry. Chess and Draughts. Ruled Account Books to Domestic Pets. do., extra, 1s. 6d. each set. Domestic Recipes.
Ocean World, The. From the French of Louis Figuier. Edited by C. O. G. NAPIER, F.G.S. Cloth, I6s. ; extra cloth gilt, 2 Is.

0ld Friends with New Faces. With 24 full-page Illustrations, beautifully printed in Colours by KRONHeim. $5 \mathrm{~s}$.

Pictures from English Literature. With 20 full-page Illustrations by J. C. HorsLeY, R.A., W. F. Yeames, A.R.A., Marcus Stone, J. Gilbert, H. K. Browne, W. Cave Thomas, Lawson, Hughes, Barnard, Fildes, \&c. \&c. The Text by Dr. Waller. Crown 4to, cloth gilt, 2 Is.

Poems and Pictures. Very handsomely bound in extra cloth gilt, 2 Is.

Reptiles and Birds. From the French of LOUis Figuier. Edited by Parker GilMORE, Esq. I8s. ; extra cloth gilt, 23 s.

Sacred Poems, The Book of. Edited by the Rev. R. H. BAynes, M.A. Cloth, plain, 7s. 6d. ; cloth, extra gilt, gilt edges, Ios. 6d. ; morocco antique, 2 Is.

Schiller Gallery, The. A Series of Choice Photographs from KaULBACH's Paintings of Scenery from ScHiller. $£ 55$ s.

Selection of One Hundred of the Finest Engravings by the late G. H. Thomas. Cloth gilt, IOs. 6d.

Thorwaldsen's Triumphal Entry of Alexander the Great into Babylon. Twenty-two Plates, folio. $42 \mathrm{~s}$.

Vegetable World, The. With 47I Illustrations. From the French of LouIS FIGUIER. Edited by C. O. G. NAPIER, F.G.S. Cloth, lettered, I6s. ; extra cloth gilt, 2 Is.

Vicar of Wakefield, The, and Poems. Beautifully printed on Toned Paper, and Illustrated with ro8 Engravings. In one handsome imperial 8vo Volume, 378 pp., bound in cloth, $7 \mathrm{~s} .6 \mathrm{~d}$. ; full gilt cloth, with gilt edges, Ios. $6 \mathrm{~d}$.; full morocco antique, 2 Is.

World before the Deluge, The. With 233 Illustrations. From the French of Lou Is Figuier. Edited by H. W. Bristow, F.R.S. Cloth, lettered, 16s. ; extra cloth gilt, 2 Is.

World of the Sea. With I 8 Coloured Plates, and numerous Wood Engravings. Cloth, lettered, 2 Is.

\section{and Guitios.}

Hand-books-continued.

Drawing - Room How to Colour a Magic.

Elocution \& Oratory.

Emergencies.

Etiquette for Ladies and Gentlemen.

Gardening.

Photography.

Photograph in Oil or Water.

Investments.

Letter-Writing.

Natural Philosophy.

Health \& Physiology. Railway Situations.

\section{Household Guide, The-}

Vol. I., with Two Coloured Plates, and 150 Illustrations. Cloth gilt, $6 \mathrm{~s}$.

Vol. II., with Two Coloured Plates, and numerous Illustrations. Cloth gilt, $6 \mathrm{~s}$.

Thames and Tweed-New Work on Fishing. By GEORGE Rooper, Author of "Flood, Field, and Forest." 2s. 6d. 


\section{Ilgistory.}

England, Illustrated History of. Complete in Eight Volumes, bound in cloth, 6s. and 7s. 6d. each. Ditto, Four Volumes, strongly bound in half-calf, with full gilt backs and cloth sides, $£ 4$. The TONED PAPER EDITION, Volumes I., II., III., IV., and V. Cloth, each 9s.
England, History of, from the First Invasion by the Romans to the Accession of William and Mary in I688. By John LingaRD, D.D. In Ten Volumes. Cloth lettered, 35s.

History of the British Army. By Sir S. D. Scotr, Bart. Two Vols. I00 Plates. $42 \mathrm{~s}$.

\section{Aniscellaneous.}

A Poet-Hero. By Countess von Bothmer. Being a Biography of the German War-Poet, Theodore Körner. Cloth, 6s.

Appropriation of the Railways by the State. By ARTHur JOH'N Williams, Barrister-at-Law. The People's Edition. Crown 8vo, Is.

Arms and Armour, in Antiquity and the Middle Ages; also a Descriptive Notice of Modern Weapons. Translated from the French of M. P. Lacombe, by Charles Boutell, M.A., Author of "English Heraldry." With Seventy-one Illustrations. Cloth, gilt top, 7s. 6d.

Belle Sauvage Library, The. Price 3s. 6d. per Volume, cloth, fcap. 8 vo.

1. Pulpit Table Talk. By Dean Ramsey, M.A. 2. The Search for the Gral. By Julia GodDARD, 3. Sermons for Boys. By the Rev. Alfred BARRY, D.D., Principal of King's College.

4. The Life of Bernard Palissy, of Saintes. By HeNRY MORLEy.

5. The Young Man in the Battle of Life. By Dr. LANDELS.

Burritt, Elihu. Thoughts and Notes at Home and Abroad. Cloth, 6s.

Cassell's Magazine. Vol. I., New Series, containing "Man and Wife," by WiLkie Collins. $600 \mathrm{pp}$. of Letterpress and Engravings. Cloth, gilt lettered, 6s. 6d.

Daybreak in Spain. By the Rev. Dr. Wylie. With Twelve Illustrations. 6s.

History of the Pianoforte. By EDGAR BRINSMEAD. Illustrated. Cloth, $3 \mathrm{~s}$.

\section{Natural}

Book of Birds, The. Translated from the Text of Dr. BREHM by T. RYMER JONEs, F.R.S. Monthly Parts, 7d., and Volumes, crown 4to, cloth plain, 7s. 6d. ; extra cloth gilt, 10s. 6d. each. Vol. I. contains Ten Coloured Plates and $384 \mathrm{pp}$. letterpress, with numerous Illustrations.

\section{Figuier Series, The.}

The World before the Deluge. With 233 Illustrations. Cloth, lettered, I6s.; extra cloth
gilt, $\mathrm{II}_{\mathrm{IS}}$.

The Vegetable World. With $47 x$ Illustrations. Cloth, lettered, r6s. ; extra cloth gilt, $€_{\mathrm{I}}$ is.

The Ocean World. With 427 Illustrations. Cloth, lettered, $16 \mathrm{~s}$. ; extra cloth gilt, $£$ I rs.

The Insect World. With 576 Illustrations. Cloth, lettered, r6s. ; extra cloth gilt, $t \mathrm{I}$ is.

Birds and Reptiles. With 307 Illustrations. Cloth, lettered, $18 \mathrm{~s}$. ; extra cloth gilt, $£$ r $3 \mathrm{~s}$.
Little Gem Series, The. Bound in cloth, $6 \mathrm{~d}$. each ; red edges, $9 \mathrm{~d}$. each.

Shall we Know One Another? By the Rev. J. C. RYLE.

The Voice of Time. By J. Stroud.

Home Religion. By the late Rev. W. B. MACKENZIE, M.A.

\section{Penny Library of Popular Authors.}

1. Foxe's Book of Martyrs. Price rd.

2. Bunyan's Pilgrim's Progress. Price Id.

Practical Poultry Keeper, The. By L. Wright. Fourth Edition. With 36 Plain Illustrations. Cloth, $3 \mathrm{~s}, 6 \mathrm{~d}$. ; with 12 Coloured ditto, ditto, crown 8vo, $5 \mathrm{~s}$.

Quiz, Sketches by. Illustrated by "Pнiz." Cloth, 3s. 6d.

\section{San Juan Water Boundary Question.}

By Viscount Milton, M.P. Cloth, lettered, IOs. $6 \mathrm{~d}$.

\section{Woman: Her Position and Power.} By W. Landels, D.D. Cloth, lettered, 3s. 6d.

Wonders, Library of. Fully Illustrated. A Series of Gift Books and School Rewards. Cloth gilt, gilt edges, each $5 \mathrm{~s}$.

Wonders of Animal Instinct.

Wonders of Bodily Strength and Skill.

Wonders in Acoustics.

Wonderful Balloon Ascents.

Wonderful Escapes.

Wonders of Architecture.

World of Wonders, The. With 130 Illustrations. Cloth, 7s. $6 \mathrm{~d}$; full gilt, ros. $6 \mathrm{~d}$.

\section{Ilisistory.}

Natural History, Picture. Edited by the Rev. C. Boutell, M.A. With 600 Illustrations. Cloth, lettered, 3s. 6d.

Natural History, Cassell's Popular. Complete in Two Vols., cloth, 30s. Do., Two Vols., half-calf, full-gilt back, $45 \mathrm{~s}$. Do., Two Vols., half-morocco, full-gilt, 50s. Do., with Coloured Illustrations, Four Vols., cloth, $42 \mathrm{~s}$.

Transformations of Insects. Translated and adapted by Dr. Duncan, Secretary of the Geological Society, and Professor of Geology, King's College, London, from the French of EMILE BlanCHARD. With 240 highly-finished Engravings. Cloth gilt, gilt edges, $16 \mathrm{~s}$.

World of the Sea. Translated from the French of MOQUiN TANDON, by the Rev. H. M. HART. With I8 Coloured and Tinted Plates, and numerous Wood Engravings. Best cloth, lettered, 2 Is. 


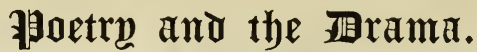

Barr's Poems. New and Revised Edit. Cl., 5 s. Book of Sacred Poems. With about 200 Illustrations. Edited by the Rev. R. H. BAynes, M.A. Cloth, 7s. 6d.; full gilt, Ios. 6d.; morocco, 2 Is.

Bright Thoughts for the Little Ones. With Twenty-seven Original Drawings by Procter. Cloth, lettered, gilt edges, $7 \mathrm{~s}$. $6 \mathrm{~d}$.

Child's Garland of Little Poems, The. With exquisite Illustrative Borders by GIACOMELLI. Cloth gilt, 7s. $6 \mathrm{~d}$.

Favourite Poems by Gifted Bards. With Twenty-four Illustrations. Cloth, gilt edges, 7s. $6 \mathrm{~d}$.

Golden Leisures. By W. Gordon Smythies. Is.

Greece, The Poets of. By Edwin Arnold, M.A., Oxon; Author of "Griselda and other Poems," \&c. Demy 8vo, 256 pp., 5s.

Hours of Sunshine. By Matthias Barr, Author of "Little Willie," \&c. With Sixteen Coloured Plates. Cloth gilt, 3s. 6d.

\section{Trabel and}

Illustrated Travels: a Record of Discovery, Geography, and Adventure. Edited by H. W. BATES, Assistant-Secretary of the Royal Geographical Society. Vols. I. and II., each, cloth, I 5s.; cloth, extra gilt, gilt edges, I8s. Or, the Two Vols. in One, cloth, lettered, 25s.; best cloth gilt, 3 Is. $6 \mathrm{~d}$.
Jewels Gathered from Painter and Poet. Cloth, gilt edges, 7s. 6d. -

Poets, Cassell's Three-and-Sixpenny Editions of the. In fcap. 8vo, printed on Toned Paper, elegantly bound in cloth, extra gold and colours, 3s. 6d. each; best morocco, inlaid with enamel letter-piece, 6s. 6d. each. LONGFEllow ; SCOTT; BYRON ; MOORE ; WORDSWORTH ; COWPER ; MILTON ; POPE ; Burns; The Casilet of Gems; Book of Humorous Poetry; Ballads, ScotTish and English; Lives of the British Poets.

Poems and Pictures. With roo Illustrations:- Cloth gilt, gilt edges, 2 Is.

Shakespeare, Cassell's Illustrated. With 500 Illustrations. Imperial 8vo. Edited by Charles and MARY COWden Clarke. Vol. I. (COMEDies), I2s.; Tol. II. (Historical Plays), IOS. 6d. ; Vol. III. (TRAGEDIES), I2s.6d. The Complete Work, in Three Volumes, cloth lettered, uniform, $£$ I I5s. ; half morocco, $£ 2$ Ios. The Separate Plays may be had, price Is. each:

\section{aybenture.}

North-West Passage by Land, The. By Viscount Milton, M.P., \&c., and W. B. Cheadle, M.A., M.D. Cantab., F.R.G.S. 2 Is. Ditto, ditto, smaller edition, complete, $6 \mathrm{~s}$.

Thoughts and Notes at Home and Abroad. By EliHu BurRitT. Crown 8vo, 320 pp., cloth, $6 \mathrm{~s}$.

\section{Serial 胿blications.}

Little Folks. Monthly, 6d. ; Weekly, Id. . Cassell's History of the War between France and Germany. Monthly, 7d.; Weekly, I $\frac{1}{2} \mathrm{~d}$.

Book of Birds. Monthly, $7 \mathrm{~d}$.

Cassell's Magazine. Monthly, 6d.; Weekly, Id.

British Poets. Monthly, 6d.

Family Bible. Monthly, 7 d. ; Weekly, I $1 \frac{1}{2} \mathrm{~d}$. Popular Educator. Monthly, 7d.; Weekly, I $\frac{1}{2} \mathrm{~d}$.

Doré Bible. Monthly, 2s. 6d.

Doré Don Quixote. Monthly, $7 \mathrm{~d}$.; Weekly, I I d d.
Household Guide. Monthly, 7d.; Weekly, I $\frac{1}{2} \mathrm{~d}$.

The Quiver. Monthly, 6d.; Weekly, Id.

Child's Book of Song and Praise. Monthly, 6d.; Weekly, Id.

Matthew Henry's Commentary. Monthly, 7d.; Weekly, I $12 \mathrm{~d}$.

Technical Educator. Monthly, 7d. ; Weekly, I $\frac{1}{2} \mathrm{~d}$.

Illustrated Travels. Monthly, Is.

History of England. Monthly, 7 d. ; Weekly, $\mathbf{I}_{2}^{2} \mathrm{~d}$.

Railway Time Tables and Trades' Directory. Monthly, 2d.

\section{Anmuals, almanacks, sx.}

THE FOLLOWING WORKS ARE PUBLISHED YEARLY, IN OCTOBER AND NOVEMBER.

MORTON'S ALMANACK for FARMERS and IANDOWNERS. By J. C. MORTON. $\mathrm{New}$ Edition, enlarged to folio size, and well illustrated. Containing a vast amount of information relating to the Farm, \&e. \&c. Price Is.

HENRY LESLIE'S MUSICAL ANNUAL. With original full-page Illustrations by the best Artists, and containing Songs, Pianoforte Pieces, New Dance Music, \&c. \&c., by eminent Composers. Royal 4to. Cloth, limp, 5s. THE HOUSEHOLD RECORD. A DoMESTIC provements, and Novelties, for the House, Garden, Farm, Stable, \&c., and every Department of the Home and Household, within doors and out of doors ; Tables of Income and Wages, Prices of Corn and Bread and Meat, \&c., and a résumé of Important Legislative Enactments affecting the Home and its Inmates. Paper, is. ; cloth, lettered, xs. 6d.

CASSELL'S ILLUSTRATED ALMANACK. Profusely Illustrated. 6d.

“THE QUIVER" CHRISTMAS ANNUAL. Illustrated. 6d.

* * For detailed particulars of all the Works inserted in the foregoing List, consult OASSELL, PETTER, and GALPIN'S DESCRIPTIVE OATALOGUE, supplied by all Booksellers, and forwarded post free by the Publishers. 



\section{2}

